\title{
NONLINEAR SEISMIC RESPONSE OF REINFORCED CONCRETE PEDESTALS IN ELEVATED WATER TANKS
}

\author{
by \\ Razmyar Ghateh \\ Master of Applied Science, \\ Tehran, Iran, 2006
}

\begin{abstract}
A dissertation
presented to Ryerson University

in partial fulfillment of the

requirements for the degree of

Doctor of Philosophy

In the program of

Civil Engineering
\end{abstract}

Toronto, Ontario, Canada, 2014

CRazmyar Ghateh 2014 


\section{Author's declaration}

I hereby declare that I am the sole author of this dissertation.

I authorize Ryerson University to lend this dissertation to other institutions or individuals for the purpose of scholarly research

Razmyar Ghateh

I further authorize Ryerson University to reproduce this dissertation by photocopying or by other means, in total or in part, at the request of other institutions or individuals for the purpose of scholarly research.

I understand that my dissertation may be made electronically available to the public.

Razmyar Ghateh 


\title{
NONLINEAR SEISMIC RESPONSE OF REINFORCED CONCRETE PEDESTALS IN ELEVATED WATER TANKS
}

\author{
Doctor of Philosophy 2014
}

Razmyar Ghateh

Department of Civil Engineering

Ryerson University

\begin{abstract}
Elevated water tanks are employed in water distribution facilities in order to provide storage and necessary pressure in water network systems. These structures have demonstrated poor seismic performance in the past earthquakes. In this study, a finite element method is employed for investigating the nonlinear seismic response of reinforced concrete $(\mathrm{RC})$ pedestal in elevated water tanks. A combination of the most commonly constructed tank sizes and pedestal heights in industry are developed and investigated. Pushover analysis is performed in order to construct the pushover curves, establish the overstrength and ductility factor, and evaluate the effect of various parameters such as fundamental period and tank size on the seismic response factors of elevated water tanks. Furthermore, a probabilistic method is implemented to verify the seismic performance and response modification factor of elevated water tanks. The effect of wall
\end{abstract}


openings in the seismic response characteristics of elevated water tanks is investigated as well. Finally, the effect of axial compression on shear strength of RC pedestals is evaluated and compared to the nominal shear strength from current guideline and standards.

The results of the study show that the tank size, pedestal height, fundamental period, and pedestal height to diameter ratio, could significantly affect the overstrength and ductility factor of RC pedestals. The nonlinear dynamic analysis results reveal that under the maximum considered earthquake (MCE) intensity, light and medium size tank models do not experience significant damages. However, heavy tank size models experience more damage in comparison with light and medium tank sizes. This study shows that the current code response modification factor values are appropriate for light and medium tank sizes; however they need to be modified for heavy tank sizes. The results of this study also reveal that if the pedestal wall openings are designed based on current design guidelines, then nearly identical nonlinear seismic response behaviour is expected from the pedestals with and without openings. Finally, it is shown that the pedestal maximum shear strength calculated by finite element method for the full tank state is higher than the nominal shear strength determined based on the current design guidelines. 


\section{Acknowledgements}

I would like to express my greatest appreciation to many people who have provided me with support and help throughout writing this thesis.

First and foremost, my sincere gratitude goes to my supervisor Professor Reza Kianoush whose knowledge, support, patience, and encouragement has helped me to the highest degree during my research. Without his guidance and trust in my research, this thesis would not have been possible. Working under his supervision has been a great opportunity in my life and I would like to show my greatest appreciation to him.

I would also like to thank the reviewing committee for their revisions and suggestions.

I also wish to thank all my colleagues in the Civil Engineering Department at Ryerson University.

Finally, I am very grateful for the financial support provided by Ryerson University in the form of a scholarship. 


\section{Table of contents}

Author's declaration $\quad$ ii

$\begin{array}{ll}\text { Abstract } & \text { iii }\end{array}$

Acknowledgement $\quad$ V

Table of contents vi

List of figures $\quad x i$

List of tables $\quad$ xvi

List of symbols $\quad$ Xviii

1 Introduction 1

1.1 Overview 1

1.2 Objectives and scope of the study 5

$\begin{array}{ll}1.3 \text { Thesis layout } & 7\end{array}$

2 Literature review $\quad 10$

2.1 General 10

2.2 Performance of elevated water tanks under earthquake loads 10

2.3 Previous research 14

2.3.1 Seismic response of liquid-field tanks 14

2.3.2 Seismic response of elevated water tanks 16

2.4 Other related studies $\quad 21$

2.4.1 Response modification factor 21

2.4.2 Design codes and standards $\quad 26$

3 Analysis methods $\quad 29$

3.1 General 29

3.2 Methods of seismic analysis 30

3.2.1 Nonlinearity in reinforced concrete structure analysis 31

3.3 Code-based analysis and design of elevated water tanks 33

3.4 Static nonlinear (pushover) analysis $\quad 34$

3.4.1 Procedure of performing pushover analysis 35

3.4.2 Types of pushover analysis 37 
3.4.3 Bilinear approximation of pushover curves 38

3.5 Transient dynamic (Time-history) analysis $\quad 40$

3.5.1 Equation of motion of a SDOF system subjected to force $\mathrm{P}(\mathrm{t})$

3.5.2 Equation of motion of a SDOF system subjected to seismic excitations $\quad 42$

3.5.3 Equation of motion of a multi-degree-of-freedom system 43

3.5.4 Equation of motion of a nonlinear system 44

3.5.5 Solution of nonlinear MDOF dynamic differential equations 46

3.6 Incremental dynamic analysis (IDA) 47

3.7 Summary 49

$4 \quad$ Finite element model development and verification $\quad 50$

$\begin{array}{ll}4.1 \text { General } & 50\end{array}$

4.2 Finite element modeling of reinforced concrete 51

4.3 SOLID65 element 51

4.3.1 FE formulation of reinforced concrete in linear state $\quad 52$

4.3.2 FE formulation of reinforced concrete after cracking 53

4.3.3 Failure criteria of reinforced concrete element $\quad 54$

4.4 Solution of static and dynamic nonlinear finite element equations 56

4.4.1 Solution method for nonlinear static analysis equation 56

4.4.2 Solution method for nonlinear dynamic equations of motion 57

4.5 Reinforced concrete material nonlinearity $\quad 59$

4.5.1 Stress-strain curve of concrete $\quad 59$

4.5.2 Stress-strain curve of steel rebar 61

4.6 Validation of proposed finite element reinforced concrete model 63

4.6.1 Reinforced concrete beam test verification 63

4.6.2 Reinforced concrete wall test verification 66

4.7 Finite element model of RC pedestal in elevated water tanks $\quad 70$

4.8 Summary $\quad 72$

5 Pushover analysis of RC elevated water tanks 74

$\begin{array}{ll}5.1 \text { General } & 74\end{array}$

5.2 Constructing the elevated water tank prototypes 75 
5.2.1 Standard dimensions and capacities of elevated water tanks 76

5.2.2 Selection criteria for constructing the prototypes 77

5.3 Design of prototypes based on code requirements $\quad 81$

$\begin{array}{ll}\text { 5.3.1 Design of RC pedestals for gravity loads } & 81\end{array}$

5.3.2 Design of RC pedestals for seismic loads $\quad 84$

5.3.2.1 Seismic base shear $\quad 86$

5.4 Pushover analysis of FE models $\quad 89$

5.4.1 Defining pilot group of FE models $\quad 89$

$\begin{array}{ll}5.4 .2 \text { Results of pushover analysis } & 91\end{array}$

5.4.3 Observed patterns in pushover curves $\quad 94$

5.5 Cracking propagation pattern 98

5.6 Summary 105

6 Analyzing pushover curves and establishing seismic response factors 108

$\begin{array}{ll}6.1 \text { General } & 108\end{array}$

6.2 Interpreting pushover curves 109

$\begin{array}{ll}6.3 \text { Bilinear approximation of pushover curves } & 109\end{array}$

6.4 Seismic response factors 113

$\begin{array}{ll}\text { 6.4.1 Overstrength factor } & 115\end{array}$

$\begin{array}{ll}\text { 6.4.2 Ductility factor } & 115\end{array}$

6.4.3 Response modification factor $\quad 118$

6.5 Calculating global seismic response factors for RC pedestals 118

$\begin{array}{ll}6.6 \text { Analysing seismic response factors } & 120\end{array}$

6.6.1 Effect of Fundamental period $\quad 120$

$\begin{array}{ll}\text { 6.6.2 Effect of height to diameter ratio } & 121\end{array}$

6.6.3 Effect of tank size on overstrength factor $\quad 122$

6.6.4 Effect of seismicity $\quad 124$

6.7 Establishing seismic response factors for RC pedestals 129

6.8 Proposed value of response modification factor 130

6.9 Summary 131

7 Nonlinear time history analysis of RC elevated water tanks 135 
7.1 General 135

7.2 Overview of FEMA P695 methodology 136

7.2.1 Selecting and analysing models 137

$\begin{array}{ll}\text { 7.2.2 Evaluating seismic performance } & 137\end{array}$

7.3 Customizing FEMA P695 methodology for elevated water tanks 140

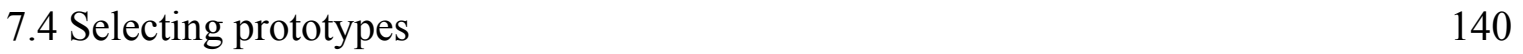

$\begin{array}{ll}7.5 \text { Ground motion record sets } & 141\end{array}$

7.5.1 Normalizing ground motion record sets 142

7.5.2 Selecting record sets for performing "full IDA" analysis 144

$\begin{array}{ll}\text { 7.6 Results of nonlinear time history analysis } & 148\end{array}$

7.6.1 Comparing responses of an RC pedestal subjected to different records $\quad 148$

7.6.2 Response of similar height pedestals subjected to Cape Mendocino 151 (1992) record

7.6.3 "Full IDA" results for FE model 25-H-3 152

7.6.4 Maximum damage location at collapse level 156

7.7 Performing IDA on elevated water tank prototypes 157

7.8 Establishing collapse margin ratio (CMR) 158

7.9 Evaluating seismic performance of elevated water tanks 163

7.9.1 Calculating adjusted collapse margin ratio 163

7.9.2 Defining sources of collapse uncertainty 165

7.9.2.1 Record-to-Record uncertainty ( $\beta$ RTR) 165

7.9.2.2 Design requirements, Test data and Modeling uncertainty ( 165 $\beta \mathrm{DR}, \beta \mathrm{TD}, \beta \mathrm{MDL})$

7.9.3 Calculating total system collapse uncertainty 166

7.9.4 Acceptable values of ACMR 168

7.10 Evaluation of R factor 169

7.10.1 "Light" tank size category evaluation 171

7.10.2 "Medium" tank size category evaluation 172

7.10.3 "Heavy" tank size category evaluation 172

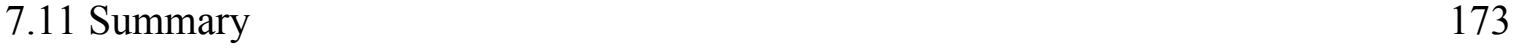


8 Evaluating the effect of wall opening and maximum shear strength in RC pedestal of elevated water tanks

$\begin{array}{ll}8.1 \text { General } & 177\end{array}$

8.2 Wall opening location and typical dimensions 178

8.3 Code provisions and requirements for structural design of openings 179

8.4 Investigating the seismic response of RC pedestals with wall opening 180

8.4.1 Critical direction of seismic loading in RC pedestals with wall opening 181

8.4.2 Seismic response characteristics of wall opening with pilaster 185

$\begin{array}{ll}\text { 8.4.2.1 Results of pushover analysis } & 187\end{array}$

8.5 Shear strength of RC pedestals 189

8.5.1 Effect of axial compression in shear strength of RC walls 190

8.5.2 Provisions of ACI371R-08 for calculating shear strength of RC walls 191

8.5.2.1 Effective shear area (Acv) 192

8.5.3 Investigating the maximum shear strength of RC pedestals 193

$\begin{array}{ll}\text { 8.5.3.1 Results of pushover analysis } & 194\end{array}$

$\begin{array}{ll}\text { 8.5.3.2 Evaluating the results of pushover analysis } & 197\end{array}$

$\begin{array}{ll}\text { 8.6 Summary } & 201\end{array}$

9 Summary, conclusions and recommendations 204

$\begin{array}{ll}9.1 \text { Summary } & 204\end{array}$

$\begin{array}{ll}9.2 \text { Conclusions } & 207\end{array}$

9.3 Recommendations for future research programs 209

Appendix A: Finite element modelling of reinforced concrete elements 212

A.1 Finite element formulation of reinforced concrete 212

A.1.1 FE formulation of reinforced concrete after cracking 212

A.2 Stress-Strain curves of concrete and steel bars 213

A.2.1 Stress-Strain curve of concrete 214

$\begin{array}{ll}\text { A.2.2 Stress-Strain curve of steel } & 214\end{array}$

A.3 Sensitivity analysis of a typical prototype 216

Appendix B: Design of prototypes based on code and guideline requirements 218

B.1 Design of prototypes based on code and guidelines 218 
C.1 Input file for FE model 35-H-1 226

References 246

\section{List of Figures}

Figure 1.1 Configuration of composite elevated water tank (a) RC pedestal Elevation

(b) RC pedestal section

Figure 2.1 Debris and remaining of the collapsed $1500 \mathrm{~m}^{3}$ water tower in Rasht during Manjil-Roudbar earthquake

Figure 2.2 The $2500 \mathrm{~m}^{3}$ water tank which partly damaged in Manjil-Roudbar earthquake (Memari and Ahmadi, 1990); (a) Before earthquake (b) finalized retrofitting and strengthening plan

Figure 2.3 (a) $200 \mathrm{~m}^{3}$ Bhachau water tank with circumferential cracks in 2001

Gujarat 2001 earthquake (b) Collapsed $265 \mathrm{~m}^{3}$ water tank in 2001 Gujarat earthquake (c) Horizontal flexural-tension cracking near the base of Gulaotal water tank in 1997 Jabalpur earthquake

Figure 2.4 Equivalent dynamic system of liquid tanks(a) elevated water tank (b) Ground supported tank (Housner, 1964)

Figure 3.1 Flowchart of seismic analysis methods employed in this study 30

Figure 3.2 Different types of nonlinearity (a) geometrical nonlinearity (P- $\Delta$ effect) in 32 RC pedestal (b) concrete material nonlinearity

Figure 3.3 Design response spectrum developed according to provisions of ASCE/SEI 7-10 standard

Figure 3.4 Typical pushover curve developed for a sample RC pedestal

Figure 3.5 Bilinear approximation of pushover curves (a) reduced stiffness equivalent elasto-plastic yield (b) equivalent elasto-plastic energy absorption

Figure 3.6 Idealized MDOF model of concrete elevated tank structure with only horizontal degrees of freedom 
Figure 3.7 Typical IDA curves for a multistory steel frame subjected to four different earthquake records (adapted from Vamvatsikos and Cornell, 2002)

Figure 4.1 Geometry and node positions of a SOLID65 element 52

Figure 4.2 Concrete mathematical Stress-strain curve (Mander et al. (1988) 60

Figure 4.3 The stress-strain model for steel rebar (Holzer et al. 1975) 62

Figure 4.4 Geometry, loading, boundary condition and section of beam specimens (a) 64

J4 beam specimen (b) typical beam section (c) T1MA beam specimen

Figure 4.5 Finite element versus experimental results for J4 beam sample 65

Figure 4.6 Finite element versus experimental results for T1MA beam specimen $\quad 66$

Figure 4.7 Geometry, loading and section of RC wall samples, Mickleborough et al 67 (1999)

Figure 4.8 Comparison between the finite element and experimental results (a) Wall

SH-L specimen (b) Wall SH-H specimen

Figure 4.9 Finite element idealization of shaft structure (a) tank elevation (b) FE idealization

Figure 4.10 Elevated water tank model (a) simplified configuration (b) finite element model

Figure 5.1 Definition of terms and components in elevated water tanks

Figure 5.2 Design response spectrum (a) high seismicity zone (b) low seismicity zone $\quad 85$

$\begin{array}{ll}\text { Figure 5.3 The pilot study group } & 90\end{array}$

Figure 5.4 Results of pushover analysis for pilot group (a) model 25-H-0.5 (b) model 92 25-H-3(c) model 35-H-0.5 (d) model 35-H-1 (e) model 35-H-3

Figure 5.5 Comparing effect of RC pedestal height on pushover curves 95

Figure 5.6 Comparing effect of RC pedestal tank sizes on pushover curves (a) $35 \mathrm{~m} \quad 96$ pedestal (b) $25 \mathrm{~m}$ pedestal

Figure 5.7 Comparing effect of RC pedestal tank sizes on pushover curves (a) model 35-H-1 (b) model 35-H-3

Figure 5.8 Contours of strain intensity in RC pedestals under progressive loading of 98 pushover analysis (a) three stages of increasing lateral loads for model 35H-1 (b) three stages of increasing lateral loads for model 35-H-3 
Figure 5.9 Cracking propagation of RC pedestals subjected to increasing lateral

loading in pushover analysis (a) four stages of growing lateral loads for model 35-H-1 (b) three stages of increasing lateral loads for model 35-H-3

Figure 5.10 Cracking propagation pattern in FE model 35-H-1 (a) elevation of the

prototype (b) front view of base level parallel to direction of lateral load (initial flexural cracks) (c) same view as part "b" showing development of flexure-shear cracks (d) side view (perpendicular to lateral load direction)of the crack propagation at base level

Figure 5.11 Cracking propagation pattern in FE model 35-H-3 (a) elevation of the prototype (b) Magnified view of cracks on the elevation (c) Initial cracking pattern on the pedestal's sides parallel to direction of loading (d) front view (perpendicular to lateral load direction)of the crack propagation at base level

Figure 6.1 Bilinear approximation of pushover curves

Figure 6.2 pushover curves and corresponding Bilinear approximation (a) $25-\mathrm{H}-0.5$

(b) $25-\mathrm{H}-3$ (c) $35-\mathrm{H}-0.5$ (d) $35-\mathrm{H}-1$ (e) $35-\mathrm{H}-3$

Figure 6.3 Definition of seismic response factors on a typical pushover curve

Figure 6.4 Ductility factor curves according to Newmark and Hall (1982)

Figure 6.5 Comparing ductility factor obtained from "Newmark and Hall", "Nassar and Krawinkler", and "Miranda and Bertero"for displacement ductility of 3

Figure 6.6 Effect of fundamental period on (a) overstrength factor (b) ductility factor

Figure 6.8 Effect of tank size on (a) overstrength factor (b) ductility factor

Figure 6.9 Pushover curves and corresponding seismic design base shear (a) 35-H-0.5

(b) $35-\mathrm{H}-1$ (c) $35-\mathrm{H}-3$

Figure 6.10 Comparing pushover curves for four levels of seismicity (a) 35-H$1(\mathrm{R}=2) /$ level one (b) 35-H-1( $\mathrm{R}=3$ )/ level two (c) 35-L-1(R=2)/ level three (d) $35-\mathrm{L}-1(\mathrm{R}=3) /$ level four

Figure 6.11 Overstrength factor (a) level one seismicity (b) level two seismicity (c) level three seismicity (d) level four seismicity 
Figure 6.12 Ductility factor (a) level one seismicity (b) level two seismicity (c) level three seismicity (d) level four seismicity

Figure 7.1 Collapse margin ratio (CMR) described in a typical pushover curve

Figure 7.2 Flowchart of seismic evaluation of structures according to FEMA P695

Figure 7.3 Ground motions record employed for full IDA study (a) Northridge(1994)

(b) Cape Mendocino(1992) (c) Duzce, Turkey (1999) (d) San Fernando (1971) (e) Landers(1992)

Figure 7.4 Acceleration response spectrum for Northridge(1994), Cape

Mendocino(1992), Duzce, Turkey (1999), San Fernando (1971) and

Landers(1992) earthquakes

Figure 7.5 Nonlinear deformation (left) and base shear (right) response of FE model

25-H-0.5 subjected to (a) DUZCE/BOL090 (b) SFERN/PEL090 (c)

NORTHR/LOS270 (d) CAPEMEND/RIO360

Figure 7.6 Comparing the maximum deformation response of three FE models of 35-

H-0.5, 35-H-1 and 35-H-3 to Cape Mendocino record

Figure 7.7 The as-recorded 5\% damping displacement spectrum for

CAPEMEND/RIO360

Figure 7.8 FE model 25-H-3 subjected to 4 stages of increasing spectral intensity of

Northridge earthquake record (NORTHR/LOS270) (a) Normalized record

(b)Maximum lateral deformation of RC pedestal (c) Maximum base shear of RC pedestal

Figure 7.9 The IDA curve for FE model 25-H-3 subjected to Northridge earthquake and 4 steps of increasing intensity

Figure 7.10 Comparing the location of maximum mechanical strain prior to collapse (a) 25-H-0.5 (b) 25-H-3

Figure 7.11 IDA and pushover curves for three FE models of (a) 25-H-0.5 (b) 35-H-1 (c) $25-\mathrm{H}-3$

Figure 7.12 IDA curves and calculated $\mathrm{S}_{\mathrm{CT}}$ and $\mathrm{S}_{\mathrm{MT}}$ for prototypes design with $\mathrm{R}=2$ (a) $25-\mathrm{H}-0.5$ (b) $35-\mathrm{H}-0.5$ (c) $35-\mathrm{H}-1$ (d) $35-\mathrm{H}-3$ (e) $25-\mathrm{H}-3$

Figure 7.13 IDA curves and calculated $\mathrm{S}_{\mathrm{CT}}$ and $\mathrm{S}_{\mathrm{MT}}$ for prototypes design with $\mathrm{R}=3$ 

(a) $25-\mathrm{H}-0.5$
(b) $35-\mathrm{H}-0.5$ (c)
(c) $35-\mathrm{H}-1$
(d) $35-\mathrm{H}-3$
(e) $25-\mathrm{H}-3$

Figure 8.1 Openings in elevated water tanks (a) Elevation (b) section

Figure 8.2 Critical loading direction of elevated water tanks with opening (a) Elevation (b) Section

Figure 8.3 Maximum strain locations prior to failure in the FE model 25- $\mathrm{H}-0.5$

subjected to lateral loading in (a) Direction "1" (b) Direction "2" (c) Direction " 3 "

Figure 8.4 Comparison between pushover curves of loading in three directions (a) FE 184 model 25-H-0.5 (b) FE model 35-H-3

Figure 8.5 Cracking propagation of RC pedestals with pilaster at openings subjected to increasing lateral loading in pushover analysis (a) three stages of increasing lateral loads for model 35-H-1 (b) three stages of increasing lateral loads for model $35-\mathrm{H}-3$

Figure 8.6 Pushover curves for group (a) model 25-H-0.5 (b) model 25-H-3(c) model 35-H-0.5 (d) model 35-H-1 (e) model 35-H-3

Figure 8.7 The parallel shear walls analogy based on ACI371R-08 193

Figure 8.8 Pushover curves for three loading states of full, half full and empty tank

(a) FE model 25-H-0.5 (b) FE model 25-H-2 (c) FE model 25-H-3

Figure 8.9 Comparison between the calculated shear strength and code nominal shear strength in two states of full and empty tank

Figure 8.10 Tank size versus (a) $\mathrm{V}_{\mathrm{n}} / \mathrm{V}_{\text {empty }}$ (b) $\mathrm{V}_{\mathrm{n}} / \mathrm{V}_{\text {Full }}$ 198

Figure 8.11 Average axial compression versus (a) $\mathrm{V}_{\mathrm{n}} / \mathrm{V}_{\text {empty }}$ (b) $\mathrm{V}_{\mathrm{n}} / \mathrm{V}_{\text {Full }}$ 199

Figure 8.12 Pedestal height to diameter ratio versus (a) $\mathrm{V}_{\text {Full }} / \mathrm{V}_{\text {empty }}$ (b) $\mathrm{V}_{\mathrm{n}} / \mathrm{V}_{\text {Full }}$ 200

Figure $8.13 \mathrm{~V}_{\text {Ful }} / \mathrm{V}_{\mathrm{n}}$ versus tank size group 200

Figure A.1 Unconfined concrete stress-strain curve for $\mathrm{f}^{\prime} \mathrm{c}=35 \mathrm{MPa}$ (Mander et al. 214 (1988)

Figure A.2 The stress-strain curve for \#11 steel rebar (Holzer et al. 1975) 215

Figure A.3 Results of pushover analysis on five FE models of prototype 35-H-1 216 


\section{List of Tables}

Table 4.1 Reference points for stress-strain curve of grade 400 steel (Hozler et al, 1975)

Table 4.2 The beam section dimensions and loading locations

Table 4.3 Material properties of beam specimens T1MA and J4 64

Table 4.4 Properties of wall specimens SH-L and SH-H 68

Table 4.5 Loading, stress and maximum deformation results of the test 68

Table 5.1 Commonly built tank sizes and dimensions (Adapted from Landmark Co.) 76

Table 5.2 Dimensions and properties of prototypes in the first group 80

Table 5.3 Seismic ground motion values for seismic design of prototypes 84

Table 5.4 Design fundamental period (Tf) and seismic response coefficient (Cs) 87

$\begin{array}{ll}\text { Table } 5.5 \text { Summary of prototype design } & 88\end{array}$

Table 5.6 The pilot group prototypes dimensions and properties 91

Table 5.7 Results of pushover analysis for the pilot group $\quad 94$

Table 5.8 cracking pattern summary for FE models 104

Table 6.1 Definition of parameters used in Figure 6.3 and related descriptions 114

Table 6.2 Seismic response factors for "high seismicity" design 119

Table 6.3 Seismic response factors for "low seismicity" design 119

Table 6.4 Four levels of seismicity for designing RC pedestals 126

Table 6.5 Categories of tanks based on tank size $\quad 128$

Table 6.6 Overstrength factor of RC pedestal 129

Table 6.7 Ductility factor of RC pedestal 130

Table 6.8 Draft values of response modification factor of RC pedestal 131

Table 7.1 Pilot group prototypes selected for IDA analysis 141

Table 7.2 Far-Field record set 142

Table 7.3 Normalized Far-Field record set 143

Table 7.4 Group of five ground motion records employed for the full IDA 145

Table 7.5 Comparing the seismic response of FE model 25-H-0.5 to various ground 150 motion records and pushover results 
Table 7.6 Maximum deformation and base shear of FE model 25-H-3 subjected to increasing intensity levels of Northridge earthquake

Table 7.7 SMT values for pilot group of prototypes

Table 7.8 CMR for prototypes designed for $\mathrm{R}=2$

Table 7.9 CMR for prototypes designed for $\mathrm{R}=3$

Table 7.10 Spectral shape factor (SSF) and adjusted collapse margin ratio (ACMR)

for prototypes designed for $\mathrm{R}=2$

Table 7.11 Spectral shape factor (SSF) and adjusted collapse margin ratio (ACMR) for prototypes designed for $\mathrm{R}=3$

Table 7.12 Quality ratings

Table 7.13 Total system collapse uncertainty for "superior" quality rating $(\mathrm{R}=2)$

Table 7.14 Total system collapse uncertainty for "superior" quality rating $(\mathrm{R}=3)$

Table 7.15 Total system collapse uncertainty for "good" quality rating $(\mathrm{R}=2)$

Table 7.16 Total system collapse uncertainty for "good" quality rating $(\mathrm{R}=3)$

Table 7.17 "Acceptable ACMR” for five collapse probability level

Table 7.18 "Superior" total system collapse uncertainty and R factor of 2

Table 7.19 "Superior" total system collapse uncertainty and R factor of 3

Table 7.20 "Good” total system collapse uncertainty and R factor of 2

Table 7.21 “Good" total system collapse uncertainty and R factor of 3

Table 8.1 Summary of the calculated shear strength based on finite element model and pushover analysis for 12 prototypes

Table 8.2 Summary of the calculated shear strength based on finite element model and pushover analysis for twelve prototypes

Table A.1 Properties of stress-strain curve for steel rebars

Table A.2 Results of sensitivity analysis on five FE models for prototype 35-H-1

Table A.3 Optimum number of elements and nodes for each prototype

Table B.1 Geometry and weight of pedestal, tank vessel and liquid for full tank condition

Table B.2 Verification of the pedestals for diamond shape and column shape buckling effects 
Table B.3 Calculation of fundamental period and seismic response coefficient

Table B.4 Calculation of factor of safety for load case $\mathrm{U}=1.4(\mathrm{D}+\mathrm{F})$ assuming the minimum reinforcement requirements

Table B.5 Calculation of vertical reinforcement for base level and mid-height of pedestal

Table B.6 Calculation of horizontal reinforcement for base level and mid-height of pedestal

Table B.7 Overstrength, ductility, maximum displacement and ductility factor for $(\mathrm{R}=2)$ group

\section{List of Symbols}

$\begin{array}{ll}A_{c v} & \begin{array}{l}\text { concrete shear area of a section, } \mathrm{mm}^{2} \\ A_{s}\end{array} \\ b_{v} & \text { area of longitudinal reinforcements, } \mathrm{mm}^{2} \\ b_{x} & \text { equivalent shear wall length not to exceed } 0.78 d_{w}, \mathrm{~mm} \\ b_{d} & \text { cumulative opening width in a distance of } b_{v}, \mathrm{~mm} \\ C_{s} & \text { width of a doorway or other opening, } \mathrm{mm} \\ C & \text { seismic response coefficient } \\ D & \text { damping matrix } \\ d_{W} & \text { dead load } \\ \text { e } & \text { mean diameter of the pedestal, } \mathrm{m} \\ E_{c} & \text { eccentricity of the axial wall load } \\ E_{S} & \text { modulus of elasticity of concrete } \\ F_{D} & \text { modulus of elasticity of steel } \\ F_{I} & \text { damping force } \\ F_{S} & \text { inertial force }\end{array}$




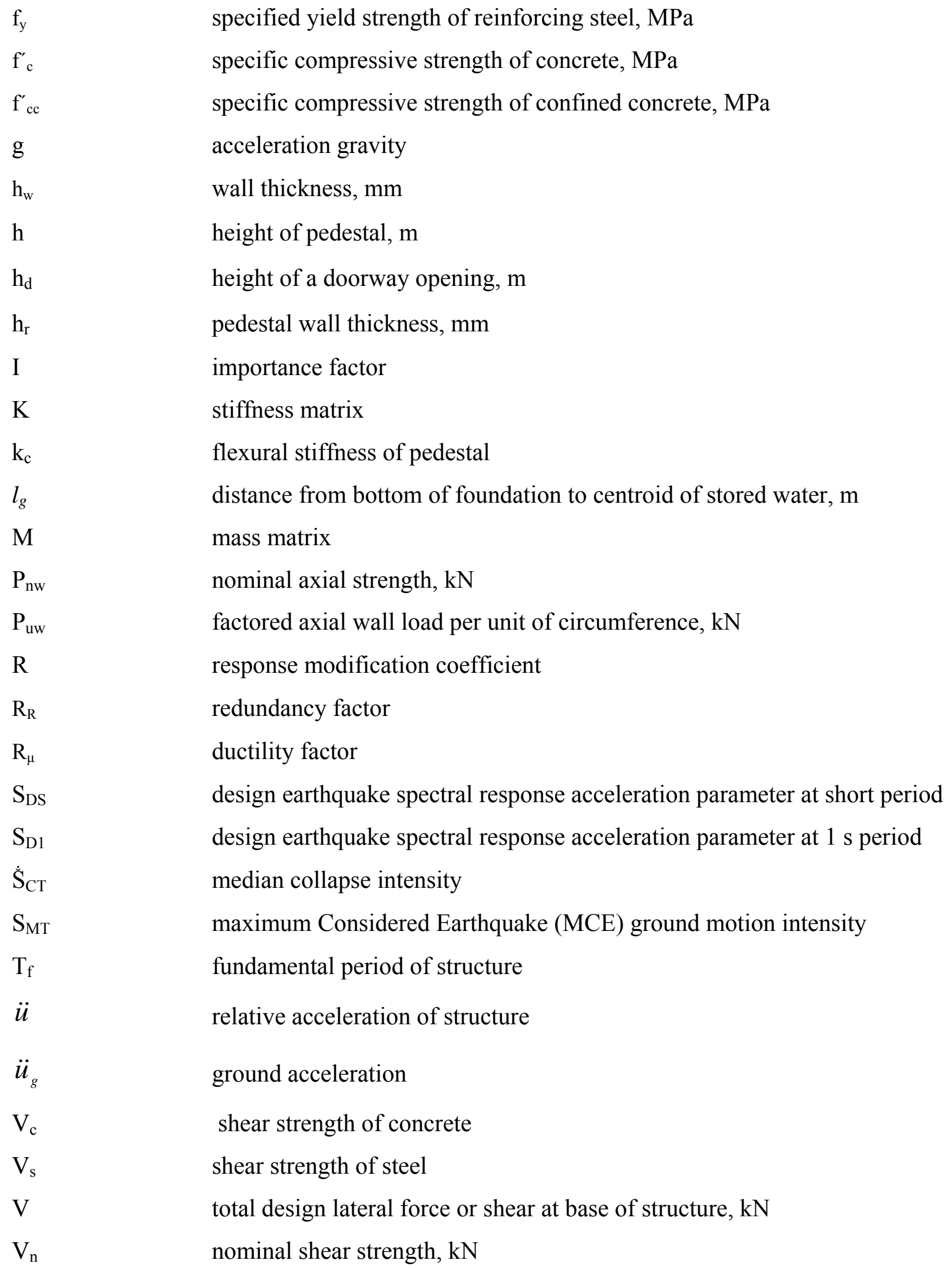


$\mathrm{V}_{\mathrm{u}}$

$\mathrm{V}_{\mathrm{d}}$

$\mathrm{V}_{\mathrm{y}}$

\section{Greek symbols}

$\rho_{h}$

$\phi$

$\rho_{v}$

$\alpha_{c}$

$\Delta_{\max }$

$\Delta \mathrm{y}$

$\mu$

$v$

$\xi$

$\Omega_{0}$

$\varepsilon_{\mathrm{cu}}$

$\varepsilon^{\prime}{ }_{\mathrm{cc}}$

$\varepsilon_{\mathrm{u}}$

$\varepsilon_{\mathrm{c}}$

factored shear force, $\mathrm{kN}$

design base shear, $\mathrm{kN}$

shear force corresponding to global yield of structure, $\mathrm{kN}$

ratio of horizontal distributed shear reinforcement on a horizontal plane

strength reduction factor

ratio of vertical distributed shear reinforcement on a vertical plane perpendicular to

$A_{c v}$;

constant used to compute in-plane nominal shear strength

maximum displacement prior to onset of stiffness reduction

effective yield displacement

displacement ductility ratio

Poisson's ratio

damping ratio

overstrength factor

ultimate concrete strain for confined concrete

concrete strain at $\mathrm{f}_{\mathrm{cc}}$

ultimate concrete strain for unconfined concrete

concrete strain at $\mathrm{f}_{\mathrm{c}}$ 


\section{Chapter 1 Introduction}

\subsection{Overview}

Elevated water tank is a water storage facility supported by a tower and constructed at an elevation to provide useful storage and pressure for a water distribution system. The height of the tower provides the pressure for the water supply system. During the high peak hours of the water system, the static potential reserved in the tank will be used to provide the pressure in the water pipes and helps the pumping systems by maintaining the necessary water pressure without increasing pumping capacity. They also present enough water pressure for firefighting when the pumping systems are not sufficient to provide large amount of water needed for fire extinguishing.

Water towers rely on hydrostatic pressure produced by elevation of water and hence are able to supply water even during power outages. This feature of elevated water tanks becomes more critical in case of power outage after severe earthquakes in which pumping systems are not able to work due to dependency on electrical power.

In general, the supporting structure of the elevated water tanks could be classified as reinforced concrete frame, steel frame, masonry pedestal and reinforced concrete pedestal. In this thesis, the term "Elevated Water Tank" only refers to the last group which is the tank mounted on the reinforced concrete pedestals and will be the subject of this research.

Reinforced concrete (RC) pedestal supported elevated water tanks commonly have two main configurations. In the first type, which is simply called "Elevated Concrete Tank", both pedestal and tank are constructed from reinforced concrete. The second type however, consists of a RC pedestal and welded steel tank and is called "Elevated Composite Steel-Concrete Tank" or 
simply “composite elevated tank". In this configuration, a welded steel tank is mounted on top of the RC pedestal. The steel tank often has a cone shape lower section and cylindrical shape in the upper part. Figure 1.1 shows an elevation of a typical composite elevated tank.

(a)

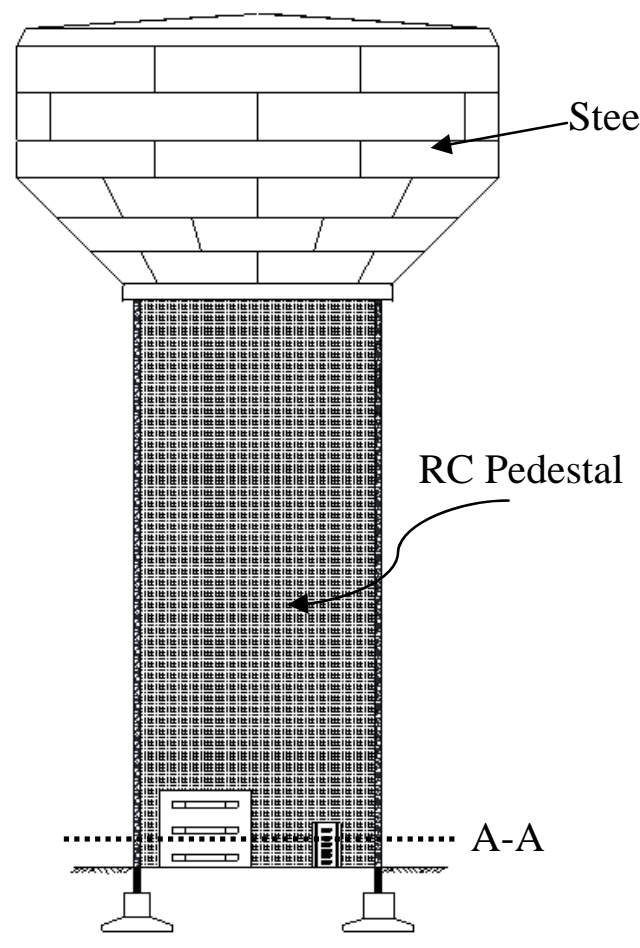

teel tank

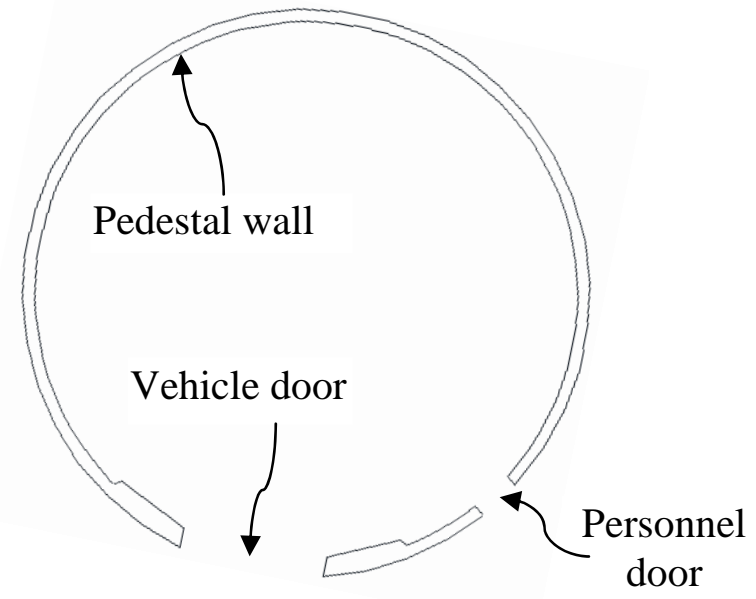

(b)

Section A-A

Figure 1.1 Configuration of composite elevated water tank (a) RC pedestal Elevation (b) RC pedestal section

Although the features of composite elevated tanks such as size, dimensions and geometry are commonly referred to in this study, yet all the research results are applicable to concrete elevated tanks as well. This is for the reason that this study is only focused on the RC pedestal seismic response behaviour which has quite the same properties for both types of elevated water tanks.

Being considered as an important element of lifelines, elevated water tanks are expected to remain functional after severe ground motions to serve as a provider of potable water as well as firefighting operations. Failure or malfunction of these infrastructures disrupts the emergency response and recovery after earthquakes. 
However, elevated water tanks have not performed up to expectations in many earthquakes in the past. The poor performance of these structures in many earthquakes such as Jabalpur 1997 (Rai, 2002), Chile 1960 (Steinbrugge, 1960), Gujarat 2001 (Rai, 2002) and Manjil-Roudbar 1990 (Memari and Ahmadi, 1990) has been reported in the literature. Extent of damages has been ranging from minor cracks in the pedestal up to complete collapse of the entire structure.

There are many grounds that could explain this undesirable performance. Configuration of these structures which resembles an inverse pendulum, lack of redundancy, very heavy gravity load (comparing to conventional structures) and poor construction detailing are among the major contributors.

Unlike most other structures which may have uniform dead and live load during their life time, elevated water tanks could experience significantly different gravity loads while working in the water system. On average, when the tank is empty, the overall weight of the structure may fall to $75 \%$ of the full tank state. This change in the gravity load adds some complication to the seismic design of elevated water tanks. Lack of redundancy is another weak point of these structures which is a result of not having any load redistribution path. During severe earthquakes, even if the tank survives without damages, failure or heavy damages in the RC pedestal could result in total collapse of structure.

Currently ACI 371R-08 is the only guideline in North America that specifically addresses the structural design aspects of elevated water tanks with RC pedestals. This guideline refers extensively to ACI 350.3-06 for design and construction of components of the tank as well as ACI 318-08 for the design and construction of RC pedestal and foundation. In addition ASCE/SEI 7-2005 must be employed in conjunction with ACI 371R-08 in order to determine 
design aspects such as loading parameters, seismic factors and so forth. ACI 371R-08 does not specify any lateral deflection limit for the RC pedestals when subjected to seismic loads.

The nonlinear response of both concrete and steel tanks subjected to ground motions has been extensively investigated by means of experimental and numerical methods. Such studies date back to as early as 1940s and later by works of Housner (1964) and other researchers. On the other hand, although the RC pedestals are an important part of the elevated water tank structures, the nonlinear seismic response of them has been the subject of only a handful of research studies.

So far, there has been no experimental test program (such as shaking table) that has studied the nonlinear response of RC pedestals to the strong ground motions. The number of numerical studies is also very few and mainly limited to only one or two elevated water tanks with certain tank weight and pedestal dimensions. This is despite the fact that elevated water tanks have a wide range of tank sizes and pedestal heights which may result in considerably different seismic response behaviours.

Furthermore, some of the design equations and requirements existing in the current codes are adopted from ACI 318-08 for designing components such as shear walls which are similar to RC pedestals. In addition, in some specific design features such as openings, the current code has adapted materials from ACI 307 (chimneys) and ACI 313 (silos). This shows the need to further evaluate some of the code requirements and equations.

Poor performance in previous earthquakes, lack of experimental results, importance of these structures as lifelines, very limited numerical studies, and evaluation of certain parts of the current code are the main drivers that necessitate a comprehensive study on the nonlinear performance of RC pedestals. 
This study aims to fill this gap and investigate various aspects of nonlinear response behaviour of RC pedestals by employing a finite element approach. All practical tank sizes and pedestal height and diameters are included in this research in order to define a comprehensive database for the seismic response factors of elevated water tanks. In addition, special topics such as effect of wall openings and shear strength of RC pedestals will be addressed and discussed.

Various analysis methods such as pushover and incremental dynamic analysis (IDA) will be employed to serve this purpose. Other than deterministic approaches, a probabilistic method is implemented as well to study the collapse probability of the RC pedestals under different conditions. The outcomes of this research will help better understand the actual nonlinear seismic response of elevated water tanks.

\subsection{Objectives and scope of the study}

The main objective of this study is to investigate the nonlinear seismic response in RC pedestal of elevated water tanks by means of a finite element approach. The general purpose finite element software ANSYS is employed for finite element modeling. The finite element model is verified by comparing to experimental test results.

This investigation is carried out with both deterministic and probabilistic methods. First by conducting pushover analysis and constructing pushover curves, the seismic response factors including overstrength and ductility factor are determined for various sizes of elevated water tanks. In addition, the effect of several parameters on these factors is studied and the proposed response modification factor is developed in accordance with ATC 19 (1995) methodology.

In the second part, a probabilistic method based on FEMA P695 is employed in order to validate the seismic design of the RC pedestals and response modification factor. Each finite 
element (FE) model is subjected to various ground motion records with increasing intensities and the incremental dynamic analysis (IDA) curves are constructed accordingly. The base shear and lateral deformation response of RC pedestals will be addressed as well.

To achieve the objectives, the following tasks will be performed:

1- Perform a comprehensive literature review on the seismic response behaviour of elevated water tanks as well as the response modification factor.

2- Develop a finite element model which is capable of predicting the nonlinear response of reinforced concrete elements and verify it by comparing to experimental test results.

3- Investigate the nonlinear response behaviour of different tank size and pedestal dimensions of elevated water tanks that are built in industry by pushover analysis and evaluate the effect of various parameters on the pushover curves.

4- Calculate overstrength and ductility factor for RC pedestals and analyse the effect of various parameters such as tank capacity and fundamental period on them.

5- Propose response modification factor for RC pedestals based on ATC 19 (1995) methodology.

6- Investigate crack propagation patterns in RC pedestals when subjected to seismic lateral loads.

7- Detect the location of major damages of RC pedestal when subjected to seismic loads.

8- Verify the current code values for response modification factor of RC pedestals by conducting a probabilistic analysis based on FEMA P695 methodology.

9- Determine the collapse probability of elevated water tanks under different seismic loading conditions and system uncertainties. 
10- Investigate the effect of wall openings in the seismic response behaviour of RC pedestals.

11- Evaluate the current shear design provisions in ACI 371R-08 and study the effect of axial shear compression in enhancing the shear strength of RC pedestals.

A summary of the assumptions of the study is as follows:

1- The foundation is assumed to be rigid and the shaft wall is fixed at the level of foundation. This is applied by constraining all degrees of freedom at the base nodes of RC pedestal FE models.

2- The sloshing response of water in the tank is not taken into account in the dynamic analysis. The liquid in the tank is modelled as a single mass with impulsive component of response. This is a conservative assumption since considering the contribution of the sloshing mode has been shown in literature (Moslemi et al., 2011) to generate lower total response comparing to ignoring it.

3- Only the effect of horizontal ground motion is studied in the nonlinear dynamic analysis of pedestals.

\subsection{Thesis layout}

This thesis consists of nine chapters. An introduction to the "Elevated water tanks" and their characteristics, objective and scopes of the thesis and the thesis layout it presented in Chapter 1.

Chapter 2 presents a comprehensive literature review on seismic response of elevated water tanks. Performance of elevated water tanks in the past earthquakes and previous research studies on dynamic properties of elevated water tanks are discussed in this chapter. In addition, a 
literature review on response modification factor as well as introduction to current codes and guidelines related to design and analysis of elevated water tanks is included.

Chapter 3 deals with seismic analysis methods employed in this thesis for studying nonlinear static and dynamic response behaviour of RC pedestals. The general equations and formulation for each analysis method is briefly reviewed in this chapter. Nonlinear static analysis, sources of nonlinearity in structure's response and equations of transient dynamic analysis are among other topics that are covered in this chapter.

Defining and verifying a finite element technique for modeling RC pedestals is the main objective of Chapter 4. Mathematical models for constructing stress-strain curve of concrete and steel material are briefly described in this chapter. The failure criteria of reinforced concrete elements subjected to ultimate loading condition is also explained. The chapter concludes with verifying proposed finite element system by comparing the finite element model to experimental tests on reinforced concrete specimens.

In chapter 5, the seismic performance of elevated water tanks is investigated by performing pushover analysis. This chapter explains the standard dimensions and capacities of elevated water tanks along with the selection criteria such as pedestal height, tank size and so forth for constructing the prototypes. The chapter continues with evaluation of pushover curves of elevated water tank prototypes and ends with analyzing the cracking propagation patterns in the RC pedestals under lateral seismic loads.

In chapter 6, the seismic response factors of elevated water tanks are calculated and discussed. The bilinear approximation, overstrength factor and ductility of the prototypes are determined based on the pushover curves in this chapter. In addition the methods for establishing the ductility factor of the structures are illustrated briefly. Finally the effect of various parameters 
such as RC pedestal height and tank size is investigated on the seismic response factors of elevated water tanks and proposed response modification factor is established.

Chapter 7 evaluates and verifies the response modification factor of RC elevated water tanks by employing a probabilistic method. In this chapter by performing several nonlinear time history analyses, the probability of collapse of finite element models RC pedestals is calculated under different seismic loading conditions and system uncertainties. This probabilistic approach is based on FEMA P695 methodology which is briefly explained in this chapter and a number of customizations made on the methodology are explained. In addition, the results of nonlinear time history analysis of RC pedestals, such as deformation and base shear versus time and potential failure modes of RC pedestals will be presented and discussed in this chapter.

Chapter 8 discusses two topics separately. In the first part the effect of wall openings of the RC pedestals on the seismic response of elevated water tanks is investigated. A number of elevated water tank finite element models with various height, tank capacities and standard wall opening dimensions are developed and investigated by conducting nonlinear static analysis. In the second part of this chapter, the proposed formula by ACI371R-08 for calculation of the nominal shear strength of RC pedestal is evaluated and verified. The chapter addresses the beneficial effects of axial compression in enhancing the shear strength of RC shear walls and investigates the similar effect in the RC pedestals.

Finally, Chapter 9 provides a summary and conclusions from the study. The chapter also presents a number of recommendations for further studies and future works. The list of references is provided at the end of the thesis. 


\section{Chapter 2 \\ Literature review}

\subsection{General}

This chapter presents a comprehensive literature review on seismic response of reinforced concrete (RC) elevated water tanks. In Section 2.2, performance of elevated water tanks under earthquake loads and reported damages is discussed. Previous research studies on dynamic properties of elevated water tanks is reviewed and summarized in Section 2.3. A number of the results and conclusions of these studies are also included in this section. Finally, Section 2.4 provides a literature review on seismic response and response modification factors. The most commonly known codes and guidelines related to design and analysis of elevated water tanks are introduced in this section as well.

\subsection{Performance of elevated water tanks under earthquake loads}

Elevated water tanks have had poor and occasionally catastrophic seismic performance during many severe earthquakes in the past. The types of damages have been ranging from minor cracks to complete collapse and failure of the tank and RC pedestals. Several examples of elevated water tank failure are reported during strong ground motions such as 1960 Chile (Steinbrugge and Cloough, 1960), 1990 Manjil-Roudbar (Memari and Ahmadi, 1990), 1997 Jabalpur(Rai, 2002), and 2001 Gujarat (Durgesh C Rai, 2002). On the other hand, as a significant part of lifelines, elevated water tanks must remain functional after severe earthquake in order to provide potable water and also supply heavy water demand for possible firefighting operations.

During 1990 Manjil-Roudbar earthquake, a $1500 \mathrm{~m}^{3} \mathrm{RC}$ elevated water tank with a height of 47 meters collapsed (Memari and Ahmadi, 1990). The concrete pedestal inside diameter was 6 

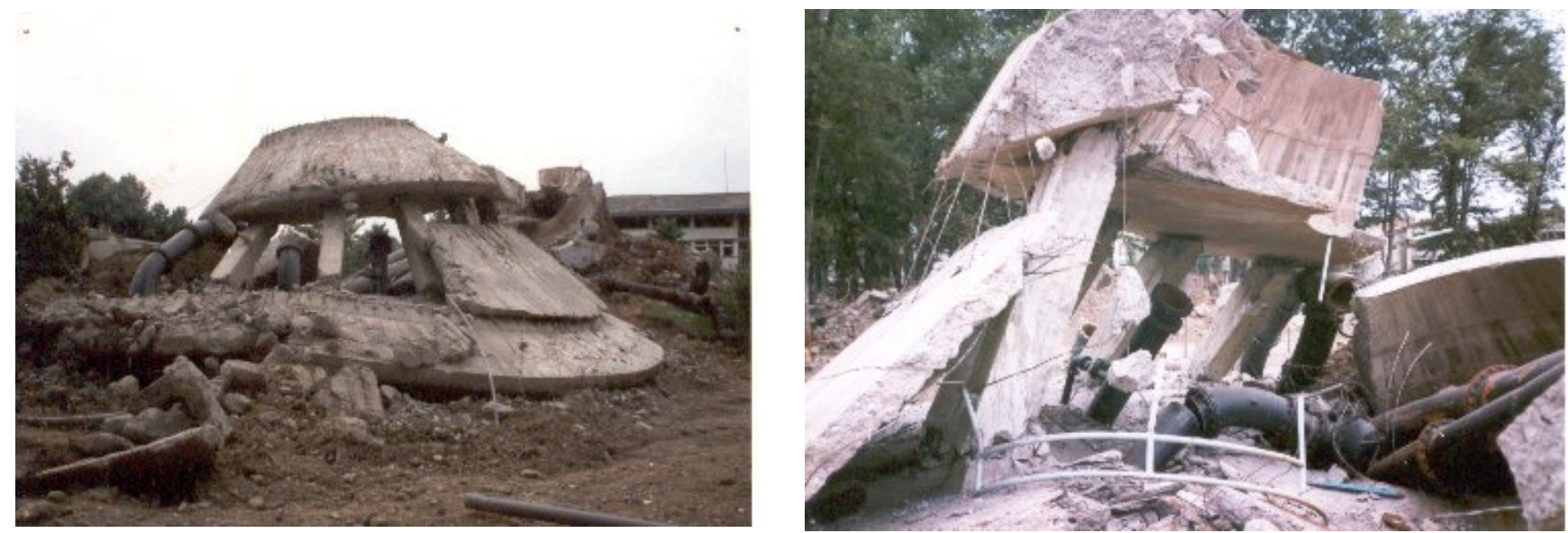

Figure 2.1 Debris and remaining of the collapsed $1500 \mathrm{~m}^{3}$ water tower in Rasht during ManjilRoudbar earthquake (Building and Housing Research Center, Iran 2006)

meters with a height of 25.5 and wall thickness of 0.3 meters. Figure 2.1 shows the debris of this collapsed elevated water tank. The water distribution was disturbed for many weeks after the failure of this structure.

Another elevated water tank with a height of $50 \mathrm{~m}$ and tank capacity of $2500 \mathrm{~m}^{3}$, which was empty at the time of earthquake, is depicted in Figure 2.2(a). The pedestal structure received peripheral cracks above the opening in the RC pedestal wall (Memari and Ahmadi, 1990). The pedestal inner diameter was 7 meters with a height of 25 meters and wall thickness of 0.5 meters. The foundation was a 20 meters diameter mat which in turn was supported by 24 piles. Several years after the earthquake, a retrofitting plan was developed and constructed around the $\mathrm{RC}$ pedestal as shown in Figure 2.2(b).

During the 1960 earthquake in Chile, one RC elevated water tank in Valdivia region received severe damages (Steinbrugge and Cloough, 1960). The RC pedestal was 30 meters high and 14.5 meters in diameters and the tank was empty at the time of earthquake. The thickness of the 
pedestal wall was $200 \mathrm{~mm}$ and the pedestal was supported on spread footing located on the firm soil. The damage was severe throughout the entire structure and wide cracks were visible.

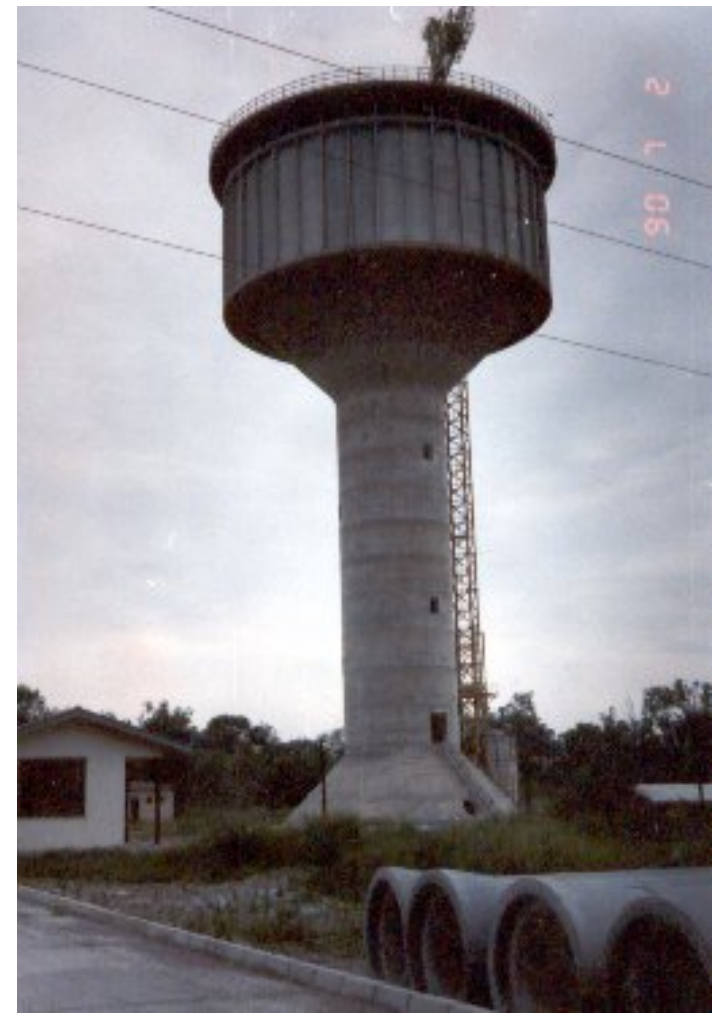

(a)

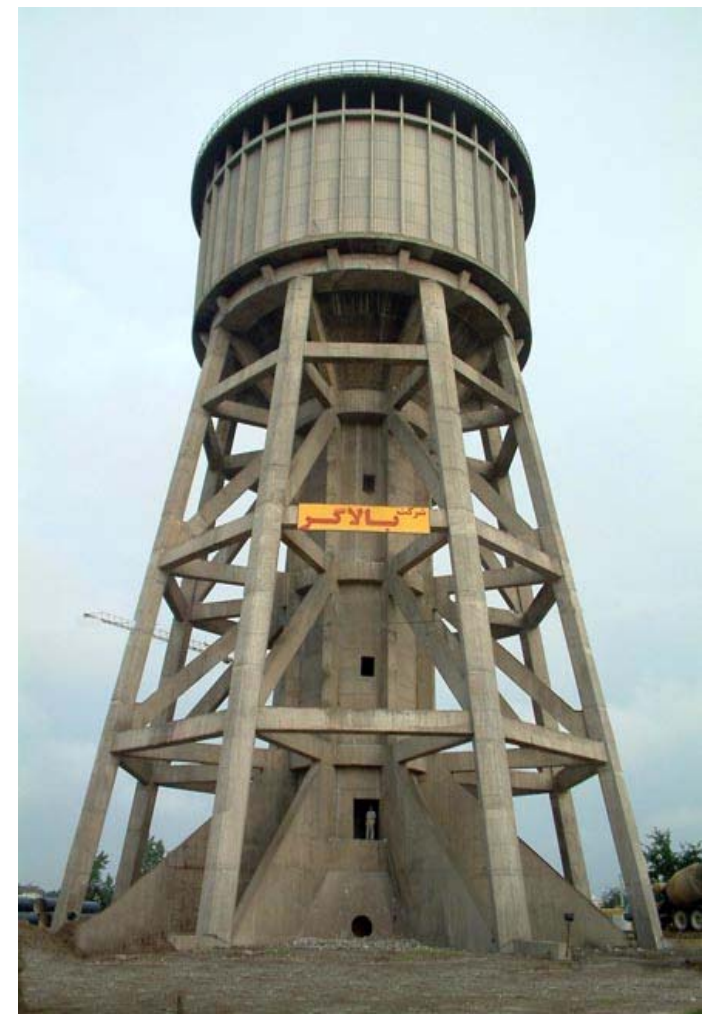

(b)

Figure 2.2 The $2500 \mathrm{~m}^{3}$ water tank which partly damaged in Manjil-Roudbar earthquake (Memari and Ahmadi, 1990); (a) Before earthquake (b) finalized retrofitting and strengthening plan (Balagar construction Co., 1998)

In the 1997 Jabalpur earthquake, two concrete elevated water tanks supported on 20 meters tall shafts developed cracks near the base (Rai, 2002). The Gulaotal elevated water tank was full during the earthquake and suffered severe damages. This tank developed flexural-tension cracks along half its perimeter, as shown in Figure 2.3(c). The flexure-tension cracks in shafts appeared at the level of the first lift and a plane of weakness, at $1.4 \mathrm{~m}$ above the ground level.

During the Gujarat earthquake of 2001, many elevated water tanks received severe damages at their RC pedestals. It has been reported that at least three of them collapsed as demonstrated in 
Figure 2.3(b) (Durgesh C Rai, 2002). The shaft heights were ranging from 10 to 20 meters and the wall thickness varied between $150 \mathrm{~mm}$ to $200 \mathrm{~mm}$. For most damaged structures, the flexure cracks in shaft walls were observed from the level of the first lift to several lifts reaching onethird the height of the shaft, as shown in Figure 2.3(a). These cracks were in a circumferential

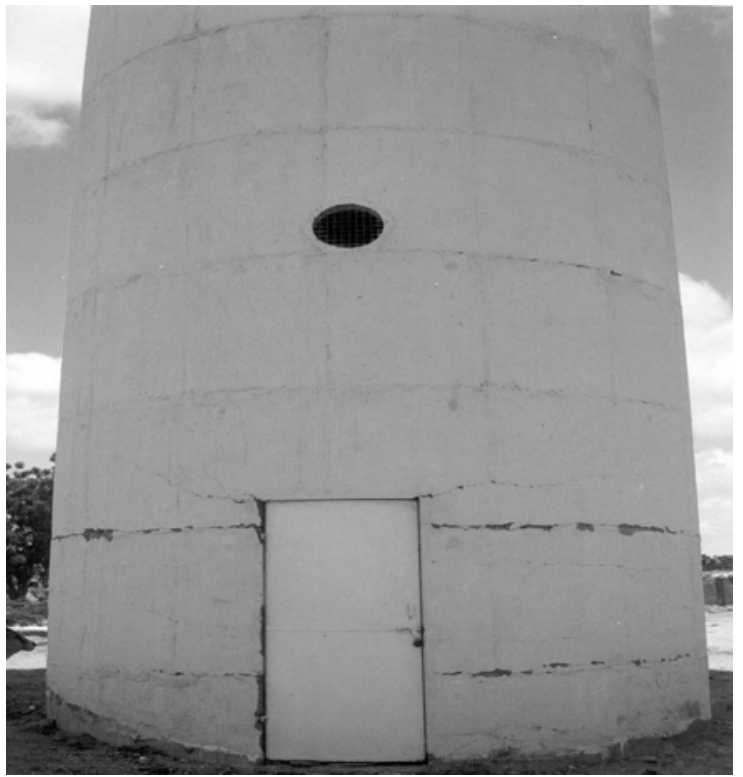

(a)

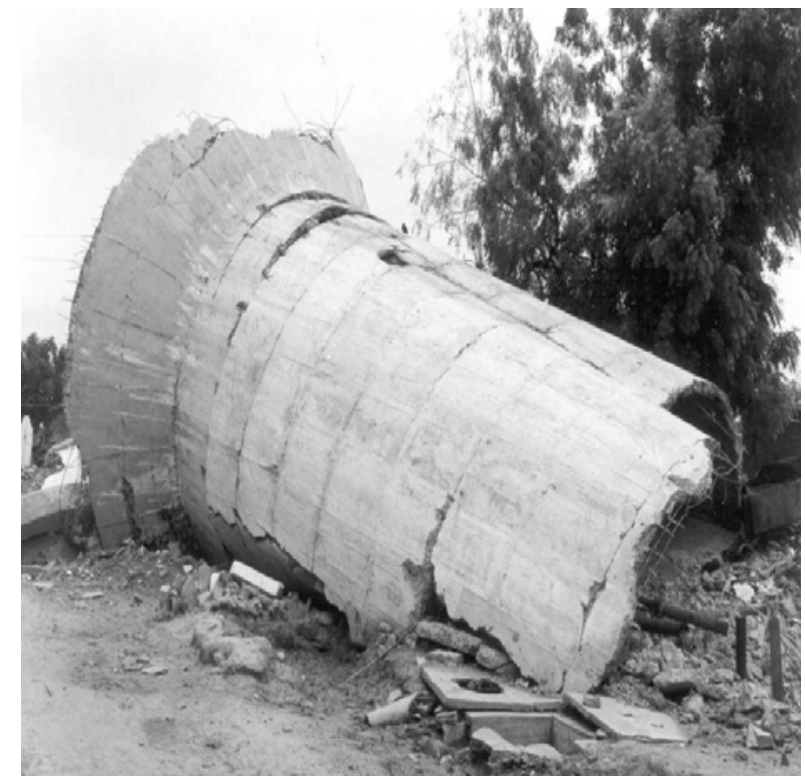

(b)

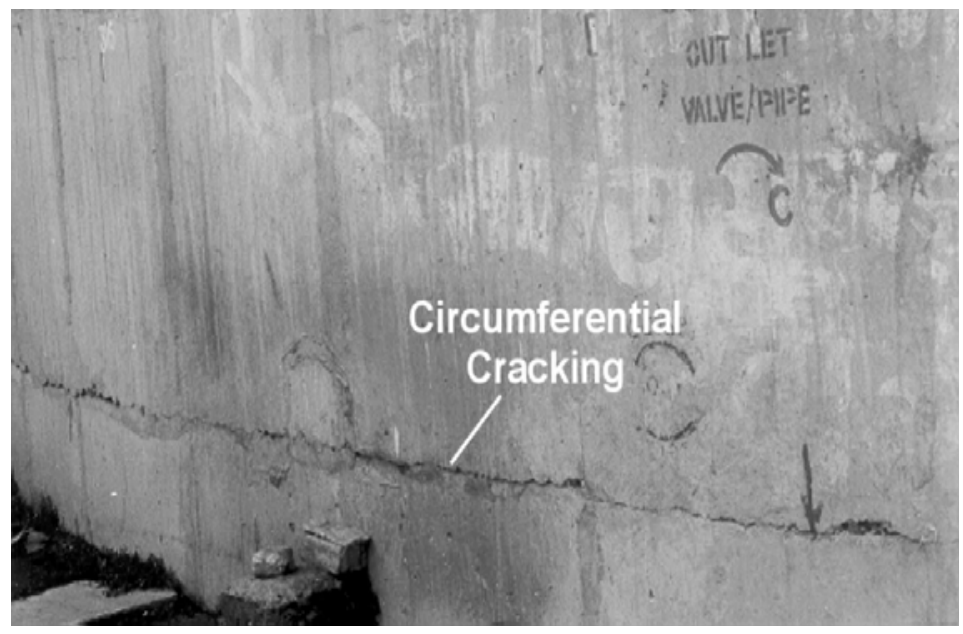

(c)

Figure 2.3 (a) $200 \mathrm{~m}^{3}$ Bhachau water tank with circumferential cracks in 2001 Gujarat 2001 earthquake (Durgesh C Rai, 2002) (b) Collapsed $265 \mathrm{~m}^{3}$ water tank in 2001 Gujarat earthquake (Durgesh C Rai, 2002) (c) Horizontal flexural-tension cracking near the base of Gulaotal water tank in 1997 Jabalpur earthquake (Rai, 2002) 
direction and covered the entire perimeter of the shaft.

\subsection{Previous research}

The number of research studies which investigated the nonlinear seismic response of RC pedestal of elevated water tanks is surprisingly very limited. Although Extensive research work on dynamic response of liquid storage tanks began in late 1940s, only a handful research studies could be found that have analyzed the nonlinear seismic behaviour of the RC pedestals individually. This section is divided into two parts. First, a brief review of research works related to seismic response of liquid-filled tanks is presented. Second part is a comprehensive literature review on the research studies regarding seismic response of elevated water tanks.

\subsubsection{Seismic response of liquid-field tanks}

Housner (1964) performed the first investigation to address the seismic response behaviour of both ground and elevated water tanks subjected to earthquake lateral loads. In this study, Housner proposed a formulation for modeling the dynamic response of the water inside the tanks which is still being widely used in engineering practice. Many current codes and guidelines such as ACI 350.3-06 and ACI 371R-08 have adapted the original Housner formulation only by applying a few adjustments.

According to Housner's proposed formulation the hydrodynamic response is divided into two components of impulsive and convective vibration. The impulsive mode of vibration is assumed to be attached to the tank wall (rigid connection). On the other hand the convective motion is the oscillation of the water surface which is modeled as a lumped mass connected to the wall using springs and has a longer period of vibration. Figure 2.4 demonstrated proposed model by 
Housner for both ground supported and elevated water tanks. As shown in Figure 2.4, the impulsive and convective components are modeled using a lumped mass. For the elevated tank model, the impulsive mass $\left(\mathrm{M}_{0}^{\prime}\right)$ represents equivalents mass of structure and impulsive mass of water.

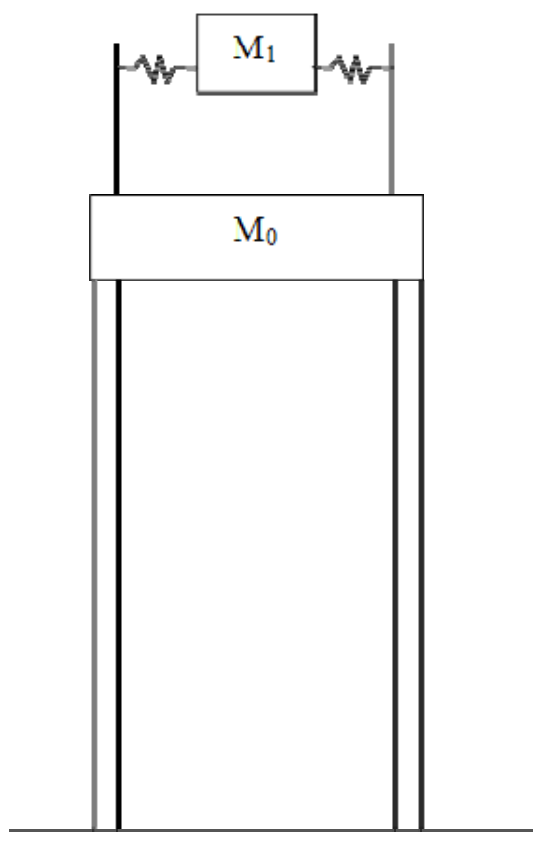

(a)

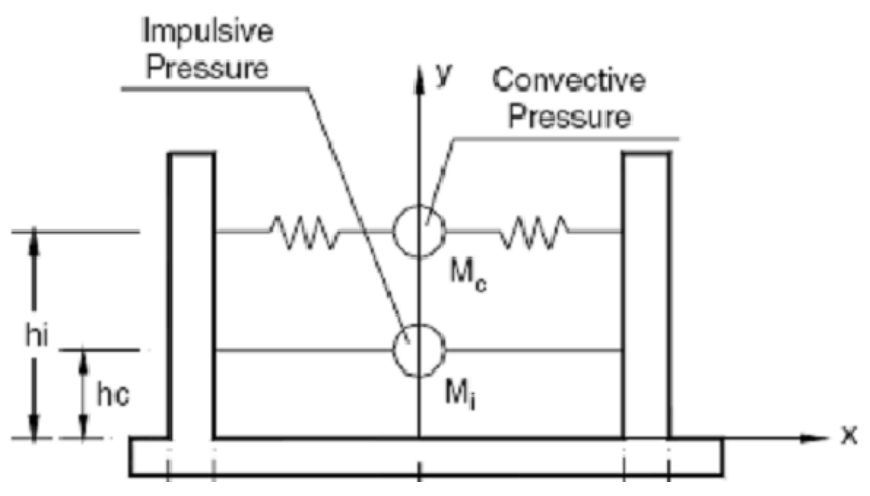

(b)

Figure 2.4 Equivalent dynamic system of liquid tanks(a) elevated water tank (b) Ground supported tank (Housner, 1964)

Veletsos and Tang (1986) analyzed liquid storage tanks subjected to vertical ground motion on both rigid and flexible supporting staging. It was concluded that soil-structure interaction could reduce the hydrodynamic effects.

El Damatty et al. (1997) developed a numerical model for studying the stability of liquidfilled conical tanks subjected to seismic loading. In this study, using a finite element method, free vibration analysis was performed and dynamic stability of conical tanks was investigated. The finite element method was able to model both geometrical and material nonlinearity. By 
performing nonlinear dynamic analysis using the horizontal and vertical components of $1971 \mathrm{San}$ Fernando earthquake it was shown that a number of tall tanks responded nonlinearly due to the localized buckling near the base of the tank. Based on similar results obtained from tall tanks it was concluded that the conical tanks, were very sensitive to seismic loading and must be designed for large static load factors in order to not collapse under strong ground motions. It was also shown that the vertical acceleration contributes significantly to the dynamic instability of liquid-filled conical vessels and cannot be ignored in a seismic analysis.

In an experimental study, El Damatty et al (2005) investigated the dynamic response behavior of liquid filled combined conical shells (tank vessels). Combined conical vessels consist of a conical part at the bottom and a cylindrical part on the top and are widely used in North America. Shaking table tests were performed on a small-scale aluminum combined conical tank and the results were in very good agreement with numerical and analytical methods.

\subsubsection{Seismic response of elevated water tanks}

In one of the earliest studies on seismic response of elevated water tanks, Shepherd (1972) validated the accuracy of the two mass representation of the water tower structures by comparing the theoretical results to the results of a dynamic test on a prestressed concrete elevated water tank. The dynamic response characteristics of the sample elevated water tower were calculated by using the Housner's method. A number of pull-back tests were performed on the water tower and the vibration of the tank was recorded. The comparison of the theoretical and experimental tests proved the efficiency and acceptable accuracy of the theoretical two mass modelling of elevated water tanks. 
Haroun and Ellaithy (1985) studied inelastic seismic response of braced towers supporting tanks. They developed a computer program to analyze the inelastic behavior of cross braced towers supporting the tanks. It was concluded that a lighter bracing system had a better seismic performance due to inelastic response and energy dissipation.

Memari and Ahmadi (1992) investigated the behaviour of two concrete elevated water tanks during the 1990 earthquake of Manjil-Roudbar. Finite element models of both structures were developed and design loads and actual loads were compared. They concluded that although the tanks were designed based on the standards of the construction time, the design loads were almost one fifth the design loads of the current standards. They also concluded that the sloshing and P- $\Delta$ effect was very minor in concrete elevated tanks. The single degree of freedom model was also known to be inadequate in modeling elevated water tanks and predominant mode of failure was indicated to be flexural (not shear).

Rai (2002), Investigated the seismic retrofitting of RC pedestal of elevated tanks by conducting a case study. The dynamic properties of the prospective tank and seismic demand levels where compared using models of Housner (1963) and Malhotra et al. (2000). Reinforced concrete jacketing was selected as the retrofitting plan solution mainly due to the convenient construction method. It was shown that concrete jacketing could change the failure mode from the concrete crushing to a more ductile tension yielding.

Sweedan and Damatty (2003) conducted an experimental program to evaluate the dynamic characteristics of liquid-filled conical elevated tanks. A number of shake table tests were performed on a small-scaled aluminum conical tank. The results of the tests were in very good agreement with a previous numerical method proposed by the same authors. 
Rai (2003) studied the performance of elevated tanks in Bhuj earthquake of 2001. Based on this investigation, it was concluded that although the elevated tank supports (both frame and cylindrical shaft) were designed according to the design codes of the time (in India), the designs did not satisfy the international building code requirements and therefore extremely vulnerable when subjected to severe ground motion. Lack of redundancy was pointed out to be extremely serious in RC pedestals mostly for the reason that lateral stability of the structure depends on pedestal alone whose failure will result in loss of integrity and collapse of the whole structure. The study concludes that in shaft type supports, the thin shaft walls are not able to dissipate the seismic energy due to lack of redundancy. Moreover the study recommends that circular thin concrete sections with high axial load behave more in a brittle manner at the flexural strength and, therefore, should be avoided.

Rai et al. (2004) carried out an analytical investigation and case study to assess seismic design of RC pedestal supported tanks. According to the damage pattern during previous earthquakes it was observed that for tanks with large aspect ratio which have long natural periods, flexural behaviour was more critical than shear under seismic loads. However, for very large tank capacities designed according to ACI $371 \mathrm{R}-08$ provisions, shear strength usually controlled design of the pedestal wall. The study suggests that ignoring the beneficial effects of axial compression could explain why the shear force was governing the design of shaft structures. The case study revealed that shear demand was more for empty tank rather than for the full tank condition. The range of wall thickness for the set of analyzed elevated tanks was between $125 \mathrm{~mm}$ to $250 \mathrm{~mm}$ and the shaft height varied between $11 \mathrm{~m}$ to $20 \mathrm{~m}$. For the 8 tanks analyzed in this research it was concluded that for all shaft aspect ratios of empty tanks, flexure strength was 
the governing failure mode. On the other hand for full tanks mounted on stiffer shafts, shear failure was proved to be the governing mode.

Livaoglu and Dogangun (2005), proposed a method for seismic analysis of "fluid-elevated tank-foundation" systems. The method provided an estimation of the base shear, overturning moment, displacement of supporting system and sloshing displacement. It was shown that the sloshing response was not basically affected by soil properties. Furthermore, it was proved that while embedment length in stiff soil did not affect roof displacement and base shear force, for relatively soft soil this was not the case and the effects of embedment length was not negligible. Generally, softer soils, increased roof displacements and decreased the base shear and overturning moment.

In another study, Livaoglu et al. (2007) analyzed the effect of foundation embedment on seismic behavior of elevated tanks using a finite element model. Two types of foundation with and without embedment were investigated. It was concluded that for soft soils, the foundation embedment has more influences on the system behaviour. On the other hand, it was shown that for stiff soils the effect of foundation embedment was negligible. This study also concluded that a larger embedment ratio decreases the lateral displacement at roof level.

Dutta et al. (2009) studied the dynamic behavior of concrete elevated tanks (both RC pedestal and frame staging) with soil structure interaction by means of finite element analysis and small scale experimentations. This study concluded that generation of axial tension in the tank staging should be commonly expected is in the empty-tank condition, while base shear is principally governed by full tank condition. Furthermore, the effect of soil-structure interaction was shown to produce considerable increase in tension at one side of the staging in comparison to fixed 
support condition. The study also indicates that soil-structure interaction may significantly change impulsive lateral period.

Nazari (2009) conducted a research to investigate the existing approach in the design of elevated water tanks. The seismic response of an elevated water tank, designed according to the current practice was investigated by performing a nonlinear static finite element analysis. The seismic response factors of the elevated water tank were calculated and the response modification factor was determined accordingly based on ATC 19 (1995) method. The response modification factor was determined to vary from 1.6 to 2.5 for different regions of Canada.

Shakib et al. (2010) employed a finite element procedure to study the seismic demand in concrete elevated water tanks (frame staging). Three reinforced concrete elevated water tanks were subjected to seismic loads and nonlinear reinforced concrete behavior was included in the finite element model. Through this study it was concluded that the maximum response did not necessarily occur in the full tanks. The study also showed that by simultaneously decreasing the stiffness of the reinforced concrete frame staging and increasing of the mass, the natural period of the structure increased.

Moslemi et al. (2011) employed the finite element technique to investigate the seismic response of liquid-filled tanks. The free vibration analyses in addition to transient analysis using modal superposition technique were carried out to investigate the fluid-structure interaction problem in elevated water tanks. It was concluded that Modal FE analyses resulted in natural frequencies and effective water mass ratios very close to those obtained from Housner's formulations with differences for water mass ratios smaller than $3 \%$ of the total mass of the fluid for all cases. The method's accuracy was confirmed by comparing the results with experimental 
results available in literature. Furthermore, the computed FE time history results were compared with those obtained from current practice and a very good agreement was observed.

\subsection{Other related studies}

\subsubsection{Response modification factor}

Response modification factor ( $\mathrm{R}$ factor) is one of the most critical elements affecting the seismic design of structures, yet many uncertainties exist for establishing this factor. Incorrect selection of $\mathrm{R}$ factor could change the design seismic loads significantly. The $\mathrm{R}$ factor is defined as the ratio of the maximum force that would develop in a completely elastic system under lateral loading to the calculated maximum lateral load in the structure based on code provisions. Currently R factor is being widely used in seismic design codes all over the world.

The first proposals for $\mathrm{R}$ factor were for the most part based on judgment and comparisons with the known response characteristics of seismic resisting systems employed at the time. There has been many advances in the seismic resisting systems utilized in modern structures and a number of them were never subjected to extreme ground motions hence there is little knowledge about actual performance of such seismic resisting systems. This issue generates the need for further research and development of a reliable method for establishing $\mathrm{R}$ factor.

Response modification factor was proposed by ATC-3-06 for the first time in 1978. The idea was based on the fact that most new structures, which were constructed based on code provisions, were able to resist higher loads than design loads due to the ductile behavior and reserved strength in structural members. There was not adequate scientific basis for the proposed $\mathrm{R}$ factor values in this report. In fact, engineering judgment and committee consensus on the 
basis of approximate value of damping, stiffness and previous performance of similar structures under past earthquakes, were employed for development of proposed $\mathrm{R}$ factor values.

One of the first experimental studies to establish R factor was carried out at the University of California in the mid-1980s. In one test, Uang and Bertero(1986) developed force-displacement curves for a code-compliant concentrically braced steel frame. Whittaker et al (1987), performed similar test on eccentrically braced steel frame. Later on, Berkley researchers proposed the first formulation for $\mathrm{R}$ factor which represented response modification factor as the product of strength factor $\left(\mathrm{R}_{\mathrm{s}}\right)$, ductility factor $\left(\mathrm{R}_{\mu}\right)$ and damping factor $\left(\mathrm{R}_{\xi}\right)$.

Many other researchers studied response modification factor in the early 1990s. Freeman (1990) proposed response modification factor as the product of strength-type factor and a ductility-type factor. Later, Uang (1991) proposed R factor as the product of overstrength factor $(\Omega)$ and ductility reduction factor $\left(\mathrm{R}_{\mu}\right)$. The damping factor which was previously proposed in the first formulation was not included explicitly in this equation. The effect of damping was assumed to be implicitly considered in ductility reduction factor. Furthermore, it was concluded that using a constant value for $\mathrm{R}$ factor does not ensure the same level of safety against collapse for all structures. It was also indicated that it was necessary to calculate overstrength of the building throughout the design or assessment procedure to make sure the overstrength is not less than the one employed in establishing the $\mathrm{R}$ factor.

In 1995, ATC 19 was published with the main objective of establishing rational basis for development of $\mathrm{R}$ factor for different structures. In this new proposed formulation, $\mathrm{R}$ factor was the product of period-dependent strength factor $\left(\mathrm{R}_{\mathrm{s}}\right)$, period dependent ductility factor $\left(\mathrm{R}_{\mu}\right)$ and redundancy factor $\left(\mathrm{R}_{\mathrm{R}}\right)$. 
Since the proposal of the first $\mathrm{R}$ factor formulation, many research studies have been performed on the essential components of response modification factor independently. Osteraas and Krawinkler (1990), studied reserve strength and ductility for distributed, perimeter and concentric moment frames. Strength factor was reported to range from 1.8 to 6.5 for the three framing systems. It was also shown that strength factor depends on period of the structure and higher period structures demonstrated less strength factor. Uang and Maarouf (1993) analyzed a six story reinforced concrete moment frame building under 1989 Loma prieta earthquake and strength factor was reported to be 1.9 .

Hwang and Shinozuka (1994) analyzed a four story reinforced concrete intermediate moment frame and reported a value of 2.2 as the strength factor.

Mwafy and Elnashai (2002) studied response modification factors adopted in modern seismic codes by analyzing 12 medium-rise RC buildings, employing inelastic pushover and incremental dynamic collapse analyses technique. It was concluded that including shear and vertical motion in assessment and calculations of $\mathrm{R}$ factor was necessary. It was also concluded that Force reduction factors adopted by the design code (Eurocode 8 ) were over-conservative and could be safely increased particularly for regular frame structures designed to lower PGA and higher ductility levels.

In another study, Mwafy and Elnashai (2002) addressed horizontal overstrength in modern code-designed RC buildings. In this study, the lateral capacity and the overstrength factor were estimated by means of inelastic static pushover as well as time-history collapse analysis for 12 buildings of various characteristics representing a wide range of contemporary RC buildings. The study showed that the buildings designed to low seismic intensity levels showed high 
overstrength factors as a result of the dominant role of gravity loads. Also the minimum observed overstrength factor was reported to be 2 .

Many researchers have studied ductility factor $(R \mu)$ in the past decades. One of the earliest studies is the one by Newmark and Hall (1982) in which ductility factor is presented in the form of a piecewise function and does not include soil type effects. Krawinkler and Nassar (1992) developed a relationship for SDOF systems on rock or stiff soil sites. They used the results of a statistical study based on 15 Western U.S. ground motion records from earthquakes ranging in magnitude from 5.7 to 7.7 .

Miranda and Bertero (1994) developed " $\mathrm{R}_{\mu}-\mu-T$ " relationships for rock, alluvium, and soft soil sites, using 124 recorded ground motions. Relationships proposed by Krawinkler and Miranda result in very similar values for ductility factor.

While extensive research studies have been carried out to establish and quantify strength factor $\left(\mathrm{R}_{\mathrm{s}}\right)$ and period dependent ductility factor $\left(\mathrm{R}_{\mu}\right)$, very few have addressed redundancy factor $\left(R_{R}\right)$. This could be explained mainly by the fact that quantifying redundancy factor is a complicated task and it could not be directly measured.

A study by Moses (1974) was among the first efforts for studying redundancy factor. This study indicated the reliability of the framing system was higher than that of individual members. It was also concluded that a partial safety factor less than or equal to one was appropriate for a redundant system.

Gollwitzer and Rackwitz (1990) showed that significant extra reliability in small systems was only available if the components were weakly dependent and have fairly ductile stress-strain behavior and if the variability of strength was not considerably affected by the load variability. It was also explained that redundant structural systems provided significant extra reliability only if 
the components were not highly correlated. Furthermore, it was concluded that for small brittle systems, there was a negative effect of redundancy for small coefficients of variation.

Wang and Wen (2000) proposed a method for calculating a uniform-risk redundancy factor as a ratio of spectral displacement capacity (for incipient collapse) over the spectral displacement corresponding to a specified allowable probability of incipient collapse.

Husain and Tsopelas (2004) introduced the redundancy strength index $r_{s}$ and the variation strength index $r_{v}$, in order to quantify the effects of redundancy on structural systems. A parametric study using two dimensional RC frames was carried out. According to this study, increasing the member ductility capacity of ordinary RC frames significantly improves the frames redundancy. Moreover, for RC frames with a member ductility ratio of 10 or more, increasing member ductility did not add significantly to the frames redundancy. It was concluded that moderately ductile and ductile RC frames develop basically the same number of plastic hinges at failure, which in turn means that the redundancy variation index $r_{v}$ remains unchanged and the only contribution to redundancy comes from the redundancy strength index $r_{s}$.

In another research, Husain and Tsopelas (2004) studied the effect of factors such as the building height, the number of stories, the beam span lengths, the number of vertical lines of resistance, and the member ductility capacity on the structural redundancy of 2D frames. An equation for quantifying redundancy factor was proposed and the required parameters involved in the expression could be obtained from a nonlinear pushover analysis of a structure.

The most recent approach for evaluating response modification factor is the one proposed by FEMA P695 (2009). The methodology proposed by FEMA P695 is fundamentally different with all other proposed approaches for quantifying response modification factor. This method combines code design concepts, static and dynamic nonlinear analysis, and risk and probability 
based procedure. Unlike other methods in which response modification factor is established as a product of two or three components, FEMA P695 establishes R factor by assessing and evaluation of trial values and confirms the one that best matches the required performance level of the structure. In fact, instead of explicit calculation of $\mathrm{R}$ factor, the proposed values for $\mathrm{R}$ factor are validated through the recommended procedure by FEMA P695.

\subsubsection{Design codes and standards}

This section addresses codes and guidelines available in North America for the design and analysis of elevated water tanks. Some of these references are merely providing recommendations while the others are more regulatory. In the following sections a number of widely used codes and guidelines will be briefly discussed.

ACI 318-08 includes general building code requirements for structural concrete. This standard covers the material, design, and construction of structural concrete used in buildings and where applicable in non-building structures. The materials in this code are employed with some modifications for analysis and design of concrete elevated tank components such as RC pedestal and foundation design. However, the requirements for design and analysis of concrete elevated tanks are not directly addressed.

ACI 371R-08 is the most important document that specifically provides guidelines for analysis, design, and construction of elevated concrete and composite steel-concrete water storage tanks. The seismic provisions for design of the RC pedestals have been entirely covered in this guideline. This guide refers extensively to ACI 350 for design and construction of those components of the structure in contact with the stored water, and to ACI 318 for design and 
construction of components not in contact with the stored water. The guide also refers to ASCE/SEI 7-2010 for determination of snow, wind, and seismic loads.

ACI 350.3-06 is the most widely used standard for design and analysis of ground supported water tanks. However, guidelines on pedestal supported elevated tanks is also provided in this document. Prescribing procedures for the seismic analysis and design of liquid-containing concrete structures is the main aim of this standard. The design procedure is based on Housner's model in which the boundary condition is considered rigid and hydrodynamic pressure is treated as added masses applied on the tank wall. Also rather than combining impulsive and convective modes by algebraic sum, this standard combines these modes by square-root-sum-of-the-squares. This standard includes the effects of vertical acceleration and also an effective mass coefficient, applicable to the mass of the walls. The dynamic response of tank wall is analyzed by modeling the tank wall as an equivalent cantilever beam.

ASCE/SEI 7-2010 provides minimum load requirements for the design of buildings and other structures that are subject to building code requirements. Loads and appropriate load combinations, which have been developed to be used together, are set forth for strength design and allowable stress design. Although this guideline does not directly address the design and analysis of elevated water tanks, some recommendations are applicable and necessary in the design procedure of elevated tanks. Response modification factor, response spectra, base shear calculation and environmental loads are among these important inputs.

ANSI/AWWA D100-96 provides guidelines for design, manufacture and procurement of welded steel tanks for the storage of water. Chapter 13 of this standard briefly provides guidelines for seismic design and analysis of elevated water tanks. Seismic design and provisions of Pedestal-type elevated water tanks has been directly addressed and discussed in this standard. 
The IBC 2000 Code, similar to ASCE/SEI 7-2010, is a general design code. In quite the same manner as ASCE code, this standard indirectly addresses some design aspects of the tanks. This standard covers material, design, fabrication, and testing requirements for vertical, cylindrical, aboveground, closed- and open-top, welded steel storage tanks in various sizes and capacities. Appendix E of this standard provides some guidelines for seismic design of welded steel tanks. 


\section{Chapter 3}

\section{Analysis methods}

\subsection{General}

This chapter describes seismic analysis methods employed in this thesis for studying nonlinear static and dynamic response behaviour of pedestal structures in reinforced concrete (RC) elevated water tanks. The design and analysis of concrete pedestals as will be explained in more details in Chapters 5 and 6 is carried out in four steps and each step is performed using a specific analysis method. These four steps are addressed and function and purpose of each one is explained in this chapter. The general equations and formulation for each analysis method is briefly reviewed. The finite element approach is used for modelling of the structures and performing the analysis.

Design of pedestals according to the current codes and standards is the first step for establishing idealized numerical model. Nonlinear static analysis as a powerful method for evaluation and development of seismic response parameters of pedestal is the second step that is addressed in this chapter. In addition, sources of nonlinearity in the nonlinear seismic analysis along with interpretation of load deformation graphs are briefly reviewed.

This chapter continues with discussing the equations of transient dynamic analysis as the third step which is also the most accurate one. Only the nonlinear transient dynamic analysis is employed in this research. The formulations for transient dynamic analysis are illustrated and followed by explaining incremental dynamic analysis method. This analysis method is the last step of evaluation of RC pedestals and is used for establishing the collapse margin ratio and eventually verification of the response modification factor. 


\subsection{Methods of seismic analysis}

Selection of analysis method for seismic design depends on many factors such as the structure type and configuration, design goals and performance, seismic design category, and importance of the structure. In general, analysis methods could be divided into two main categories of static and dynamic analysis. On the other hand, each one of static and dynamic analysis could be performed as linear or nonlinear. Figure 3.1 demonstrates four categories of seismic analysis conducted in this research. Modal and spectral analyses are other categories of dynamic analysis which are excluded in Figure 3.1 as they are not employed in this study.

Code based seismic analysis is used for design of elevated tank prototypes (numerical model) according to ACI 371R-08 and is classified as static linear analysis. Code based design is also known as equivalent static analysis since the lateral dynamic load of earthquake is simplified as an equivalent static lateral load. Nonlinear static (pushover) analysis is also categorized as static analysis except the nonlinearity and failure mechanism of material is also included. This type of

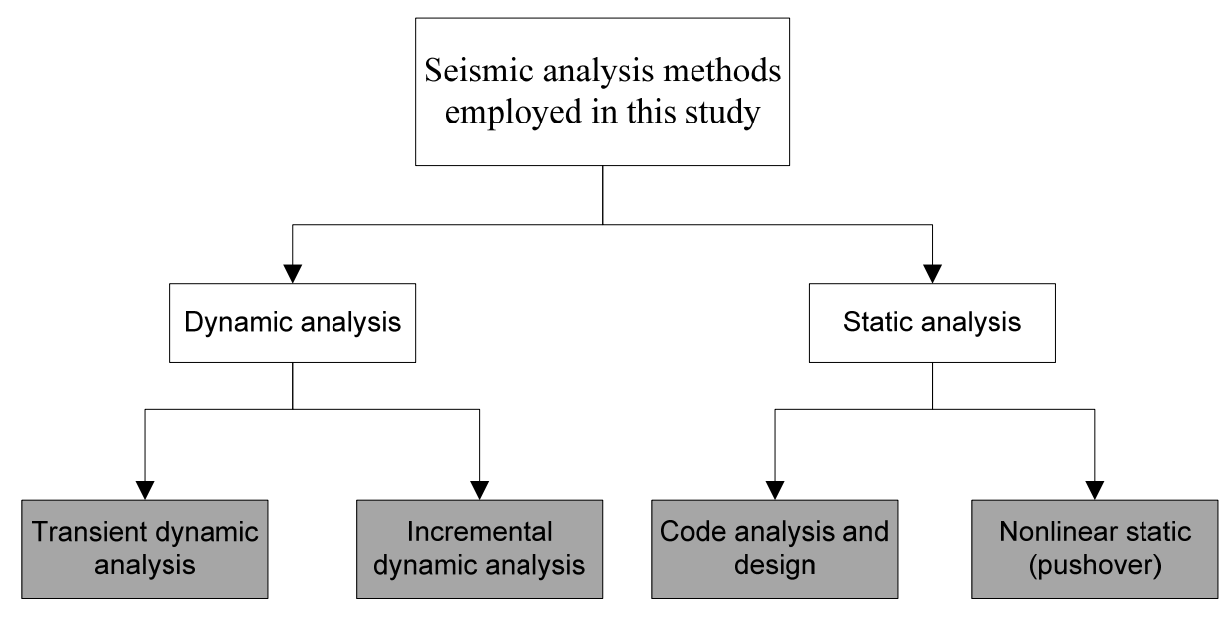

Figure 3.1 Flowchart of seismic analysis methods employed in this study 
analysis is much more elaborate and time consuming than code based analysis. Transient dynamic analysis is the most accurate method for finding the actual response of structures subjected to strong ground motions.

Transient dynamic analysis could be performed as linear or nonlinear. In this research study, the nonlinear transient dynamic analysis is carried out. This analysis technique is the most accurate and sophisticated method for validation and analysis of the actual nonlinear response of structures subjected to seismic loads.

Incremental dynamic analysis is an application of nonlinear transient dynamic analysis in which the response of structure is analyzed by increasing the intensity of earthquake records.

\subsubsection{Nonlinearity in reinforced concrete structure analysis}

In general there are different categories of nonlinear response that could be observed in the reinforced concrete structures. In this research, two types of nonlinear behavior known as "geometrical nonlinearity" and "material nonlinearity" are considered for inclusion in the finite element modeling of concrete pedestal structure.

Geometrical nonlinearity is usually the result of large deformations in either the structure's elements (local) or the entire structure (global). Large deformations could affect the analysis of the structure by changing the stiffness matrix and therefore the equilibrium equation of the structure.

The most common effect of geometric nonlinearity is generally known as P- $\Delta$ effect which is shown in Figure 3.2(a). When the elevated tank structure is subjected to seismic loads, large deformation at the top levels of concrete shaft takes place and combined with the considerably large gravity loads of the tank, global instability and collapse of the entire structure could occur. 
Generally, taller pedestals with large height to diameter ratio and larger tank capacities are more susceptible to P- $\Delta$ effect.

On the other hand, material nonlinearity is generated as a result of nonlinear stress-strain relationship of reinforced concrete and subsequent changes in stiffness of pedestal. During performing a pushover or nonlinear dynamic analysis, stress level in pedestal increases beyond the elastic limit of concrete as shown in Figure 3.2(b) and causes nonlinearity in stress-strain behavior.

Concrete cracking or crushing could also change modulus of elasticity and stress-strain relationship of reinforced concrete elements which will be fully addressed in Chapter 4 .

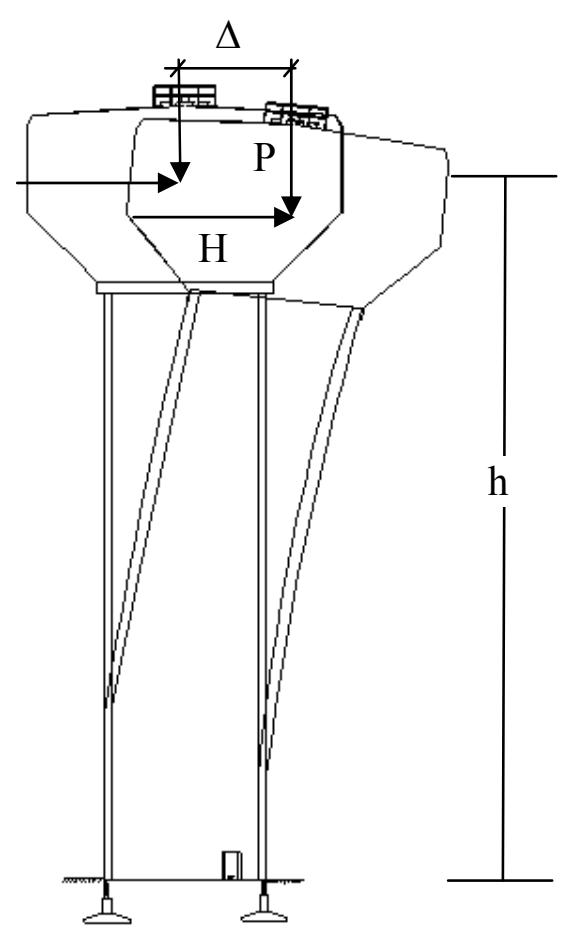

(a)

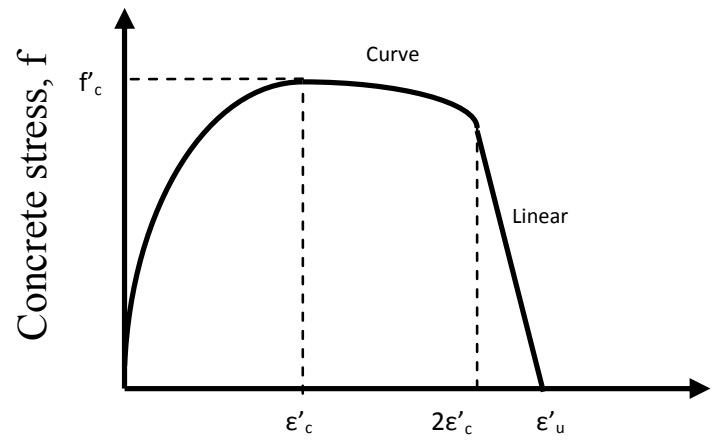

Concrete strain, $\varepsilon$

Figure 3.2 Different types of nonlinearity (a) geometrical nonlinearity (P- $\Delta$ effect) in RC pedestal (b) concrete material nonlinearity 


\subsection{Code-based analysis and design of elevated water tanks}

Static linear analysis (code-design) is the most simplified and cost effective seismic analysis and design approach which is widely used for design of variety of structures. In this method, the structure is assumed to remain linear elastic under all loading circumstances which means the modulus of elasticity of the material is constant during the analysis procedure. Moreover, plastic deformations are not modeled and therefore the deformations are not permanent.

As described in Chapter 2, design of concrete pedestal structures for elevated water tanks is primarily based on ACI 371R-08 along with ACI 350.3-06 and ASCE/SEI 7-10. Basically in code-based seismic analysis of elevated water tanks, the horizontal seismic loads are replaced with equivalent static loads applied laterally to the tank and pedestal structure. The seismic loads are computed according to ASCE/SEI 7-10 standard. In order to do so, based on the seismicity of the site and soil classification the design response spectrum is first developed.

Figure 3.3 demonstrates the design response spectrum developed according to provisions of ASCE/SEI 7-10. This procedure is explained in Chapter 5. The effective weight $\left(\mathrm{W}_{\mathrm{e}}\right)$, is calculated based on the requirements of ACI 350.3-06. Subsequently the seismic response coefficient $\left(\mathrm{C}_{\mathrm{s}}\right)$ which is a function of Importance factor, spectral response acceleration $\left(\mathrm{S}_{\mathrm{a}}\right)$ and response modification factor $(\mathrm{R})$, is determined.

The seismic base shear which is the product of seismic response coefficient and effective weight could be established at this stage. Finally, according to the distribution of mass across the height of the elevated tank, the seismic base shear is distributed in pedestal and tank vessel levels. The overturning moments at various levels are calculated and the critical section of pedestal with maximum shear and moment is found. 


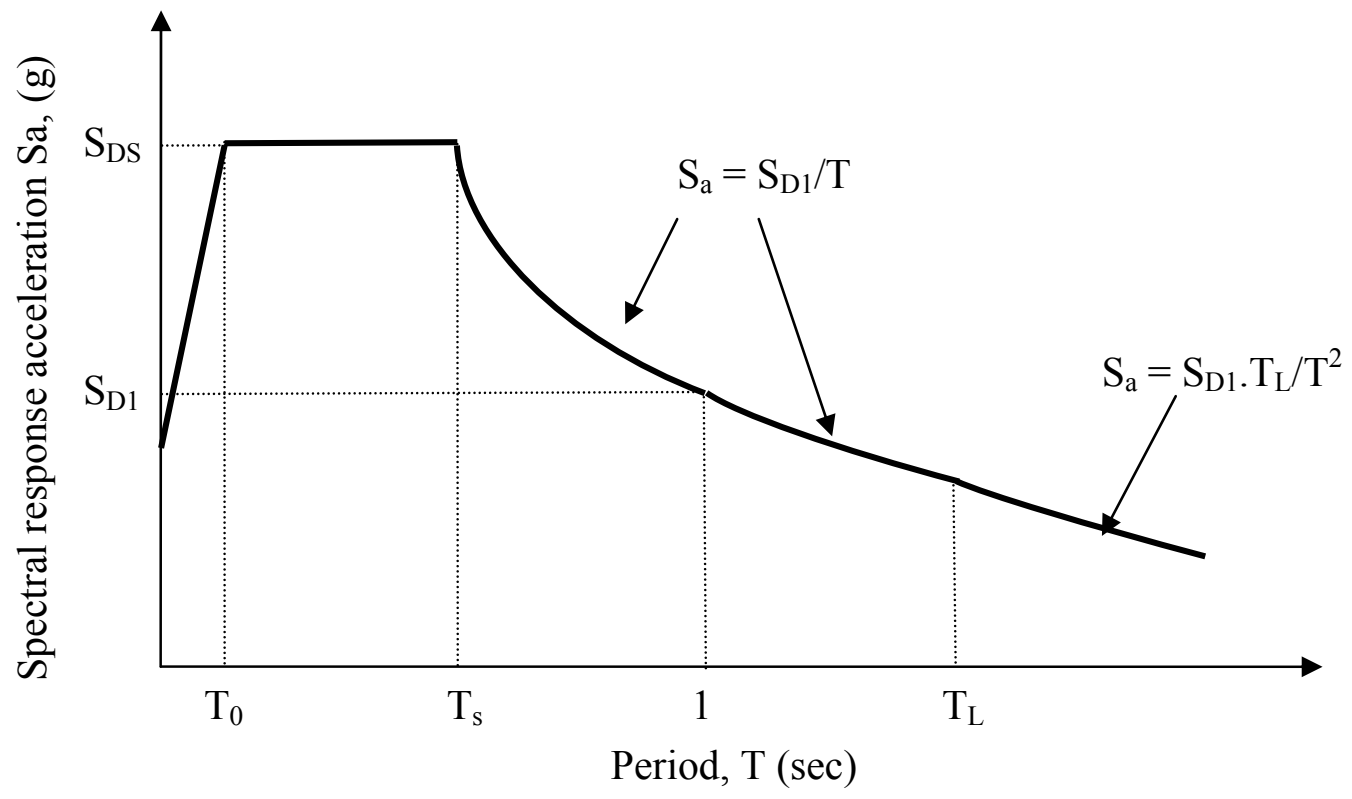

Figure 3.3 Design response spectrum developed according to provisions of ASCE/SEI 7-10 standard

\subsection{Static nonlinear (pushover) analysis}

Pushover analysis was introduced in the early 1980s and ever since has been subjected to modifications in many aspects. Originally, pushover was an analytical method for nonlinear analysis of structures and was used to establish weak points and potential structural damages during an earthquake. There are many research studies that could be found in the literature on the subject of the pushover analysis. Saiidi and Sozen (1981) and Fajfar and Gaspersic (1996) are among the first studies of the type.

Later on in 1997, National Earthquake Hazard Reduction Program (NEHRP) published FEMA 273 guideline for seismic rehabilitation of existing buildings. Pushover method or "nonlinear static procedure" according to FEMA 273 was first introduced in this guideline as a standard procedure for seismic assessment of structures. 
Based on this guideline, initially, a target displacement which can represent the maximum possible displacement the structure could undergo during an earthquake is determined according to a certain procedure. Next the pushover analysis is performed and the results of the analysis will be recorded. The results including displacement, rotation and stresses in elements are then compared to specific maximum permitted response for each element and the weak or undesirable elements are detected.

The main purpose of conducting a pushover analysis in this thesis is to establish the "pushover curve" for elevated water tanks. This curve which is also called "base shear versus roof displacement curve" could provide valuable information regarding seismic response properties of structures. Maximum developed base shear, ductility of the structure and maximum deformation prior to collapse are among the most useful information that might be derived from pushover curve. Figure 3.4 shows a typical pushover curve developed for an RC pedestal.

\subsubsection{Procedure of performing pushover analysis}

In order to perform a nonlinear static analysis, initially the gravity load is applied to the mathematical model of structure. Next according to the defined load (or displacement) pattern, the structural model is subjected to an incremental lateral load (or displacement). The load pattern must be similar to the force or deformations produced in the structure during earthquakes.

Subsequently, the lateral load is increased until either the displacement at controlling point reaches a certain target or the structure collapses. At each increment level, the base shear along with the corresponding displacement at the controlling point is recorded. Equation 3.1 represents the static equilibrium of the structure with small increments in linear region: 

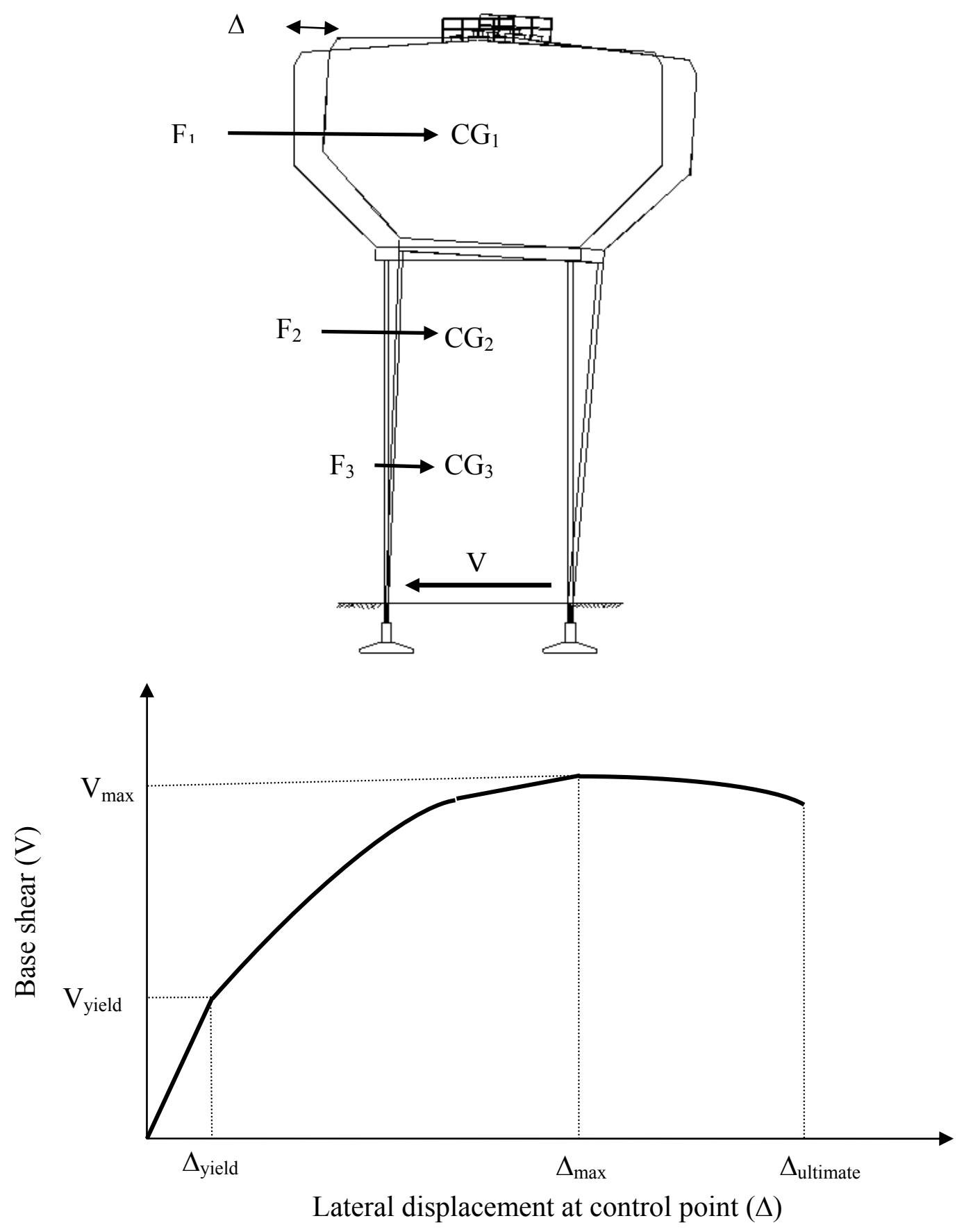

Figure 3.4 Typical pushover curve developed for a sample RC pedestal 
Accordingly this equation could be revised by including the tangent stiffness matrix and accounting for nonlinear variation of both geometry and material in each load increment:

$$
F=K_{t} \Delta U+R_{t}
$$

In the above equation "i" represents the current equilibrium iteration, $K_{t}$ represents the tangent stiffness matrix and $\mathrm{R}_{\mathrm{t}}$ is the restoring forces at the beginning of each load increment as illustrated in Equation 3.3:

$$
R_{t}=\sum_{i=1}^{j-1} K_{t, i} \Delta U_{i}
$$

There are many numerical methods for solving the above equations from which the "NewtonRaphson" method is selected and employed in this research. This numerical method will be explained in Chapter 4. In each step, after convergence of equations, the tangent stiffness matrix is revised and next load (or displacement) increment is applied. The increments will continue until either the structure reaches to the target displacement (or performance level) or the integrations cease to converge.

\subsubsection{Types of pushover analysis}

In general there are two main categories of pushover analysis known as "Conventional pushover analysis" and "adaptive pushover analysis" (Elnashai, 2008). In conventional pushover analysis, distribution of force or displacement remains constant during the analysis. In other words, it is assumed that the load or displacement pattern is not influenced by changes in mode shapes. On the other hand, the load (or displacement) pattern could change due to the nonlinear response of structure while performing the pushover analysis. These variations are taken into account in adaptive pushover analysis by changing the force pattern in different steps of analysis. 
Selection of the proper method of pushover analysis highly depends on the configuration of the structures. In an extensive investigation, Papanikolaou et al. (2006) concluded that in general the adaptive pushover was not providing considerable advantages over the conventional pushover analysis. Although adaptive analysis can demonstrate better performance comparing to conventional analysis for irregular structures, this advantage is not valid for all cases. In the case of symmetrical structures with no specific irregularities in configuration, conventional pushover analysis will result in adequate accuracy. For the purpose of this study, since elevated water tanks are symmetrical structures and have no irregularities in the plan, the conventional method is selected over adaptive.

Elevated water tanks resemble an inverse pendulum and often more than $80 \%$ of the weight concentrates in the tank. In these structures more than $90 \%$ of the modal mass participates in the first mode which is in line with selection of conventional pushover analysis.

\subsubsection{Bilinear approximation of pushover curves}

In order to extract meaningful and practical information from the pushover curve, it is often required to develop an equivalent bilinear approximation of pushover curve. As an example, consider displacement ductility of structure $(\mu)$ which is defined as the ratio of maximum displacement $\left(\Delta_{\max }\right)$ to yield displacement $\left(\Delta_{\mathrm{y}}\right)$. These parameters are shown in Figure 3.5.

The pushover curve alone does not specifically display a distinct yield and maximum displacement mainly due to the nonlinearity of material and therefore ambiguity of the location of these points. As a result these points need to be detected with an analytical procedure. In case of RC structures this could be a difficult practice due to cracking and crushing properties of 
concrete material. Moreover distribution of steel rebars adds to the complexity of detecting the global yielding point of the structure.

Park (1988) investigated ductility by evaluating laboratory results and analytical testing. This study addresses four different strategies of detecting yield and maximum displacement on a pushover curve. In the first method, global yield point is assumed to be at the first yielding point of the structure.

The second method is based on an equivalent elasto-plastic structure. This equivalent system has the same elastic stiffness and ultimate load as the original structure. The third approach, as depicted in Figure 3.5(a), defines the yield point as the yield point of an equivalent elasto-plastic system with reduced stiffness at $75 \%$ of $\mathrm{V}_{\max }$ (ultimate base shear). Last method, as shown in Figure 3.5(b), establishes the yield point according to the principle of equal energy.

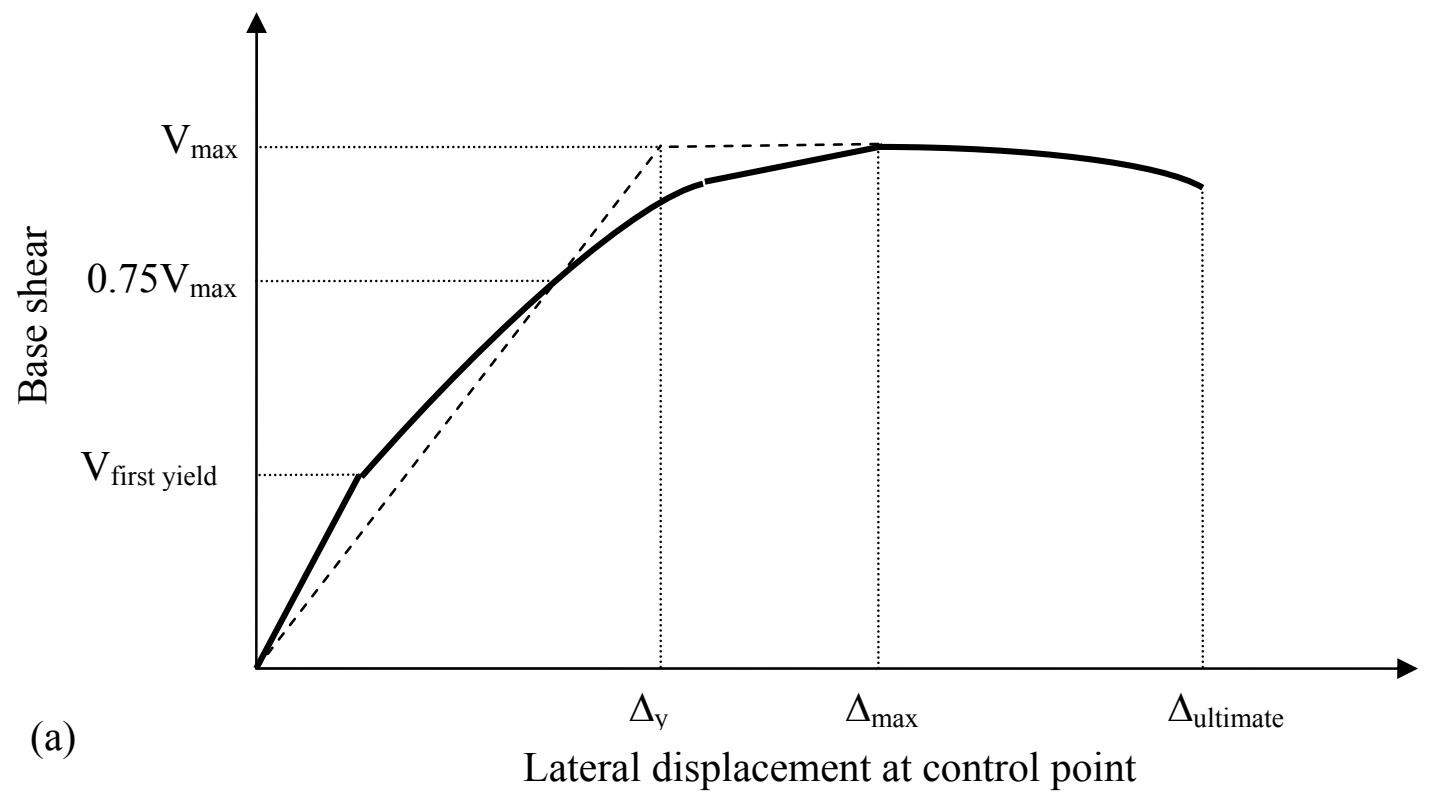

Figure 3.5 Bilinear approximation of pushover curves (a) reduced stiffness equivalent elastoplastic yield (b) equivalent elasto-plastic energy absorption 


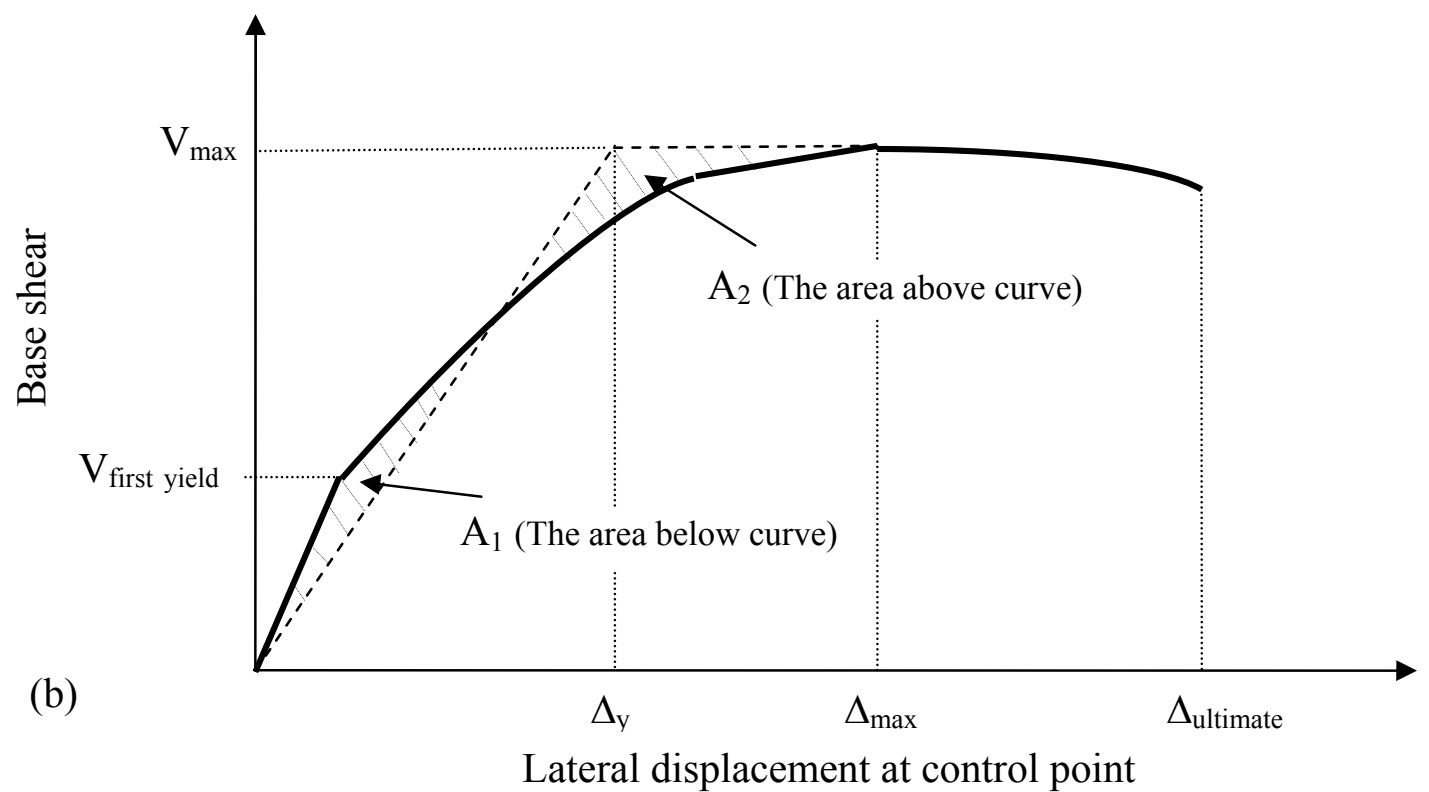

Figure 3.5 (Cont.)

According to this last method, the elasto-plastic equivalent system absorbs the same energy as the original structure and as a result the area enclosed between the curve and bilinear approximation must be equal below and above the curve $\left(\mathrm{A}_{1}=\mathrm{A}_{2}\right)$.

\subsection{Transient dynamic (Time-history) analysis}

Dynamic analysis is the most accurate method for seismic analysis of structures. Static analysis of structures does not consider effects of damping, inertia forces of higher modes of vibration, hysteresis behaviour of material and velocity of masses. All these effects are taken into account in the dynamic analysis.

Dynamic analysis could also be classified as linear or nonlinear analysis. In a dynamic linear analysis, effects of parameters such as higher modes of vibration, damping of material and geometrical nonlinearity are reflected in analysis. 
As discussed before, structures undergo extreme deformation when subjected to severe seismic motions, and therefore respond in a nonlinear fashion. Nonlinear dynamic analysis is the most realistic and sophisticated method of analysis which applies all of the abovementioned parameters including material nonlinearity in the analysis processes. In this research the dynamic nonlinear method is employed.

The major problem with this method is being highly demanding in terms of time and computational memory. A number of solution techniques exist which will be discussed in next sections.

\subsubsection{Equation of motion of a SDOF system subjected to force $P(t)$}

Equation of motion of a single-degree-of-freedom system (SDOF) could be formulated using the d'Alembert principle. In Equation 3.4, the index " $t$ " represents time and describes the force as a function of time and $\mathrm{P}(\mathrm{t})$ is the dynamic external force applied to the mass.

The resisting loads consist of inertia force $F_{I}(t)$, damping force $F_{D}(t)$ and stiffness force $F_{S}(t)$. Equation 3.4 expresses the equilibrium state of the above forces acting on the structure:

$$
P(t)=F_{I}(t)+F_{D}(t)+F_{S}(t)
$$

According to d'Alembert principle, the inertia force is the product of mass and acceleration. The damping force $\mathrm{F}_{\mathrm{D}}(\mathrm{t})$, assuming a viscous damping mechanism, may be also expressed as the product of velocity and damping constant. Finally, the stiffness force $F_{S}(t)$ is the product of structure stiffness and displacement. By replacing the above terms in Equation 3.4 the equation of motion of a SDOF system subjected to a force $\mathrm{P}(\mathrm{t})$ is presented as shown in Equation 3.5:

$$
P(t)=M \ddot{u}(t)+C \dot{u}(t)+K u(t)
$$




\subsubsection{Equation of motion of a SDOF system subjected to seismic excitations}

Equation of motion of a SDOF structure subjected to seismic excitations could be formulated

in quite the same fashion as for external load. The seismic motion affects the structure by imposing horizontal ground motions at the support level. The forces acting on the free-body diagram of the system at time " $t$ " are inertia force $F_{I}(t)$, damping force $F_{D}(t)$ and stiffness force $F_{S}(t)$. The equation of dynamic equilibrium of these forces could be expressed as:

$$
F_{I}(t)+F_{D}(t)+F_{S}(t)=0
$$

In addition $\mathrm{u}^{\mathrm{t}}(\mathrm{t})$ represents the total displacement of the system respecting to the original location of structure:

$$
u^{t}(t)=u(t)+u_{g}(t)
$$

Subsequently by substituting Equation 3.7 in Equation 3.6 and performing the appropriate derivations combined with d'Alembert principle, Equation 3.6 is expressed as:

$$
M \ddot{u}(t)+M \ddot{u}_{g}(t)+C \dot{u}(t)+K u(t)=0
$$

The above equation will be more practical and meaningful by moving the term $M \ddot{u}_{g}(t)$ to the right side of the equation:

$$
M \ddot{u}(t)+C \dot{u}(t)+K u(t)=-M \ddot{u}_{g}(t)=p_{\text {eff }}(t)
$$

$p_{\text {eff }}(t)$ is the effective force at the support which is equivalent to $-M \ddot{u}_{g}(t)$. In other words, structural response of a SDOF system subjected to a ground motion $\ddot{u}_{g}(t)$ is the same as the one subjected to an external force $p_{\text {eff }}(t)$. 


\subsubsection{Equation of motion of a multi-degree-of-freedom system}

In most of engineering practice situations, the SDOF idealization of a system will not have enough accuracy to model the dynamic response of structures. This is shown in Figure 3.6 as an example. In case of an elevated water tank, although most of the weight is concentrated in the tank, the assumption of a SDOF system may not result in a realistic dynamic response. Instead, the weight of shaft is replaced with lump masses distributed along shaft height.
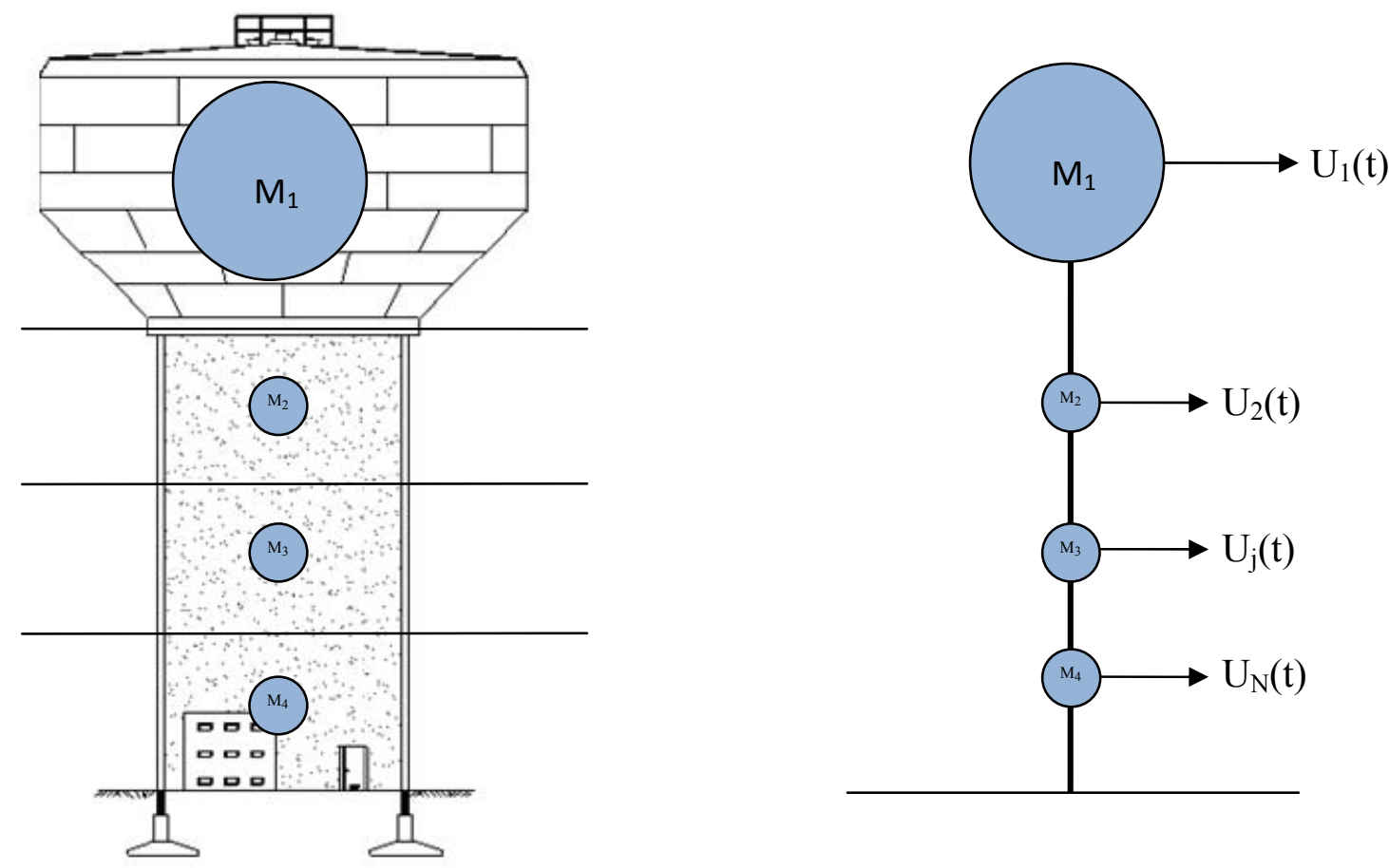

Figure 3.6 Idealized MDOF model of concrete elevated tank structure with only horizontal degrees of freedom

Developing the dynamic equations of motion for a MDOF is carried out based on the same principle employed for SDOF dynamic equilibrium. Instead of scalars, vectors and matrices are used in the equations. The equilibrium equation of a typical MDOF system subjected to excitations at the supports is: 


$$
[M]\{\ddot{U}\}+[C]\{\dot{U}\}+[K]\{U\}=-[M]\{J\} \ddot{U}_{g}
$$

Equation 3.10 contains $\mathrm{N}$ differential equations in which $\mathrm{N}$ represents the number of degrees of freedom. The vector $\{\mathrm{J}\}$ in Equation 3.10, is called the influence vector which contains 1 and 0 . Number 1 is assigned to horizontal degree of freedom and 0 is assigned to vertical and rotational degrees of freedom.

\subsubsection{Equation of motion of a nonlinear system}

In the last two sections, the equations of motion of a seismically excited system was developed assuming linear response of the structures. In other words, material nonlinearity and therefore variation of stiffness was not taken into account. In reality structures exhibit nonlinear response to seismic loads and adjustment of equation of motion is necessary during the solution.

In order to develop the equation of motion of a nonlinear system, one more time consider the equation of motion of a MDOF elastic system in Equation 3.11 (Villaverde R. 2009):

$$
[M]\{\ddot{U}\}+[C]\{\dot{U}\}+[K]\{U\}=-[M]\{J\} \ddot{U}_{g}
$$

In the above equation, matrices $[\mathrm{C}]$ and $[\mathrm{K}]$ are dependent variables of time. In order to consider effects of nonlinearity, they will be expressed as matrices $[\mathrm{C}(\mathrm{t})]$ and $[\mathrm{K}(\mathrm{t})]$ or $\left\{F_{D}\left(t_{i}\right)\right\}$ and $\left\{F_{S}\left(t_{i}\right)\right\}$ in vector form. The equation of motion of such system at time $t_{i}$ is:

$$
[M]\left\{\ddot{U}\left(t_{i}\right)\right\}+\left\{F_{D}\left(t_{i}\right)\right\}+\left\{F_{S}\left(t_{i}\right)\right\}=-[M]\{J\} \ddot{U}_{g}\left(t_{i}\right)
$$

In the above equation, $\mathrm{t}=\mathrm{t}_{\mathrm{i}}=\mathrm{i} \Delta \mathrm{t}$, in which " $\mathrm{i}$ " is an integer, $\Delta \mathrm{t}$ is a small time increment and $\tau$ is a small time variable between 0 and $\Delta \mathrm{t}$. Also the equation of motion of the system at the time $\mathrm{t}=\mathrm{t}_{\mathrm{i}}+\tau$ is: 


$$
[M]\left\{\ddot{U}\left(t_{i}+\tau\right)\right\}+\left\{F_{D}\left(t_{i}+\tau\right)\right\}+\left\{F_{S}\left(t_{i}+\tau\right)\right\}=-[M]\{J\} \ddot{U}_{g}\left(t_{i}+\tau\right)
$$

By assuming that properties of the system do not change in the time interval $\Delta \mathrm{t}$ :

$$
\begin{aligned}
& \left\{F_{S}\left(t_{i}+\tau\right)\right\}=\left\{F_{S}\left(t_{i}\right)\right\}+[K]_{i}\{\Delta U(\tau)\} \\
& \left\{F_{D}\left(t_{i}+\tau\right)\right\}=\left\{F_{D}\left(t_{i}\right)\right\}+[C]_{i}\{\Delta \dot{U}(\tau)\}
\end{aligned}
$$

In the above equation $[\mathrm{K}]_{\mathrm{i}}$ and $[\mathrm{C}]_{\mathrm{i}}$ are the properties of the system at the beginning of the interval and:

$$
\begin{aligned}
& \{\Delta U(\tau)\}=\left\{U\left(t_{i}+\tau\right)\right\}-\left\{U\left(t_{i}\right)\right\} \\
& \{\Delta \dot{U}(\tau)\}=\left\{\dot{U}\left(t_{i}+\tau\right)\right\}-\left\{\dot{U}\left(t_{i}\right)\right\}
\end{aligned}
$$

As a result the Equation 3.13 might be rewritten as:

$$
\begin{aligned}
& {[M]\left\{\ddot{U}\left(t_{i}+\tau\right)\right\}+\left\{F_{D}\left(t_{i}\right)\right\}+[C]_{i}\{\Delta \dot{U}(\tau)\}+\left\{F_{S}\left(t_{i}\right)\right\}+} \\
& {[K]_{i}\{\Delta U(\tau)\}=-[M]\{J\} \ddot{U}_{g}\left(t_{i}+\tau\right)}
\end{aligned}
$$

Equation 3.18 is further expanded into Equation 3.20 by employing Equation 3.19:

$$
\begin{aligned}
& \{\Delta \ddot{U}(\tau)\}=\left\{\dddot{U}\left(t_{i}+\tau\right)\right\}-\left\{\ddot{U}\left(t_{i}\right)\right\} \\
& {[M]\left\{\ddot{U}_{i}(t)\right\}+[M]\{\Delta \ddot{U}(\tau)\}+\left\{F_{D}\left(t_{i}\right)\right\}+[C]_{i}\{\Delta \dot{U}(\tau)\}+\left\{F_{S}\left(t_{i}\right)\right\}+} \\
& {[K]_{i}\{\Delta U(\tau)\}=-[M]\{J\} \ddot{U}_{g}\left(t_{i}\right)-[M]\{J\} \Delta \ddot{U}_{g}(\tau)}
\end{aligned}
$$

And finally by applying $\Delta \ddot{U}_{g}(\tau)=\ddot{U}_{g}\left(t_{i}+\tau\right)-\ddot{U}_{g}(t)$ and also Equation 3.12 combined with Equation 3.20, the equation of motion of MDOF nonlinear system will be summarized as:

$$
[M]\{\Delta \ddot{U}(\tau)\}+[C]_{i}\{\Delta \dot{U}(\tau)\}+[K]_{i}\{\Delta U(\tau)\}=-[M]\{J\} \Delta \ddot{U}_{g}(\tau)
$$

Equation 3.21 represents a differential equation with the incremental displacement factor $\{\Delta U(\tau)\}$ as the unknown and is solvable using conventional numerical methods of solution. By solving Equation 3.21, the value of the displacement vector at the end of the time interval $\left\{U\left(t_{i}+\tau\right)\right\}$ could be found. 


\subsubsection{Solution of nonlinear MDOF dynamic differential equations}

Equation of motion of MDOF dynamic systems (such as Equations 3.11 and 3.21) is solved either in time domain or frequency domain. The most widely used frequency domain analyses methods are Modal and spectral analysis. In modal analysis, MDOF equations of motion are decomposed to a number of SDOF systems. Next each SDOF system is solved and the responses are combined using certain algebraic methods. In spectral analysis, only the values of maximum responses are found using the response spectrum.

The main problem with both modal and spectral analysis is that they are not capable of solving nonlinear systems. This is because the superposition approach is implemented and nonlinear variations are ignored.

The effects of nonlinearity could be applied in time domain solution method. The main approach in time domain solution which is also known as response history analysis is based on step-by-step integration. In all the step-by-step methods the loading and the response history are divided into series of time intervals. In this process, the structural properties are assumed to be constant and the equation of motion remains elastic in each time increment $\Delta$ t. The response during each time increment is calculated from initial condition.

In case of performing a nonlinear dynamic analysis the equations are adjusted for the effects of geometrical and material nonlinearity in between time increments by modifying the tangent stiffness matrix. Otherwise (for linear dynamic analysis), these properties remain the same during all time intervals.

The step-by-step method is carried out by employing either explicit or implicit approach. In implicit method, the new response values for a time increment has one or more values related to the same step and as a result it requires a trial value and successive iterations are necessary. 
On the other hand, in an explicit method, the new response values calculated in each time increment only depend on the response quantities existing at the beginning of the step.

In this study, implicit method is employed for the nonlinear response history analysis of elevated water tanks. The numerical solution algorithm will be discussed in next chapter.

\subsection{Incremental dynamic analysis (IDA)}

Incremental dynamic analysis involves subjecting a structural model to one or several ground motion records, each scaled to increasing levels of intensity, hence producing one or more curves of response parameterized versus intensity level (Vamvatsikos and Cornell, 2002). It is also called dynamic pushover analysis mainly due to the similarity to static pushover method except it is carried out by gradually increasing ground motion records rather than gradually increasing static loads.

The concept of incremental dynamic analysis (IDA) was first introduced by Bertero (1977) and evolved during the time by other research studies such as Nassar and Krawinkler (1991). The most important parameter affecting the popularity of the IDA method is the recent advances in the computer memories and speed of computing processors.

Performing a nonlinear IDA is a highly time and computing demanding task and requires a huge amount of computer memory and a robust processor unit which was not commonly available until the last decades.

The result of each nonlinear dynamic analysis carried out on the structural model is plotted on a graph. This graph which very much resembles the static pushover curve is called an IDA curve. A damage measure (or structural state variable) must be defined to represent the state of structure after performing each analysis. This measure might be local or global. Selection of damage 
measure completely depends on the objectives of analysis and could be parameters such as base shear, story drift, rotation of joints, and maximum deformation of the structure at the roof level.

In an IDA curve, the graph is plot of the damage measure versus one or more intensity measure as shown in Figure 3.7. The intensity measure also depends on the analysis objectives. Typical intensity measures include peak ground acceleration (or velocity) and spectral acceleration at structure's first mode period $\left(\mathrm{S}_{\mathrm{a}}\right)$.

The structure may respond inconsistently when subjected to different records. Figure 3.7 displays four different respond behaviours of the same structure.

(a) A softening case

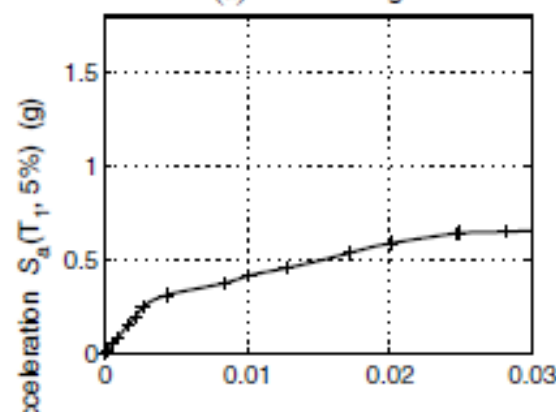

(c) Severe hardening

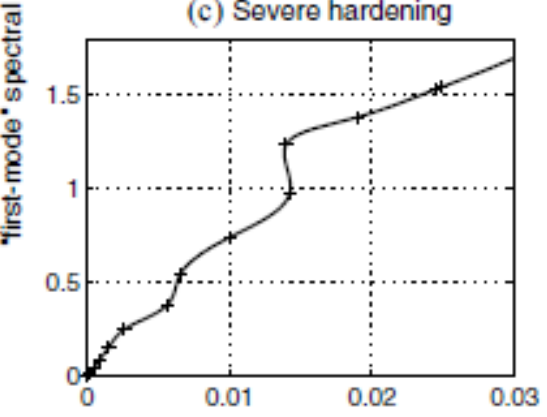

(b) A bit of hardening

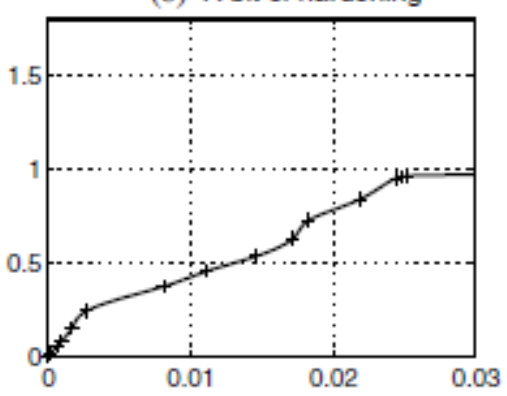

(d) Weaving behavior

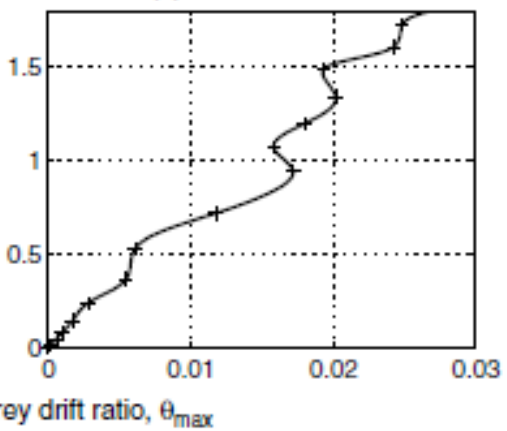

Figure 3.7 Typical IDA curves for a multistory steel frame subjected to four different earthquake records (adapted from Vamvatsikos and Cornell, 2002)

The structure demonstrates a softening IDA curve when subjected to a certain record while it displays a severe hardening behaviour in respond to another record. It is for this inconsistent 
behaviour that the IDA must be performed using a reasonable number of records to assure the generality of the study and covering all possible response behaviours.

In this study IDA is carried out based on the instructions of FEMA P695. Performing IDA analysis helps to establish collapse margin ratio (CMR) for concrete pedestals and also understand the behaviour of the elevated water tanks when subjected to seismic loads.

\subsection{Summary}

In this chapter four methods of seismic analysis of structures which are employed in this thesis were explained. The fundamentals of each method were discussed and the formulation and equations were established.

The main differences between linear and nonlinear analysis were addressed and sources of nonlinearity in structures were introduced. Moreover, nonlinear static analysis as a powerful tool for studying the response of structures under the extreme deformation was explained and the pushover curves and their application were addressed. In this thesis the pushover curves are employed in order to establish global dynamic responses of RC pedestals in elevated water tanks. The bilinear approximation of the pushover curve, as an essential technique for studying ductility behaviour of structures, was completely discussed in this chapter as well.

General formulation of nonlinear equations of motions of MDOF structures was illustrated and numerical methods for solving these differential equations were discussed. The nonlinear dynamic analysis of structures is used as a tool for developing the IDA curves. The IDA curves

are indirectly used for verification of the response modification factor in this study. The chapter concludes with explaining the IDA curves and the main characteristics of them. 


\section{Chapter 4 \\ Finite element model development and verification}

\subsection{General}

The main objective of this chapter is to define and verify a finite element (FE) technique for modeling reinforced concrete (RC) pedestals of elevated water tanks in order to to perform a proper and accurate seismic analysis. The general purpose FE modeling software ANSYS is employed for this purpose.

A major step in developing the reinforced concrete finite element model is to define each element's response and characteristics under different loading stages. This chapter begins with explaining this subject by addressing the building blocks of the prospective finite element model and the method employed for defining reinforced concrete elements. Moreover the material nonlinearity which was discussed in the previous chapter is further elaborated. Numerous mathematical approximations are proposed to model the stress-strain curve of concrete and steel material and are briefly described in this chapter as well.

The chapter continues with analyzing the failure criteria of reinforces concrete elements when subjected to ultimate loading condition. This analysis is required for detecting the failure points of RC pedestals when performing pushover and nonlinear dynamic analysis.

In the previous chapter the equations of motion of a nonlinear MDOF system were established. This chapter will provide numerical solution methods for solving these differential equations along with nonlinear static equilibrium equations.

In the last part of the chapter, the proposed finite element system is verified by comparing to experimental tests on reinforced concrete specimens. Finally the configuration, geometry and assumptions of FE model for seismic analysis of RC shafts is illustrated. 


\subsection{Finite element modeling of reinforced concrete}

Numerous general and specific purpose finite element programs have been developed in the last few decades. Among these computer programs, ANSYS is a popular software in both academic and commercial applications. As a general finite element program, ANSYS is capable of modeling reinforced concrete using SOLID65 element. The reinforced concrete element is nonlinear by nature due to the cracking of concrete under tension and requires an iterative solution. This element is able to model essential mechanical characteristics of concrete and steel materials. The steel rebars (reinforcement) are modeled using two different approaches. The SOLID65 element has the ability to model the rebars as smeared throughout the element. On the other hand the rebars could also be separately modeled with a uniaxial tension-compression element such as Link8. The properties and specifications of SOLID65 element are explained in the next section.

\subsection{SOLID65 element}

SOLID65 is a 3D solid model which is capable of cracking and crushing under tension and compression loads respectively. This element can take into account the nonlinear behaviour of concrete and steel such as plastic deformation, cracking in three orthogonal directions and nonlinear stress-strain response under different loading stages.

Figure 4.1 displays the geometry and node positions of a SOLID65 element. The element consists of eight nodes and has one solid and three rebar materials. The rebars are introduced as a volume ratio (rebar volume divided by total element volume) in case that they are defined as smeared throughout the element. In addition, Figure 4.1 demonstrates a typical rebar and the corresponding angles (PHI,THETA) with respect to local coordination of element. 


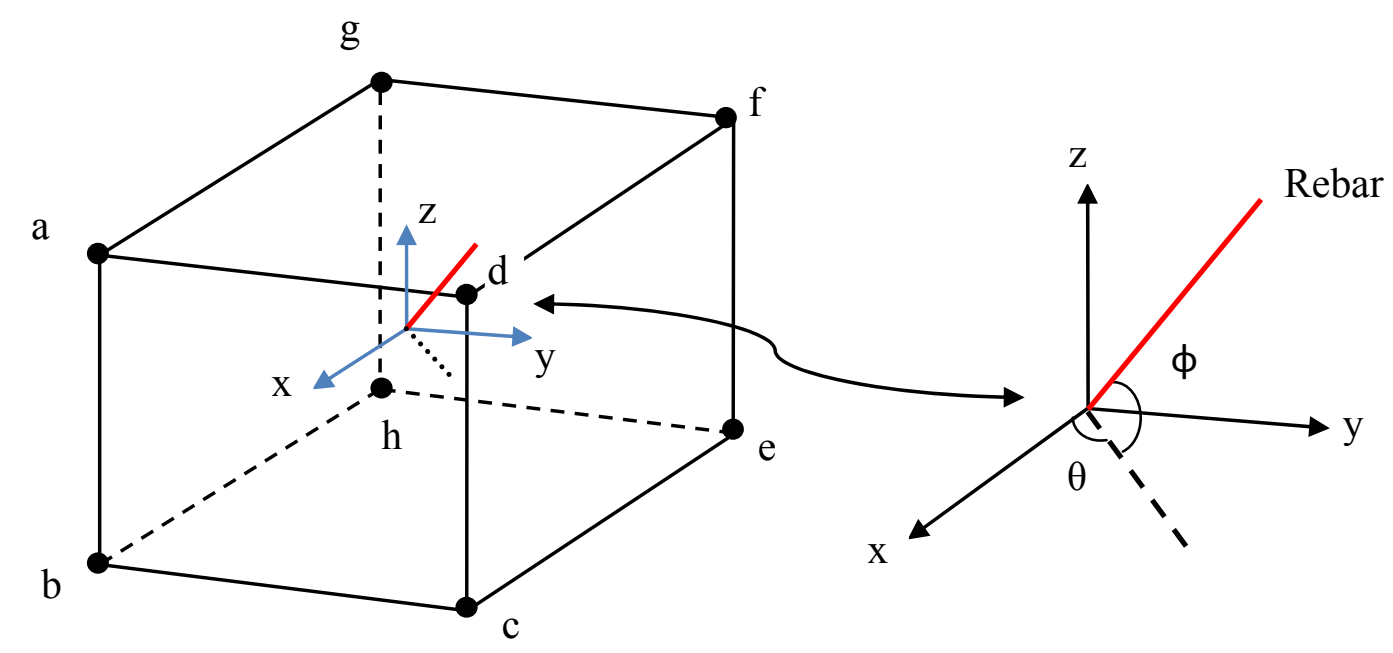

Figure 4.1 Geometry and node positions of a SOLID65 element

\subsubsection{FE formulation of reinforced concrete in linear state}

Solid65 reinforced concrete element is generally in three states of linear elastic, cracked and crushed. Normally, the reinforced concrete elements are linear elastic at the initial state of loading. By increasing the loads, the tension stresses may reach above maximum cracking stress and the concrete cracks. Further increase in the loads, will either cause the reinforcement to yield or the concrete to crush. For properly designed RC structures, yielding of rebars must occur prior to crushing of concrete.

The stress-strain matrix of Solid65 element in the linear elastic state is:

$$
[D]=\left(1-\sum_{i=1}^{N r} V_{i}^{R}\right)\left[D^{c}\right]+\sum_{i=1}^{N_{r}} V_{i}^{R}\left[D^{r}\right]_{i}
$$

Where:

$\mathrm{Nr}=$ number of reinforcing material (between one to three)

$\mathrm{V}_{\mathrm{i}}^{\mathrm{R}}=$ reinforcement ratio 
$\left[D^{c}\right]=$ concrete elastic stiffness matrix

$\left[D^{r}\right]_{i}=$ elastic stiffness matrix for reinforcement number "i”"

\subsubsection{FE formulation of reinforced concrete after cracking}

The effects of plasticity and variation of modulus of elasticity of concrete is applied by few modifications on the stiffness matrix. However, modifying the concrete stiffness matrix for the cracking requires more sophisticated adjustments in the stiffness matrix and is briefly described in this section.

The crack is reflected in the stiffness matrix of concrete by defining a weak plane normal to the crack face. This weak plane is applied to the matrix by employing two factors $\beta_{t}$ and $R_{t}$ as illustrated in Equation 4.2:

$$
\left[D_{c}^{c k}\right]=\frac{E}{(1+v)}\left[\begin{array}{cccccc}
\frac{R^{t}(1+v)}{E} & 0 & 0 & 0 & 0 & 0 \\
0 & \frac{1}{1-v} & \frac{v}{1-v} & 0 & 0 & 0 \\
0 & \frac{v}{1-v} & \frac{1}{1-v} & 0 & 0 & 0 \\
0 & 0 & 0 & \frac{\beta_{t}}{2} & 0 & 0 \\
0 & 0 & 0 & 0 & \frac{1}{2} & 0 \\
0 & 0 & 0 & 0 & 0 & \frac{\beta_{t}}{2}
\end{array}\right]
$$

Where:

$\beta_{\mathrm{t}}=$ shear transfer coefficient

$\mathrm{R}_{\mathrm{t}}=$ secant modulus of cracked concrete stress-strain graph

The shear transfer coefficient $\beta_{\mathrm{t}}$, accounts for the reduction in shear strength of concrete. The stiffness matrix presented in Equation 4.2 is only valid for an open crack in one direction. 
If the crack closes due to the compression loads then the shear transfer coefficient $\beta_{\mathrm{t}}$ needs to be modified to account for the effect of compression normal to the cracking plane. In this case another coefficient denoted as $\beta_{\mathrm{c}}$ is introduced which is generally larger than $\beta_{\mathrm{t}}$. Stiffness matrices for other closed or open cracked conditions can be derived by applying a number of modifications to Equation 4.2 and are presented in Appendix A.

It should be noted that he effect of thermal strains is not considered in Equation 4.1. Moreover, the crushing state of concrete element represents the complete degradation of material which indicates no more contribution of the element in the stiffness matrix.

\subsubsection{Failure criteria of reinforced concrete element}

Failure of concrete material could be due to cracking or crushing. Several failure theories exist in literature such as maximum principal stress theory, maximum principal strain theory, maximum shear stress theory, internal friction theory and maximum strain energy theory.

ANSYS employs William and Warnke failure criterion (William and Warnke, 1975) in order to detect failure of reinforced concrete elements. According to this criterion, failure of concrete under multiaxial stress is identified by Equation 4.3:

$$
\frac{F}{f_{c}}-S \geq 0
$$

Where:

$\mathrm{F}=\mathrm{a}$ function of the principal stresses $\left(\sigma_{\mathrm{xp}}, \sigma_{\mathrm{yp}}, \sigma_{\mathrm{zp}}\right)$

$\mathrm{S}=$ Failure surface which is a function of principal stresses and various strength factors

$f_{c}=$ ultimate uniaxial compressive strength

If Equation 4.3 is satisfied, then concrete cracks or crushes. 
In general defining the failure surface according to William and Warnke failure criterion requires prior knowledge of the principal stresses acting on the element along with the following strength factors:

$f_{t}=$ ultimate uniaxial tensile strength

$\mathrm{f}_{\mathrm{c}}=$ ultimate uniaxial compressive strength

$f_{\mathrm{cb}}=$ ultimate biaxial compressive strength

$f_{1}=$ ultimate compressive strength for state of biaxial compression superimposed on hydrostatic stress state

$f_{2}=$ ultimate compressive strength for state of uniaxial compression superimposed on hydrostatic stress state

For the purpose of establishing $\mathrm{F}$ and $\mathrm{S}$, the principal stresses are used with the notions of $\sigma_{1}$, $\sigma_{2}, \sigma_{3}$, in which $\sigma_{1}$ and $\sigma_{3}$ are the maximum and minimum stresses respectively. Four different domains of concrete failure are defined based on stress state of the element:

- (CCC) compression- compression- compression: $0 \geq \sigma_{1} \geq \sigma_{2} \geq \sigma_{3}$

- (TCC) tensile- compression- compression: $\sigma_{1} \geq 0 \geq \sigma_{2} \geq \sigma_{3}$

- (TTC) tensile - tensile - compression: $\sigma_{1} \geq \sigma_{2} \geq 0 \geq \sigma_{3}$

- (TTT) tensile - tensile - tensile: $\sigma_{1} \geq \sigma_{2} \geq \sigma_{3} \geq 0$

As an example, for the CCC domain, the "F" function according to William and Warnke failure criterion will be determined based on Equation 4.4:

$$
F=\frac{1}{\sqrt{15}}\left[\left(\sigma_{1}-\sigma_{2}\right)^{2}+\left(\sigma_{2}-\sigma_{3}\right)^{2}+\left(\sigma_{3}-\sigma_{1}\right)^{2}\right]^{1 / 2}
$$

And the failure surface " $\mathrm{S}$ " is defined as: 


$$
S=\frac{2 r_{2}\left(r_{2}^{2}-r_{1}^{2}\right) \cos \eta+r_{2}\left(2 r_{1}-r_{2}\right)\left[4\left(r_{2}^{2}-r_{1}^{2}\right) \cos ^{2} \eta+5 r_{1}^{2}-4 r_{1} r_{2}\right]^{1 / 2}}{4\left(r_{2}^{2}-r_{1}^{2}\right) \cos ^{2} \eta+\left(r_{2}-2 r_{1}\right)^{2}}
$$

The complete solution to Equations 4.4 and 4.5 and other failure domains of reinforced concrete element might be found in William and Warnke (1975). The three other domains of failures could be experienced depending on the configuration of the multiaxial loading of concrete element.

\subsection{Solution of static and dynamic nonlinear finite element equations}

In Chapter 3, the nonlinear static and nonlinear dynamic differential equations of a MDOF system were developed but the solution method was not discussed in details. Solving the nonlinear dynamic differential equation of a MDOF system is possible using numerical methods and by employing step by step integration. Each equation of motion is divided into several time intervals known as steps. Next, the response at the end of each time step is found in a sequential fashion using the initial stage and loading condition during the time interval.

On the other hand, a step by step numerical method is also required for solving the nonlinear static equations. The stiffness matrix needs updating at each load increment due to the geometrical and material nonlinearity of the structure as explained in Chapter 3. In the following sections, numerical methods employed for solving each of the static and dynamic nonlinear equations are presented.

\subsubsection{Solution method for nonlinear static analysis equation}

Solving nonlinear problems requires a numerical method and ANSYS employs the "NewtonRaphson" scheme. According to this method the load is divided into a number of load increments 
which could be applied during several load steps. The equation of equilibrium of a nonlinear static system subjected to a loading denoted by vector $\{\mathrm{F}\}$ is:

$$
\{F\}=[K]\{U\}
$$

In which $[\mathrm{K}]$, not only depends on the primary stiffness and geometry, but also is a function of displacement vector $\{\mathrm{U}\}$. For one iteration, the equation of equilibrium might be written as:

$\left[K_{i}^{T}\right]\left\{\Delta U_{i}\right\}=\left\{F^{a}\right\}-\left\{F_{i}^{r}\right\}$

$\left\{U_{i+1}\right\}=\left\{U_{i}\right\}+\left\{\Delta U_{i}\right\}$

In the above equations $\left[\mathrm{K}_{\mathrm{i}}^{\mathrm{T}}\right]$ is the tangent or Jacobian matrix, "i" is an index indicating the current iteration and $\left\{\mathrm{F}_{\mathrm{i}}^{\mathrm{r}}\right\}$ is the restoring load vector. The following algorithm is employed until the convergence is reached:

1. Initial state: Assume $\mathrm{U}_{0}$, at the beginning $\mathrm{U}_{0}$ is usually $\{0\}$

2. Calculation for each iteration:

- Calculate Jacobian matrix $\left[\mathrm{K}_{\mathrm{i}}^{\mathrm{T}}\right]$ and restoring vector $\left\{\mathrm{F}_{\mathrm{i}}^{\mathrm{r}}\right\}$ for the current step

- Calculate $\Delta \mathrm{U}_{\mathrm{i}}$

- Substitute $\Delta \mathrm{U}_{\mathrm{i}}$ in equation 4.22 and find $\Delta \mathrm{U}_{\mathrm{i}+1}$

3. Repeat step 2 until the convergence is attained.

\subsubsection{Solution method for nonlinear dynamic equations of motion}

The nonlinear differential equation of motion of MDOF system was developed in the previous chapter. Many numerical solution methods have been developed and could be found in the literature. ANSYS employs the Newmark method along with Newton-Raphson approach (in order to take into account nonlinearity) for solving this equation. 
Recalling the dynamic equation of motion from Chapter 3:

$$
[M]\{\ddot{U}\}+[C]\{\dot{U}\}+[K]\{U\}=\{F\}
$$

The matrices and vectors in Equation 4.9 were explained previously. According to Newmark method, velocity and displacement at the time $t_{i+1}$ might be calculated based on Equations 4.10 and 4.11 respectively:

$$
\begin{aligned}
& \left\{\dot{U}_{n+1}\right\}=\left\{\dot{U}_{n}\right\}+\left[(1-\delta)\left\{\ddot{U}_{n}\right\}+\delta\left\{\ddot{U}_{n+1}\right\}\right] \Delta t \\
& \left\{U_{n+1}\right\}=\left\{U_{n}\right\}+\left\{U_{n}\right\} \Delta t+\left[\left(\frac{1}{2}-\alpha\right)\left\{\ddot{U}_{n}\right\}+\alpha\left\{\ddot{U}_{n+1}\right\}\right] \Delta t^{2}
\end{aligned}
$$

Where:

$\alpha$ and $\delta=$ Newmark integration parameters

$$
\Delta t=t_{n+1}-t_{n}
$$

At the time $t_{n+1}$ Equation 4.9 will be converted into:

$$
[M]\left\{\ddot{U}_{n+1}\right\}+[C]\left\{\dot{U}_{n+1}\right\}+[K]\left\{U_{n+1}\right\}=\{F\}
$$

By rearranging Equations 4.10 and 4.11 and adjusting for Equation 4.12, acceleration and velocity at time $t_{n+1}$ will be computed as:

$$
\begin{aligned}
& \left\{\ddot{U}_{n+1}\right\}=a_{0}\left(\left\{U_{n+1}\right\}-\left\{U_{n}\right\}\right)-a_{2}\left\{\dot{U}_{n}\right\}-a_{3}\left\{\ddot{U}_{n}\right\} \\
& \left\{\dot{U}_{n+1}\right\}=\left\{\dot{U}_{n}\right\}-a_{6}\left\{\ddot{U}_{n}\right\}+a_{7}\left\{\ddot{U}_{n+1}\right\}
\end{aligned}
$$

Substituting $\left\{\ddot{U}_{n+1}\right\}$ in Equation 4.14 and combining the results with Equation 4.12 results in an equation which could be solved for $\left\{\mathrm{U}_{\mathrm{n}+1}\right\}$. Next, $\left\{\mathrm{U}_{\mathrm{n}+1}\right\}$ is substituted in Equations 4.13 and 4.14 in order to update velocity and acceleration vectors. This solution method is absolutely stable if Equation 4.15 is satisfied: 


$$
\alpha \geq \frac{1}{4}\left(\frac{1}{2}+\delta\right)^{2} \quad \delta \geq \frac{1}{2} \quad \frac{1}{2}+\delta+\alpha>0
$$

Convergence of the structural system highly depends on the selection of time steps, meshing sizes and geometry of the structure.

\subsection{Reinforced concrete material nonlinearity}

A proper finite element modeling of reinforced concrete structures requires defining an accurate stress-strain curve for both concrete and steel. Pushover and nonlinear dynamic analysis, investigate the response of the structures up to extreme deformations in which concrete and still material reach failure point and and the RC shaft structures will become unstable. Analysing the structures in these final stages is only possible if the responses of both concrete and still under extreme stresses and strains are known. Several mathematical models have been proposed and could be found in the literature. These mathematical models are discussed in the following sections. Appendix A provides further details of concrete and steel models employed in finite element modeling of this study.

\subsubsection{Stress-strain curve of concrete}

The general observed trend in concrete compression test is increasing stress and strain in the primary branch of loading and subsequent descent in stress and loading capacity after reaching the maximum strength of concrete samples. A number of mathematical models are proposed and are implemented in analytical models of reinforced concrete structures. One of the first mathematical models for concrete is the one proposed by Hognestad (1951).

The modified Hognestad (Eivind Hognestad, 1951) stress-strain concrete model consists of two branches. The first section is an increasing parabola and the second one a decreasing line. 
This model is valid for maximum strength up to approximately 40Mpa. In another study, Todeschini (Todeschini et al, 1964) proposed a stress-strain curve which is made of one single curve and is appropriate for maximum concrete strength of 40Mpa as well.

The stress-strain model proposed by Mander et al. (1988) is selected for modeling concrete in this study. The model is displayed in Figure 4.2 for two conditions of confined and unconfined concrete. As shown in this Figure, the unconfined model consists of two parts: a curve and a linear portion. The unconfined model is adjusted by the two parameters concrete compressive strength $\left(f^{\prime}\right)$ and concrete strain at $f_{c}^{\prime}\left(\varepsilon_{c}^{\prime}\right)$. If the confined model is employed then three other parameters $\mathrm{f}^{\prime}{ }_{\mathrm{cc}}$ (Compressive strength of confined concrete), $\varepsilon_{\mathrm{cc}}^{\prime}\left(\right.$ Concrete strain at $\mathrm{f}_{\mathrm{cc}}$ ) and $\varepsilon_{\mathrm{cu}}$ (Ultimate concrete strain for confined concrete) must be defined as well. $\mathrm{f}_{\mathrm{cc}}^{\prime}, \varepsilon_{\mathrm{cc}}^{\prime}$ and $\varepsilon_{\mathrm{cc}}^{\prime}$ are determined based on the type, size and spacing of confinement.

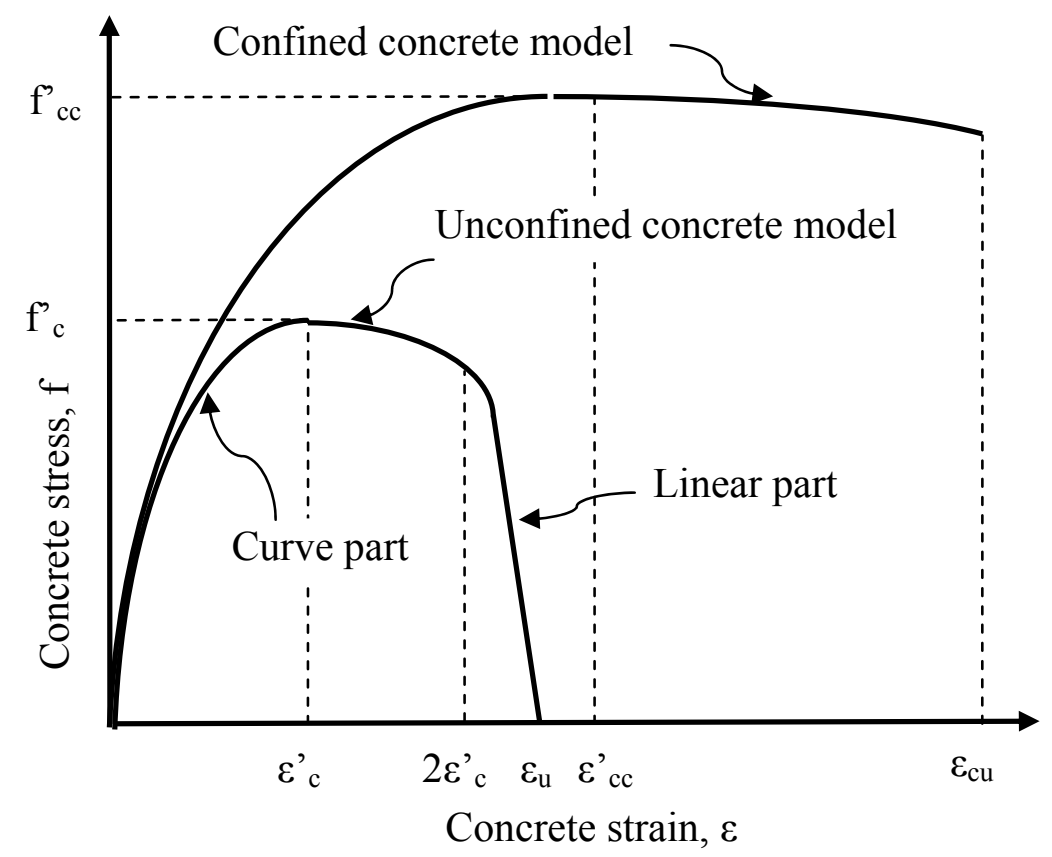

Figure 4.2 Concrete mathematical Stress-strain curve (Mander et al. (1988)

The equation of the curve branch of the Mander stress-strain curve for unconfined model is: 


$$
f=\frac{f_{c}^{\prime} x r}{r-1+x^{r}}
$$

Where:

$$
\begin{aligned}
& x=\frac{\varepsilon}{\varepsilon_{c}^{\prime}} \\
& r=\frac{E}{E-\left(f_{c}^{\prime} / \varepsilon_{c}^{\prime}\right)}
\end{aligned}
$$

In the above equations, $\mathrm{E}$ is the modulus of elasticity and $\varepsilon_{\mathrm{u}}$ is the ultimate concrete strain capacity. The equation of the linear part is also demonstrated in Equation 4.19:

$$
f=\left(\frac{2 f_{c}^{\prime} r}{r-1+2^{r}}\right)\left(\frac{\varepsilon_{u}-\varepsilon}{\varepsilon_{u}-2 \varepsilon_{c}^{\prime}}\right)
$$

The equation of the confined model is fully addressed in literature (Mander et al. 1988). The stress-strain curve of the concrete is developed using a reasonable number of plotted points. The coordination of each point of the graph is introduced as the input to the finite element software.

\subsubsection{Stress-strain curve of steel rebar}

The stress-strain curve of the steel rebar mainly depends on steel grade and rebar's sizes. Figure 4.3 depicts the stress-strain model for steel rebar proposed by Holzer (Holzer et al., 1975). This model consists of three branches of linear, perfectly plastic and a strain hardening portion. The calibration of the curve is based on the grade and size of steel reinforcement.

The equation of the linear branch is:

$$
f_{s}=E_{s} \varepsilon_{s} \quad 0 \leq \varepsilon_{s} \leq \varepsilon_{y}
$$

and the perfectly plastic branch:

$$
f_{s}=f_{y} \quad \varepsilon_{y} \leq \varepsilon_{s} \leq \varepsilon_{s h}
$$


And the strain hardening is defined by Equation 4.22:

$$
f_{s}=f_{y}\left[1+\frac{\varepsilon_{s}-\varepsilon_{s h}}{\varepsilon_{u}-\varepsilon_{s h}}\left(\frac{f_{u}}{f_{y}}-1\right) \exp \left(1-\frac{\varepsilon_{s}-\varepsilon_{s h}}{\varepsilon_{u}-\varepsilon_{s h}}\right)\right] \quad \varepsilon_{s h} \leq \varepsilon_{s} \leq \varepsilon_{r}
$$

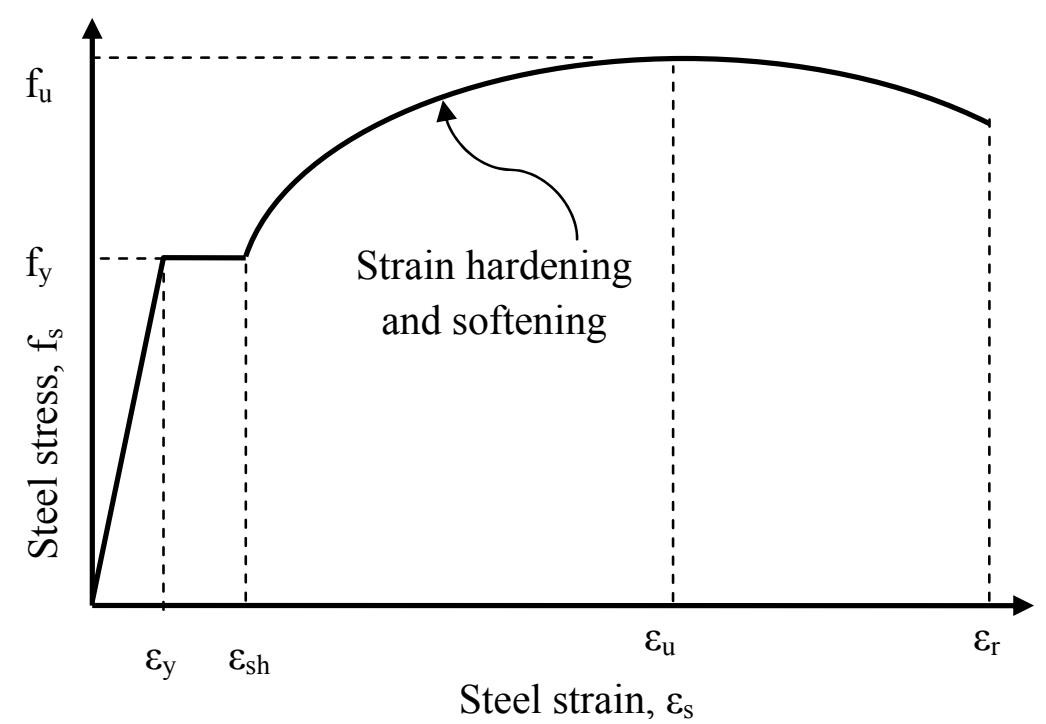

Figure 4.3 The stress-strain model for steel rebar (Holzer et al. 1975)

The stress-strain curve could be calibrated by defining the four strain stages and corresponding stresses. Table 4.1 demonstrates reference points for stress-strain curve proposed by Hozler (1975) for grade 400 steel rebars:

Table 4.1 Reference points for stress-strain curve of grade 400 steel (Hozler et al, 1975)

\begin{tabular}{cccccc}
\hline $\mathrm{f}_{\mathrm{y}}(\mathrm{Mpa})$ & $\mathrm{f}_{\mathrm{u}}(\mathrm{Mpa})$ & $\varepsilon_{\mathrm{y}}$ & $\varepsilon_{\mathrm{sh}}$ & $\varepsilon_{\mathrm{u}}$ & $\varepsilon_{\mathrm{r}}$ \\
\hline 400 & 730 & 0.00207 & 0.006 & 0.087 & 0.136 \\
\hline
\end{tabular}

Where:

$\varepsilon_{\mathrm{sh}}=$ strain at the onset of strain hardening 
$\varepsilon_{\mathrm{u}}=$ strain at maximum steel strength

$\varepsilon_{\mathrm{r}}=$ strain at steel failure

\subsection{Validation of proposed finite element reinforced concrete model}

The proposed finite element mathematical model requires validation by means of comparing to results of real experimental tests. Four experimental tests performed on RC beams and shear walls are selected for this purpose. The geometry of the RC shaft of elevated water tank resembles a shear wall with circular plan thus makes the shear wall an excellent choice for verifying the finite element model.

In all selected experimental tests the load is applied until the structure reaches the failure stage and partial or global collapse occurs. This is very similar to the procedure of pushover analysis of RC shaft walls. The entire loading procedure and corresponding response of the finite element model is recorded and compared to the actual load deflection results of the tests. The results are presented in the following sections.

\subsubsection{Reinforced concrete beam test verification}

Two simply supported Reinforced Concrete beam specimens were selected for investigation. These beams are specimens T1MA tested by Gaston et al. (1972) and J4 tested by Burns and Siess (1962). Table 4.2 provides the lengths of loading spans and beam section dimensions.

Table 4.2 Beam section dimensions and loading locations

\begin{tabular}{cccc}
\hline Beam & $\mathrm{b}(\mathrm{mm})$ & $\mathrm{h}(\mathrm{mm})$ & $\mathrm{d}(\mathrm{mm})$ \\
\hline T1MA & 152 & 305 & 272 \\
\hline J4 & 200 & 500 & 460 \\
\hline
\end{tabular}


The geometry, loading, boundary condition and general section of each beam are shown in Figure 4.4. Both beams are one end pinned and other end roller.

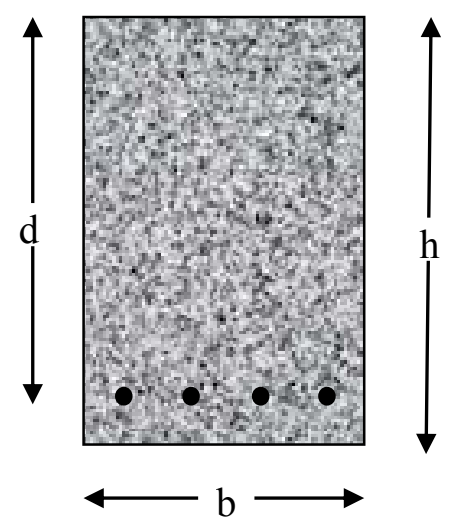

(b)

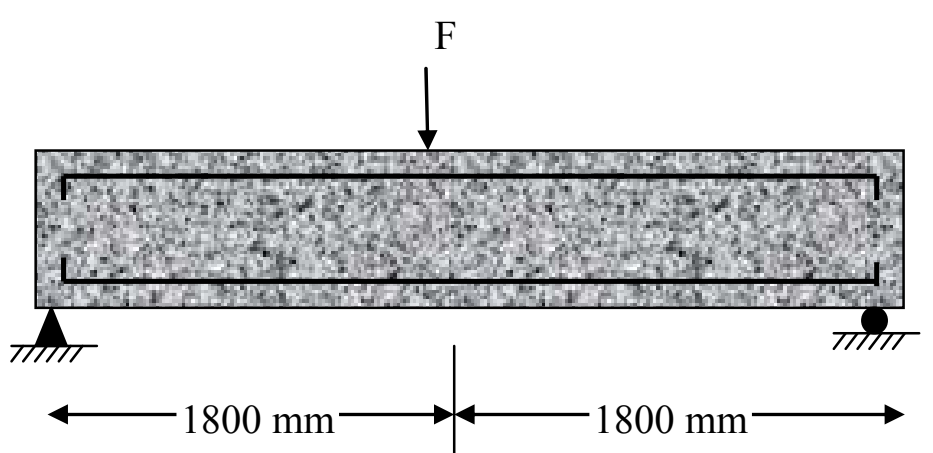

(a)

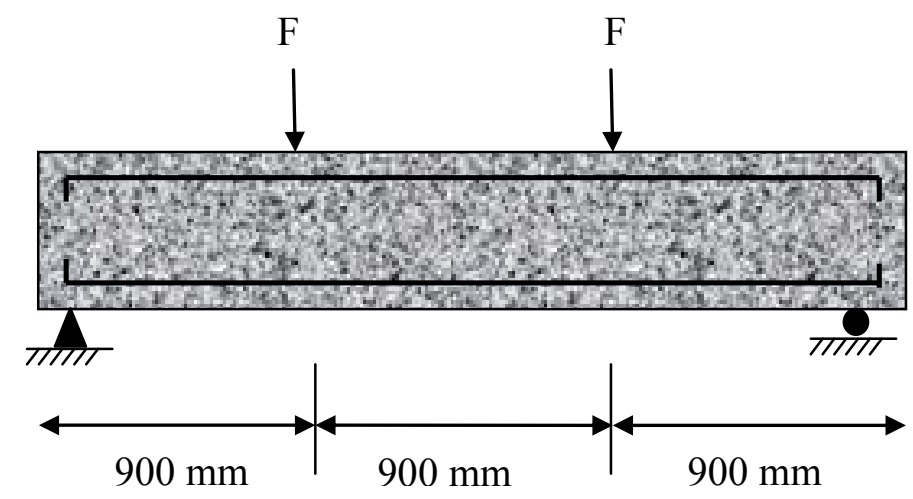

Figure 4.4 Geometry, loading, boundary condition and section of beam specimens (a) J4 beam specimen (b) typical beam section (c) T1MA beam specimen

The beams were modeled in ANSYS using the Solid65 element. The material properties of beam specimens are presented in Table 4.3.

Table 4.3 Material properties of beam specimens T1MA (Gaston et al. 1972) and J4 (Burns and Siess 1962)

\begin{tabular}{cccccc}
\hline Beam & $\mathrm{E}_{\mathrm{c}}(\mathrm{MPa})$ & $\mathrm{E}_{\mathrm{s}}(\mathrm{MPa})$ & $\mathrm{f}_{\mathrm{c}}(\mathrm{MPa})$ & $\mathrm{f}_{\mathrm{y}}(\mathrm{MPa})$ & $\rho=\mathrm{A}_{\mathrm{st}} / \mathrm{Bd}$ \\
\hline T1MA & 26585 & 194238 & 31.6 & 318 & 0.0062 \\
\hline J4 & 26192 & 203067 & 33.3 & 310 & 0.0099 \\
\hline
\end{tabular}


The experimental results display the Mid-span deflection versus applied load. The comparison between the finite element and experimental results for the two beam specimens are shown in Figures 4.5 and 4.6.

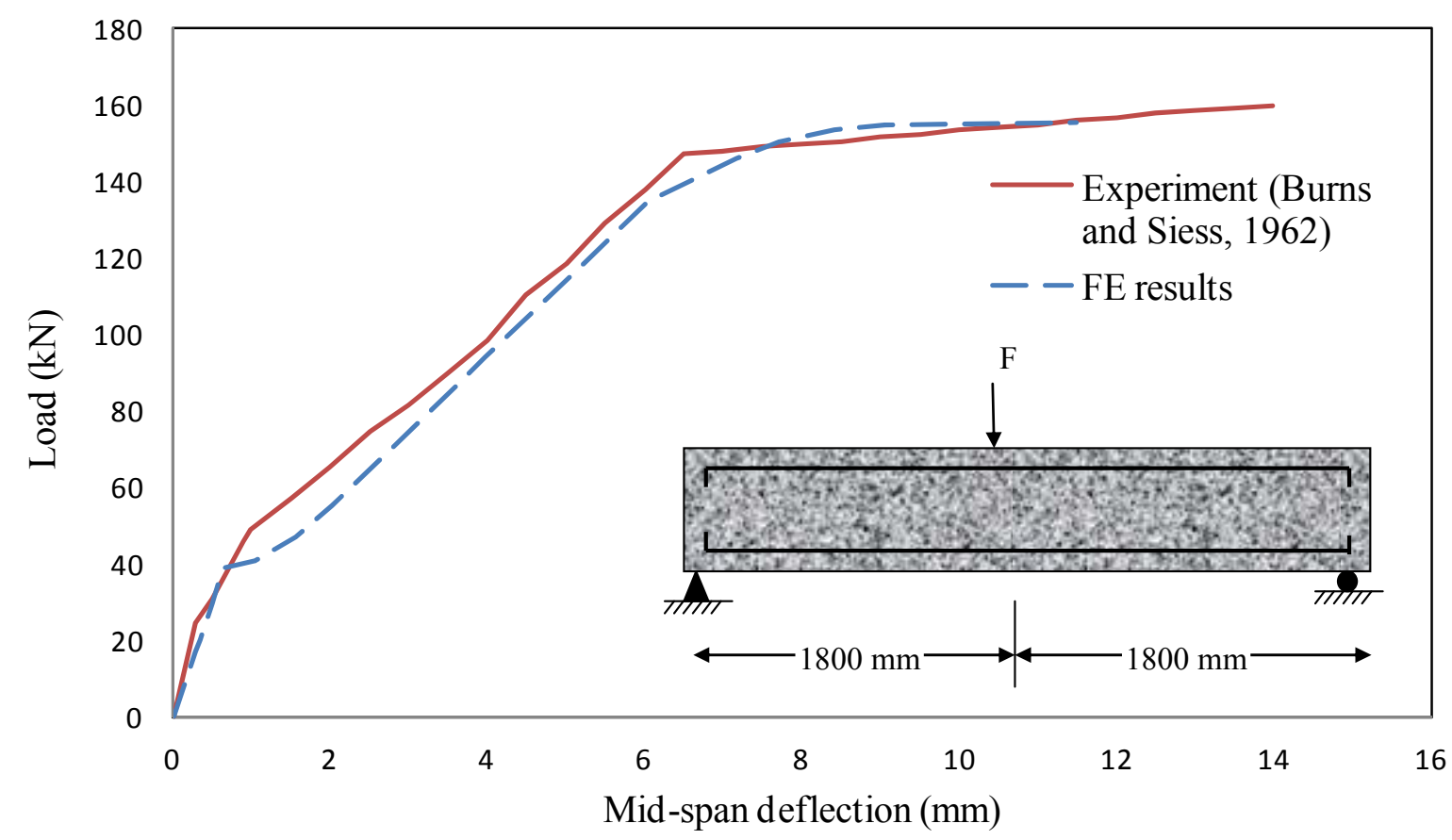

Figure 4.5 Finite element versus experimental results for J4 beam sample, Burns and Siess (1962)

The Figures are confirming that finite element model load-deformation predictions are in very good agreement with the laboratory test results. In this study, three main criteria were required for the FE results to be considered as satisfactory. According to the first criterion, the general FE load-deflection pattern must be similar to results from laboratory load test. This criterion is completely satisfied in both tests. The tangent slope and stiffness at different stages of the graphs are very close to each other. Secondly, for both beam specimens J4 and T1MA, the ultimate load before failure is predicted by the FE model with a very high accuracy. 


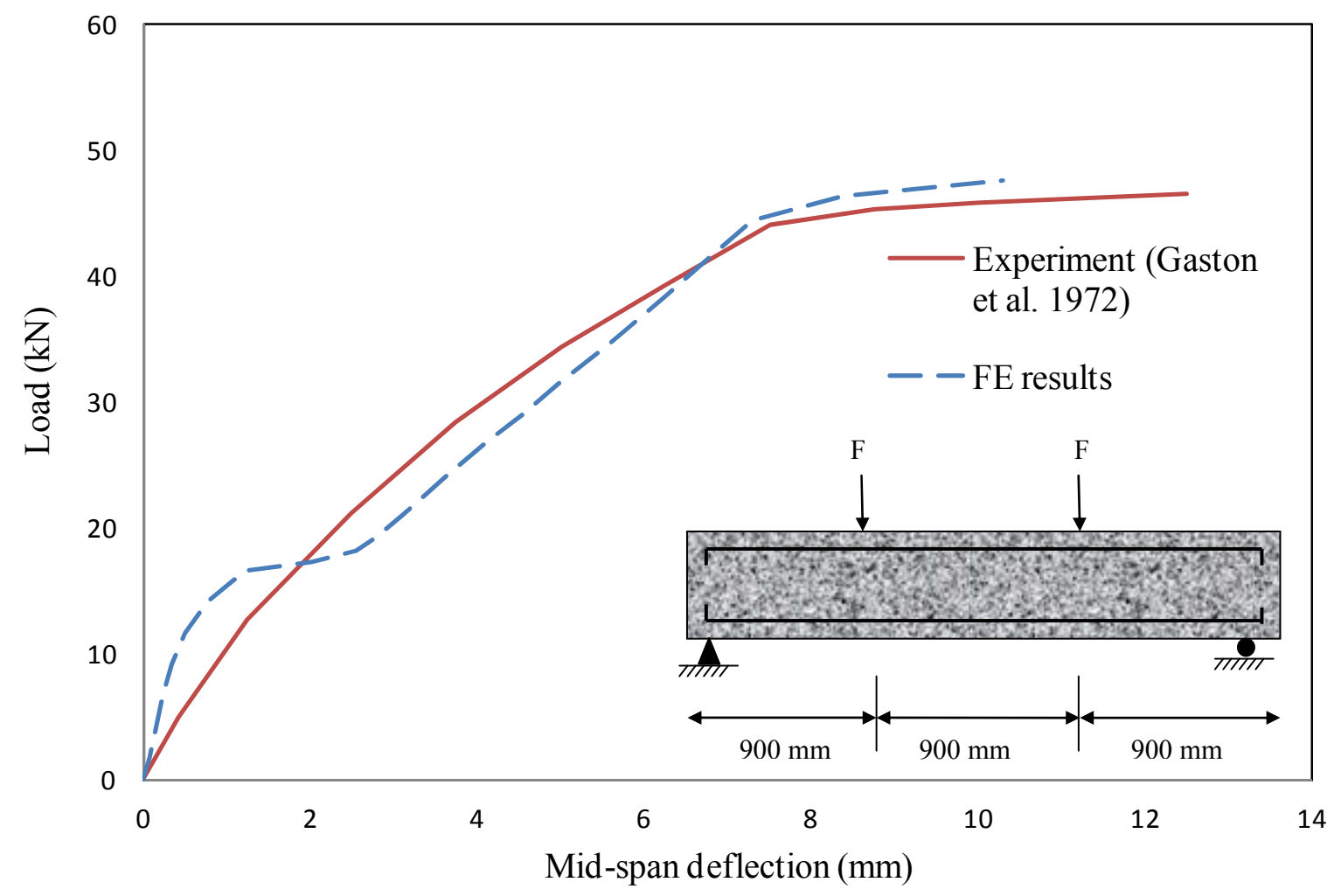

Figure 4.6 Finite element versus experimental results for T1MA beam specimen,

Gaston et al. (1972)

\subsubsection{Reinforced concrete wall test verification}

As mentioned earlier, the $\mathrm{RC}$ pedestals are essentially wall structures with circular plan section. For that reason, investigating the capability of the FE model in predicting the loaddeformation behaviour of an $\mathrm{RC}$ wall can provide an excellent means of validating the numerical model. The SOLID65 concrete element is employed for the FE modeling of the RC shear walls.

Mickleborough et al (1999) conducted an extensive experimental and theoretical study on reinforced concrete shear walls with a variety of height to width ratios. Two of the $\mathrm{RC}$ wall 
specimens with a height to width ratio of two are selected for further investigation and validation of FE model.

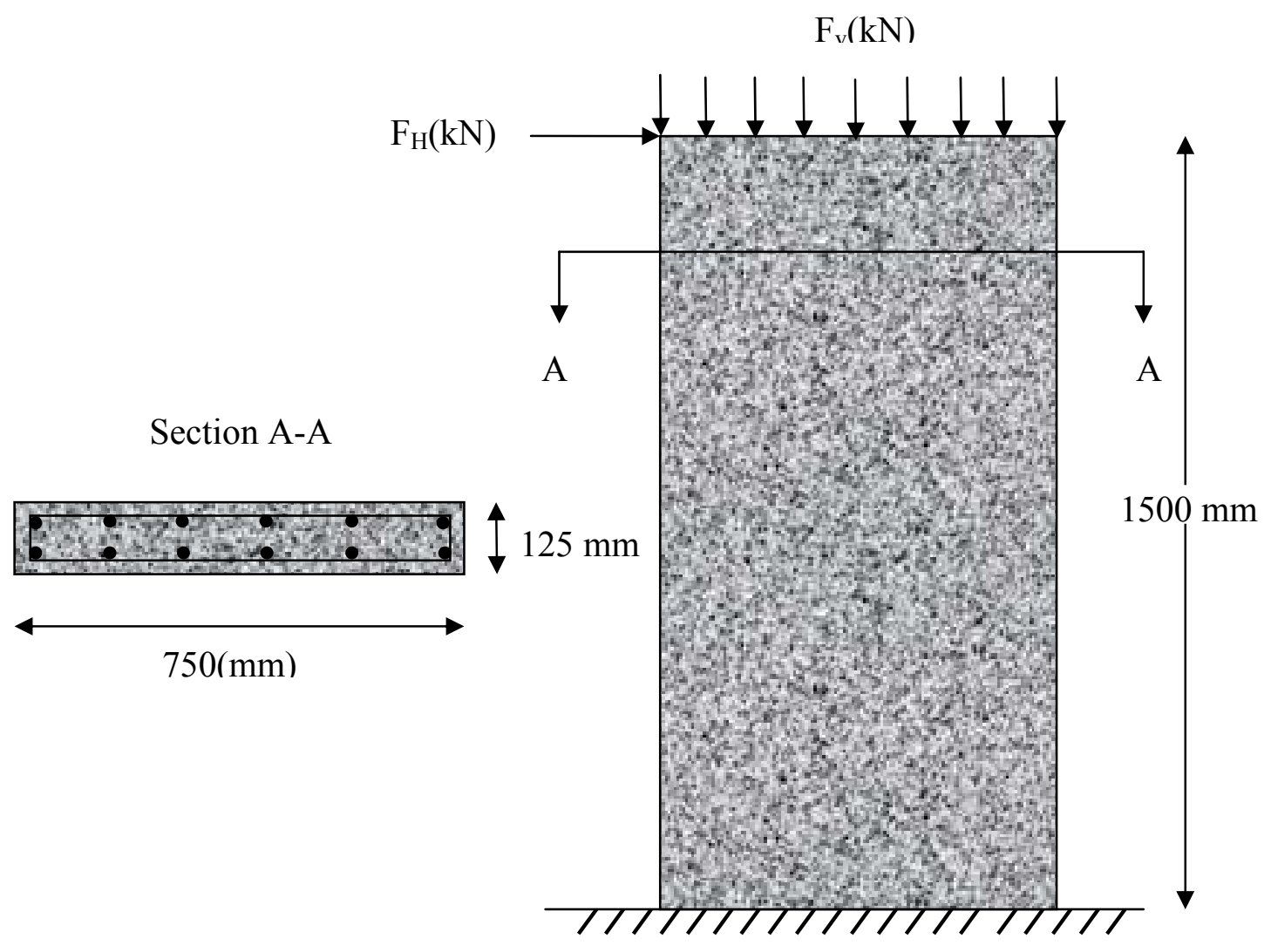

Figure 4.7 Geometry, loading and section of RC wall samples, Mickleborough et al. (1999)

Figure 4.7 shows the geometry, loading and the typical section of the shear wall samples. In all tests the walls were first loaded with a constant vertical load $\left(F_{v}\right)$. Next, the lateral load $\left(F_{H}\right)$ was applied progressively until the failure occurred. The two selected walls are samples SH-L and SH-H. Table 4.4 provides material properties, wall dimensions and vertical $\left(\rho_{\text {ver }}\right)$ and horizontal $\left(\rho_{\text {hor }}\right)$ reinforcement ratios of the two specimens.

The condition of the test procedure is similar to the pushover analysis of RC pedestal in the elevated water tanks. 
Table 4.4 Properties of wall specimens SH-L and SH-H (Mickleborough et al. 1999)

\begin{tabular}{cccccccccc}
\hline Wall ID & Height & Width & Thickness & $\begin{array}{c}\mathrm{f}_{\mathrm{c}} \\
(\mathrm{MPa})\end{array}$ & $\begin{array}{c}\mathrm{f}_{\mathrm{y}} \\
(\mathrm{MPa})\end{array}$ & $\begin{array}{c}\mathrm{E}_{\mathrm{c}} \\
(\mathrm{MPa})\end{array}$ & $\begin{array}{c}\mathrm{E}_{\mathrm{s}} \\
(\mathrm{MPa})\end{array}$ & $\begin{array}{c}\rho_{\mathrm{ver}} \\
(\%)\end{array}$ & $\begin{array}{c}\rho_{\text {hor }} \\
(\%)\end{array}$ \\
\hline SH-L & 1500 & 750 & 125 & 44.7 & 460 & 23788 & $2 \mathrm{e} 5$ & $1.17 \%$ & $0.39 \%$ \\
\hline SH-H & 1500 & 750 & 125 & 56 & 460 & 28990 & $2 \mathrm{e} 5$ & $1.17 \%$ & $0.39 \%$ \\
\hline
\end{tabular}

The vertical load which is first applied resembles the weight of the water tank and the gradually increasing lateral load simulates the force function in the pushover analysis.

Table 4.5 gives the loading, stress and maximum deformation prior to failure in each test. The term "Stress" in the table denotes the vertical compression stress component inside the walls. Sample SH-H demonstrates higher level of ultimate strength and deformation. This could be explained by the beneficial effects of compressive stresses that result in resisting more shear in the RC walls.

Table 4.5 Loading, stress and maximum deformation results of the test

\begin{tabular}{ccccc}
\hline Wall ID & $\mathrm{F}_{\mathrm{v}}(\mathrm{kN})$ & Stress $(\mathrm{MPa})$ & $\mathrm{F}_{\mathrm{H}}(\mathrm{kN})$ & $\Delta(\mathrm{mm})$ \\
\hline SH-L & 357 & 3.8 & 156 & 6.44 \\
\hline SH-H & 493 & 5.3 & 235 & 10 \\
\hline
\end{tabular}

The comparison between the finite element and experimental results is shown in Figure 4.8. The graphs demonstrate excellent agreement between the load-deflection patterns of FE and experimental results. Proposed FE model is perfectly capable of estimating maximum lateral strength of the shear walls. The difference between the actual test result and FE estimation of final lateral strength is limited to less than 5\%. Moreover the FE model is satisfactorily approximating the final drift of the walls before failure as well. 

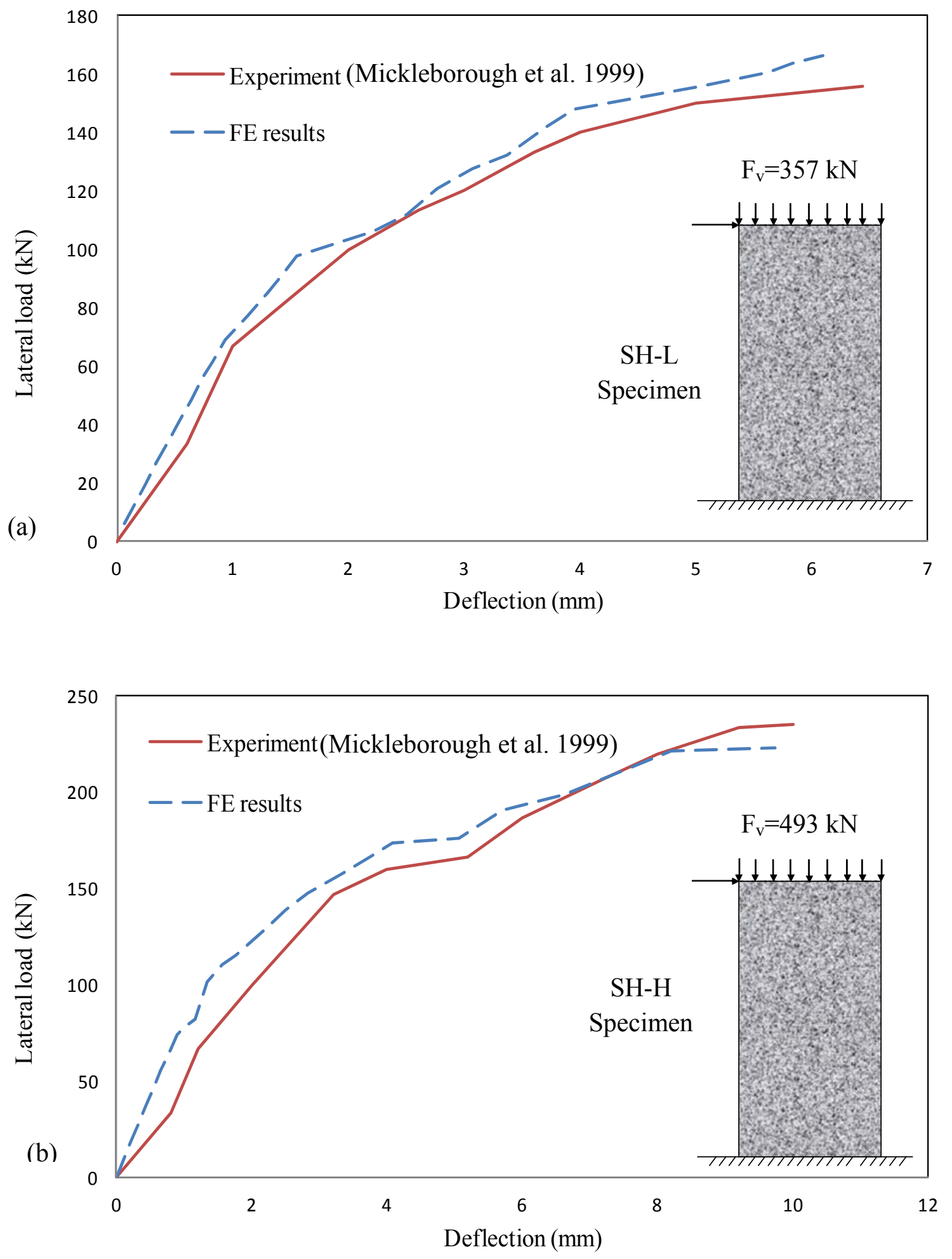

Figure 4.8 Comparison between the finite element and experimental results (a) Wall SH-L specimen (b) Wall SH-H specimen (Mickleborough et al. 1999) 


\subsection{Finite element model of RC pedestal in elevated water tanks}

In Figure 4.9(a) the simplified configuration of an $\mathrm{RC}$ elevated water tank is displayed. Generally, the RC elevated tank structures could be divided into three substructures including the tank, pedestal and foundation. This study is focused on the nonlinear response of the RC pedestal substructure and therefore a number of simplifications are made for modeling of the other two substructures.

The tank itself consists of the vessel (either steel or reinforced concrete) and the liquid inside. This system is replaced with a mass element located at the center of gravity of the tank (Figure 4.9(b)). The mass is coupled with the RC pedestal structure.

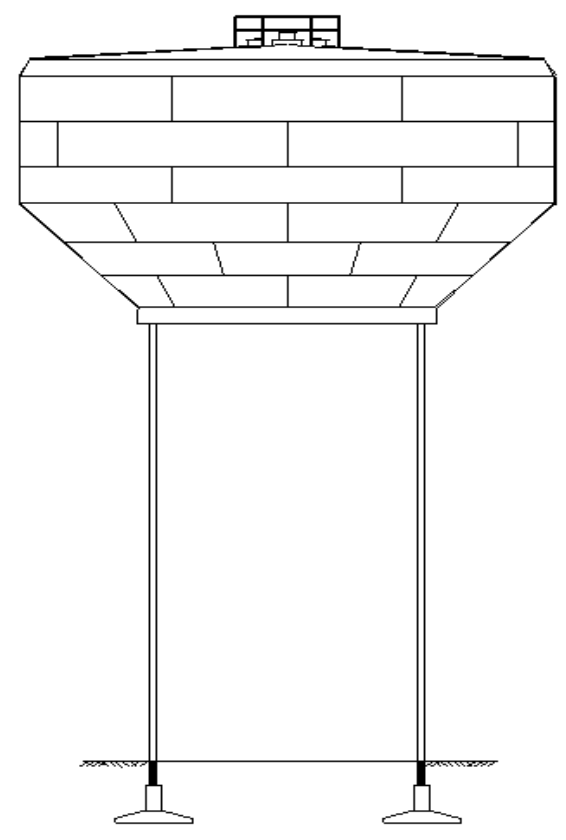

(a)

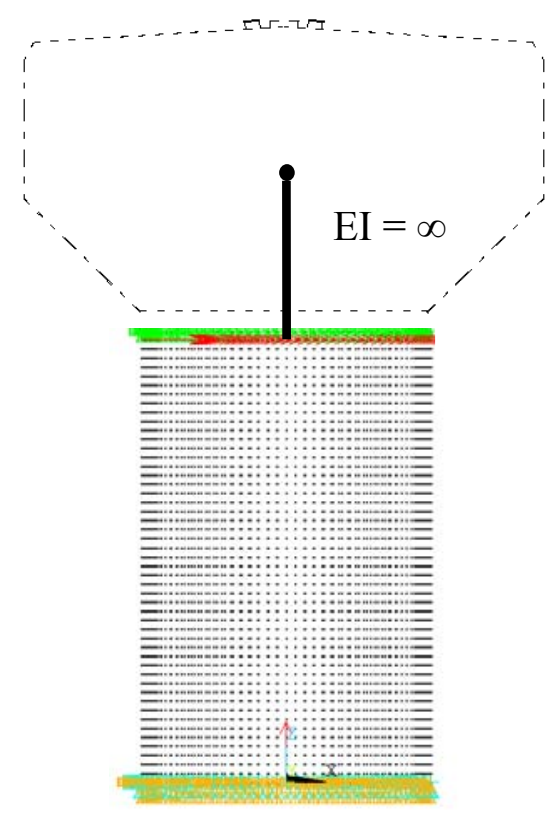

(b)

Figure 4.9 Finite element idealization of shaft structure (a) tank elevation (b) FE idealization 
A rigid reinforced concrete slab is constructed at the bottom layer of the tank and supports the vessel contents inside the pedestal. This slab is placed on top of the ring beam. The slab might also have a dome, flat or cone shape configuration. Existence of the ring beam and the RC slab together can tie the top layer of the RC pedestal as a rigid diaphragm. This is taken into account in the finite element model by coupling horizontal, vertical and rotational degrees of freedom at the top of RC pedestal. This is illustrated in Figure 4.10.

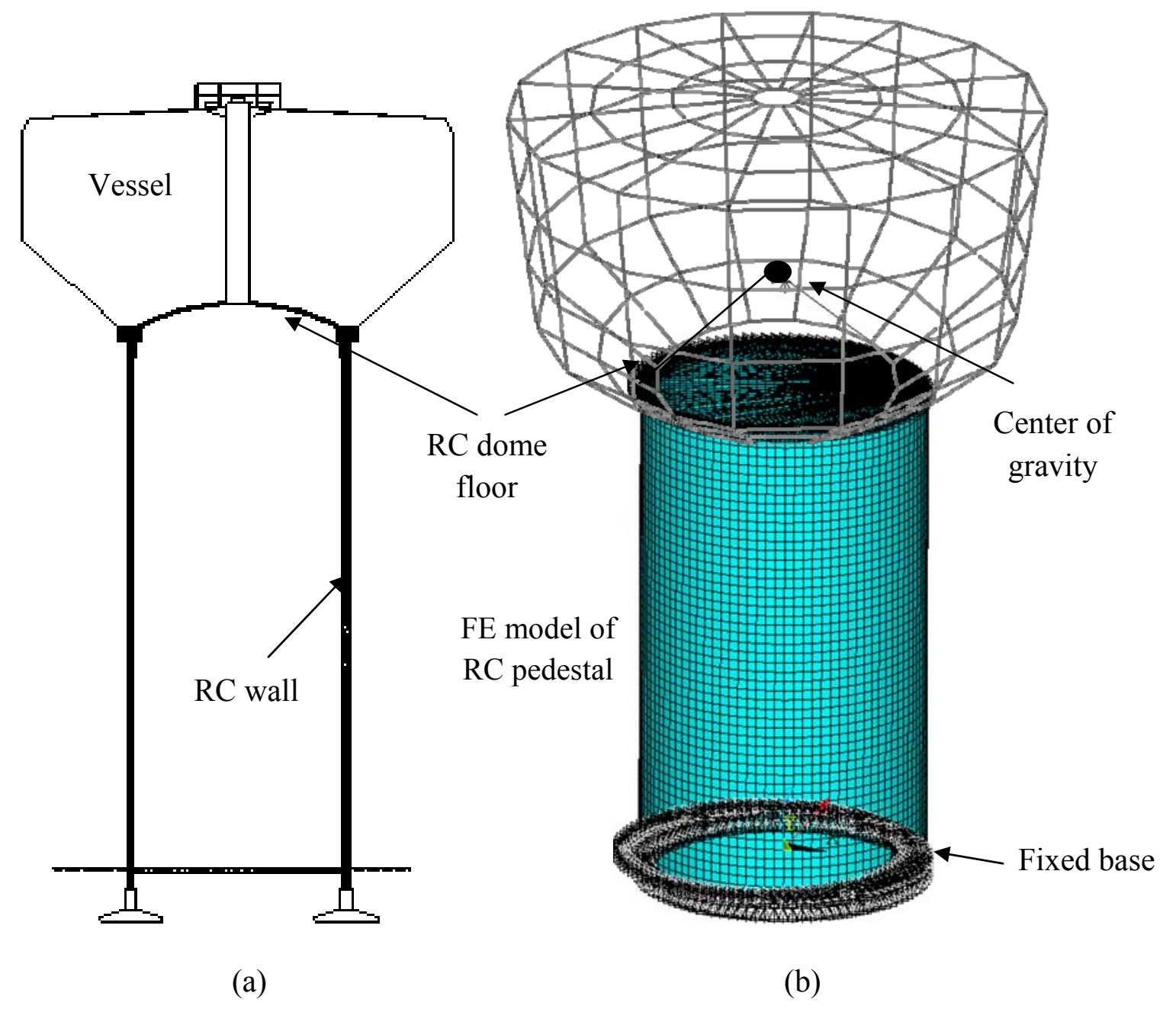

Figure 4.10 Elevated water tank model (a) simplified configuration (b) finite element model 
The foundation is assumed to be rigid and shaft wall is fixed at the level of foundation. This is applied by constraining all degrees of freedom at the base level of RC pedestal.

The number of elements required for modeling the RC pedestal depends on the shaft height, thickness, and meshing size. This will be further explained in next chapter. The geometrical, material properties as well as sensitivity analysis of the typical finite elopement models employed in this study are given in Appendix A of the thesis.

\subsection{Summary}

In this chapter, a finite element technique for modeling reinforced concrete structures was introduced. The SOLID65 element as a powerful numerical model used in ANSYS software for modeling reinforced concrete was discussed. Furthermore, the stiffness matrices for the SOLID65 element under different loading stages such as before and after cracking were developed. The chapter also covered the equations of failure of concrete element under multiaxial stress condition.

The nonlinear static and dynamic equations which are used in seismic analysis of the RC pedestals were developed in Chapter 3. This chapter addressed numerical solution techniques employed for solving these equations.

The chapter also provided numerical models for stress-strain behaviour of concrete and steel. These models are necessary for both nonlinear static and dynamic analysis of RC pedestals.

In addition, the proposed finite element method was validated by comparing to the laboratory test results. Two beams and two shear walls were considered for conducting this verification. The comparison of the finite element and laboratory results indicated excellent capability of the 
proposed finite element method in modelling the load-deflection behaviour at different stages of loading procedure.

The chapter concludes by introducing the proposed finite element model of elevated water tanks. In this section the simplifications and assumptions that are made for performing the finite element analysis were addressed and the boundary conditions of the finite element model were illustrated. 


\section{Chapter 5 \\ Pushover analysis of RC elevated water tanks}

\subsection{General}

This chapter investigates the seismic performance of RC elevated water tanks by conducting pushover (nonlinear static) analysis. The focus is on evaluating the pushover curves that are obtained from the nonlinear static analysis of RC pedestals. Pushover curves present valuable information regarding the seismic response behaviour of structures. The seismic response factors of elevated water tanks, which are determined based on the pushover curves, will be addressed in the next chapter.

The chapter starts with constructing multiple prototypes (elevated water tanks designed based on provisions of code) based on a number of selection criteria. The prototypes' dimensions and sizes are selected based on the most widely used tank sizes and pedestal heights. In total, 48 prototypes will be designed and analyzed. Each prototype is designed for high and low seismicity.

The prototypes are designed based on the requirements of ACI371R-08, ASCE/SEI 7-2010 and ACI 350.3-06. A finite element model is developed for each prototype. Subsequently, a pushover analysis is conducted on each finite element model. By extracting the load-deformation results of the pushover analysis, the pushover curves are generated. Due to the large number of finite element models, a set of 10 models are selected as the representative of all 48 models for further investigation.

The pushover curves of the pilot group are then presented and compared to each other. There are some general patterns exhibited by pushover curves which will be discussed. The effect of various factors in the pushover curves will be addressed as well. Finally, the cracking propagation patterns which are observed in the process of pushover analysis will be presented. These patterns are compared and categorized based on the geometry and dimensions of the elevated water tanks. 


\subsection{Constructing the elevated water tank prototypes}

Elevated water tanks are built in different heights and sizes depending on the demand in the water system network. Many factors could affect pedestal height and tank size among which the site location, pumping facility capacity, seismicity and water pressure demand are the most significant to mention.

In conventional structures such as buildings, the dead and live load values do not differ significantly from each other for similar occupancies. In other words, for two building structures of the same configuration, height and occupancy, overall gravity loads do not vary much from each other. As a result, the seismic response of one RC frame structure is not expected to differ significantly from another one with the same height and configuration. However, in case of elevated water tanks, the gravity load may dramatically change from one to another depending on the size of the tank. This issue can generate considerable variation in the seismic response behaviour characteristics of the elevated water tank structures of the same height but different tank sizes. Furthermore, the combination of different RC pedestal heights with same tank size can also result in different responses.

In order to address abovementioned issues, several elevated water tank models (prototypes) with variable structural characteristics and dimensions are developed in this research. The goal has been to investigate a reasonably wide range of elevated water tank dimensions that are identical to the ones constructed in industry. Furthermore, effect of other parameters such as seismicity of the site and code requirements is included in the selection of prototypes.

Studying this broad range of prototypes will examine all possible seismic response behaviours and make it more logical and reliable to establish the general global seismic response of the elevated water tanks. 
Selection of the prototypes is made based on various selection criteria which will be fully discussed in later parts of this chapter. The prototypes are first designed according to the provisions of the pertinent codes and guidelines. Next, pushover analysis is performed on each prototype in order to establish the pushover curve. The pushover curves are then further simplified to bilinear curves in order to extract ductility and overstrength factor. Finally these results will be investigated and compared to each other by means of tables and graphs.

\subsubsection{Standard dimensions and capacities of elevated water tanks}

According to ACI371R-08 common tank sizes in elevated water tanks is between 500,000 to 3,000,000 gal (1900 to $\left.11,000 \mathrm{~m}^{3}\right)$ and RC pedestal heights range from 8 to 60 meters. In practice, other tank sizes below or above these ranges are also being constructed. Table 5.1 presents a number of commonly built tank sizes and dimensions. The parameter used in Table 5.1 including head range, tank diameter and pedestal diameter are demonstrated in Figure 5.1.

Table 5.1 commonly built tank sizes and dimensions (Adapted from Landmark Co.)

\begin{tabular}{cccc}
\hline Capacity (gal) & Head range (meter) & Tank diameter (meter) & Pedestal diameter (meter) \\
\hline 500,000 & $9-10.5$ & $15.3-16.5$ & 7.2 \\
\hline 750,000 & $10.5-12$ & $17.7-19.5$ & 8.4 \\
\hline $1,000,000$ & $10.5-12$ & $20.4-22.2$ & 9.6 \\
\hline $1,250,000$ & $11.25-12$ & $22.5-24$ & 11.4 \\
\hline $1,500,000$ & $11.25-12$ & $24.6-26.1$ & 12.6 \\
\hline $1,750,000$ & 12 & $27-28.5$ & 13.8 \\
\hline $2,000,000$ & 12 & $28.5-30$ & 13.8 \\
\hline $2,500,000$ & $12-13.5$ & $30.6-33.6$ & 16.2 \\
\hline $3,000,000$ & 13.5 & $32.4-34.5$ & 18 \\
\hline $3,000,000$ & 15 & $32.4-34.5$ & 18 \\
\hline
\end{tabular}




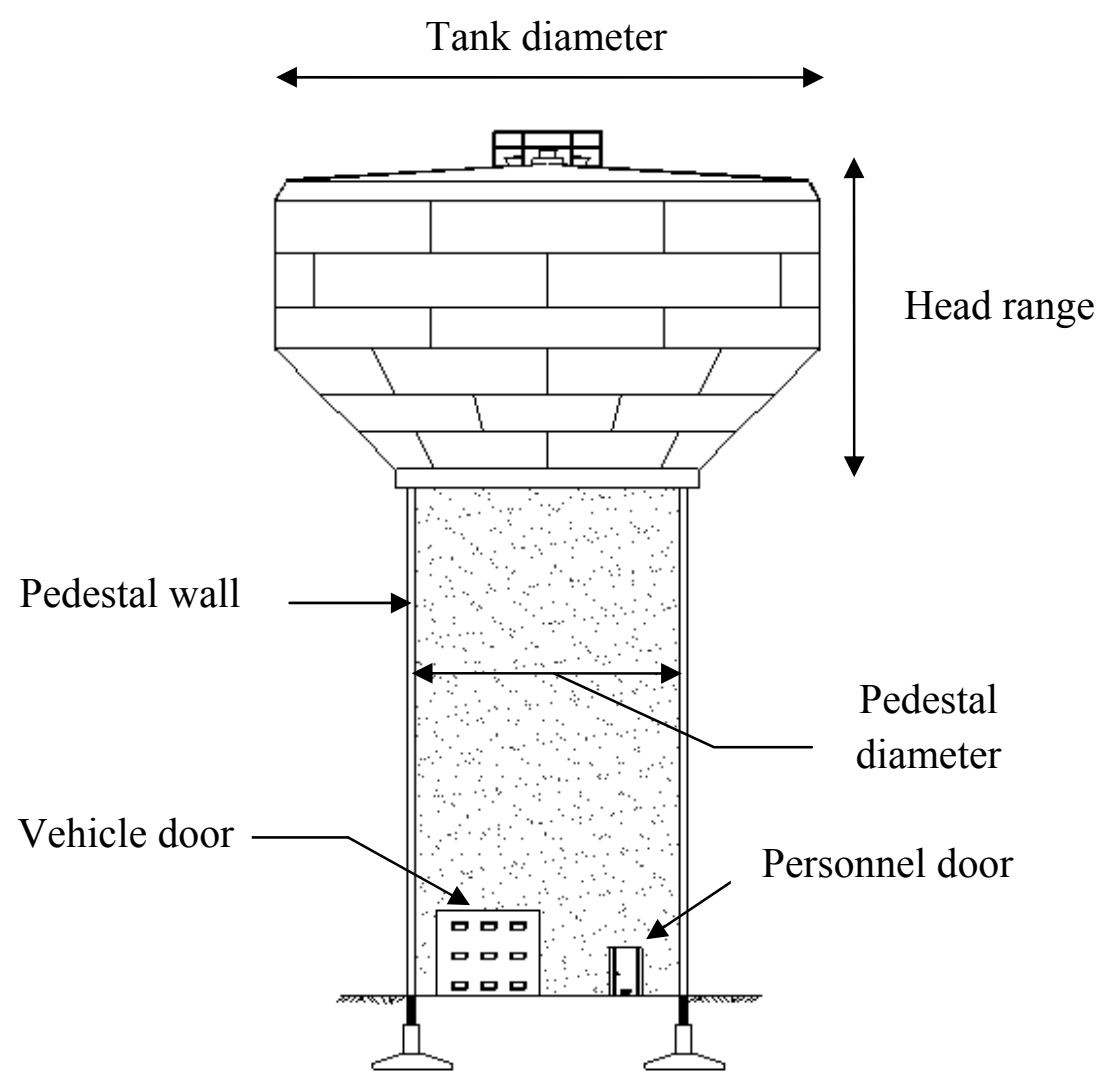

Figure 5.1 Definition of terms and components in elevated water tanks

\subsubsection{Selection criteria for constructing the prototypes}

Selecting the number and configuration of the prototypes in the study group is a multiobjective task. The number of prototypes in the study group should be reasonably chosen to be both feasible and sufficient. The study group must be broad enough to include all possible designs built in practice. At the same time, the number of selected prototypes must be practical. This objective is best satisfied if a number of selection criterions are defined to assist in developing the prototypes. 
The selection criterions must be able to address all design features of elevated water tanks. In addition, any other parameter that may affect the seismic response of the structure should be considered. The main selection criteria employed in this research for choosing the prototypes include pedestal height, tank capacity, site seismicity and response modification factor. These factors are explained in detail hereafter.

Generally, the effect of structural plan configuration must also be considered as a criterion (frame structures for example). This is not required in the case of the elevated tanks as the plans of all structures are identical in shape (circular RC wall) and no specific irregularity exists.

In addition, structures demonstrate different seismic response when subjected to seismic loads in different directions. This will lead towards adding the seismic load direction as another criterion for developing the prototype. Such a criterion is redundant for the analysis of the elevated water tanks due to the symmetrical plan of these structures provided that the effect of openings are not considered.

Pedestal height: Pedestal height could range between 15 to 60 meters. The most commonly built height of pedestals in North America is around 30 to 35 meters. Four pedestal heights of 15, 25,35 and 45 are determined to be investigated. The selected heights are reasonably encompassing majority of those built in industry. The height of pedestal has a significant effect on the fundamental period of the elevated water tanks. Subsequently, the fundamental period can considerably influence code-based seismic loads and therefore alternate seismic response behaviour. 
Tank size: Tank size can measure between 0.5 MGal to 3.5 MGal. Four tank sizes of 0.5, 1, 2 and $3 \mathrm{MGal}$ which are considered to be the most widely built tank sizes are included in this study. The tank size has a significant effect on pedestal wall thickness, pedestal diameter, and fundamental period of the elevated water tank structure.

Site seismicity: The site seismicity affects the design response spectrum and consequently seismic load intensity. The elevated tank structure will be investigated for two levels of high and low seismicity. The details about site class and coefficients will be illustrated later in this chapter. The design earthquake spectral response acceleration parameter at short period and 1 sec period are 0.84 and 0.44 respectively for the high seismicity category. These values are determined to be 0.2 and 0.11 respectively for the low seismicity.

Response modification factor: According to ASCE/SEI 7-2010, response modification factor of elevated water tanks might be considered as 2 or 3 depending on the special seismic detailing provided in the construction of $\mathrm{RC}$ pedestals. For the $\mathrm{R}=2$ prototypes no special detailing is required. For the $\mathrm{R}=3$ prototypes, the special detailing (according to provisions of ACI 318-08) must be provided, therefore the concrete has more confinement and the confined model as described in Chapter 4 (Section 4.5.1), is employed. Both values of R factors will be included in the design of prototypes for investigation and effect of each value is studied separately.

The above four criteria are considered to be capable of sufficiently covering all design aspects and issues in a variety of elevated water tank dimensions. By applying a combination of all 
above mentioned criteria, 48 prototypes are developed. The prototypes are categorized into two main groups. The first group is designed for $\mathrm{R}=2$ (Response modification factor) and consists of 24 prototypes. The second group is identical to the first one in terms of height, tank size and seismicity except all the prototypes are designed with the assumption of $\mathrm{R}=3$. Table 5.2 demonstrates all 24 prototype's of the first group. For each prototype the specific design aspect and dimensions are shown.

Table 5.2 Dimensions and properties of prototypes in the first group

\begin{tabular}{|c|c|c|c|c|}
\hline \multicolumn{5}{|c|}{ Prototypes group one $(\mathrm{R}=2)$} \\
\hline \multirow[b]{2}{*}{$\begin{array}{c}\text { prototype } \\
\text { No. }\end{array}$} & \multirow[b]{2}{*}{$\begin{array}{c}\text { pedestal } \\
\text { Height }\end{array}$} & \multicolumn{2}{|c|}{ Design Load Level } & \multirow[b]{2}{*}{$\begin{array}{l}\text { FE model } \\
\text { ID }\end{array}$} \\
\hline & & $\begin{array}{l}\text { Seismic Design } \\
\text { Category(SDC) }\end{array}$ & $\begin{array}{l}\text { Gravity load } \\
\text { (Tank size) }\end{array}$ & \\
\hline P-1 & \multirow{6}{*}{$15 \mathrm{~m}$} & \multirow{3}{*}{ SDC high } & Low & $15-\mathrm{H}-0.5$ \\
\hline P-2 & & & Medium & $15-\mathrm{H}-1$ \\
\hline $\mathrm{P}-3$ & & & High & $15-\mathrm{H}-2$ \\
\hline P-4 & & \multirow{3}{*}{ SDC low } & Low & $15-\mathrm{L}-0.5$ \\
\hline $\mathrm{P}-5$ & & & Medium & 15-L-1 \\
\hline $\mathrm{P}-6$ & & & High & $15-\mathrm{L}-2$ \\
\hline $\mathrm{P}-7$ & \multirow{6}{*}{$25 \mathrm{~m}$} & \multirow{3}{*}{ SDC high } & Low & $25-\mathrm{H}-0.5$ \\
\hline P-8 & & & Medium & $25-\mathrm{H}-2$ \\
\hline P-9 & & & High & $25-\mathrm{H}-3$ \\
\hline P-10 & & \multirow{3}{*}{ SDC low } & Low & $25-\mathrm{L}-0.5$ \\
\hline $\mathrm{P}-11$ & & & Medium & $25-\mathrm{L}-2$ \\
\hline $\mathrm{P}-12$ & & & High & $25-\mathrm{L}-3$ \\
\hline P-13 & \multirow{6}{*}{$35 \mathrm{~m}$} & \multirow{3}{*}{ SDC high } & Low & $35-\mathrm{H}-0.5$ \\
\hline $\mathrm{P}-14$ & & & Medium & $35-\mathrm{H}-1$ \\
\hline P-15 & & & High & $35-\mathrm{H}-3$ \\
\hline $\mathrm{P}-16$ & & \multirow{3}{*}{ SDC low } & Low & $35-\mathrm{L}-0.5$ \\
\hline P-17 & & & Medium & $35-\mathrm{L}-1$ \\
\hline P-18 & & & High & $35-\mathrm{L}-3$ \\
\hline P-19 & \multirow{6}{*}{$45 \mathrm{~m}$} & \multirow{3}{*}{ SDC high } & Low & $45-\mathrm{H}-0.5$ \\
\hline $\mathrm{P}-20$ & & & Medium & 45-H-1 \\
\hline $\mathrm{P}-21$ & & & High & $45-\mathrm{H}-3$ \\
\hline $\mathrm{P}-22$ & & \multirow{3}{*}{ SDC low } & Low & $45-\mathrm{L}-0.5$ \\
\hline P-23 & & & Medium & $45-\mathrm{L}-1$ \\
\hline P-24 & & & High & $45-\mathrm{L}-3$ \\
\hline
\end{tabular}


Each prototype has been assigned a finite element model identification number (FE model ID) as displayed in Table 5.2. The first term represents the pedestal height and the second and third terms stand for the seismicity category and tank size respectively. Therefore the FE model ID 35H-1 represents an elevated water tank with a pedestal height of 35 meters and tank size of 1 Mega gallon which is located in a high seismicity zone. In the next step each prototype will be designed in accordance with the current practice.

\subsection{Design of prototypes based on code requirements}

Elevated water tanks are principally designed based on ACI 371R-08 and supplementary guidelines from ACI 350.3-06 and ASCE/SEI 7-2010. All of the prototypes must be designed for the provisions of these standards. In previous chapter, the assumptions for designing the elevated tanks were discussed. In this section the procedure for design of RC pedestal is briefly described. Dead load, stored water load and earthquake load are taken into account for design purposes. The design process could be divided into two separate procedures of gravity and seismic design.

\subsubsection{Design of RC pedestals for gravity loads}

The prototypes are designed for the dead load (D) and the weight of water in the tank (F). The $\mathrm{RC}$ pedestals of the prototypes will be designed for the related factored load combination in Equation 5.1:

$\mathrm{U}=1.4(\mathrm{D}+\mathrm{F})$

The axial load resistance of the RC pedestal wall must satisfy Equation 5.2: 


$$
P_{u w} \leq \phi P_{n w}
$$

Where:

$\varphi=0.65$

$\mathrm{P}_{\mathrm{uw}}=$ factored axial wall load per unit of circumference

$\mathrm{P}_{\mathrm{nw}}$ is the nominal axial strength and is found with Equation 5.3:

$P_{n w}=C_{e}\left[0.85 f_{c}^{\prime}\left(A_{w}-A_{s}\right)+f_{y} A_{s}\right]$

Where:

$\mathrm{A}_{\mathrm{w}}=$ gross horizontal cross-sectional concrete area of wall in RC pedestal

$\mathrm{A}_{\mathrm{s}}=$ reinforcement area

$f_{y}=$ Specified yield strength of steel bars

In Equation 5.3, $\mathrm{C}_{\mathrm{e}}$ is an eccentricity coefficient that accounts for the resultant of factored axial load $\mathrm{P}_{\mathrm{uw}}$ to be eccentric to the centroid of the pedestal thickness.

RC pedestal structures have relatively thin wall which is susceptible to axial load and may buckle in different modes. The buckling mode depends on the thickness of the wall, pedestal diameter and height of wall. Medium height pedestals are more vulnerable to buckling in diamond shape mode while tall pedestals may experience column mode buckling.

All of the 48 prototypes are checked for the buckling effects of both modes. The effect of column buckling mode is investigated using Equation 5.4:

$$
P_{c r}=\pi^{2} E I /\left(k L_{g}\right)^{2}
$$


And the factor of safety against buckling is:

$F_{s}=\left[\pi^{2} E I /\left(k L_{g}\right)^{2}\right] / 0.85 f_{c}^{\prime} A_{w}$

Where:

$\mathrm{L}_{\mathrm{g}}=$ distance from bottom of foundation to centroid of stored water

$\mathrm{k}=2.1$

The factors of safety against column buckling $\left(\mathrm{F}_{\mathrm{s}}\right)$ of the prototypes were determined to be between minimum of 2.9 to a maximum of 41.7 . The lowest factor of safety belonged to the tallest pedestals and the highest one belonged to the shortest pedestal.

RC elevated water tanks with a medium height must be checked against diamond shape buckling failure. Equation 5.6 gives the critical axial load for controlling the diamond shape buckling effect:

$P_{c r}=2 C E h A_{w} / d_{w}$

Where:

$\theta=0.0442\left(d_{w} / h\right)^{1 / 2} \quad C=0.6[1.0-0.9(1.0-e-\theta)]$

$\mathrm{h}=$ height from grade to the top of the vessel shell

$\mathrm{E}=$ modulus of elasticity of concrete

$\mathrm{e}=$ eccentricity of the axial wall load

$\mathrm{d}_{\mathrm{w}}=$ mean diameter of $\mathrm{RC}$ pedestal

and the factor of safety against buckling is:

$F_{s}=2 C E A_{w}\left(h / d_{w}\right) / C 0.855 f_{c}^{\prime} A_{w}$

The factor of safety for all prototypes was found to be approximately above 7 . 


\subsubsection{Design of RC pedestals for seismic loads}

The prototypes are designed for earthquake loads by employing the equivalent lateral force procedure. The design is performed using the following load combinations:

$$
\begin{aligned}
& \mathrm{U}=1.2(\mathrm{D}+\mathrm{F})+1.0 \mathrm{E} \\
& \mathrm{U}=0.9 \mathrm{D}+1.0 \mathrm{~F}+1.0 \mathrm{E} \\
& \mathrm{U}=0.9 \mathrm{D}+\mathrm{E}
\end{aligned}
$$

The seismic design is according to the ACI 371R-08 along with ASCE/SEI 7-2010 and ACI 350.3-06. Prototypes are designed for two levels of high and low seismicity. Table 5.3

\begin{tabular}{|c|c|c|c|}
\hline \multicolumn{4}{|c|}{ Design response spectrum parameters } \\
\hline Parameter & Description & $\begin{array}{l}\text { High } \\
\text { seismicity }\end{array}$ & $\begin{array}{l}\text { Low } \\
\text { seismicity }\end{array}$ \\
\hline $\mathrm{S}_{\mathrm{s}}$ & $\begin{array}{c}\text { Mapped MCER spectral response acceleration } \\
\text { parameter at short period }\end{array}$ & 1.25 & 0.25 \\
\hline $\mathrm{S}_{1}$ & $\begin{array}{l}\text { Mapped MCER spectral response acceleration } \\
\text { parameter at a period of } 1 \mathrm{~s}\end{array}$ & 0.5 & 0.1 \\
\hline $\mathrm{F}_{\mathrm{a}}$ & Site coefficient for short period (site class C) & 1 & 1.2 \\
\hline $\mathrm{F}_{\mathrm{v}}$ & Site coefficient for $1(\mathrm{sec})$ period (site class C) & 1.3 & 1.7 \\
\hline $\mathrm{S}_{\mathrm{MS}}=\mathrm{F}_{\mathrm{a}} \mathrm{S}_{\mathrm{s}}$ & $\begin{array}{l}\text { spectral response acceleration parameter at short } \\
\text { period adjusted for site class effects }\end{array}$ & 1.25 & 0.3 \\
\hline $\mathrm{S}_{\mathrm{M} 1}=\mathrm{F}_{\mathrm{v}} \mathrm{S}_{1}$ & $\begin{array}{l}\text { spectral response acceleration parameter at } 1 \mathrm{~s} \text { period } \\
\text { adjusted for site class effects }\end{array}$ & 0.65 & 0.17 \\
\hline $\mathrm{S}_{\mathrm{DS}}=2 / 3 \mathrm{~S}_{\mathrm{Ms}}$ & $\begin{array}{l}\text { Design earthquake spectral response acceleration } \\
\text { parameter at short period }\end{array}$ & 0.84 & 0.2 \\
\hline $\mathrm{S}_{\mathrm{D} 1}=2 / 3 \mathrm{~S}_{\mathrm{M} 1}$ & $\begin{array}{l}\text { Design earthquake spectral response acceleration } \\
\text { parameter at } 1 \mathrm{~s} \text { period }\end{array}$ & 0.44 & 0.11 \\
\hline
\end{tabular}
demonstrates assumptions made for the two seismicity zones:

Table 5.3 Seismic ground motion values for seismic design of prototypes 
Next, according to the provisions of ASCE/SEI 7-2010 and calculated values of design earthquake spectral response acceleration parameters at short and $1 \mathrm{sec}$ period, the design response spectrum for lateral acceleration is constructed.

Figure 5.2 shows the design response spectrum for both seismic zones:
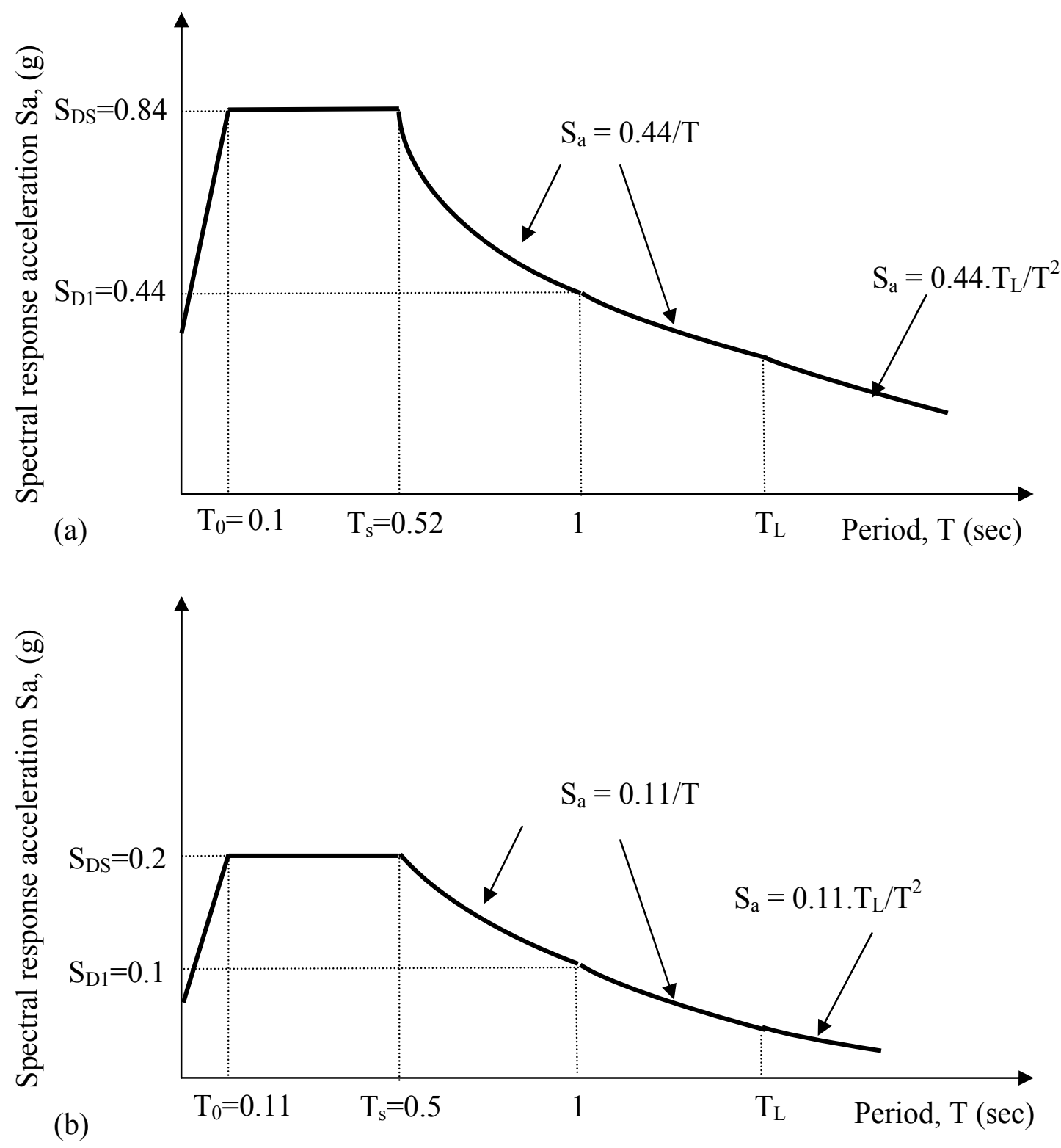

Figure 5.2 Design response spectrum (a) high seismicity zone (b) low seismicity zone 
Where: $\quad \mathrm{T}_{0}=0.2 \mathrm{~S}_{\mathrm{D} 1} / \mathrm{S}_{\mathrm{DS}}$

$\mathrm{T}_{\mathrm{S}}=\mathrm{S}_{\mathrm{D} 1} / \mathrm{S}_{\mathrm{DS}}$

$T_{L}=$ "long-period" transition period (read from the maps)

\subsubsection{Seismic base shear}

The seismic base shear is calculated based on Equation 5.8:

$\mathrm{V}=\mathrm{C}_{\mathrm{s}} \mathrm{W}_{\mathrm{e}}$

where $\mathrm{C}_{\mathrm{s}}$ is the seismic response coefficient and $\mathrm{W}_{\mathrm{e}}$ is the effective weight which is calculated in accordance with ACI 350.3-06 requirements. The seismic response coefficient is determined based on Equations 5.9 to 5.11:

$\mathrm{C}_{\mathrm{s}}=\mathrm{S}_{\mathrm{DS}} \mathrm{I} / \mathrm{R}$

Cs $<\mathrm{S}_{\mathrm{D} 1} \mathrm{I} / \mathrm{T}_{\mathrm{f}} \mathrm{R}$

Cs $>0.044 \mathrm{~S}_{\mathrm{DS}} \mathrm{I}$

$\mathrm{C}_{\mathrm{s}}$ is initially calculated based on Equation 5.9 and then verified by the upper and lower bound limits provided in Equations 5.10 and 5.11. In the above equations parameter "I" is the seismic important factor and $\mathrm{T}_{\mathrm{f}}$ is the fundamental period of the elevated tank. The fundamental period may be calculated by employing Equation 5.12:

$T_{f}=2 \pi \sqrt{\frac{W_{l}}{g k_{c}}}$

Where $\mathrm{W}_{\mathrm{l}}$ is the mass of the water and tank. The flexural stiffness of the RC pedestal, $\mathrm{k}_{\mathrm{c}}$, may also be determined using the principles of solid mechanics as indicated in Equation 5.13:

$$
k_{c}=\frac{3 E_{c} I_{c}}{l_{c g}^{3}}
$$


Parameters $E_{c}$ and $I_{c}$ are modulus of elasticity of concrete and moment of inertia of the gross concrete section of the $\mathrm{RC}$ pedestal respectively. $1_{\mathrm{cg}}$ also represents the distance from bottom of foundation to the centroid of stored water. Table 5.4 provides fundamental period and seismic response coefficient $\mathrm{C}_{\mathrm{s}}$ for all 48 prototypes:

Table 5.4 Design fundamental period $\left(\mathrm{T}_{\mathrm{f}}\right)$ and seismic response coefficient $\left(\mathrm{C}_{\mathrm{s}}\right)$

\begin{tabular}{|c|c|c|c|c|c|c|}
\hline prototype No. & FE model ID & $\mathrm{S}_{\mathrm{DS}}$ & $\mathrm{S}_{\mathrm{D} 1}$ & $\mathrm{~T}_{\mathrm{f}}(\mathrm{sec})$ & Cs $(\mathrm{R}=2)$ & $\mathrm{C}_{\mathrm{S}}(\mathrm{R}=3)$ \\
\hline $\mathrm{P}-1$ & $15-\mathrm{H}-0.5$ & 0.8 & 0.4 & 0.43 & 0.63 & 0.42 \\
\hline $\mathrm{P}-2$ & 15-H-1 & 0.8 & 0.4 & 0.34 & 0.63 & 0.42 \\
\hline $\mathrm{P}-3$ & $15-\mathrm{H}-2$ & 0.8 & 0.4 & 0.36 & 0.63 & 0.42 \\
\hline $\mathrm{P}-4$ & $15-\mathrm{L}-0.5$ & 0.2 & 0.1 & 0.52 & 0.15 & 0.10 \\
\hline $\mathrm{P}-5$ & 15-L-1 & 0.2 & 0.1 & 0.40 & 0.15 & 0.10 \\
\hline P-6 & $15-\mathrm{L}-2$ & 0.2 & 0.1 & 0.44 & 0.15 & 0.10 \\
\hline $\mathrm{P}-7$ & $25-\mathrm{H}-0.5$ & 0.8 & 0.4 & 0.75 & 0.44 & 0.29 \\
\hline $\mathrm{P}-8$ & $25-\mathrm{H}-2$ & 0.8 & 0.4 & 0.61 & 0.54 & 0.36 \\
\hline P-9 & $25-\mathrm{H}-3$ & 0.8 & 0.4 & 0.47 & 0.63 & 0.42 \\
\hline $\mathrm{P}-10$ & $25-\mathrm{L}-0.5$ & 0.2 & 0.1 & 0.90 & 0.09 & 0.06 \\
\hline $\mathrm{P}-11$ & $25-\mathrm{L}-2$ & 0.2 & 0.1 & 0.74 & 0.11 & 0.07 \\
\hline $\mathrm{P}-12$ & 25-L-3 & 0.2 & 0.1 & 0.54 & 0.15 & 0.10 \\
\hline $\mathrm{P}-13$ & $35-\mathrm{H}-0.5$ & 0.8 & 0.4 & 1.15 & 0.29 & 0.19 \\
\hline $\mathrm{P}-14$ & 35-H-1 & 0.8 & 0.4 & 0.90 & 0.37 & 0.25 \\
\hline $\mathrm{P}-15$ & $35-\mathrm{H}-3$ & 0.8 & 0.4 & 0.69 & 0.48 & 0.32 \\
\hline $\mathrm{P}-16$ & $35-\mathrm{L}-0.5$ & 0.2 & 0.1 & 1.36 & 0.06 & 0.04 \\
\hline P-17 & 35-L-1 & 0.2 & 0.1 & 1.04 & 0.08 & 0.05 \\
\hline P-18 & 35-L-3 & 0.2 & 0.1 & 0.79 & 0.10 & 0.07 \\
\hline P-19 & $45-\mathrm{H}-0.5$ & 0.8 & 0.4 & 1.60 & 0.21 & 0.14 \\
\hline P-20 & 45-H-1 & 0.8 & 0.4 & 1.25 & 0.26 & 0.18 \\
\hline P-21 & $45-\mathrm{H}-3$ & 0.8 & 0.4 & 0.95 & 0.35 & 0.23 \\
\hline $\mathrm{P}-22$ & $45-\mathrm{L}-0.5$ & 0.2 & 0.1 & 1.89 & 0.04 & 0.03 \\
\hline $\mathrm{P}-23$ & 45-L-1 & 0.2 & 0.1 & 1.44 & 0.06 & 0.04 \\
\hline $\mathrm{P}-24$ & $45-\mathrm{L}-3$ & 0.2 & 0.1 & 1.08 & 0.08 & 0.05 \\
\hline
\end{tabular}

By implementing seismic response coefficient values $\left(\mathrm{C}_{\mathrm{s}}\right)$ calculated from Table 5.4 in Equation 5.8, the seismic base shear was calculated for each prototype. Subsequently, the seismic base shear values will be distributed vertically along the height of elevated water tanks. These 
horizontal loads in turn generate overturning moment in the RC pedestal. Finally, the RC pedestal is designed for the shear and generated overturning moments. A summary of this design is provided in Table 5.5. $\mathrm{h}_{\mathrm{r}}$ in Table 5.5 represents the RC pedestal wall thickness. More details on code design and seismic analysis of the prototypes is presented in Appendix B. In addition, the input ANSYS file for FE model 35-H-1 $(\mathrm{R}=2)$ is given in Appendix $\mathrm{C}$ of the thesis.

Table 5.5 Summary of prototype design

\begin{tabular}{cccccccc}
\hline $\begin{array}{c}\text { prototype } \\
\text { No. }\end{array}$ & $\begin{array}{c}\text { FE model } \\
\text { ID }\end{array}$ & $\begin{array}{c}\text { Shaft } \\
\text { height } \\
(\mathrm{m})\end{array}$ & $\begin{array}{c}\mathrm{h}_{\mathrm{r}} \\
(\mathrm{mm})\end{array}$ & $\begin{array}{c}\mathrm{d}_{\mathrm{w}} \\
(\mathrm{m})\end{array}$ & $\begin{array}{c}\text { Tank } \\
\text { capacity } \\
\left(\mathrm{m}^{3}\right)\end{array}$ & $\begin{array}{c}\text { vertical } \\
\text { reinforcement } \\
\text { ratio }(\mathrm{R}=3)\end{array}$ & $\begin{array}{c}\text { vertical } \\
\text { reinforcement } \\
\text { ratio (R=2) }\end{array}$ \\
\hline P-1 & $15-\mathrm{H}-0.5$ & 15 & 300 & 8.6 & 1900 & $0.87 \%$ & $1.99 \%$ \\
\hline P-2 & $15-\mathrm{H}-1$ & 15 & 350 & 12 & 3800 & $0.72 \%$ & $1.52 \%$ \\
\hline P-3 & $15-\mathrm{H}-2$ & 15 & 380 & 14.5 & 7600 & $0.73 \%$ & $1.51 \%$ \\
\hline P-4 & $15-\mathrm{L}-0.5$ & 15 & 200 & 8.6 & 1900 & $0.50 \%$ & $0.50 \%$ \\
\hline P-5 & $15-\mathrm{L}-1$ & 15 & 250 & 12 & 3800 & $0.50 \%$ & $0.50 \%$ \\
\hline P-6 & $15-\mathrm{L}-2$ & 15 & 250 & 14.5 & 7600 & $0.50 \%$ & $0.50 \%$ \\
\hline P-7 & $25-\mathrm{H}-0.5$ & 25 & 300 & 8.6 & 1900 & $1.06 \%$ & $2.36 \%$ \\
\hline P-8 & $25-\mathrm{H}-2$ & 25 & 380 & 14.5 & 7600 & $1.08 \%$ & $2.62 \%$ \\
\hline P-9 & $25-\mathrm{H}-3$ & 25 & 400 & 20 & 11400 & $0.92 \%$ & $2.20 \%$ \\
\hline P-10 & $25-\mathrm{L}-0.5$ & 25 & 200 & 8.6 & 1900 & $0.50 \%$ & $0.50 \%$ \\
\hline P-11 & $25-\mathrm{L}-2$ & 25 & 250 & 14.5 & 7600 & $0.50 \%$ & $0.50 \%$ \\
\hline P-12 & $25-\mathrm{L}-3$ & 25 & 300 & 20 & 11400 & $0.50 \%$ & $0.50 \%$ \\
\hline P-13 & $35-\mathrm{H}-0.5$ & 35 & 300 & 8.6 & 1900 & $0.93 \%$ & $2.11 \%$ \\
\hline P-14 & $35-\mathrm{H}-1$ & 35 & 350 & 12 & 3800 & $1.11 \%$ & $2.29 \%$ \\
\hline P-15 & $35-\mathrm{H}-3$ & 35 & 400 & 20 & 11400 & $0.92 \%$ & $2.40 \%$ \\
\hline P-16 & $35-\mathrm{L}-0.5$ & 35 & 200 & 8.6 & 1900 & $0.50 \%$ & $0.50 \%$ \\
\hline P-17 & $35-\mathrm{L}-1$ & 35 & 250 & 12 & 3800 & $0.50 \%$ & $0.50 \%$ \\
\hline P-18 & $35-\mathrm{L}-3$ & 35 & 300 & 20 & 11400 & $0.50 \%$ & $0.50 \%$ \\
\hline P-19 & $45-\mathrm{H}-0.5$ & 45 & 300 & 8.6 & 1900 & $0.81 \%$ & $1.86 \%$ \\
\hline P-20 & $45-\mathrm{H}-1$ & 45 & 350 & 12 & 3800 & $0.99 \%$ & $2.06 \%$ \\
\hline P-21 & $45-\mathrm{H}-3$ & 45 & 400 & 20 & 11400 & $0.88 \%$ & $2.08 \%$ \\
\hline P-22 & $45-\mathrm{L}-0.5$ & 45 & 200 & 8.6 & 1900 & $0.50 \%$ & $0.50 \%$ \\
\hline P-23 & $45-\mathrm{L}-1$ & 45 & 250 & 12 & 3800 & $0.50 \%$ & $0.50 \%$ \\
\hline P-24 & $45-\mathrm{L}-3$ & 45 & 300 & 20 & 11400 & $0.50 \%$ & $0.50 \%$ \\
\hline & & & & & & & \\
\hline
\end{tabular}




\subsection{Pushover analysis of FE models}

In the previous section, the prototype designs including the height, diameter, pedestal wall thickness, and vertical and horizontal reinforcement ratios for each prototype were established. The primary assumptions and theories for developing finite element models of the RC pedestal prototypes were illustrated in Chapter 4. At this stage, the finite element model of each prototype is constructed in accordance with those assumptions.

In order to preserve the generality of the analysis, the openings of the pedestals will not be included in the finite element models in this chapter. This is due to the fact that openings are found in different sizes and locations on the RC pedestal structures. Considering all the possible opening dimensions and locations for each prototype will add several more analysis cases which is not practical. Instead, the effect of opening will be studied later by employing a number of case studies in which the effect of the openings on the pushover curves will be addressed.

\subsubsection{Defining pilot group of FE models}

Presenting and analysing the results of the pushover analysis curves for all prototypes in the thesis is not practical. Although the final results of the seismic response parameters of all the prototypes will be presented in tables and charts, the pushover curves will be only further investigated for a pilot group of prototypes.

Defining the pilot group prototypes is based on a number of selection criteria. The pilot group must be able to precisely represent majority of the possible response features of the 48 designed prototypes. Figure 5.3 shows the selected prototypes for including in the pilot group. 


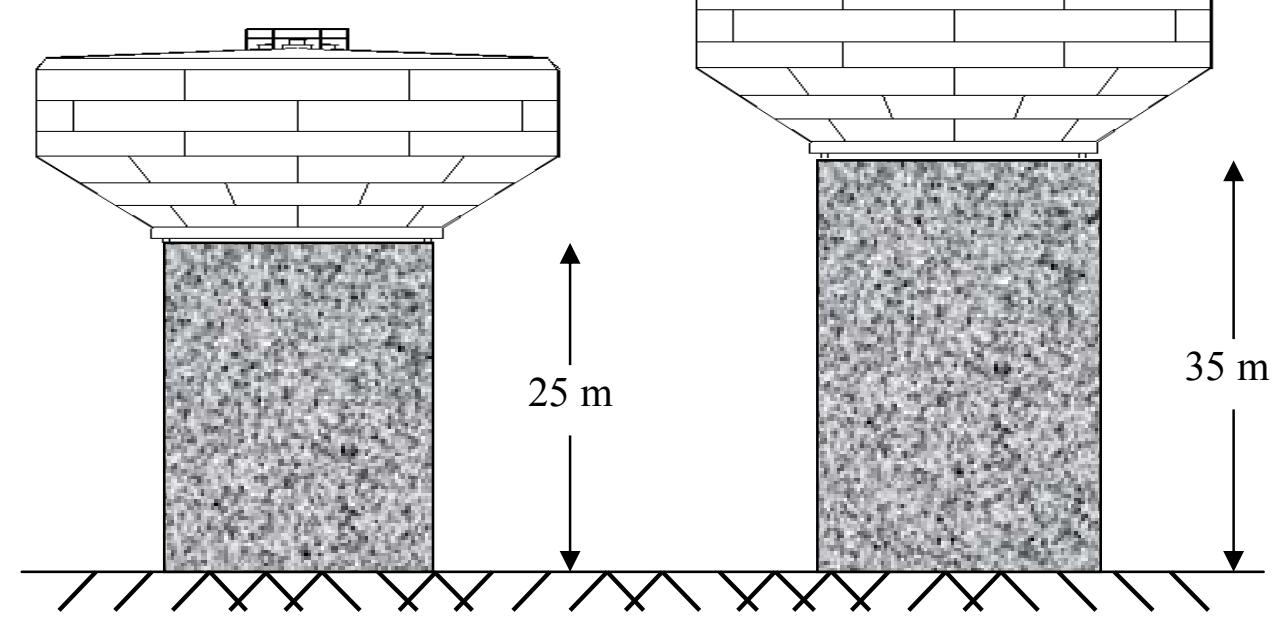

Model 25-H-3

Model 35-H-3

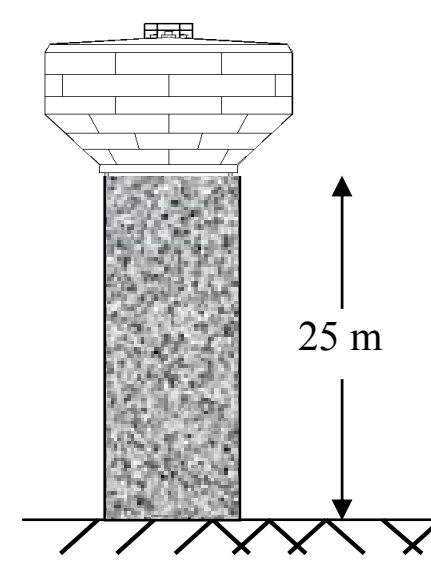

Model 25-H-0.5

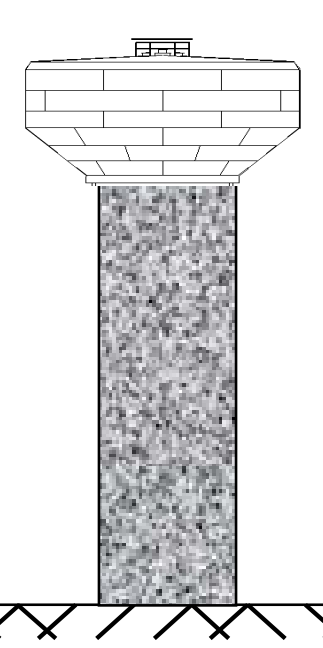

Model 35-H-0.5

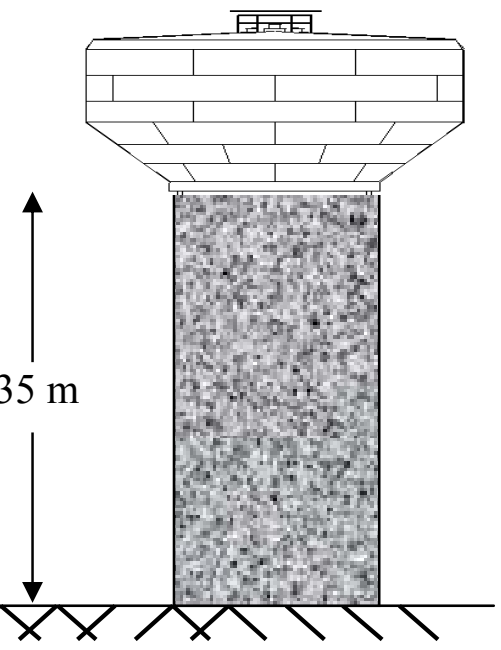

Model 35-H-1

Figure 5.3 The pilot study group

One parameter that represents both geometry and dynamic response properties of the structures is the fundamental period. According to Table 5.4, the fundamental period ranges between as low as $0.34 \mathrm{sec}$ for FE model $15-\mathrm{H}-1$ and $1.6 \mathrm{sec}$ as the highest for FE model $45-\mathrm{H}-$ 
0.5. In the selected prototypes for pilot study group, the values of fundamental periods are covering most of this domain.

As displayed in Table 5.6 the fundamental periods of the prototypes include $0.47,0.69,0.75$, 0.90 and 1.15 in ascending order. For majority of the elevated water tanks, the fundamental period falls in this range and therefore the pilot group is a good representation of the actual built elevated water tanks.

Table 5.6 The pilot group prototypes dimensions and properties

\begin{tabular}{ccccccccc}
\hline $\begin{array}{c}\text { prototype } \\
\text { No. }\end{array}$ & $\begin{array}{c}\text { FE model } \\
\mathrm{ID}\end{array}$ & $\mathrm{T}_{\mathrm{f}}(\mathrm{sec})$ & $\begin{array}{c}\mathrm{Cs} \\
(\mathrm{R}=2)\end{array}$ & $\begin{array}{c}\mathrm{C}_{\mathrm{S}} \\
(\mathrm{R}=3)\end{array}$ & $\begin{array}{c}\text { Shaft } \\
\text { height } \\
(\mathrm{m})\end{array}$ & $\begin{array}{c}\mathrm{h}_{\mathrm{r}} \\
(\mathrm{mm})\end{array}$ & $\begin{array}{c}\mathrm{d}_{\mathrm{w}} \\
(\mathrm{m})\end{array}$ & $\begin{array}{c}\text { Tank } \\
\text { capacity } \\
\left(\mathrm{m}^{3}\right)\end{array}$ \\
\hline P-7 & $25-\mathrm{H}-0.5$ & 0.75 & 0.44 & 0.29 & 25 & 300 & 8.6 & 1900 \\
\hline P-9 & $25-\mathrm{H}-3$ & 0.47 & 0.63 & 0.42 & 25 & 400 & 20 & 11400 \\
\hline P-13 & $35-\mathrm{H}-0.5$ & 1.15 & 0.29 & 0.19 & 35 & 300 & 8.6 & 1900 \\
\hline P-14 & $35-\mathrm{H}-1$ & 0.90 & 0.37 & 0.25 & 35 & 350 & 12 & 3800 \\
\hline P-15 & $35-\mathrm{H}-3$ & 0.69 & 0.48 & 0.32 & 35 & 400 & 20 & 11400 \\
\hline
\end{tabular}

In addition, the tank sizes and pedestal heights are the most commonly used dimensions in industry. This could be verified by referring to Table 5.1 .

\subsubsection{Results of pushover analysis}

The procedure of performing a pushover analysis in this study is adapted from FEMA 273. First, the gravity loads including weights of tank, stored water, pedestal wall and other equipments is applied to the FE model. Next a gradually increasing lateral load is applied to the model until the structure collapses. The lateral load must resemble the effects of actual seismic loads as much as possible.

In case of elevated water tanks, the lateral load is applied with a load pattern similar to the first (fundamental) mode shape. The reason is, most of the weight is concentrated in the tank and 
the modal mass participation factor of the first mode is above $90 \%$ for all models and therefore the effect of other mode shapes in the load pattern is negligible.

The results of pushover analysis for the pilot group are shown in Figure 5.4. Each graph demonstrates the pushover curve for one prototype which is designed for two response modifications factors (two FE models) of $\mathrm{R}=2$ and $\mathrm{R}=3$. The comparison between the results of high and low seismic zones will be discussed in the next chapter.

(a)
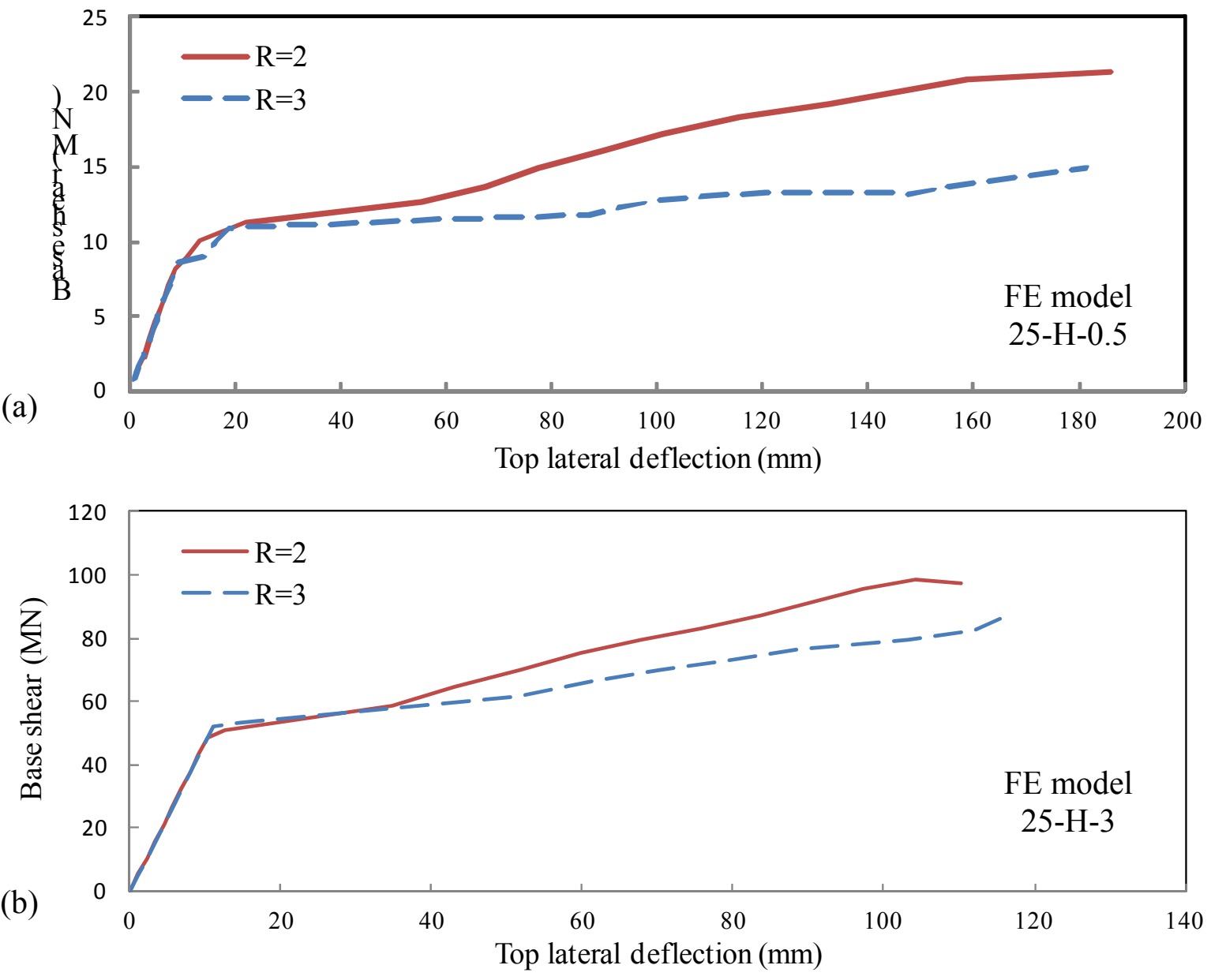

Figure 5.4 Results of pushover analysis for pilot group (a) model 25-H-0.5 (b) model 25-H-3 (c) model 35-H-0.5 (d) model 35-H-1 (e) model 35-H-3 

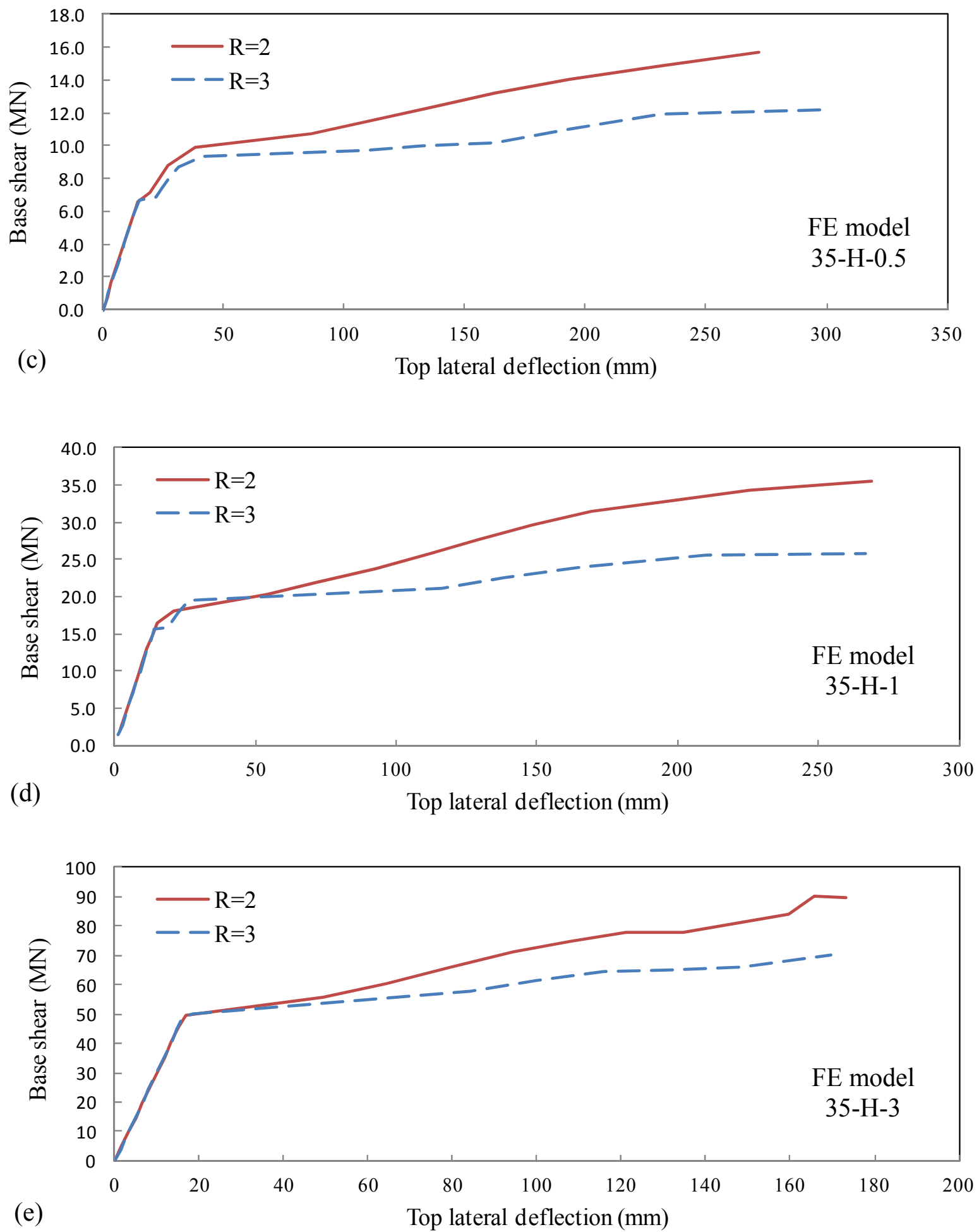

Figure 5.4 (Cont.) 
Table 5.7 summarizes the results of the pushover analysis for the pilot group. This table presents results including the maximum lateral deflection $\left(\Delta_{\max }\right)$ and maximum base shear prior to collapse $\left(\mathrm{V}_{\max }\right)$.

Table 5.7 Results of pushover analysis for the pilot group

\begin{tabular}{cccccc}
\hline \multirow{2}{*}{$\begin{array}{c}\text { prototype } \\
\text { No. }\end{array}$} & $\begin{array}{c}\text { FE model } \\
\text { ID }\end{array}$ & $\mathrm{R}=2$ & $\mathrm{R}=2$ & $\mathrm{R}=3$ & $\mathrm{R}=3$ \\
\cline { 3 - 6 } & & $\mathrm{V}_{\max }(\mathrm{MN})$ & $\Delta_{\max }(\mathrm{mm})$ & $\mathrm{V}_{\max }(\mathrm{MN})$ & $\Delta_{\max }(\mathrm{mm})$ \\
\hline $\mathrm{P}-7$ & $25-\mathrm{H}-0.5$ & 21.4 & 180 & 14.8 & 180 \\
\hline $\mathrm{P}-9$ & $25-\mathrm{H}-3$ & 98.4 & 104 & 87.6 & 117 \\
\hline $\mathrm{P}-13$ & $35-\mathrm{H}-0.5$ & 15.7 & 271 & 12.2 & 301 \\
\hline $\mathrm{P}-14$ & $35-\mathrm{H}-1$ & 35.4 & 260 & 25.8 & 266 \\
\hline $\mathrm{P}-15$ & $35-\mathrm{H}-3$ & 90 & 165 & 70 & 169 \\
\hline
\end{tabular}

\subsubsection{Observed patterns in pushover curves}

Further analysis of the pushover curves indicates a number of general patterns in the loaddeflection behaviour of prototypes. It could be observed that these patterns are generally functions of response modification factor values, height of shaft, and the tank sizes.

As discussed earlier, each prototype was designed for two values of $\mathrm{R}=2$ and $\mathrm{R}=3$ as for the response modification factor. In all of the pushover analysis results, prototypes with response modification factor of $\mathrm{R}=3$ are presenting less maximum base shear than the same prototype which is designed for $\mathrm{R}=2$. This effect is more considerable for models with lower capacity tanks. For example, in case of model $25-\mathrm{H}-0.5$ the ratio of $\mathrm{V}_{\max }(\mathrm{R}=2)$ to $\mathrm{V}_{\max }(\mathrm{R}=3)$ is approximately 1.5 . This ratio decreases to 1.1 for model $25-\mathrm{H}-3$.

In addition, response modification factor does not appear to have a considerable effect on the maximum displacement $\left(\Delta_{\max }\right)$ of the prototypes. The difference between the $\Delta_{\max }$ for prototypes designed with $\mathrm{R}=2$ and $\mathrm{R}=3$ is not significant. 
Another factor that affects the nonlinear response of elevated tanks is the height of $\mathrm{RC}$ pedestal. This effect is illustrated in Figure 5.5.

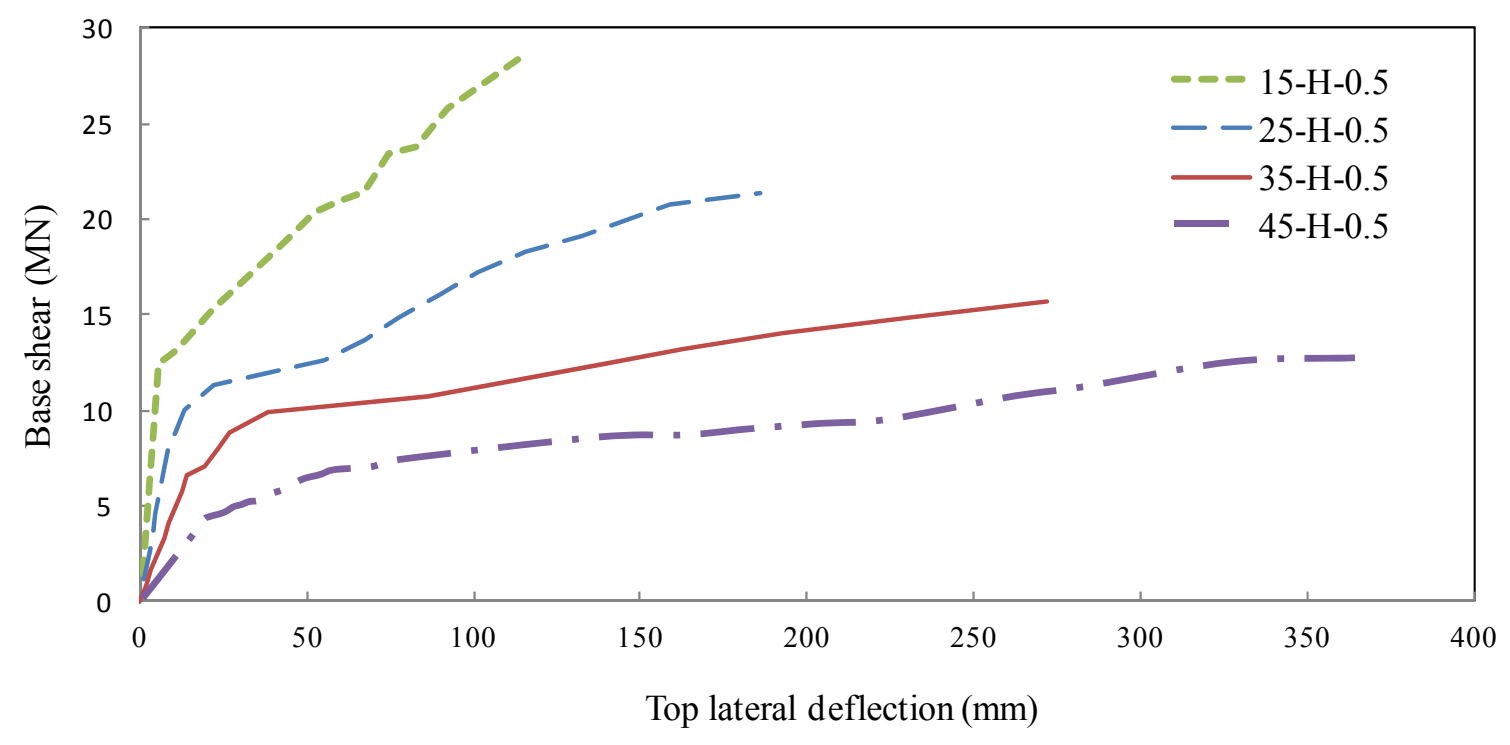

Figure 5.5 Comparing effect of RC pedestal height on pushover curves

All four pushover curves belong to prototypes with a tank capacity of 0.5 but with different heights. The first observation is that prototypes with shorter RC pedestal heights demonstrate higher maximum base shear comparing to taller ones. On the other hand, models with short pedestals are not able to tolerate as much lateral displacement capacity as the tall pedestals do.

This might be further addresses by comparing the pushover curves of model 15-H-0.5 and 45H-0.5. The maximum displacement that model $45-\mathrm{H}-0.5$ could undergo before failure is approximately $370 \mathrm{~mm}$ while this value is limited to $120 \mathrm{~mm}$ for tank $15-\mathrm{H}-0.5$. This means that model $45-\mathrm{H}-0.5$ has three times more maximum lateral displacement capacity than model $15-\mathrm{H}-$ 0.5. In addition the maximum lateral load capacity of the model $15-\mathrm{H}-0.5$ is almost twice as for model 45-H-0.5. This subject will be further investigated in next chapter under the ductility and strength factor. 
Another noticeable trend is the effect of tank sizes on the pushover curves. This pattern is shown in Figure 5.6 for two pedestal heights of $25 \mathrm{~m}$ and $35 \mathrm{~m}$.
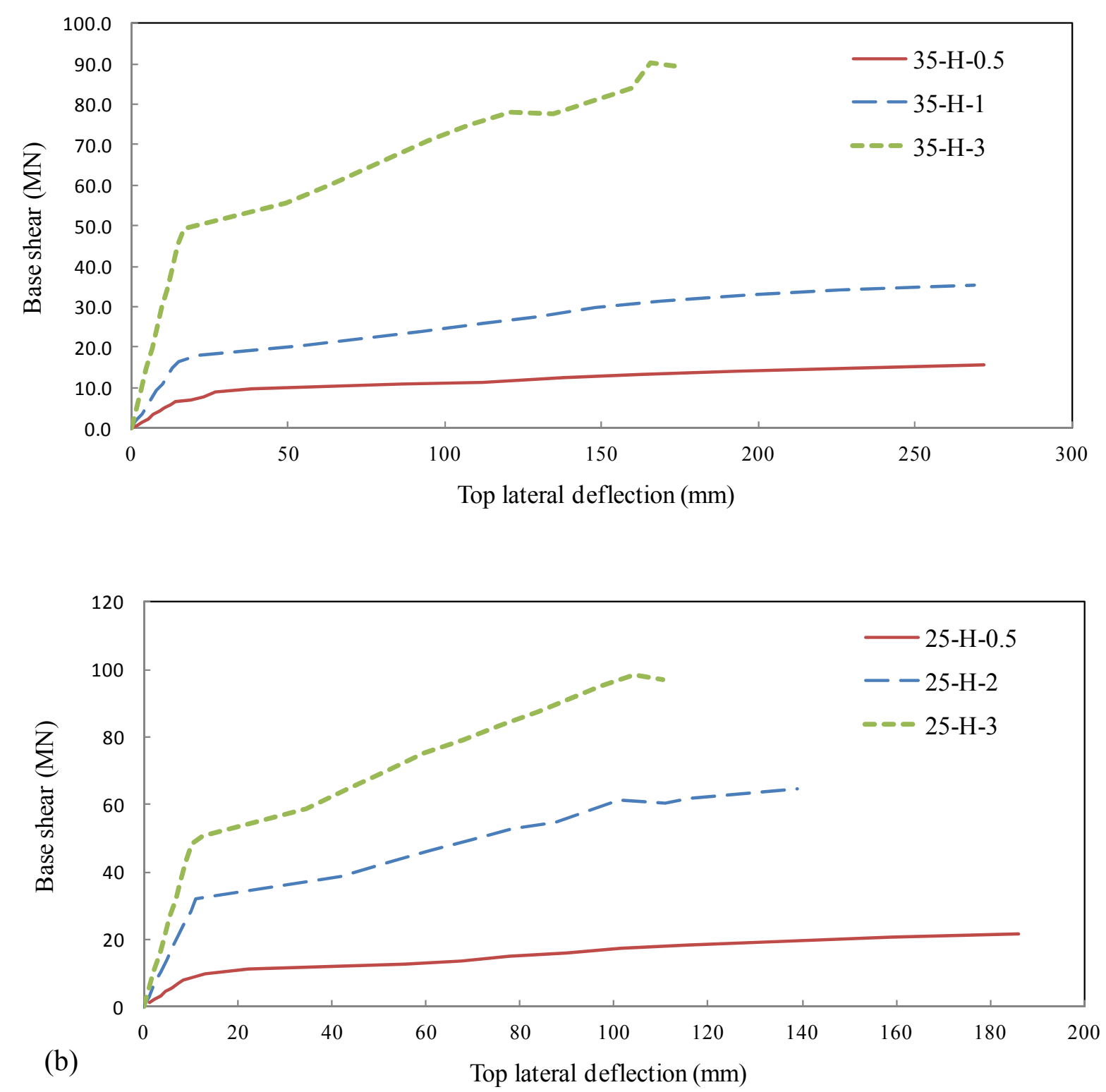

Figure 5.6 Comparing effect of RC pedestal tank sizes on pushover curves $\begin{array}{lll}\text { (a) } 35 \mathrm{~m} \text { pedestal } & \text { (b) } 25 \mathrm{~m} \text { pedestal }\end{array}$

It could be observed that for the same pedestal height, prototypes with smaller tank sizes are providing more lateral displacement capacity comparing to models with bigger tank sizes. 
Figure 5.7 shows the effect of seismicity for models 35-H-1, 35-L-1, 35-H-3 and 35-L-3. As it was expected, the structures which were designed for a low seismicity zone are presenting lower maximum base shear capacity. "R factor" does not have an effect in seismic response of 35-L-1 and 35-L-3 as these structures are designed for the minimum reinforcement requirements.

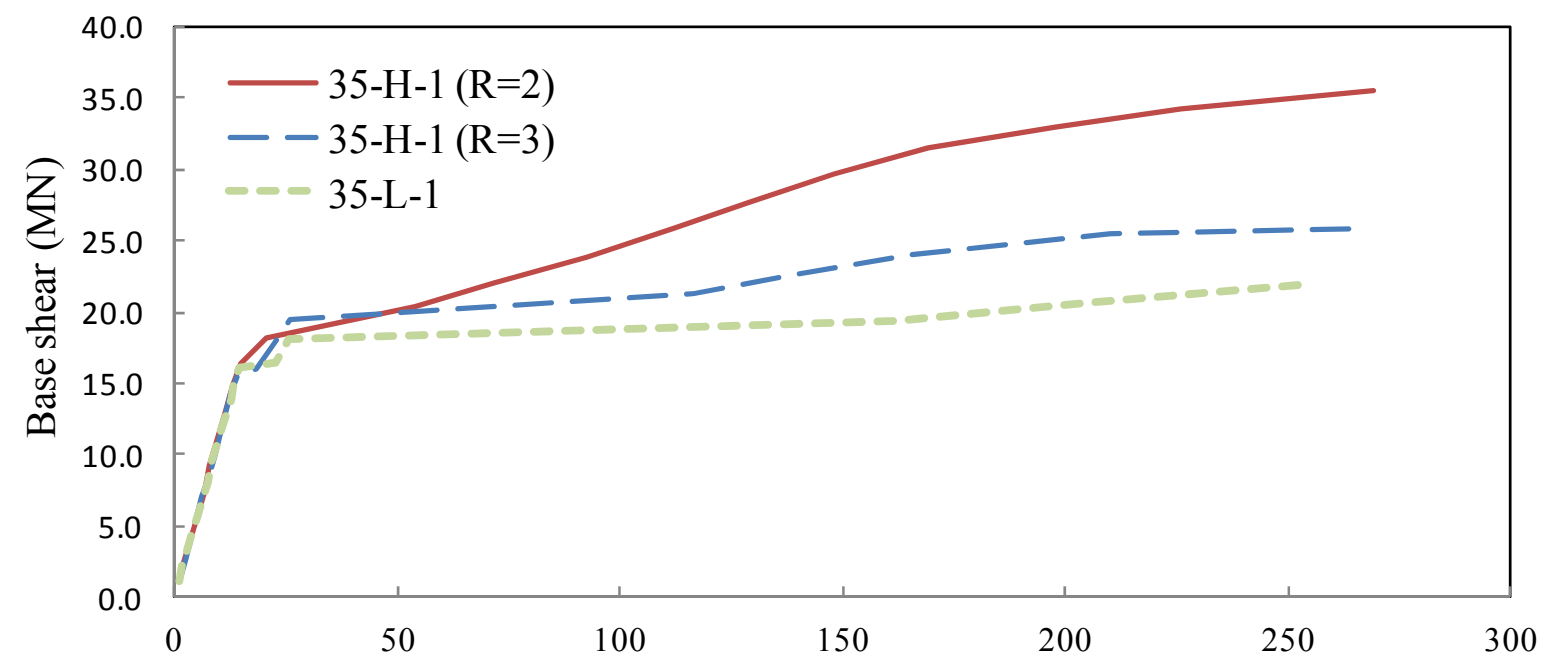

(a)

Top lateral deflection (mm)

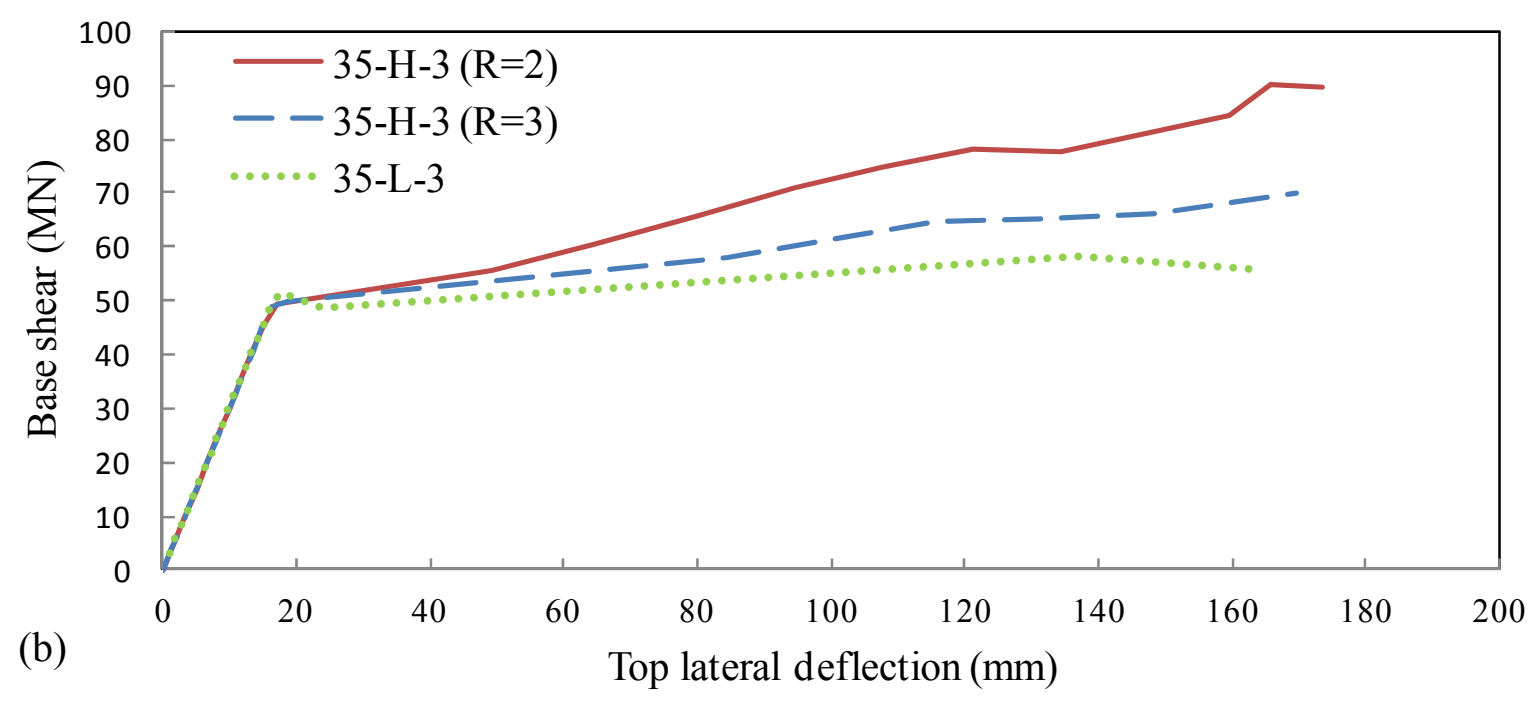

Figure 5.7 Comparing effect of RC pedestal tank sizes on pushover curves

(a) model 35-H-1 (b) model 35-H-3 


\subsection{Cracking propagation pattern}

The principles of the finite element model of reinforced concrete elements including cracking and crushing equations were explained in Chapter 4 of the thesis. Studying the locations of first cracks and their propagation pattern provides better understanding of structure's weak points and response behaviour under seismic loads.

The results of pushover analysis indicate two categories of cracking patterns in the RC pedestal structures. These two categories are classified with respect to the height to mean diameter $\left(h / d_{\mathrm{w}}\right)$ ratios of pedestals. This concept is best explained by studying the graphs of strain intensities presented in Figure 5.8.

Figures 5.8(a) and 5.8(b) demonstrate three stages of the pushover analysis of FE models 35-

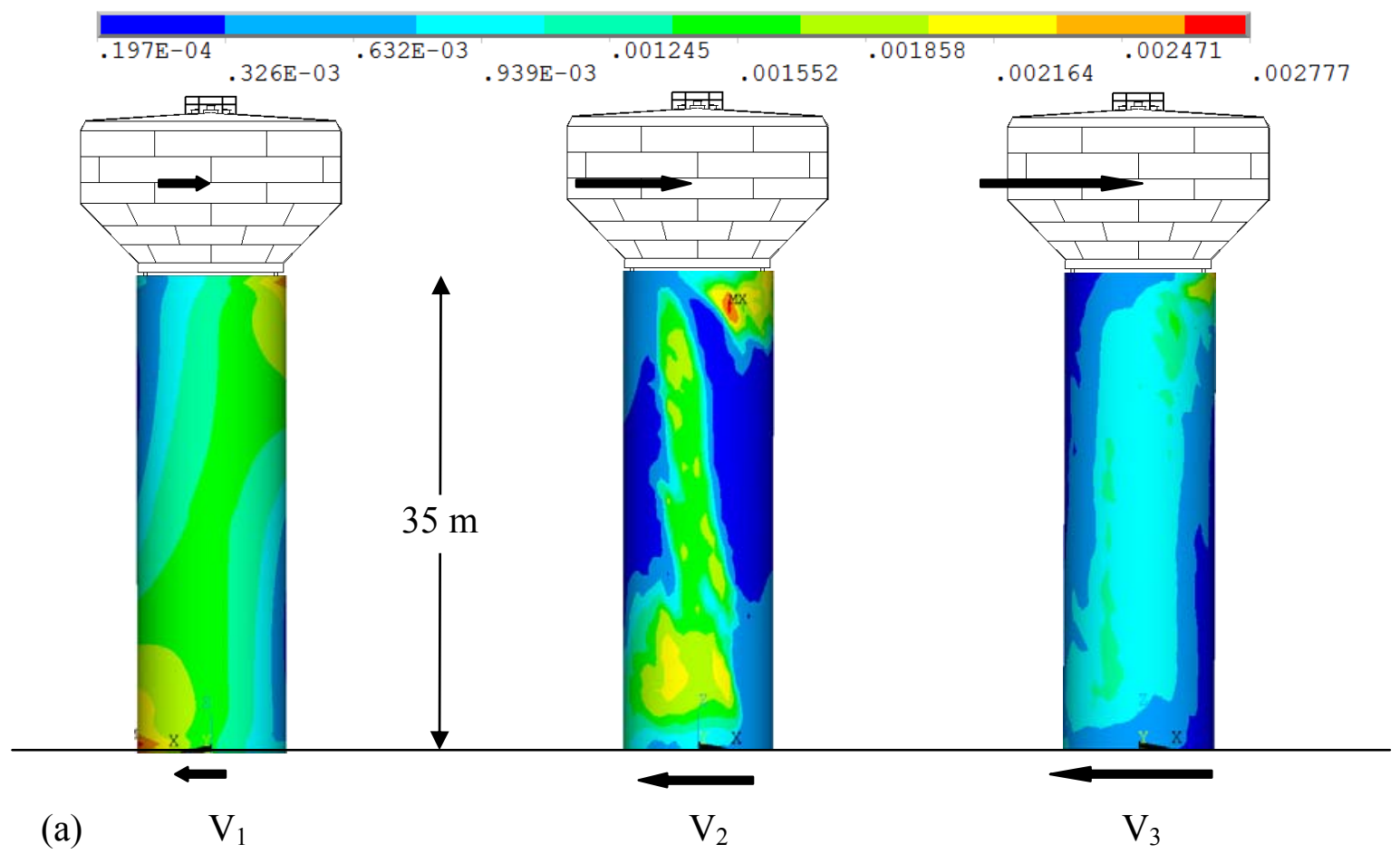

Figure 5.8 Contours of total mechanical strain intensity in RC pedestals under progressive loading of pushover analysis (a) three stages of increasing lateral loads for model $35-\mathrm{H}-1$ (b) three stages of increasing lateral loads for model 35-H-3

(Strain contours are related to stage $\mathrm{V}_{2}$ ) 


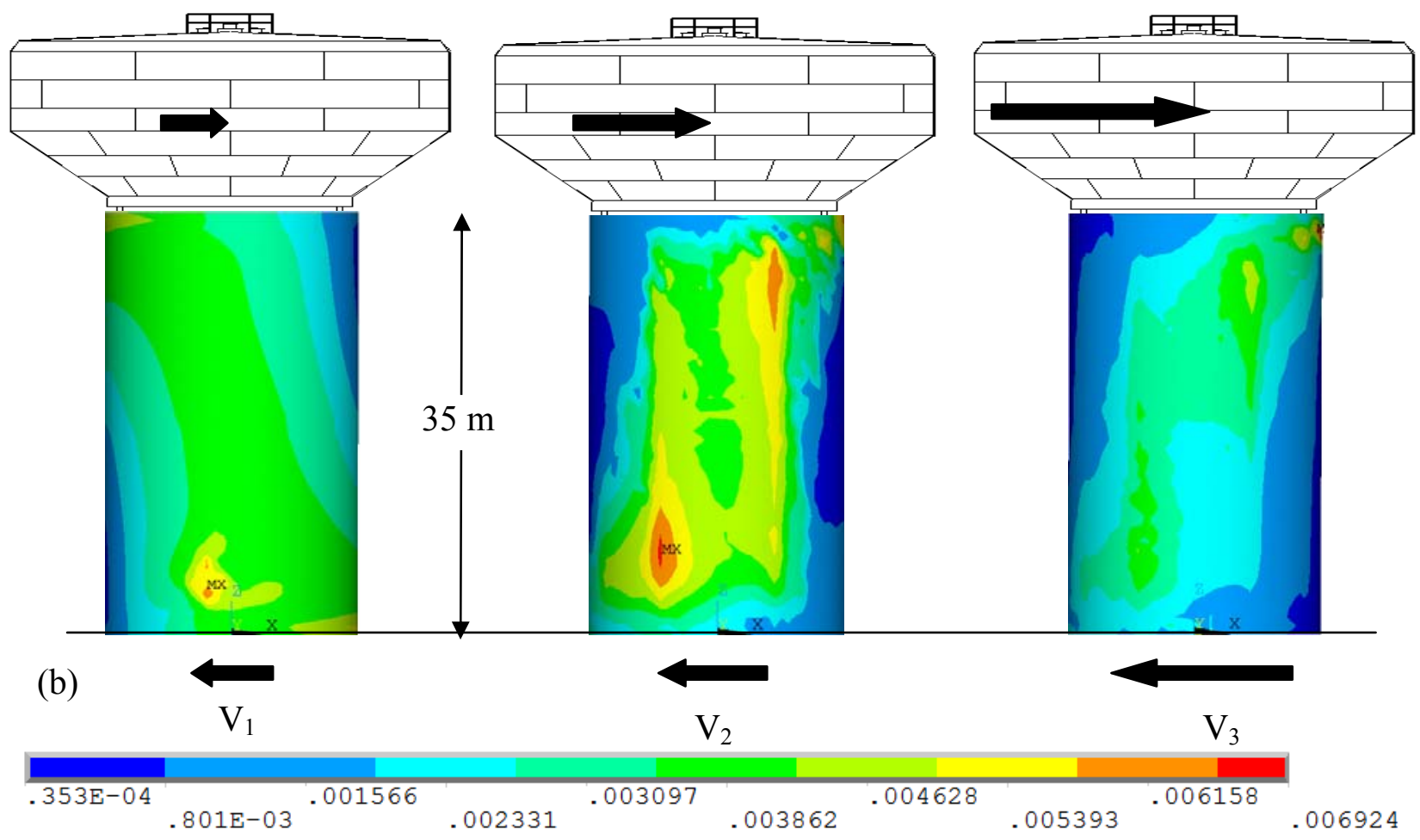

Figure 5.8 (Cont.)

$\mathrm{H}-1$ and 35-H-3 respectively. Stage one which is denoted by base shear of $\mathrm{V}_{1}$ is when the lateral loading reaches to the level that cracking has just begun. The base shear $\mathrm{V}_{2}$ represents the second stage of loading in which the cracks are considerably propagated across the pedestal and structure has experienced substantial lateral deflection. Finally, base shear $\mathrm{V}_{3}$ shows the RC pedestal at the third stage in which structure is just prior to failure. At this stage the cracks are propagated all over the structure and pedestal has undergone extensive deformation.

As Figure 5.8 indicates, the location of maximum strain at the first stage is different for the two models. For model 35-H-1, the maximum strain is concentrated in the opposite top and bottom corners of the pedestal. On the other hand for model 35-H-3, the maximum strain in stage one is located at the bottom centre of the pedestal. This difference can explain dissimilar cracking locations at the first stage which is shown in Figure 5.9. 

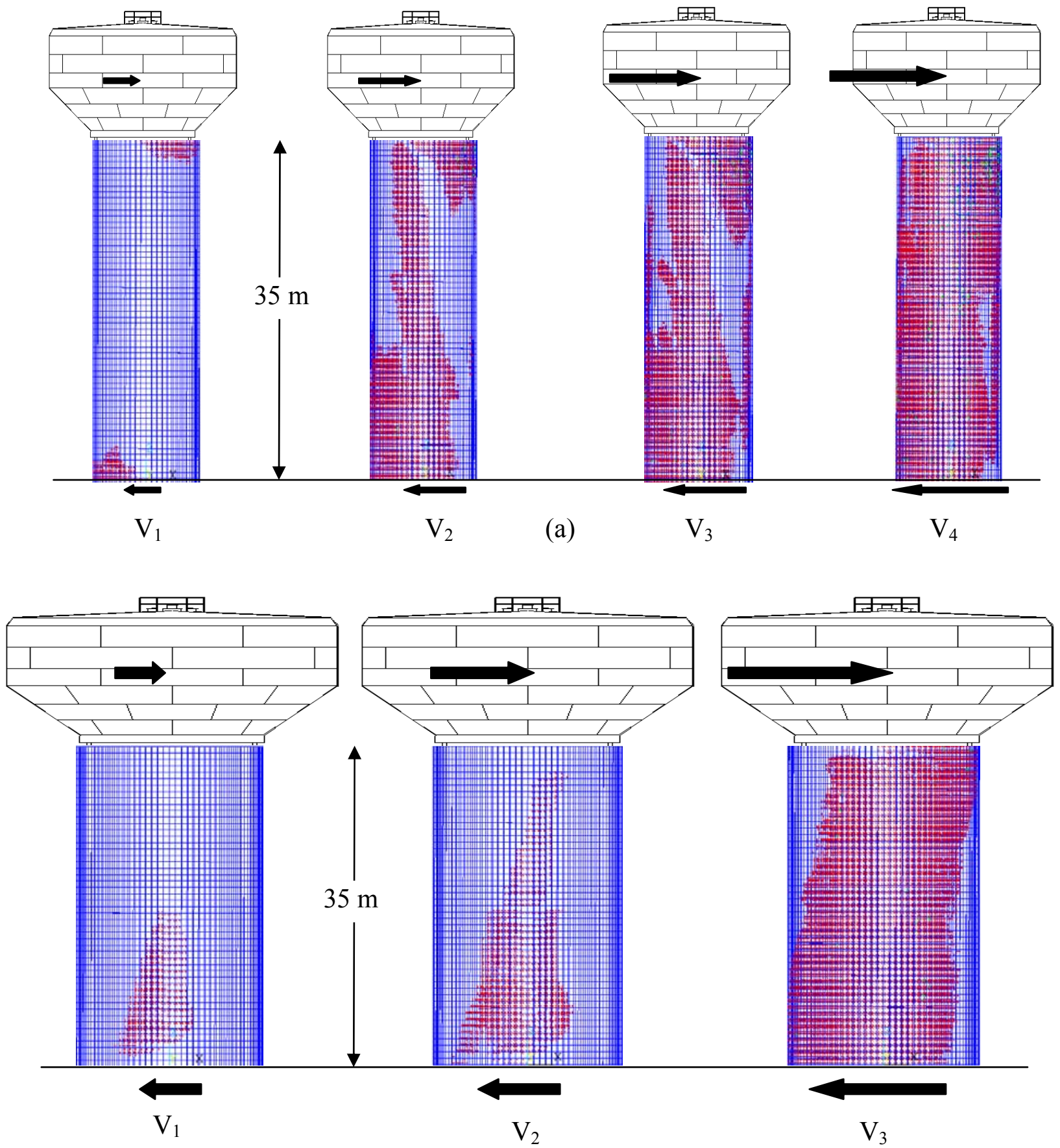

(b)

Figure 5.9 Cracking propagation of RC pedestals subjected to increasing lateral loading in pushover analysis (a) four stages of growing lateral loads for model $35-\mathrm{H}-1$ (b) three stages of increasing lateral loads for model $35-\mathrm{H}-3$ 
In case of model 35-H-1, as shown in further details in Figure 5.10, the cracking development begins with flexural tension cracks at the base of pedestal. These cracks are horizontal and

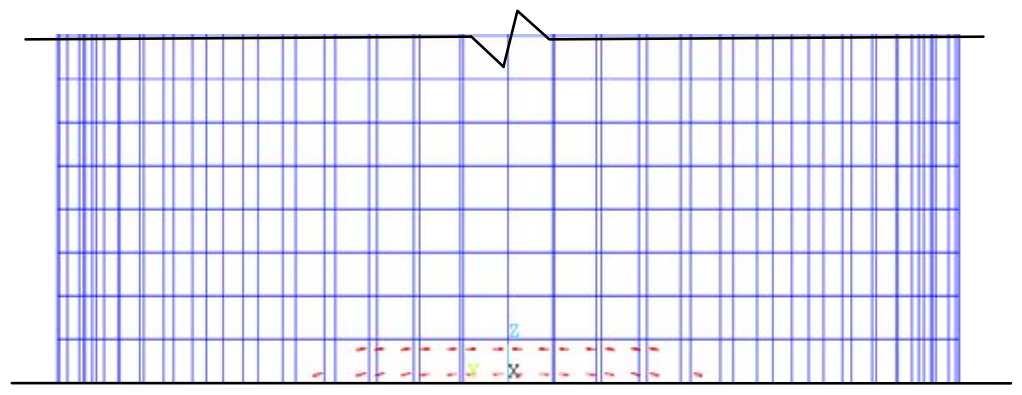

(b)
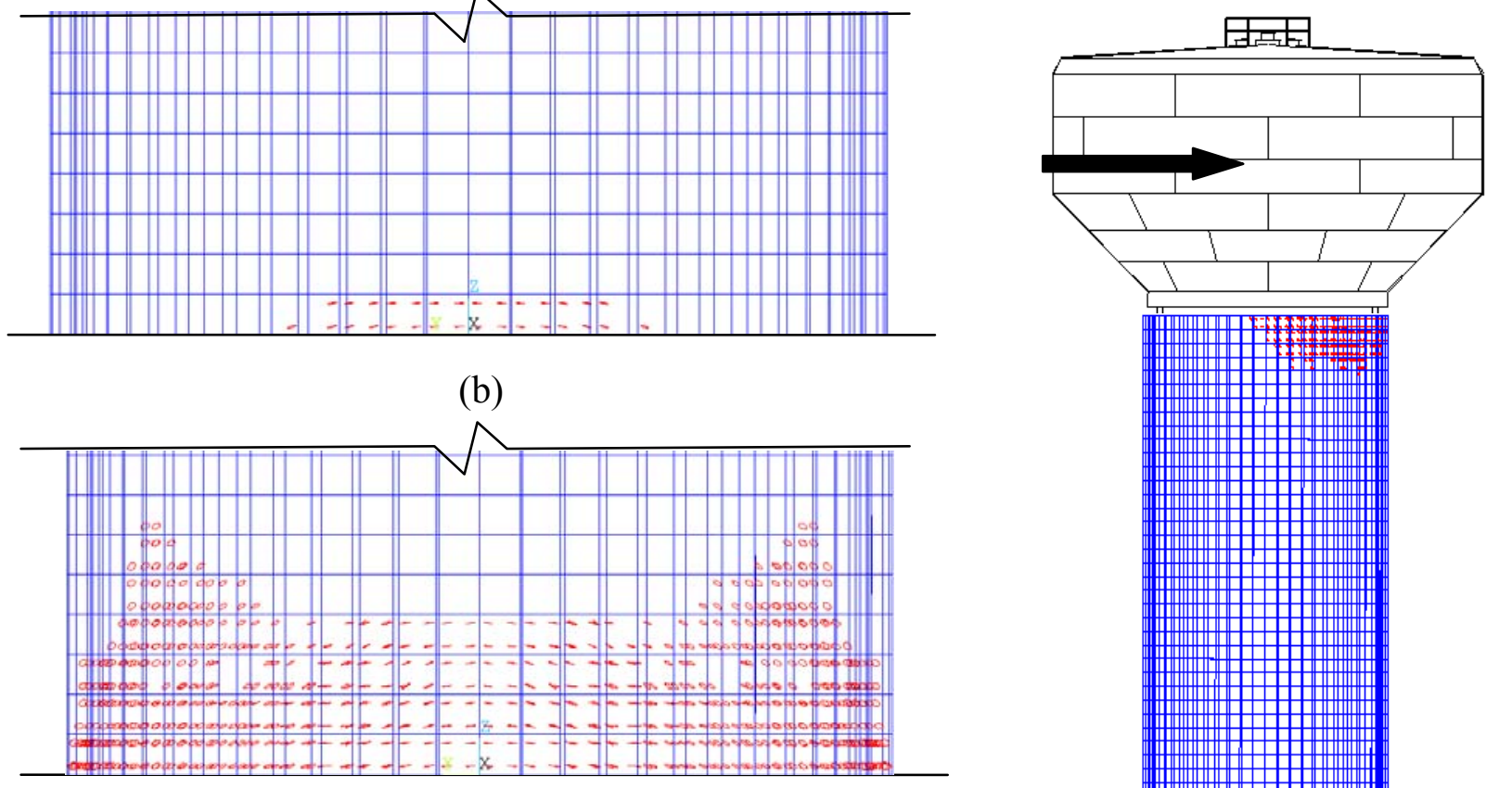

(c)

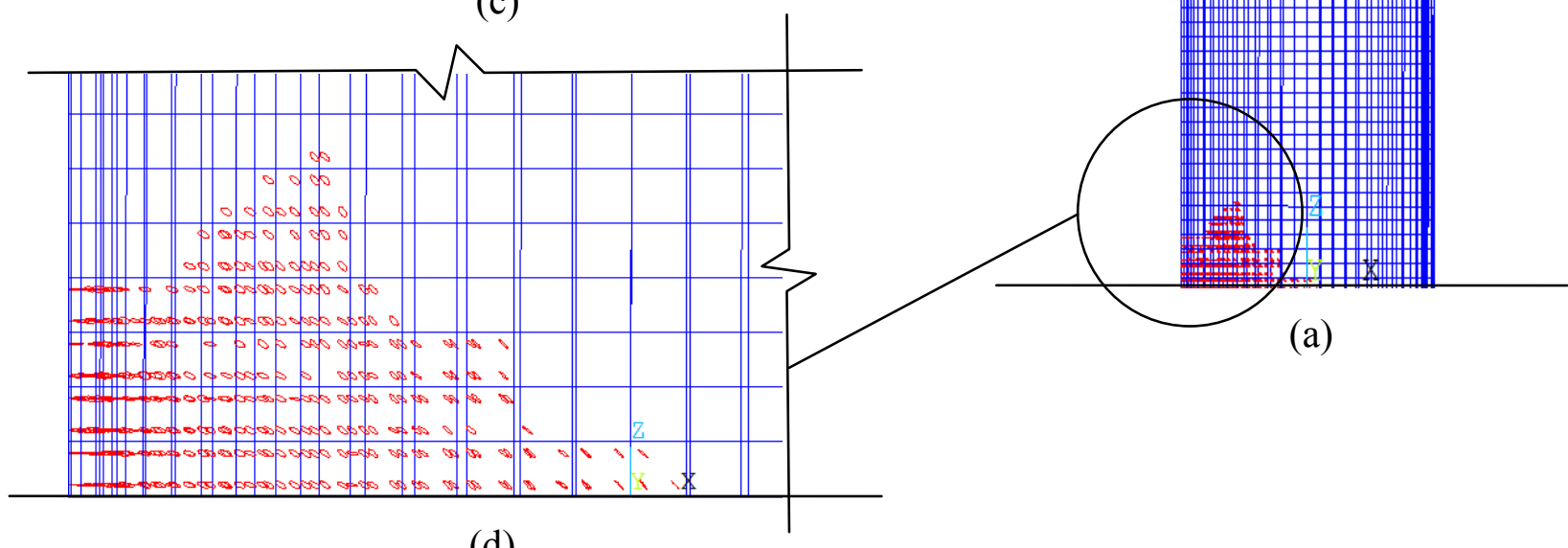

(d)

Figure 5.10 Cracking propagation pattern in FE model 35-H-1 (a) elevation of the prototype (b) front view of base level parallel to direction of lateral load (initial flexural cracks) (c) same view as part "b" showing development of flexure-shear cracks (d) side view (perpendicular to lateral load direction)of the crack propagation at base level

located at the pedestal side perpendicular to the direction of lateral loading. These cracks are shown in Figure 5.10(b). By further increasing the lateral loads, inclined cracks will develop 
around the initial flexural cracks toward the sides of pedestal and parallel to the lateral load direction. These are flexure-shear cracks which are the result of combined effects of flexure and shear at the base of the pedestal. The same pattern is observed on the opposite corner of the pedestal as shown in Figure 5.10(a).

The observed cracking pattern for FE model $35-\mathrm{H}-3$ differs from model $35-\mathrm{H}-1$. In this model, initial cracks are inclined as displayed in Figure 5.11(b). These cracks are classified as web-shear cracks. Unlike the flexure-shear cracks which initiates simultaneously at opposite top and bottom corners of pedestal, web-shear cracks develop first only near to the base on the sides

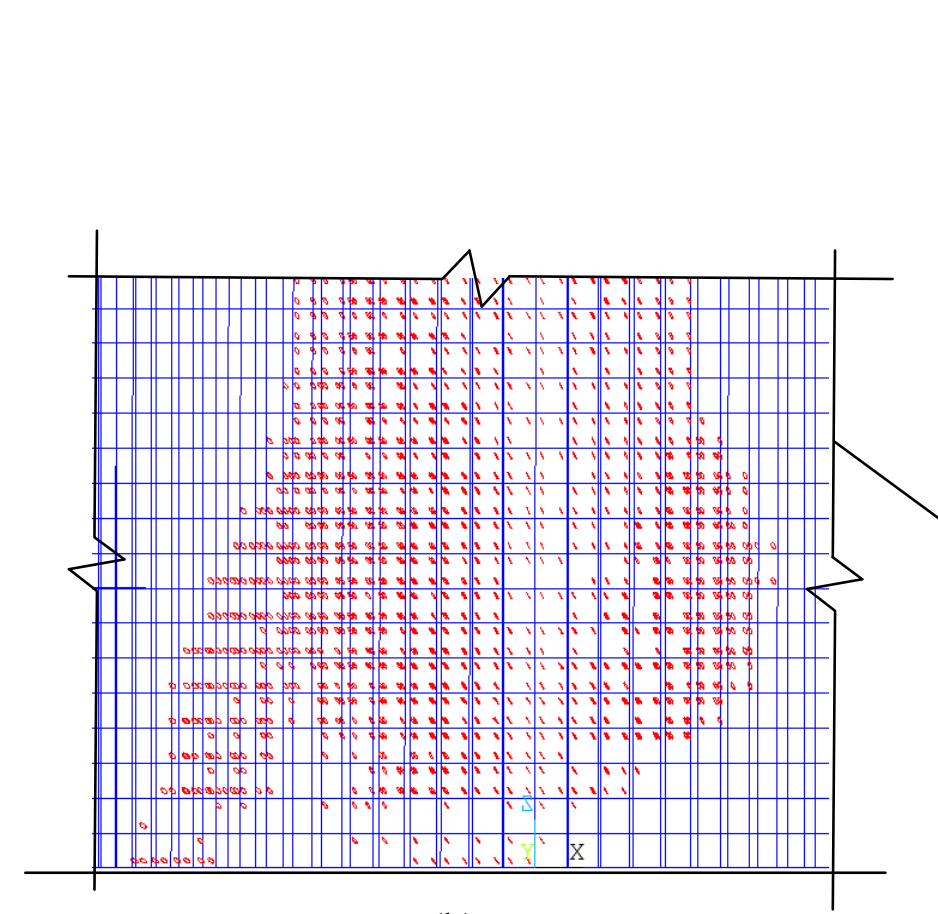

(b)

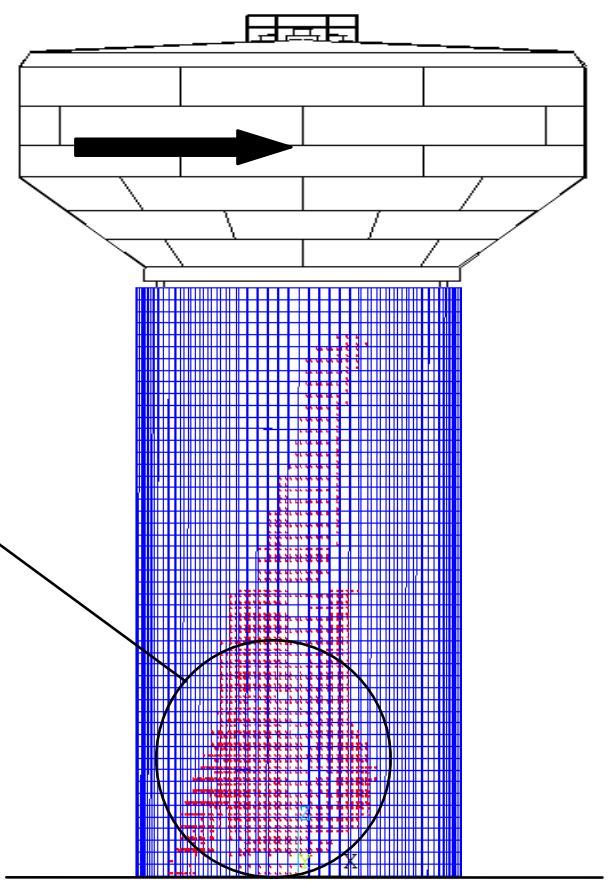

(a)

Figure 5.11 Cracking propagation pattern in FE model 35-H-3 (a) elevation of the prototype (b) Magnified view of cracks on the elevation (c) Initial cracking pattern on the pedestal's sides parallel to direction of loading (d) front view (perpendicular to lateral load direction)of the crack propagation at base level 
(c)

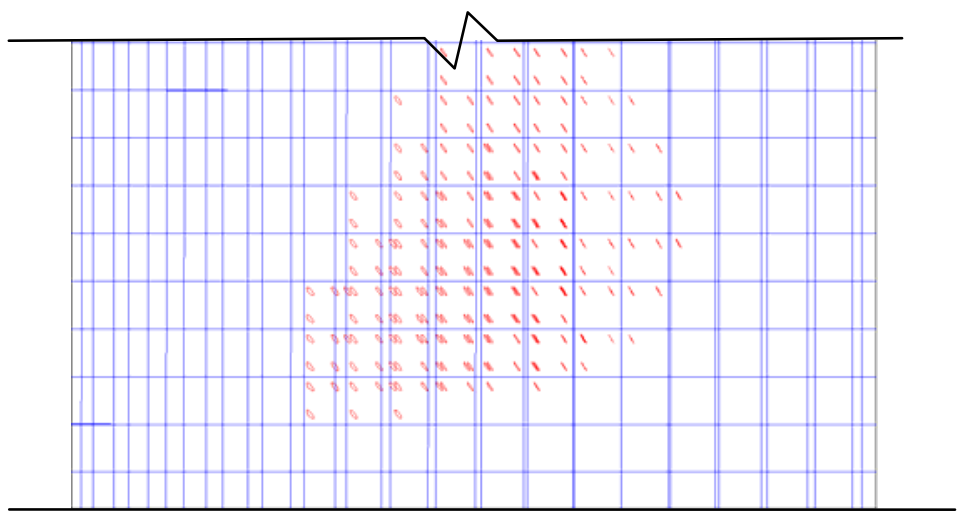

(d)

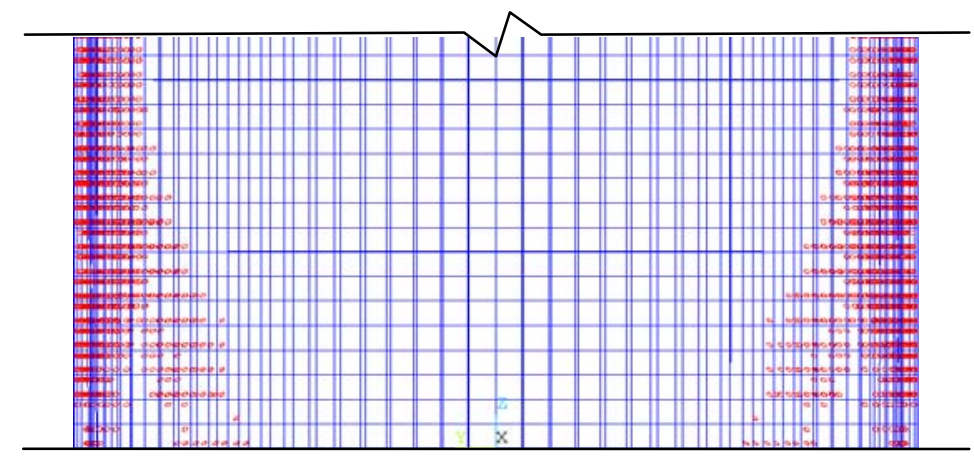

Figure 5.11 (Cont.)

parallel to the lateral load direction.(Figure 5.11(c))

By increasing the lateral load, the web-shear cracks propagate throughout the height and eventually the pedestal collapses. This is shown in Figures 5.11(a), 5.9 (b) and 5.11(d).

\subsubsection{Investigating cracking patterns}

The cracking pattern in RC pedestal structures is directly related to the height of pedestal (h) and indirectly related to the tank size. Basically flexure-shear cracking is more likely to occur in taller pedestals and web-shear cracking is possibly observed in shorter pedestals. The definition of tall and short is relative and needs to be normalized. 
The tank size also indirectly influences the cracking pattern by changing the diameter of the pedestals. Elevated water tanks with bigger tank size have higher diameter of pedestal comparing to smaller tank sizes. Investigating the results of pushover analysis indicates that the diameter of the pedestal may be used for normalizing the effect of pedestal height.

Table 5.8 presents a summary of the ratios of pedestal height (h) to mean diameter of the pedestal $\left(d_{w}\right)$. These ratios are in the range of a minimum of 1 which belongs to FE model $15-\mathrm{H}-$ 2 to maximum of 5.2 for FE model 45-H-0.5.

Table 5.8 cracking pattern summary for FE models

\begin{tabular}{ccccc}
\hline $\begin{array}{c}\text { FE model } \\
\text { ID }\end{array}$ & $\mathrm{h}(\mathrm{m})$ & $\mathrm{d}_{\mathrm{w}}(\mathrm{m})$ & $\mathrm{h} / \mathrm{d}_{\mathrm{w}}$ & Cracking mechanism \\
\hline $15-\mathrm{H}-0.5$ & 15 & 8.6 & 1.7 & web-shear cracking \\
\hline $15-\mathrm{H}-1$ & 15 & 12 & 1.3 & web-shear cracking \\
\hline $15-\mathrm{H}-2$ & 15 & 14.5 & 1.0 & web-shear cracking \\
\hline $25-\mathrm{H}-0.5$ & 25 & 8.6 & 2.9 & flexure-shear cracking \\
\hline $25-\mathrm{H}-2$ & 25 & 14.5 & 1.7 & web-shear cracking \\
\hline $25-\mathrm{H}-3$ & 25 & 20 & 1.3 & web-shear cracking \\
\hline $35-\mathrm{H}-0.5$ & 35 & 8.6 & 4.1 & flexure-shear cracking \\
\hline $35-\mathrm{H}-1$ & 35 & 12 & 2.9 & flexure-shear cracking \\
\hline $35-\mathrm{H}-3$ & 35 & 20 & 1.8 & web-shear cracking \\
\hline $45-\mathrm{H}-0.5$ & 45 & 8.6 & 5.2 & flexure-shear cracking \\
\hline $45-\mathrm{H}-1$ & 45 & 12 & 3.8 & flexure-shear cracking \\
\hline $45-\mathrm{H}-3$ & 45 & 20 & 2.3 & flexure-shear cracking \\
\hline
\end{tabular}

The results in Table 5.8 suggest that for all of the prototypes with height to diameter ratio below 1.8, the web-shear cracking pattern is observed. On the other hand, prototypes with height to diameter ratio of above 2.3, exhibit a flexure-shear cracking pattern. By performing a linear interpolation, the approximate threshold to determine the cracking pattern is calculated to be " $\mathrm{h} / \mathrm{d}_{\mathrm{w}}=2 "$. This value is approximation and recommends a fairly accurate threshold. 
Accordingly, the elevated tanks which are mounted on an RC pedestal with a height to diameter ratio of 2 and above are expected to have flexure-shear cracks patterns. On the other hand, if the height to width ratio is below 2 , then a web-shear cracking is more likely to occur in the RC pedestals.

It should be mentioned that the above recommended threshold value is valid for RC pedestals which are designed according the the provisions of codes and standards. If the structure is over or under reinforced or does not conform to the design requirements, then the above statements may not be valid.

\subsection{Summary}

This chapter aimed to evaluate the nonlinear seismic response of elevated water tanks by conducting nonlinear static (pushover) analysis. A finite element method was employed for this purpose which was verified before in Chapter 4. The results of pushover analysis will be implemented for establishing seismic response factors of elevated water tanks in the next chapter.

In order to perform a comprehensive investigation on the nonlinear seismic response of elevated water tanks, a large group of elevated water tanks with various pedestal height and tank sizes were generated. This study group represents majority of the elevated water tank sizes and dimensions built in industry. The height of the pedestals in the study group varied between $15 \mathrm{~m}$ to $45 \mathrm{~m}$. The selected tank sizes were in the range of 0.5 to 3 mega gallon.

Each elevated water tank was then designed according to the provisions of related codes and standards. The standards included ACI371R-08, ASCE/SEI 7-2010 and ACI 350.3-06. The elevated water tanks (prototypes) were designed for two categories of high and low seismicity. 
The selected design response spectrum parameters for the high seismicity zone were $\mathrm{S}_{\mathrm{DS}}=0.84$ and $\mathrm{S}_{\mathrm{D} 1}=0.44$. These values were $\mathrm{S}_{\mathrm{DS}}=0.2$ and $\mathrm{S}_{\mathrm{D} 1}=0.11$ for the low seismicity region. In addition each prototype was designed for two response modification factor values of "2" and " 3 ". This concluded in 48 prototypes in total.

A 3D finite element model was then developed for each prototype. The finite element model was capable of simulating cracking and crushing of reinforced concrete elements. Afterward, a pushover analysis was performed on each finite element model. The procedure of the pushover analysis was adopted from FEMA 273. The finite element models of elevated water tanks were subjected to a gradually increasing lateral load. The lateral load was increased until the failure in the structure occurred. The results of each pushover analysis were recorded as a load-deflection graph which is called a pushover curve.

Since it was not practical to include the results of pushover analysis for all 48 prototypes, a group of five elevated water tanks were introduced as the pilot group. This group is capable of representing most important properties of the prototypes.

The pushover curves of all of the prototypes demonstrated two distinct branches of linear and nonlinear response. The strain hardening branch during the nonlinear response phase was significant. This indicates a considerable ductility in the RC pedestal structures.

The pushover curves indicated a number of certain patterns existing in the nonlinear seismic response of elevated tanks. The prototypes which were designed for response modification factor of 2 presented higher maximum base shear comparing to identical prototype designed for $\mathrm{R}$ factor of 3. This is due to higher percentage of reinforcement in $\mathrm{R}=2$ group. However response modification factor does not have a considerable effect in the maximum lateral deflection capacity. 
The height of RC pedestals also has substantial effect on the pushover curves. When the tank size was kept constant, taller RC pedestals demonstrated lower ultimate base shear capacity. In other words, pedestal height has inverse relation with maximum base shear. However, models with taller pedestals could undergo greater top lateral deflection prior to collapse.

Generally, models with higher tank size presented larger maximum base shear capacity. The reason is higher pedestal diameter is required for bigger tanks which results in stiffer pedestals. It could also be observed that prototypes which were designed for low seismicity sites are able to resist lower base shear prior to failure.

Two types of cracking propagation were observed. Each type was found to be related to a certain ratio of height to diameter ratio in the RC pedestals. It was concluded that elevated water tanks with a pedestal height to mean diameter $\left(\mathrm{h} / \mathrm{d}_{\mathrm{w}}\right)$ ratio of above 2 demonstrated flexure-shear cracking pattern. However, if the $\mathrm{h} / \mathrm{d}_{\mathrm{w}}$ ratio is less than 2 , then the cracking propagation will be in the category of web-shear cracking. 


\section{Chapter 6 \\ Analyzing pushover curves and establishing seismic response factors}

\subsection{General}

In this chapter the seismic response factors of RC elevated water tanks will be established. The results of pushover analysis of elevated water tanks which were developed in the previous chapter will be employed for this purpose. The pushover curves require further processing in order to establish the seismic response factors. This process is addressed in this chapter.

The chapter starts with explaining the procedure for mathematical idealization of the existing pushover curves by constructing the idealized bilinear approximation relationship. The bilinear approximation is required for detecting the effective yield displacement $\left(\Delta_{\mathrm{y})}\right.$, ultimate base shear capacity $\left(\mathrm{V}_{\max }\right)$ and maximum lateral deflection $\left(\Delta_{\max }\right)$. These bilinear relationships will be constructed by combining three methods. The pushover curves and related bilinear idealizations for the pilot group of prototypes will be presented.

Next, the seismic response factors including ductility, overstrength factor and ductility factor will be addressed. The parameters affecting each of the abovementioned response factors will be discussed as well. The methods for establishing the ductility factor of the structures will be illustrated briefly. The results of processing the pushover analysis for all 48 prototypes will be presented in the form of graphs and tables. Furthermore, overstrength and ductility factors will be calculated and analysed for the effect of a number of parameters. The observed trends affecting the seismic response factors will also be investigated.

Finally, by implementing a procedure proposed by ATC 19 (1995), the draft values for the response modification factor of RC pedestals in elevated water tanks will be calculated. It must be noted that the effect of openings is not considered in the estimated values of response factors. 


\subsection{Interpreting pushover curves}

Valuable seismic response characteristics of the structures could be extracted from the pushover curves. Maximum lateral displacement capacity $\left(\Delta_{\max }\right)$, maximum base shear $\left(\mathrm{V}_{\max }\right)$, displacement ductility $(\mu)$, weak points of structures, and effective yield displacement $\left(\Delta_{y}\right)$ are among these important response characteristics.

In the previous chapter, 48 prototypes were defined and subjected to pushover analysis. The pushover curves were developed for all prototypes. In order to extract the above mentioned parameters, a bilinear approximation for each pushover curve must be constructed.

By implementing the idealized bilinear approximation $\Delta_{\mathrm{y}}, \Delta_{\max }$ and $\mathrm{V}_{\max }$ for each prototype will be found. The procedure for finding these parameters is addressed in next pages.

\subsection{Bilinear approximation of pushover curves}

The principles of constructing the bilinear approximation were explained in Chapter 3 . In order to construct the two branches of the bilinear idealization, three points must be defined. These points are $\Delta_{\mathrm{y}}, \Delta_{\max }$ and $\mathrm{V}_{\max }$. Defining maximum base shear $\left(\mathrm{V}_{\max }\right)$ is straightforward as it denotes the maximum base shear developed in the structure prior to stiffness degradation. This is shown is Figure 6.1.

The second factor that must be determined is $\Delta_{\max }$. Unlike $\mathrm{V}_{\max }$, defining $\Delta_{\max }$ requires judgment and depends on the structure type and its occupancy. Generally, $\Delta_{\max }$ might be defined in a way to account for post-peak deformation. This is shown in Figure 6.1 as $\Delta_{\text {ultimate }}$ which denotes the deformation of the structure after a certain reduction in the stiffness. 


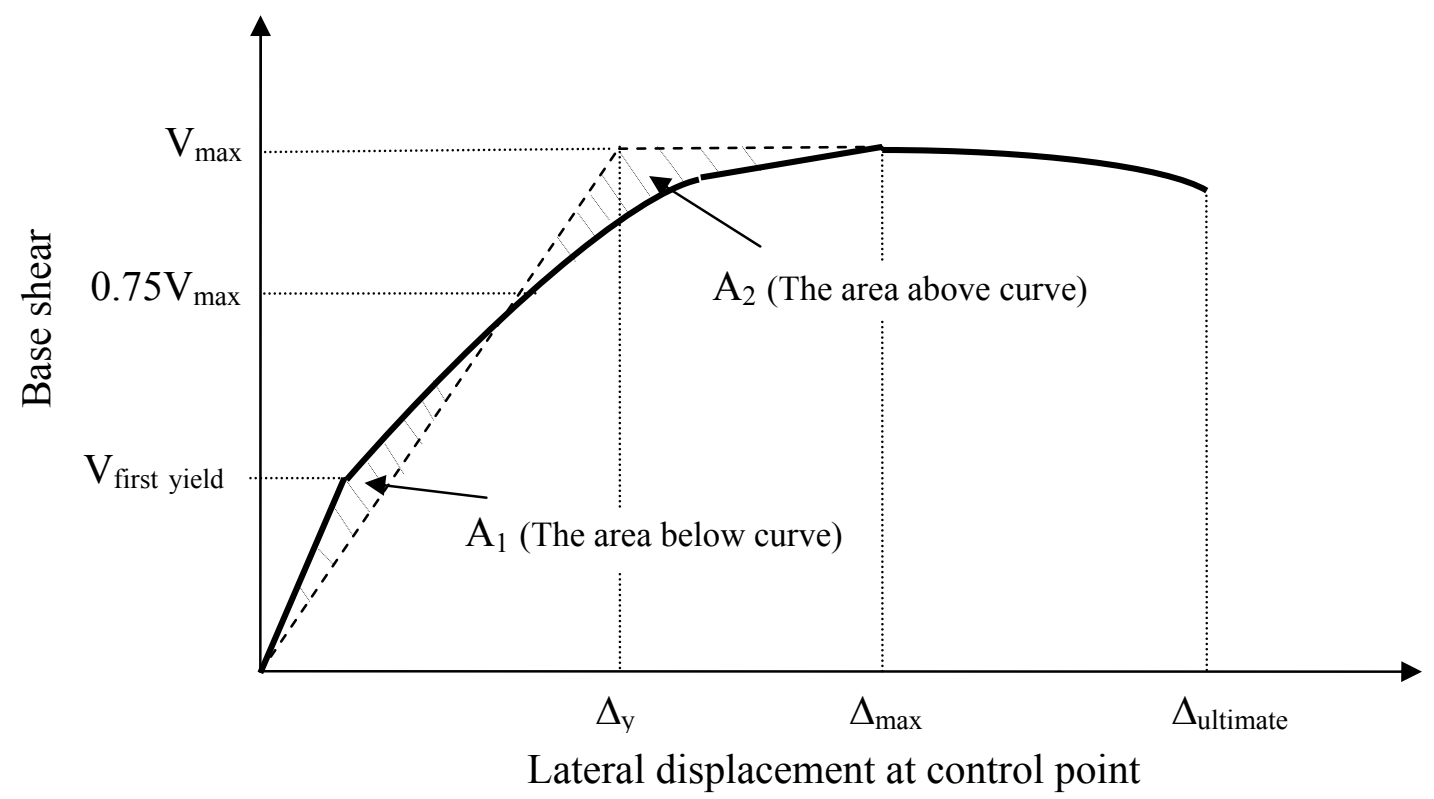

Figure 6.1 Bilinear approximation of pushover curves

According to FEMA P695 (2009), the $\Delta_{\max }$ is defined at the point where the structure stiffness falls to $80 \%$ of $\mathrm{V}_{\max }$. Some other studies suggest maximum displacement to be defined at a certain level of buckling or fracture in structure (Park, 1988). However, the abovementioned definitions are appropriate for structures with high level of redundancy such as RC frames.

RC pedestals of elevated water tanks have very low level of redundancy. Reduction in the stiffness could lead to extreme failure modes such as collapse of structure. This would suggest a more conservative and yet realistic definition of $\Delta_{\max }$ for elevated water tanks. In this study, the maximum displacement $\Delta_{\max }$ is defined at the onset of stiffness reduction when base shear reaches its peak value. In fact, $\Delta_{\max }$ is defined at $V_{\max }$ as this point represents the onset of stiffness reduction.

Another parameter that needs to be defined is $\Delta_{\mathrm{y}}$ or effective yield displacement. Due to the nonlinear characteristics of reinforced concrete structures, which involves cracking and crushing of concrete and also yielding of steel, determining the global yield point could be complicated. 
In this study three requirements are implemented for finding the effective yield point. The first one is the relationship suggested by FEMA P695 as shown in Equation 6.1:

$\Delta_{y}=C_{0} \frac{V_{\max }}{W}\left[\frac{g}{4 \pi^{2}}\right]\left(\max \left(T, T_{1}\right)\right)^{2}$

where:

$\mathrm{W}=$ weight of structure

$\mathrm{T}=$ Fundamental period of structure calculated based on code

$\mathrm{T}_{1}=$ Fundamental period of structure calculated using eigenvalue analysis

$\mathrm{C}_{0}=\mathrm{A}$ coefficient that accounts for the difference between roof displacement of a MDOF structure and displacement of the equivalent SDOF system and is calculated with Equation 6.2:

$C_{0}=\phi_{1, r} \frac{\sum_{1}^{N} m_{x} \phi_{1, x}}{\sum_{1}^{N} m_{x} \phi^{2}{ }_{1, x}}$

where:

$\mathrm{m}_{\mathrm{x}}=$ the mass at level $\mathrm{x}$

$\varphi_{1, \mathrm{x}}=$ ordinate of fundamental mode at level $\mathrm{x}$

$\mathrm{N}=$ number of levels

The value of $\mathrm{C}_{0}$ for elevated water tanks is approximately one as the mass participation factor of the first mode is very close to one. Second criterion for the effective yield is based on the equal energy principle which was discussed in Chapter 3 and displayed in Figure 6.1. The third one is the yield displacement corresponding to the yield point of an equivalent elasto-plastic system in which the first branch intersects the pushover curve at $0.75 \mathrm{~V}_{\max }$. While developing the idealized bilinears, effort was made to satisfy all above three criterions. The pushover curves and related 
bilinears for models in pilot group are demonstrated in Figure 6.2. In the same manner, the bilinears were constructed for al 48 prototypes.

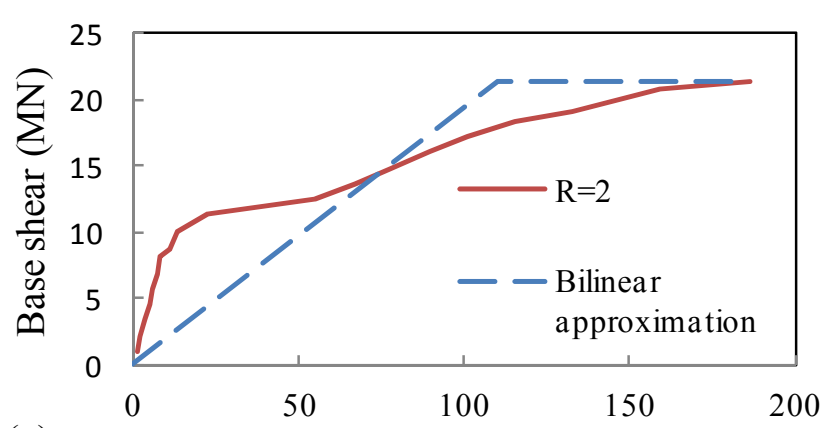

(a)

Top lateral deflection $(\mathrm{mm})$
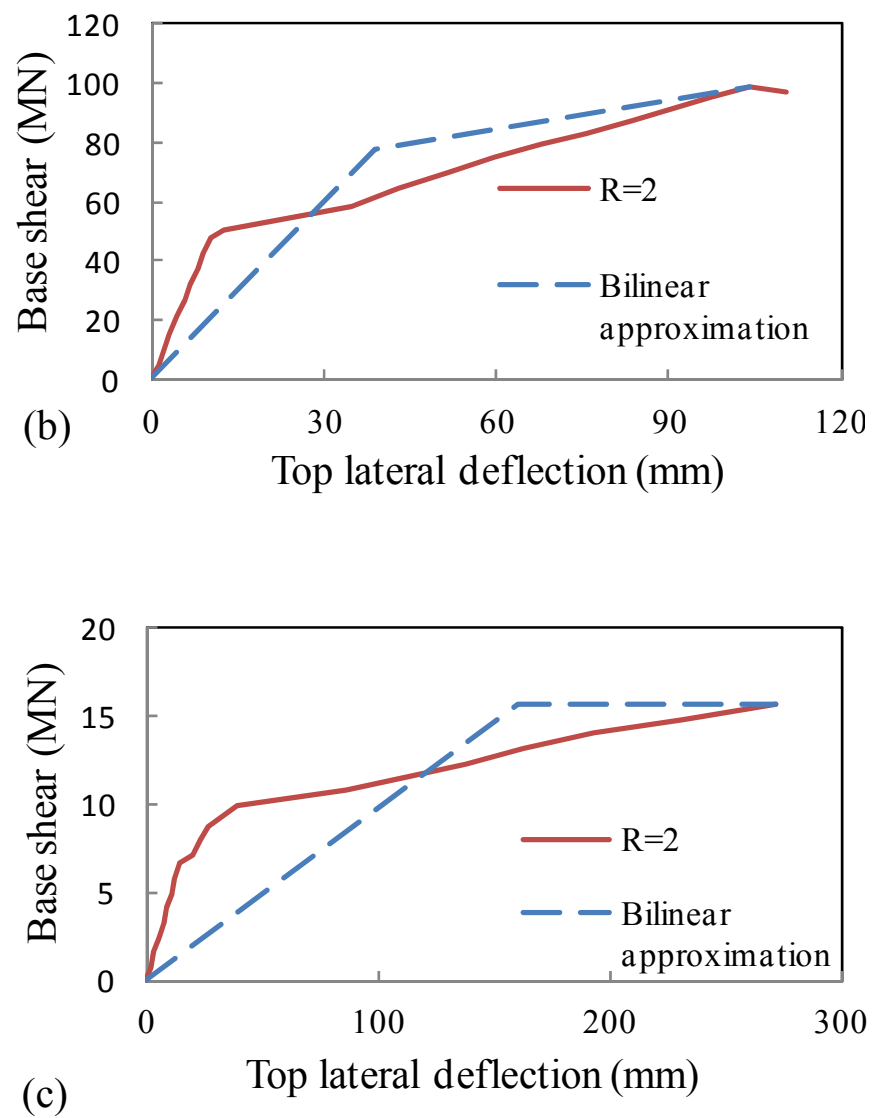
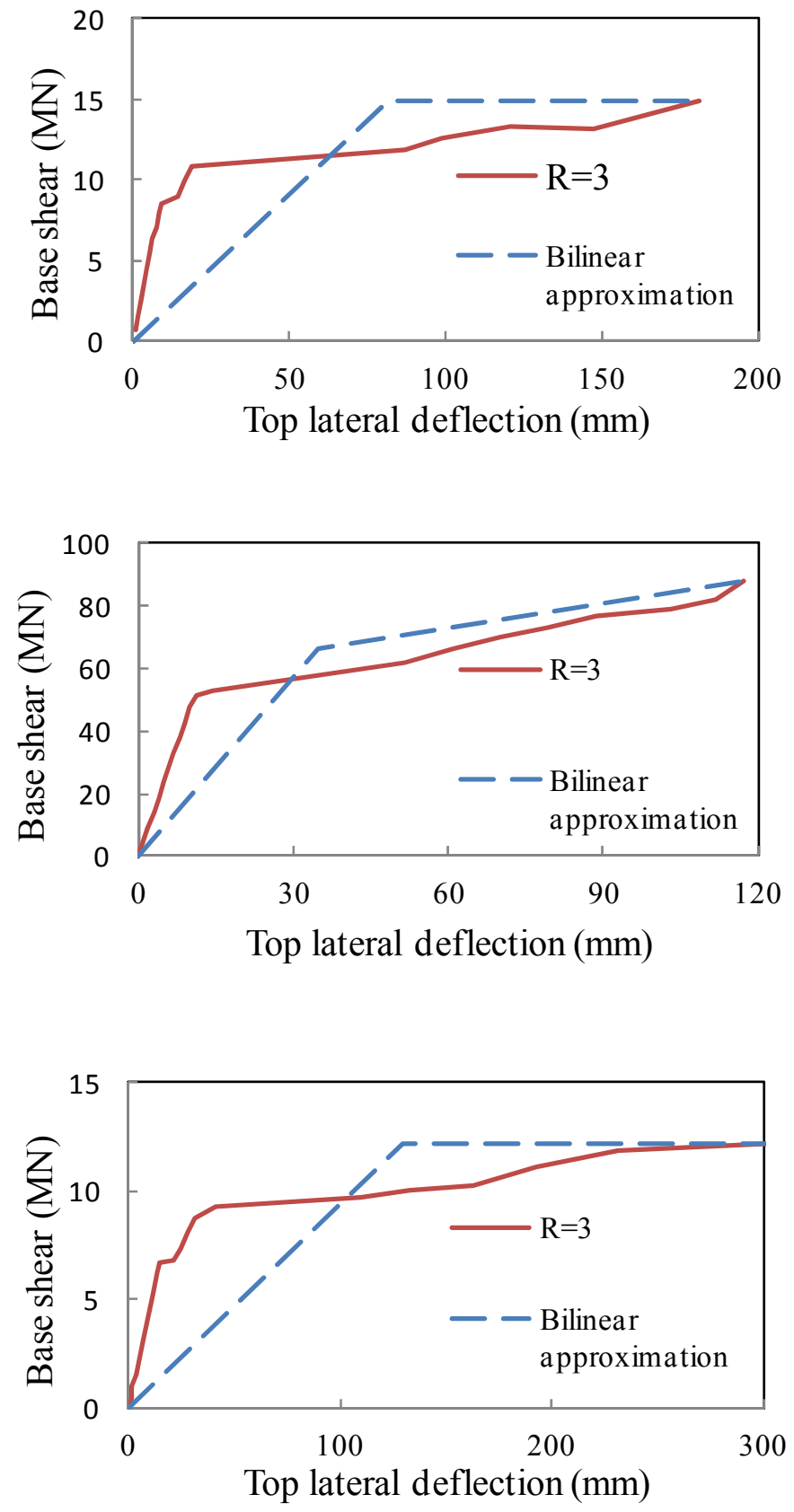

Figure 6.2 pushover curves and corresponding Bilinear approximation (a) 25-H-0.5 (b) $25-\mathrm{H}-3$ (c) $35-\mathrm{H}-0.5$ (d) $35-\mathrm{H}-1$ (e) $35-\mathrm{H}-3$ 


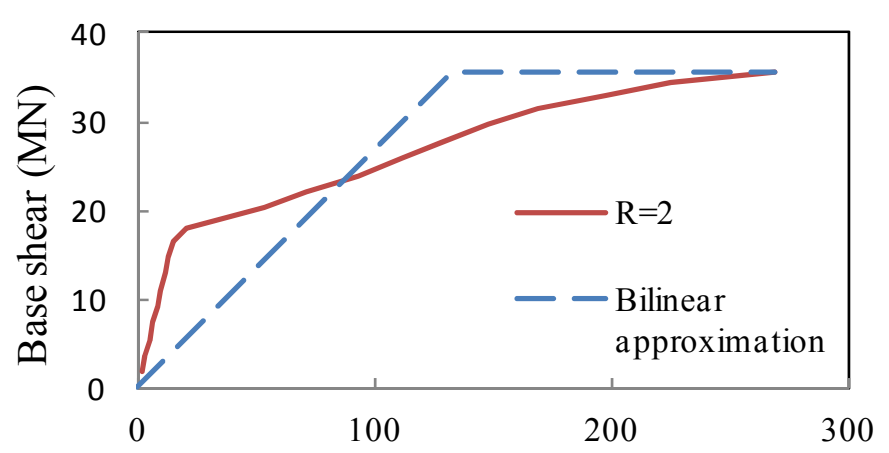

(d)

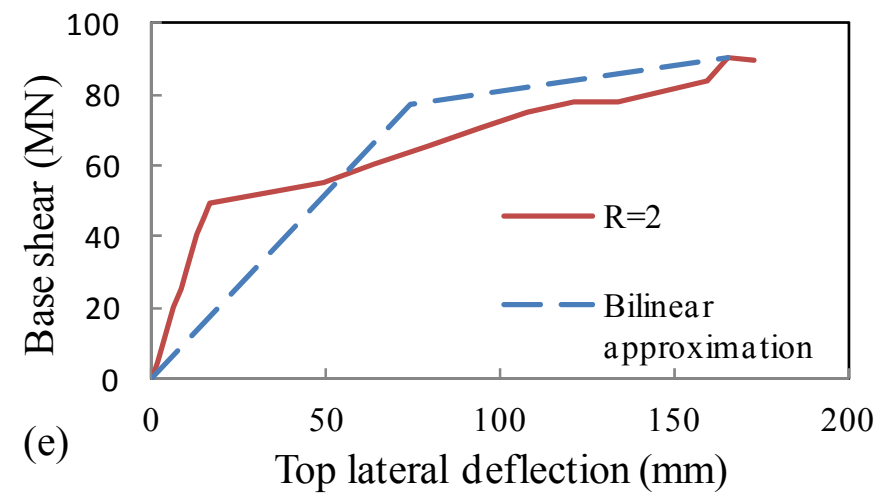

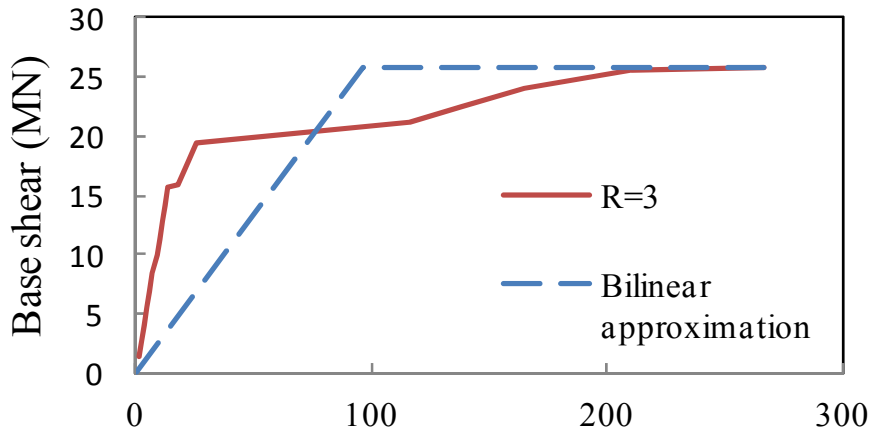

Top lateral deflection (mm)

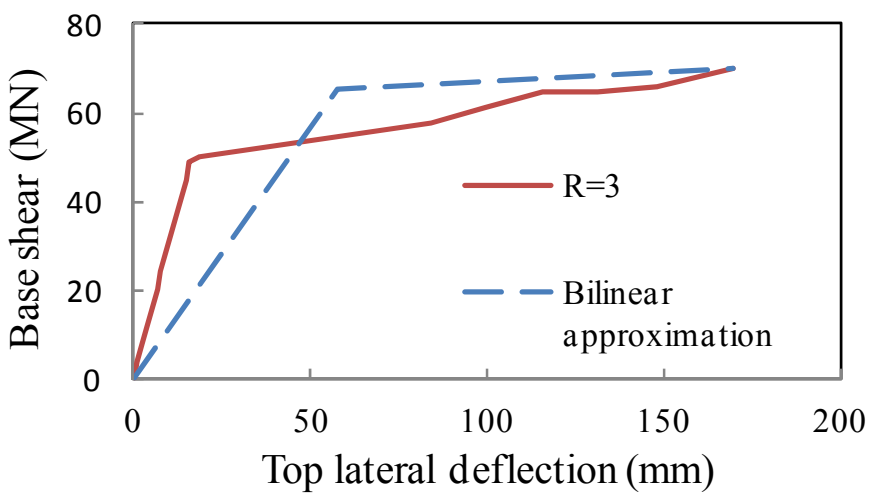

Figure 6.2 (cont.)

\subsection{Seismic response factors}

The seismic response factors are displayed in Figure 6.3. Each of the parameters shown on Figure 6.3 is explained in Table 6.1. In Figure 6.3, $\mathrm{V}_{\mathrm{e}}$ represents the maximum base shear that could be developed in an idealized fully linear-elastic equivalent structure.

However, $\mathrm{V}_{\max }$ denotes the actual maximum base shear (prior to stiffness reduction) in a structure which has experienced extreme yielding and cracking. In addition, the difference between "displacement ductility ratio" and "ductility factor" is illustrated in this figure. Overstrength factor $\left(\Omega_{0}\right)$ and ductility factor $\left(R_{\mu}\right)$ are discussed in more details in the next pages. 


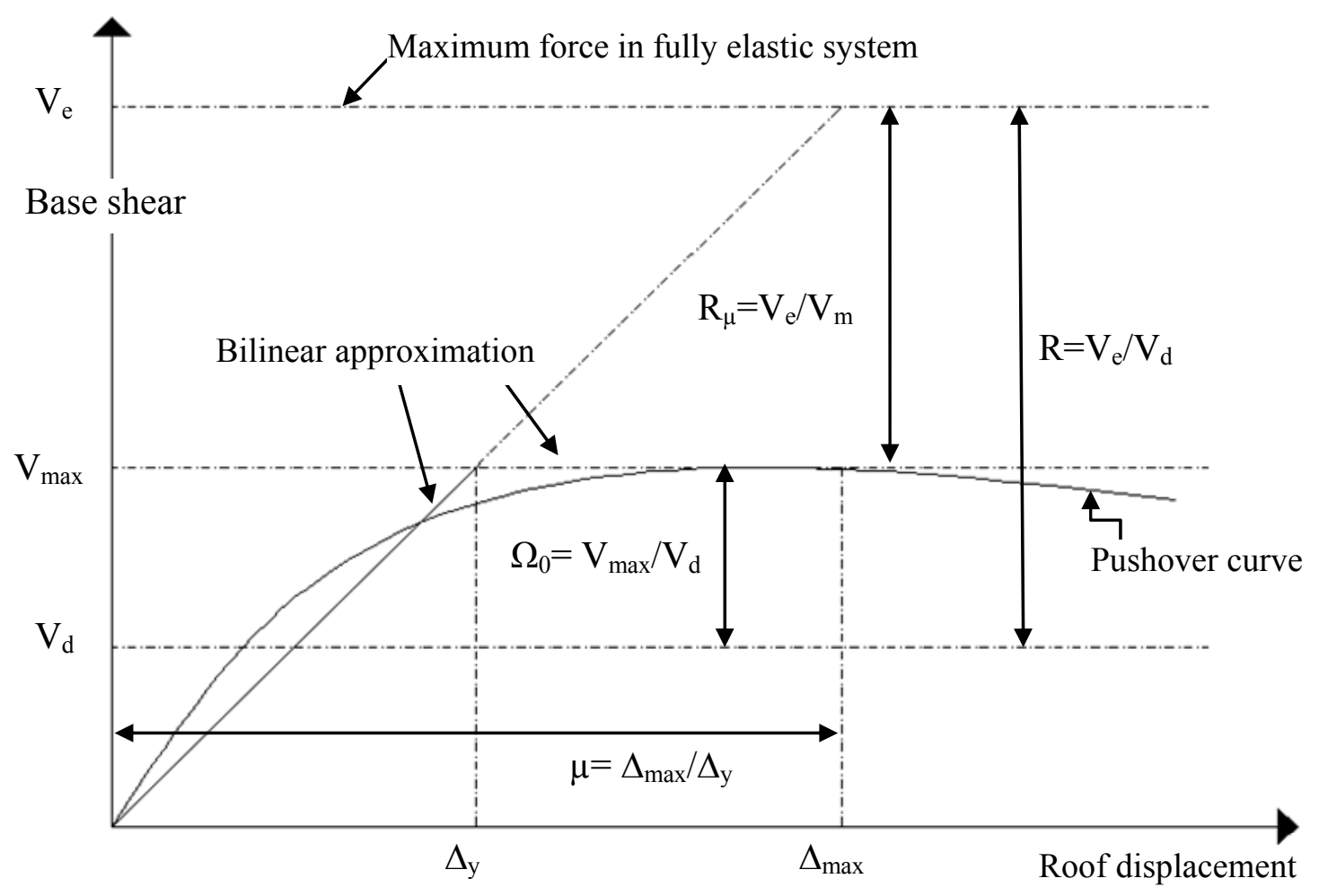

Figure 6.3 Definition of seismic response factors on a typical pushover curve

Table 6.1 Definition of parameters used in Figure 6.3 and related descriptions

\begin{tabular}{cc}
\hline Parameter & Description \\
\hline $\mathrm{R}=\mathrm{V}_{\mathrm{e} /} \mathrm{V}_{\mathrm{d}}$ & Response modification factor (R factor) \\
\hline $\mathrm{R}_{\mu=\mathrm{V}_{\mathrm{e}} / \mathrm{V}_{\max }}$ & Ductility factor \\
\hline$\Omega_{0}=\mathrm{V}_{\max /} \mathrm{V}_{\mathrm{d}}$ & Overstrength factor \\
\hline $\mathrm{V}_{\mathrm{e}}$ & Maximum base shear in an equivalent entirely elastic structure \\
\hline $\mathrm{V}_{\max }$ & Maximum base shear developed in actual nonlinear structure \\
\hline $\mathrm{V}_{\mathrm{d}}$ & Design base shear (according to pertinent code) \\
\hline$\Delta_{\mathrm{y}}$ & effective yield displacement \\
\hline$\Delta_{\max }$ & maximum displacement prior to onset of stiffness reduction \\
\hline$\mu$ & Displacement ductility ratio \\
\hline
\end{tabular}




\subsubsection{Overstrength factor}

Overstrength factor of a structure indicates the difference between code-design strength of the structure and the actual strength. The overstrength factor is expressed as the ratio of maximum base shear to design base shear as shown in Equation 6.3:

$\Omega_{0}=\mathrm{V}_{\max /} \mathrm{V}_{\mathrm{d}}$

Some research studies (Uang, 1991 and Whittaker et al., 1999) suggest overstrength factor to be a function of parameters such as:

- Higher actual material strength compared to design material strength

- Strain hardening in material

- Minimum reinforcement and member sizes exceeding the design requirements

- The safety margins included in the design process such as load factors and load combination

Overstrength factor has significant effect on the seismic response of structures. Studies have shown that higher values of overstrength factor could provide more resistance to collapse of structures (Elnashai and Mwafy, 2002). Currently ASCE/SEI 7-2010 proposes overstrength factor value of "2" for RC pedestals.

\subsubsection{Ductility factor}

Ductility factor quantifies the global seismic nonlinear response of the structure. Ductility factor is mainly a function of fundamental period of the structure and displacement ductility $(\mu)$. Many research studies have addressed this subject and proposed relationships for calculating ductility factor. 
One of the first research studies which addressed ductility factor is the one carried out by Newmark and Hall (1982) and is given in Equation 6.4. In this relationship, ductility factor is presented in the form of a piecewise function and does not include soil type effects.

$$
\begin{array}{lr}
\mathrm{R} \mu=1 & \mathrm{~T}(\text { period })<0.03_{\mathrm{sec}} \\
\mathrm{R} \mu=\sqrt{2 \mu-1} & 0.12_{\mathrm{sec}}<\mathrm{T}(\text { period })<0.5_{\mathrm{sec}} \\
\mathrm{R} \mu=\mu & 1_{\mathrm{sec}}<\mathrm{T} \text { (period) }
\end{array}
$$

A linear interpolation might be used to calculate $\mathrm{R} \mu$ for fundamental periods between $0.03 \mathrm{sec}$ to $0.12 \mathrm{sec}$ and $0.5 \mathrm{sec}$ to $1 \mathrm{sec}$. Figure 6.4 shows ductility factor versus fundamental period according to Newmark and Hall relationship for displacement ductility of 2, 4 and 6.

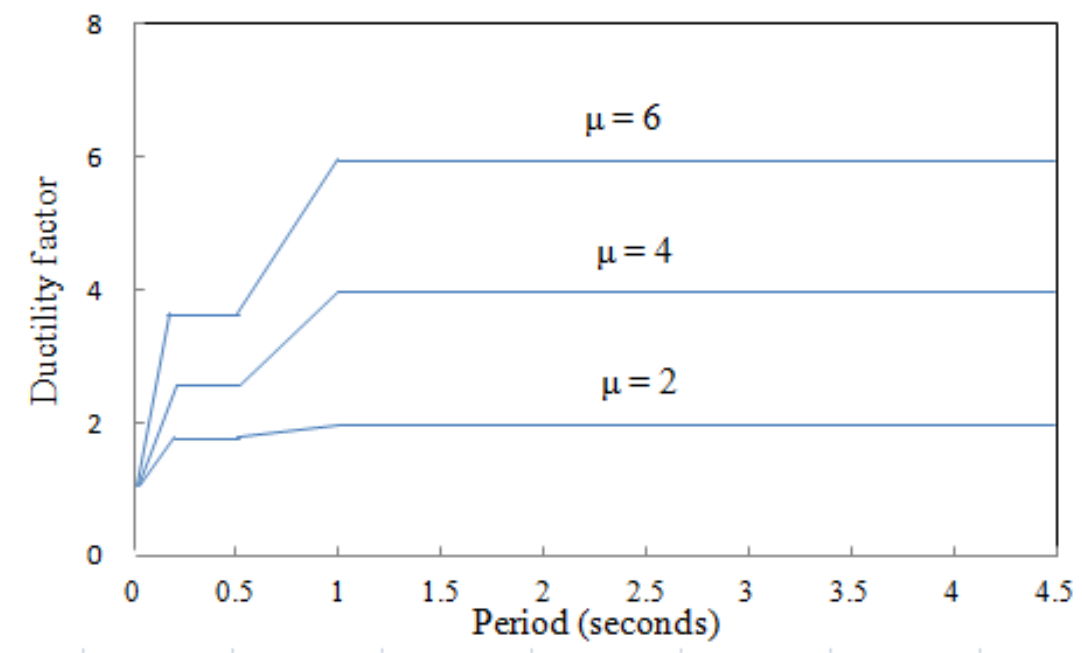

Figure 6.4 Ductility factor curves according to Newmark and Hall (1982)

Krawinkler and Nassar (1992) developed a relationship for SDOF systems on rock or stiff soil sites. They used the results of a statistical study based on 15 western U.S. ground motion records from earthquakes with magnitude of 5.7 to 7.7. This relationship is presented in Equation 6.5:

$$
\mathrm{R} \mu=[\mathrm{c}(\mu-1)+1]^{1 / \mathrm{c}}
$$

where variable "c" is determined according to Equation 6.6: 


$$
C(T, \alpha)=\frac{T^{a}}{1+T^{a}}+\frac{b}{T}
$$

In Equation 6.6, $\alpha$ is a function of strain-hardening ratio and $\mathrm{a}$ and $\mathrm{b}$ are regression parameters. Miranda and Bertero (1994) introduced a relationship for ductility factor as presented in Equation 6.7. This relationship was developed for rock, alluvium, and soft soil sites by implementing 124 ground motions.

$$
\mathrm{R} \mu=(\mu-1) / \varphi+1
$$

where $\varphi$ is determined based on soil type, fundamental period and displacement ductility. Equation 6.8 gives the relationship for calculating $\varphi$ for rock site:

$$
\phi=1+\frac{1}{10 T-\mu T}-\frac{1}{2 T} e^{-1.5(\ln (T)-0.6)^{2}}
$$

Figure 6.5 displays a comparison between "Newmark and Hall", "Nassar and Krawinkler" and "Miranda and Bertero" for displacement ductility of 3. It could be observed that all three

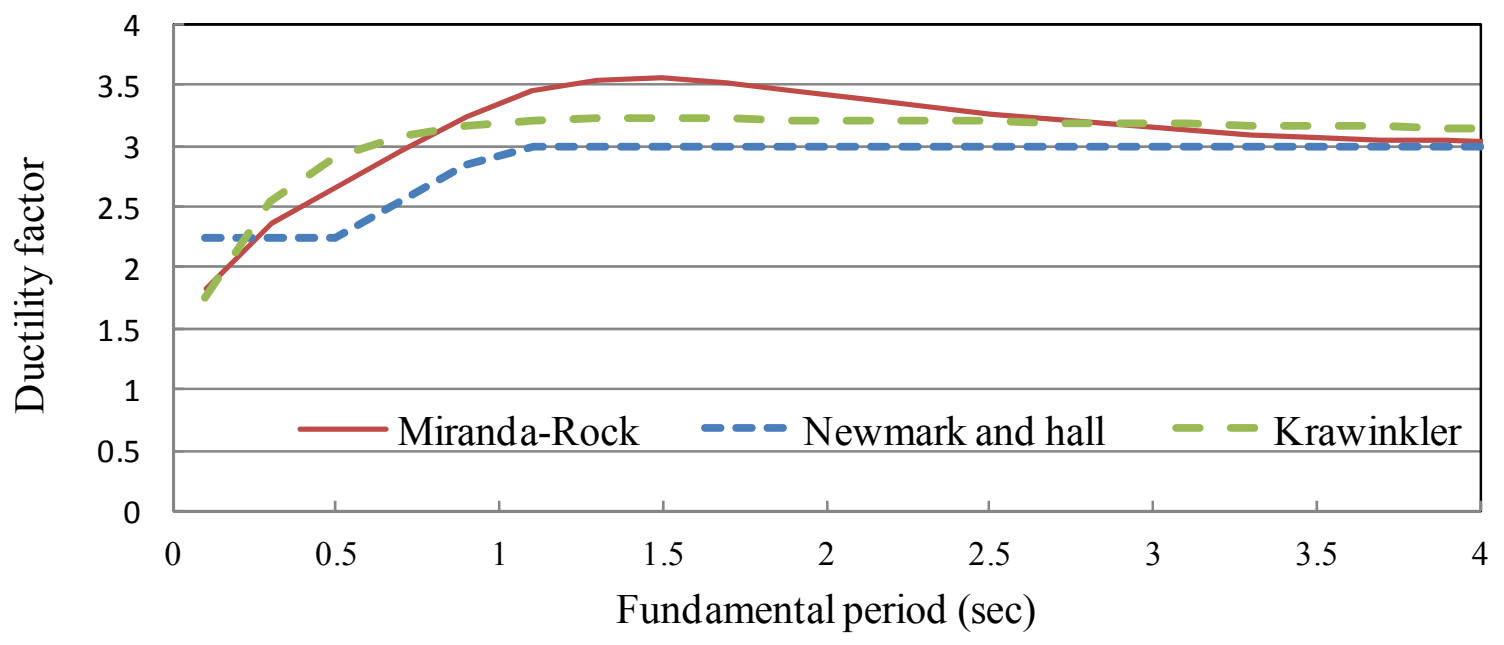

Figure 6.5 Comparing ductility factor obtained from "Newmark and Hall”, "Nassar and Krawinkler", and "Miranda and Bertero" for displacement ductility of 3 
relations are resulting in fairly close values for ductility factor. In this study, the Newmark and Hall relationship is employed mainly because it is offering a more conservative lower bound which seems more reasonable for essential infrastructures such as water storage facilities.

\subsubsection{Response modification factor}

A comprehensive literature review on the subject of response modification factor was presented in Chapter 2 of the thesis. The draft values of $\mathrm{R}$ factor will be calculated by implementing the relationship proposed by ATC 19 (1995) and is given by Equation 6.9:

$$
\mathrm{R}=\Omega_{0} \mathrm{R} \mu \mathrm{R}_{\mathrm{R}}
$$

The first two terms in Equation 6.9 are overstrength factor $\left(\Omega_{0)}\right.$ and ductility factor $(\mathrm{R} \mu)$ which were discussed before. The last term is the redundancy factor $\left(R_{R}\right)$ which is a factor of structural redundancy. According to ATC 19, response modification factor must be reduced for structural systems with low level of redundancy. It also proposes draft values for redundancy factor depending on the lines of vertical seismic framing.

The proposed draft redundancy factor for a system with two lines of vertical seismic framing is equal to 0.71 . Due to the low redundancy of the RC pedestal structure, this value is selected for the $\mathrm{R}$ factor calculation in this research.

\subsection{Calculating global seismic response factors for RC pedestals}

At this stage, methods explained in Sections 6.3 and 6.4 are implemented in order to extract seismic response factors from the pushover results which were obtained in Chapter 5 of the thesis. The calculated values of the overstrength factor and ductility factor for the prototypes are demonstrated in Tables 6.2 and 6.3 . 
Table 6.2 Seismic response factors for "high seismicity" design

\begin{tabular}{|c|c|c|c|c|c|c|c|c|}
\hline \multirow[b]{3}{*}{ FE model ID } & \multirow{2}{*}{\multicolumn{2}{|c|}{$\begin{array}{c}\Omega_{0} \\
\text { (overstrength } \\
\text { factor) }\end{array}$}} & \multicolumn{6}{|c|}{$\mathrm{R} \mu$ (Ductility factor) } \\
\hline & & & \multicolumn{2}{|c|}{ Newmark } & \multicolumn{2}{|c|}{$\begin{array}{c}\text { Miranda } \\
\text { (Rock) }\end{array}$} & \multicolumn{2}{|c|}{ Krawinkler } \\
\hline & $\mathrm{R}=2$ & $\mathrm{R}=3$ & $\mathrm{R}=2$ & $\mathrm{R}=3$ & $\mathrm{R}=2$ & $\mathrm{R}=3$ & $\mathrm{R}=2$ & $\mathrm{R}=3$ \\
\hline $15-\mathrm{H}-0.5$ & 1.9 & 2.3 & 1.7 & 2.2 & 1.8 & 2.4 & 2.0 & 2.7 \\
\hline $15-\mathrm{H}-1$ & 1.5 & 1.9 & 2.0 & 2.5 & 2.1 & 2.8 & 2.3 & 3.1 \\
\hline $15-\mathrm{H}-2$ & 1.2 & 1.6 & 2.1 & 2.5 & 2.2 & 2.9 & 2.4 & 3.2 \\
\hline $25-\mathrm{H}-0.5$ & 1.9 & 2.0 & 1.5 & 2.0 & 1.5 & 2.2 & 1.5 & 2.2 \\
\hline $25-\mathrm{H}-2$ & 1.3 & 1.6 & 1.9 & 2.3 & 2.1 & 2.7 & 2.2 & 2.8 \\
\hline $25-\mathrm{H}-3$ & 1.2 & 1.6 & 2.1 & 2.4 & 2.4 & 2.9 & 2.6 & 3.2 \\
\hline $35-\mathrm{H}-0.5$ & 2.0 & 2.3 & 1.5 & 2.1 & 1.6 & 2.4 & 1.5 & 2.2 \\
\hline $35-\mathrm{H}-1$ & 1.8 & 2.0 & 1.9 & 2.6 & 2.1 & 3.0 & 2.0 & 2.9 \\
\hline $35-\mathrm{H}-3$ & 1.3 & 1.6 & 2.0 & 2.5 & 2.2 & 2.9 & 2.3 & 3.0 \\
\hline $45-\mathrm{H}-0.5$ & 2.1 & 2.4 & 1.4 & 1.8 & 1.5 & 2.1 & 1.4 & 1.9 \\
\hline $45-\mathrm{H}-1$ & 1.8 & 2.0 & 1.8 & 2.5 & 2.1 & 2.9 & 1.9 & 2.6 \\
\hline $45-\mathrm{H}-3$ & 1.4 & 1.7 & 2.0 & 2.7 & 2.2 & 3.1 & 2.1 & 2.9 \\
\hline
\end{tabular}

Table 6.3 Seismic response factors for "low seismicity" design

\begin{tabular}{|c|c|c|c|c|c|c|c|c|}
\hline \multirow[b]{3}{*}{ FE model ID } & \multirow{2}{*}{\multicolumn{2}{|c|}{$\begin{array}{c}\Omega_{0} \\
\text { (overstrength } \\
\text { factor) }\end{array}$}} & \multicolumn{6}{|c|}{$\mathrm{R} \mu$ (Ductility factor) } \\
\hline & & & \multicolumn{2}{|c|}{ Newmark } & \multicolumn{2}{|c|}{$\begin{array}{l}\text { Miranda } \\
\text { (Rock) }\end{array}$} & \multicolumn{2}{|c|}{ Krawinkler } \\
\hline & $\mathrm{R}=2$ & $\mathrm{R}=3$ & $\mathrm{R}=2$ & $\mathrm{R}=3$ & $\mathrm{R}=2$ & $R=3$ & $\mathrm{R}=2$ & $\mathrm{R}=3$ \\
\hline $15-\mathrm{L}-0.5$ & 3.8 & 5.6 & 2.3 & 2.3 & 2.8 & 2.8 & 3.0 & 3.0 \\
\hline $15-\mathrm{L}-1$ & 3.4 & 5.1 & 2.8 & 3.0 & 3.4 & 3.7 & 3.8 & 4.3 \\
\hline $15-\mathrm{L}-2$ & 2.8 & 4.0 & 2.7 & 3.0 & 3.3 & 3.8 & 3.8 & 4.5 \\
\hline 25 -L-0.5 & 4.8 & 7.2 & 2.2 & 2.2 & 2.4 & 2.4 & 2.3 & 2.3 \\
\hline $25-\mathrm{L}-2$ & 3.0 & 4.2 & 2.9 & 3.2 & 3.4 & 3.7 & 3.6 & 4.0 \\
\hline $25-\mathrm{L}-3$ & 2.5 & 3.4 & 2.7 & 3.1 & 3.4 & 4.1 & 3.8 & 4.8 \\
\hline $35-\mathrm{L}-0.5$ & 5.4 & 8.1 & 1.5 & 1.5 & 1.7 & 1.7 & 1.6 & 1.6 \\
\hline 35-L-1 & 4.2 & 7.0 & 2.7 & 2.5 & 3.1 & 2.8 & 2.9 & 2.6 \\
\hline $35-\mathrm{L}-3$ & 3.5 & 4.8 & 2.8 & 4.0 & 3.2 & 4.7 & 3.3 & 5.2 \\
\hline $45-\mathrm{L}-0.5$ & 6.3 & 9.4 & 1.2 & 1.2 & 1.3 & 1.3 & 1.2 & 1.2 \\
\hline $45-\mathrm{L}-1$ & 5.0 & 7.5 & 2.0 & 2.0 & 2.3 & 2.3 & 2.1 & 2.1 \\
\hline $45-\mathrm{L}-3$ & 4.2 & 6.3 & 2.4 & 2.4 & 2.7 & 2.7 & 2.5 & 2.5 \\
\hline
\end{tabular}




\subsection{Analysing seismic response factors}

In this section, effect of various parameters including fundamental period, height to diameter ratio, seismic design category, and tank size on the seismic response factors of elevated water tanks will be studied.

\subsubsection{Effect of Fundamental period}

Fundamental period of structure is an indication of mass, stiffness, height and section properties of the structures and could affect the seismic response factors. The effect of fundamental period is demonstrated in Figure 6.6 for all prototypes. An exponential trend line is added to the graphs as well.
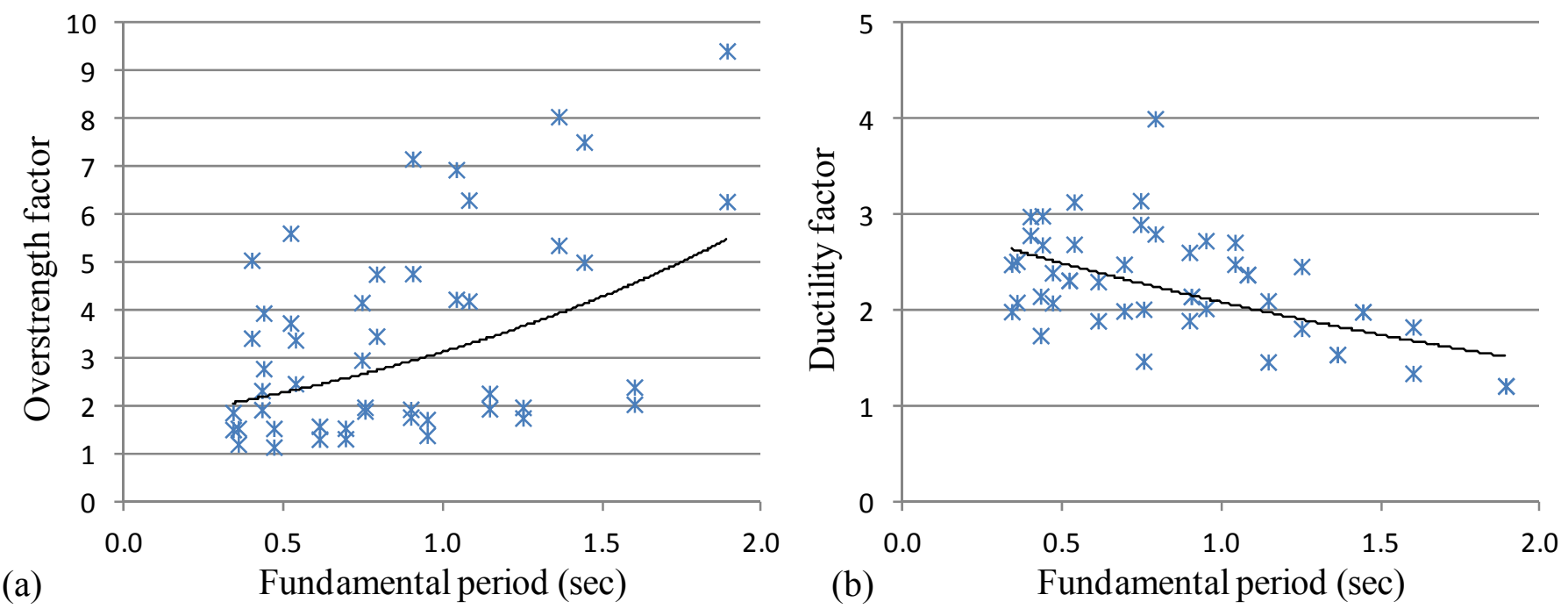

Figure 6.6 Effect of fundamental period on (a) overstrength factor (b) ductility factor

As shown in Figure 6.6, none of the the graphs are demonstrating noticeable regular pattern. This is more obvious in Figure 6.6 (a) in which data is further scattered. Generally, according to trend lines, overstrength factor increases by increasing the fundamental period. On the other hand, ductility factor declines when fundamental period increases. Other than the general trend 
lines, no specific relation could be found to relate the fundamental period to either of the seismic response factors.

\subsubsection{Effect of height to diameter ratio}

A more distinct pattern might be observed in Figure 6.7 which demonstrates height to diameter ratio $\left(\mathrm{h} / \mathrm{d}_{\mathrm{w}}\right)$ versus seismic response factors. The height to diameter ratio contains various structural properties of the RC pedestal. Height (h) is an excellent indicator of fundamental period. On the other hand the diameter $(\mathrm{dw})$ indicates pedestal section stiffness and tank size (tank size is related to pedestal diameter).
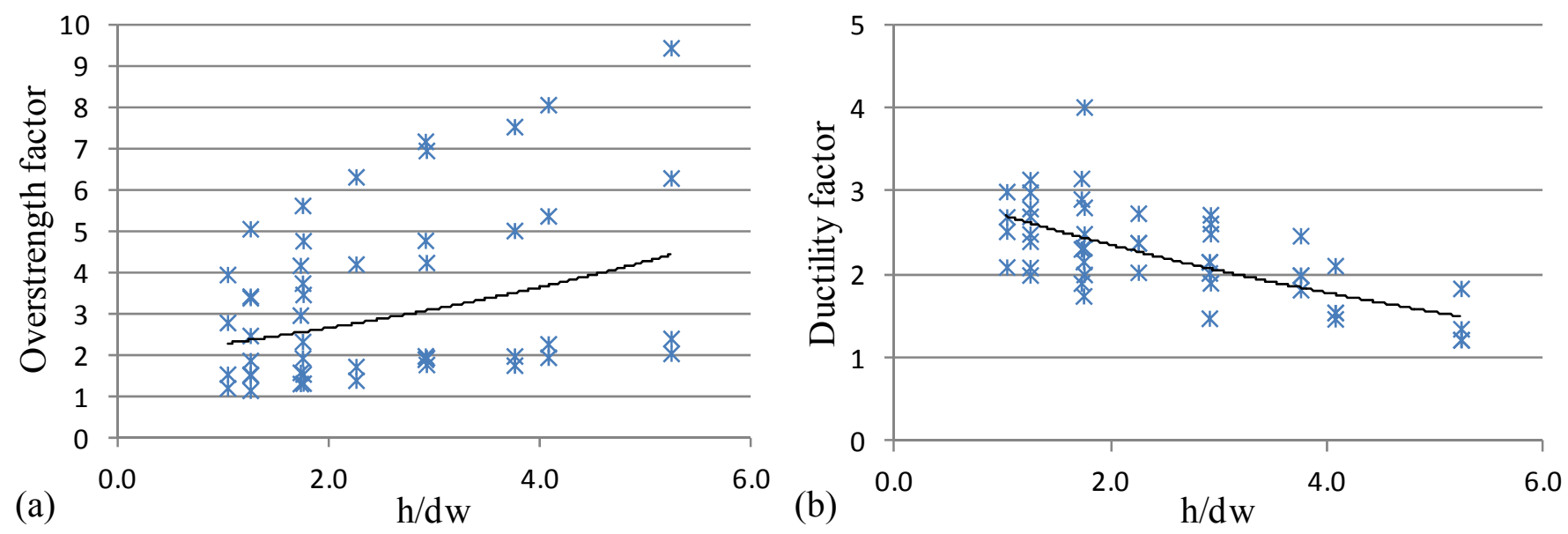

Figure 6.7 Effect of " $\mathrm{h} / \mathrm{d}_{\mathrm{w}}$ " ratio on (a) overstrength factor (b) ductility factor

According to Figure 6.7 (a) it could be concluded that overstrength factor increases when the $\mathrm{h} / \mathrm{d}_{\mathrm{w}}$ ratio goes up. In addition, ductility factor has inverse relation with $\mathrm{h} / \mathrm{d}_{\mathrm{w}}$. However, in quite the same manner as Figure 6.6, there is no specific relation between $\mathrm{h} / \mathrm{d}_{\mathrm{w}}$ ratio and overstrength or ductility factor. For $\mathrm{h} / \mathrm{d}_{\mathrm{w}}$ ratios below 2 , overstrength factor ranges from 1.3 to 5 . This range increases to a wider range of 2 to 8 for elevated water tanks with an $h / d_{w}$ ratio of 4 . 


\subsubsection{Effect of tank size on overstrength factor}

Figure 6.8 shows graphs of tank size versus overstrength factor and ductility factor. A more distinct pattern comparing to the last two sections could be observed. Figure 6.8(a) indicates that elevated water tanks with higher tank sizes will demonstrate lower overstrength factor and vice versa. This trend is further explained in Figure 6.9.

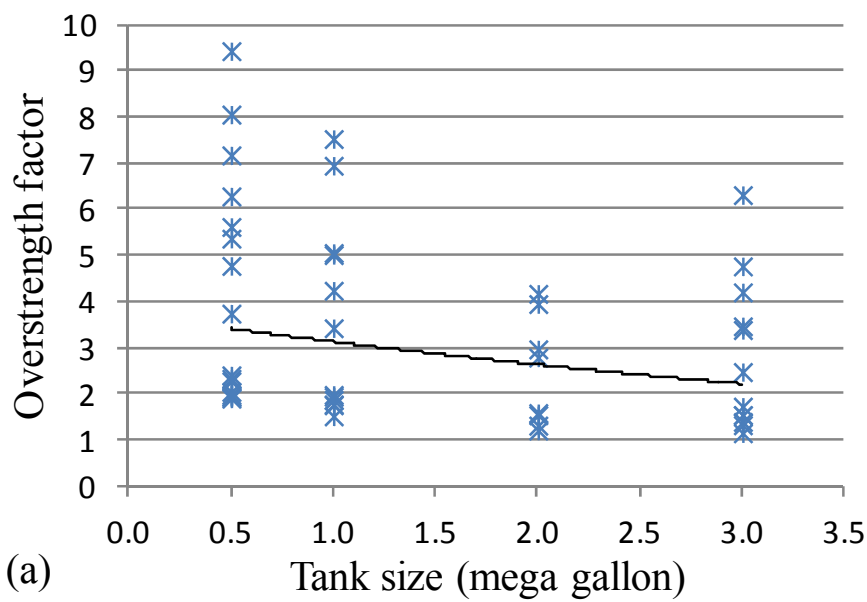

Figure 6.8 Effect of tank size on (a) overstrength factor (b) ductility factor

Figure 6.9 displays pushover curves of models $35-\mathrm{H}-0.5,35-\mathrm{H}-1$ and $35-\mathrm{H} 3$ and related design base shear for each one. It could be concluded from the graphs that by increasing the tank
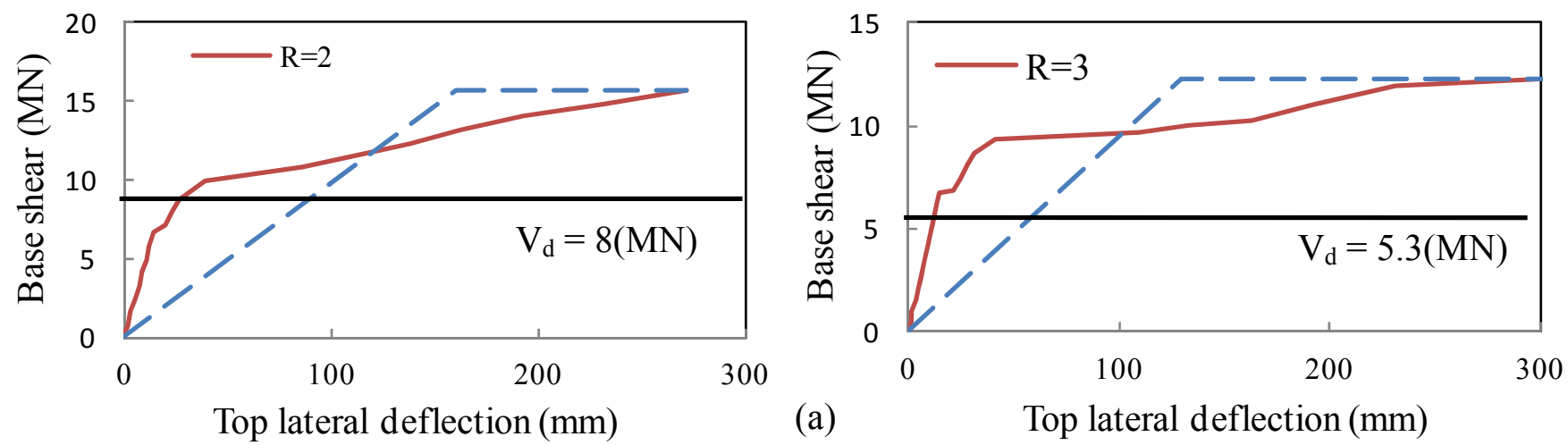

Figure 6.9 Pushover curves and corresponding seismic design base shear (a) $35-\mathrm{H}-0.5$ (b) $35-\mathrm{H}-1$ (c) $35-\mathrm{H}-3$ 

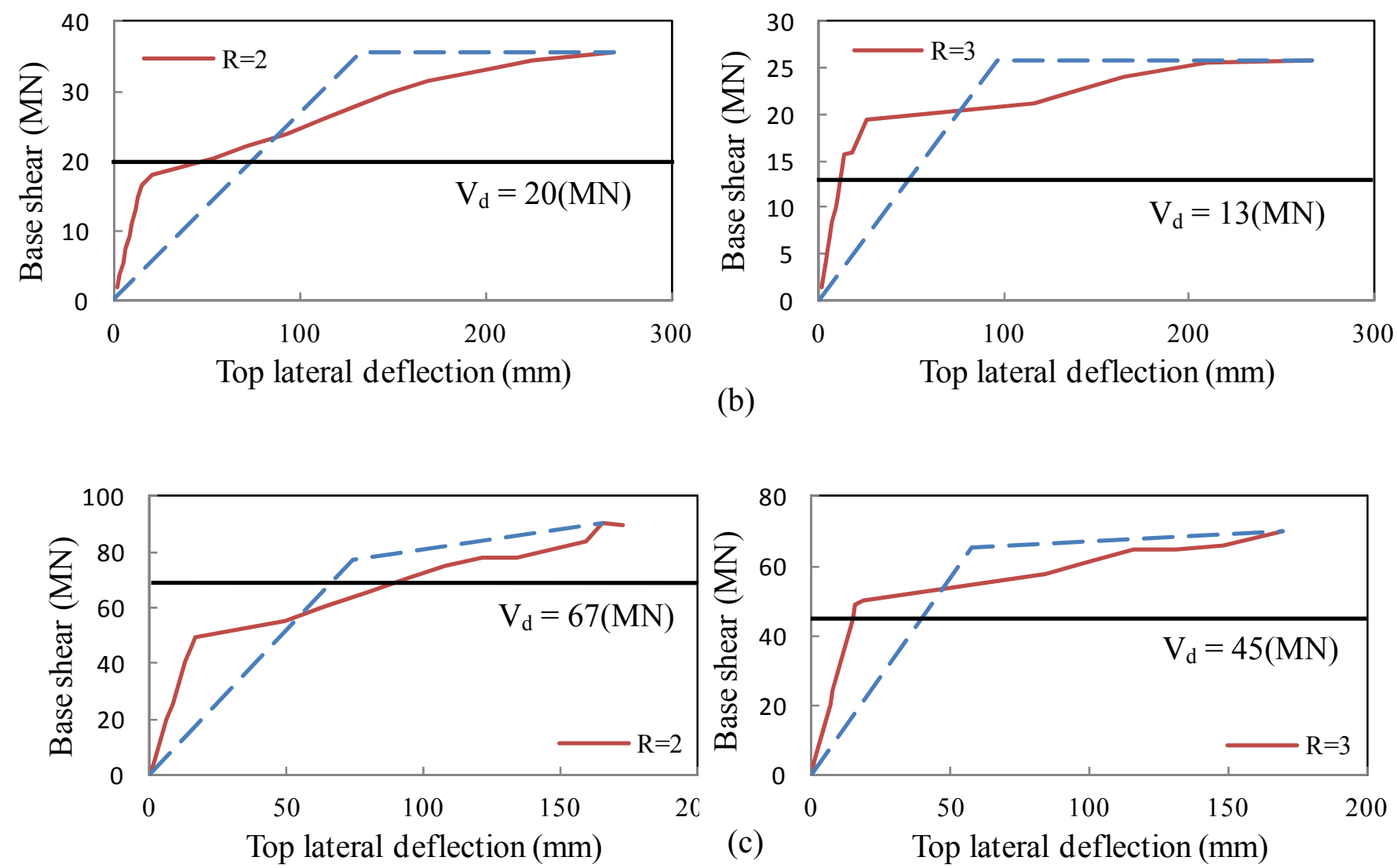

Figure 6.9 (Cont.)

size, the design base shear further extends to the nonlinear response branch of the pushover curves. For the models designed for $\mathrm{R}=3$, the design base shear falls in the linear branch of pushover curve. The level of seismic forces is reduced by $2 / 3$ in this case (compared to $R=2$ ).

As the weight of the tank increases, the design base shear intersects the pushover curves in higher deflection stages. As shown in Figure 6.9 (a), for FE model 35-H-0.5, $\mathrm{V}_{\mathrm{d}}$ (design seismic base shear) crosses the pushover curve at a deflection of around $20 \mathrm{~mm}$. This is far before the final deflection of approximately $280 \mathrm{~mm}$ and the RC pedestal does not undergo considerable lateral deformation. The maximum developed base shear prior to failure of this model is nearly twice the $V_{d}$ which indicates a significant reserved strength in the structure. 
Figure 6.9 (b) demonstrates FE model $35-\mathrm{H}-1$ which has a response quite the same as FE model $35-\mathrm{H}-0.5$. In this model, the lateral deformation corresponding to design seismic base shear is not significant and for both models $(\mathrm{R}=2$ and $\mathrm{R}=3)$ is limited to less than $50 \mathrm{~mm}$. Moreover, the model can develop acceptable level of strength above the design seismic base shear.

As the tank size is further increased, the lateral deflection at $\mathrm{V}_{\mathrm{d}}$ becomes larger. As shown in Figure 6.9 (c), Model 35-H-3 $(\mathrm{R}=2)$, demonstrates a lateral deflection of nearly $100 \mathrm{~mm}$ at $\mathrm{V}_{\mathrm{d}}$. Although in model 35-H-3 $(\mathrm{R}=3), \mathrm{V}_{\mathrm{d}}$ intersect pushover curve at a low lateral deflection, both models are presenting much lower overstrength compared to smaller tank size models. In summary, as Figure 6.9 implies, model 35-H-3 $(\mathrm{R}=2)$ which has the largest tank size of the three models, will potentially experience the highest structural damages due to the design seismic base shear $\mathrm{V}_{\mathrm{d}}$. This trend will be employed in later sections for classifying the seismic performance of elevated water tanks based on the the rank sizes.

\subsubsection{Effect of seismicity}

Seismic design category has the most significant influence on the seismic response factors. In this research, the seismic category effect is included both explicitly and implicitly. The explicit effect of seismic category was explained before by designing the prototypes for two levels of high and low seismicity. On the other hand, each prototype was designed for two R factors of 2 and 3. Variation of $\mathrm{R}$ factor can directly affect the seismic base shear. $\mathrm{R}$ factor has an inverse linear relationship with $\mathrm{V}_{\mathrm{d}}$ according to Equation 5.9 in Chapter 5. The FE models designed for $\mathrm{R}=2$ in the high seismic category are experiencing the highest seismic loads and FE models designed for $\mathrm{R}=3$ in the low seismic region are subjected to the lowest seismic loads. 
This is further illustrated in Figure 6.10 by comparing the $35 \mathrm{~m}$ model with a tank size of 1 mega gallon designed for four levels of seismicity. There are four FE models depicted in Figure 6.10 which are $35-\mathrm{H}-1(\mathrm{R}=2), 35-\mathrm{H}-1(\mathrm{R}=3), 35-\mathrm{L}-1 \quad(\mathrm{R}=2)$, and 35-L-1 $(\mathrm{R}=3)$.

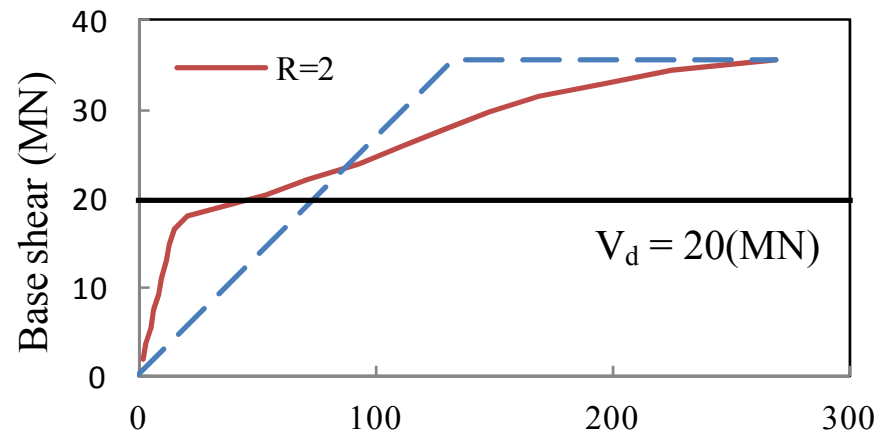

(a)

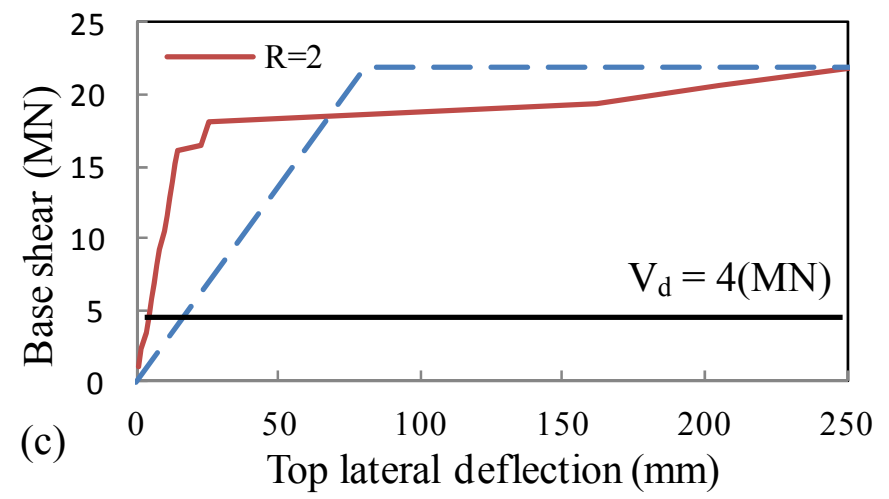

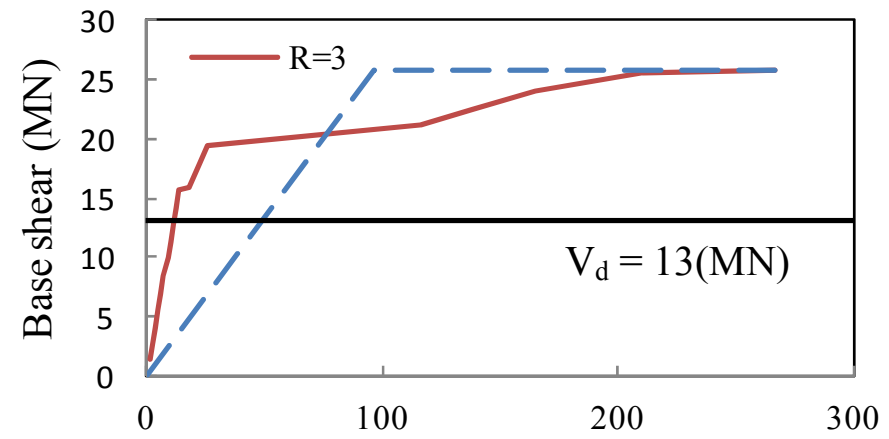

(b)

Top lateral deflection (mm)

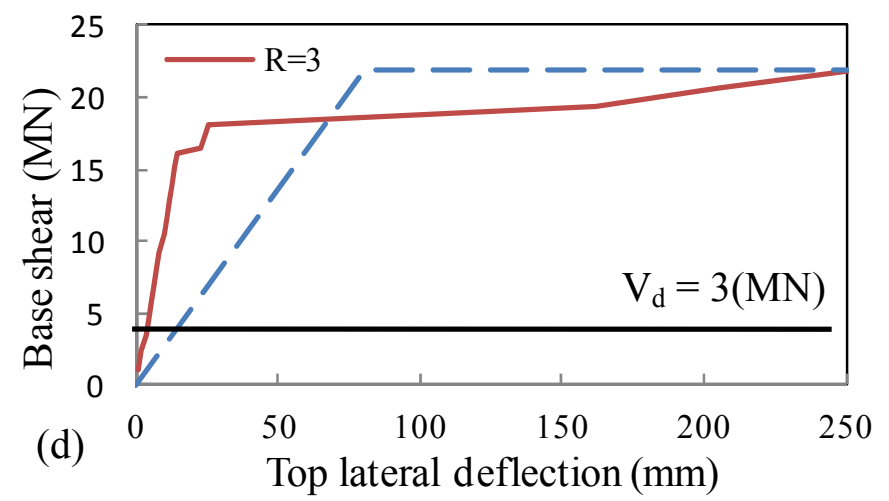

Figure 6.10 Comparing pushover curves for four levels of seismicity (a) $35-\mathrm{H}-1(\mathrm{R}=2) /$ level one (b) $35-\mathrm{H}-1(\mathrm{R}=3) /$ level two (c) $35-\mathrm{L}-1(\mathrm{R}=2) /$ level three (d) $35-\mathrm{L}-1(\mathrm{R}=3) /$ level four

The design seismic base shear is highest for model $35-\mathrm{H}-1(\mathrm{R}=2)$ and is equal to $20 \mathrm{MN}$. $\mathrm{V}_{\mathrm{d}}$ decreases by a factor of $2 / 3$ for the second model $(35-\mathrm{H}-1, \mathrm{R}=3)$ due to the effect of $\mathrm{R}$ factor and is as low as $13 \mathrm{MN}$. In fact, selecting a response modification factor of $\mathrm{R}=3$ instead of $\mathrm{R}=2$ is equivalent to decreasing $\mathrm{V}_{\mathrm{d}}$ by a factor of $2 / 3$. The third model $(35-\mathrm{L}-1, \mathrm{R}=2)$ is designed for a very low design base shear of $\mathrm{V}_{\mathrm{d}}=4 \mathrm{MN}$.

In addition, it could be observed that although the seismicity has a significant effect on the overstrength factor, this effect is not considerable on the ductility factor of the models. 
Accordingly, the elevated water tanks are designed and analysed for four seismic levels as demonstrated in Table 6.4:

Table 6.4 Four levels of seismicity for designing RC pedestals

\begin{tabular}{|c|c|c|c|}
\hline $\begin{array}{c}\text { Level "one" } \\
\text { seismicity }\end{array}$ & $\begin{array}{c}\text { Level "two" } \\
\text { seismicity }\end{array}$ & $\begin{array}{c}\text { Level "three" } \\
\text { seismicity }\end{array}$ & $\begin{array}{c}\text { Level "four" } \\
\text { seismicity }\end{array}$ \\
\hline $\begin{array}{c}\mathrm{S}_{\mathrm{D}}=0.8 \\
\mathrm{~S}_{\mathrm{D} 1}=0.4\end{array}$ & $\begin{array}{c}\mathrm{S}_{\mathrm{DS}}=0.8 \times 2 / 3=0.53 \\
\mathrm{~S}_{\mathrm{D} 1}=0.4 \times 2 / 3=0.26\end{array}$ & $\begin{array}{c}\mathrm{S}_{\mathrm{DS}}=0.2 \\
\mathrm{~S}_{\mathrm{D} 1}=0.1\end{array}$ & $\begin{array}{c}\mathrm{S}_{\mathrm{DS}}=0.2 \times 2 / 3=0.13 \\
\mathrm{~S}_{\mathrm{D} 1}=0.1 \times 2 / 3=0.06\end{array}$ \\
\hline $\begin{array}{c}\text { FE model designed } \\
\text { for "high" seismic } \\
\text { region and R=2 }\end{array}$ & $\begin{array}{c}\text { FE model designed } \\
\text { for "high" seismic } \\
\text { region and R=3 }\end{array}$ & $\begin{array}{c}\text { FE model designed } \\
\text { for "low" seismic } \\
\text { region and R=2 }\end{array}$ & $\begin{array}{c}\text { FE model designed } \\
\text { for "low" seismic } \\
\text { region and R=3 }\end{array}$ \\
\hline $\begin{array}{c}\text { seismic design } \\
\text { category "D" }\end{array}$ & $\begin{array}{c}\text { seismic design } \\
\text { category "D" }\end{array}$ & $\begin{array}{c}\text { seismic design } \\
\text { category "C" }\end{array}$ & $\begin{array}{c}\text { seismic design } \\
\text { category "A" }\end{array}$ \\
\hline
\end{tabular}

Level one represents the highest and level four is the lowest seismicity which are employed for the seismic design of elevated water tanks in this research. Figure 6.11 demonstrates overstrength factor for the four seismic levels.
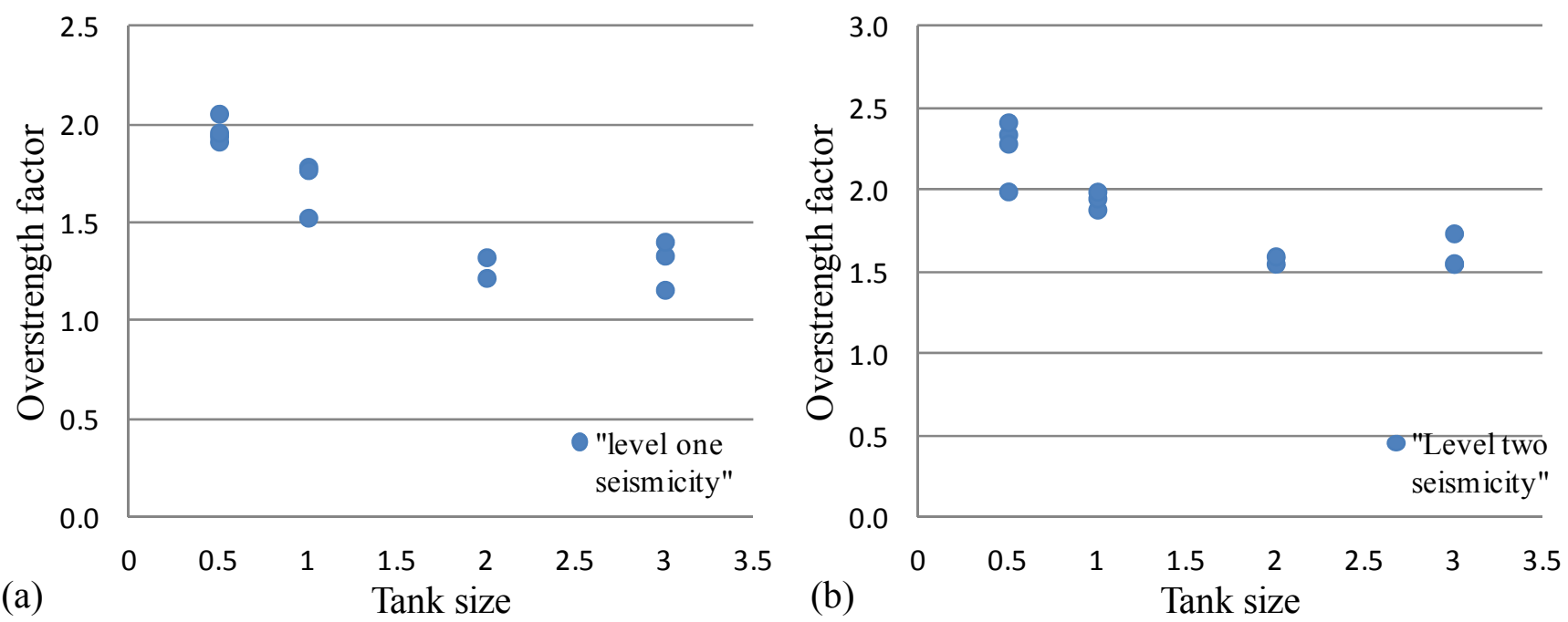

Figure 6.11 Overstrength factor (a) level one seismicity (b) level two seismicity (c) level three seismicity (d) level four seismicity 

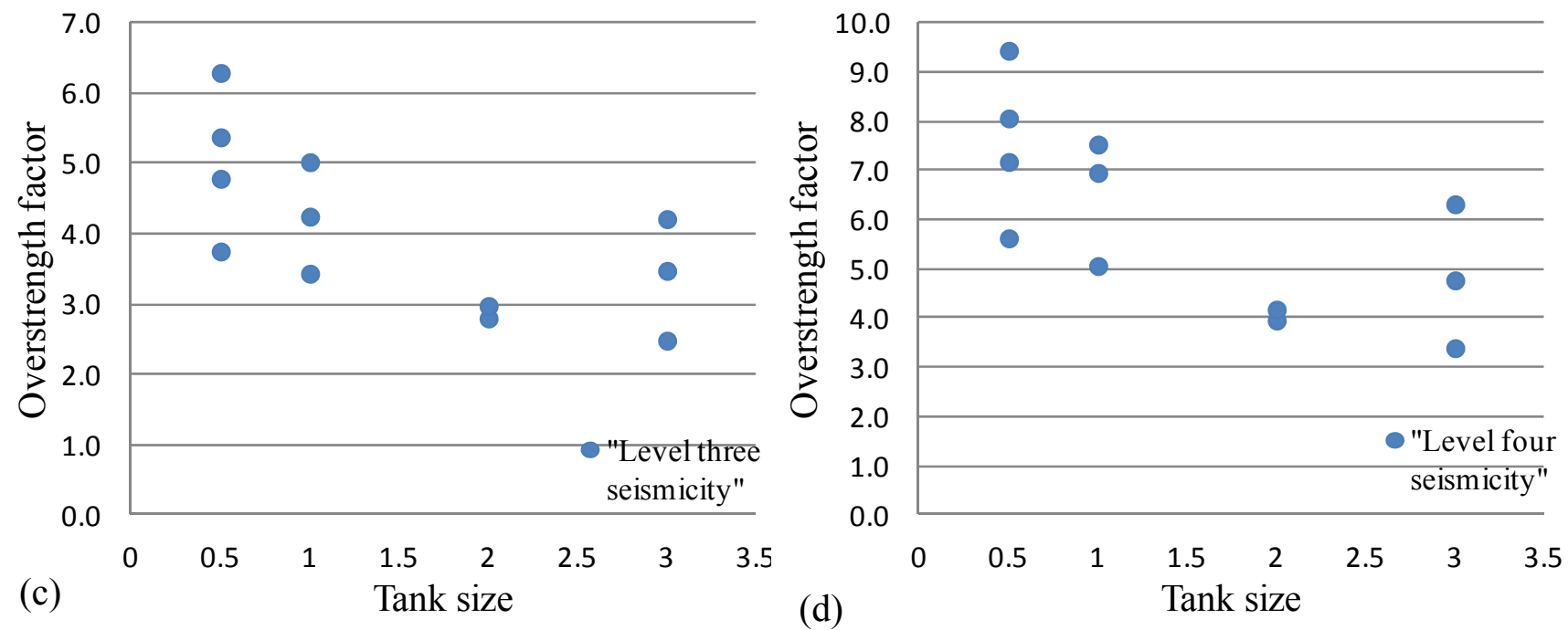

Figure 6.11 (Cont.)

Figure 6.11 indicates that overstrength factors of low seismicity group (level four) are considerably higher than the high seismicity models (level one). In the low seismicity group models, the gravity load is governing the design and the models are mainly designed for the minimum reinforcement.

In addition, for all four levels of seismicity, 0.5 mega gallon elevated water tanks are giving the highest value of overstrength independent of the height of RC pedestal. According to Figure 6.11, as discussed before, by increasing the tank size, overstrength factor gradually decreases. However, increasing the tank size from $2 \mathrm{MG}$ to $3 \mathrm{MG}$ does not appear to have a considerable effect on the overstrength factor.

This pattern suggests dividing the elevated water tanks into three categories based on the size of the tank. Table 6.5 illustrates these three categories of light, medium and heavy size tanks. Figure 6.12 displays the ductility factor versus tank size for the four seismicity levels. It could be observed that the range of variation of ductility factor is not as wide as overstrength factor. 
Table 6.5 Categories of tanks based on tank size

\begin{tabular}{cc}
\hline Tank size (mega gallon) & Tank size category \\
\hline Tank size $\leq 0.5$ & Light \\
\hline $0.5<$ Tank size $<1.5$ & Medium \\
\hline $1.5 \leq$ Tank size & Heavy \\
\hline
\end{tabular}

Moreover, in an opposite trend in comparison to overstrength factor, the ductility factor is increasing as the tank size goes up. However, for the models designed for high seismicity region, the ductility factor is not very sensitive to the changes in the tank size as shown in Figure 6.12(a) and Figure 6.12(b).

Other than the 0.5 mega gallon tank, the other tank sizes are providing nearly the same ductility factor. It could also be concluded that unlike overstrength factor, seismicity does not have a significant influence on ductility factor.
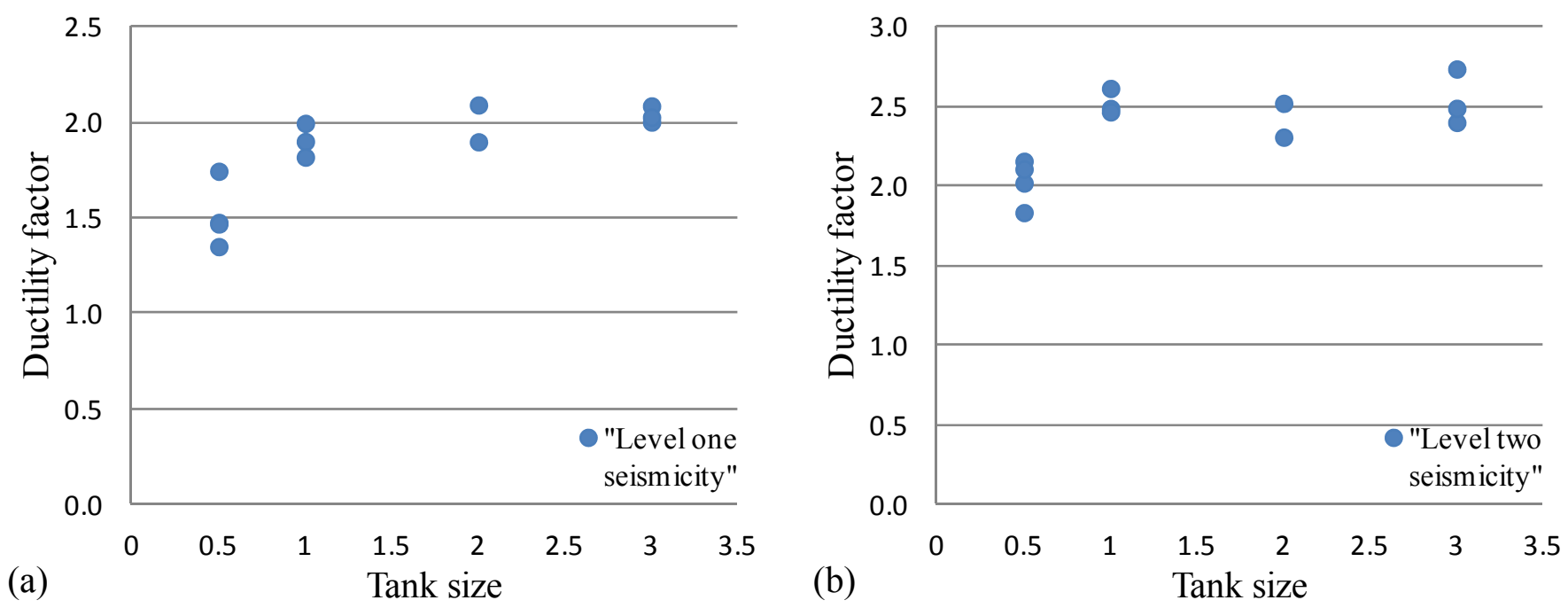

Figure 6.12 Ductility factor (a) level one seismicity (b) level two seismicity (c) level three seismicity (d) level four seismicity 

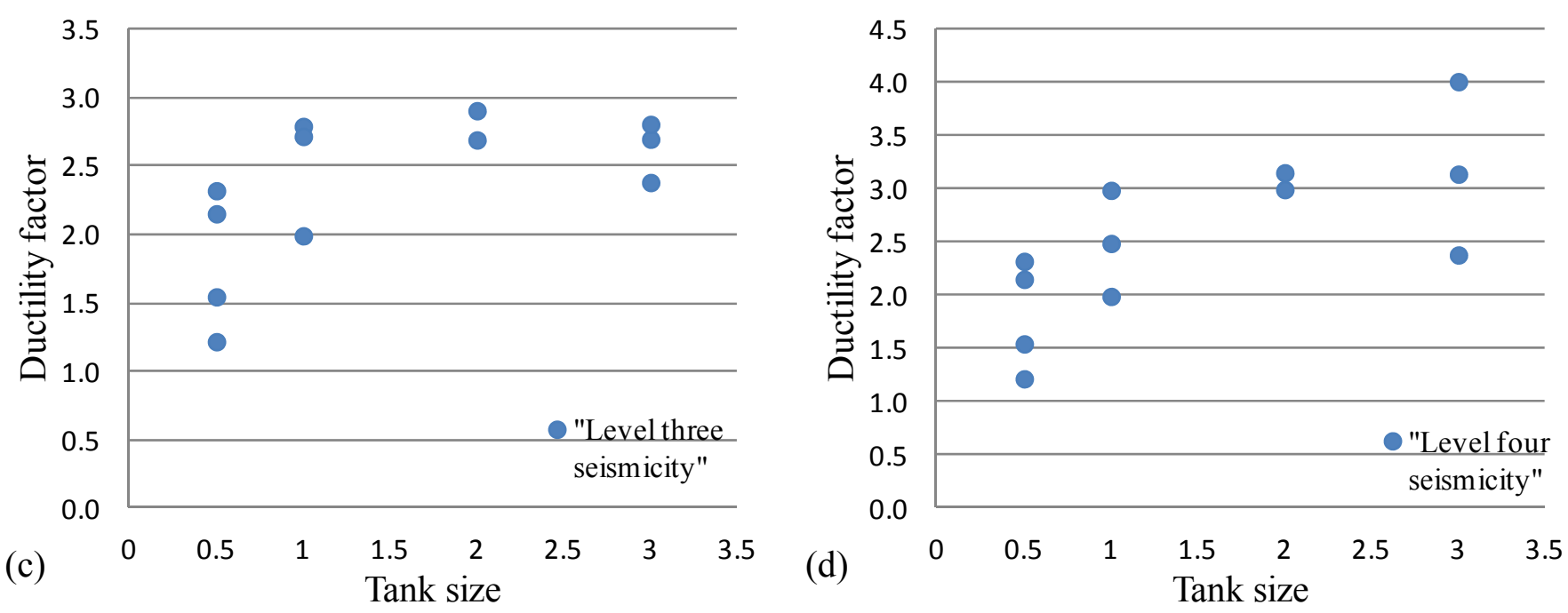

Figure 6.12 (Cont.)

\subsection{Establishing seismic response factors for RC pedestals}

In this section, by employing the graphs presented in Figures 6.11 and 6.12 combined with the tank size classification of Table 6.5 and seismic levels provided in Table 6.4, the seismic response modification factors will be established.

Table 6.6 demonstrates overstrength factor for three categories of tank sizes under the defined levels of seismicity. The overstrength factor ranges between 1.3 (heavy tanks located in high seismicity regions) to 7 (light tanks located in low seismicity regions).

Table 6.6 Overstrength factor of RC pedestal

\begin{tabular}{|c|c|c|c|c|c|}
\hline \multirow{2}{*}{\multicolumn{2}{|c|}{$\begin{array}{l}\text { Overstrength } \\
\text { factor }\end{array}$}} & \multicolumn{4}{|c|}{ Seismicity level } \\
\hline & & \multirow{2}{*}{$\begin{array}{c}\begin{array}{c}\text { Level } \\
\text { "one" } \\
\text { seismicity }\end{array} \\
2\end{array}$} & \multirow{2}{*}{$\begin{array}{c}\begin{array}{c}\text { Level } \\
\text { "two" } \\
\text { seismicity }\end{array} \\
2.3\end{array}$} & \multirow{2}{*}{$\begin{array}{c}\begin{array}{c}\text { Level } \\
\text { "three" } \\
\text { seismicity }\end{array} \\
4.5\end{array}$} & \multirow{2}{*}{$\begin{array}{c}\begin{array}{c}\text { Level } \\
\text { "four" } \\
\text { seismicity }\end{array} \\
7\end{array}$} \\
\hline \multirow{3}{*}{$\begin{array}{c}\text { Tank } \\
\text { size }\end{array}$} & Light & & & & \\
\hline & Medium & 1.6 & 1.8 & 4 & 6 \\
\hline & Heavy & 1.3 & 1.5 & 3 & 4 \\
\hline
\end{tabular}


In cases where the overstrength factor of a specific group is more scattered, a simple averaging method is employed. According to Table 6.6, medium and heavy tank sizes structures located in high seismicity zone are exhibiting an overstrength factor of below the coderecommended (ASCE/SEI 7-2010) value of "2". Ductility factor values are calculated with the same approach and are demonstrated in Table 6.7.

Table 6.7 Ductility factor of RC pedestal

\begin{tabular}{|c|c|c|c|c|c|}
\hline \multirow{2}{*}{\multicolumn{2}{|c|}{$\begin{array}{l}\text { Ductility } \\
\text { factor }\end{array}$}} & \multicolumn{4}{|c|}{ Seismicity level } \\
\hline & & \multirow{2}{*}{$\begin{array}{c}\begin{array}{c}\text { Level } \\
\text { "one" } \\
\text { seismicity }\end{array} \\
1.5\end{array}$} & \multirow{2}{*}{$\begin{array}{c}\begin{array}{c}\text { Level } \\
\text { "two" } \\
\text { seismicity }\end{array} \\
2 \\
\end{array}$} & \multirow{2}{*}{$\begin{array}{c}\begin{array}{c}\text { Level } \\
\text { "three" } \\
\text { seismicity }\end{array} \\
1.6 \\
\end{array}$} & \multirow{2}{*}{$\begin{array}{c}\begin{array}{c}\text { Level } \\
\text { "four" } \\
\text { seismicity }\end{array} \\
1.6\end{array}$} \\
\hline \multirow{3}{*}{$\begin{array}{l}\text { Tank } \\
\text { size }\end{array}$} & Light & & & & \\
\hline & Medium & 1.8 & 2.5 & 2.5 & 2.5 \\
\hline & Heavy & 2 & 2.5 & 2.5 & 3 \\
\hline
\end{tabular}

As discussed before the range of variation of ductility factor is not wide and it is fluctuating between 1.5 (lightest tank in highest seismicity zone) to 3 (heaviest tank in lowest seismicity zone). For all four categories of seismicity, the ductility factor increases as the tank size goes up.

\subsection{Proposed value of response modification factor}

The response modification factor is calculated at this stage by implementing Equation 6.9 as discussed before. The response modification factor is the product of overstrength factor, ductility factor and redundancy factor and is demonstrated in Table 6.7.

The lowest calculated $\mathrm{R}$ factor belongs to the heavy group of tanks located in areas with high seismicity and is equal to 1.8 . This value is less than the recommended values of 2 and 3 by 
ASCE/SEI 7-2010. In addition, the maximum calculated value of $\mathrm{R}$ factor for the tanks located in high seismicity region is approximately 2.

On the other hand, higher value compared to recommendations of ASCE/SEI 7-2010 is found for all tank sizes located in low seismicity regions.

Table 6.8 Draft values of response modification factor of RC pedestal

\begin{tabular}{|c|c|c|c|c|c|}
\hline \multirow{2}{*}{\multicolumn{2}{|c|}{$\begin{array}{l}\text { Response } \\
\text { modification } \\
\text { factor }\end{array}$}} & \multicolumn{4}{|c|}{ Seismicity level } \\
\hline & & \multirow{2}{*}{$\begin{array}{c}\begin{array}{c}\text { Level } \\
\text { "one" } \\
\text { seismicity }\end{array} \\
2.1\end{array}$} & \multirow{2}{*}{$\begin{array}{c}\begin{array}{c}\text { Level } \\
\text { "two" } \\
\text { seismicity }\end{array} \\
3.2\end{array}$} & \multirow{2}{*}{$\begin{array}{c}\begin{array}{c}\text { Level } \\
\text { "three" } \\
\text { seismicity }\end{array} \\
5\end{array}$} & \multirow{2}{*}{$\begin{array}{c}\begin{array}{c}\text { Level } \\
\text { "four" } \\
\text { seismicity }\end{array} \\
7.8\end{array}$} \\
\hline \multirow{3}{*}{$\begin{array}{c}\text { Tank } \\
\text { size }\end{array}$} & Light & & & & \\
\hline & Medium & 2 & 3.1 & 7 & 10.5 \\
\hline & Heavy & 1.8 & 2.6 & 5.2 & 8.4 \\
\hline
\end{tabular}

\subsection{Summary}

In this chapter, the results of pushover analysis from previous chapter were employed in order to establish the seismic response factors of elevated water tanks. The calculated seismic response factors were slightly different from the recommended values by current codes and standards such as ASCE/SEI 7-2010.

The pushover curves which were developed for 48 elevated water tanks in the previous chapters were raw and needed further processing. A mathematical technique known as "idealized bilinear approximation" was used to determine the critical points of the pushover curves. These critical points include maximum lateral displacement capacity $\left(\Delta_{\max }\right)$, maximum base shear $\left(\mathrm{V}_{\mathrm{max}}\right)$, and effective yield displacement $\left(\Delta_{\mathrm{y}}\right)$. 
The effective yield displacement was found by implementing a relationship proposed by FEMA P695 combined with energy and equivalent elasto-plastic system methods. After constructing the bilinear curves, displacement ductility $(\mu)$ and overstrength factor $\left(\Omega_{0}\right)$, were extracted for each prototype.

Next, three approaches for estimating the ductility factor $\left(\mathrm{R}_{\mu}\right)$ were addressed and compared. These relationships are generally functions of ductility factor and fundamental period of structure. Ductility factor was calculated for all prototypes by employing the three methods and finally one of the most widely used and accepted relationships proposed Newmark and Hall (1982) was selected for further studying.

Subsequently, overstrength factor and ductility factor were calculated for the 48 prototypes. The effect of various parameters such as fundamental period, height to diameter ratio, seismic design category, and tank size on the seismic response factors of elevated water tanks was then studied.

The general pattern of the graphs showed that increasing the fundamental period resulted in higher overstrength factor and lowered ductility factor of elevated water tank. Nevertheless, no specific relationship could be found to relate the fundamental period and either of the seismic response factors.

The effect of height to diameter ratio $\left(\mathrm{h} / \mathrm{d}_{\mathrm{w}}\right)$ of $\mathrm{RC}$ pedestal on the seismic response factors was also investigated. The observed trend line in the graphs revealed that higher height to diameter ratio would result in higher overstrength factor. On the other hand, ductility factor decreased as the height to diameter ratio was increased. This pattern is similar to the effect of fundamental period. This could be explained by the fact that height to diameter ratio is related to fundamental period. Generally as $\mathrm{h} / \mathrm{d}_{\mathrm{w}}$ increases, fundamental period of the structure increases as 
well. It should be mentioned that the graphs of $h / d_{w}$ versus seismic response factors were scattered and no specific pattern or relationship could be found.

A more distinct pattern could be found by analysing the graphs of the tank size versus seismic response factors. It was shown that although the ductility factor increases as tank size goes up, yet the tank size does not have significant influence on the ductility factor of elevated water tanks. Furthermore, for each group of the tank sizes, the range of ductility factor is not very wide and scattered. It was also shown that as the tank size increases the overstrength factor declines.

The effect of seismicity on the seismic response factors was addressed in this chapter as well. The tanks were originally designed for four seismicity levels and the seismic response of the models was categorized under these four groups. Each seismicity group was characterized by $\mathrm{S}_{\mathrm{DS}}$ and $\mathrm{S}_{\mathrm{D} 1}$. Moreover, the models were also categorized into three groups according to the tank sizes. Subsequently, 12 values for each of the overstrength and ductility factor were developed based on "seismicity level" and "tank size".

The results of the study showed that the models which were designed for higher seismicity regions were exhibiting the lowest overstrength factor and therefore were most vulnerable to seismic excitations. According to this study, the overstrength factor of the elevated water tanks could be as low as 1.3 for the heavy tank sizes located in areas with high seismicity. This is well below the overstrength value of "2" recommended by the current codes. For all medium and heavy size tanks located in "level one" and "level two" seismicity regions, the overstrength factor is shown to be below " 2 ".

In addition, the seismicity zone appeared to have a minor effect on ductility factor. The ductility factor is the lowest for the light tank size group and highest for the heavy size tanks. 
Finally the draft values of response modification factor were established by implementing the relationship recommended by ATC 19 (1995). A redundancy factor of 0.71 was assumed in order to account for low redundancy of the pedestal structures.

The proposed R factor ranged from 1.8 to 3.2 for the prototypes located in level one and two seismicity. Furthermore, for the models in high seismicity zone the R factor decreases as the tank size increases. For the prototypes designed for low seismicity regions, medium size tanks are demonstrating the highest $\mathrm{R}$ factor.

It should be mentioned that the effect of the shaft opening is not considered in this study. This effect will be investigated in later chapters of the thesis. 


\section{Chapter 7 \\ Nonlinear time history analysis of RC elevated water tanks}

\subsection{General}

In this chapter the response modification factor of RC elevated water tanks will be evaluated and verified by employing a probabilistic method. According to this method, by performing several nonlinear time history analyses, the probability of collapse of RC pedestals is calculated under different seismic loading conditions and system uncertainties. The procedure of performing this analysis is adapted from FEMA P695 (2009).

At the beginning of the chapter, an overview of FEMA P695 methodology is provided and explained. Since this methodology was originally developed for the building structures, certain customizations are made for accommodating specific features of non-building structures. These customizations are addressed in this chapter. The "pilot group" of RC pedestals which was introduced in previous chapters will be employed for conducting the analysis.

Performing the nonlinear time history analysis and constructing the incremental dynamic analysis (IDA) curves requires several ground motion records which are selected according to certain criteria. These records are normalized and scaled up to carry out IDA and construct IDA curves. These selection criteria and scaling strategies are provided and introduced in this chapter.

In addition, the results of nonlinear time history analysis of $\mathrm{RC}$ pedestals, such as deformation and base shear and potential failure modes of RC pedestals will be presented and discussed in this chapter. These results are later employed for constructing the IDA curves. The effect of various parameters in the nonlinear dynamic response of $\mathrm{RC}$ pedestals is also addressed.

The chapter continues by establishing the collapse margin ration (CMR) for the prototypes. The IDA curves which are developed for the selected prototypes are implemented to determine 
the CMR. Two types of "full" and "partial" IDA analysis will be carried out for the purpose of determining CMR. Each of these types is discussed and results are evaluated. The CMR values are then adjusted by applying spectral shape factor (SSF) which will result in ACMR (adjusted collapse margin ratio).

According to the provisions of FEMA P695, four sources of uncertainties are included for developing the total structure collapse uncertainties. These sources are explained in this chapter briefly. Subsequently, by combining all the sources of uncertainty, the total collapse uncertainty values for all prototypes are determined.

Finally, the calculated ACMR values are verified against accepted values of ACMR corresponding to the intended total system uncertainty level. If the ACMR passes the requirements of accepted ACMR then the preliminary R factor used for the seismic design of the $\mathrm{RC}$ pedestal is accepted. Otherwise, the $\mathrm{R}$ factor should be revised.

\subsection{Overview of FEMA P695 methodology}

In 2009, FEMA published the report "quantification of building seismic performance factors" or "FEMA P695". This report was originally prepared by Applied Technology Council (ATC) under the ATC-63 project. It provides a methodology for determination and verification of seismic response factors of buildings.

According to FEMA P695, although the methodology was originally prepared for building structures, yet it is applicable to non-building structures. The methodology establishes the seismic factors based on the "life safety" performance objective. "The methodology achieves the primary life safety performance objective by requiring an acceptably low probability of collapse 
of the seismic-force-resisting system when subjected to Maximum Considered Earthquake (MCE) ground motions" (FEMA P695).

Therefore, it must be clarified that in case of the elevated water tanks, they will be verified against a very low probability of collapse. If other performance objectives are expected from these structures, then they must be verified against lower probability of collapse. In the following, the procedure of the methodology will be briefly described.

\subsubsection{Selecting and analysing models}

In order to determine and verify the seismic response factors of any seismic-force-resisting system, a number of models according to certain criteria should be constructed. These models as discussed in Chapter 5 are called prototypes (or archetypes according to FEMA P695) and must include all important structural features of the seismic-force-resisting system. These prototypes were developed in Chapter 5 and are used in this chapter for further analysis.

FEMA P695 employs both nonlinear static and nonlinear dynamic analysis for investigating the nonlinear seismic response of structures. The pushover analysis is applied in order to establish overstrength factor and draft values of $\mathrm{R}$ factor (Chapters 5 and 6).

Nonlinear dynamic analysis is implemented for performing incremental dynamic analysis (IDA) and determining collapse level ground motion $\left(\dot{\mathrm{S}}_{\mathrm{CT}}\right)$ which subsequently will be used to determine CMR (collapse margin ratio).

\subsubsection{Evaluating seismic performance}

Based on FEMA P695 definition, the collapse margin ratio (CMR), is the ratio of the median $5 \%$-damped spectral acceleration of the collapse level ground motion, $\dot{\mathrm{S}}_{\mathrm{CT}}$, to the $5 \%$-damped 
spectral acceleration of the MCE ground motions, $\mathrm{S}_{\mathrm{MT}}$, at the fundamental period of the structure. This ratio (CMR) must be established for all prototypes.

The concept of collapse margin ratio is depicted in Figure 7.1. The CMR values are determined by conducting incremental dynamic analysis (IDA).

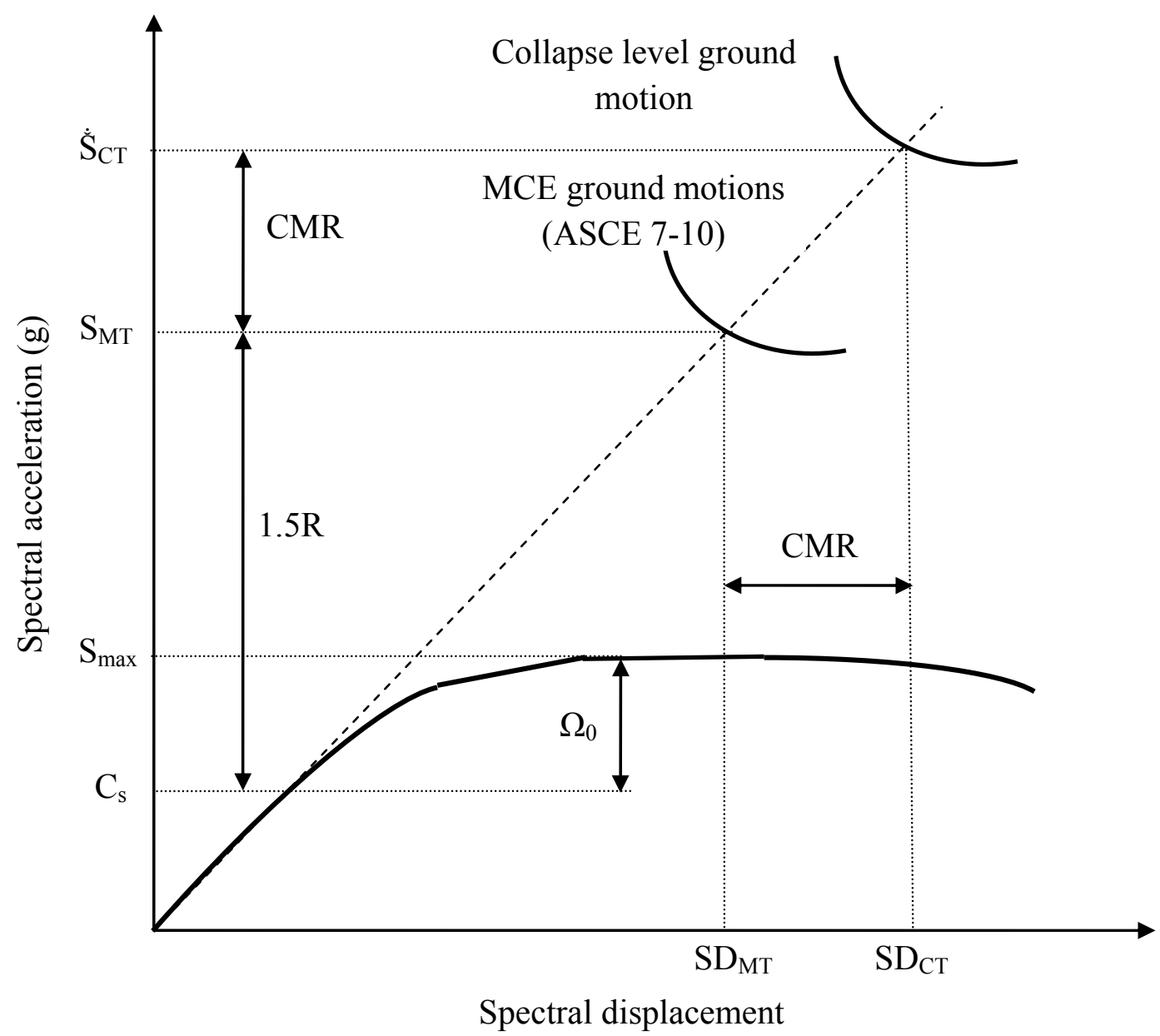

Figure 7.1 Collapse margin ratio (CMR) described in a typical pushover curve

In an IDA process, the ground motions are scaled to increasing intensities until the structure reaches a collapse point. Defining the collapse point depends on engineering judgment, type of structure and expected performance during and after extreme loading cycles. For many essential structures, the collapse point may be defined far before the global failure of the structure. 
After establishing CMR value, it should be adjusted for frequency content (spectral shape) properties of the ground motion record set. The adjusted collapse margin ratio, ACMR is the product of the spectral shape factor and CMR.

Next, the adjusted collapse margin ratio (ACMR) will be verified against the acceptable collapse probabilities of different percentages. If ACMR surpasses the recommended collapse probability ratio, then the seismic design is acceptable and the preliminary $\mathrm{R}$ factor is verified. However, if any of the prototypes fails to pass the requirements, then further investigation must be carried out and trial value for response modification factor should be revised.

Finally, by reviewing results of the analyses, the most appropriate value for the seismic response factors will be recommended. This process is demonstrated in Figure 7.2.

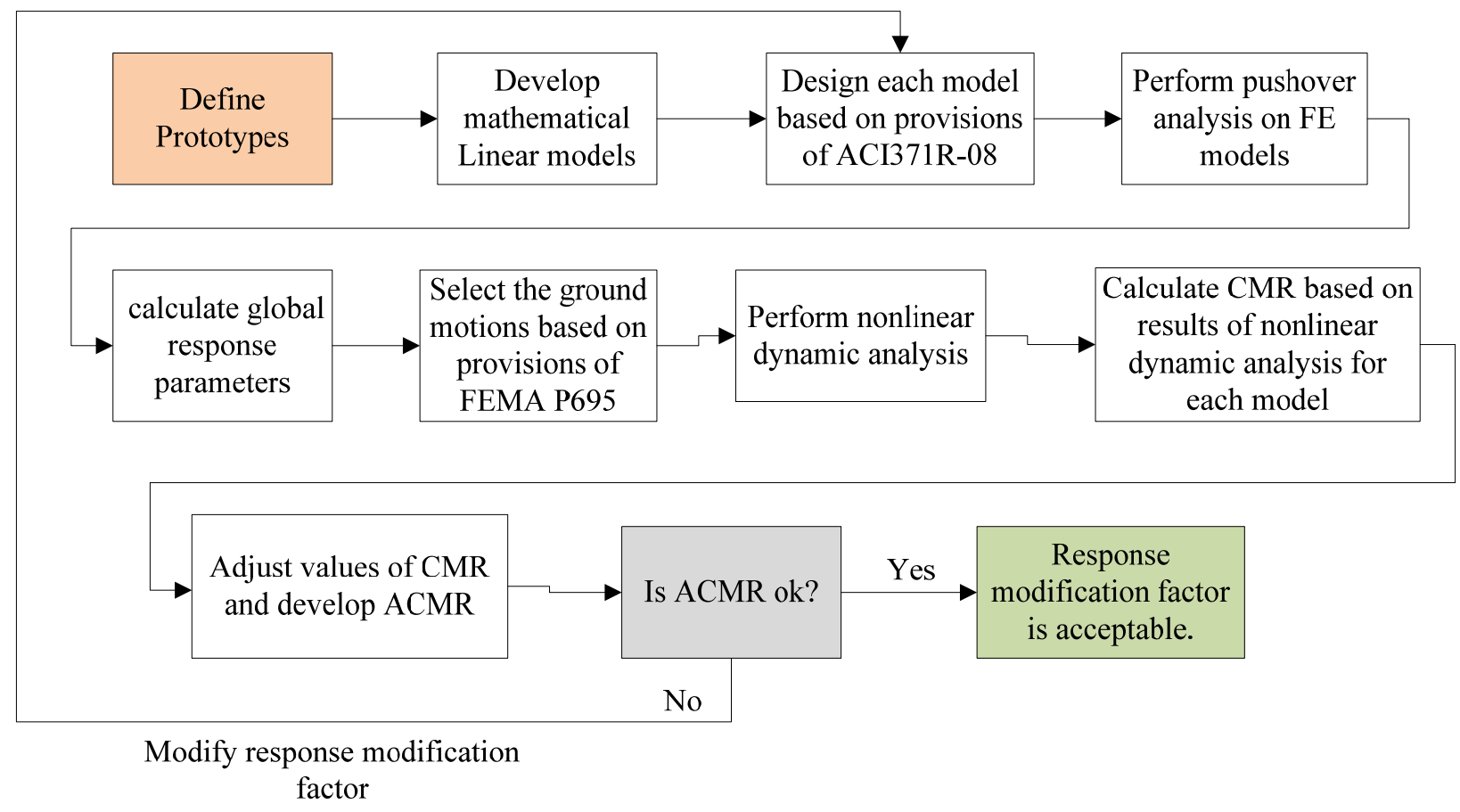

Figure 7.2 Flowchart of seismic evaluation of structures according to FEMA P695 


\subsection{Customizing FEMA P695 methodology for elevated water tanks}

As explained in above lines, the FEMA P695 methodology is conducted in two phases of static and dynamic nonlinear analysis. The first phase (pushover analysis) which aims to establish overstrength factor, displacement ductility and validating the behaviour of the nonlinear models was performed in Chapters 5 and 6 of this study.

Since FEMA P695 is originally developed for building structures, some modification and customizations were applied to accommodated specific characteristics of elevated water tanks (as non-building structures). One example of such customizations is that, According to FEMA P695, each earthquake record component must be applied in two perpendicular directions which due to the symmetrical configuration of the RC pedestals will become unnecessary.

As another example, ultimate roof drift displacement according to FEMA P695 is defined at the point where the structure has lost $20 \%$ of the base shear capacity (lateral stiffness). While this seems reasonable for building structures with capability of stress redistribution and considerable redundancy, it is not appropriate for RC pedestals which have very low level of redundancy. Therefore, the ultimate roof displacement is modified as the point where the stiffness reduction begins (or maximum base shear). Other modifications are explained in the following sections.

\subsection{Selecting prototypes}

Performing the nonlinear dynamic analysis is a highly time consuming task. Although initially 48 prototypes were defined for investigation, it is not practical to conduct the IDA analysis for all of them. This problem will be solved by selecting a number of prototypes that are best representing most properties and seismic response characteristics of the initially designed prototype group. 
This group was previously addressed in Chapter 5 as the "pilot group" which consists of five prototypes each designed for two seismic response factors of $\mathrm{R}=2$ and $\mathrm{R}=3$ (ten prototypes in total) as demonstrated in Table 7.1.

Table 7.1 Pilot group prototypes selected for IDA analysis

\begin{tabular}{ccccccc}
\hline $\begin{array}{c}\text { prototype } \\
\text { No. }\end{array}$ & $\begin{array}{c}\text { FE model } \\
\text { ID }\end{array}$ & $\mathrm{T}_{\mathrm{f}}(\mathrm{sec})$ & $\begin{array}{c}\text { Shaft } \\
\text { height } \\
(\mathrm{m})\end{array}$ & $\begin{array}{c}\mathrm{h}_{\mathrm{r}} \\
(\mathrm{mm})\end{array}$ & $\begin{array}{c}\mathrm{d}_{\mathrm{w}} \\
(\mathrm{m})\end{array}$ & $\begin{array}{c}\text { Tank } \\
\text { capacity } \\
\left(\mathrm{m}^{3}\right)\end{array}$ \\
\hline P-7 & $25-\mathrm{H}-0.5$ & 0.75 & 25 & 300 & 8.6 & 1900 \\
\hline P-9 & $25-\mathrm{H}-3$ & 0.47 & 25 & 400 & 20 & 11400 \\
\hline P-13 & $35-\mathrm{H}-0.5$ & 1.15 & 35 & 300 & 8.6 & 1900 \\
\hline P-14 & $35-\mathrm{H}-1$ & 0.90 & 35 & 350 & 12 & 3800 \\
\hline P-15 & $35-\mathrm{H}-3$ & 0.69 & 35 & 400 & 20 & 11400 \\
\hline
\end{tabular}

\subsection{Ground motion record sets}

The nonlinear dynamic analysis of the FE models is carried out with a number of earthquake records. FEMA P695 defines two sets of ground motions. The first set is "Far-Field" which consists of 22 earthquake record pairs (44 components in total) at sites located $10 \mathrm{~km}$ or greater from the rupture fault. The second set is "Near-Field" which consists of 28 earthquakes record pairs which occurred at sites located less than $10 \mathrm{~km}$ from the fault rupture.

FEMA P695 specifies that only the "Far-Field" record set is required for the purpose of collapse probability evaluation. The "Far-Field" record set includes large number of records selected from very strong ground motions. All the records were selected from the PEER NGA database (PEER, 2006a.).

Each earthquake record consists of two horizontal components of acceleration. All of the records are selected from strong motion events with a PGA of greater than $0.2 \mathrm{~g}$ and magnitudes larger than 6.5. Table 7.2 shows the Far-Field record set. The peak ground acceleration ranges 
between a minimum of $0.21 \mathrm{~g}$ (San Fernando, 1971, magnitude of 6.6) to a maximum of $0.82 \mathrm{~g}$ (Duzce, Turkey, 1999, magnitude of 7.1).

Table 7.2 Far-Field record set

\begin{tabular}{|c|c|c|c|c|c|c|c|}
\hline \multirow{2}{*}{$\begin{array}{l}\text { ID } \\
\text { No. }\end{array}$} & \multicolumn{7}{|c|}{ Far-Field Earthquake record set } \\
\hline & $\mathrm{M}$ & Year & Name & Component 1 & Component 2 & $\mathrm{PGA}_{\max }(\mathrm{g})$ & $\begin{array}{c}\mathrm{PGV}_{\text {max }} \\
(\mathrm{cm} / \mathrm{s})\end{array}$ \\
\hline 1 & 6.7 & 1994 & Northridge & NORTHR/MUL009 & NORTHR/MUL279 & 0.52 & 63 \\
\hline 2 & 6.7 & 1994 & Northridge & NORTHR/LOS000 & NORTHR/LOS270 & 0.48 & 45 \\
\hline 3 & 7.1 & 1999 & Duzce, Turkey & DUZCE/BOL000 & DUZCE/BOL090 & 0.82 & 62 \\
\hline 4 & 7.1 & 1999 & Hector Mine & HECTOR/HEC000 & HECTOR/HEC090 & 0.34 & 42 \\
\hline 5 & 6.5 & 1979 & Imperial & IMPVALL/H- & IMPVALL/H-DLT352 & 0.35 & 33 \\
\hline 6 & 6.5 & 1979 & Imperial & IMPVALL/H-E11140 & IMPVALL/H-E11230 & 0.38 & 42 \\
\hline 7 & 6.9 & 1995 & Kobe, Japan & KOBE/NIS000 & KOBE/NIS090 & 0.51 & 37 \\
\hline 8 & 6.9 & 1995 & Kobe, Japan & KOBE/SHI000 & KOBE/SHI090 & 0.24 & 38 \\
\hline 9 & 7.5 & 1999 & Kocaeli, & KOCAELI/DZC180 & KOCAELI/DZC270 & 0.36 & 59 \\
\hline 10 & 7.5 & 1999 & Kocaeli, & KOCAELI/ARC000 & KOCAELI/ARC090 & 0.22 & 40 \\
\hline 11 & 7.3 & 1992 & Landers & LANDERS/YER270 & LANDERS/YER360 & 0.24 & 52 \\
\hline 12 & 7.3 & 1992 & Landers & LANDERS/CLW-LN & LANDERS/CLW-TR & 0.42 & 42 \\
\hline 13 & 6.9 & 1989 & Loma Prieta & LOMAP/CAP000 & LOMAP/CAP090 & 0.53 & 35 \\
\hline 14 & 6.9 & 1989 & Loma Prieta & LOMAP/G03000 & LOMAP/G03090 & 0.56 & 45 \\
\hline 15 & 7.4 & 1990 & Manjil, Iran & MANJIL/ABBAR--L & MANJIL/ABBAR--T & 0.51 & 54 \\
\hline 16 & 6.5 & 1987 & Superstition & SUPERST/B-ICC000 & SUPERST/B-ICC090 & 0.36 & 46 \\
\hline 17 & 6.5 & 1987 & Superstition & SUPERST/B-POE270 & SUPERST/B-POE360 & 0.45 & 36 \\
\hline 18 & 7 & 1992 & Cape & CAPEMEND/RIO270 & CAPEMEND/RIO360 & 0.55 & 44 \\
\hline 19 & 7.6 & 1999 & Chi-Chi, & CHICHI/CHY101-E & CHICHI/CHY101-N & 0.44 & 115 \\
\hline 20 & 7.6 & 1999 & Chi-Chi, & CHICHI/TCU045-E & CHICHI/TCU045-N & 0.51 & 39 \\
\hline 21 & 6.6 & 1971 & San Fernando & SFERN/PEL090 & SFERN/PEL180 & 0.21 & 19 \\
\hline 22 & 6.5 & 1976 & Friuli, Italy & FRIULI/A-TMZ000 & FRIULI/A-TMZ270 & 0.35 & 31 \\
\hline
\end{tabular}

FEMA P695 also specifies that in order to avoid the event bias, only a maximum of two records from the strong earthquake is included in the Far-Field record set.

\subsubsection{Normalizing ground motion record sets}

According to FEMA P695 requirements, the record sets are scaled in two steps. In the first step, the records are normalized based on a specific procedure known as "Normalization of 
records". Each record is normalized with respect to its peak ground velocity. During this normalization procedure some records are scaled up while others may be scaled down.

The normalization procedure is required in order to balance the differences between the records. These differences are due to dissimilarity between earthquake characteristics such as magnitude, frequency content, PGA and PGV.

Table 7.3 displays the normalization factor for each record and corresponding normalized peak ground acceleration and velocity. This table also demonstrates the spectral acceleration corresponding to a fundamental period of $1 \mathrm{sec}$ for each component.

Table 7.3 Normalized Far-Field record set

\begin{tabular}{|c|c|c|c|c|c|c|}
\hline \multirow{3}{*}{ ID } & \multicolumn{3}{|c|}{ As-recorded parameters } & \multirow{3}{*}{$\begin{array}{l}\text { Normalization } \\
\text { Factor }\end{array}$} & \multirow{2}{*}{\multicolumn{2}{|c|}{ Normalized Motions }} \\
\hline & \multicolumn{2}{|c|}{$1 \mathrm{Sec}$. Spec. Accel $(\mathrm{g})$} & \multirow{2}{*}{$\begin{array}{l}\text { PGVPeer } \\
(\mathrm{cm} / \mathrm{sec})\end{array}$} & & & \\
\hline & Comp 1 & Comp 2 & & & $\begin{array}{c}\text { PGA } \\
\max (\mathrm{g})\end{array}$ & $\begin{array}{l}\text { PGV max } \\
(\mathrm{cm} / \mathrm{sec})\end{array}$ \\
\hline 1 & 1.02 & 0.94 & 57.2 & 0.65 & 0.34 & 41 \\
\hline 2 & 0.38 & 0.63 & 44.8 & 0.83 & 0.4 & 38 \\
\hline 3 & 0.72 & 1.16 & 59.2 & 0.63 & 0.52 & 39 \\
\hline 4 & 0.35 & 0.37 & 34.1 & 1.09 & 0.37 & 46 \\
\hline 5 & 0.26 & 0.48 & 28.4 & 1.31 & 0.46 & 43 \\
\hline 6 & 0.24 & 0.23 & 36.7 & 1.01 & 0.39 & 43 \\
\hline 7 & 0.31 & 0.29 & 36 & 1.03 & 0.53 & 39 \\
\hline 8 & 0.33 & 0.23 & 33.9 & 1.1 & 0.26 & 42 \\
\hline 9 & 0.43 & 0.61 & 54.1 & 0.69 & 0.25 & 41 \\
\hline 10 & 0.11 & 0.11 & 27.4 & 1.36 & 0.3 & 54 \\
\hline 11 & 0.5 & 0.33 & 37.7 & 0.99 & 0.24 & 51 \\
\hline 12 & 0.2 & 0.36 & 32.4 & 1.15 & 0.48 & 49 \\
\hline 13 & 0.46 & 0.28 & 34.2 & 1.09 & 0.58 & 38 \\
\hline 14 & 0.27 & 0.38 & 42.3 & 0.88 & 0.49 & 39 \\
\hline 15 & 0.35 & 0.54 & 47.3 & 0.79 & 0.4 & 43 \\
\hline 16 & 0.31 & 0.25 & 42.8 & 0.87 & 0.31 & 40 \\
\hline 17 & 0.33 & 0.34 & 31.7 & 1.17 & 0.53 & 42 \\
\hline 18 & 0.54 & 0.39 & 45.4 & 0.82 & 0.45 & 36 \\
\hline 19 & 0.49 & 0.95 & 90.7 & 0.41 & 0.18 & 47 \\
\hline 20 & 0.3 & 0.43 & 38.8 & 0.96 & 0.49 & 38 \\
\hline 21 & 0.25 & 0.15 & 17.8 & 2.1 & 0.44 & 40 \\
\hline 22 & 0.25 & 0.3 & 25.9 & 1.44 & 0.5 & 44 \\
\hline
\end{tabular}


In the second step, which is a part of IDA analysis, the normalized records are collectively scaled up (increased intensity) until half of the records (24 components overall) cause the structure to reach the collapse point. This level is called the median collapse intensity or $\dot{\mathrm{S}}_{\mathrm{CT}}$.

\subsubsection{Selecting record sets for performing "full IDA" analysis}

An IDA analysis is performed in order to achieve two main objectives. The first goal is to construct the IDA curves for investigating the nonlinear response behaviour of the structure. This objective requires performing a "Full IDA Analysis".

In a full IDA analysis, the structure is subjected to ground motion records with increasing intensity up to the failure point. The analysis may begin by applying the normalized record set and then increasing the intensity in small steps. This procedure will provide a broad range of nonlinear responses of structure to various earthquakes with different magnitude and characteristics. The resulting IDA curves can reveal valuable information for investigation of the possible maximum and minimum responses of the structure under the investigation.

However, the abovementioned procedure is not necessarily required for establishing the median collapse intensity $\dot{\mathrm{S}}_{\mathrm{CT}}$ which is the second objective of performing the IDA. Determining $\dot{\mathrm{S}}_{\mathrm{CT}}$, demands much less calculation and analysis effort to be accomplished. According to the definition provided by FEMA P695, "the lowest intensity at which one-half of the records cause collapse is the median collapse intensity or $\dot{\mathrm{S}}_{\mathrm{CT}}$ ". Therefore, in order to calculate $\dot{\mathrm{S}}_{\mathrm{CT}}$, much less nonlinear dynamic analysis should be carried out compared to a full IDA analysis.

In this research a rather similar strategy is employed. As it was not practical to perform the full IDA on all FE models, a group of five earthquake records were selected from the Far-Field record set. These five records are employed for conducting the full IDA. The resulting IDA 
curves were used to establish the approximate median collapse intensity (芜T). Subsequently, this approximate intensity was used as a guide for conducting "partial IDA" using the other remaining 39 records.

The term "partial IDA" is introduced here as opposed to "full IDA". The term "partial IDA" is defined as performing an IDA which starts at ground motion intensities slightly lower than the approximate collapse intensity instead of beginning with normalized record.

The remaining 39 records were first scaled up to a range between MCE intensity and the

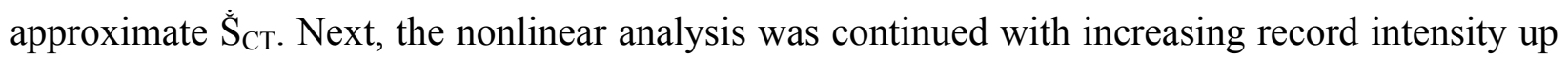
to the point where half of the records (22 in total) induced collapse in the FE models of RC pedestal structures.

This approach will reduce the computational time and effort significantly. In addition, the approximate median collapse intensity $\left(\dot{\mathrm{S}}_{\mathrm{CT}}\right)$ was proved to be a reliable representative of the actual finalized $\dot{\mathrm{S}}_{\text {Ст. }}$ This is mainly due to the selection method of these five ground motion records which are demonstrated in Table 7.4.

Table 7.4 Group of five ground motion records employed for the full IDA

\begin{tabular}{|c|c|c|c|c|c|c|c|c|c|}
\hline \multirow{2}{*}{$\begin{array}{l}\text { ID } \\
\text { No. }\end{array}$} & \multicolumn{4}{|c|}{ Earthquake record } & \multirow{2}{*}{$\begin{array}{c}\text { PGA }_{\text {max }} \\
\text { (g) }\end{array}$} & \multirow{2}{*}{$\begin{array}{c}\mathrm{PGV}_{\max } \\
(\mathrm{cm} / \mathrm{s})\end{array}$} & \multirow{2}{*}{$\begin{array}{c}1 \text { sec. } \\
\text { Spec. } \\
\text { Accel } \\
(\mathrm{g})\end{array}$} & \multicolumn{2}{|c|}{$\begin{array}{l}\text { Normalized } \\
\text { Motions }\end{array}$} \\
\hline & $\mathrm{M}$ & Year & Name & Component & & & & $\begin{array}{c}P^{P_{\text {max }}} \\
(\mathrm{g})\end{array}$ & $\begin{array}{c}P G V_{\text {max }} \\
(\mathrm{g})\end{array}$ \\
\hline 2 & 6.7 & 1994 & Northridge & NORTHR/LOS270 & 0.48 & 45 & 0.63 & 0.4 & 38 \\
\hline 3 & 7.1 & 1999 & $\begin{array}{l}\text { Duzce, } \\
\text { Turkey }\end{array}$ & DUZCE/BOL090 & 0.82 & 62 & 1.16 & 0.52 & 39 \\
\hline 11 & 7.3 & 1992 & Landers & LANDERS/YER270 & 0.24 & 52 & 0.5 & 0.24 & 51 \\
\hline 18 & 7 & 1992 & $\begin{array}{c}\text { Cape } \\
\text { Mendocino } \\
\end{array}$ & CAPEMEND/RIO360 & 0.55 & 44 & 0.39 & 0.45 & 36 \\
\hline 21 & 6.6 & 1971 & $\begin{array}{c}\text { San } \\
\text { Fernando }\end{array}$ & SFERN/PEL090 & 0.21 & 19 & 0.25 & 0.44 & 40 \\
\hline
\end{tabular}


These records are selected in a way to represent upper, lower and medium range ground motions of the Far-Field record set. The magnitude of the selected ground motion records ranges from 6.6 to 7.3. In addition, the peak ground accelerations are not only covering the extremes but also an average PGA such as $0.55 \mathrm{~g}$ (Cape Mendocino earthquake, 1992) is included as well. Figure 7.3 shows the five selected earthquake records employed to carry out the full IDA. The " 1 second" spectral acceleration also ranges between $0.25 \mathrm{~g}$ to $1.16 \mathrm{~g}$ which is basically including most practical spectral accelerations.
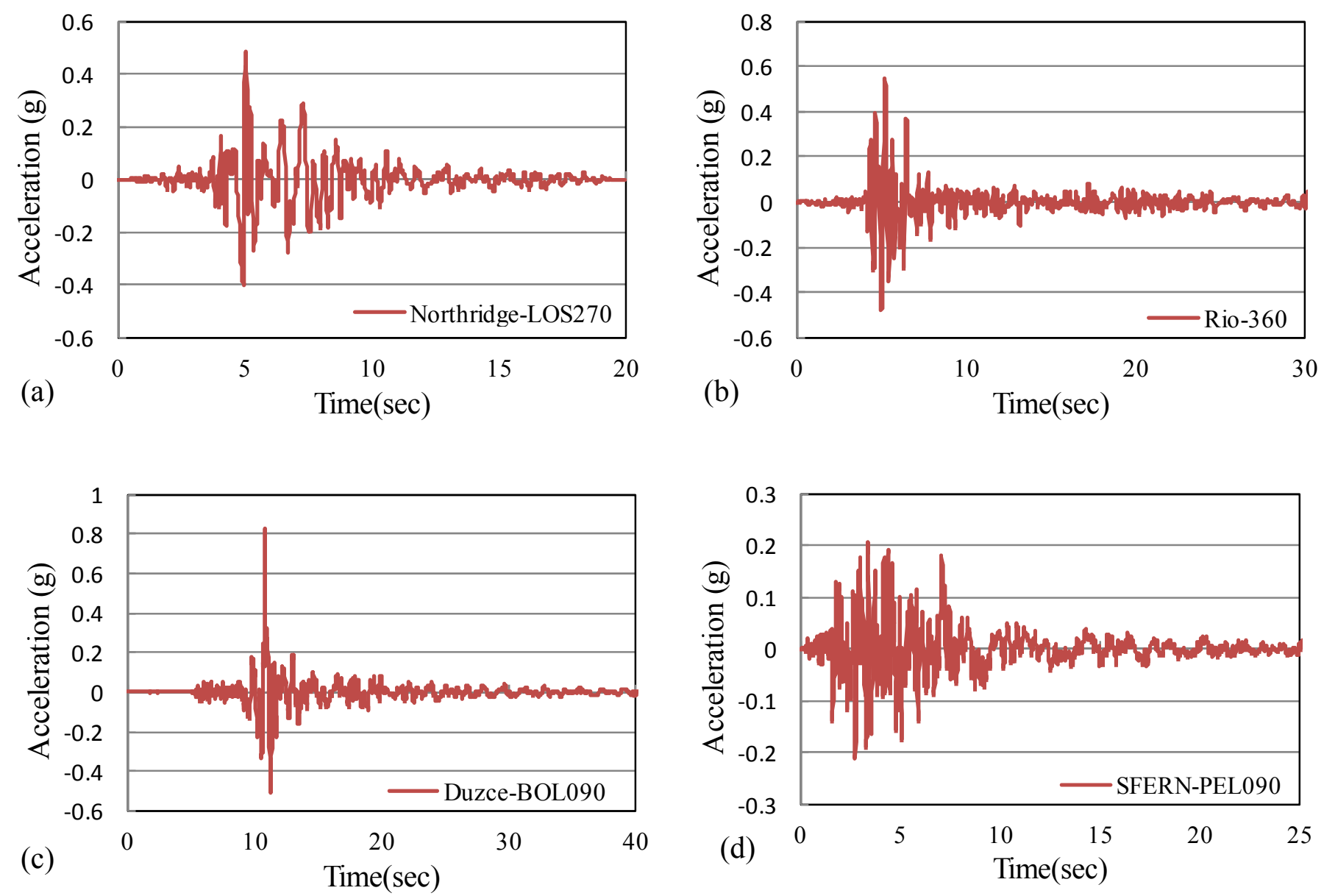

Figure 7.3 Ground motions record employed for full IDA study (a) Northridge(1994) (b) Cape Mendocino(1992) (c) Duzce, Turkey (1999) (d) San Fernando (1971) (e) Landers(1992) 


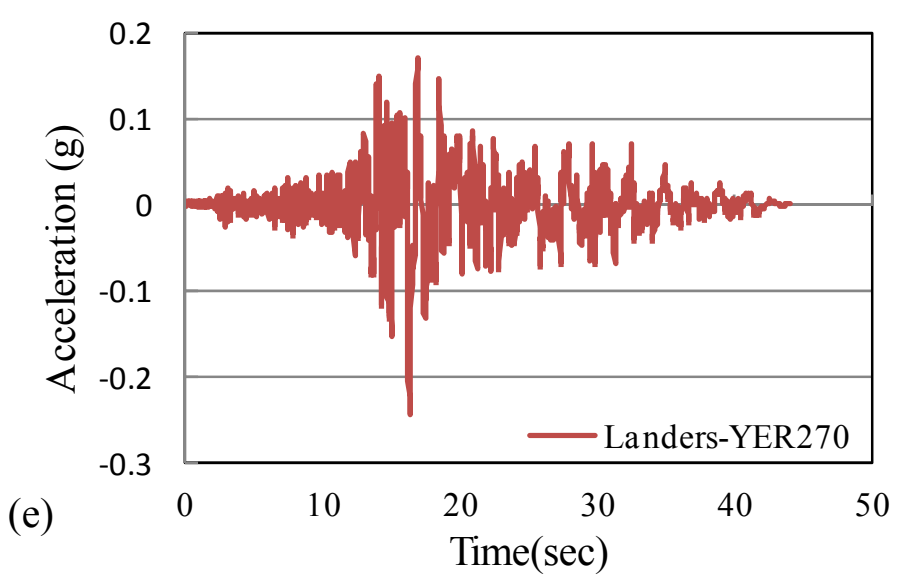

Figure 7.3 (Cont.)

Figure 7.4 depicts the response spectra for the 5 selected ground motions (spectral accelerations are not normalized). The "1 second spectral acceleration" is displayed as well.

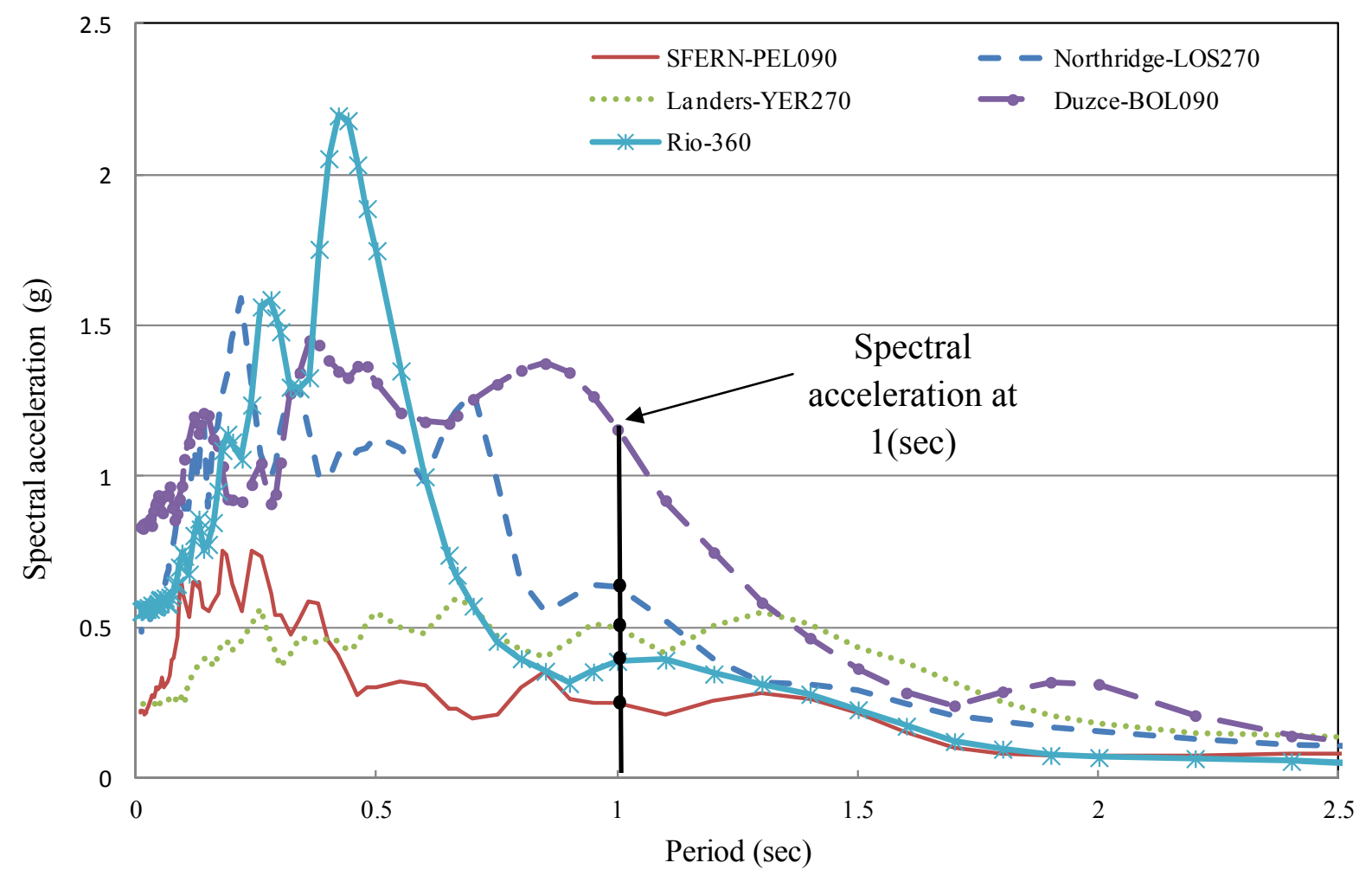

Figure 7.4 Acceleration response spectrum for Northridge(1994), Cape Mendocino(1992), Duzce, Turkey (1999), San Fernando (1971) and Landers(1992) earthquakes 


\subsection{Results of nonlinear time history analysis}

In this section the results of nonlinear dynamic analysis of the FE models of RC pedestals will be presented and discussed. The ground motion records which were shown in Table 7.4 are employed for conducting the analysis.

\subsubsection{Comparing responses of an $\mathrm{RC}$ pedestal subjected to different records}

One of the main purposes of employing several ground motion records rather than only a few, is to study all the possible response characteristics of structures subjected to various ground motions. This effect is reflected in Figure 7.5 for FE model 25-H-0.5.
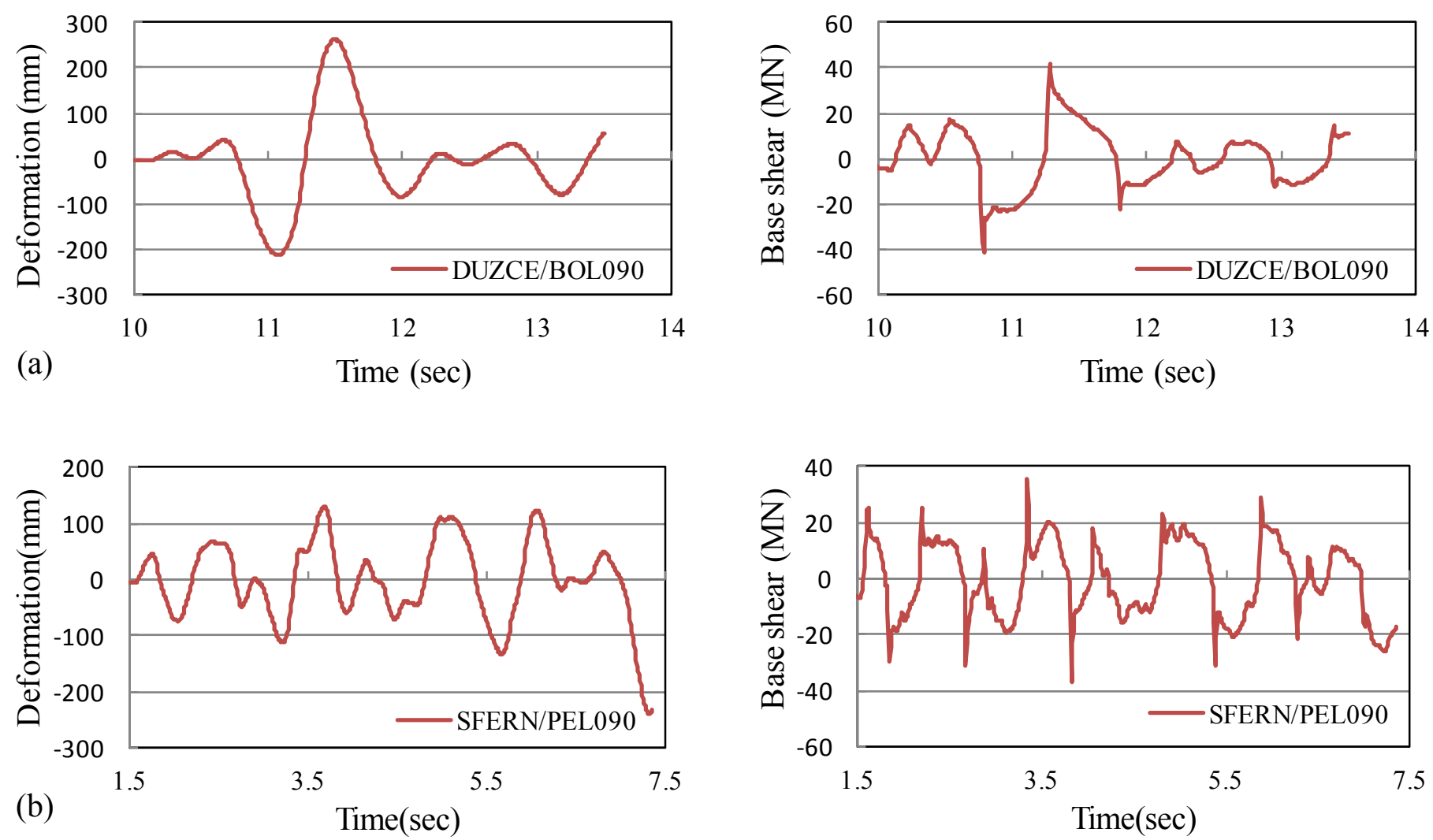

Figure 7.5 Nonlinear deformation (left) and base shear (right) response of FE model 25-H-0.5 subjected to (a) DUZCE/BOL090 (b) SFERN/PEL090 (c) NORTHR/LOS270 (d) CAPEMEND/RIO360 

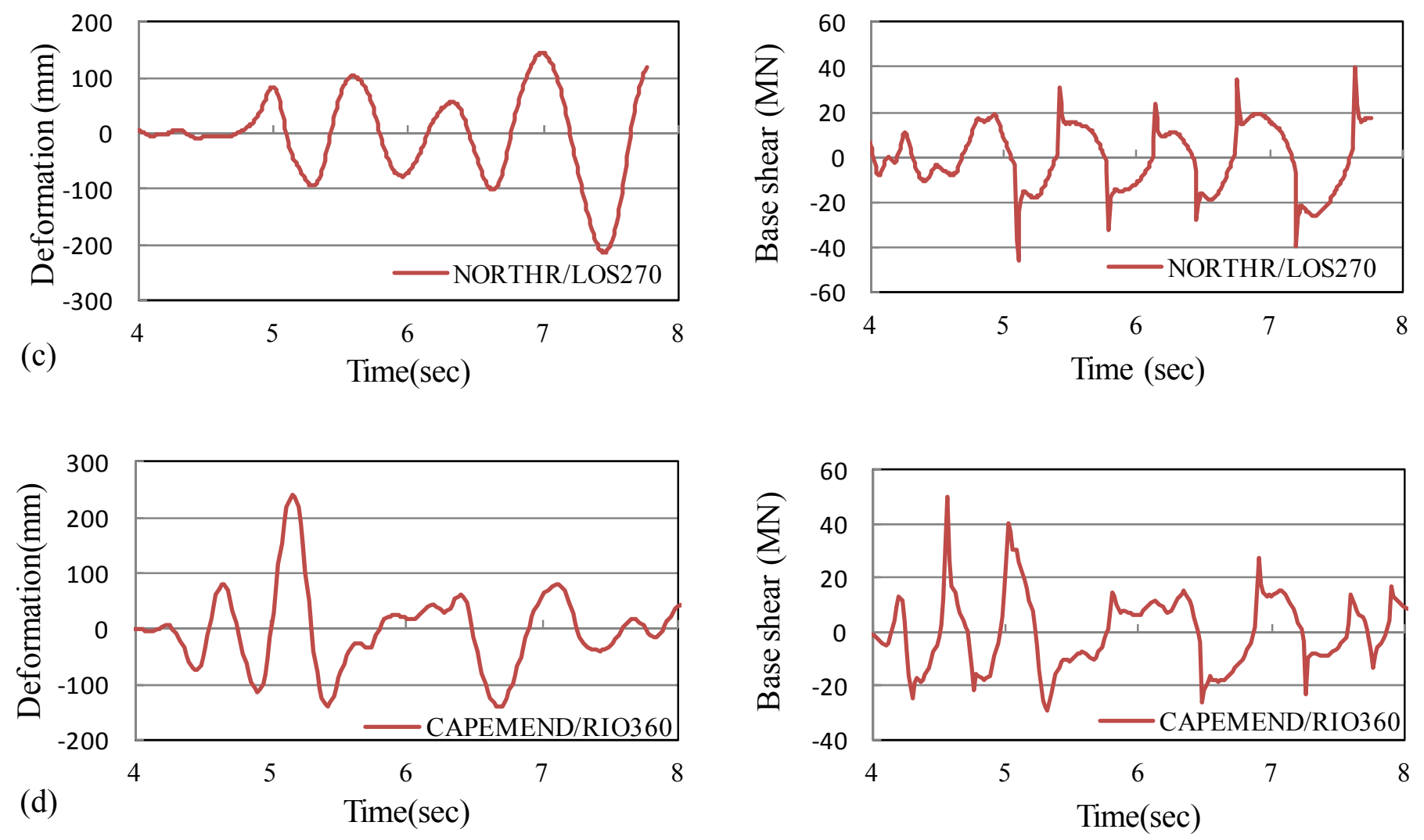

Figure 7.5 (Cont.)

This figure demonstrates nonlinear response of the the $25-\mathrm{H}-0.5$ finite element model subjected to four different ground motion records, each scaled to the level of slightly below collapse inducing ground motion. Both of the values of maximum lateral deflection and base shear response are given in Table 7.5.

It could be observed that the maximum base shear developed in the RC pedestal prior to failure varies depending on the ground motion record set. The maximum base shear prior to failure ranges from as low as $36 \mathrm{MN}$ for San Fernando (SFERN/PEL090) to $49 \mathrm{MN}$ for Cape Mendocino (CAPEMEND/RIO360). This is equal to approximately $25 \%$ difference between the $\mathrm{V}_{\max }$ developed in the RC pedestal prior to collapse. 
Table 7.5 Comparing the seismic response of FE model 25-H-0.5 to various ground motion records and pushover results

\begin{tabular}{cccccc}
\hline $\begin{array}{c}\text { Ground motion } \\
\text { record }\end{array}$ & Component & $\begin{array}{c}\text { Max. lateral } \\
\text { deflection(mm) }\end{array}$ & $\begin{array}{c}\text { Max. base } \\
\text { shear(MN) }\end{array}$ & $\begin{array}{c}\text { PGA as } \\
\text { recorded } \\
(\mathrm{g})\end{array}$ & $\begin{array}{c}\text { Scaled } \\
\text { PGA(g) }\end{array}$ \\
\hline Northridge & NORTHR/LOS270 & 214 & 46.5 & 0.48 & 1.4 \\
\hline Duzce, Turkey & DUZCE/BOL090 & 262 & 41 & 0.82 & 1.86 \\
\hline Cape Mendocino & CAPEMEND/RIO360 & 242 & 49 & 0.55 & 2.43 \\
\hline San Fernando & SFERN/PEL090 & 239 & 36 & 0.21 & 1.94 \\
\hline Pushover & - & 180 & 21.4 & - & 0.92 \\
\hline
\end{tabular}

In addition, maximum lateral deflection prior to failure fluctuates between $214 \mathrm{~mm}$ for Northridge earthquake record up to $262 \mathrm{~mm}$ for Duzce record which indicates nearly $18 \%$ difference.

Table 7.5 also shows scaled PGA values for each ground motion record. According to this table, the scaled PGAs range from $1.4 \mathrm{~g}$ (NORTHR/LOS270) to $2.43 \mathrm{~g}$ (Cape Mendocino). This variation is mainly related to the properties of each earthquake records including frequency content, PGV and PGD. It is for such reasons that several ground motion records are required in order to completely investigate and study the nonlinear seismic response behaviour of each RC pedestal.

Maximum lateral deflection and base shear from the pushover analysis is given in Table 7.5 for comparison as well. The maximum base shear calculated based on pushover analysis (21.4 $\mathrm{MN}$ ) is nearly half of the average base shear (43 MN) from the nonlinear dynamic analysis. In a similar pattern, the maximum lateral deflection prediction of pushover analysis $(180 \mathrm{~mm})$ is lower than the the average from nonlinear dynamic analysis $(240 \mathrm{~mm})$.

This trend is observed in all other FE models as well. One reason for this substantial difference is the damping factor which is not included in pushover analysis. Another important 
reason is the stress redistribution and energy absorption in the shaft wall which occurs during the nonlinear dynamic analysis.

\subsubsection{Response of similar height pedestals subjected to Cape Mendocino (1992) record}

In Chapter 6, the elevated water tanks were classified in accordance with the tank sizes in which three groups of light, medium and heavy elevated water tanks were defined. A comparison between the seismic responses of these groups is demonstrated in Figure 7.6.

Three FE models of $35-\mathrm{H}-0.5,35-\mathrm{H}-1$ and $35-\mathrm{H}-3$ are subjected to the Cape Mendocino record (component CAPEMEND/RIO360) and the deformation response of each FE model is shown in Figure 7.6. The ground motion record was scaled up by a factor of "3.2". The as recorded PGA of component CAPEMEND/RIO360 is $0.55 \mathrm{~g}$ which by applying the normalization and above scaling factor will rise to $1.45 \mathrm{~g}$.

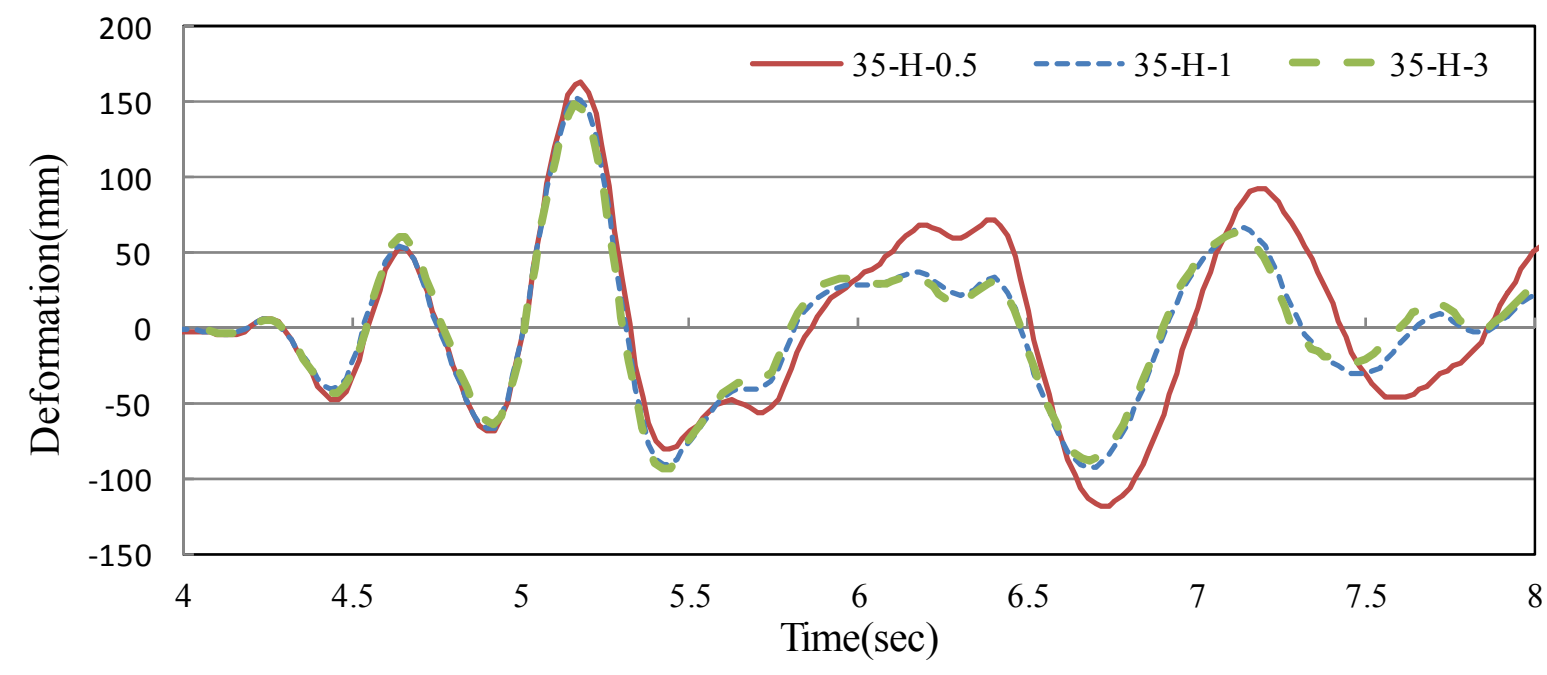

Figure 7.6 Comparing the maximum deformation response of three FE models of 35-H-0.5, 35- $\mathrm{H}-1$ and 35-H-3 to Cape Mendocino record 
Figure 7.6 shows that FE models $35-\mathrm{H}-1$ and $35-\mathrm{H}-3$ have nearly similar lateral deformation response. On the other hand, the lateral deformation response of FE model 35-H-0.5 is similar to the other two models at the beginning and deviates from them after 2 seconds.

The 5\% damping displacement spectrum of the Cape Mendocino record and locations of the fundamental period of each FE model on the spectrums are displayed in Figures 7.7

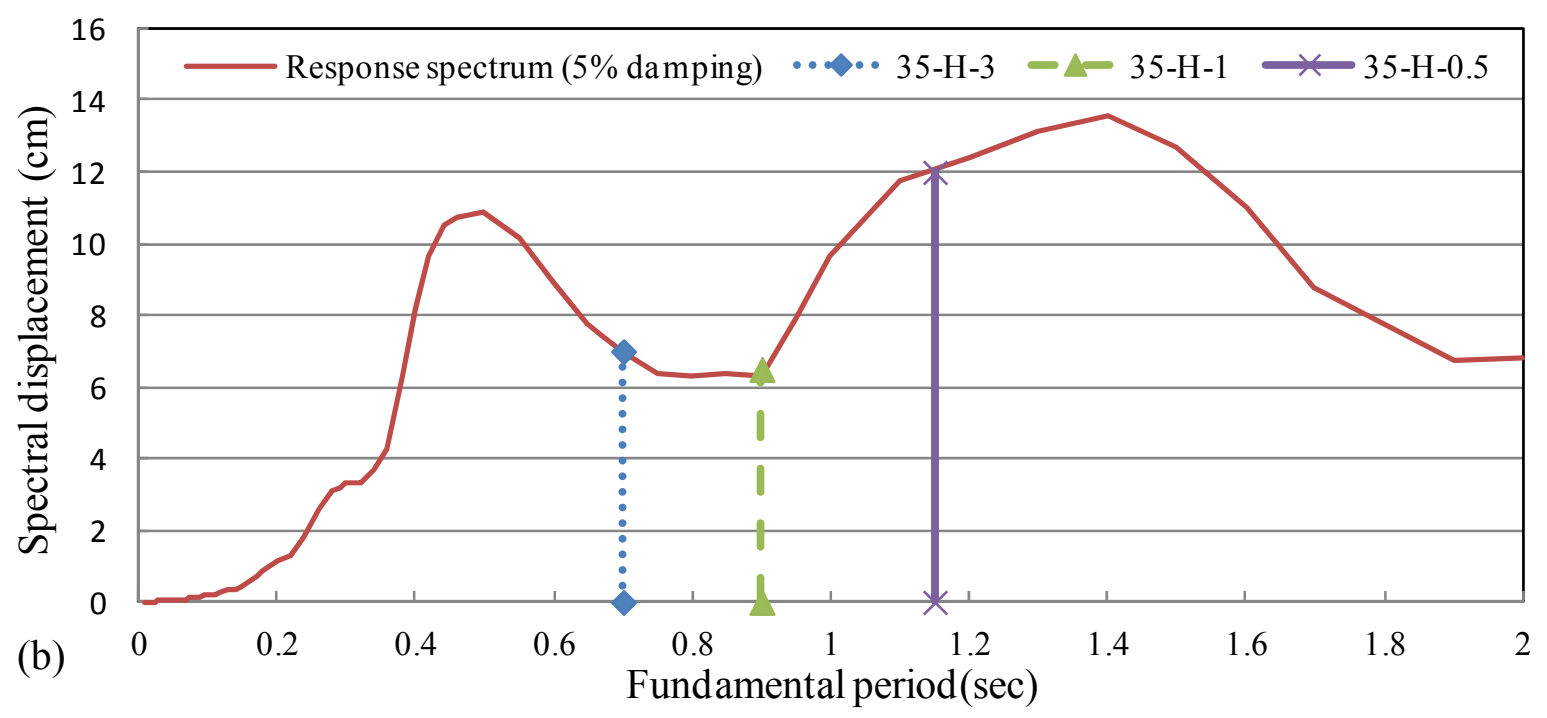

Figure 7.7 The as-recorded 5\% damping displacement spectrum for CAPEMEND/RIO360

\subsection{3 "Full IDA" results for FE model 25-H-3}

The results of a full IDA is presented and discussed in this section. In a typical full IDA, the FE model is initially subjected to a normalized ground motion. Figure $7.8($ a) demonstrates the normalized ground motion record of the Northridge earthquake as an example. The PGA of this record is $0.48 \mathrm{~g}$ which falls to $0.4 \mathrm{~g}$ after normalization.

The FE model 25-H-3 is subjected to this normalized ground motion record and the nonlinear responses including the lateral deformation and base shear are obtained as demonstrated in figures 7.8(b) and 7.8(c). The maximum deformation corresponding to the normalized record set 
is denoted by $D_{N}$. Next, the intensity of the record is increased by a factor of approximately 2 (this factor is arbitrary and depends on engineering judgment). The FE model will then be subjected to this scaled up record and the maximum lateral deformation is recorded as $\mathrm{D}_{2}$. The procedure will be continued until the point that the structure collapses. The collapse of the structure is defined as satisfying either of the following two conditions:
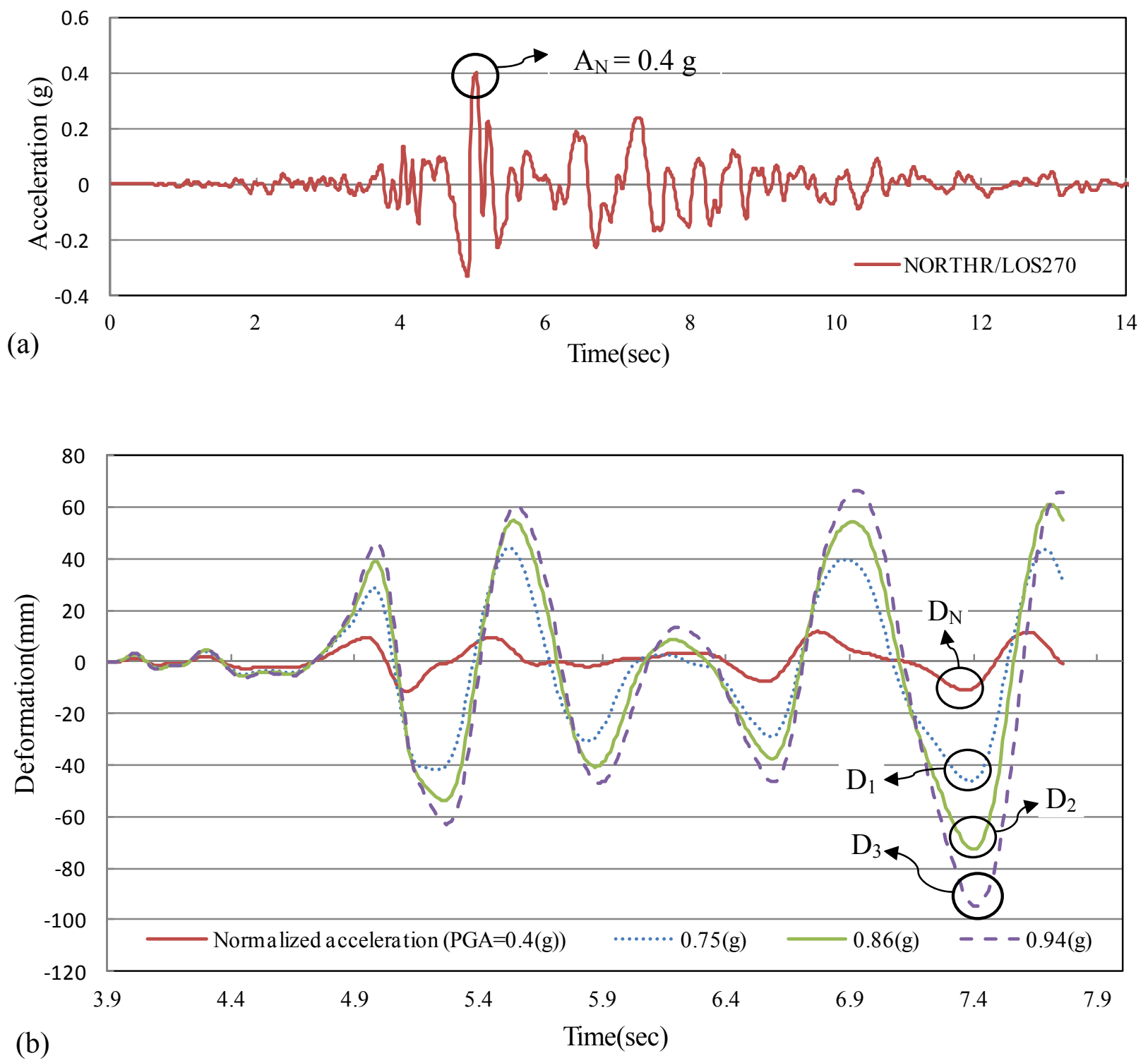

Figure 7.8 FE model 25-H-3 subjected to 4 stages of increasing spectral intensity of Northridge earthquake record (NORTHR/LOS270) (a) Normalized record

(b)Maximum lateral deformation of RC pedestal (c) Maximum base shear of RC pedestal 


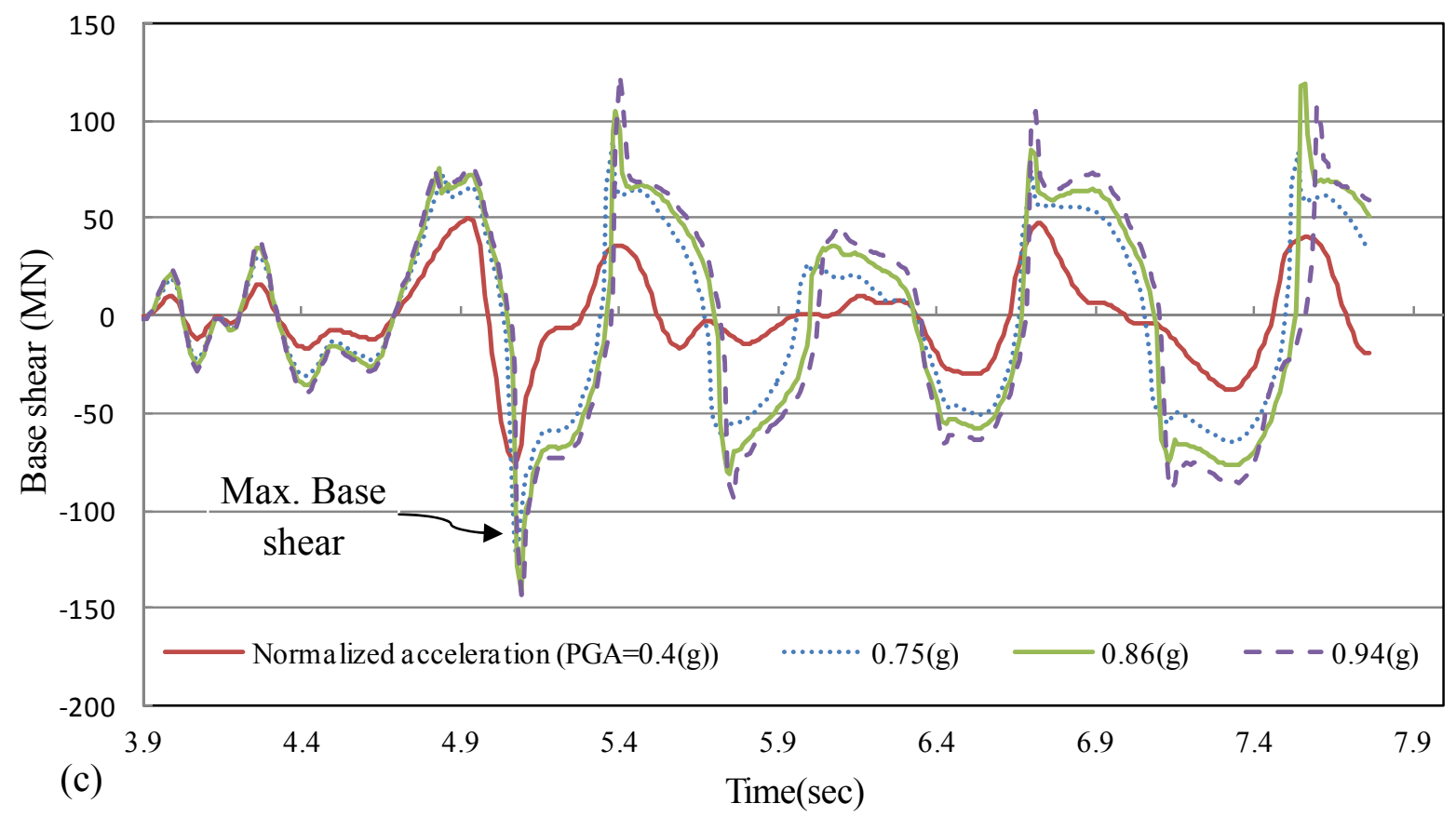

Figure 7.8 (Cont.)

1- Scaling up the intensity of the ground motion record, results in no significant increase in the base shear.

2- By increasing ground motion intensity, the lateral deformation increases unreasonably compared to the amount of increase in the intensity. This is usually also confirmed by large amount of total mechanical strain (combined elastic and plastic strain) on many locations of the shaft wall.

The results of IDA on FE model 25-H-3 including maximum deformation, maximum base shear and corresponding spectral acceleration (at each stage of scaling up the ground motion record) are demonstrated in Table 7.6. This table shows that the maximum base shear has practically stopped increasing between the last two steps which (as discussed above) is an indication of reaching the collapse point of the structure. 
Table 7.6 Maximum deformation and base shear of FE model 25-H-3 subjected to increasing intensity levels of Northridge earthquake

\begin{tabular}{ccccc}
\hline & PGA $(\mathrm{g})$ & $\mathrm{S}_{\mathrm{a}}(\mathrm{g})$ & Deformation $(\mathrm{mm})$ & Base shear $(\mathrm{MN})$ \\
\hline Normalized record $\left(\mathrm{A}_{\mathrm{N}}\right)$ & 0.4 & 0.74 & 11 & 49 \\
\hline First scaling $\left(\mathrm{A}_{1}\right)$ & 0.75 & 1.4 & 46 & 124 \\
\hline Second scaling $\left(\mathrm{A}_{2}\right)$ & 0.86 & 1.6 & 72 & 141 \\
\hline Third scaling $\left(\mathrm{A}_{3}\right)$ & 0.95 & 1.75 & 95 & 143 \\
\hline
\end{tabular}

Finally the recorded values of spectral acceleration versus maximum lateral deformation are plotted in a graph which is called an IDA curve. The IDA curve for the FE model 25-H-3 subjected to Northridge record is shown in Figure 7.9.

The parameter $\mathrm{S}_{\mathrm{CT}}$ represents the collapse level spectral acceleration. It should be mentioned that the above procedure is a "Full IDA" which is very time consuming and therefore is not performed for all the ground motion records.

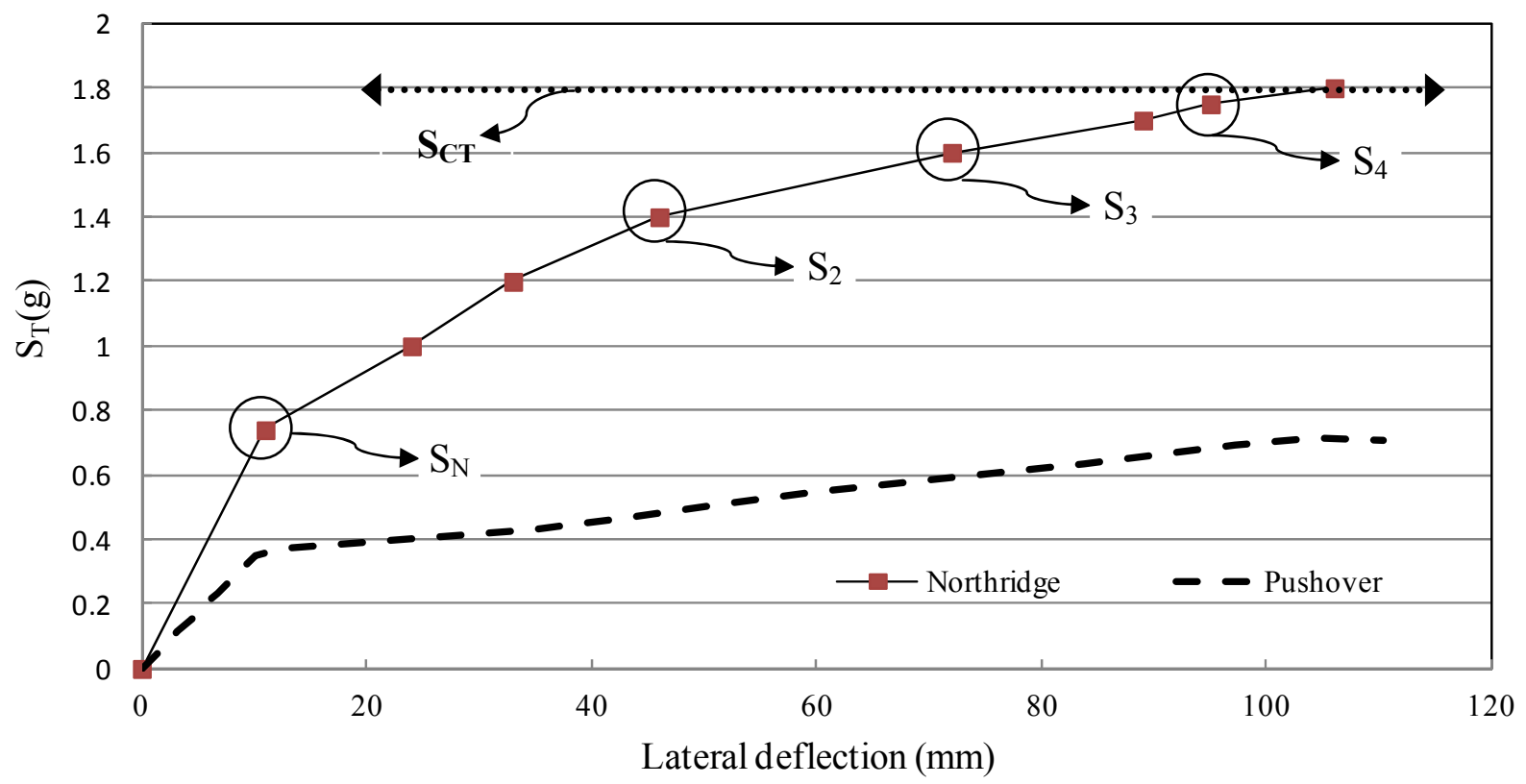

Figure 7.9 The IDA curve for FE model 25-H-3 subjected to Northridge earthquake and 4 steps of increasing intensity 


\subsubsection{Maximum damage location at collapse level}

The cracking propagation patterns of the RC pedestals were discussed in Chapter 5. It was shown that the RC pedestals could be categorized into two classes depending on the height to diameter ratio and related cracking propagation pattern. The same behaviour is observed by investigating the results of the nonlinear dynamic analysis.

Generally, two patterns of maximum mechanical strain location at the collapse level ground motion are observed. If the $\mathrm{h} / \mathrm{d}_{\mathrm{w}}$ ratio is lower than 2 then a pattern similar to Figure $7.10(\mathrm{~b})$ is expected. The location of maximum mechanical strain for FE model $25-\mathrm{H}-3$ is demonstrated in this figure. According to this pattern, it is expected to have maximum damages in shaft wall sides parallel to the direction of ground motion as a result of excessive web-shear cracking. The same pattern is also observed for other RC pedestals with $\mathrm{h} / \mathrm{d}_{\mathrm{w}}$ ratio of below 2 .

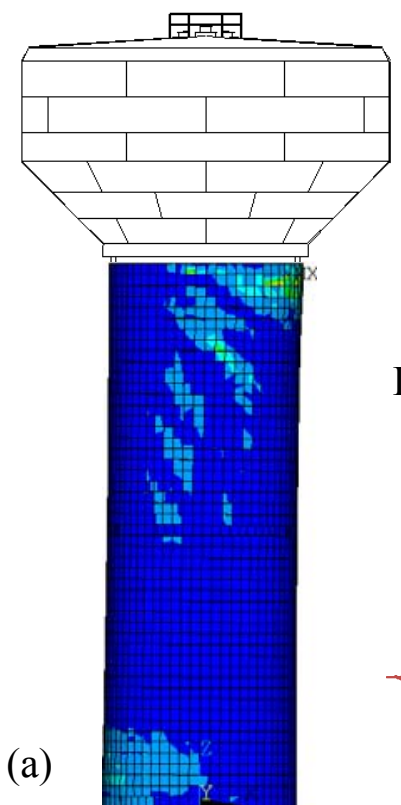

Direction of applying earthquake record

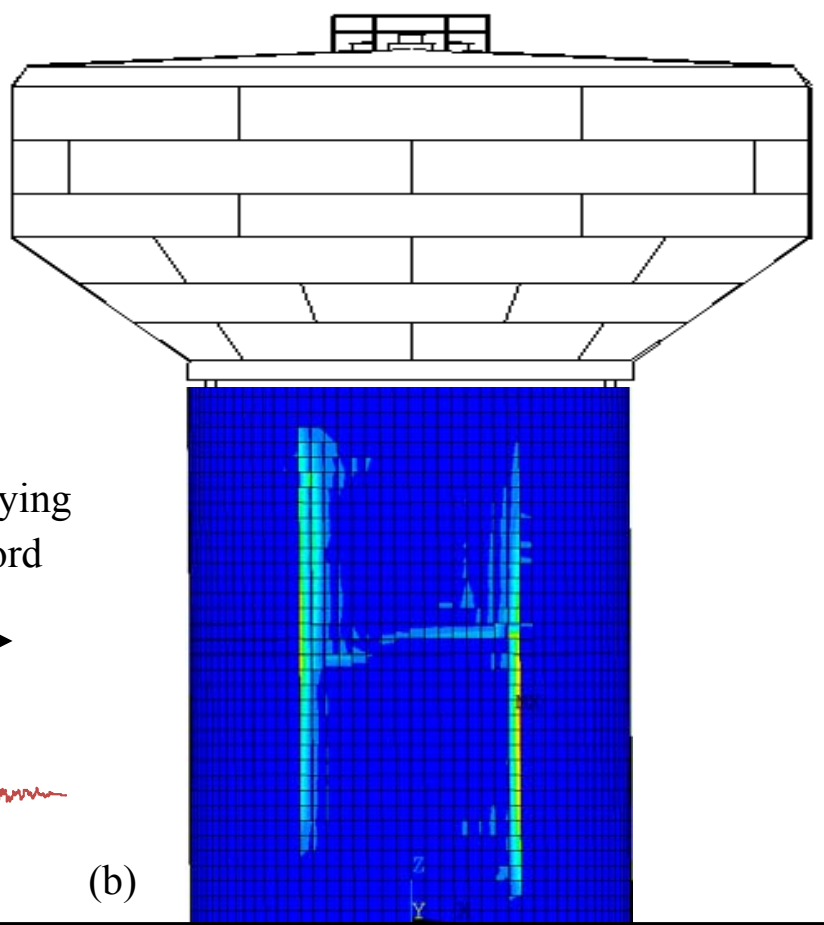

Figure 7.10 Comparing the location of maximum mechanical strain prior to collapse (a) $25-\mathrm{H}-0.5$

(b) $25-\mathrm{H}-3$ 
It could be concluded that a possible mode of failure for this category of RC pedestals is the shear failure which is not desirable. The shear failure is a non-ductile mode which could lead to losing vertical load resistance in the RC pedestal.

On the other hand if the $\mathrm{h} / \mathrm{d}_{\mathrm{w}}$ ratio is above 2 , then a pattern similar to the one shown in Figure 7.10 (a) for FE model $25-\mathrm{H}-0.5$ is observed. In this pattern, the maximum mechanical strain at the collapse level ground motion, occurs at the opposite top and bottom corners of the wall sides perpendicular to the direction of earthquake which indicates excessive damage and deformation due to the flexural cracks developed at these locations.

As a result it could be concluded that the RC pedestals with $\mathrm{h} / \mathrm{d}_{\mathrm{w}}$ ratio of above 2 will probably demonstrate a flexure mode of failure which is more ductile. The damages are expected to be at the bottom of the tank and near to the base of pedestal.

\subsection{Performing IDA on elevated water tank prototypes}

The results of performing a full IDA on three FE models of $25-\mathrm{H}-0.5,35-\mathrm{H}-1$ and $25-\mathrm{H}-3$ are shown in Figure 7.11. The pushover curve is also shown in all graphs for comparison. Generally, the dynamic analysis resuts in higher collapse spectral intensity comparing to static analysis.

The Duzce (DUZCE/BOL090) record causes all three models to collapse in the lowest spectral intensity. This is mainly due to the extremeley high PGA of this record $(\mathrm{PGA}=0.85 \mathrm{~g}$ ). In addition, comparing the three graphs indicates that for FE models $25-\mathrm{H}-0.5$ and $35-\mathrm{H}-1$ the earthquake record Cape Mendocino (CAPEMEND/RIO360) is exhibiting the highest spectral intensity at the collapse level. On the other hand, the same record is shown to establish the lowest spectral collapse level for FE model 25-H-3. In all three cases, the dynamic nonlinear analysis results in higher maximum base shear capacity comparing to pushover curve. 

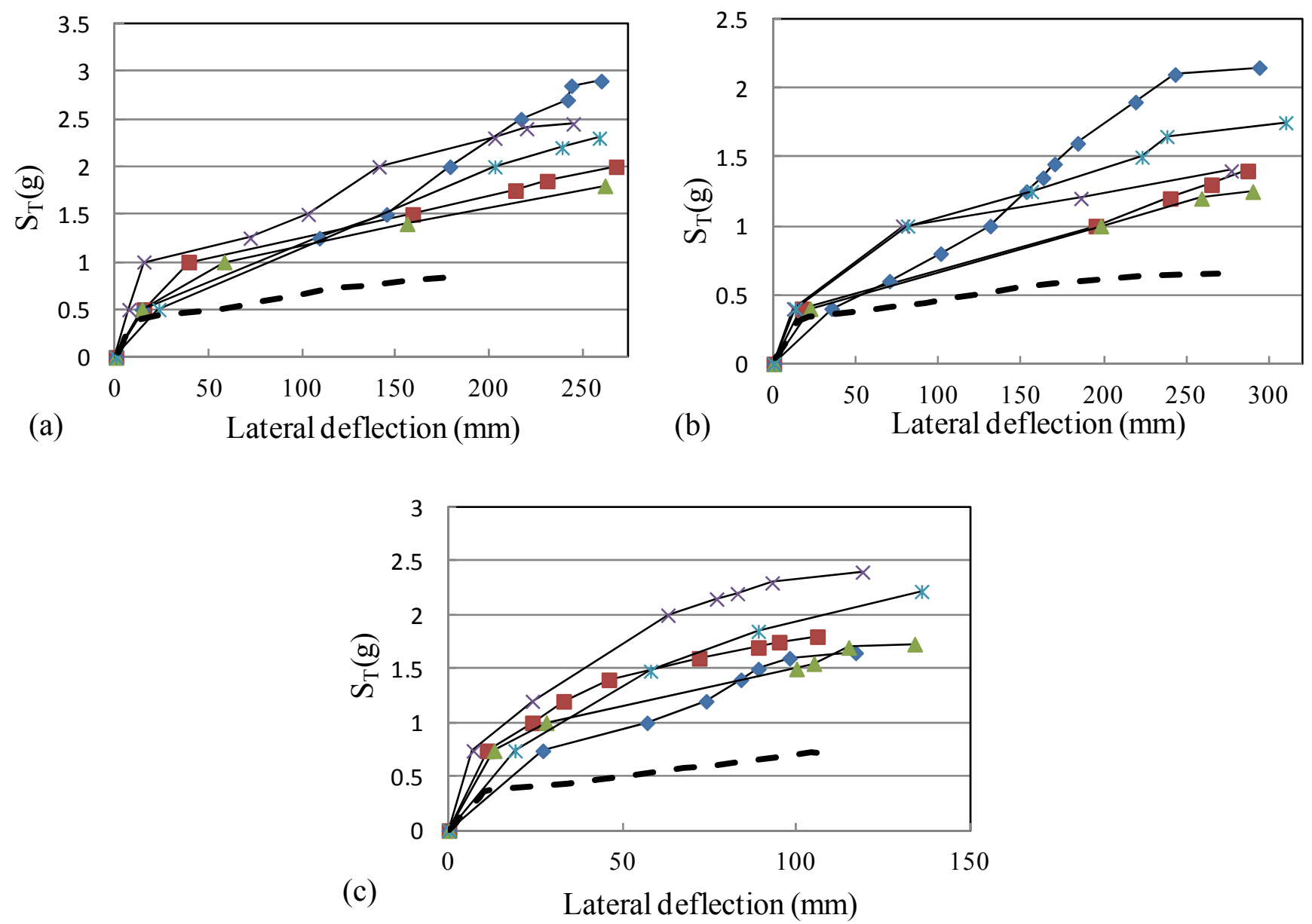

$\longrightarrow$ - Northridge $\longrightarrow$ Rio $\longrightarrow$ Duzce $\longrightarrow$ Landers $\longrightarrow$ san fernando - Pushover

Figure 7.11 IDA and pushover curves for three FE models of (a) 25-H-0.5 (b) 35-H-1 (c) 25-H-3

\subsection{Establishing collapse margin ratio (CMR)}

The IDA curves and calculated values of $\mathrm{S}_{\mathrm{CT}}$ and $\mathrm{S}_{\mathrm{MT}}$ for all ten prototypes are shown in

Figures 7.12 and 7.13. Equation 7.1 gives the relationship for calculating the CMR:

$$
C M R=\frac{\hat{S}_{C T}}{S_{M T}}
$$

where 

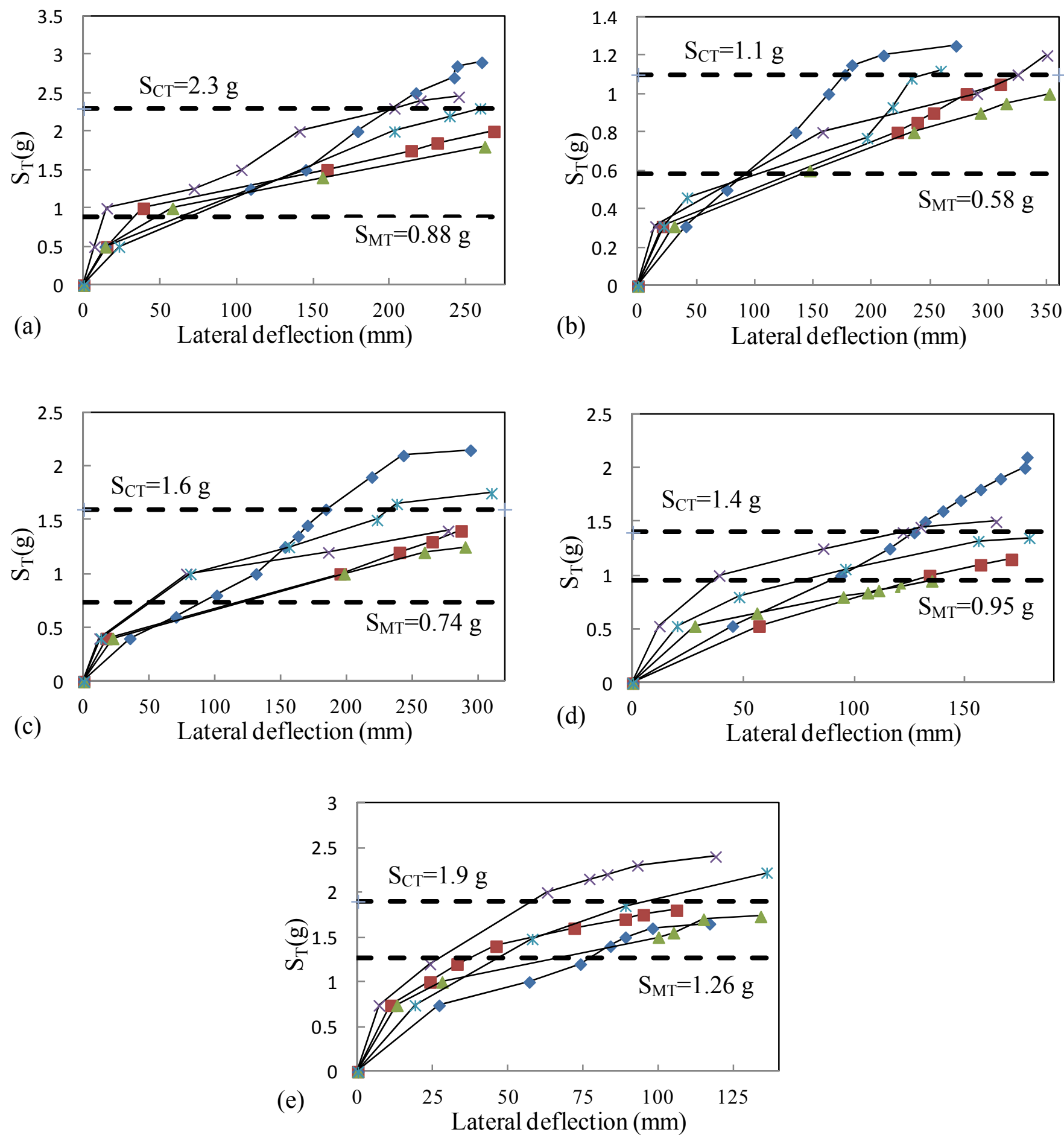

$\longrightarrow$ - Northridge $\longrightarrow$ Rio $\longrightarrow$ Duzce $\longrightarrow$ Landers $\longrightarrow$ san fernando

Figure 7.12 IDA curves and calculated $\mathrm{S}_{\mathrm{CT}}$ and $\mathrm{S}_{\mathrm{MT}}$ for prototypes design with $\mathrm{R}=2$ (a) 25-H-0.5 (b) $35-\mathrm{H}-0.5$ (c) $35-\mathrm{H}-1$ (d) $35-\mathrm{H}-3$ (e) $25-\mathrm{H}-3$ 

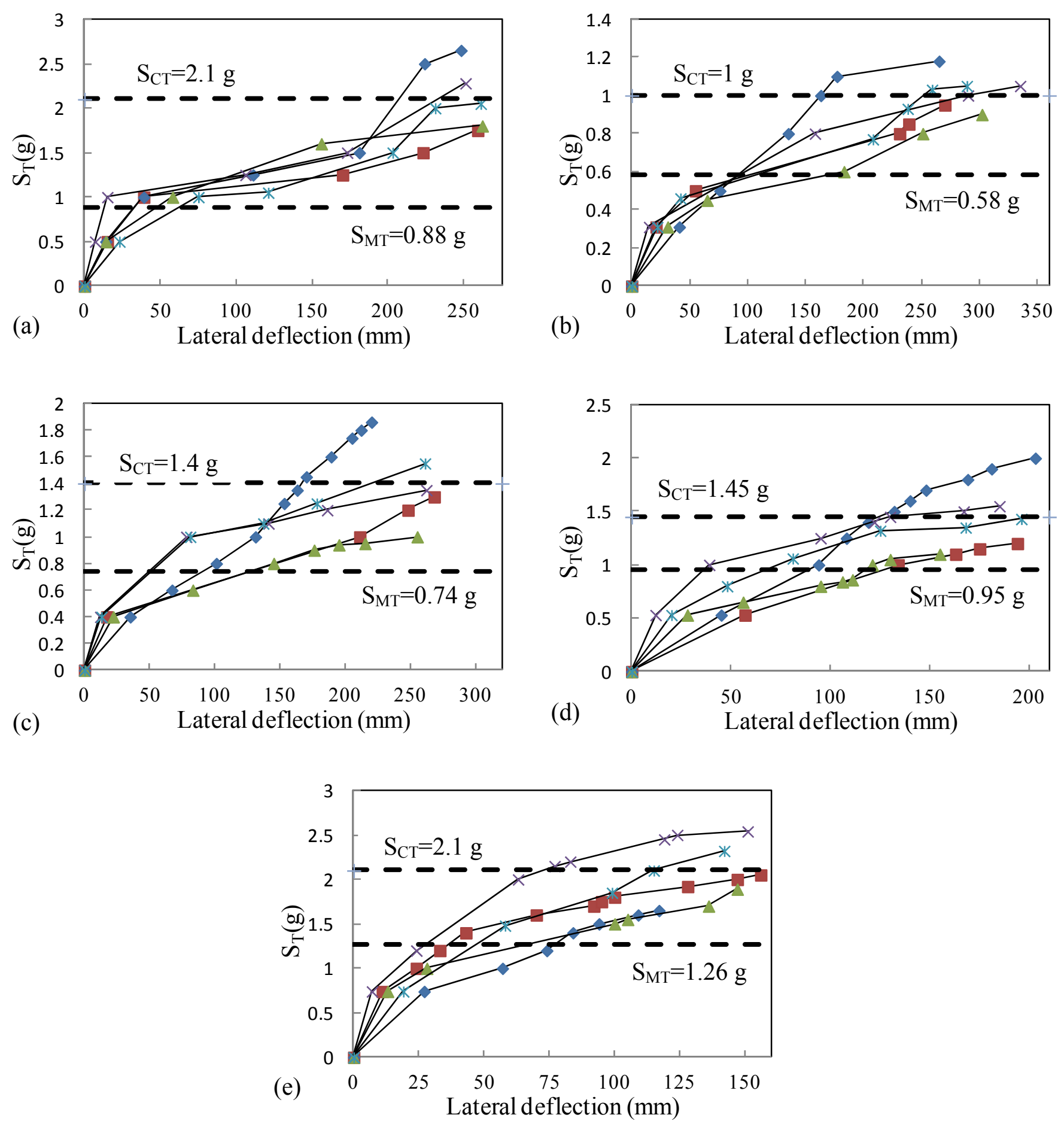

$\longrightarrow$ Northridge $\multimap$ Rio $\longrightarrow$ Duzce $\longrightarrow$ Landers $\longrightarrow$ san fernando

Figure 7.13 IDA curves and calculated $\mathrm{S}_{\mathrm{CT}}$ and $\mathrm{S}_{\mathrm{MT}}$ for prototypes design with $\mathrm{R}=3$ (a) 25- $\mathrm{H}-0.5$

(b) $35-\mathrm{H}-0.5$ (c) $35-\mathrm{H}-1$ (d) $35-\mathrm{H}-3$ (e) $25-\mathrm{H}-3$ 
$\dot{\mathrm{S}}_{\mathrm{CT}}=$ Median collapse intensity

$\mathrm{S}_{\mathrm{MT}}=$ Maximum Considered Earthquake (MCE) ground motion intensity.

The $\mathrm{S}_{\mathrm{MT}}$ is determined by Equation 7.2:

$S_{M T}=S_{M S} \quad$ If $\quad T \leq T_{S}$

$S_{M T}=\frac{S_{M 1}}{T} \quad$ If $\quad T>T_{S}$

Table 7.7 gives the $\mathrm{S}_{\mathrm{MT}}$ for the prototypes of the pilot group.

Table 7.7 $\mathrm{S}_{\mathrm{MT}}$ values for pilot group of prototypes

\begin{tabular}{ccccccc}
\hline $\begin{array}{c}\text { FE model } \\
\text { ID }\end{array}$ & $\mathrm{S}_{\mathrm{DS}}$ & $\mathrm{S}_{\mathrm{D} 1}$ & $\mathrm{~T}_{\mathrm{f}}(\mathrm{sec})$ & $\mathrm{T}_{\mathrm{s}}(\mathrm{sec})$ & $\mathrm{S}_{\mathrm{DT}}$ & $\mathrm{S}_{\mathrm{MT}}$ \\
\hline $25-\mathrm{H}-0.5$ & 0.84 & 0.44 & 0.75 & 0.52 & 0.58 & 0.88 \\
\hline $25-\mathrm{H}-3$ & 0.84 & 0.44 & 0.47 & 0.52 & 0.84 & 1.26 \\
\hline $35-\mathrm{H}-0.5$ & 0.84 & 0.44 & 1.15 & 0.52 & 0.38 & 0.58 \\
\hline $35-\mathrm{H}-1$ & 0.84 & 0.44 & 0.90 & 0.52 & 0.49 & 0.74 \\
\hline $35-\mathrm{H}-3$ & 0.84 & 0.44 & 0.69 & 0.52 & 0.64 & 0.95 \\
\hline
\end{tabular}

Further investigation of Figures 7.12 and 7.13 reveals valuable information concerning the seismic performance of the prototypes. The average lateral deformation of FE model $25-\mathrm{H}-0.5$ is approximately $50 \mathrm{~mm}$ at the MCE level which is far less than the maximum lateral deformation of nearly $250 \mathrm{~mm}$ at the collapse intensity ground motion level. The MCE lateral deformation ratio is calculated to be $20 \%$ for this prototype.

The same pattern is observed in FE models $35-\mathrm{H}-0.5$ and $35-\mathrm{H}-1$ in which the average MCE lateral deformation is $125 \mathrm{~mm}$ and $90 \mathrm{~mm}$ respectively. The maximum lateral deformation for both structures is approximately $300 \mathrm{~mm}$ which results in nearly $41 \%$ and $30 \%$ MCE lateral deformation ratios for FE models $35-\mathrm{H}-0.5$ and $35-\mathrm{H}-1$ respectively. These ratios are indicating a fairly safe seismic performance of the abovementioned three prototypes when subjected to the MCE intensity ground motion. 
All three structures will certainly experience some level of nonlinear response; however the intensity of the damages will not be significant or cause global collapse. The lateral deformation is an excellent indication of the expected damages in the structures and for these three structures it is limited to an average of $40 \%$ of the collapse level deformation. It should be noted that these three prototypes are the representatives of the light and medium tank size category. This subject will be further addressed and verified by establishing the ACMR values of the prototypes.

On the other hand, in case of the FE models 25-H-3 and 35-H-3 which are the representatives of the heavy tank sizes, although the MCE lateral deformation is rather higher comparing to the light and medium tank size group, yet there is considerable safety margin as the MCE lateral deformation ratio is calculated to be nearly less than $50 \%$ for both of heavy size tank prototypes.

A summary of the calculated values of approximate $\mathrm{S}_{\mathrm{CT}}$ and $\dot{\mathrm{S}}_{\mathrm{CT}}$ (median collapse intensity) and calculated CMR is given in Tables 7.8 and 7.9 for ten prototypes of the pilot group.

Table 7.8 CMR for prototypes designed for $\mathrm{R}=2$

\begin{tabular}{ccccc}
\hline $\begin{array}{c}\text { FE model } \\
\text { ID }\end{array}$ & $\mathrm{S}_{\mathrm{MT}}$ & $\mathrm{S}_{\mathrm{CT}}$ & $\dot{\mathrm{S}}_{\mathrm{CT}}$ & CMR \\
\hline $25-\mathrm{H}-0.5$ & 0.88 & 2.3 & 2.2 & 2.5 \\
\hline $25-\mathrm{H}-3$ & 1.26 & 1.9 & 1.9 & 1.5 \\
\hline $35-\mathrm{H}-0.5$ & 0.58 & 1.1 & 1.05 & 1.81 \\
\hline $35-\mathrm{H}-1$ & 0.74 & 1.6 & 1.65 & 2.22 \\
\hline $35-\mathrm{H}-3$ & 0.95 & 1.4 & 1.45 & 1.52 \\
\hline
\end{tabular}

Table 7.9 CMR for prototypes designed for $\mathrm{R}=3$

\begin{tabular}{ccccc}
\hline $\begin{array}{c}\text { FE model } \\
\text { ID }\end{array}$ & $\mathrm{S}_{\mathrm{MT}}$ & $\mathrm{S}_{\mathrm{CT}}$ & $\dot{\mathrm{S}}_{\mathrm{CT}}$ & $\mathrm{CMR}$ \\
\hline $25-\mathrm{H}-0.5$ & 0.88 & 2.1 & 2.05 & 2.33 \\
\hline $25-\mathrm{H}-3$ & 1.26 & 2.1 & 2 & 1.58 \\
\hline $35-\mathrm{H}-0.5$ & 0.58 & 1 & 1 & 1.72 \\
\hline $35-\mathrm{H}-1$ & 0.74 & 1.4 & 1.5 & 2.02 \\
\hline $35-\mathrm{H}-3$ & 0.95 & 1.45 & 1.5 & 1.58 \\
\hline
\end{tabular}


In a same pattern which is consistent with the results of Chapter 6, the highest collapse margin ratio belongs to the light and medium size tank group (1.5 mega Gallon and less tank size) while the lowest CMR belongs to the heavy tank size group.

\subsection{Evaluating seismic performance of elevated water tanks}

At this stage, the trial values of response modification factor $(\mathrm{R}=2$ and $\mathrm{R}=3)$ are verified by comparing the adjusted CMR (ACMR) values against a set of predefined acceptance criteria. This procedure is explained in the following lines.

\subsubsection{Calculating adjusted collapse margin ratio}

Each ground motion record has unique and distinct characteristic such as frequency content, peak ground acceleration, duration, and so forth. In order to consider such distinct features, the collapsed margin ratio is adjusted by applying spectral shape factor (SSF). FEMA P695 recommends a simplified formula for calculation of ACMR which is given in Equation 7.3:

$$
\mathrm{ACMR}=\mathrm{SSF} \times \mathrm{CMR}
$$

where SSF is a function of fundamental period of structure $(T)$, period based ductility $\left(\mu_{T}\right)$ and seismic design category. FEMA P695 prescribes Equation 7.4 for computing SSF:

$$
S S F=\exp \left[\beta_{1}\left(\overline{\varepsilon_{0}}(T)-\bar{\varepsilon}(T)_{, r e c o r d s}\right)\right]
$$

where $\beta_{1}$ is a function of inelastic deformation capacity of the structure and in calculated as given in Equation 7.5:

$\beta_{1}=0.14\left(\mu_{T}-1\right)^{0.42}$ 
"Epsilon, $\varepsilon$, is defined as the number of logarithmic standard deviations between the observed spectral value and the median prediction from an attenuation function" (FEMA P695). Epsilon is defined at each period (T) separately. The expected epsilon, $\overline{\varepsilon_{0}}(T)$, depends on both the site and hazard level of interest(FEMA P695)". In addition, $\bar{\varepsilon}(T)_{\text {,records }}$ is calculated for the Far-Field record set.

In general, as ductility and fundamental period of the structure go up, spectral shape factor increases and vice versa. For a structure with a ductility of one $(\mu=1)$, the spectral shape factor under all circumstances will remain equal to one. Accordingly, spectral shape factor (SSF) and ACMR for the prototypes are calculated as shown in Tables 7.10 and 7.11:

Table 7.10 Spectral shape factor (SSF) and adjusted collapse margin ratio (ACMR) for prototypes designed for $\mathrm{R}=2$

\begin{tabular}{cccccc}
\hline $\begin{array}{c}\text { FE model } \\
\text { ID }\end{array}$ & $\mathrm{T}_{\mathrm{f}}(\mathrm{sec})$ & $\mu$ & SSF & CMR & ACMR \\
\hline $25-\mathrm{H}-0.5$ & 0.75 & 1.5 & 1.06 & 2.5 & 2.33 \\
\hline $25-\mathrm{H}-3$ & 0.47 & 2.7 & 1.07 & 1.5 & 1.6 \\
\hline $35-\mathrm{H}-0.5$ & 1.15 & 1.5 & 1.08 & 1.81 & 1.95 \\
\hline $35-\mathrm{H}-1$ & 0.90 & 2 & 1.09 & 2.22 & 2.42 \\
\hline $35-\mathrm{H}-3$ & 0.69 & 2.2 & 1.08 & 1.52 & 1.64 \\
\hline
\end{tabular}

Table 7.11 Spectral shape factor (SSF) and adjusted collapse margin ratio (ACMR) for prototypes designed for $\mathrm{R}=3$

\begin{tabular}{cccccc}
\hline $\begin{array}{c}\text { FE model } \\
\text { ID }\end{array}$ & $\mathrm{T}_{\mathrm{f}}(\mathrm{sec})$ & $\mu$ & SSF & CMR & ACMR \\
\hline $25-\mathrm{H}-0.5$ & 0.75 & 2.2 & 1.09 & 2.33 & 2.54 \\
\hline $25-\mathrm{H}-3$ & 0.47 & 3.4 & 1.08 & 1.58 & 1.7 \\
\hline $35-\mathrm{H}-0.5$ & 1.15 & 2.1 & 1.11 & 1.72 & 1.91 \\
\hline $35-\mathrm{H}-1$ & 0.90 & 2.7 & 1.12 & 2.02 & 2.26 \\
\hline $35-\mathrm{H}-3$ & 0.69 & 3 & 1.1 & 1.58 & 1.74 \\
\hline
\end{tabular}




\subsubsection{Defining sources of collapse uncertainty}

There are many sources of uncertainties in calculating the collapse capacity of structures. According to the provisions of FEMA P695, four sources of uncertainties must be considered for computing the total system collapse uncertainties and are explained in the following lines.

\subsubsection{Record-to-Record uncertainty $\left(\beta_{\mathrm{RTR}}\right)$}

The Record-to-Record uncertainty is the result of variability in the seismic response of prototypes to various ground motions of the Far-Field record set.

Equation 7.6 is employed for calculating $\beta_{\mathrm{RTR}}$ :

$\beta_{R T R}=0.1+0.1 \mu_{T} \leq 0.4$

$\beta_{\mathrm{RTR}}$ must be greater than 0.2 as the lower bound. In addition, for structures with ductility above " 3 ", $\beta_{\mathrm{RTR}}$ is constant and equal to 0.4 .

\subsubsection{Design requirements, Test data and Modeling uncertainty $\left(\beta_{\mathrm{DR},}, \beta_{\mathrm{TD}}, \boldsymbol{\beta}_{\mathrm{MDL}}\right)$}

Besides the record-to-record uncertainty, FEMA P695 also requires three other factors to be included in calculations of overall uncertainty. The first factor is "Design Requirements Uncertainty" ( $\beta_{\mathrm{DR})}$ and is related to accuracy and reliability of the design requirements. If there is high confidence in the design requirements and all unanticipated modes of failure are addressed then the design requirement uncertainty may be rated as superior.

The second factor is "Test Data Uncertainty" $\left(\beta_{\mathrm{TD}}\right.$ and indicates the exactness and robustness of the test data used for defining the system. A high confidence in test results combined with excellent knowledge of material, component, connection and structural behaviour will result in 
superior rating of the test data uncertainty. There is limited information about the performance of elevated water tanks subjected to earthquakes in the past. Moreover, there is very little (or no) full scale test performed on the RC pedestals which results in a higher test data uncertainty.

The last uncertainty parameter is the "Modeling Uncertainty" ( $\beta_{\mathrm{MDL})}$ which reflects the comprehensiveness of the group of prototypes being studied. A set of prototypes which is capable to represent all seismic response characteristics of the seismic-force-resisting system under investigation, would have least uncertainties.

The above three sources of uncertainty are essentially quality based parameters and need engineering judgment to be qualified. They are rated as Superior, Good, Fair and Poor in descending order. However, in order to to be taken into account in the calculation of total system collapse uncertainty, they need to be quantified.

\subsubsection{Calculating total system collapse uncertainty}

The four uncertainty factors $\beta_{\mathrm{RTR}}, \beta_{\mathrm{DR}}, \beta_{\mathrm{TD}}$ and $\beta_{\mathrm{MDL}}$ are combined according to Equation 7.7 in order to establish the total system collapse uncertainty factor $\left(\beta_{\mathrm{TOT}) \text { : }}\right.$

$\beta_{T O T}=\left(\beta_{R T R}^{2}+\beta_{D R}^{2}+\beta_{T D}^{2}+\beta_{M D L}^{2}\right)^{1 / 2}$

The $\beta_{\text {RTR }}$ uncertainty was previously described in Equation 7.6. However the other three uncertainty factors are quality based and need to be converted to quantities. This is carried out by employing Table 7.12:

Table 7.12 Quality ratings

\begin{tabular}{ccccc}
\hline & \multicolumn{3}{c}{ Quality rating } \\
\cline { 2 - 5 } & Superior & Good & Fair & Poor \\
\hline$\beta_{\mathrm{DR},} \beta_{\mathrm{TD},} \beta_{\mathrm{MDL}}$ & 0.1 & 0.2 & 0.35 & 0.5 \\
\hline
\end{tabular}


As demonstrated in this table, the quality rating ranges between 0.1 (superior) to 0.5 (poor). By substituting the above values in Equation 7.7, the total system collapse uncertainty is determined. The total system collapse uncertainty ranges from $\beta_{\mathrm{TOT}}=0.275$ for the highest certainty in the system to $\beta_{\mathrm{TOT}}=0.95$ for the lowest certainty. For a system with lowest certainty $\beta_{\mathrm{RTR}}$ is equal to 0.4 and all other three certainty parameters are rated as poor. On the other hand, a system with highest certainty has $\beta_{\mathrm{RTR}}$ of 0.2 with all other certainty parameters rated as superior. In this research, two quality ratings of "superior" and "good" for $\beta_{\mathrm{DR},} \beta_{\mathrm{TD}}, \beta_{\mathrm{MDL}}$ are investigated.

Tables 7.13 through 7.16 show the total system collapse uncertainty for the prototypes. The total system uncertainty ranges between a minimum of 0.3 to maximum of 0.53 . As the total system uncertainty increases, the acceptable value of ACMR raises. Although it is possible to have a "superior" quality rating of the RC pedestals in the elevated water tanks in practice, yet it sounds more rational and reasonable to more rely on the "Good" quality rating as it is a more realistic evaluation of uncertainties in this case.

Table 7.13 Total system collapse uncertainty for "superior" quality rating $(\mathrm{R}=2)$

\begin{tabular}{cccccccc}
\hline FE model ID & $\mathrm{T}_{\mathrm{f}}(\mathrm{sec})$ & Ductility & $\beta_{\mathrm{RTR}}$ & $\beta_{\mathrm{TD}}$ & $\beta_{\mathrm{MDL}}$ & $\beta_{\mathrm{DR}}$ & $\beta_{\mathrm{TOT}}$ \\
\hline $25-\mathrm{H}-0.5$ & 0.75 & 1.5 & 0.25 & 0.1 & 0.1 & 0.1 & 0.31 \\
\hline $25-\mathrm{H}-3$ & 0.47 & 2.7 & 0.37 & 0.1 & 0.1 & 0.1 & 0.41 \\
\hline $35-\mathrm{H}-0.5$ & 1.15 & 1.5 & 0.25 & 0.1 & 0.1 & 0.1 & 0.30 \\
\hline $35-\mathrm{H}-1$ & 0.90 & 2.0 & 0.30 & 0.1 & 0.1 & 0.1 & 0.34 \\
\hline $35-\mathrm{H}-3$ & 0.69 & 2.2 & 0.32 & 0.1 & 0.1 & 0.1 & 0.37 \\
\hline
\end{tabular}

Table 7.14 Total system collapse uncertainty for "superior" quality rating $(\mathrm{R}=3)$

\begin{tabular}{cccccccc}
\hline FE model ID & $\mathrm{T}_{\mathrm{f}}(\mathrm{sec})$ & Ductility & $\beta_{\mathrm{RTR}}$ & $\beta_{\mathrm{TD}}$ & $\beta_{\mathrm{MDL}}$ & $\beta_{\mathrm{DR}}$ & $\beta_{\mathrm{TOT}}$ \\
\hline $25-\mathrm{H}-0.5$ & 0.75 & 2.2 & 0.32 & 0.1 & 0.1 & 0.1 & 0.36 \\
\hline $25-\mathrm{H}-3$ & 0.47 & 3.4 & 0.40 & 0.1 & 0.1 & 0.1 & 0.44 \\
\hline $35-\mathrm{H}-0.5$ & 1.15 & 2.1 & 0.31 & 0.1 & 0.1 & 0.1 & 0.36 \\
\hline $35-\mathrm{H}-1$ & 0.90 & 2.7 & 0.37 & 0.1 & 0.1 & 0.1 & 0.41 \\
\hline $35-\mathrm{H}-3$ & 0.69 & 2.9 & 0.39 & 0.1 & 0.1 & 0.1 & 0.43 \\
\hline
\end{tabular}


Table 7.15 Total system collapse uncertainty for "good" quality rating $(\mathrm{R}=2)$

\begin{tabular}{cccccccc}
\hline FE model ID & $\mathrm{T}_{\mathrm{f}}(\mathrm{sec})$ & Ductility & $\beta_{\mathrm{RTR}}$ & $\beta_{\mathrm{TD}}$ & $\beta_{\mathrm{MDL}}$ & $\beta_{\mathrm{DR}}$ & $\beta_{\text {TOT }}$ \\
\hline $25-\mathrm{H}-0.5$ & 0.75 & 1.5 & 0.25 & 0.2 & 0.2 & 0.2 & 0.43 \\
\hline $25-\mathrm{H}-3$ & 0.47 & 2.7 & 0.37 & 0.2 & 0.2 & 0.2 & 0.51 \\
\hline $35-\mathrm{H}-0.5$ & 1.15 & 1.5 & 0.25 & 0.2 & 0.2 & 0.2 & 0.43 \\
\hline $35-\mathrm{H}-1$ & 0.90 & 2.0 & 0.30 & 0.2 & 0.2 & 0.2 & 0.46 \\
\hline $35-\mathrm{H}-3$ & 0.69 & 2.2 & 0.32 & 0.2 & 0.2 & 0.2 & 0.47 \\
\hline
\end{tabular}

Table 7.16 Total system collapse uncertainty for "good" quality rating $(\mathrm{R}=3)$

\begin{tabular}{cccccccc}
\hline FE model ID & $\mathrm{T}_{\mathrm{f}}(\mathrm{sec})$ & Ductility & $\beta_{\mathrm{RTR}}$ & $\beta_{\mathrm{TD}}$ & $\beta_{\mathrm{MDL}}$ & $\beta_{\mathrm{DR}}$ & $\beta_{\mathrm{TOT}}$ \\
\hline $25-\mathrm{H}-0.5$ & 0.75 & 2.2 & 0.32 & 0.2 & 0.2 & 0.2 & 0.47 \\
\hline $25-\mathrm{H}-3$ & 0.47 & 3.4 & 0.40 & 0.2 & 0.2 & 0.2 & 0.53 \\
\hline $35-\mathrm{H}-0.5$ & 1.15 & 2.1 & 0.31 & 0.2 & 0.2 & 0.2 & 0.47 \\
\hline $35-\mathrm{H}-1$ & 0.90 & 2.7 & 0.37 & 0.2 & 0.2 & 0.2 & 0.51 \\
\hline $35-\mathrm{H}-3$ & 0.69 & 2.9 & 0.39 & 0.2 & 0.2 & 0.2 & 0.52 \\
\hline
\end{tabular}

\subsubsection{Acceptable values of ACMR}

Table 7.17 illustrates different values of total structure collapse uncertainty and corresponding acceptable values of ACMR for five collapse probabilities. At this stage, the ACMR value for each RC pedestal FE model is determined. In addition, total structure collapse uncertainty was established for each prototype and related uncertainty value in last section.

Table 7.17 "Acceptable ACMR" for five collapse probability level

\begin{tabular}{cccccc}
\hline Total structure & \multicolumn{5}{c}{ Collapse probability } \\
\cline { 2 - 6 } collapse \\
uncertainty $\left(\beta_{\text {TOT })}\right.$ & $5 \%$ & $10 \%$ & $15 \%$ & $20 \%$ & $25 \%$ \\
\hline 0.275 & 1.57 & 1.42 & 1.33 & 1.26 & 1.2 \\
\hline 0.3 & 1.64 & 1.47 & 1.36 & 1.29 & 1.22 \\
\hline 0.4 & 1.93 & 1.67 & 1.51 & 1.4 & 1.31 \\
\hline 0.5 & 2.28 & 1.9 & 1.68 & 1.52 & 1.4 \\
\hline 0.6 & 2.68 & 2.16 & 1.86 & 1.66 & 1.5 \\
\hline 0.7 & 3.16 & 2.45 & 2.07 & 1.8 & 1.6 \\
\hline 0.8 & 3.73 & 2.79 & 2.29 & 1.96 & 1.72 \\
\hline 0.9 & 4.39 & 3.17 & 2.54 & 2.13 & 1.83 \\
\hline 0.95 & 4.77 & 3.38 & 2.68 & 2.22 & 1.9 \\
\hline
\end{tabular}


Subsequently, by choosing the intended collapse probability (for example 15\%), the accepted ACMR value for each collapse uncertainty level is selected from Table 7.17. As the total system collapse uncertainty increases, the acceptable ACMR increases and vice versa. The collapse probability has inverse relation with the acceptable ACMR.

For each level of collapse probability if ACMR exceeds the accepted ACMR (according to Table 7.17) then the seismic performance of the corresponding prototype is approved and validity of the implemented response modification factor ( $\mathrm{R}$ factor) is confirmed.

However, if the calculated ACMR is less than accepted ACMR value, then the seismic performance of the structure is not acceptable and the response modification factor should be revised.

Acceptable performance according to provisions of FEMA P695 is defined as follows:

$$
\begin{array}{cc}
\text { Calculated ACMR }>\text { Acceptable } \operatorname{ACMR}(20 \%) & \text { for each prototype } \\
\text { Average Calculated ACMR }>\text { Acceptable } \operatorname{ACMR}(10 \%) & \text { for each structural category }
\end{array}
$$

In Chapter 6, three structural categories of light, medium and heavy tank sizes were defined. The average value of calculated ACMR will be calculated for all three categories and verified against the accepted ACMR for 10\% collapse probability.

If a higher seismic performance objective is required for the elevated water tanks, then the $5 \%$ collapse probability (or lower) might be employed for verification and investigation.

\subsection{Evaluation of $\mathbf{R}$ factor}

The results of comparing the calculated ACMR with the accepted ACMR are given in Tables 7.18 to 7.21 . All of the prototypes from both groups designed with $R=2$ and $R=3$ and quality rating of superior and good are shown in these tables. 
The cells of the tables that are highlighted are showing the failure of the prototype in passing the acceptable ACMR criteria for the specific collapse probability. The tables are indicating that all of the prototypes are passing the criteria of $20 \%$ probability of collapse for both Superior and Good quality rating.

The calculated ACMR are the lowest for the heavy tank sizes and highest for light tank size group. Moreover, Tables 7.18 and 7.19 indicate that, if there is a high confidence in design, modeling and testing of the RC pedestal structure, all of the prototypes (both designed for response modification factor of 2 and 3) will pass the $15 \%$ probability of failure. In addition, other than FE model 25-H-3, all other prototypes in the Superior quality rating will pass the 10\% collapse criteria.

Table 7.18 "Superior" total system collapse uncertainty and R factor of 2

Acceptable ACMR for four collapse probabilities

\begin{tabular}{ccccccc}
\hline FE model ID & $\beta_{\text {TOT }}$ & Calculated ACMR & $5 \%$ & $10 \%$ & $15 \%$ & $20 \%$ \\
\hline $25-\mathrm{H}-0.5$ & 0.31 & 2.33 & 1.64 & 1.47 & 1.36 & 1.29 \\
\hline $25-\mathrm{H}-3$ & 0.41 & 1.6 & 1.3 & 1.67 & 1.51 & 1.4 \\
\hline $35-\mathrm{H}-0.5$ & 0.30 & 1.95 & 1.64 & 1.47 & 1.36 & 1.29 \\
\hline $35-\mathrm{H}-1$ & 0.34 & 2.42 & 1.77 & 1.56 & 1.43 & 1.33 \\
\hline $35-\mathrm{H}-3$ & 0.37 & 1.64 & 1.85 & 1.62 & 1.48 & 1.37 \\
\hline
\end{tabular}

Table 7.19 "Superior" total system collapse uncertainty and R factor of 3

Acceptable ACMR for four collapse probabilities

\begin{tabular}{ccccccc}
\hline FE model ID & $\beta_{\text {TOT }}$ & Calculated ACMR & $5 \%$ & $10 \%$ & $15 \%$ & $20 \%$ \\
\hline $25-\mathrm{H}-0.5$ & 0.36 & 2.54 & 1.81 & 1.59 & 1.46 & 1.35 \\
\hline $25-\mathrm{H}-3$ & 0.44 & 1.7 & 2.08 & 1.76 & 1.58 & 1.45 \\
\hline $35-\mathrm{H}-0.5$ & 0.36 & 1.91 & 1.81 & 1.59 & 1.46 & 1.35 \\
\hline $35-\mathrm{H}-1$ & 0.41 & 2.26 & 1.3 & 1.67 & 1.51 & 1.4 \\
\hline $35-\mathrm{H}-3$ & 0.43 & 1.74 & 2.03 & 1.73 & 1.56 & 1.44 \\
\hline
\end{tabular}


Table 7.20 "Good" total system collapse uncertainty and R factor of 2

Acceptable ACMR for four collapse probabilities

\begin{tabular}{ccccccc}
\hline FE model ID & $\beta_{\text {ТОт }}$ & Calculated ACMR & $5 \%$ & $10 \%$ & $15 \%$ & $20 \%$ \\
\hline $25-\mathrm{H}-0.5$ & 0.43 & 2.33 & 2.03 & 1.73 & 1.56 & 1.44 \\
\hline $25-\mathrm{H}-3$ & 0.51 & 1.6 & 2.32 & 1.93 & 1.7 & 1.54 \\
\hline $35-\mathrm{H}-0.5$ & 0.43 & 1.95 & 2.03 & 1.73 & 1.56 & 1.44 \\
\hline $35-\mathrm{H}-1$ & 0.46 & 2.42 & 2.13 & 1.81 & 1.61 & 1.47 \\
\hline $35-\mathrm{H}-3$ & 0.47 & 1.64 & 2.17 & 1.83 & 1.63 & 1.48 \\
\hline
\end{tabular}

Table 7.21"Good" total system collapse uncertainty and R factor of 3

Acceptable ACMR for four collapse probabilities

\begin{tabular}{ccccccc}
\hline FE model ID & $\beta_{\text {ТОт }}$ & Calculated ACMR & $5 \%$ & $10 \%$ & $15 \%$ & $20 \%$ \\
\hline $25-\mathrm{H}-0.5$ & 0.47 & 2.54 & 2.17 & 1.83 & 1.63 & 1.48 \\
\hline $25-\mathrm{H}-3$ & 0.53 & 1.7 & 2.39 & 1.97 & 1.73 & 1.56 \\
\hline $35-\mathrm{H}-0.5$ & 0.47 & 1.91 & 2.17 & 1.83 & 1.63 & 1.48 \\
\hline $35-\mathrm{H}-1$ & 0.51 & 2.26 & 2.32 & 1.93 & 1.7 & 1.54 \\
\hline $35-\mathrm{H}-3$ & 0.52 & 1.74 & 2.36 & 1.95 & 1.71 & 1.55 \\
\hline
\end{tabular}

\subsection{1 "Light" tank size category evaluation}

Two FE models $25-\mathrm{H}-0.5$ and $35-\mathrm{H}-0.5$ represent the light tank size category in the pilot group of prototypes. The light tank size category demonstrates acceptable seismic performance for both values of $\mathrm{R}$ factor and quality ratings.

The FE model $25-\mathrm{H}-0.5$ passes the $5 \%$ collapse probability for both quality ratings which indicates very high safety factor of this prototype against collapse.

It could be concluded that the light tank size category passes the $10 \%$ and $20 \%$ criteria for "group average" and "single (individual) prototype" respectively. As a result, both response modification factors of $\mathrm{R}=2$ and $\mathrm{R}=3$ are verified and confirmed for the light tank size category. This is consistent with the results of Chapter 6 in which the light tank size group presented the highest draft value of $\mathrm{R}$ factor. 


\subsection{2 "Medium" tank size category evaluation}

The FE models $35-\mathrm{H}-1$ is the representative of the Medium tank size category in the pilot group of prototypes. This prototype exhibits an acceptable seismic performance by passing the $10 \%$ probability of collapse for both $\mathrm{R}$ factors and quality ratings. Therefore, both $\mathrm{R}$ factor $\mathrm{s}$ of 2 and 3 are verified for the medium size tank category.

This prototype also passes the $5 \%$ collapse probability for all circumstances except for $\mathrm{R}=3$ design with the Good quality rating which indicates a very high seismic performance against global collapse of structure.

\subsection{3 "Heavy" tank size category evaluation}

Two FE models $25-\mathrm{H}-3$ and $35-\mathrm{H}-3$ are representing the heavy tank size category in the pilot group of prototypes. The heavy tank size category does not demonstrate an acceptable seismic performance comparing to the medium and small tank size categories.

The most critical prototype is the FE model $25-\mathrm{H}-3$ which only passes the $20 \%$ collapse probability for the Good quality rating. These results suggest the design $\mathrm{R}$ factor must be lowered to less than $\mathrm{R}=2$ for the heavy tank size group.

Although the heavy tank size group prototypes pass the $20 \%$ acceptable ACMR criteria, none of them can pass the $10 \%$ acceptable ACMR for the Good quality rating. In addition, FE model $25-\mathrm{H}-3$ does not pass the $10 \%$ probability of collapse criteria under all quality ratings and design $\mathrm{R}$ factors. This is in line with the results of Chapter 6 in which a lower than $\mathrm{R}=2(\mathrm{R}=1.8)$ was determined as the draft $\mathrm{R}$ factor for the heavy tank size group.

Therefore, this study suggests that for the heavy tank size category (Tank size larger than 1.5 Mega Gallon) the maximum $\mathrm{R}$ factor be limited to $\mathrm{R}=1.8$ as was determined in Chapter 6 . 


\subsection{Summary}

In this chapter a probabilistic approach was implemented to verify and evaluate the seismic performance and response modification factor of elevated water tanks. Ten prototypes were selected for this evaluation. The heights of the models were $25 \mathrm{~m}$ and $35 \mathrm{~m}$ and the tank sizes were $0.5 \mathrm{MG}, 1 \mathrm{MG}$ and $3 \mathrm{MG}$. The $\mathrm{R}$ factor which was used for designing the RC pedestals was 2 and 3 as recommended by ASCE/SEI 7-2010. The procedure of seismic performance evaluation of the prototypes was adapted from FEMA P695 (2009).

At the beginning, a general overview of the seismic performance evaluation procedure of the elevated water tanks was presented. Then the concept of collapse margin ratio (CMR) was explained. Since FEMA P695 is originally developed for building structures, few customizations were required to made in order to adapt the methodology for the elevated water tanks. These customizations were briefly explained in this chapter.

Establishing the spectral collapse intensity of each structure is accomplished by employing a large number of nonlinear dynamic analyses. Performing each nonlinear dynamic analysis requires a strong ground motion record from historical earthquake data. On the other hand, Due to the differences between the characteristics of earthquake records such as frequency content, PGA, PGV and so forth, the number of selected ground motion records must be large enough to cover most of these characteristics.

A group of 22 ground motion records (each containing two components), were introduced as defined by FEMA P695. In addition, the procedure of normalizing and scaling of the ground motion records was explained briefly.

As the process of performing incremental dynamic analysis (IDA) is very time consuming, The "Full IDA" was only performed for 5 ground motion records in order to establish the 
approximate spectral collapse intensity $\mathrm{S}_{\mathrm{CT}}$ and analysing the IDA curve. However since the IDA curves were not necessary for determining the $\dot{\mathrm{S}}_{\mathrm{CT}}$, for the rest of the earthquake records (remaining 39), it was only enough to determine the spectral collapse intensity.

The results of nonlinear dynamic analysis of the $\mathrm{RC}$ pedestals were demonstrated and discussed. At first, the nonlinear response of the the 25-H-0.5 FE model subjected to four different ground motion records, each scaled to the level of slightly below collapse inducing ground motion was shown. It was concluded that he maximum base shear prior to failure ranged from as low as $36 \mathrm{MN}$ to $49 \mathrm{MN}$ for San Fernando and Cape Mendocino records respectively. In addition, lateral deflection prior to failure was shown to fluctuate between $214 \mathrm{~mm}$ to $262 \mathrm{~mm}$ for Northridge and Duzce earthquake records. The results of the nonlinear dynamic analysis were also shown to establish much higher levels of maximum base shear and lateral deflection in comparison to pushover analysis.

The chapter continued with evaluating the results of "Full IDA" analysis of FE model 25-H-3. The criteria for determination of the collapse of the RC pedestal was explained and discussed. Furthermore, the procedure of developing the IDA curve of FE model 25-H-3 subjected to four increasing intensities of Northridge record was demonstrated.

Subsequently, after conducting the IDA on all ten prototypes, the IDA curves and calculated values of median collapse intensity $\dot{\mathrm{S}}_{\mathrm{CT}}$ were obtained and illustrated in figure sand tables. Later the Maximum Considered Earthquake (MCE) ground motion intensity $\left(\mathrm{S}_{\mathrm{MT}}\right)$, was determined for the prototypes. The CMR values were computed which ranges between 1.5 for $25-\mathrm{H}-3(\mathrm{R}=2)$ to 2.5 for $25-\mathrm{H}-0.5(\mathrm{R}=2)$. It was shown that the highest $\mathrm{CMR}$ belonged to the light and medium tank size category. 
It was also shown that under the Maximum Considerable Earthquake (MCE) ground motion intensity $\left(\mathrm{S}_{\mathrm{MT}}\right)$, FE models $25-\mathrm{H}-0.5,35-\mathrm{H}-0.5$ and $35-\mathrm{H}-1$ had the lateral deformation of less than $40 \%$ of the maximum lateral deformation. This indicated that although these structures had experience some levels of nonlinearity, yet the damages were not severe.

The FE models 25-H-3 and 35-H-3 experienced higher lateral deformation at the MCE intensity comparing to the maximum lateral deformation at the collapse level. This indicated that the elevated water tanks with heavy tank size can experience more severe level of damage under the MCE ground motion intensity comparing to the light and medium tank sizes.

In order to determine the ACMR, the spectral shape factor (SSF) for each prototype was developed. The SSF was higher for the $\mathrm{R}=3$ prototypes as this group had higher ductility. After that, the sources of uncertainty in developing the structural models were explained and the total system uncertainty ( $\left.\beta_{\text {ТОт }}\right)$ for two quality ratings of "Superior" and "Good" was determined. The $\beta_{\text {TOT }}$ was lowest for $\mathrm{FE}$ model $35-\mathrm{H}-0.5\left(\beta_{\mathrm{TOT}}=0.3\right)$ and highest for $\mathrm{FE}$ model $25-\mathrm{H}-3$ $\left(\beta_{\mathrm{TOT}}=0.53\right)$.

The calculated ACMR values were shown to range between 2.54 for $25-\mathrm{H}-0.5(\mathrm{R}=3)$, to 1.6 for 25-H-3 $(\mathrm{R}=2)$. In addition FE models $25-\mathrm{H}-0.5,35-\mathrm{H}-0.5$ and 35-H-1 (light and medium tanks) were shown to have higher ACMR comparing to FE models 25-H-3, 35-H-3 (Heavy tanks). As a result it was concluded that the light and medium tank sizes had higher safety margin against global collapse of the RC pedestal comparing to the heavy tanks.

Finally, by comparing the calculated ACMR to the acceptable values of ACMR it was proved that the light and medium tank size group were passing the seismic performance requirements and hence the employed $\mathrm{R}$ factors of $\mathrm{R}=2$ and $\mathrm{R}=3$ were verified and approved. 
On the other hand it was shown that implementing the $\mathrm{R}$ factors of 2 and 3 for seismic design of heavy tank sizes resulted in unsatisfactory ACMR levels. As a result it was proposed that the $\mathrm{R}$ facto for the seismic design of the heavy tank size group be limited to the draft value of 1.8 as was calculated in Chapter 6 of the thesis.

The IDA curves that were developed in this chapter may be used for studying other performance objectives. For example, if the "operational level" as defined by FEMA 273 is intended for the elevated water tank, then the lateral deformation and damages under the MCE ground motion must be very limited. By defining these limitations (which are mainly related to non-structural elements such as piping) and comparing to the IDA curves, such performance objectives may be verified and evaluated.

In the same manner, if higher or lower probability of collapse is intended for a specific elevated water tanks, Tables 7.18 to 7.21 could be extremely useful. These tables could be modified for any intended quality rating or collapse probability. As an example, if a retrofitting plan is needed to be developed for an elevated water tank, then these tables could be implemented for various quality ratings and performance objectives.

Furthermore, determination of the potential failure modes which was addressed in this chapter may be used for seismic performance evaluation of the existing elevated water tanks. Depending on the ratio of H/D it was shown that two different modes of failure could be expected which is very helpful in case of developing a seismic retrofitting and rehabilitation plan. 


\section{Chapter 8 \\ Evaluating the effect of wall opening and maximum shear strength in RC pedestal of elevated water tanks}

\subsection{General}

This chapter is divided into two main parts. The first part will address the wall openings of the $\mathrm{RC}$ pedestals and investigates their effect on the seismic response of elevated water tanks. In part two, the actual maximum shear capacity of the RC pedestals is evaluated and compared to the nominal shear capacity determined according to the code.

During the past earthquakes, a number of elevated water tanks suffered from damages in the areas around the wall openings. Examples of such damages were addressed in Chapter 2. When the elevated water tanks are subjected to the ground motion excitation, maximum moment and shear will be developed at the base of the RC pedestals which is where the wall openings are commonly located. This can turn around the wall opening to the most critical section of the RC pedestals during the earthquakes.

In this chapter a finite element approach is implemented in order to model the behaviour of wall openings under extreme lateral deformation of RC pedestals and study their effects on the seismic response characteristics of elevated water tanks. A number of elevated water tank FE models with various heights, tank capacities and standard wall opening dimensions are developed and nonlinear static analysis is performed.

In the second part of this chapter, the proposed formula by ACI371R-08 for calculation of the nominal shear strength of RC pedestal is evaluated and verified. The current equation only takes into account the strength from steel (horizontal reinforcement) and concrete (concrete shear area) in order to calculate the nominal shear strength of the RC pedestal. However, the experimental 
and numerical research studies have shown that the axial compression increases the shear capacity of RC walls significantly. This beneficial effect of the axial compression is not included in the current equation.

This chapter will address this issue by employing a finite element approach and computing the maximum shear strength of 12 elevate water tank models under three states of full, half and empty tank. The calculated values are then compared to the nominal shear strength determined by the code. In addition, the effect of various parameters such as average axial compression in RC pedestal, tank size and height to diameter ratio on the shear strength of the RC pedestal section will be addressed and discussed.

\subsection{Wall opening location and typical dimensions}

In general, two doors are usually constructed for accessing inside of the RC pedestals. One personnel and one vehicle (truck) door. These doors are located at the base (ground) level of the $\mathrm{RC}$ pedestals as the main entrances. The personnel door's width is commonly less than one meter. The vehicle door on the other hand must be large enough to allow the access of the largest anticipated equipment or truck inside the pedestal structure. The height and width of the vehicle door may range between 3 to 4.2 meters depending on the intended application and size of the pedestals.

Figure 8.1 shows a typical elevation of an elevated water tank and related section of the RC pedestal wall. The section demonstrates two personnel and vehicle doors. A pilaster (buttress) is provided on the sides of the vehicle door in this section. The buttress is normally provided for elevated water tanks with large tank size or the tanks located in high seismicity zones. 

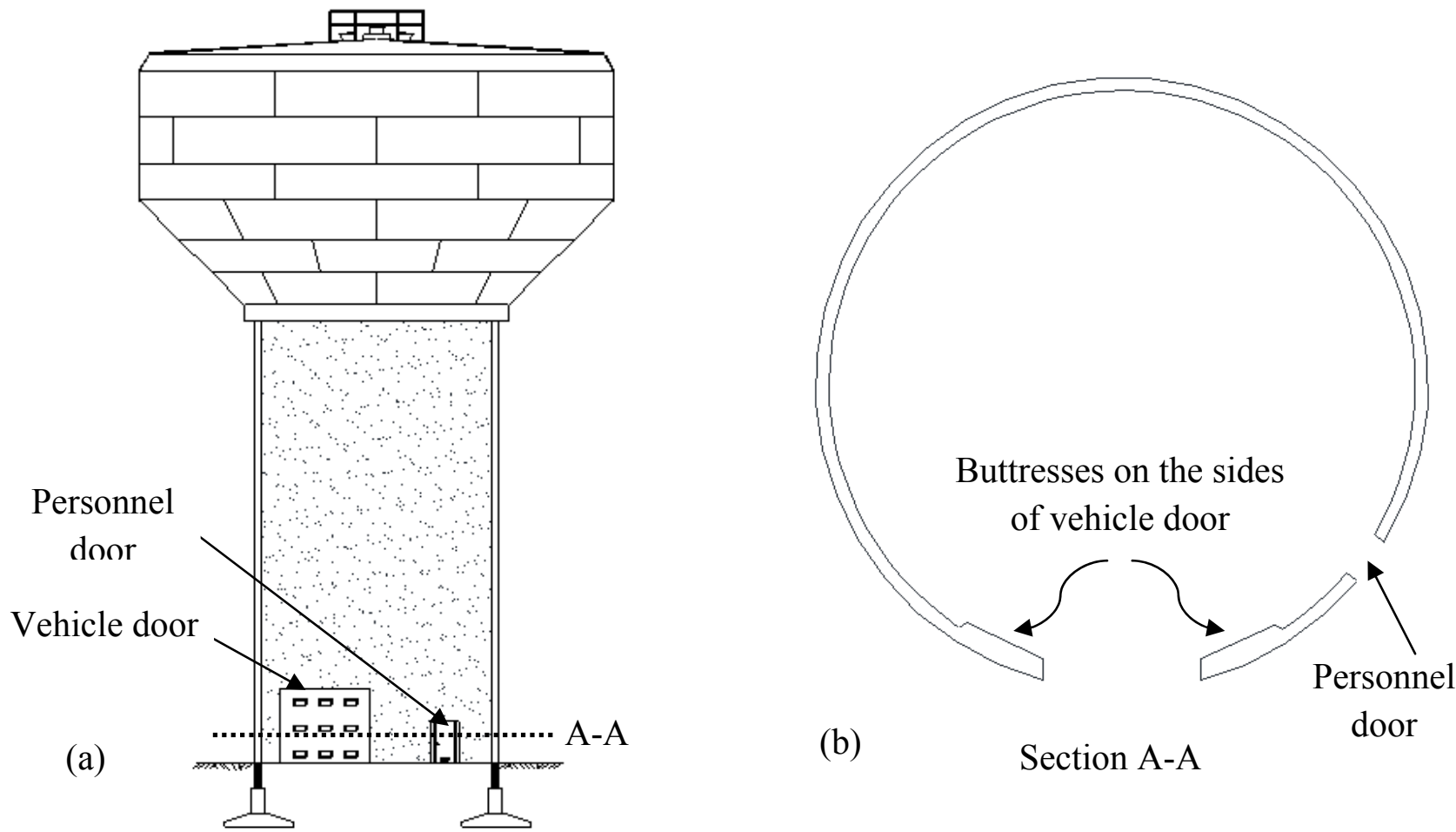

Figure 8.1 Openings in elevated water tanks (a) Elevation (b) section

\subsection{Code provisions and requirements for structural design of openings}

Based on the provisions of ACI371R-08, the wall openings are divided into two groups depending on the dimensions of the wall. If the width and height of the door are less than $0.9 \mathrm{~m}$ and $12 \mathrm{~h}_{\mathrm{r}}(3.6 \mathrm{~m}$ on average) respectively, then a simplified method is prescribed for structural design of the wall openings, otherwise a more elaborate analysis is required.

According to simplified method, which is commonly applicable to the personnel doors, the interrupted area of the wall is basically replaced by adding more reinforcement around the door opening. The code introduces minimum reinforcement criteria for around the wall opening. However, the simplified method is only applicable to the personnel door or any other opening that satisfies the maximum dimensions criteria. 
If the dimensions of the wall openings are larger than the above values, which is the case for all vehicle doors, then a more detailed method is prescribed by the code. The walls on the two sides of the opening must be designed as braced columns. This method is known as "equivalent column" approach in the code.

If designing the walls as equivalent columns does not meet the seismic design requirements, then a monolithic pilaster may be provided for the walls adjacent to the openings. ACI371R-08 requires the pilasters to extend above and below the opening by a length equal to half of the opening height. The pilasters provide significant lateral stiffness around the wall opening area as they increase the section size of the pedestal. ACI371R-08 also requires an additional band of horizontal reinforcement to be provided above and below the wall opening.

\subsection{Investigating the seismic response of RC pedestals with wall opening}

As discussed in previous section, the personnel doors have small dimensions comparing to the vehicle doors. The area of a vehicle door is approximately more than 10 times greater than the personnel doors. As a result, the effect of personnel doors on the seismic response of elevated water tanks is not as important as opposed to the vehicle doors. Due to the above reasons, in this study, only the effect of vehicle doors will be investigated.

The FE models of the RC pedestals and design assumptions were explained in Chapters 4 and 5 of this thesis. All of the finite element modeling assumptions which were described will remain the same in this chapter. The most typical vehicle door sizes are employed in the FE models. The effect of the wall opening on the seismic response characteristics of the elevated water tanks is evaluated by performing pushover analysis and investigating the pushover curves. 


\subsubsection{Critical direction of seismic loading in RC pedestals with wall opening}

Figure 8.2 demonstrates a typical FE model of elevated water tank with vehicle door included in the pedestal. The cross-section of the opening is provided in this figure as well. The pushover analysis of the model could be performed in three main lateral loading directions as shown in Figure 8.2(b). Each loading direction represents a possible path of subjecting to the seismic loads. In order to investigate the seismic response behaviour of elevated water tanks with opening, the critical seismic loading direction must be determined first.

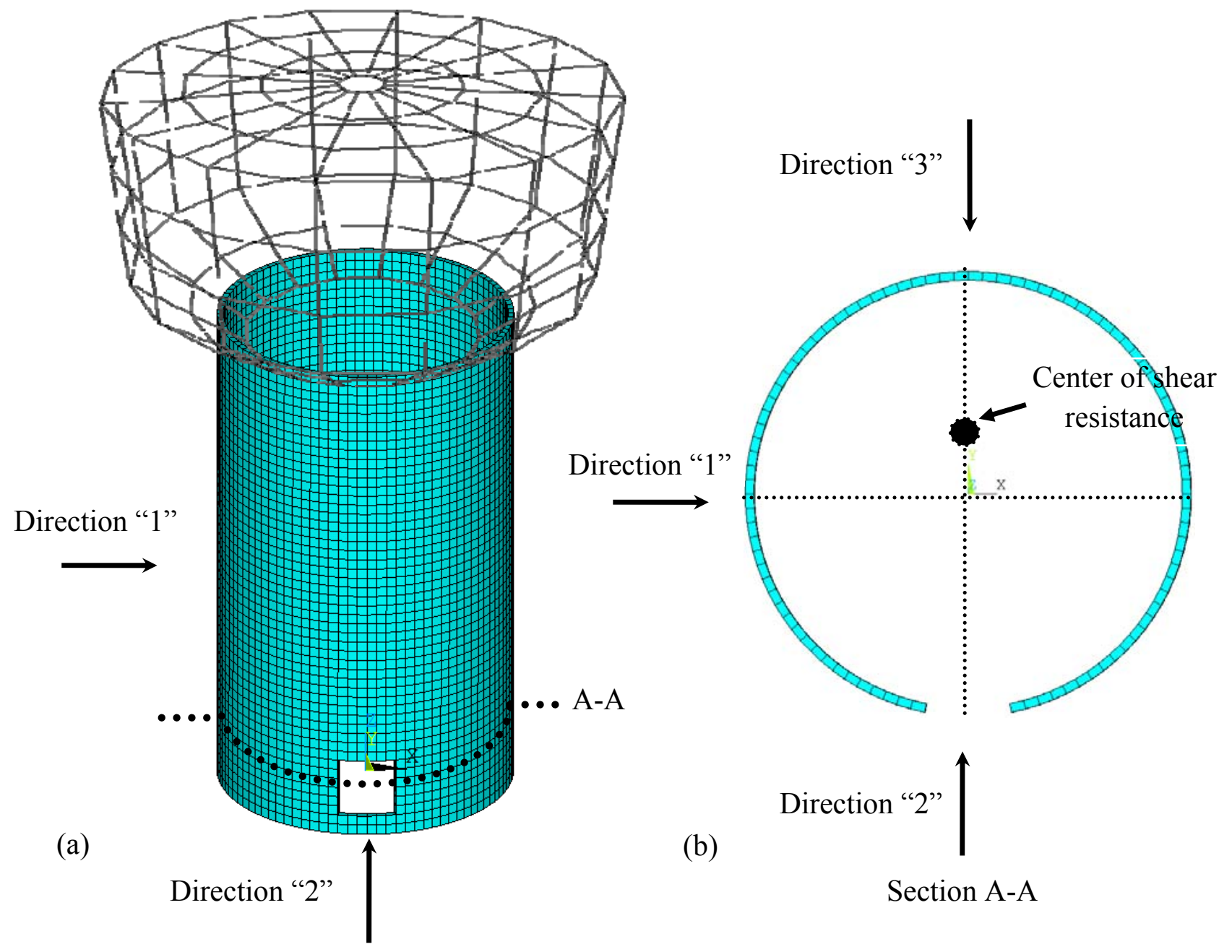

Figure 8.2 Critical loading direction of elevated water tanks with opening (a) Elevation (b) Section 
Direction "1" as shown in Figure 8.2 is parallel to the opening plane and therefore will develop significant shear stress in the opening region. By adding the opening to the FE model, the center of shear resistance displaces from the center as shown in Figure 8.2(b). This will cause torsional effects in the section when the model is subjected to lateral loading in direction "1".

Direction "2" is perpendicular to the opening plane and generates axial tension and flexure in the opening region. Direction " 3 " is perpendicular to the opening plane but creates compression and flexure in the opening. In order to determine and verify the critical loading among the above three lateral loading directions, two prototypes are selected for investigation. FE models $25-\mathrm{H}-$ 0.5 and $35-\mathrm{H}-3$ are chosen since they have height to diameter ratios of 2.9 and 1.3 respectively and therefore represent two different seismic response behaviours.

Each FE model is subjected to a nonlinear static analysis in all three directions. It must be noted that since this is only a comparative study for determining the critical loading direction, no pilaster is added to the openings at this point. The opening sizes for FE models $25-\mathrm{H}-0.5$ and $35-$ H-3 are $3 \times 3$ meters $\left(10^{\prime} \times 10^{\prime}\right)$ and $3.7 \times 3.7$ meters $\left(12^{\prime} \times 12^{\prime}\right)$ respectively. Additional horizontal and vertical reinforcement is added around the opening walls according to the code requirements. A vertical reinforcement ratio of approximately $3 \%$ is provided in the effective width of wall (between $1.5 \mathrm{~m}$ to $1.8 \mathrm{~m}$ ) adjacent to the openings.

The locations of the maximum total mechanical strain prior to failure in the FE model 25-H0.5 are shown in Figure 8.3. The response of this model to the lateral loading in direction "1" is shown in Figure 8.3(a). According to this figure, the maximum strains and damages are expected to occur on the sides of the opening and top of RC pedestal below the tank vessel. When the opening is under tension, which is the case in the direction " 2 " lateral loading, nearly the same damage pattern as direction "1" is observed as shown in Figure 8.3(b). 

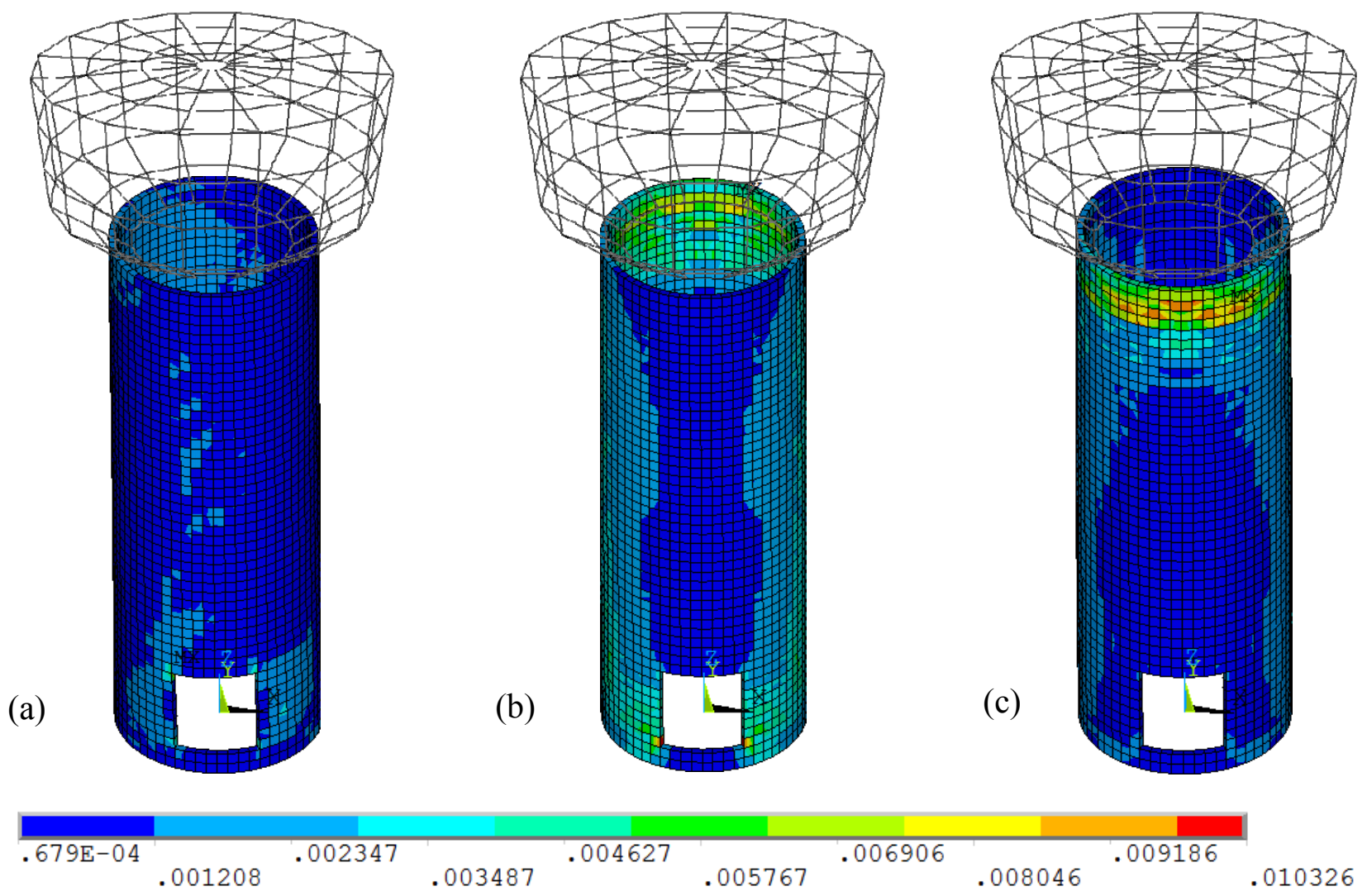

Figure 8.3 Maximum strain locations prior to failure in the FE model 25-H-0.5 subjected to lateral loading in (a) Direction "1" (b) Direction "2" (c) Direction "3" (contour is related to graph (a))

However, when the RC pedestal is subjected to lateral loading in direction " 3 ", as shown in Figure $8.3(\mathrm{c})$, the maximum strain and damages is likely to occur at the top of the pedestal and underside of the tank vessel and no considerable damage is observed around the opening.

The results of the pushover analysis are shown in Figure 8.4. According to Figure 8.4(a) which demonstrates the pushover curves of FE model $25-\mathrm{H}-0.5$ in the three loading directions, there is no significant difference between the maximum lateral deformations of the structure. This pattern is also observed in Figure 8.4(b) which displays the resulting pushover curves from pushover analysis of the FE model 35-H-3.

On the other hand, for both structures, the maximum lateral strength of the RC pedestal is lowest when the structure is subjected to lateral loading in Direction " 1 ". This pattern is also 
observed in other FE models. The obtained maximum base shear from loading in direction "1" is nearly $5 \%$ to $8 \%$ lower than the other two directions for all cases.
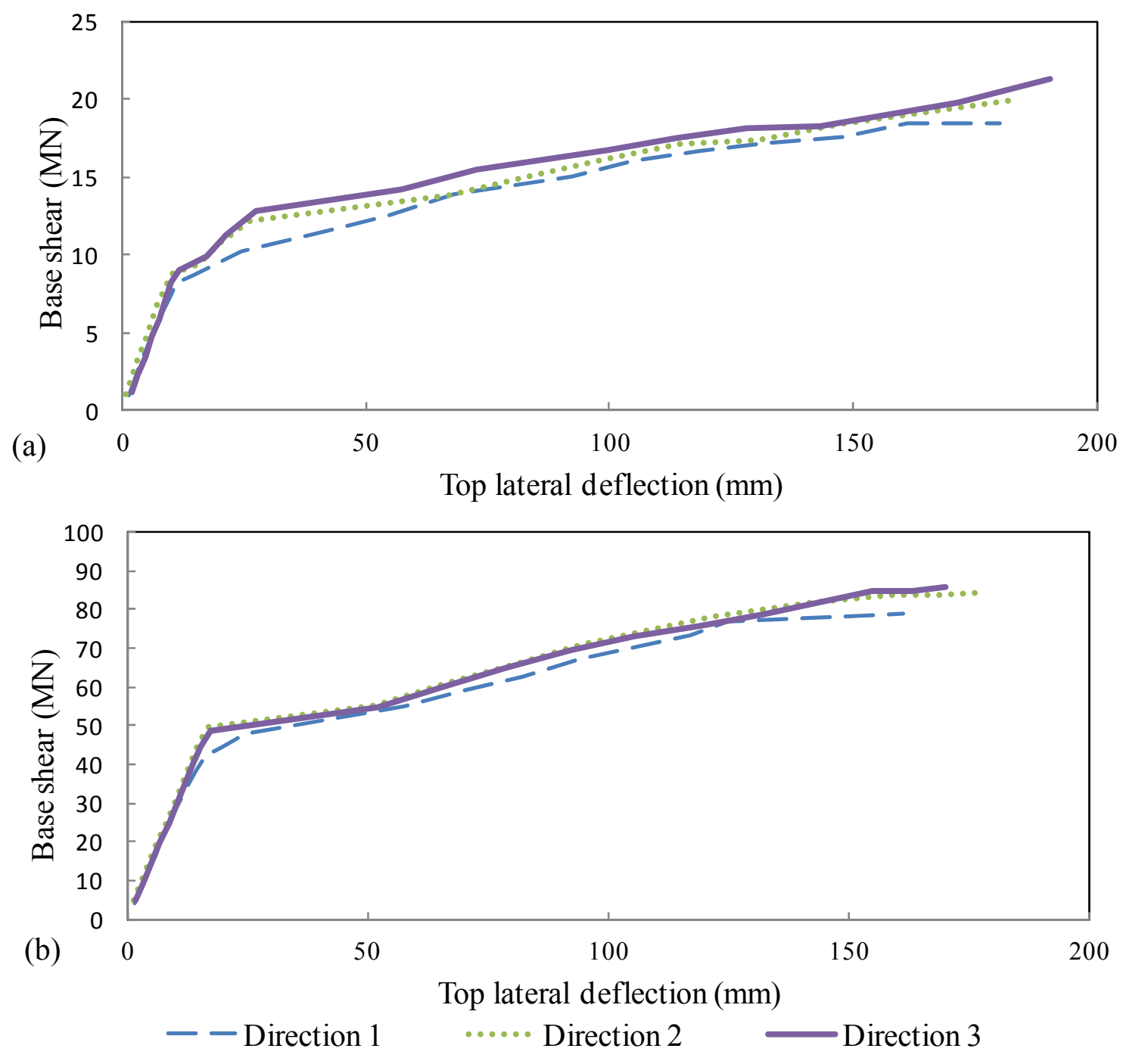

Figure 8.4 Comparison between pushover curves of loading in three directions (a) FE model 25-H-0.5 (b) FE model 35-H-3

It could be concluded that direction "1" is the most critical lateral loading direction for the RC pedestals with opening. For this reason, in the following sections, the seismic response of the RC pedestal with opening will be studied in loading direction " 1 ". 


\subsubsection{Seismic response characteristics of wall opening with pilaster (buttress)}

In this section, the seismic response of elevated water tanks with pilasters constructed on the adjacent walls of the openings is investigated. The pilasters are included as the FE models were originally designed for high seismicity zones. The FE models introduced in Chapter 5 as the pilot group are employed for this study. Depending on the RC pedestal and vehicle door sizes, the dimensions of the pilasters are determined. The openings height and width range from 3 to 4.2 meters.

The minimum thickness of the pilaster is $150 \mathrm{~mm}$ greater than wall thickness. The width of the pilasters ranges between a minimum of $1.1 \mathrm{~m}$ to $1.5 \mathrm{~m}$ depending on the size of opening. An additional vertical reinforcement of up to $3 \%$ is provided in the pilasters as well.

The pilasters extend by a height of $0.5 h_{d}$ above the opening. The parameter $h_{d}$ represents the height of the vehicle door. They also extend below the opening to the top of foundation level (base support). This is because ACI371R-08 requires the pilaster to extend by $0.5 \mathrm{~h}_{\mathrm{d}}$ below the opening which is generally greater than the distance from the bottom of the doors to the top of the foundation level. Additional horizontal reinforcement is added above and below the opening according to ACI371R-08.

Next, pushover analysis is conducted on each of the five FE models of the pilot group. As discussed before, direction "1" was determined as the critical lateral loading path and therefore chosen for this analysis. Figure 8.5 demonstrates three steps of applying increasing horizontal loads for FE models $35-\mathrm{H}-1$ and $35-\mathrm{H}-3$. Each step shows the propagation in cracking of the RC pedestals. In both models, the cracking begins around the top of opening region where a combination of web-shear and flexural shear cracks are developed. The pushover curves for all five models are constructed and will be evaluated in the next section. 

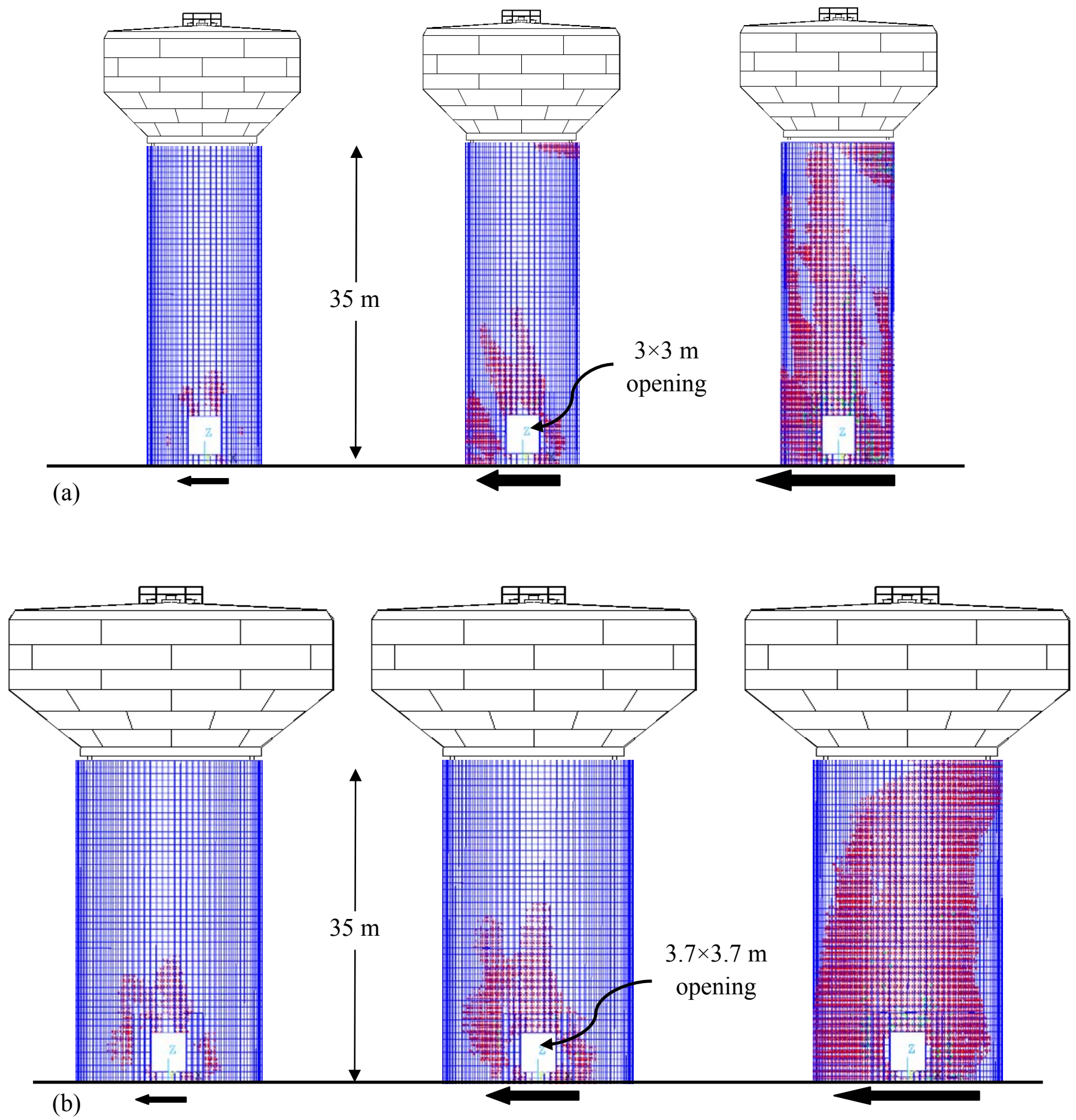

Figure 8.5 Cracking propagation of RC pedestals with pilaster at openings subjected to increasing lateral loading in pushover analysis (a) three stages of increasing lateral loads for model $35-\mathrm{H}-1$ (b) three stages of increasing lateral loads for model $35-\mathrm{H}-3$ 


\subsubsection{Results of pushover analysis}

Figure 8.6 shows the pushover curves belonging to the five FE models of pilot group. In each graph two curves are demonstrated. The solid line represents the pushover curve of the FE model without opening which was discussed and analysed in Chapters 5 and 6 in detail. The second curve (dashed line) belongs to the same structure with an opening (vehicle door) in the pedestal. The openings are designed according to the provisions of ACI371R-08 and are strengthened by adding pilasters as described in Section 8.4.2.

A comparison between the two curves reveals that for all models, the RC pedestal with opening is capable of demonstrating nearly the same maximum lateral deformation as the RC pedestal without opening. In addition, maximum base shear capacity of RC pedestals with opening is only slightly lower than pedestals without opening. This difference approximately ranges ranges from $3.5 \%$ to $7 \%$.

The effect of opening in the stiffness of the RC pedestal section is more distinctive for smaller size tanks as they have lower diameter pedestals and therefore the opening cross section area

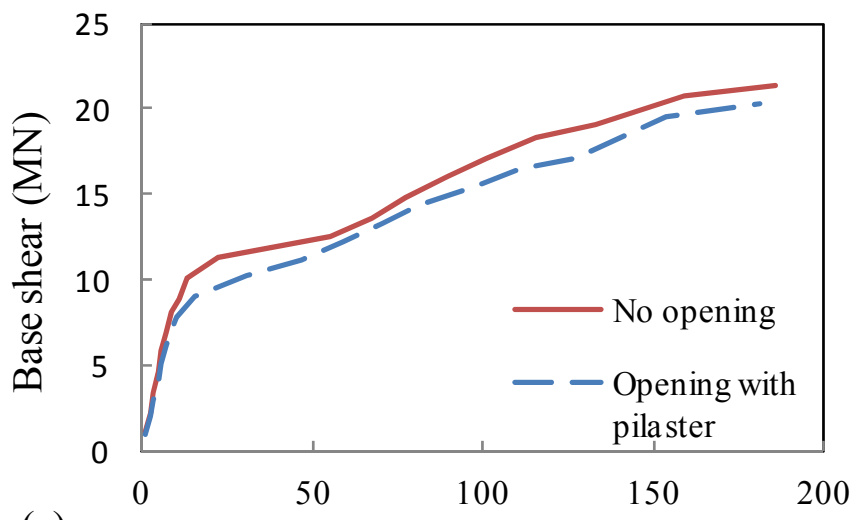

(a)

Top lateral deflection $(\mathrm{mm})$

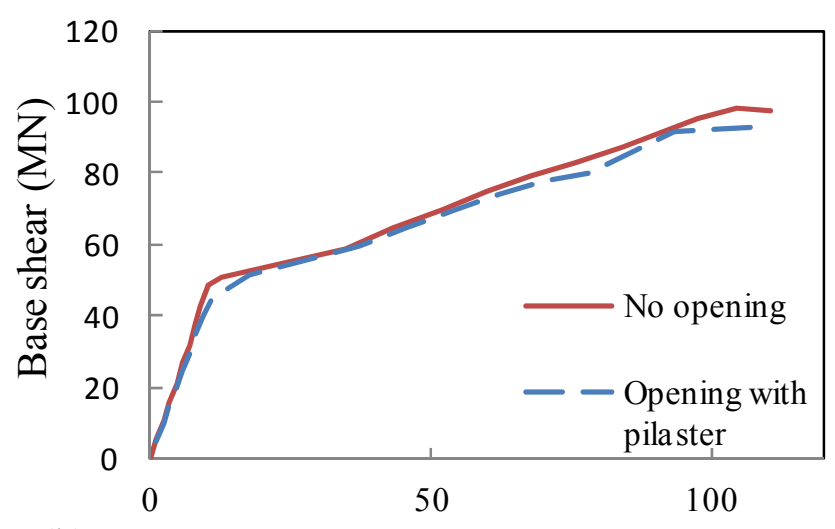

(b)

Top lateral deflection (mm)

Figure 8.6 Pushover curves for group (a) model 25- $\mathrm{H}-0.5$ (b) model 25-H-3

(c) model 35-H-0.5 (d) model 35-H-1 (e) model 35-H-3 


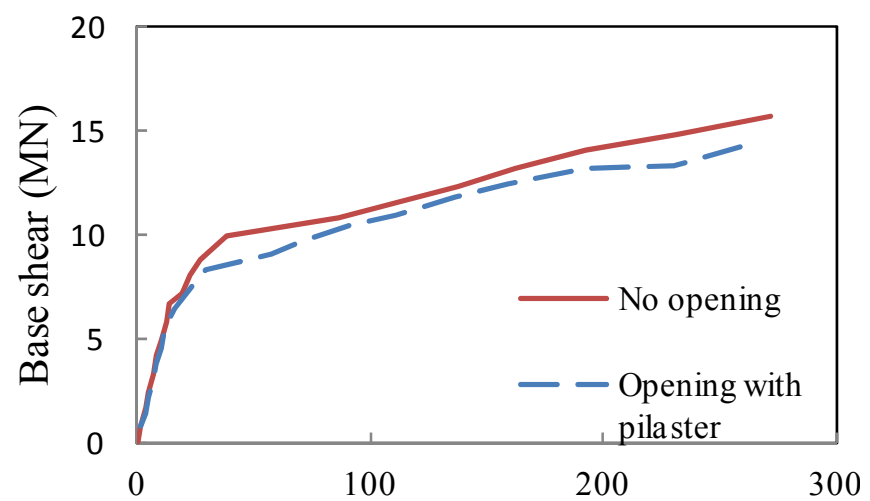

(c)

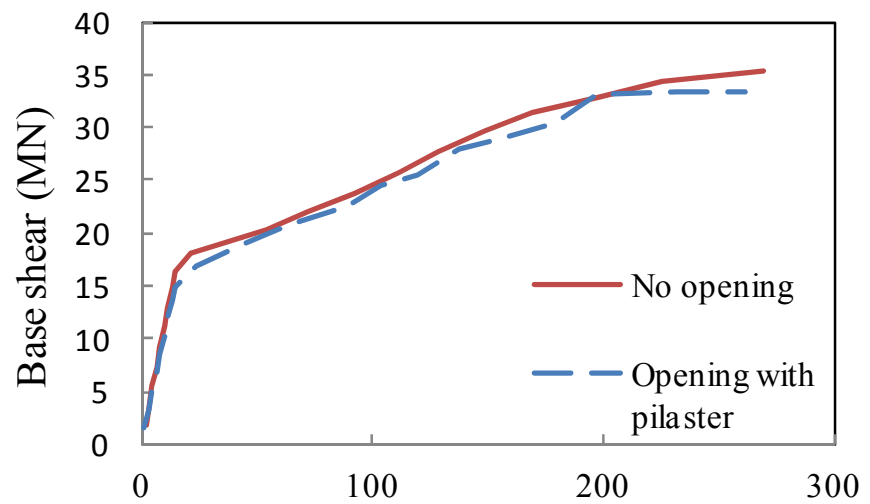

(d)

Top lateral deflection $(\mathrm{mm})$

(e)

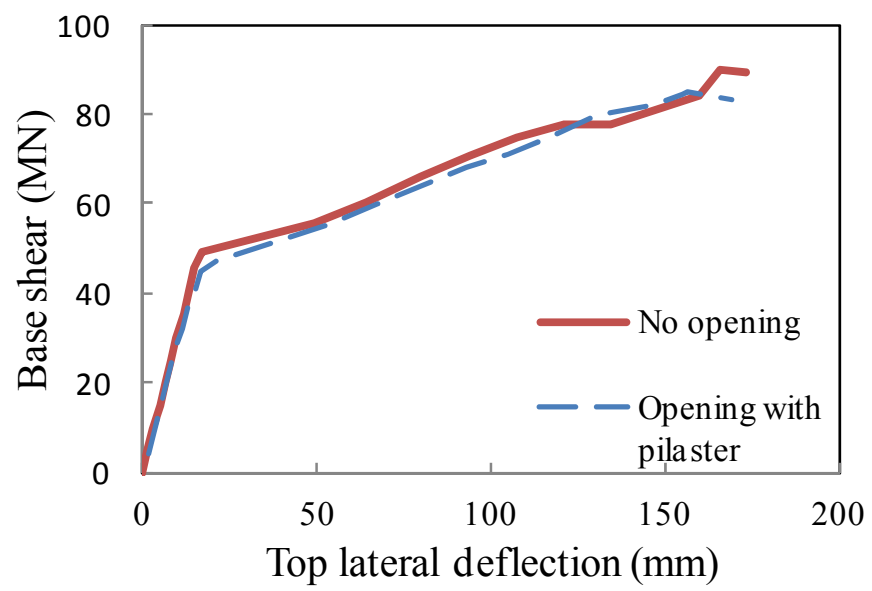

Figure 8.6 (Cont.)

represents a higher percentage of total cross section. This is demonstrated in Figures 8.6(a) and (c) for pushover curves of FE models $25-\mathrm{H}-0.5$ and $35-\mathrm{H}-0.5$ respectively. The primary yield occurs under lower base shear for these models which is an indication of lower lateral stiffness.

The pushover curves of Figure 8.6 have shown that if the openings are designed in accordance with the provisions of ACI371R-08, they have negligible influence on the seismic response factors of the pedestals with opening comparing to same pedestals without opening.

The highest reduction of base shear capacity (less than 7\%) is observed in light tank groups which were shown to have highest overstrength in Chapter 5 and hence having insignificant change in overstrength factor. 
In addition, the ductility factor will not be affected as all the pedestals with opening are capable to demonstrate nearly the same maximum lateral deflection as the pedestals without opening.

The response modification factor of a structure as discussed in Chapter 5 is a function of the product of overstrength factor and ductility factor. These factors are in turn mainly dependent on maximum base shear and displacement of structure obtained from the pushover curve. None of these factors as shown in Figure 8.6 are significantly changed. As a result, it could be concluded that the response modification factor ( $\mathrm{R}$ factor) of elevated water tanks will not be affected by openings in the RC pedestals provided the openings are designed based on the requirements of ACI371R-08.

\subsection{Shear strength of RC pedestals}

The shear stress is generated in the RC pedestal section as a result of seismic and wind lateral loads. The section of an RC pedestal consists of curved RC walls and therefore the seismic response behaviour and shear strength of the RC pedestal resembles those of RC shear walls. It is for this reason that some equations that are employed for structural design of RC pedestals are either adapted or similar to the formulas implemented for design of $\mathrm{RC}$ walls. One example of such adaptations is the shear strength equation which is used for designing RC pedestals.

The current nominal shear strength equation in ACI371R-08 is adopted from ACI 318-08 formula for calculation of nominal shear strength of RC walls with some modifications. In this equation the shear strength is determined by adding the strength of concrete $\left(\mathrm{V}_{\mathrm{c}}\right)$ and steel $\left(\mathrm{V}_{\mathrm{s}}\right)$. However, there is a major difference between the RC shear walls and RC pedestal which is the significant axial compression existing in the elevated water tanks. 
The axial compression in the RC shear walls of building structures is commonly not considerable comparing to the RC pedestal. This is due to the heavy weight of the water tanks comparing to the typical gravity loads existing in frame structures and buildings. Furthermore, the seismic shear force generated in the RC pedestal is mostly the result of the tank weight as it usually consists around $80 \%$ of the overall gravity load of the elevated water tanks.

As a result, the seismic shear force is directly related to the axial compression in the RC pedestal and therefore this effect must be included in the pedestal shear strength formula. In an extreme case, when the tank is empty, although the axial compression decreases, the maximum seismic shear force decreases proportionally as well. This part of the chapter intends to investigate the effect of axial compression in the shear strength of the RC pedestal by employing a finite element approach and conducting pushover analysis.

\subsubsection{Effect of axial compression in shear strength of RC walls}

The beneficial effects of axial compression in enhancing the shear resistance of the RC shear walls has been studied and investigated in many research studies. Mickleborough et al (1999) conducted an extensive experimental and numerical study on RC shear walls with various height to width ratios and axial compression. It was shown that increasing the vertical load could significantly enhance the shear strength of the RC walls. The experimental results were also verified by finite element analysis conducted in this study as described in Chapter 4 (Section 4.6.2).

Kowalsky and Priestley (2000), proposed a model for the calculation of shear strength of RC walls which is shown in Equation 8.1:

$V_{n}=V_{c}+V_{s}+V_{p}$ 
Where $\mathrm{V}_{\mathrm{c}}$ and $\mathrm{V}_{\mathrm{s}}$ represent concrete and horizontal reinforcement contribution respectively. In addition the term $\mathrm{V}_{\mathrm{p}}$ is introduced which stands for the contribution of axial compression in shear strength of RC wall.

Mander et al (2001) proposed an equation similar to Equation 8.1 for calculating the shear strength of RC members. This equation represents the term $V_{p}$ as the product of three parameters. The first parameter is the fixity factor which is determined in accordance with member supports and restrains. The second factor is the axial compression load and the last one represents member length and internal lever arm.

Krolicki et al (2011), proposed a new shear strength model which is basically a modified version of the shear model proposed by Kowalsky and Priestley (2000) and includes the term $V_{p}$ in order to consider the axial compression effect. Their proposed equation calculates the shear capacity and predicts the displacement ductility of reinforced concrete walls in diagonal tension. The term $\mathrm{V}_{\mathrm{p}}$ in their proposed equation is a function of axial compression, height and width of $\mathrm{RC}$ wall and the supporting condition.

\subsubsection{Provisions of ACI371R-08 for calculating shear strength of RC walls}

Currently ACI371R-08 uses Equation 8.2 for calculating the nominal shear strength of RC pedestals:

$V_{n}=\left(\alpha_{c} \sqrt{f_{c}^{\prime}}+\rho_{h} f_{y}\right) A_{c v}$

Where

$\mathrm{f}_{\mathrm{c}}{ }_{\mathrm{c}}=$ Specified compressive strength of concrete

$\rho_{\mathrm{h}}=$ Ratio of horizontal reinforcement 
$f_{y}=$ Specified yield strength of steel

$A_{c v}=$ Effective shear area (further explained in Section 8.7.1)

$\alpha_{c}=$ a parameter which represents the type of cracking and height to diameter ratio of pedestal (further explained in next section)

Equation 8.1 is in the factored form and could be expanded as shown in Equation 8.3:

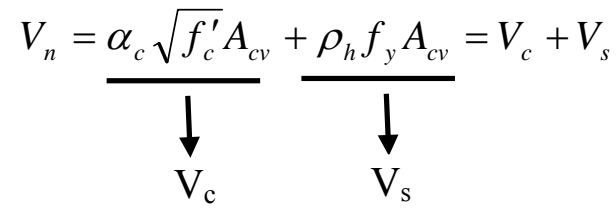

It could be observed that Equation 8.2 only takes into account the contribution of concrete and steel strength for determining the nominal shear strength of RC pedestal. This equation does not include the contribution of axial compression in the shear strength of RC pedestal. In other words, this formula does not differentiate between an empty and a full tank condition.

However, since the water inside the tank could consist up to nearly $70 \%$ of the overall gravity load of the elevated water tank structure, there is a significant difference between the seismic shear forces induced in empty and full tank states.

\subsubsection{Effective shear area $\left(A_{c v}\right)$}

According to ACI371R-08, the shear force is resisted by two parallel shear walls with a maximum length of $0.78 \mathrm{~d}_{\mathrm{w}}$ and width of $\mathrm{h}_{\mathrm{r}}$ as demonstrated in Figure 8.7. If an opening exists in the pedestal then the area of the opening cross-section must be deducted from the wall area. Equation 8.4 gives the effective shear area based on ACI371R-08:

$A_{c v}=2 b_{v} h_{r}$ (no opening in pedestal)

$A_{c v}=2 b_{v} h_{r}-b_{x} h_{r} \quad$ (opening included) 
Where $b_{x}$ represents the cumulative width of openings, $h_{r}$ is the wall thickness and $d_{w}$ is the mean diameter of the pedestal.
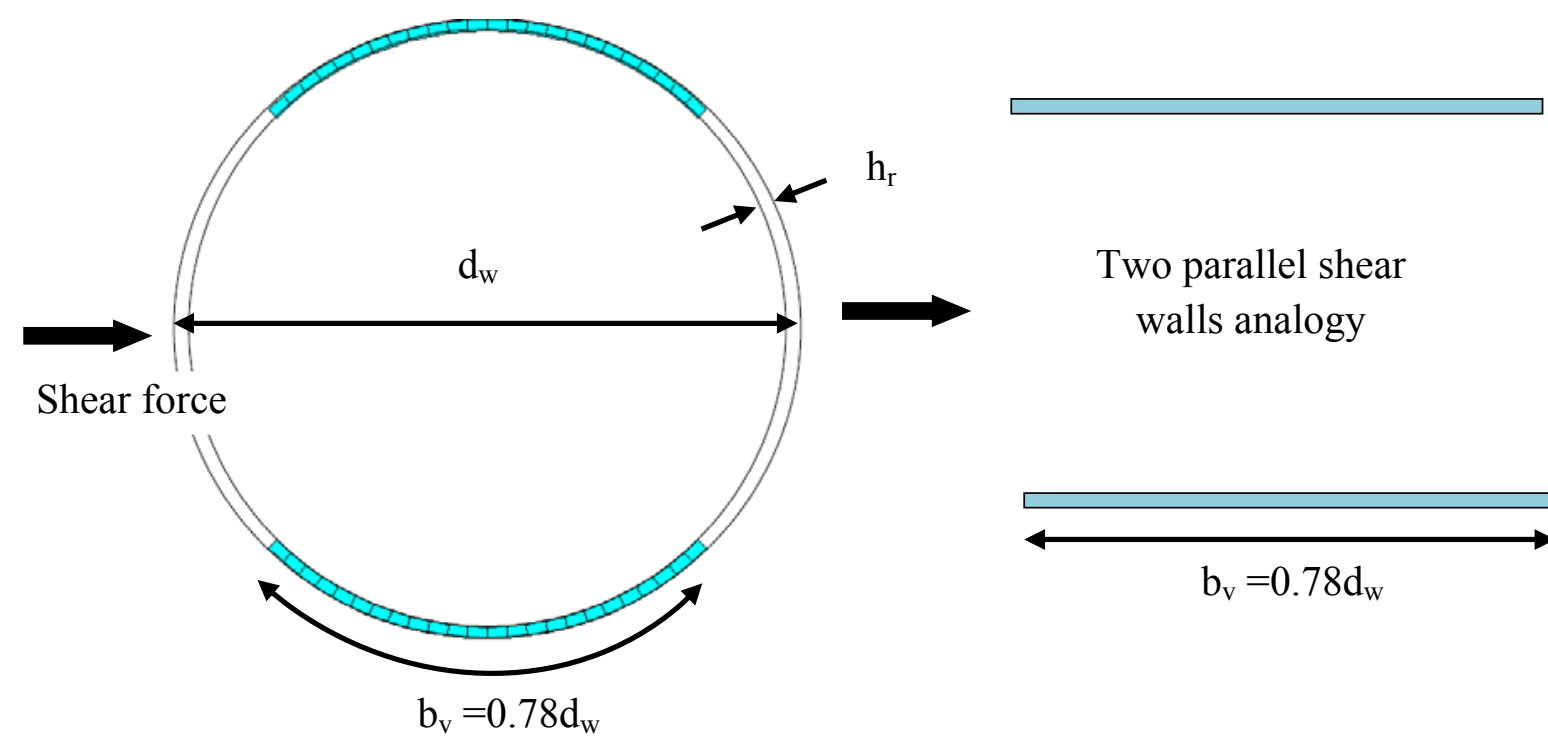

Two parallel shear walls analogy

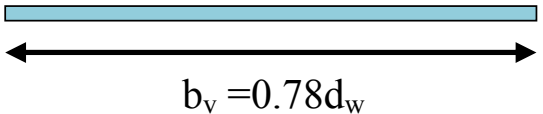

Figure 8.7 The parallel shear walls analogy based on ACI371R-08

The parameter $\alpha_{c}$ is determined in accordance with cracking pattern and is a factor of height to width ratio of the $\mathrm{RC}$ wall. When the height to width ratio is greater than 2 , a flexure-shear cracking is expected and $\alpha_{c}$ is taken as 0.16 . If the height to width ratio is less than 1.5 , then a web-shear is predicted and $\alpha_{c}$ is equal to 0.25 .

\subsubsection{Investigating the maximum shear strength of RC pedestals}

In previous chapters, the maximum bases shear capacity of the prototypes of elevated water tanks were determined by means of pushover analysis and finite element modeling. The maximum base shear represents the maximum shear strength that may be developed in the RC 
pedestal section. In order to investigate the beneficial effects of axial compression, a similar finite element approach is employed in this chapter.

In total, 12 prototypes are selected for this study. The prototypes are chosen from the $\mathrm{R}=3$ design group. A pushover analysis is performed on FE models of prototypes under three gravity loading states of full, half full and empty tank. From each analysis case, the maximum base shear is determined and compared to the nominal shear strength computed based on ACI371R-08.

\subsubsection{Results of pushover analysis}

The results of pushover analysis of three FE models $25-\mathrm{H}-0.5,25-\mathrm{H}-2$ and $25-\mathrm{H}-3$ are shown in Figure 8.8. The nominal shear strength $\left(\mathrm{V}_{\mathrm{n}}\right)$ of the $\mathrm{RC}$ pedestal which is determined base on Equation 8.2 is included in each graph as well.

In all three graphs, the nominal shear strength is below the maximum shear strength calculated for the full tank state. As the tank size increases, the horizontal line which represents $\mathrm{V}_{\mathrm{n}}$, is gradually moving upward. In other words, the code shear strength is lowest for FE models 25-H-0.5 which belongs to the light tank size group. The maximum calculated shear strength for this FE model is in the full tank state and is equal to $15 \mathrm{MN}$ which is approximately 1.5 times greater than the nominal shear strength of $9.9 \mathrm{MN}$ determined according to the code.

For larger tank sizes, $V_{n}$ gives a closer estimation of maximum shear strength to the one determined by finite element models. This is depicted in Figure 8.8(b) for FE model 25-H-2 in which the nominal shear strength line reaches to the maximum shear strength corresponding to half full tank state. In this case the code nominal shear strength is approximately $83 \%$ of the finite element model shear strength in full tank state. 

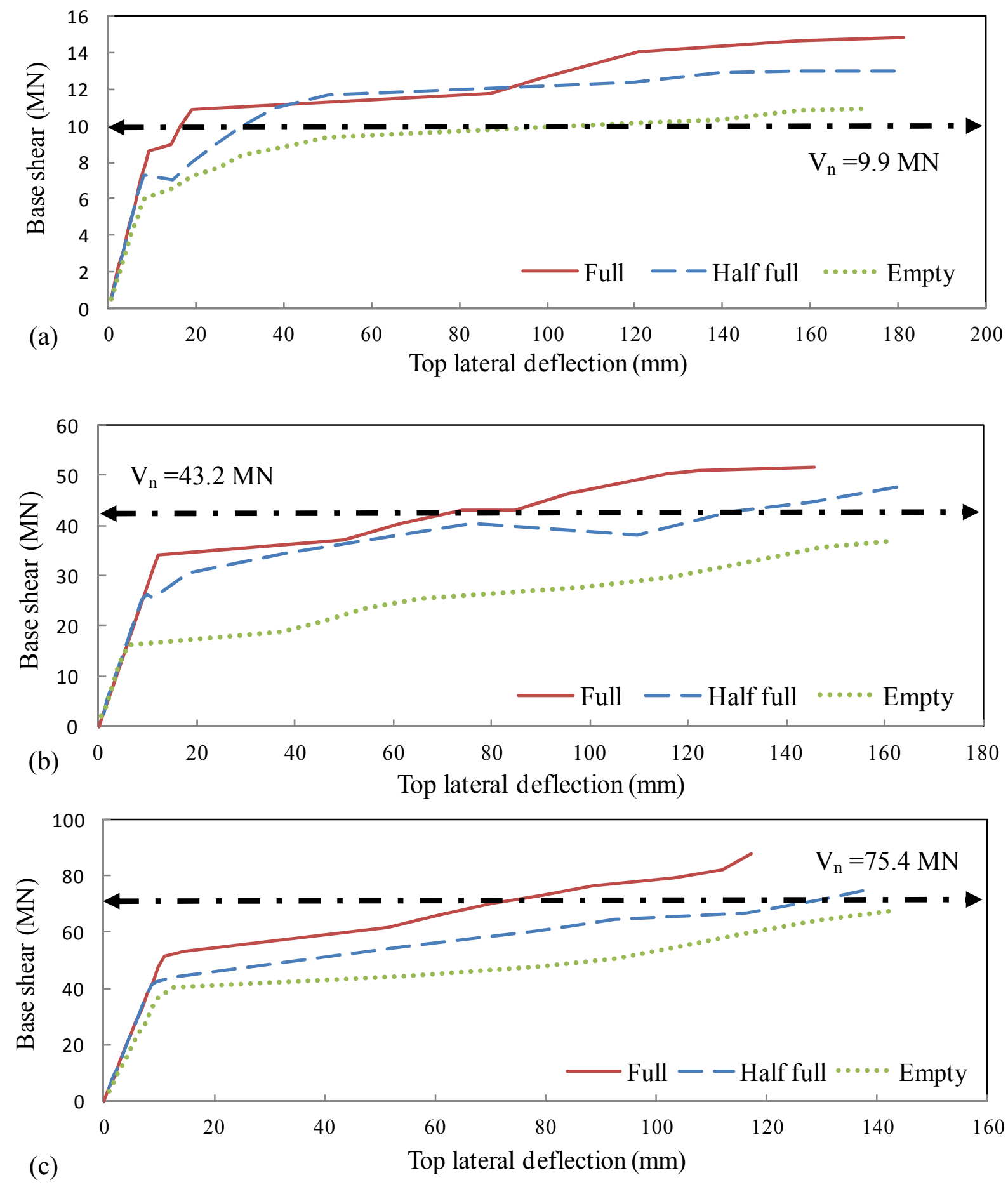

Figure 8.8 Pushover curves for three loading states of full, half full and empty tank (a) FE model 25-H-0.5 (b) FE model 25-H-2 (c) FE model 25-H-3 
Table 8.1 Summary of the calculated shear strength based on finite element model and pushover analysis for 12 prototypes

\begin{tabular}{ccccccc}
\hline FE model ID & $\mathrm{h} / \mathrm{d}_{\mathrm{w}}$ & $\begin{array}{c}\text { Average axial } \\
\text { compression } \\
(\mathrm{Mpa})\end{array}$ & $\begin{array}{c}\mathrm{V}_{\mathrm{n}}(\mathrm{MN})- \\
\text { Code }\end{array}$ & Empty & $\begin{array}{c}\text { Half } \\
\text { full }\end{array}$ & Full \\
\hline $15-\mathrm{H}-0.5$ & 1.7 & 2.9 & 13.0 & 17 & 21 & 22.9 \\
\hline $15-\mathrm{H}-1$ & 1.3 & 3.5 & 26.1 & 26 & 33 & 36.8 \\
\hline $15-\mathrm{H}-2$ & 1.0 & 5.1 & 47.7 & 45 & 51 & 55.5 \\
\hline $25-\mathrm{H}-0.5$ & 2.9 & 3.2 & 9.9 & 10 & 12.5 & 14.9 \\
\hline $25-\mathrm{H}-2$ & 1.7 & 5.4 & 43.2 & 37 & 50 & 51.7 \\
\hline $25-\mathrm{H}-3$ & 1.3 & 5.5 & 75.4 & 67 & 78 & 87.7 \\
\hline $35-\mathrm{H}-0.5$ & 4.1 & 3.4 & 7.1 & 8 & 11.2 & 12.2 \\
\hline $35-\mathrm{H}-1$ & 2.9 & 4.0 & 17.6 & 18 & 21 & 25.8 \\
\hline $35-\mathrm{H}-3$ & 1.8 & 5.8 & 60.0 & 49 & 65.5 & 70.0 \\
\hline $45-\mathrm{H}-0.5$ & 5.2 & 3.7 & 5.5 & 6 & 8.5 & 10.0 \\
\hline $45-\mathrm{H}-1$ & 3.8 & 4.3 & 13.5 & 14.7 & 17.9 & 20.2 \\
\hline $45-\mathrm{H}-3$ & 2.3 & 6.1 & 46.0 & 37 & 51.2 & 59.9 \\
\hline
\end{tabular}

Finally, as displayed in Figure 8.8(c), the FE model 25-H-3 (with the heaviest tank size) gives the closest estimation of shear strength to the nominal shear strength based on ACI 371R-08. In this model, the nominal shear strength (based on ACI 371R-08) is $86 \%$ of the FE model shear strength in full tank state.

Table 8.1 gives a summary of pushover analysis results of the twelve FE models under three loading states of full, half full and empty tank. The third column in this table is the "average axial compression" which is equal to the total nominal gravity load of each elevated water tank at the base in the full tank state divided by the cross-section area of the pedestal.

The results of Table 8.1 are presented as column chart in Figure 8.9 for a better comparison between the shear strength calculated from code and finite element analysis for empty and full tank conditions. As Figure 8.9 indicates, for all twelve FE models, the code nominal shear strength is below the finite element model shear strength in the full tank state. 
In addition, for all of the FE models with light and medium tank size (0.5 and $1 \mathrm{MG})$, the nominal shear strength according to the code $\left(\mathrm{V}_{\mathrm{n}}\right)$, is equal or less than the maximum shear strength of the RC pedestal in empty tank state.

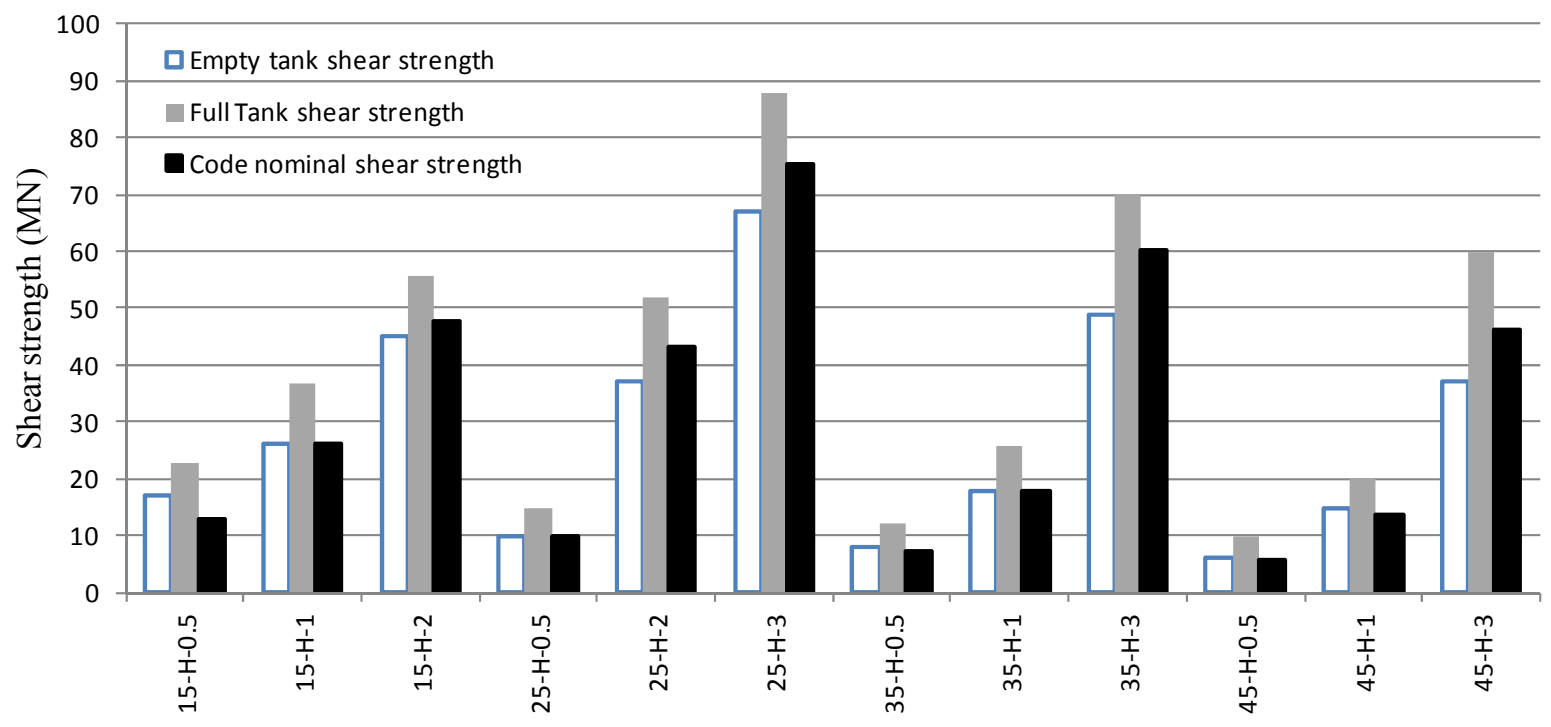

FE model ID

Figure 8.9 Comparison between the calculated shear strength and code nominal shear strength in two states of full and empty tank

On the other hand, in the heavy tank size models, the code nominal shear strength ranges between the empty and full state FE model shear strength.

\subsubsection{Evaluating the results of pushover analysis}

The correlation between code and finite element shear strength of RC pedestal with parameters such as tank size, axial compression and height to width ratio is discussed hereafter. The relationship between $\mathrm{V}_{\mathrm{n}} / \mathrm{V}_{\text {empty }}$ and $\mathrm{V}_{\mathrm{n}} / \mathrm{V}_{\text {Full }}$ with the tank size is depicted in Figure 8.10. $V_{\text {Full }}$ and $V_{\text {Empty }}$ represent the shear strength calculated with FE models for full and empty tank state respectively. In both graphs a linear trend line is added which specifies that the ratios of $\mathrm{V}_{\mathrm{n}} / \mathrm{V}_{\text {empty }}$ and $\mathrm{V}_{\mathrm{n}} / \mathrm{V}_{\text {Full }}$ are increasing as the tank size increases. 

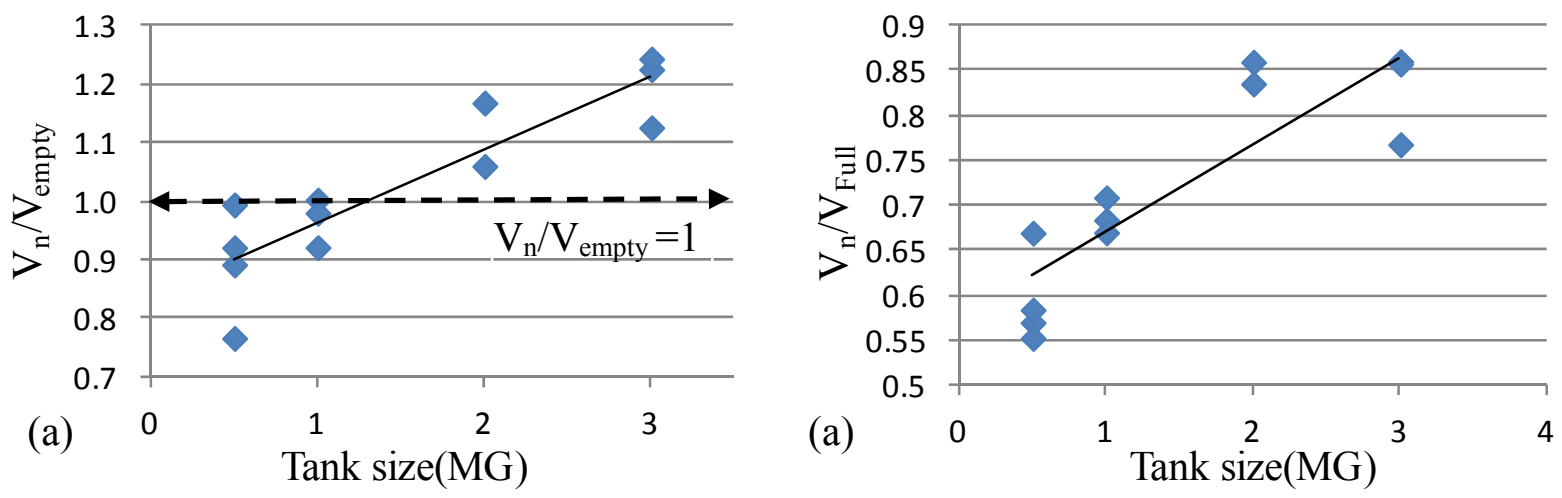

Figure 8.10 Tank size versus (a) $\mathrm{V}_{\mathrm{n}} / \mathrm{V}_{\text {empty }}$ (b) $\mathrm{V}_{\mathrm{n}} / \mathrm{V}_{\text {Full }}$

The ratio of $\mathrm{V}_{\mathrm{n}} / \mathrm{V}_{\text {Full }}$ is as low as 0.55 for the lightest tanks which as discussed before indicates that the code estimation of shear strength is nearly half of the FE model shear strength in full tank state. This ratio increases and reaches to the maximum of 0.85 for heavy tanks as shown in Figure 8.10(b). Figure 8.10(a) shows that the $\mathrm{V}_{\mathrm{n}} / \mathrm{V}_{\text {empty }}$ ratio is below one for light and medium tank sizes. In other words, the code estimates the shear strength equal or lower than the FE model shear strength in the empty tank state (very low axial compression in pedestal). Table 8.2 gives a summary of $\mathrm{V}_{\mathrm{n}} / \mathrm{V}_{\text {empty }}, \mathrm{V}_{\text {Full }} / \mathrm{V}_{\mathrm{n}}$ and $\mathrm{V}_{\text {full }} / \mathrm{V}_{\text {empty }}$ for all twelve prototypes.

Table 8.2 Summary of the calculated shear strength based on finite element model and pushover analysis for twelve prototypes

\begin{tabular}{cccc}
\hline FE model ID & $\mathrm{V}_{\mathrm{n}} / \mathrm{V}_{\text {empty }}$ & $\mathrm{V}_{\text {Full }} / \mathrm{V}_{\mathrm{n}}$ & $\mathrm{V}_{\text {full }} / \mathrm{V}_{\text {empty }}$ \\
\hline $15-\mathrm{H}-0.5$ & 0.8 & 1.8 & 1.3 \\
\hline $15-\mathrm{H}-1$ & 1.0 & 1.4 & 1.4 \\
\hline $15-\mathrm{H}-2$ & 1.1 & 1.2 & 1.2 \\
\hline $25-\mathrm{H}-0.5$ & 1.0 & 1.5 & 1.5 \\
\hline $25-\mathrm{H}-2$ & 1.2 & 1.2 & 1.4 \\
\hline $25-\mathrm{H}-3$ & 1.1 & 1.2 & 1.3 \\
\hline $35-\mathrm{H}-0.5$ & 0.9 & 1.7 & 1.5 \\
\hline $35-\mathrm{H}-1$ & 1.0 & 1.5 & 1.4 \\
\hline $35-\mathrm{H}-3$ & 1.2 & 1.2 & 1.4 \\
\hline $45-\mathrm{H}-0.5$ & 0.9 & 1.8 & 1.7 \\
\hline $45-\mathrm{H}-1$ & 0.9 & 1.5 & 1.4 \\
\hline $45-\mathrm{H}-3$ & 1.2 & 1.3 & 1.6 \\
\hline \multicolumn{5}{c}{198} & &
\end{tabular}


According to Table 8.2 the ratio of $\mathrm{V}_{\text {Full }} / \mathrm{V}_{\mathrm{n}}$ ranges between 1.2 for heaviest tanks to 1.8 for lightest tank sizes. The two ratios of $\mathrm{V}_{\mathrm{n}} / \mathrm{V}_{\text {empty }}$ and $\mathrm{V}_{\mathrm{n}} / \mathrm{V}_{\text {Full }}$ versus the average axial compression are depicted in Figure 8.11.
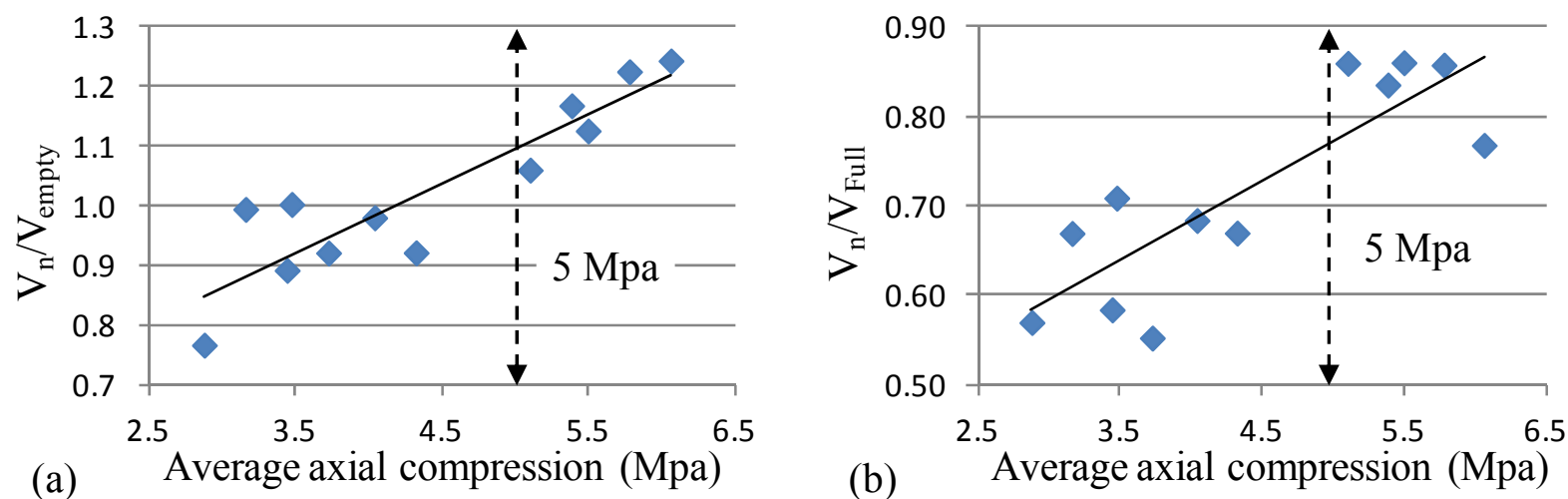

Figure 8.11 Average axial compression versus (a) $\mathrm{V}_{\mathrm{n}} / \mathrm{V}_{\text {empty }}(\mathrm{b}) \mathrm{V}_{\mathrm{n}} / \mathrm{V}_{\text {Full }}$

The average axial compression is related to the tank size and pedestal dimensions. The linear trend lines in both graphs are indicating that the ratios of $V_{n} / V_{\text {empty }}$ and $V_{n} / V_{\text {Full }}$ are increasing as the average axial compression increases. This is consistent with the results of Figure 8.10.

As shown in both graphs, the average axial compression of 5 Mpa separates the $V_{n} / V_{\text {empty }}$ as well as $\mathrm{V}_{\mathrm{n}} / \mathrm{V}_{\text {Full }}$ values. The ratio of $\mathrm{V}_{\mathrm{n}} / \mathrm{V}_{\text {Full }}$ has an average of 0.65 when axial compression is below $5 \mathrm{Mpa}$. On the other hand, when the axial compression is above $5 \mathrm{Mpa}$, the $\mathrm{V}_{\mathrm{n}} / \mathrm{V}_{\text {Full }}$ ratio has an average of 0.85 . Moreover, Figure 8.11(a) shows that the $\mathrm{V}_{\mathrm{n}} / \mathrm{V}_{\text {empty }}$ ratio is in the range of 0.9 to 1 for average axial compression below $5 \mathrm{Mpa}$. This ratio varies approximately from 1.1 to 1.2 when average axial compression is above $5 \mathrm{Mpa}$.

The relationship between $V_{\text {Full }} / V_{\text {empty }}$ and $V_{n} / V_{\text {Full }}$ with height to diameter $\left(h / d_{w}\right)$ of $R C$ pedestals is shown in Figure 8.12. The ratio of $\mathrm{V}_{\text {Full }} / \mathrm{V}_{\text {empty }}$ is a good representation to measure the effect of axial load in increasing the shear strength of pedestals. As Figure 8.12 (a) shows, 
$\mathrm{V}_{\text {Ful }} / \mathrm{V}_{\text {empty }}$ increases as the $\mathrm{h} / \mathrm{d}_{\mathrm{w}}$ increases. In other words the effect of axial compression is more significant in pedestals with higher height to diameter ratio.

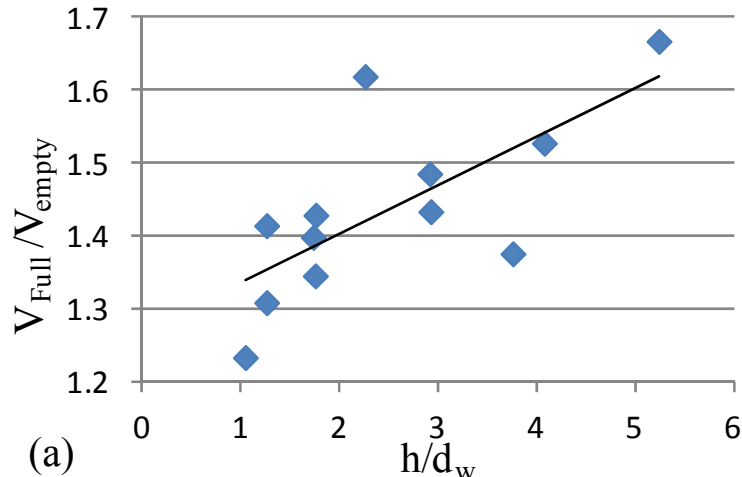

Figure 8.12 Pedestal height to diameter ratio versus (a) $\mathrm{V}_{\text {Full }} / \mathrm{V}_{\text {empty }}(\mathrm{b}) \mathrm{V}_{\mathrm{n}} / \mathrm{V}_{\text {Full }}$

Furthermore, Figure 8.12(b) shows the inverse correlation between the $V_{n} / V_{\text {Full }}$ ratio and $h / d_{w}$. This pattern shows that the code shear strength is more consistent with the results of finite element analysis for lower values of $\mathrm{h} / \mathrm{d}_{\mathrm{w}}$.

Figure 8.13, describes a comparison between code and FE model shear strength by showing the relationship between $\mathrm{V}_{\mathrm{Full}} / \mathrm{V}_{\mathrm{n}}$ and tank size category.

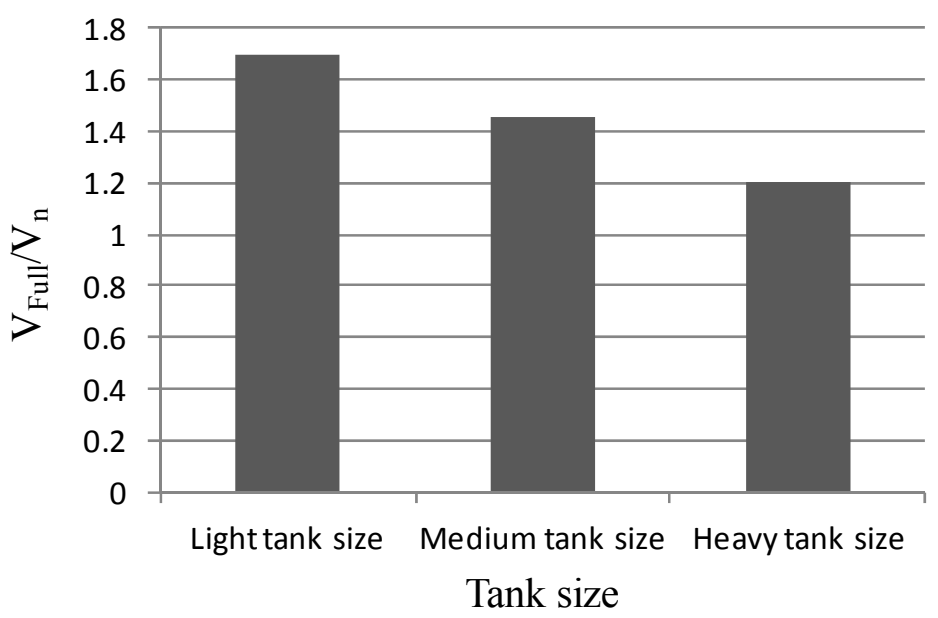

Figure $8.13 \mathrm{~V}_{\text {Full }} / \mathrm{V}_{\mathrm{n}}$ versus tank size group 
It could be concluded that the shear strength calculated by finite element method for the full tank state is higher than the code shear strength by a factor of $1.7,1.45$ and 1.2 for light, medium and heavy tank sizes respectively. This difference is because the current code equation does not include the effect of axial compression in enhancing the shear strength of the pedestals. In addition, the contribution of axial compression is shown to be more significant in light thanks comparing to heavy tanks.

The results of this section have also shown that the axial compression can at least increase the code nominal shear strength by $20 \%$ for heavy tanks and this increase reaches up to $70 \%$ for light tank sizes.

\subsection{Summary}

In this chapter a finite element approach was employed along with nonlinear static analysis in order to investigate the effect of wall opening in the seismic response characteristics of elevated water tanks as well as the effect of axial compression in shear strength of RC pedestals.

The chapter started with addressing the typical opening dimension and location in the elevated water tanks. Next, the provisions of the ACI371R-08 for structural design of openings were presented. It was explained that only the vehicle doors were selected for the investigation as they are almost 10 times larger than other openings such as personnel doors.

In order to study the effect of openings in the seismic response characteristics of elevated water tanks, five finite element models previously introduced as pilot group were selected. Afterwards, the critical direction of lateral loading was determined by conducting pushover analysis on the FE model of two prototypes in three directions. It was shown that direction "1" which is parallel to the plane of opening gives the lowest base shear. 
In the next part, five FE models were modified by adding the openings and pilaster. The width of the pilasters ranged between a minimum of $1.1 \mathrm{~m}$ to $1.5 \mathrm{~m}$ depending on the size of opening. Additional vertical and horizontal reinforcement were provided around the opening based on requirements of ACI371R-08. The pilasters extended above and below the openings by a height equal to half of the height of openings.

Pushover analysis was conducted on the five FE models with openings and the resulting pushover curves were compared to the one developed for pedestals without openings. The cracking propagation pattern was studied as well and it was shown that the primary cracks were generated around the opening area for all models.

A comparison between the pushover graphs of FE models with and without opening revealed that if the openings are designed based on requirements of ACI371R-08 then nearly identical nonlinear seismic response behaviour is expected. The effect of openings in the response of heavy tank size models is minor comparing to the light tank size models. This could be explained by the fact that less percentage of the cross-section area of the heavy tanks comparing to light tanks is deducted by openings. It was also shown that the difference between maximum base shear developed in models with and without openings is limited to less than $7 \%$. However, no considerable change between the maximum lateral deformations was observed.

In the second part, the shear strength of RC pedestals was investigated. At first, the differences between the elevated water tanks and building structures were addressed. It was explained that the seismic shear force generated in the RC pedestal is mostly the result of the tank weight as it usually consists around $80 \%$ of the overall gravity load of the elevated water tanks. 
Next a brief literature review was performed on the subject of effect of axial compression on the shear strength of $\mathrm{RC}$ walls. The proposed equations for considering the contribution of the axial compression in the shear strength of RC walls were also discussed. The current ACI371R08 equation for computing the shear strength of pedestals was described and the terms in this formula were explained.

Subsequently, the twelve prototypes for conducting the investigation were introduced. The prototypes were chosen from the $\mathrm{R}=3$ design group and pushover analysis was performed under three gravity loading states of full, half full and empty tank.

It was shown that the shear strength calculated by finite element method for the full tank state was higher than the code shear strength by a factor of $1.7,1.45$ and 1.2 for light, medium and heavy tank sizes respectively. In addition it was concluded that for all of the FE models with light and medium tank size, the nominal shear strength according to the code, was equal or less than the maximum shear strength of the RC pedestal in empty tank state.

In summary, the positive effect of axial compression in enhancing the shear strength of the RC pedestals was shown by a finite element approach and it was concluded that ACI371R-08 underestimates the actual shear strength of RC pedestals by not including the beneficial effects of axial compression. 


\section{Chapter 9 \\ Summary, conclusions and recommendations}

\subsection{Summary}

In this study, a finite element method was employed in order to investigate the nonlinear seismic response of elevated water tanks. Three methods of analysis including nonlinear static, nonlinear dynamic and incremental dynamic analyses were employed in this research. The general purpose finite element program ANSYS was selected for conducting the analyses. Since the elevated water tanks are built in various tank capacities and pedestal heights, a combination of the most commonly constructed tank sizes and pedestal heights in industry were investigated in the research.

In order to better understand the behaviour of elevated water tanks subjected to seismic loads, a comprehensive literature review about the performance of elevated water tanks in the past earthquakes as well as previous research studies was carried out. Furthermore, since a part of the study was focused on the seismic response factors of RC pedestals, a comprehensive literature review regarding the overstrength factor, ductility factor and response modification factor of structures was performed. The capability of the proposed finite element model in predicting the nonlinear response of reinforced concrete was validated by employing experimental test results. The research was divided into three main parts and a summary of each is presented as follows:

\section{Part I: Pushover analysis and establishing the seismic response factors}

Pushover analysis was conducted on the prototypes of elevated water tanks in order to construct the pushover curves and establish the overstrength and ductility factor. The procedure of the pushover analysis was adapted from FEMA 273. The height of the pedestals varied 
between $15 \mathrm{~m}$ to $45 \mathrm{~m}$ and the tank sizes were in the range of 0.5 to 3 mega gallons. The prototypes were designed according to the provisions of ACI371R-08, ASCE/SEI 7-2010 and ACI 350.3-06. In addition, the prototypes were designed for two categories of high and low seismicity and two response modification factor values of " 2 " and " 3 " which resulted in 48 prototypes in total. A 3D finite element model was then developed for the prototypes and the pushover curves and related bilinear approximations were constructed accordingly by conducting pushover analysis. In addition the cracking patterns were analyzed for several prototypes.

The overstrength and ductility factors were calculated based on pushover curves and the effect of various parameters such as fundamental period, height to diameter ratio, seismic design category, and tank size on the seismic response factors of elevated water tanks was studied. Finally the proposed values of response modification factor were established by implementing the method recommended by ATC 19 (1995).

Part II: Incremental dynamic analysis and verification of response modification factor with probabilistic method

A probabilistic method adapted from FEMA P695 was implemented to evaluate and verify the seismic performance and response modification factor of elevated water tanks. Ten prototypes were selected for this evaluation. The heights of the models were $25 \mathrm{~m}$ and $35 \mathrm{~m}$ and the tank sizes were $0.5 \mathrm{MG}, 1 \mathrm{MG}$ and $3 \mathrm{MG}$. The proposed $\mathrm{R}$ factors which were used for designing the RC pedestals were 2 and 3 as recommended by ASCE/SEI 7-2010. A group of 22 ground motion records were employed in order to conduct the nonlinear dynamic analysis and construct the IDA curves. 
The values of median collapse intensity $\stackrel{\mathrm{S}}{\mathrm{CT}}_{\mathrm{T}}$ were calculated and divided by the Maximum Considered Earthquake (MCE) ground motion intensity $\left(\mathrm{S}_{\mathrm{MT}}\right)$, in order to determine the collapse margin ratio (CMR). Finally by employing a probabilistic method the probability of collapse for each prototype under different condition was evaluated and response modification factors of the prototypes were verified.

\section{Part III: Effect of opening in the seismic response of pedestal and evaluating shear} strength of RC pedestals

A finite element approach was employed along with nonlinear static analysis in order to investigate the effect of wall opening in the seismic response characteristics of elevated water tanks as well as the effect of axial compression in shear strength of RC pedestals.

Five FE models of RC pedestals were employed and modified by adding the openings and pilaster. The height and width of the openings inspected in this study were in the range of 3 to 4.2 meters depending on the intended application and size of the pedestals. Pushover analysis was conducted and the resulting pushover curves were compared to the one developed for pedestals without openings. The cracking propagation pattern was studied as well

Twelve prototypes were selected for investigating the shear strength of RC pedestals. The prototypes were chosen from the $\mathrm{R}=3$ design group and a pushover analysis was performed under three gravity loading states of full, half full and empty tank. The pedestal shear strength determined from the finite element model was then compared to the one by the code and the effect of axial compression was discussed. 


\subsection{Conclusions}

The following conclusions are drawn based on the results of this study in each part:

\section{Part I: Pushover analysis and establishing the seismic response factors}

1- The comparison of the finite element and experimental test results which were performed on RC beams and walls indicated excellent capability of the proposed finite element method in predicting the nonlinear load-deflection behaviour of reinforced concrete elements at different stages of loading procedure.

2- Two types of cracking propagation were observed in the pushover analysis. It was concluded that elevated water tanks with a pedestal height to mean diameter $\left(\mathrm{h} / \mathrm{d}_{\mathrm{w}}\right)$ ratio of above 2 demonstrated flexure-shear cracking pattern. However, for $\mathrm{h} / \mathrm{d}_{\mathrm{w}}$ ratios less than 2 , the cracking propagation was due to web-shear cracking.

3- Increasing the fundamental period resulted in higher overstrength factor and lowered ductility factor of elevated water tank. In addition, higher " $\mathrm{h} / \mathrm{d}_{\mathrm{w}}$ " resulted in higher overstrength factor. On the other hand, ductility factor decreased as " $\mathrm{h} / \mathrm{d}_{\mathrm{w}}$ " was increased. The graphs of " $\mathrm{h} / \mathrm{d}_{\mathrm{w}}$ " versus seismic response factors were scattered and no specific pattern or relationship could be found.

4- Although the ductility factor increases as tank size increases, yet the tank size does not have a significant influence on the ductility factor of elevated water tanks. Furthermore, for each group of the tank sizes, the range of ductility factor is not very wide and scattered. The tank size has an inverse relationship with overstrength factor. 
5- For all medium and heavy size tanks located in "level one" and "level two" seismicity regions, the overstrength factor was shown to be below " 2 ". The ductility factor is the lowest for the light tank size group and highest for the heavy size tanks.

6- The proposed $\mathrm{R}$ factor ranges from 1.8 to 3.2 for the prototypes located in levels one and two seismicity. Furthermore, for the models in high seismicity zone the R factor decreases as the tank size increases. For the prototypes designed for low seismicity regions, medium size tanks are demonstrating the highest $\mathrm{R}$ factor.

\section{Part II: Incremental dynamic analysis and verification of response modification factor with probabilistic method}

1- The maximum base shear and lateral deflection of elevated water tanks which are calculated from the nonlinear dynamic analysis demonstrate higher values in comparison to pushover analysis.

2- Under the MCE ground motion intensity, light and medium size tank models have the lateral deformation of less than $40 \%$ of the maximum lateral deformation which indicates that although these structures demonstrated nonlinear response in some level, yet the damages are not severe. However, heavy tank size models experience higher lateral deformation at the MCE intensity comparing to light and medium tank sizes. This indicates that the elevated water tanks with heavy tank size can experience more severe damage under the MCE ground motion intensity comparing to the light and medium tank sizes. The light and medium tank sizes have higher safety margins against global collapse of the RC pedestal comparing to the heavy tanks. 
3- The light and heavy tank size group pass the seismic performance requirements and hence the employed $\mathrm{R}$ factors of $\mathrm{R}=2$ and $\mathrm{R}=3$ are verified and approved. On the other hand, implementing the $\mathrm{R}$ factors of 2 and 3 for seismic design of heavy tank is proved to be unacceptable.

\section{Part III: Effect of openings in the seismic response of pedestal and evaluating shear strength of RC pedestals}

1- In the RC pedestals with vehicle doors subjected to pushover analysis, the primary cracks generate around the openings for all models.

2- If the openings are designed based on requirements of ACI371R-08 then nearly identical nonlinear seismic response behaviour is expected from the pedestals with and without openings. The effect of openings in the response of heavy tank size models is minor comparing to the light tank size models.

3- The shear strength calculated by finite element method for the full tank state is higher than the code nominal shear strength by a factor of $1.7,1.45$ and 1.2 for light, medium and heavy tank sizes respectively. In addition for all of the FE models with light and medium tank size, the nominal shear strength according to the code is equal to or less than the maximum shear strength of the RC pedestal in empty tank state.

4- The ACI371R-08 equation for nominal shear strength underestimates the actual shear strength of RC pedestals because of ignoring the beneficial effects of axial compression.

\subsection{Recommendations for future research programs}

There are some aspects of this research that could be further investigated as a future research program and are summarized as follows: 
1- The effect of soil-structure interaction may be the main subject of future works. This effect was not considered in this study for the dynamic analysis.

2- As there has been no experimental test on the RC pedestals so far, an experimental full size test such as shaking table test can be very beneficial for better understanding the actual response of $\mathrm{RC}$ pedestals.

3- In this study the effect of vehicle door which is the biggest wall opening was evaluated. In future works the effect of smaller openings such as personnel doors might be studied as well.

4- In some RC pedestals, floors with different applications are constructed. This effect was not studied in this research and may be further investigated.

5- The sloshing component of water was not taken into account in the nonlinear dynamic analysis of the FE models. This effect can be included by modeling the water inside the tank in future studies.

6- The application of seismic isolators or energy dissipaters can be investigated in controlling the seismic response of RC pedestals.

7- Since the base of the pedestal was assumed to be rigid, other restraining conditions at the base level could be investigated as well.

8- The effect of axial compression in the shear strength of RC pedestal was only studied for pedestals without openings. This effect may be further investigated by including the openings in the pedestal.

9- The beneficial effect of axial compression in enhancing the shear strength of RC pedestals may be studied and analysed in more detail in order to propose an equation 
that modifies the current code equation by adding a specific term for the axial compression contribution.

10- The seismic response behaviour of the RC pedestal may also be investigated by employing stick models for comparison and further investigation. 


\section{Appendix A \\ Finite element modelling of reinforced concrete elements}

\section{A.1 Finite element formulation of reinforced concrete}

The stiffness matrix of reinforced concrete element was briefly discussed in Chapter 4 . This section provides further details of finite element formulation and equations of SOLID65 element.

\section{A.1.1 FE formulation of reinforced concrete after cracking}

The stiffness matrix corresponding to cracked state in one direction was explained in Chapter 4. If concrete cracks in two direction then equation A.1 will be employed:

$$
\left[D_{c}^{c k}\right]=E\left[\begin{array}{cccccc}
\frac{R^{t}}{E} & 0 & 0 & 0 & 0 & 0 \\
0 & \frac{R^{t}}{E} & 0 & 0 & 0 & 0 \\
0 & 0 & 1 & 0 & 0 & 0 \\
0 & 0 & 0 & \frac{\beta_{t}}{2(1+v)} & 0 & 0 \\
0 & 0 & 0 & 0 & \frac{\beta_{t}}{2(1+v)} & 0 \\
0 & 0 & 0 & 0 & 0 & \frac{\beta_{t}}{2(1+v)}
\end{array}\right]
$$

Where:

$\beta_{\mathrm{t}}=$ shear transfer coefficient

$\mathrm{R}_{\mathrm{t}}=$ secant modulus of cracked concrete stress-strain graph

If the crack closes due to the compression loads, then the shear transfer coefficient $\beta_{\mathrm{t}}$ needs to be modified to account for the effect of compression normal to the cracking plane. In this case, another coefficient denoted as $\beta_{\mathrm{c}}$ is introduced as shown in equation A.2. Equation A.2 represents a concrete element with a closed crack in one direction: 


$$
\left[D_{c}^{c k}\right]=\frac{E}{(1+v)(1-2 v)}\left[\begin{array}{cccccc}
(1-v) & v & v & 0 & 0 & 0 \\
v & (1-v) & v & 0 & 0 & 0 \\
v & v & (1-v) & 0 & 0 & 0 \\
0 & 0 & 0 & \beta_{c} \frac{(1-2 v)}{2} & 0 & 0 \\
0 & 0 & 0 & 0 & \frac{(1-2 v)}{2} & 0 \\
0 & 0 & 0 & 0 & 0 & \beta_{c} \frac{(1-2 v)}{2}
\end{array}\right]
$$

Where

$\beta_{\mathrm{c}}=$ The coefficient for closed crack condition (generally $\beta_{\mathrm{c}}$ must be greater than $\beta_{\mathrm{t}}$ )

Finally for a concrete element cracked in all three directions, the open cracked stiffness matrix will be:

$$
\left[D_{c}^{c k}\right]=E\left[\begin{array}{cccccc}
\frac{R^{t}}{E} & 0 & 0 & 0 & 0 & 0 \\
0 & \frac{R^{t}}{E} & 0 & 0 & 0 & 0 \\
0 & 0 & 1 & 0 & 0 & 0 \\
0 & 0 & 0 & \frac{\beta_{t}}{2(1+v)} & 0 & 0 \\
0 & 0 & 0 & 0 & \frac{\beta_{t}}{2(1+v)} & 0 \\
0 & 0 & 0 & 0 & 0 & \frac{\beta_{t}}{2(1+v)}
\end{array}\right]
$$

Stiffness matrices for other closed cracked conditions might be derived in the same way as shown in equation A.2. The crushing state of concrete element represents the complete degradation of material which indicates no more contribution of the element in the stiffness matrix.

\section{A.2 Stress-Strain curves of concrete and steel bars}


The mathematical models that are employed for finite element modelling of reinforced concrete elements were described in Chapter 4. In this section, further details are provided in this regard.

\section{A.2.1 Stress-Strain curve of concrete}

The stress-strain model proposed by Mander et al. (1988) is selected for modeling concrete as explained in Chapter 4. The stress-strain curve of the concrete is developed using a reasonable number of plotted points. Figure A.1 demonstrates stress-strain curve of concrete constructed based on Mander model for $\mathrm{f}_{\mathrm{c}}=35 \mathrm{MPa}$ concrete. The model is adjusted by the two parameters concrete compressive strength $\left(\mathrm{f}^{\prime}{ }_{\mathrm{c}}\right)$ and concrete strain at $\mathrm{f}_{\mathrm{c}}\left(\varepsilon_{\mathrm{c}}{ }_{\mathrm{c}}\right)$.

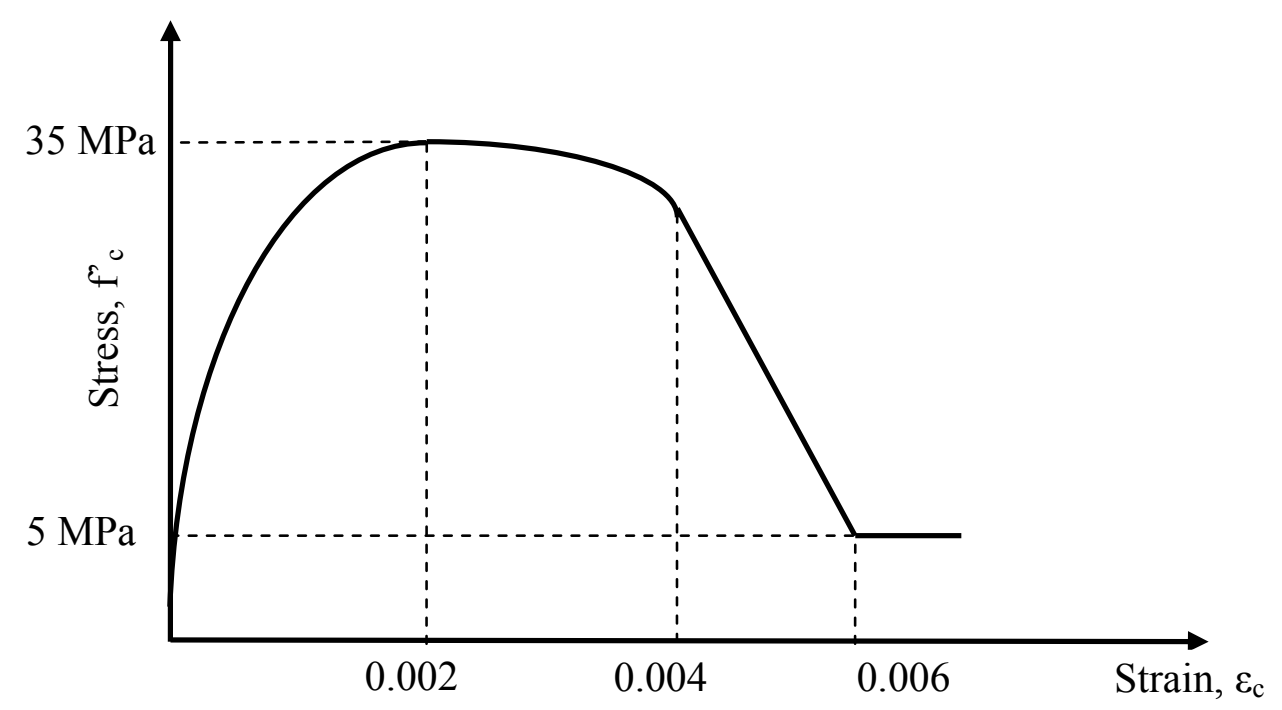

Figure A.1 Unconfined concrete stress-strain curve for $\mathrm{f}^{\prime}{ }_{\mathrm{c}}=35 \mathrm{MPa}$ (Mander et al. (1988)

\section{A.2.2 Stress-Strain curve of steel}

In this study the stress-strain model for steel rebar proposed by Holzer (Holzer et al., 1975) is employed. This model consists of three branches of linear, perfectly plastic and a strain hardening portion. The calibration of the curve is based on the grade and size of steel 
reinforcement. The stress-strain curve could be calibrated by defining four strain stages and corresponding stresses. Table A.1 demonstrates reference points for stress-strain curve of grade 400 steel for two rebar sizes employed in designing the RC pedestals:

Table A.1 Properties of stress-strain curve for steel rebars

\begin{tabular}{ccccccc}
\hline Rebar size & $\mathrm{f}_{\mathrm{y}}(\mathrm{Mpa})$ & $\mathrm{f}_{\mathrm{u}}(\mathrm{Mpa})$ & $\varepsilon_{\mathrm{y}}$ & $\varepsilon_{\text {sh }}$ & $\varepsilon_{\mathrm{u}}$ & $\varepsilon_{\mathrm{r}}$ \\
\hline \#5 rebar & 400 & 730 & 0.002 & 0.015 & 0.09 & 0.136 \\
\hline$\# 11$ rebar & 400 & 730 & 0.002 & 0.0115 & 0.06 & 0.101 \\
\hline
\end{tabular}

Where:

$\varepsilon_{\mathrm{sh}}=$ strain at the onset of strain hardening

$\varepsilon_{\mathrm{u}}=$ strain at maximum steel strength

$\varepsilon_{\mathrm{r}}=$ strain at steel failure

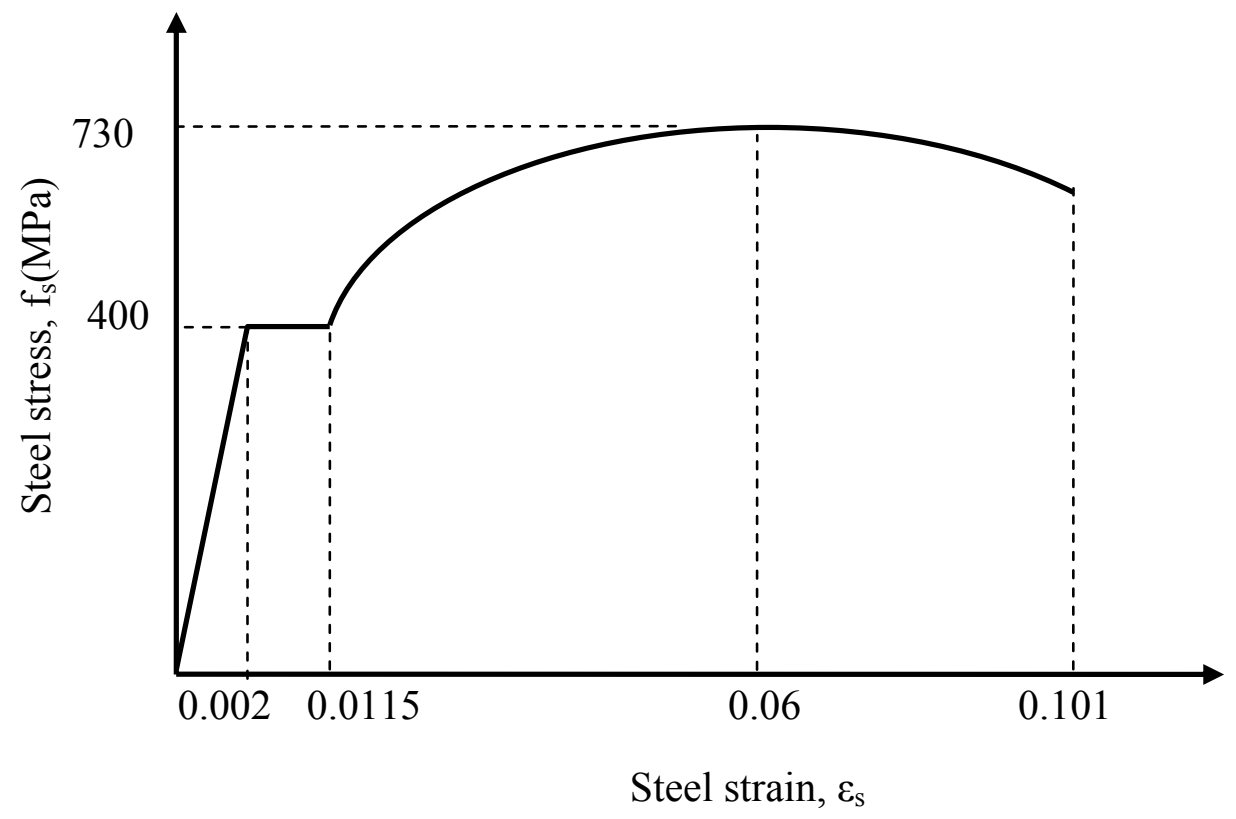

Figure A.2 The stress-strain curve for \#11 steel rebar (Holzer et al. 1975) 


\section{A.3 Sensitivity analysis of a typical prototype}

The sensitivity analysis is required in order to determine the optimum number of elements and nodes in the finite element model. Table A.2 and Figure A.3 show the sensitivity analysis conducted by employing five FE models for prototype $35-\mathrm{H}-1$. Model 1 is a very coarse model with 1505 elements and represents the lower bound for the number of elements in the FE model. Model 5 is a very fine model with 6481 elements which represents the upper bound for the number of elements.

Table A.2 Results of sensitivity analysis on five FE models for prototype 35-H-1

\begin{tabular}{ccccc}
\hline $\begin{array}{c}\text { Model } \\
\text { No. }\end{array}$ & $\begin{array}{c}\text { Number of } \\
\text { elements }\end{array}$ & Number of nodes & $\mathrm{V}_{\max }(\mathrm{MN})$ & Max Displacement $(\mathrm{m})$ \\
\hline 1 & 1505 & 6143 & 39995 & 0.31 \\
\hline 2 & 2513 & 10253 & 37711 & 0.28 \\
\hline 3 & 3491 & 14241 & 35433 & 0.26 \\
\hline 4 & 5147 & 21051 & 35133 & 0.255 \\
\hline 5 & 6481 & 26392 & 34893 & 0.254 \\
\hline
\end{tabular}

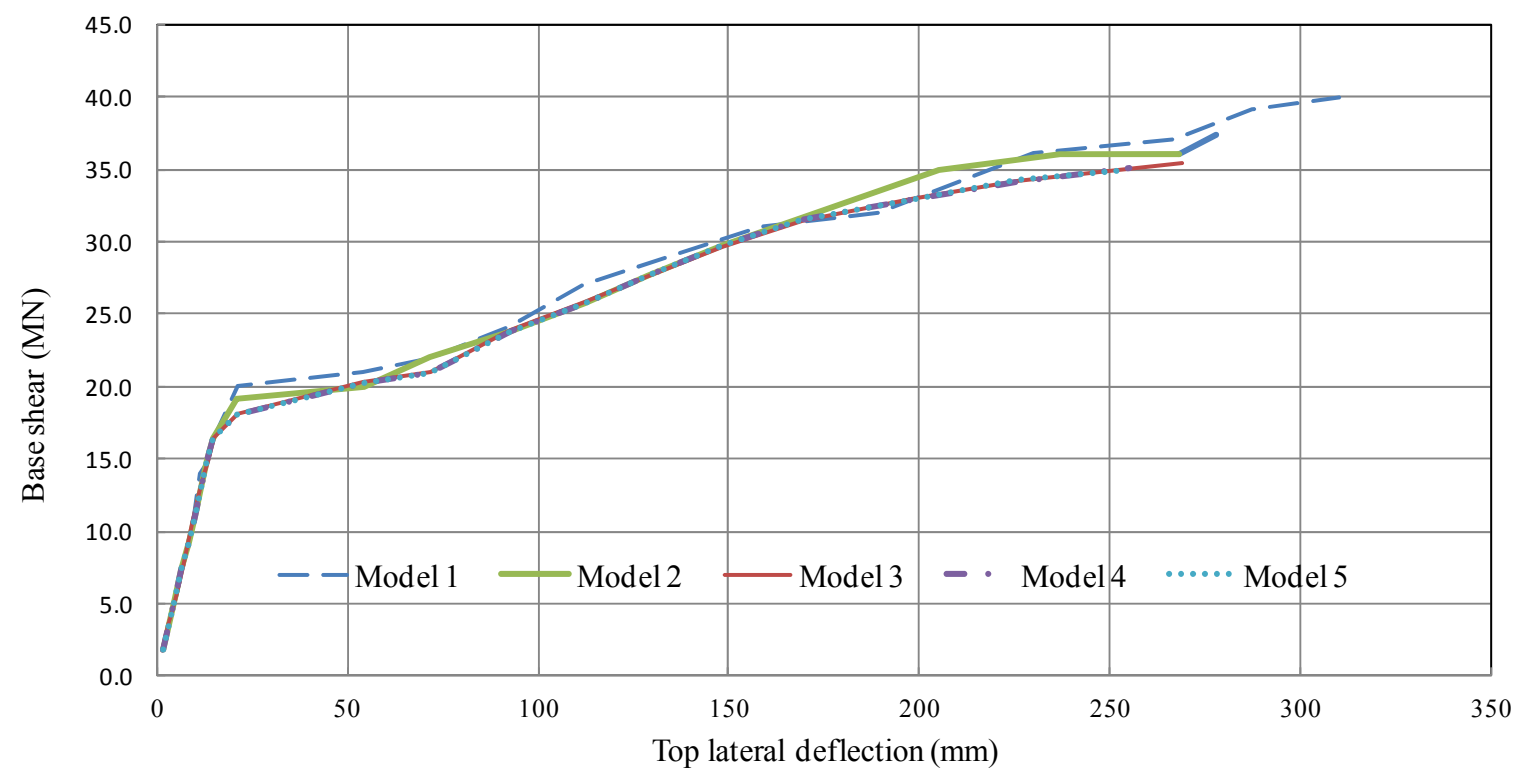

Figure A.3 Results of pushover analysis on five FE models of prototype $35-\mathrm{H}-1$ 
The pushover analysis was performed on all five models and the results are presented in Table A.2. The pushover curves are depicted in Figure A.3. Table A.2 indicates that change in the $\mathrm{V}_{\max }$ and maximum displacement practically stops from Model 3 to 4 and subsequently in Model 4 to 5. As a result, Model 3 is selected as the optimum model for performing the study. The same analysis is performed for other prototypes and the optimum number of elements is calculated as shown in Table A.3.

Table A.3 Optimum number of elements and nodes for each prototype

\begin{tabular}{ccccccc}
\hline $\begin{array}{c}\text { Prototype } \\
\text { No. }\end{array}$ & $\begin{array}{c}\text { FE model } \\
\text { ID }\end{array}$ & $\begin{array}{c}\text { Pedestal } \\
\text { height }(\mathrm{m})\end{array}$ & $\mathrm{h}_{\mathrm{r}}(\mathrm{mm})$ & $\begin{array}{c}\mathrm{d}_{\mathrm{w}} \\
(\mathrm{m})\end{array}$ & $\begin{array}{c}\text { Number } \\
\text { of } \\
\text { elements }\end{array}$ & $\begin{array}{c}\text { Number of } \\
\text { nodes }\end{array}$ \\
\hline PG-1 & $15-\mathrm{H}-0.5$ & 15 & 300 & 8.6 & 1801 & 7521 \\
\hline PG-2 & $15-\mathrm{H}-1$ & 15 & 350 & 12 & 1511 & 6321 \\
\hline PG-3 & $15-\mathrm{H}-2$ & 15 & 380 & 14.5 & 1813 & 7585 \\
\hline PG-4 & $15-\mathrm{L}-0.5$ & 15 & 200 & 8.6 & 1801 & 7521 \\
\hline PG-5 & $15-\mathrm{L}-1$ & 15 & 250 & 12 & 1511 & 6321 \\
\hline PG-6 & $15-\mathrm{L}-2$ & 15 & 250 & 14.5 & 1813 & 7585 \\
\hline PG-7 & $25-\mathrm{H}-0.5$ & 25 & 300 & 8.6 & 3011 & 12321 \\
\hline PG-8 & $25-\mathrm{H}-2$ & 25 & 380 & 14.5 & 3037 & 12481 \\
\hline PG-9 & $25-\mathrm{H}-3$ & 25 & 400 & 20 & 3473 & 14337 \\
\hline PG-10 & $25-\mathrm{L}-0.5$ & 25 & 200 & 8.6 & 3011 & 12321 \\
\hline PG-11 & $25-\mathrm{L}-2$ & 25 & 250 & 14.5 & 3037 & 12481 \\
\hline PG-12 & $25-\mathrm{L}-3$ & 25 & 300 & 20 & 3473 & 14337 \\
\hline PG-13 & $35-\mathrm{H}-0.5$ & 35 & 300 & 8.6 & 4212 & 17125 \\
\hline PG-14 & $35-\mathrm{H}-1$ & 35 & 350 & 12 & 3491 & 14241 \\
\hline PG-15 & $35-\mathrm{H}-3$ & 35 & 400 & 20 & 4817 & 19713 \\
\hline PG-16 & $35-\mathrm{L}-0.5$ & 35 & 200 & 8.6 & 4212 & 17125 \\
\hline PG-17 & $35-\mathrm{L}-1$ & 35 & 250 & 12 & 3491 & 14241 \\
\hline PG-18 & $35-\mathrm{L}-3$ & 35 & 300 & 20 & 4817 & 19713 \\
\hline PG-19 & $45-\mathrm{H}-0.5$ & 45 & 300 & 8.6 & 5411 & 21921 \\
\hline PG-20 & $45-\mathrm{H}-1$ & 45 & 350 & 12 & 4511 & 18321 \\
\hline PG-21 & $45-\mathrm{H}-3$ & 45 & 400 & 20 & 6161 & 25089 \\
\hline PG-22 & $45-\mathrm{L}-0.5$ & 45 & 200 & 8.6 & 5411 & 21921 \\
\hline PG-23 & $45-\mathrm{L}-1$ & 45 & 250 & 12 & 4511 & 18321 \\
\hline PG-24 & $45-\mathrm{L}-3$ & 45 & 300 & 20 & 6161 & 25089 \\
\hline & & & & & & \\
\hline
\end{tabular}




\section{Appendix B \\ Design of prototypes based on code and guideline requirements}

\section{B.1 Design of prototypes based on code and guidelines}

Elevated water tanks are principally designed based on ACI 371R-08 and additional guidelines from ACI 350.3-06 and ASCE/SEI 7-2010. All of the prototypes are designed for the provisions of these standards. In this appendix, the procedure for design of RC pedestal is explained. Dead load, stored water load and earthquake load are taken into account for design purposes. The design process is divided into two separate procedures of gravity and seismic loads design.

Tables B.1 through B.6 demonstrate a summary of calculations for 24 prototypes designed with response modification factor of $\mathrm{R}=2$. The mass of structures, buckling check, fundamental period, seismic response coefficient, moment at base level and mid-shaft due to seismic load, and vertical and horizontal reinforcement ratios are among the main parameters that are addressed in these tables.

Finally, Table B.7 demonstrates the results of pushover analysis on 24 prototypes including maximum displacement, ductility, design base shear, maximum base shear, overstrength and ductility factor. 
Table B.1 Geometry and weight of pedestal, tank vessel and liquid for full tank condition

\begin{tabular}{|c|c|c|c|c|c|c|c|c|c|c|}
\hline $\begin{array}{c}\text { Prototype } \\
\text { No. }\end{array}$ & $\begin{array}{l}\text { FE model } \\
\text { ID }\end{array}$ & $\begin{array}{l}\text { Pedestal } \\
\text { height } \\
\text { (m) }\end{array}$ & $\begin{array}{c}\mathrm{h}_{\mathrm{r}} \\
(\mathrm{mm})\end{array}$ & $\begin{array}{l}\mathrm{dw}_{\mathrm{w}} \\
(\mathrm{m})\end{array}$ & $\begin{array}{l}W_{\text {roof }} \\
(\mathrm{kN})\end{array}$ & $\begin{array}{c}\mathrm{W}_{\text {cylinder }} \\
(\mathrm{kN})\end{array}$ & $\begin{array}{c}\mathrm{W}_{\text {conical }} \\
(\mathrm{kN})\end{array}$ & $\begin{array}{c}W_{\text {floor }} \\
(\mathrm{kN})\end{array}$ & $\begin{array}{c}\mathrm{W}_{\text {shaft }} \\
(\mathrm{kN})\end{array}$ & $\begin{array}{c}\mathrm{W}_{\text {water }} \\
(\mathrm{kN})\end{array}$ \\
\hline PG-1 & $15-\mathrm{H}-0.5$ & 15 & 300 & 8.6 & 89 & 199 & 183 & 750 & 3435 & 18639 \\
\hline PG-2 & $15-\mathrm{H}-1$ & 15 & 350 & 12 & 162 & 386 & 385 & 2000 & 5592 & 37278 \\
\hline PG-3 & $15-\mathrm{H}-2$ & 15 & 380 & 14.5 & 330 & 514 & 1006 & 4500 & 7336 & 74556 \\
\hline PG-4 & $15-\mathrm{L}-0.5$ & 15 & 200 & 8.6 & 89 & 199 & 183 & 750 & 2290 & 18639 \\
\hline PG-5 & 15-L-1 & 15 & 250 & 12 & 162 & 386 & 385 & 2000 & 3994 & 37278 \\
\hline PG-6 & 15-L-2 & 15 & 250 & 14.5 & 330 & 514 & 1006 & 4500 & 4826 & 74556 \\
\hline PG-7 & 25-H-0.5 & 25 & 300 & 8.6 & 89 & 199 & 183 & 750 & 5725 & 18639 \\
\hline PG-8 & $25-\mathrm{H}-2$ & 25 & 380 & 14.5 & 330 & 514 & 1006 & 4500 & 12226 & 74556 \\
\hline PG-9 & $25-\mathrm{H}-3$ & 25 & 400 & 20 & 400 & 910 & 1653 & 5500 & 17751 & 111834 \\
\hline PG-10 & 25-L-0.5 & 25 & 200 & 8.6 & 89 & 199 & 183 & 750 & 3817 & 18639 \\
\hline PG-11 & 25-L-2 & 25 & 250 & 14.5 & 330 & 514 & 1006 & 4500 & 8044 & 74556 \\
\hline PG-12 & 25-L-3 & 25 & 300 & 20 & 400 & 910 & 1653 & 5500 & 13313 & 111834 \\
\hline PG-13 & $35-\mathrm{H}-0.5$ & 35 & 300 & 8.6 & 89 & 199 & 183 & 750 & 8015 & 18639 \\
\hline PG-14 & $35-\mathrm{H}-1$ & 35 & 350 & 12 & 162 & 386 & 385 & 2000 & 13047 & 37278 \\
\hline PG-15 & $35-\mathrm{H}-3$ & 35 & 400 & 20 & 400 & 910 & 1653 & 5500 & 24852 & 111834 \\
\hline PG-16 & 35-L-0.5 & 35 & 200 & 8.6 & 89 & 199 & 183 & 750 & 5343 & 18639 \\
\hline PG-17 & 35-L-1 & 35 & 250 & 12 & 162 & 386 & 385 & 2000 & 9319 & 37278 \\
\hline PG-18 & 35-L-3 & 35 & 300 & 20 & 400 & 910 & 1653 & 5500 & 18639 & 111834 \\
\hline PG-19 & 45-H-0.5 & 45 & 300 & 8.6 & 89 & 199 & 183 & 750 & 10305 & 18639 \\
\hline PG-20 & $45-\mathrm{H}-1$ & 45 & 350 & 12 & 162 & 386 & 385 & 2000 & 16775 & 37278 \\
\hline PG-21 & $45-\mathrm{H}-3$ & 45 & 400 & 20 & 400 & 910 & 1653 & 5500 & 31952 & 111834 \\
\hline PG-22 & 45-L-0.5 & 45 & 200 & 8.6 & 89 & 199 & 183 & 750 & 6870 & 18639 \\
\hline PG-23 & 45-L-1 & 45 & 250 & 12 & 162 & 386 & 385 & 2000 & 11982 & 37278 \\
\hline PG-24 & 45-L-3 & 45 & 300 & 20 & 400 & 910 & 1653 & 5500 & 23964 & 111834 \\
\hline
\end{tabular}


Table B.2 Verification of the pedestals for diamond shape and column shape buckling effects

\begin{tabular}{|c|c|c|c|c|c|c|c|c|}
\hline $\begin{array}{l}\text { FE model } \\
\text { ID }\end{array}$ & $\lg (\mathrm{m})$ & $\begin{array}{c}\mathrm{h}_{\mathrm{r}} \\
(\mathrm{mm})\end{array}$ & $\begin{array}{l}\mathrm{d}_{\mathrm{w}} \\
(\mathrm{m})\end{array}$ & $\begin{array}{c}E_{c} \\
(\mathrm{MPa})\end{array}$ & $\begin{array}{l}\mathrm{A}_{\mathrm{w}} \\
\left(\mathrm{m}^{2}\right)\end{array}$ & $\mathrm{I}_{\mathrm{c}}\left(\mathrm{m}^{4}\right)$ & $\begin{array}{l}\text { Diamond } \\
\text { shape } \\
\text { buckling }\end{array}$ & $\begin{array}{l}\text { Column shape } \\
\text { buckling Factor } \\
\text { of Safety }\end{array}$ \\
\hline $15-\mathrm{H}-0.5$ & 23.39 & 300 & 8.6 & 12000 & 8.11 & 74.9 & 29 & 15.2 \\
\hline 15-H-1 & 23.32 & 350 & 12 & 12000 & 13.19 & 237.5 & 34 & 29.8 \\
\hline 15-H-2 & 23.85 & 380 & 14.5 & 12000 & 17.31 & 454.9 & 38 & 41.7 \\
\hline $15-L-0.5$ & 23.39 & 200 & 8.6 & 12000 & 5.40 & 50.0 & 43 & 15.2 \\
\hline 15-L-1 & 23.32 & 250 & 12 & 12000 & 9.42 & 169.6 & 48 & 29.8 \\
\hline 15-L-2 & 23.85 & 250 & 14.5 & 12000 & 11.39 & 299.3 & 58 & 41.7 \\
\hline 25-H-0.5 & 33.39 & 300 & 8.6 & 12000 & 8.11 & 74.9 & 29 & 7.5 \\
\hline 25-H-2 & 33.85 & 380 & 14.5 & 12000 & 17.31 & 454.9 & 38 & 20.7 \\
\hline 25-H-3 & 34.85 & 400 & 20 & 12000 & 25.13 & 1256.6 & 50 & 37.1 \\
\hline 25-L-0.5 & 33.39 & 200 & 8.6 & 12000 & 5.40 & 50.0 & 43 & 7.5 \\
\hline 25-L-2 & 33.85 & 250 & 14.5 & 12000 & 11.39 & 299.3 & 58 & 20.7 \\
\hline 25-L-3 & 34.85 & 300 & 20 & 12000 & 18.85 & 942.5 & 67 & 37.1 \\
\hline 35-H-0.5 & 43.39 & 300 & 8.6 & 12000 & 8.11 & 74.9 & 29 & 4.4 \\
\hline 35-H-1 & 43.32 & 350 & 12 & 12000 & 13.19 & 237.5 & 34 & 8.6 \\
\hline 35-H-3 & 44.85 & 400 & 20 & 12000 & 25.13 & 1256.6 & 50 & 22.4 \\
\hline 35-L-0.5 & 43.39 & 200 & 8.6 & 12000 & 5.40 & 50.0 & 43 & 4.4 \\
\hline 35-L-1 & 43.32 & 250 & 12 & 12000 & 9.42 & 169.6 & 48 & 8.6 \\
\hline 35-L-3 & 44.85 & 300 & 20 & 12000 & 18.85 & 942.5 & 67 & 22.4 \\
\hline $45-\mathrm{H}-0.5$ & 53.39 & 300 & 8.6 & 12000 & 8.11 & 74.9 & 29 & 2.9 \\
\hline 45-H-1 & 53.32 & 350 & 12 & 12000 & 13.19 & 237.5 & 34 & 5.7 \\
\hline 45-H-3 & 54.85 & 400 & 20 & 12000 & 25.13 & 1256.6 & 50 & 15.0 \\
\hline 45-L-0.5 & 53.39 & 200 & 8.6 & 12000 & 5.40 & 50.0 & 43 & 2.9 \\
\hline 45-L-1 & 53.32 & 250 & 12 & 12000 & 9.42 & 169.6 & 48 & 5.7 \\
\hline 45-L-3 & 54.85 & 300 & 20 & 12000 & 18.85 & 942.5 & 67 & 15.0 \\
\hline
\end{tabular}


Table B.3 Calculation of fundamental period and seismic response coefficient

\begin{tabular}{|c|c|c|c|c|c|c|c|c|c|}
\hline \multicolumn{2}{|c|}{$\mathrm{R}=2$} & \multirow[b]{2}{*}{$\mathrm{S}_{\mathrm{Ds}}$} & \multirow[b]{2}{*}{$\mathrm{S}_{\mathrm{D} 1}$} & \multirow[b]{2}{*}{$\mathrm{Cs}=\mathrm{S}_{\mathrm{Ds}} \mathrm{I} / \mathrm{R}$} & \multirow[b]{2}{*}{$\mathrm{Cs}<\mathrm{S}_{\mathrm{DI}} \mathrm{I} / \mathrm{T}_{\mathrm{f}} \mathrm{R}$} & \multirow[b]{2}{*}{ Cs $>0.044 \mathrm{~S}_{\mathrm{Ds}} \mathrm{I}$} & \multirow[b]{2}{*}{$\mathrm{T}_{\mathrm{f}}(\mathrm{sec})$} & \multirow[b]{2}{*}{$\mathrm{T}_{\mathrm{s}}(\mathrm{sec})$} & \multirow[b]{2}{*}{ Cs } \\
\hline $\begin{array}{c}\text { Prototype } \\
\text { No. }\end{array}$ & $\begin{array}{l}\text { FE model } \\
\text { ID }\end{array}$ & & & & & & & & \\
\hline PG-1 & $15-\mathrm{H}-0.5$ & 0.84 & 0.44 & 0.63 & 0.77 & 0.06 & 0.431 & 0.52381 & 0.63 \\
\hline PG-2 & 15-H-1 & 0.84 & 0.44 & 0.63 & 0.97 & 0.06 & 0.340 & 0.52381 & 0.63 \\
\hline PG-3 & $15-\mathrm{H}-2$ & 0.84 & 0.44 & 0.63 & 0.93 & 0.06 & 0.356 & 0.52381 & 0.63 \\
\hline PG-4 & 15-L-0.5 & 0.2 & 0.11 & 0.15 & 0.16 & 0.01 & 0.521 & 0.55 & 0.15 \\
\hline PG-5 & 15-L-1 & 0.2 & 0.11 & 0.15 & 0.21 & 0.01 & 0.399 & 0.55 & 0.15 \\
\hline PG-6 & 15-L-2 & 0.2 & 0.11 & 0.15 & 0.19 & 0.01 & 0.436 & 0.55 & 0.15 \\
\hline PG-7 & $25-\mathrm{H}-0.5$ & 0.84 & 0.44 & 0.63 & 0.44 & 0.06 & 0.754 & 0.52381 & 0.44 \\
\hline PG-8 & $25-\mathrm{H}-2$ & 0.84 & 0.44 & 0.63 & 0.54 & 0.06 & 0.611 & 0.52381 & 0.54 \\
\hline PG-9 & $25-\mathrm{H}-3$ & 0.84 & 0.44 & 0.63 & 0.70 & 0.06 & 0.468 & 0.52381 & 0.63 \\
\hline PG-10 & 25-L-0.5 & 0.2 & 0.11 & 0.15 & 0.09 & 0.01 & 0.904 & 0.55 & 0.09 \\
\hline PG-11 & 25-L-2 & 0.2 & 0.11 & 0.15 & 0.11 & 0.01 & 0.745 & 0.55 & 0.11 \\
\hline PG-12 & $25-\mathrm{L}-3$ & 0.2 & 0.11 & 0.15 & 0.15 & 0.01 & 0.536 & 0.55 & 0.15 \\
\hline PG-13 & $35-\mathrm{H}-0.5$ & 0.84 & 0.44 & 0.63 & 0.29 & 0.06 & 1.145 & 0.52381 & 0.29 \\
\hline PG-14 & $35-\mathrm{H}-1$ & 0.84 & 0.44 & 0.63 & 0.37 & 0.06 & 0.898 & 0.52381 & 0.37 \\
\hline PG-15 & $35-\mathrm{H}-3$ & 0.84 & 0.44 & 0.63 & 0.48 & 0.06 & 0.693 & 0.52381 & 0.48 \\
\hline PG-16 & 35-L-0.5 & 0.2 & 0.11 & 0.15 & 0.06 & 0.01 & 1.363 & 0.55 & 0.06 \\
\hline PG-17 & 35-L-1 & 0.2 & 0.11 & 0.15 & 0.08 & 0.01 & 1.041 & 0.55 & 0.08 \\
\hline PG-18 & $35-L-3$ & 0.2 & 0.11 & 0.15 & 0.10 & 0.01 & 0.791 & 0.55 & 0.10 \\
\hline PG-19 & $45-\mathrm{H}-0.5$ & 0.84 & 0.44 & 0.63 & 0.21 & 0.06 & 1.600 & 0.52381 & 0.21 \\
\hline PG-20 & $45-\mathrm{H}-1$ & 0.84 & 0.44 & 0.63 & 0.26 & 0.06 & 1.250 & 0.52381 & 0.26 \\
\hline PG-21 & $45-\mathrm{H}-3$ & 0.84 & 0.44 & 0.63 & 0.35 & 0.06 & 0.950 & 0.52381 & 0.35 \\
\hline PG-22 & $45-\mathrm{L}-0.5$ & 0.2 & 0.11 & 0.15 & 0.04 & 0.01 & 1.891 & 0.55 & 0.04 \\
\hline PG-23 & 45-L-1 & 0.2 & 0.11 & 0.15 & 0.06 & 0.01 & 1.442 & 0.55 & 0.06 \\
\hline PG-24 & 45-L-3 & 0.2 & 0.11 & 0.15 & 0.08 & 0.01 & 1.080 & 0.55 & 0.08 \\
\hline
\end{tabular}


Table B.4 Calculation of factor of safety for load case $U=1.4(D+F)$ assuming the minimum reinforcement requirements

$\mathrm{U}=1.4(\mathrm{D}+\mathrm{F})$

\begin{tabular}{|c|c|c|c|c|c|c|c|c|c|c|c|}
\hline $\begin{array}{c}\text { Prototype } \\
\text { No. }\end{array}$ & $\begin{array}{l}\text { FE model } \\
\text { ID }\end{array}$ & $\begin{array}{l}\text { WF } \\
(\mathrm{kN})\end{array}$ & $\mathrm{WD}(\mathrm{kN})$ & $\mathrm{P}_{\mathrm{uw}}(\mathrm{MN})$ & $\begin{array}{c}\mathrm{f}_{\mathrm{c}} \\
(\mathrm{MPa})\end{array}$ & $\begin{array}{c}\text { Min } \\
\text { As } \\
\text { ratio }\end{array}$ & $\mathrm{Ce}$ & $\begin{array}{l}\text { As } \\
\left(m^{2}\right)\end{array}$ & $\mathrm{P}_{\mathrm{nw}}(\mathrm{MN})$ & $0.65 * \mathrm{P}_{\mathrm{nw}}$ & $\begin{array}{l}\text { Factor } \\
\text { of } \\
\text { safety }\end{array}$ \\
\hline PG-1 & $15-\mathrm{H}-0.5$ & 18639 & 4656 & 32.6 & 35 & 0.005 & 0.65 & 0.04 & 166 & 108 & 3.3 \\
\hline PG-2 & $15-\mathrm{H}-1$ & 37278 & 8525 & 64.1 & 35 & 0.005 & 0.65 & 0.07 & 271 & 176 & 2.7 \\
\hline PG-3 & $15-\mathrm{H}-2$ & 74556 & 13686 & 123.5 & 35 & 0.005 & 0.65 & 0.09 & 356 & 231 & 1.9 \\
\hline PG-4 & 15-L-0.5 & 18639 & 3511 & 31.0 & 35 & 0.005 & 0.65 & 0.03 & 111 & 72 & 2.3 \\
\hline PG-5 & 15-L-1 & 37278 & 6927 & 61.9 & 35 & 0.005 & 0.65 & 0.05 & 194 & 126 & 2.0 \\
\hline PG-6 & 15-L-2 & 74556 & 11176 & 120.0 & 35 & 0.005 & 0.65 & 0.06 & 234 & 152 & 1.3 \\
\hline PG-7 & 25-H-0.5 & 18639 & 6946 & 35.8 & 35 & 0.005 & 0.65 & 0.04 & 166 & 108 & 3.0 \\
\hline PG-8 & $25-\mathrm{H}-2$ & 74556 & 18576 & 130.4 & 35 & 0.005 & 0.65 & 0.09 & 356 & 231 & 1.8 \\
\hline PG-9 & $25-\mathrm{H}-3$ & 111834 & 26214 & 193.3 & 35 & 0.005 & 0.65 & 0.13 & 516 & 336 & 1.7 \\
\hline PG-10 & 25-L-0.5 & 18639 & 5038 & 33.1 & 35 & 0.005 & 0.65 & 0.03 & 111 & 72 & 2.2 \\
\hline PG-11 & 25-L-2 & 74556 & 14394 & 124.5 & 35 & 0.005 & 0.65 & 0.06 & 234 & 152 & 1.2 \\
\hline PG-12 & 25-L-3 & 111834 & 21776 & 187.1 & 35 & 0.005 & 0.65 & 0.09 & 387 & 252 & 1.3 \\
\hline PG-13 & $35-\mathrm{H}-0.5$ & 18639 & 9236 & 39.0 & 35 & 0.005 & 0.65 & 0.04 & 166 & 108 & 2.8 \\
\hline PG-14 & $35-\mathrm{H}-1$ & 37278 & 15980 & 74.6 & 35 & 0.005 & 0.65 & 0.07 & 271 & 176 & 2.4 \\
\hline PG-15 & $35-\mathrm{H}-3$ & 111834 & 33315 & 203.2 & 35 & 0.005 & 0.65 & 0.13 & 516 & 336 & 1.7 \\
\hline PG-16 & 35-L-0.5 & 18639 & 6564 & 35.3 & 35 & 0.005 & 0.65 & 0.03 & 111 & 72 & 2.0 \\
\hline PG-17 & 35-L-1 & 37278 & 12252 & 69.3 & 35 & 0.005 & 0.65 & 0.05 & 194 & 126 & 1.8 \\
\hline PG-18 & 35-L-3 & 111834 & 27102 & 194.5 & 35 & 0.005 & 0.65 & 0.09 & 387 & 252 & 1.3 \\
\hline PG-19 & 45-H-0.5 & 18639 & 11526 & 42.2 & 35 & 0.005 & 0.65 & 0.04 & 166 & 108 & 2.6 \\
\hline PG-20 & $45-\mathrm{H}-1$ & 37278 & 19708 & 79.8 & 35 & 0.005 & 0.65 & 0.07 & 271 & 176 & 2.2 \\
\hline PG-21 & $45-\mathrm{H}-3$ & 111834 & 40415 & 213.1 & 35 & 0.005 & 0.65 & 0.13 & 516 & 336 & 1.6 \\
\hline PG-22 & 45-L-0.5 & 18639 & 8091 & 37.4 & 35 & 0.005 & 0.65 & 0.03 & 111 & 72 & 1.9 \\
\hline PG-23 & 45-L-1 & 37278 & 14915 & 73.1 & 35 & 0.005 & 0.65 & 0.05 & 194 & 126 & 1.7 \\
\hline PG-24 & 45-L-3 & 111834 & 32427 & 202.0 & 35 & 0.005 & 0.65 & 0.09 & 387 & 252 & 1.2 \\
\hline
\end{tabular}

$\mathrm{W}_{\mathrm{F}}=$ Weight of liquid

$\mathrm{W}_{\mathrm{D}}=$ Dead load (weight of tank and pedestal)

$\mathrm{C}_{\mathrm{e}}=$ eccentricity coefficient

$\mathrm{P}_{\mathrm{uw}}=$ factored axial pedestal wall load

$\mathrm{P}_{\mathrm{uw}}=$ nominal axial load strength of pedestal wall 
Table B.5 Calculation of vertical reinforcement for base level and mid-height of pedestal

\begin{tabular}{|c|c|c|c|c|c|c|c|c|c|c|c|}
\hline $\mathrm{R}=2$ & $\mathrm{U}=0.9 \mathrm{D}+\mathrm{F}+\mathrm{E}$ & $\begin{array}{l}\text { Base } \\
\text { level }\end{array}$ & $\begin{array}{l}\text { Mid- } \\
\text { shaft }\end{array}$ & & & & & & & \multicolumn{2}{|c|}{ Final } \\
\hline 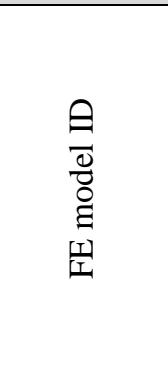 & 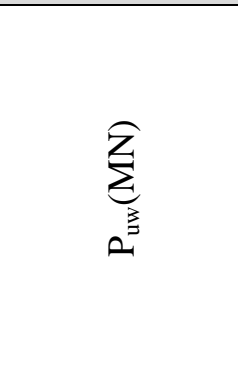 & 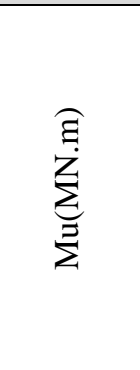 & 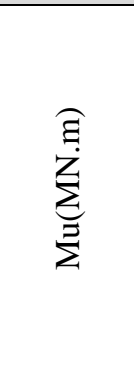 & 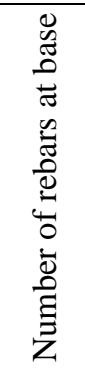 & 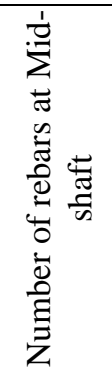 & 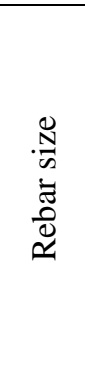 & 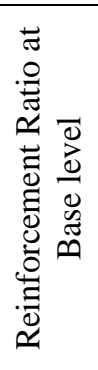 & 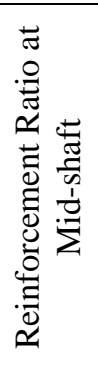 & 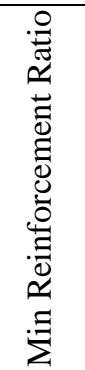 & 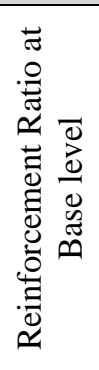 & 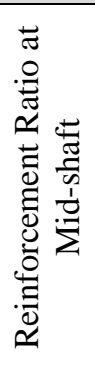 \\
\hline $15-\mathrm{H}-0.5$ & 22.8 & 301.1 & 191.2 & 160 & 80.0 & $\# 11$ & 1.99 & 0.99 & 0.5 & 1.99 & 0.99 \\
\hline $15-\mathrm{H}-1$ & 45.0 & 610.7 & 390.8 & 200 & 95.0 & $\# 11$ & 1.52 & 0.72 & 0.5 & 1.52 & 0.72 \\
\hline $15-\mathrm{H}-2$ & 86.9 & 1159.4 & 756.9 & 260 & 100.0 & $\# 11$ & 1.51 & 0.58 & 0.5 & 1.51 & 0.58 \\
\hline 15-L-0.5 & 21.8 & 69.0 & 44.1 & 20 & 50.0 & $\# 5$ & 0.19 & 0.19 & 0.5 & 0.50 & 0.50 \\
\hline 15-L-1 & 43.5 & 141.6 & 91.0 & 20 & 50.0 & $\# 5$ & 0.11 & 0.11 & 0.5 & 0.50 & 0.50 \\
\hline 15-L-2 & 84.6 & 269.8 & 176.8 & 20 & 50.0 & \#5 & 0.09 & 0.09 & 0.5 & 0.50 & 0.50 \\
\hline 25-H-0.5 & 24.9 & 341.7 & 201.9 & 190 & 80.0 & $\# 11$ & 2.36 & 0.99 & 0.5 & 2.36 & 0.99 \\
\hline $25-\mathrm{H}-2$ & 91.3 & 1501.4 & 893.7 & 450 & 150.0 & $\# 11$ & 2.62 & 0.87 & 0.5 & 2.62 & 0.87 \\
\hline $25-\mathrm{H}-3$ & 135.4 & 2706.4 & 1645.7 & 550 & 170.0 & $\# 11$ & 2.20 & 0.68 & 0.5 & 2.20 & 0.68 \\
\hline 25-L-0.5 & 23.2 & 66.5 & 39.5 & 20 & 50.0 & \#5 & 0.19 & 0.19 & 0.5 & 0.50 & 0.50 \\
\hline 25-L-2 & 87.5 & 297.4 & 178.5 & 20 & 50.0 & $\# 5$ & 0.09 & 0.09 & 0.5 & 0.50 & 0.50 \\
\hline 25-L-3 & 131.4 & 628.4 & 384.2 & 20 & 50.0 & $\# 5$ & 0.05 & 0.05 & 0.5 & 0.50 & 0.50 \\
\hline 35-H-0.5 & 27.0 & 318.9 & 178.4 & 170 & 60.0 & $\# 11$ & 2.11 & 0.74 & 0.5 & 2.11 & 0.74 \\
\hline 35-H-1 & 51.7 & 797.5 & 450.1 & 300 & 100.0 & $\# 11$ & 2.29 & 0.76 & 0.5 & 2.29 & 0.76 \\
\hline $35-\mathrm{H}-3$ & 141.8 & 2849.9 & 1668.1 & 600 & 200.0 & $\# 11$ & 2.40 & 0.80 & 0.5 & 2.40 & 0.80 \\
\hline 35-L-0.5 & 24.5 & 61.4 & 34.7 & 20 & 50.0 & $\# 5$ & 0.19 & 0.19 & 0.5 & 0.50 & 0.50 \\
\hline 35-L-1 & 48.3 & 161.5 & 91.8 & 20 & 50.0 & $\# 5$ & 0.11 & 0.11 & 0.5 & 0.50 & 0.50 \\
\hline 35-L-3 & 136.2 & 600.0 & 352.4 & 20 & 50.0 & $\# 5$ & 0.05 & 0.05 & 0.5 & 0.50 & 0.50 \\
\hline $45-\mathrm{H}-0.5$ & 29.0 & 302.7 & 162.8 & 150 & 40.0 & $\# 11$ & 1.86 & 0.50 & 0.5 & 1.86 & 0.50 \\
\hline $45-\mathrm{H}-1$ & 55.0 & 751.7 & 408.9 & 270 & 80.0 & $\# 11$ & 2.06 & 0.61 & 0.5 & 2.06 & 0.61 \\
\hline $45-\mathrm{H}-3$ & 148.2 & 2670.1 & 1505.9 & 520 & 150.0 & $\# 11$ & 2.08 & 0.60 & 0.5 & 2.08 & 0.60 \\
\hline 45-L-0.5 & 25.9 & 57.7 & 31.5 & 20 & 50.0 & $\# 5$ & 0.19 & 0.19 & 0.5 & 0.50 & 0.50 \\
\hline 45-L-1 & 50.7 & 151.1 & 83.0 & 20 & 50.0 & $\# 5$ & 0.11 & 0.11 & 0.5 & 0.50 & 0.50 \\
\hline 45-L-3 & 141.0 & 559.0 & 316.9 & 20 & 50.0 & \#5 & 0.05 & 0.05 & 0.5 & 0.50 & 0.50 \\
\hline
\end{tabular}


Table B.6 Calculation of horizontal reinforcement for base level and mid-height of pedestal

\begin{tabular}{|c|c|c|c|c|c|c|c|c|c|c|c|}
\hline & & & & & & & & \\
\hline & & 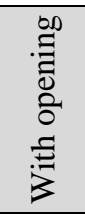 & 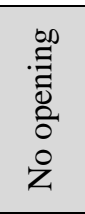 & & & & 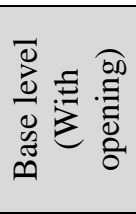 & 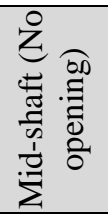 & & 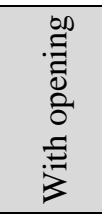 & 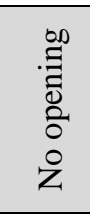 \\
\hline 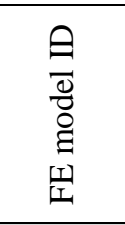 & $\sum_{>}^{Z}$ & 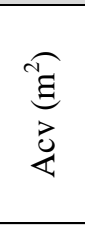 & 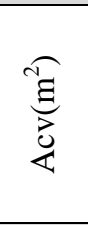 & 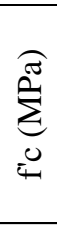 & 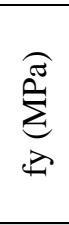 & $\sum_{j}^{\sum_{j}^{Z}}$ & 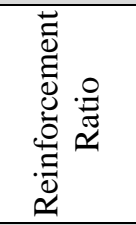 & 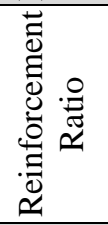 & 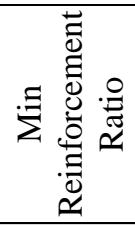 & 夽 & 茎 \\
\hline $15-\mathrm{H}-0.5$ & 14.7 & 3.42 & 4.02 & 35 & 400 & 19.55 & 0.0118 & 0.0095 & 0.0025 & 0.0118 & 0.0095 \\
\hline $15-\mathrm{H}-1$ & 29.3 & 5.85 & 6.55 & 35 & 400 & 39.10 & 0.0142 & 0.0112 & 0.0025 & 0.0142 & 0.0112 \\
\hline $15-\mathrm{H}-2$ & 53.7 & 7.84 & 8.60 & 35 & 400 & 71.56 & 0.0201 & 0.0171 & 0.0025 & 0.0201 & 0.0171 \\
\hline 15-L-0.5 & 3.3 & 2.28 & 2.68 & 35 & 400 & 4.43 & 0.0024 & 0.0015 & 0.0025 & 0.0025 & 0.0025 \\
\hline 15-L-1 & 6.7 & 4.18 & 4.68 & 35 & 400 & 8.99 & 0.0029 & 0.0011 & 0.0025 & 0.0029 & 0.0025 \\
\hline $15-\mathrm{L}-2$ & 12.4 & 5.16 & 5.66 & 35 & 400 & 16.54 & 0.0053 & 0.0036 & 0.0025 & 0.0053 & 0.0036 \\
\hline 25-H-0.5 & 11.2 & 3.42 & 4.02 & 35 & 400 & 14.92 & 0.0084 & 0.0068 & 0.0025 & 0.0084 & 0.0068 \\
\hline $25-\mathrm{H}-2$ & 48.6 & 7.84 & 8.60 & 35 & 400 & 64.82 & 0.0182 & 0.0154 & 0.0025 & 0.0182 & 0.0154 \\
\hline $25-\mathrm{H}-3$ & 84.9 & 11.68 & 12.48 & 35 & 400 & 113.14 & 0.0218 & 0.0190 & 0.0025 & 0.0218 & 0.0190 \\
\hline 25-L-0.5 & 2.2 & 2.28 & 2.68 & 35 & 400 & 2.88 & 0.0007 & 0.0002 & 0.0025 & 0.0025 & 0.0025 \\
\hline 25-L-2 & 9.5 & 5.16 & 5.66 & 35 & 400 & 12.69 & 0.0037 & 0.0022 & 0.0025 & 0.0037 & 0.0025 \\
\hline 25-L-3 & 19.5 & 8.76 & 9.36 & 35 & 400 & 26.05 & 0.0050 & 0.0033 & 0.0025 & 0.0050 & 0.0033 \\
\hline $35-\mathrm{H}-0.5$ & 8.0 & 3.42 & 4.02 & 35 & 400 & 10.70 & 0.0053 & 0.0042 & 0.0025 & 0.0053 & 0.0042 \\
\hline $35-\mathrm{H}-1$ & 19.8 & 5.85 & 6.55 & 35 & 400 & 26.47 & 0.0088 & 0.0076 & 0.0025 & 0.0088 & 0.0076 \\
\hline $35-\mathrm{H}-3$ & 67.5 & 11.68 & 12.48 & 35 & 400 & 90.04 & 0.0168 & 0.0145 & 0.0025 & 0.0168 & 0.0145 \\
\hline 35-L-0.5 & 1.5 & 2.28 & 2.68 & 35 & 400 & 2.03 & -0.0002 & -0.0006 & 0.0025 & 0.0025 & 0.0025 \\
\hline 35-L-1 & 4.0 & 4.18 & 4.68 & 35 & 400 & 5.31 & 0.0007 & 0.0004 & 0.0025 & 0.0025 & 0.0025 \\
\hline 35-L-3 & 14.1 & 8.76 & 9.36 & 35 & 400 & 18.86 & 0.0029 & 0.0015 & 0.0025 & 0.0029 & 0.0025 \\
\hline 45-H-0.5 & 6.2 & 3.42 & 4.02 & 35 & 400 & 8.29 & 0.0036 & 0.0027 & 0.0025 & 0.0036 & 0.0027 \\
\hline $45-\mathrm{H}-1$ & 15.2 & 5.85 & 6.55 & 35 & 400 & 20.32 & 0.0062 & 0.0053 & 0.0025 & 0.0062 & 0.0053 \\
\hline $45-\mathrm{H}-3$ & 51.7 & 11.68 & 12.48 & 35 & 400 & 68.99 & 0.0123 & 0.0109 & 0.0025 & 0.0123 & 0.0109 \\
\hline 45-L-0.5 & 1.2 & 2.28 & 2.68 & 35 & 400 & 1.55 & -0.0008 & -0.0010 & 0.0025 & 0.0025 & 0.0025 \\
\hline 45-L-1 & 3.0 & 4.18 & 4.68 & 35 & 400 & 4.04 & -0.0001 & -0.0003 & 0.0025 & 0.0025 & 0.0025 \\
\hline 45-L-3 & 10.8 & 8.76 & 9.36 & 35 & 400 & 14.35 & 0.0016 & 0.0010 & 0.0025 & 0.0025 & 0.0025 \\
\hline
\end{tabular}


Table B.7 Overstrength, ductility, maximum displacement and ductility factor for $(\mathrm{R}=2)$ group

\begin{tabular}{|c|c|c|c|c|c|c|c|c|c|}
\hline $\begin{array}{l}\text { FE model } \\
\text { ID }\end{array}$ & $\begin{array}{c}\mathrm{T}_{\mathrm{f}} \\
\text { (sec) }\end{array}$ & $\mathrm{V}_{\mathrm{d}}(\mathrm{kN})$ & $\begin{array}{c}\text { over } \\
\text { strength } \\
\text { factor }\end{array}$ & $\begin{array}{l}V_{\max } \\
(\mathrm{kN})\end{array}$ & Ductility & $\begin{array}{c}\text { yield } \\
\text { displacement } \\
\text { (m) }\end{array}$ & $\begin{array}{c}\text { Max } \\
\text { Displacement } \\
(\mathrm{m})\end{array}$ & $\begin{array}{c}\text { max drift } \\
\text { percentage }\end{array}$ & $\mathrm{R} \mu$ \\
\hline $15-\mathrm{H}-0.5$ & 0.431 & 14663 & 1.94 & 28464 & 2.02 & 0.056 & 0.114 & 0.76 & 1.74 \\
\hline $15-\mathrm{H}-1$ & 0.340 & 29325 & 1.53 & 44774 & 2.49 & 0.028 & 0.07 & 0.47 & 2.00 \\
\hline $15-\mathrm{H}-2$ & 0.356 & 53667 & 1.22 & 65516 & 2.69 & 0.023 & 0.063 & 0.42 & 2.09 \\
\hline 15-L-0.5 & 0.521 & 3319 & 3.75 & 12452 & 3.12 & 0.038 & 0.118 & 0.79 & 2.32 \\
\hline 15-L-1 & 0.399 & 6743 & 3.44 & 23162 & 4.40 & 0.021 & 0.091 & 0.61 & 2.79 \\
\hline 15-L-2 & 0.436 & 12401 & 2.80 & 34724 & 4.12 & 0.019 & 0.079 & 0.53 & 2.69 \\
\hline 25-H-0.5 & 0.754 & 11186 & 1.91 & 21401 & 1.52 & 0.118 & 0.18 & 0.72 & 1.48 \\
\hline $25-\mathrm{H}-2$ & 0.611 & 48618 & 1.33 & 64463 & 2.16 & 0.064 & 0.139 & 0.56 & 1.90 \\
\hline $25-\mathrm{H}-3$ & 0.468 & 84857 & 1.16 & 98486 & 2.68 & 0.039 & 0.104 & 0.42 & 2.09 \\
\hline 25-L-0.5 & 0.904 & 2159 & 4.78 & 10328 & 2.22 & 0.089 & 0.197 & 0.79 & 2.15 \\
\hline 25-L-2 & 0.745 & 9516 & 2.98 & 28332 & 3.42 & 0.044 & 0.15 & 0.60 & 2.91 \\
\hline 25-L-3 & 0.536 & 19538 & 2.48 & 48547 & 3.89 & 0.026 & 0.101 & 0.40 & 2.70 \\
\hline 35-H-0.5 & 1.145 & 8028 & 1.96 & 15726 & 1.47 & 0.184 & 0.27 & 0.77 & 1.47 \\
\hline $35-\mathrm{H}-1$ & 0.898 & 19850 & 1.79 & 35433 & 1.95 & 0.133 & 0.26 & 0.74 & 1.90 \\
\hline $35-\mathrm{H}-3$ & 0.693 & 67531 & 1.33 & 90071 & 2.23 & 0.074 & 0.165 & 0.47 & 2.00 \\
\hline 35-L-0.5 & 1.363 & 1525 & 5.37 & 8194 & 1.55 & 0.150 & 0.232 & 0.66 & 1.55 \\
\hline 35-L-1 & 1.041 & 3985 & 4.25 & 16921 & 2.72 & 0.092 & 0.25 & 0.71 & 2.72 \\
\hline 35-L-3 & 0.791 & 14147 & 3.48 & 49173 & 3.16 & 0.055 & 0.174 & 0.50 & 2.81 \\
\hline 45-H-0.5 & 1.600 & 6218 & 2.06 & 12778 & 1.35 & 0.269 & 0.364 & 0.81 & 1.35 \\
\hline $45-\mathrm{H}-1$ & 1.250 & 15239 & 1.77 & 26946 & 1.82 & 0.184 & 0.334 & 0.74 & 1.82 \\
\hline $45-\mathrm{H}-3$ & 0.950 & 51745 & 1.48 & 76676 & 1.95 & 0.113 & 0.22 & 0.49 & 1.92 \\
\hline 45-L-0.5 & 1.891 & 1165 & 6.29 & 7328 & 1.22 & 0.244 & 0.297 & 0.66 & 1.22 \\
\hline 45-L-1 & 1.442 & 3028 & 5.02 & 15202 & 1.99 & 0.151 & 0.3 & 0.67 & 1.99 \\
\hline 45-L-3 & 1.080 & 10761 & 4.21 & 45324 & 2.38 & 0.091 & 0.217 & 0.48 & 2.38 \\
\hline
\end{tabular}




\section{Appendix C \\ Text command file of finite element model for a typical prototype}

\section{C.1 Input file for FE model 35-H-1}

The text command file for FE model 35-H-1 $(\mathrm{R}=2)$ is given below:

\begin{tabular}{|c|c|}
\hline & \\
\hline /BATCH & FITEM, 5, -24 \\
\hline /input, menust & FITEM, 5, 41 \\
\hline , tmp, ' ', , , & FITEM, 5, - 44 \\
\hline,,,,,,, 1 & $\mathrm{CM},-\mathrm{Y}, \mathrm{LINE}$ \\
\hline WPSTYLE, , , , , , & LSEL, , , \\
\hline, 0 & , P51X \\
\hline /PREP7 & CM,_Y1, LINE \\
\hline $\mathrm{ET}, 1, \mathrm{MASS} 21$ & CMSEL, , YY \\
\hline ET, 2, LINK8 & LESIZE,_Y1, , \\
\hline ET, 3, SOLID65 & $, 4,,,, 1$ \\
\hline ET, 4, SOLID65 & LSEL, S, LOC, Z, \\
\hline ETDEL, 4 & $.1,1.5$ \\
\hline $\mathrm{R}, 1, ;,$, & LSEL, S, LOC , Z, \\
\hline 'RMORE. & $\begin{array}{l}0,1 \\
\text { ALISEL,ALL }\end{array}$ \\
\hline RIMURE, ' ' & LSEL, S, LOC, Z, \\
\hline RMORE, , & $.2, .5$ \\
\hline $\mathrm{R}, 2,2, \quad$, & LSEL, S, LOC, Z, \\
\hline $\mathrm{R}, 3,3, \quad$, & $0, .1$ \\
\hline $\mathrm{R}, 4,500,500,5$ & LSEL, S, LOC, Z, \\
\hline ००, , ', & $.49, .5$ \\
\hline MPTEMP $, 1,1,1$, & $\begin{array}{l}\text { LSEL, S, LOC, Z, } \\
.1, .5\end{array}$ \\
\hline MPTEMP, 1,0 & LSEL, S, LOC, Z, \\
\hline MPDATA, EX, 1, , & $.01, .5$ \\
\hline 1 & LSEL, S, LOC, Z, \\
\hline MPDATA, PRXY, 1 & $0, .49$ \\
\hline, 1 & LSEL, S, LOC, Z, \\
\hline MPTEMP, $,{ }_{1},{ }_{1}, r$ & $0, .24$ \\
\hline & LSEL, S, LOC, Z, \\
\hline MPTEMP , 1, 0 & $0, .26$ \\
\hline $\begin{array}{l}\text { MPDATA, EX, 2, , } \\
3\end{array}$ & $\begin{array}{l}\text { LSEL, S, LOC, Z, } \\
.1, .26\end{array}$ \\
\hline MPDATA, PRXY, 2 & LSEL, S, LOC, Z, \\
\hline, 3 & $\theta$ \\
\hline $\mathrm{tb}$, conc & LSEL, S, LOC, Z, \\
\hline CYL4, $0,0,9$, & .5 \\
\hline$, 9.14,, .5$ & LSEL, S, LOC, Z, \\
\hline CYL4, $0,0,9.14$ & .5 \\
\hline , $, 9.26,, .5$ & FLST, 5, 16, 4, 0 \\
\hline CYL4, $0,0,9.26$ & RDE, 6 \\
\hline$,, 9.38,, .5$ & FITEM, 5, 9 \\
\hline NUMMRG, KP， , & FITEM, 5, -16 \\
\hline , , LOW & FITEM, 5, 29 \\
\hline /UI, MESH, OFF & FITEM, 5, - 32 \\
\hline LSEL, S, LOC, Z, & FITEM, 5, 49 \\
\hline $0 \ldots 1$ & FITEM, 5, - 52 \\
\hline LSEL, S, LOC, Z, & CM,_Y, LINE \\
\hline $0, .1$ & LSEL, , \\
\hline FLST $, 5,16,4,0$ & , P51X \\
\hline RDE, 6 & CM,_Y1, LINE \\
\hline FITEM, 5,1 & CMSEL, , YY \\
\hline FITEM, 5, - 8 & LESIZE，_Y1, \\
\hline FITEM , 5, 21 & $, 4,,,, 1$ \\
\hline
\end{tabular}

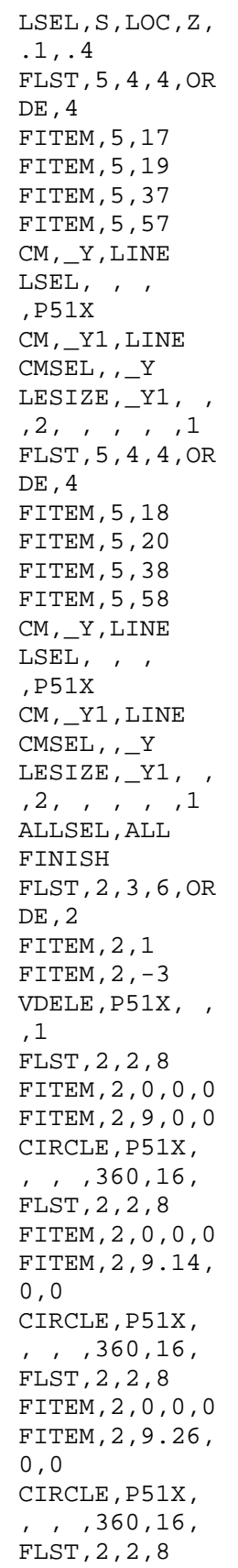

226

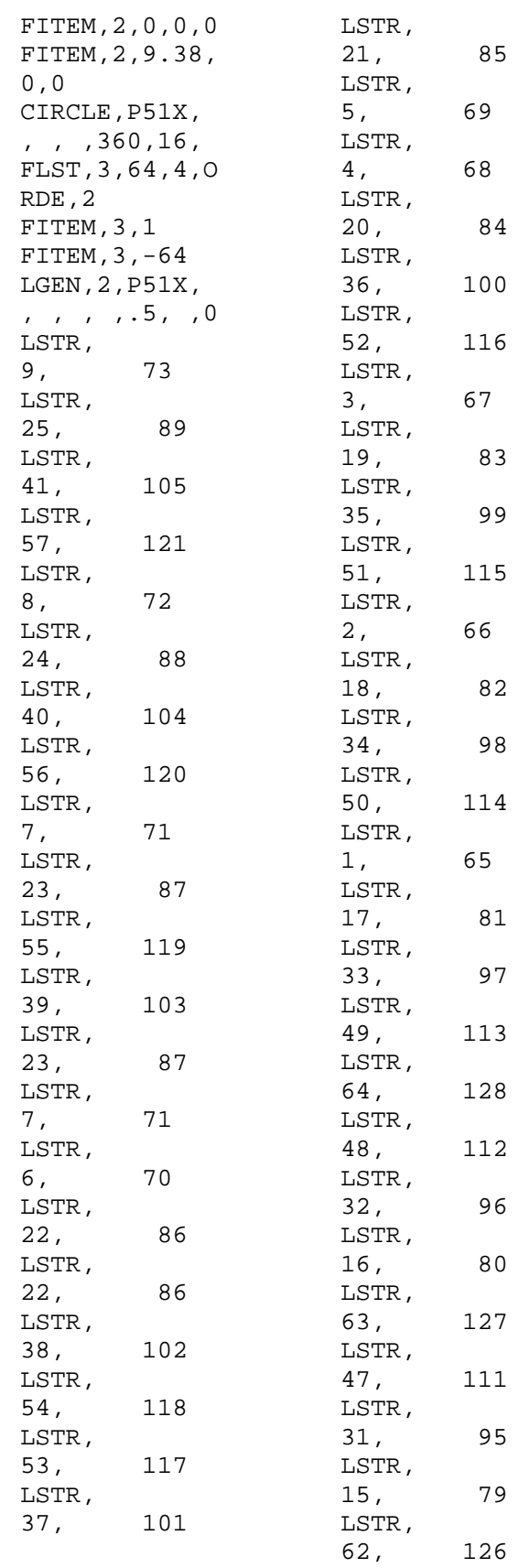




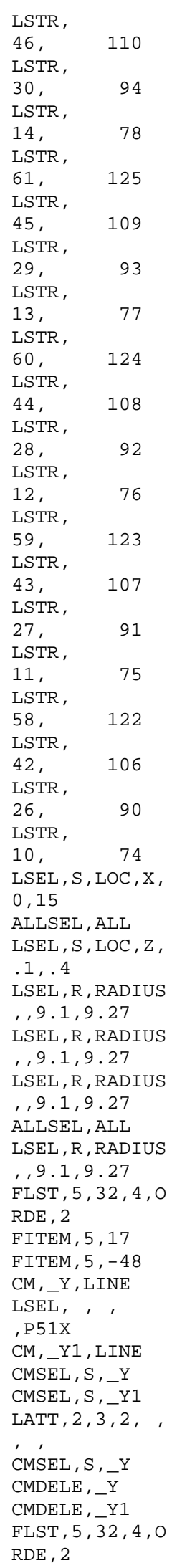

FITEM , 5, 17

FITEM, 5, - 48

CM,_Y, LINE

LSEL, , ,

, P51X

CM,_Y1, LINE

CMSEL, , Y

LESIZE, ,Y1,

$1,1,1$

FLST, 2, 32, 4, 0

RDE, 2

FITEM, 2, 17

FITEM, 2, - 48

LMESH, P51X

ALLSEL, ALL

/UI, MESH, OFF

LSEL, R, LOC , Z,

$.1, .4$

LSEL, R, LOC , Z,

.1, . 4

FLST , 5, 32, 4, 0

$\mathrm{RDE}, 32$

FITEM, 5, 130

FITEM, 5, -131

FITEM, 5, 134

FITEM, 5, - 135

FITEM, 5, 138

FITEM, 5, 140

FITEM, 5, 142

FITEM, 5, -143

FITEM, 5, 146

FITEM, 5, -147

FITEM, 5, 150

FITEM, 5, -151

FITEM, 5, 154

FITEM, 5, - 155

FITEM, 5, 158

FITEM, 5, -159

FITEM, 5, 162

FITEM, 5, - 163

FITEM, 5, 166

FITEM, 5, -167

FITEM, 5, 170

FITEM, 5, -171

FITEM, 5, 174

FITEM, 5, - 175

FITEM, 5, 178

FITEM, 5, -179

FITEM, 5, 182

FITEM, 5, -183

FITEM, 5, 186

FITEM, 5, -187

FITEM, 5, 190

FITEM, 5, -191

CM,_Y, LINE

LSEL, , ,

, P51X

CM,_Y1, LINE

CMSEL, S, Y Y

CMSEL, S, Y Y1

LATT , 2, 2, 2, ,

'CMSEL, $S, Y Y$

CMDELE, $Y$

CMDELE, Y1

FLST, 5, 32, 4, 0

$\mathrm{RDE}, 32$

FITEM, 5, 130

FITEM, 5, -131
FITEM, 5, 134

FITEM, 5, -135

FITEM, 5, 138

FITEM, 5, 140

FITEM, 5, 142

FITEM, 5, - 143

FITEM, 5, 146

FITEM, 5, -147

FITEM, 5, 150

FITEM, 5, -151

FITEM, 5, 154

FITEM, 5, - 155

FITEM, 5, 158

FITEM, 5, -159

FITEM, 5, 162

FITEM, 5, -163

FITEM, 5, 166

FITEM, 5, -167

FITEM, 5, 170

FITEM, 5, -171

FITEM, 5, 174

FITEM, 5, -175

FITEM, 5, 178

FITEM, 5, -179

FITEM, 5, 182

FITEM, 5, -183

FITEM, 5, 186

FITEM, 5, -187

FITEM, 5, 190

FITEM, 5, -191

CM,_Y, LINE

LSEL, , ,

, P51X

CM,_Y1, LINE

CMSEL, , Y Y

LESIZE,_Y1, ,

$, 2,,, 1$

FLST, 2, 32, 4, 0

$\mathrm{RDE}, 32$

FITEM, 2, 130

FITEM, 2, - 131

FITEM, 2, 134

FITEM, 2, -135

FITEM, 2, 138

FITEM, 2, 140

FITEM, 2, 142

FITEM, 2, -143

FITEM, 2, 146

FITEM, 2, - 147

FITEM, 2, 150

FITEM, 2, - 151

FITEM, 2, 154

FITEM, 2, - 155

FITEM, 2, 158

FITEM, 2, -159

FITEM, 2, 162

FITEM, 2, - 163

FITEM, 2, 166

FITEM, 2, -167

FITEM, 2, 170

FITEM, 2, - 171

FITEM, 2, 174

FITEM, 2, - 175

FITEM, 2, 178

FITEM, 2, -179

FITEM, 2, 182

FITEM, 2, - 183

FITEM, 2, 186

FITEM, 2, -187
FITEM, 2, 190

FITEM , 2, - 191 LMESH, P51X

ESEL, R, REAL, , 2

NUMMRG, NODE,

' ' , LOW

ALLSEL, ALL

CYL4, $\odot, \odot, 9$,

$, 9.38, \quad, 5$

CM, Y Y, VOLU

VSEL, , , ,

1

CM,_Y1, VOLU

CMSEL, S, Y Y

CMSEL, S, _Y1

VATT,

$1, \quad 1$,

CMSEL, $S_{,}, Y$

CMDELE, $Y Y$

CMDELE, Y1

FLST , 2, 212, 4, ORDE, 2

FITEM, 2, 1

FITEM , 2, - 212

LDELE, P51X

ALLSEL, ALL

/PREP7

FLST , 2, 84, 4, 0

RDE, 36

FITEM, 2, 17

FITEM, 2, - 48

FITEM, 2, 130

FITEM , 2, - 131

FITEM, 2, 134

FITEM , 2, - 135

FITEM, 2, 138

FITEM, 2, 140

FITEM, 2, 142

FITEM, 2, - 143

FITEM, 2, 146

FITEM, 2, -147

FITEM, 2, 150

FITEM, 2, - 151

FITEM, 2, 154

FITEM, 2, - 155

FITEM, 2, 158

FITEM, 2, - 159

FITEM, 2, 162

FITEM, 2, - 163

FITEM, 2, 166

FITEM, 2, -167

FITEM, 2, 170

FITEM, 2, - 171

FITEM, 2, 174

FITEM , 2, -175

FITEM, 2, 178

FITEM, 2, -179

FITEM, 2, 182

FITEM, 2, - 183

FITEM, 2, 186

FITEM, 2, -187

FITEM, 2, 190

FITEM, 2, - 191

FITEM, 2, 193

FITEM, 2, - 212

LDELE, P51X， ， , 1
VDELE,

$1,, 1$

FLST, 2, 128, 3 ,

ORDE, 2

FITEM, 2, 1

FITEM, 2, - 128

KDELE, P51X

FLST , 2, 64, 4, 0

RDE, 34

FITEM, 2, 17

FITEM, 2, - 48

FITEM, 2, 130

FITEM, 2, - 131

FITEM, 2, 134

FITEM , 2, - 135

FITEM, 2, 138

FITEM, 2, 140

FITEM, 2, 142

FITEM, 2, -143

FITEM, 2, 146

FITEM, 2, -147

FITEM, 2, 150

FITEM, 2, -151

FITEM, 2, 154

FITEM, 2, - 155

FITEM, 2, 158

FITEM, 2, -159

FITEM, 2, 162

FITEM, 2, - 163

FITEM, 2, 166

FITEM, 2, - 167

FITEM, 2, 170

FITEM, 2, -171

FITEM, 2, 174

FITEM, 2, - 175

FITEM, 2, 178

FITEM, 2, -179

FITEM, 2, 182

FITEM, 2, - 183

FITEM, 2, 186

FITEM, 2, - 187

FITEM, 2, 190

FITEM, 2, - 191

LDELE, P51X， ， , 1

FLST , 2, 96, 2, 0

RDE, 2

FITEM , 2, 1

FITEM, 2, - 96

EDELE, P51X

FLST , 2, 96, 1, 0

RDE, 2

FITEM, 2, 1

FITEM, 2, - 96

NDELE, P51X

FLST , 2, 64, 3, 0

RDE, 4

FITEM, 2, 17

FITEM, 2, -48

FITEM, 2, 81

FITEM, 2, - 112

KDELE, P51X

FLST , 2, 96, 2, 0

RDE, 2

FITEM, 2, 1

FITEM, 2, - 96

EDELE, P51X

lclear , 1, 1000 


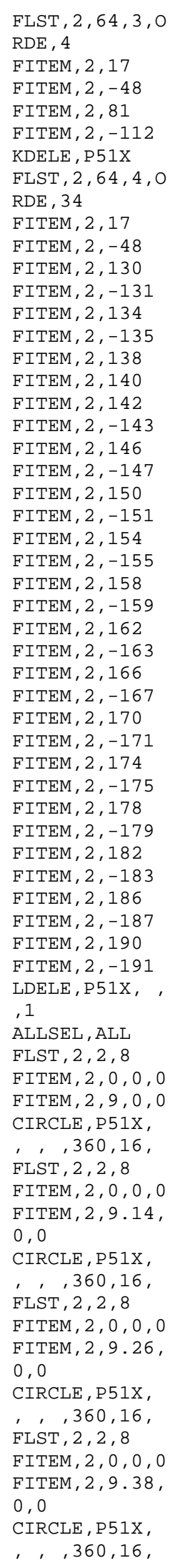

\begin{tabular}{|c|c|}
\hline FLST, $2,64,4,0$ & CM,_Y, LINE \\
\hline $\mathrm{RDE}$, 2 & LSEL', , , \\
\hline FITEM , 2, 1 & , P51X \\
\hline FITEM, 2, - 64 & CM,_Y1, LINE \\
\hline LDELE, P51X & CMSEL, , YY \\
\hline FLST, $3,64,3,0$ & LESIZE,_Y1, \\
\hline $\mathrm{RDE}, 2$ & $4,4,1,1$ \\
\hline FITEM, 3, 1 & LSEL, S, LOC, Z, \\
\hline FITEM, 3, - 64 & .5 \\
\hline KGEN , 2, P51X, & FLST $, 5,16,4,0$ \\
\hline${ }^{\prime},{ }^{\prime}, 5,0$ & $\mathrm{RDE}, 6$ \\
\hline CYL4, $0,0,9$, & FITEM, 5, 9 \\
\hline $\begin{array}{l}9.14, \quad, .5 \\
\text { CYL } 4,0,0,9.14\end{array}$ & FITEM, 5, - 16 \\
\hline $\begin{array}{l}C Y 4,0,0,9.14 \\
, \quad 9.26,-.5\end{array}$ & FITEM, 5, -32 \\
\hline CYL $4, \odot, \odot, 9.26$ & FITEM, 5, 49 \\
\hline$, 9.38,, .5$ & FITEM, 5, - 52 \\
\hline LSEL, S, LOC, Z, & $\mathrm{CM},-\mathrm{Y}, \mathrm{LINE}$ \\
\hline 0 & LSEL, , , , \\
\hline ALLSEL, ALL & , P51X \\
\hline ALLSEL, ALL & CM,_Y1, LINE \\
\hline NUMMRG, KP, , & CMSEL, , _Y \\
\hline , , LOW & LESIZE,_Y1, , \\
\hline $\begin{array}{l}\text { NUMMRG, KP， ， } \\
\text { LOW }\end{array}$ & $\begin{array}{l}\text { 4, ', ' , L'OC, } 1 \\
\text { LSEL, S, LOC, Z, }\end{array}$ \\
\hline $\begin{array}{l}\text { LSEL, S, LOC , Z, } \\
\odot\end{array}$ & $\begin{array}{l}.1, .4 \\
\text { FLST, } 5,8,4, \text { OR }\end{array}$ \\
\hline /UI, MESH, OFF & $\mathrm{DE}, 6$ \\
\hline LSEL, S, LOC , Z, & FITEM, 5, 17 \\
\hline .5 & FITEM, $5,-20$ \\
\hline ALLSEL, ALL & FITEM, 5,37 \\
\hline LSEL, S, LOC, Z, & FITEM, 5, - 38 \\
\hline .5 & FITEM, 5, 57 \\
\hline FLST, $5,3,6,0 R$ & FITEM, 5, - 58 \\
\hline $\mathrm{DE}, 2$ & CM,_Y, LINE \\
\hline FITEM, 5,1 & LSEL, , , \\
\hline FITEM, 5, - 3 &, $\mathrm{P} 51 \mathrm{X}$ \\
\hline $\mathrm{CM},-\mathrm{Y}, \mathrm{VOLU}$ & CM,_Y1, LINE \\
\hline VSEL, , & CMSEL, ,_Y \\
\hline , P51X & LESIZE,_Y1, \\
\hline CM,_Y1, VOLU & $, 2,,, 1$ \\
\hline CMSEL, $\mathrm{S},-\mathrm{Y}$ & ALLSEL, ALL \\
\hline FLST, $5,3,6$, OR & FLST, 5, 3, 6, OR \\
\hline $\mathrm{DE}, 2$ & $\mathrm{DE}, 2$ \\
\hline FITEM, 5, 1 & FITEM, 5,1 \\
\hline FITEM, $5,-3$ & FITEM, 5, -3 \\
\hline CM,_Y, VOLU & CM,_Y, VOLU \\
\hline VSEL, , , & VSEL, , , \\
\hline , P51X &, $\mathrm{P} 51 \mathrm{X}$ \\
\hline CM,_Y1, VOLU & CM,_Y1, VOLU \\
\hline CMSEL, S,_Y & CHKMSH, 'VOLU' \\
\hline CMSEL, S,_Y1 & CMSEL, S,_Y \\
\hline VATT, & VSWEEP,_Y1 \\
\hline 1, & CMDELE,_Y \\
\hline 3, & CMDELE,_Y1 \\
\hline CMSEL, $, \mathrm{S},-\mathrm{Y}$ & CMDELE,_Y2 \\
\hline CMDELE,_Y & /UI, MESH, OFF \\
\hline CMDELE,_Y1 & LSEL, S, LOC , Z, \\
\hline /UI, MESH, OFF & $\odot$ \\
\hline $\begin{array}{l}\text { LSEL, S, LOC, Z, } \\
\odot\end{array}$ & $\begin{array}{l}\text { LSEL, S, LOC, Z, } \\
\text { CSYS, } 1\end{array}$ \\
\hline FLST $, 5,16,4,0$ & CSYS, 1 \\
\hline $\mathrm{RDE}, 6$ & WPSTYLE $, 1,,$, , \\
\hline FITEM, 5,1 &, 1 \\
\hline FITEM, $5,-8$ & DSYS, 1 \\
\hline FITEM , 5, 21 & /UI, MESH, OFF \\
\hline FITEM, 5, - 24 & CSYS, 0 \\
\hline FITEM, 5, 41 & DSYS, 0 \\
\hline
\end{tabular}

wpstyle, 0.05 ,

$0.1,-$

$1,1,0.003,1,2$

$$
\text { , } 5
$$

WPSTYLE, , , , ,

, 0

WPSTYLE, , , , ,

$$
\text { , } 0
$$

WPSTYLE, , , , ,

$$
, 1
$$$$
\text { WPSTYLE, , , , , , }
$$$$
, 0
$$

WPSTYLE, , , , ,

, 0

LSEL, S, LOC, Z,

WPSTYLE, , , , , ,

wpstyle, -

$1,0.1,-$

$1,1,0.003,0,2$

,, 5

wpstyle, -

$1,0.1$, -

$1,1,0.003,0,2$

, 5

wpstyle, .001,

. 001 , -

$1,1,0.003, \odot, 0$

, 5

WPSTYLE,,,,, ,

,, 0

wpstyle, 0.001

, 0.001 , -

$.0001, .0001,0$

$.003,0,0,-5$

WPSTYLE, , , , ,

, , $\odot$

FLST , 5, 8, 4, OR

$\mathrm{DE}, 4$

FITEM $, 5,1$

FITEM, 5, - 4

FITEM, 5, 21

FITEM, 5, -24

CM, Y Y, LINE

LSEL, , ,

, P51X

CM,_Y1, LINE

CMSEL, S, YY

CMSEL, $S$, YY1

LATT , 2, 3, 2, ,

CMSEL, $S,-Y$

CMDELE, $Y$

CMDELE, Y1

FLST , 5, 8, 4, OR

$\mathrm{DE}, 4$

FITEM, 5, 1

FITEM, 5, - 4

FITEM, 5, 21

FITEM, 5, - 24

CM, Y Y, LINE

LSEL, , ,

, P51X

CM,_Y1, LINE

CMSEL, , Y

LESIZE, _Y1, ,

$4,,, 1$
FLST , 2, 8, 4, OR

$\mathrm{DE}, 4$

FITEM, 2, 1

FITEM, 2, - 4

FITEM, 2, 21

FITEM, 2, - 24

LMESH, P51X

ESEL, S, MAT, , 2

ALLSEL, ALL

LSTR,

25,

LSTR,

41, $\quad 105$

LSTR,

24, 88

LSTR,

40,

LSTR,

$23, \quad 87$

LSTR,

39, $\quad 103$

LSTR,

38, $\quad 102$

LSTR,

22, 86

LSTR,

37, 101

LSTR,

$21, \quad 85$

LSTR,

20, 84

LSTR,

36 ,

LSTR,

19,

LSTR,

35,

LSTR,

18 ,

LSTR,

34, $\quad 98$

LSTR,

17,

LSTR,

33,

LSTR,

32,

LSTR,

48,

LSTR,

31,

LSTR,

47,

LSTR,

30 ,

LSTR,

46,

LSTR,

45 ,

LSTR,

29,

LSTR,

28,

LSTR,

44,

LSTR,

27,

LSTR,

43 , 


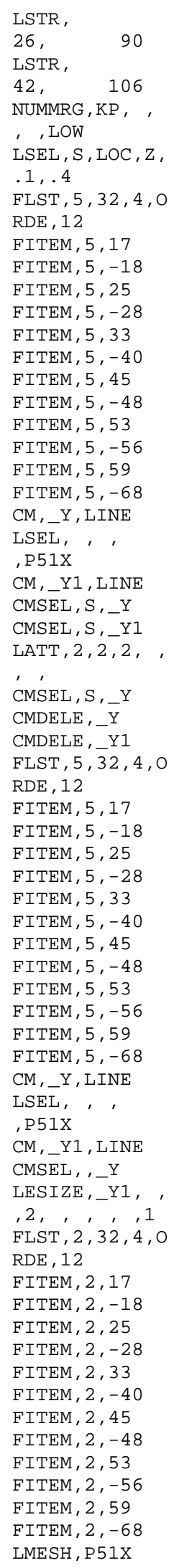

\begin{tabular}{|c|c|}
\hline ESEL, S, MAT, , 2 & FINISH \\
\hline FINISH & /SOL \\
\hline /PREP7 & ACEL $, \odot, \odot, 9.81$ \\
\hline TBDE, CONC , 1, & \\
\hline & FINISH \\
\hline TB, CONC $, 1,1,9$ & /PREP7 \\
\hline , & NUMMRG, NODE, \\
\hline TBTEMP, $\odot$ &, , , LOW \\
\hline TBDATA $,, .2, .2$ & NUMMRG, KP， , \\
\hline 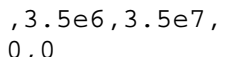 & $\begin{array}{l}\text { ', LOW } \\
\text { NUMMRG, ELEM, }\end{array}$ \\
\hline TBDATA $, \odot, \odot,$. & , , LOW \\
\hline 7,1, & ALLSEL, ALL \\
\hline MPTEMP, $, r, r$, & FINISH \\
\hline & /PREP7 \\
\hline MPTEMP $, 1,0$ & FLST, 2, 3, 6, OR \\
\hline MPDE, EX, 1 & $\mathrm{DE}, 2$ \\
\hline MPDE, PRXY, 1 & FITEM, 2, 1 \\
\hline MPDATA, EX, 1, & FITEM, 2, - 3 \\
\hline $2.66 \mathrm{e} 10$ & VDELE, P51X, \\
\hline MPDATA, PRXY, 1 &, 1 \\
\hline,, .2 & FLST, 2, 68, 4, 0 \\
\hline TB, MELA, $1,1,3$ & $\mathrm{RDE}, 2$ \\
\hline & FITEM, 2, 1 \\
\hline TBTEMP, $\odot$ & FITEM, 2, -68 \\
\hline $\begin{array}{l}\text { TBPT, , . } 00085, \\
2.66 \mathrm{e} 7\end{array}$ & LDELE, P51X， , \\
\hline TBPT, $, .002,3$. & FLST, $2,14,5,0$ \\
\hline $5 e 7$ & $\mathrm{RDE}, 4$ \\
\hline TBPT, , .1, $3.5 \mathrm{e}$ & FITEM, 2,1 \\
\hline 7 & FITEM, $2,-10$ \\
\hline MPTEMP, , , , , , & FITEM, 2, 13 \\
\hline & FITEM, 2, - 16 \\
\hline MPTEMP, 1,0 & ADELE, P51X, , \\
\hline MPDATA, DENS, 1 & 1 \\
\hline, 2400 & FLST, 2, 192, 2, \\
\hline MPTEMP, , , , , , & ORDE, 2 \\
\hline & FITEM, 2, 1 \\
\hline MPTEMP $, 1,0$ & FITEM, 2, -192 \\
\hline MPDE, EX, 2 & EDELE, P51X \\
\hline MPDE, PRXY, 2 & vclear \\
\hline MPDATA, EX, 2, & FLST, 2, 192, 1, \\
\hline $2 \mathrm{e} 11$ & ORDE, 2 \\
\hline MPDATA, PRXY, 2 & FITEM, 2, 1 \\
\hline, .3 & FITEM, 2, - 192 \\
\hline MPTEMP, , , , , , & NDELE, P51X \\
\hline & FLST, $2,3,6,0 \mathrm{R}$ \\
\hline MPTEMP $, 1, \odot$ & $\mathrm{DE}, 2$ \\
\hline MPDE, EX, 2 & FITEM, 2, 1 \\
\hline MPDE, PRXY, 2 & FITEM, 2, -3 \\
\hline MPDATA, EX, 2, & VDELE, P51X， , \\
\hline $2 \mathrm{E}+011$ & $\begin{array}{l}1 \\
{ }^{\prime}\end{array}$ \\
\hline $\begin{array}{l}\text { MPDATA, PRXY, } 2 \\
0.3\end{array}$ & $\begin{array}{l}\text { FLST, 2, 192, 2, } \\
\text { ORDE, } 2\end{array}$ \\
\hline TB, MELA, 2, 1, 2 & FITEM, 2, 1 \\
\hline & FITEM, 2, - 192 \\
\hline TBTEMP, $\odot$ & EDELE, P51X \\
\hline TBPT, , . $. \odot 2,4 \mathrm{e}$ & vclear $, \odot, 3$ \\
\hline 8 & vclear, 1, 2 \\
\hline TВPT, , . 1, 4e8 & FLST, 2, 128, 2, \\
\hline ESEL, S, REAL, , & ORDE, 4 \\
\hline 2 & FITEM , 2, 1 \\
\hline ALLSEL, ALL & FITEM, 2, - 32 \\
\hline ESEL, S, REAL, , & FITEM, 2, 97 \\
\hline 1 & FITEM, 2, - 192 \\
\hline FINISH & EDELE, P51X \\
\hline /SOL & vclear 1,1000 \\
\hline ESEL， S, REAL, & $\odot$ \\
\hline 3 & ALLS \\
\hline
\end{tabular}

\begin{tabular}{|c|c|}
\hline lclear , 1, $100 \odot$ & CMSEL, , YY \\
\hline$\odot$ & LESIZE,_Y1, \\
\hline ALLSEL, ALL &, 22.5, , , , \\
\hline $\begin{array}{l}\text { FLST, 2, 128, 3, } \\
\text { ORDE, } 2\end{array}$ & ÁLL' 11 \\
\hline FITEM, 2,1 & LSEL, S, LOC, Z, \\
\hline FITEM, 2, -128 & .5 \\
\hline KDELE, P51X & FLST, 5, 24, 4, 0 \\
\hline FLST $, 2,68,4,0$ & $\mathrm{RDE}, 6$ \\
\hline $\mathrm{RDE}, 2$ & FITEM $, 5,9$ \\
\hline FITEM, 2, 1 & FITEM, 5, -16 \\
\hline FITEM, 2, - 68 & FITEM, 5, 29 \\
\hline LDELE，P51X， ， & FITEM, 5, - 36 \\
\hline & FITEM, 5, 49 \\
\hline FLST, 2, 14, 5, 0 & FITEM, 5, - 56 \\
\hline RDE, 4 & CM,_Y, LINE \\
\hline FITEM , 2, 1 & LSEL, , , , \\
\hline FITEM, 2, -10 & , P51X \\
\hline FITEM, 2, 13 & CM,_Y1, LINE \\
\hline FITEM, 2, - 16 & CMSEL, , Y Y \\
\hline ADELE, P51X, & LESIZE,_Y1, \\
\hline &, 22.5, \\
\hline FLST, 2, 3, 6, OR &, 1 \\
\hline $\mathrm{DE}, 2$ & ALLSEL, ALL \\
\hline FITEM, 2, 1 & FLST $, 5,6,4,0 R$ \\
\hline FITEM, 2, - 3 & $\mathrm{DE}, 6$ \\
\hline VDELE, P51X, & FITEM $, 5,18$ \\
\hline & FITEM, 5,20 \\
\hline FINISH & FITEM, 5,38 \\
\hline /PREP7 & FITEM $, 5,40$ \\
\hline CYL4, $\odot, \odot, 9$, & FITEM, 5, 58 \\
\hline$, 9.14,, .5$ & FITEM $, 5,60$ \\
\hline CYL $4,0,0,9.14$ & $\mathrm{CM},-\mathrm{Y}, \mathrm{LINE}$ \\
\hline$, 9.26,, .5$ & LSEL, , , \\
\hline CYL4, $\odot, \odot, 9.26$ & , P51X \\
\hline$, 9.38,, .5$ & CM,_Y1, LINE \\
\hline FLST, $5,3,6$, OR & CMSEL, , Y Y \\
\hline$D E, 2$ & LESIZE,_Y1, \\
\hline FITEM, 5,1 & $, 2,,,, 1$ \\
\hline FITEM, $5,-3$ & FLST, $5,6,4,0 R$ \\
\hline $\mathrm{CM}, \_\mathrm{Y}, \mathrm{VOLU}$ & $\mathrm{DE}, 6$ \\
\hline VSEL, , , & FITEM, 5,17 \\
\hline , P51X & FITEM, 5, 19 \\
\hline $\mathrm{CM}, \_\mathrm{Y} 1, \mathrm{VOLU}$ & FITEM, 5, 37 \\
\hline CMSEL, $S,{ }_{-} Y$ & FITEM, 5, 39 \\
\hline CMSEL, S,_Y1 & FITEM, 5, 57 \\
\hline VATT, & FITEM, 5, 59 \\
\hline 1, & CM,_Y, LINE \\
\hline 3, & LSEL, , \\
\hline CMSEL, S,_Y & , P51X \\
\hline CMDELE,_Y & CM,_Y1, LINE \\
\hline CMDELE,_Y1 & CMSEL, ,_Y \\
\hline $\mathrm{LSEL}, \mathrm{S}, \mathrm{LOC}, \mathrm{Z}$, & LESIZE,_Y1, \\
\hline$\odot$ & $, 2,,, 1$ \\
\hline /UI, MESH, OFF & ALLSEL, ALL \\
\hline LDELE， & FLST, $5,3,6,0 R$ \\
\hline 1 & $\mathrm{DE}, 2$ \\
\hline FLST $, 5,24,4,0$ & FITEM, 5,1 \\
\hline $\mathrm{RDE}, 6$ & FITEM, 5, -3 \\
\hline FITEM $, 5,1$ & CM,_Y, VOLU \\
\hline FITEM, 5, - 8 & VSEL, \\
\hline FITEM, 5, 21 & , P51X \\
\hline FITEM, 5, - 28 & $\mathrm{CM},-\mathrm{Y} 1, \mathrm{VOLU}$ \\
\hline FITEM, 5, 41 & CMSEL, S, YY \\
\hline FITEM, 5, - 48 & CMSEL, S,_Y1 \\
\hline $\mathrm{CM}, \_\mathrm{Y}, \mathrm{LINE}$ & VATT, \\
\hline LSEL, , , , & 1, \\
\hline , P51X & 3, \\
\hline $\mathrm{CM},-\mathrm{Y} 1, \mathrm{LINE}$ & CMSEL, $S, \quad Y$ \\
\hline
\end{tabular}




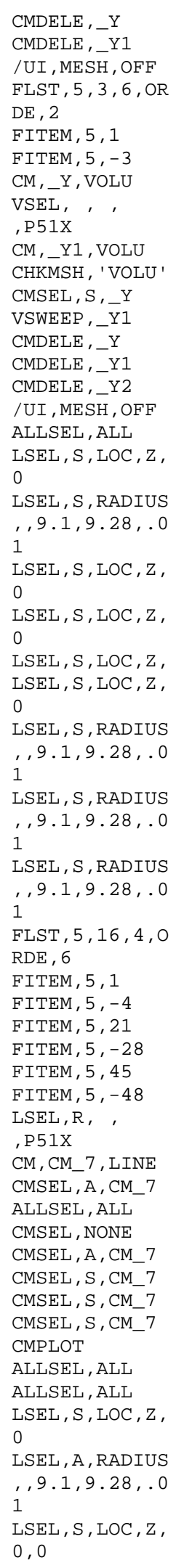

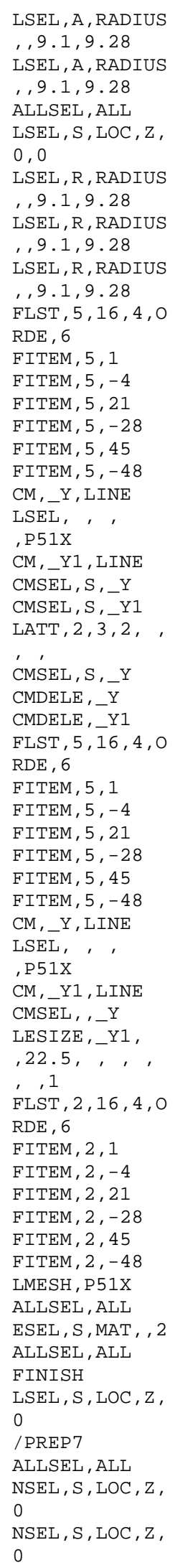

CSYS, 1

NSEL, R, LOC, Z,

ALLSEL, ALL

NSEL, R, LOC , Z,

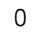

ALLSEL, ALL

NSEL, S, LOC, Z, 0

FLST , 3, 28, 1, 0

$\mathrm{RDE}, 8$

FITEM , 3, 1

FITEM, 3, - 7

FITEM, 3, 9

FITEM, 3, - 15

FITEM, 3, 33

FITEM, 3, - 39

FITEM, 3, 41

FITEM, 3, - 47

KNODE, $\odot$, P51X

ALLSEL, ALL

NSEL, S, LOC, Z,

.5

FLST , 3, 28, 1, 0

$\mathrm{RDE}, 8$

FITEM, 3, 136

FITEM, 3, - 142

FITEM, 3, 154

FITEM, 3, -160

FITEM, 3, 200

FITEM, 3, -206

FITEM, 3, 218

FITEM, 3, - 224

KNODE, $\odot$, P51X

ALLSEL, ALL

DSYS, 1

ALLSEL, ALL

DSYS, 0

DSYS, 5

DSYS, 0

LSTR,

58, $\quad 79$

LSTR,

72 ,

LSTR,

$57, \quad 78$

FLST , 2, 3, 4, OR

$\mathrm{DE}, 2$

FITEM, 2, 61

FITEM, 2, -63

LDELE, P51X

LSTR,

$58, \quad 79$

LSTR,

72 ,

LSTR,

57 ,

LSTR,

71,

LSTR,

56 ,

LSTR,

70 ,

LSTR,

LSTR,

65,

LSTR,

74,

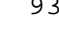

78

92

77

91

86

100

94 $\begin{array}{ll}\text { LSTR, } & \\ 60, & 80 \\ \text { LSTR, } & \\ \text { 75, } & \\ \text { LSTR, } & 95 \\ 61, & \\ \text { LSTR, } & 81 \\ 67, & \\ \text { LSTR, } & 101 \\ \text { 53, } & \\ \text { LSTR, } & 87 \\ 68, & \\ \text { LSTR, } & 102 \\ 54, & 88\end{array}$

FLST, 2, 2, 4, OR

$\mathrm{DE}, 2$

FITEM, 2, 75

FITEM, 2, - 76

LDELE, P51X

LSTR,

68,

LSTR,

102

54

LSTR,

69,

LSTR,

55, 90

LSTR,

17,

1 ,

63

63,

49,

LSTR,

20,

LSTR

4,

LSTR,

76 ,

LSTR,

62 ,

LSTR,

64,

LSTR,

$50, \quad 85$

LSEL, S, LOC , Z,

$.2, .8$

ALLSEL, ALL

LSEL, S, LOC , Z,

$.4, .8$

ALLSEL, ALL

LSEL, S, LOC, Z,

$.3, .7$

ALLSEL, ALL

LSEL, S, LOC , Z,

$.3, .4$

LSEL, S, LOC , Z,

. 2, . 4

LSEL, R, LENGTH

, , 9.1, 9.28

ALLSEL, ALL

LSEL, S, RADIUS

$, 9.1,9.28$

LSEL, S, RADIUS

, 9.1, 9.28

LSEL, S, RADIUS

$, 9.1,9.28$
LSEL, R, LOC , Z,

$.2, .4$

ALLSEL, ALL

LSEL, S, LOC , Z,

$.2, .4$

FLST , 5, 36, 4, 0

RDE, 6

FITEM, 5, 17

FITEM, 5, - 18

FITEM , 5, 37

FITEM, 5, -40

FITEM, 5, 59

FITEM, 5, - 88

LSEL, R, ，

, P51X

FLST , 5, 36, 4, 0

RDE, 6

FITEM , 5, 17

FITEM, 5, - 18

FITEM , 5, 37

FITEM, 5, -40

FITEM, 5, 59

FITEM, 5, - 88

CM,_Y, LINE

LSEL, , ,

, P51X

CM,_Y1, LINE

CMSEL, S, Y

CMSEL, S, YY1

LATT , 2, 2, 2, ,

'CMSEL, $S, Y Y$

CMDELE, $-\bar{Y}$

CMDELE, Y1

FLST , 5, 36, 4, 0

RDE, 6

FITEM, 5, 17

FITEM, 5, -18

FITEM, 5, 37

FITEM, 5, -40

FITEM, 5, 59

FITEM, 5, - 88

CM, Y Y, LINE

LSEL, ,

, P51X

CM,_Y1, LINE

CMSEL, , Y Y

LESIZE,_Y1, ,

, 2, ' ', '1

FLST, 2, 36, 4, 0

RDE, 6

FITEM, 2, 17

FITEM, 2, - 18

FITEM, 2, 37

FITEM, 2, -40

FITEM, 2, 59

FITEM, 2, - 88

LMESH, P51X

ESEL, R, REAL , , 2

ALLSEL, ALL

ESEL, R, MAT , , 2 NUMMRG, NODE,

', , LOW

FINISH

vclear , 1, 1000

lclear , 1, 5555

55 


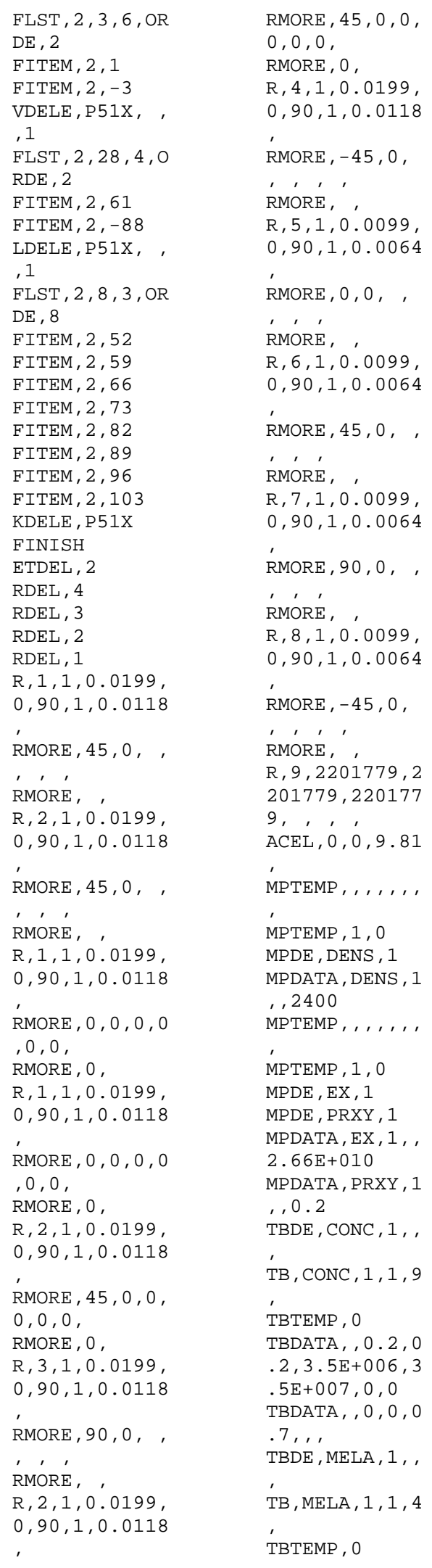

\begin{tabular}{|c|c|}
\hline $\begin{array}{l}\text { TBPT, , } 0.00085 \\
2.66 \mathrm{E}+007\end{array}$ & TBDE, MELA, 2 , , \\
\hline $\begin{array}{l}\text { TBPT, , } \odot . \odot \odot 2,3 \\
.5 \mathrm{E}+\odot \odot 7\end{array}$ & 'TB, MELA, 2, 1, 2 \\
\hline TВPT, ,, $.0 \odot 35$, & TВTEMP, $\odot$ \\
\hline $2 \mathrm{E}+007$ & ТВРТ, $, 0.002,4$ \\
\hline TBPT, , $, . .005,1$ & $E+008$ \\
\hline $\begin{array}{l}\text { e7 } \\
\text { TBDE, MELA, } 1\end{array}$ & $\begin{array}{l}\text { TBPT, , } 0.1,4 \mathrm{E}+ \\
\odot \odot 8\end{array}$ \\
\hline & FINISH \\
\hline TB, MELA, $1,1,6$ & /SOL \\
\hline & ANTYPE, $\odot$ \\
\hline TBTEMP, $\odot$ & CNVTOL, F， \\
\hline TBPT, , $\odot . \odot \odot \odot 85 ~$ & $, 0.15,2$, \\
\hline, $2.66 \mathrm{E}+007$ & CNVTOL, U, \\
\hline $\begin{array}{l}\text { TBPT, , } 0.002,3 \\
.5 \mathrm{E}+\odot \odot 7\end{array}$ & $\begin{array}{l}\prime .15,2,{ }^{\prime} \\
\text { ANTYPE, } \odot\end{array}$ \\
\hline TBPT, , , .0035, & NLGEOM, 1 \\
\hline $2 \mathrm{E}+007$ & NSUBST, 15,30 , \\
\hline TBPT, , $0.005,1$ & 10 \\
\hline$E+007$ & AUTOTS, 1 \\
\hline $\begin{array}{l}\text { TBPT, , } 0.01,0 . \\
5 \mathrm{e} 7\end{array}$ & $\begin{array}{l}\text { NCNV }, \Theta, \Theta, \odot, \Theta, \\
\odot\end{array}$ \\
\hline TBPT, $, \odot .02, \odot$. & RESCONTRL, DEF \\
\hline $5 e 7$ & INE, ALL, ALL, 1 \\
\hline TBDE, MELA, 1, & $\begin{array}{l}\text { OUTRES, ERASE } \\
\text { OUTRES, ALL, AL }\end{array}$ \\
\hline TB, MELA $, 1,1,7$ & $\mathrm{~L}$ \\
\hline ' & FINISH \\
\hline TBTEMP, $\odot$ & /PREP7 \\
\hline ТВРТ, , ,. $.0 \odot \odot 85$ & FINISH \\
\hline, $2.66 \mathrm{E}+007$ & /PREP7 \\
\hline $\begin{array}{l}\text { TBPT, , } \odot . \odot \odot 2,3 \\
5 E+\odot \odot 7\end{array}$ & $\mathrm{R}, 1,1,0.0199$, \\
\hline TВPТ, ,, .0021, & \\
\hline $3.5 \mathrm{e} 7$ & RMORE $, \odot, \odot, \odot, \odot$ \\
\hline TBPT, , $\odot .0035$, & $, 0,0$ \\
\hline $2 \mathrm{E}+007$ & RMORE, $\odot$, \\
\hline $\begin{array}{l}\text { TBPT, , } 0.005,1 \\
E+007\end{array}$ & $\begin{array}{l}\mathrm{R}, 2,1,0.0199, \\
0,90,1,0.0118\end{array}$ \\
\hline ТВРТ, $, 0.01,5 \mathrm{E}$ & \\
\hline$+\odot \odot 6$ & RMORE $, 45, \odot, \odot$, \\
\hline TBPT, $, 0.02,5 \mathrm{E}$ & $\odot, \odot, \odot$, \\
\hline $\begin{array}{l}+006 \\
\text { MPTEMP }\end{array}$ & $\begin{array}{l}\text { RMORE, } 0, \\
R, 3,1,0.0199\end{array}$ \\
\hline & $0,90,1,0.0118$ \\
\hline MPTEMP , 1, $\odot$ & , \\
\hline MPDE, DENS, 1 & RMORE, $9 \odot, \odot, \odot$, \\
\hline MPDATA, DENS, 1 & $0,0,0$, \\
\hline,, 2400 & RMORE, $\odot$, \\
\hline MPTEMP, , r, r, & $\begin{array}{l}\mathrm{R}, 4,1,0.0199, \\
\odot, 9 \odot, 1,0.0118\end{array}$ \\
\hline MPTEMP, $1, \odot$ & , \\
\hline MPDE, EX, 1 & RMORE, \\
\hline MPDE, PRXY, 1 & $45, \odot, \odot, \odot, \odot, \odot$, \\
\hline MPDATA, EX, 1, , & RMORE, $\odot$, \\
\hline $2.66 \mathrm{E}+010$ & $\mathrm{R}, 5,1,0.0099$, \\
\hline MPDATA, PRXY, 1 & $\odot, 90,1,0.0064$ \\
\hline, 0.2 & , \\
\hline MPTEMP, $, 1, r$, & RMORE, $\odot, \odot, \odot, \odot$ \\
\hline MPTEMP $, 1, \odot$ & RMORE, $\odot$ \\
\hline MPDE, EX, 2 & $\mathrm{R}, 6,1,0.0099$ \\
\hline MPDE, PRXY, 2 & $\odot, 90,1, \odot .0064$ \\
\hline MPDATA, EX, 2, & \\
\hline $2 \mathrm{E}+011$ & RMORE, $45, \odot, \odot$, \\
\hline MPDATA, PRXY, 2 & $\odot, 0, \Theta$ \\
\hline, 0.3 & RMORE, $\odot$ \\
\hline
\end{tabular}

$\mathrm{R}, 7,1,0.0099$, $\odot, 90,1,0.0 \odot 64$ RMORE, $90,0,0$, $\odot, \odot, \odot$, RMORE, $\odot$, $\mathrm{R}, 8,1,0.0099$, $0,90,1,0.0064$

RMORE, -

$45,0,0,0,0,0$, RMORE, $\odot$,

$\mathrm{R}, 9,2201779,2$ 201779,220177 $9,0,0,0$,

TBDE, CONC, 1, TB, CONC , 1, 1, 9 TBTEMP, $\odot$ TBDATA, , $0.2,0$ $.2,3.5 \mathrm{E}+006,3$ . 5E+०07, 0,0 TBDATA, $, \odot, \odot, \odot$ .7, , MPTEMP, , , ו ו , MPTEMP, 1,0 MPDE, DENS, 1 MPDATA, DENS, 1 , 2400 TBDE, CONC, 1, 'TB, CONC , 1, 1, 9 'TBTEMP, $\odot$ TBDATA, , $0.2,0$ $.2,3.5 \mathrm{E}+006,3$ $.5 \mathrm{E}+007,0,0$ TBDATA, $, \odot, \odot, \odot$ .7, TBDE, MELA, 1, , TB, MELA, 1, 1, 7 'TBTEMP, $\odot$ TBPT, , 0.00085 , $2.66 \mathrm{E}+007$ TBPT, , $0.002,3$ $.5 \mathrm{E}+007$ TBPT, , 0.0021 , 3. $5 \mathrm{E}+007$ TBPT, , 0.0035 , $2 \mathrm{E}+007$

TBPT, , $0.005,1$ $\mathrm{E}+007$

TBPT, , $0.01,5 \mathrm{E}$ $+006$ TBPT, , $0.02,5 \mathrm{E}$ $+006$ TBDE, MELA, 2 , , 'TB, MELA , 2, 1, 2 'TBTEMP, $\odot$ TBPT, , $0.002,4$ $\mathrm{E}+008$ TBPT, , $0.1,4 \mathrm{E}+$ $\odot \odot 8$ 


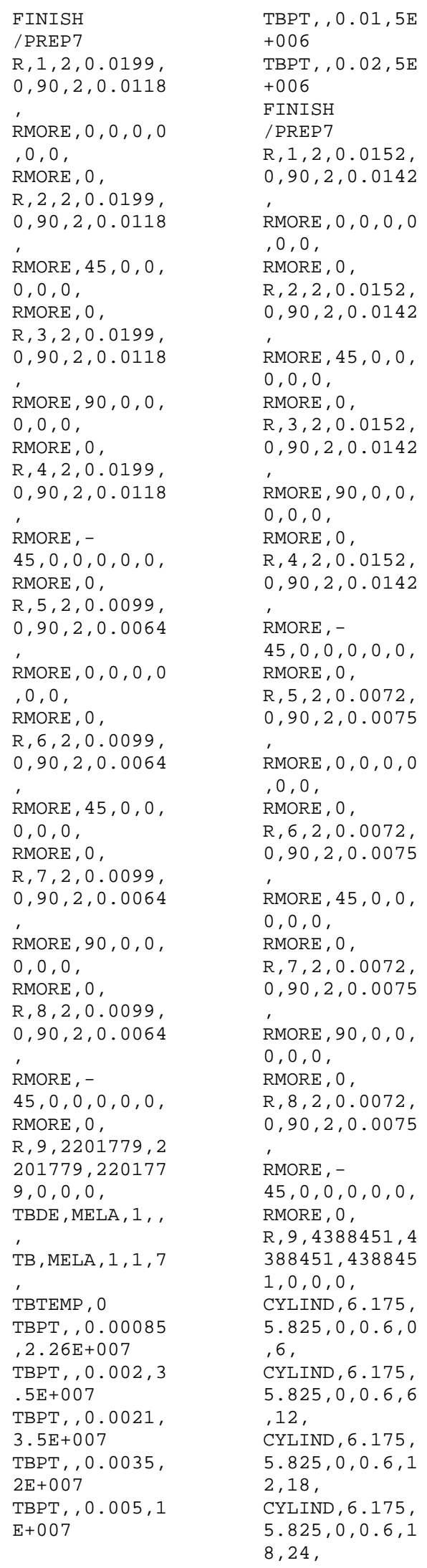

CYLIND, 6.175 ,

$5.825,0,0.6,2$

4, 30,

CYLIND, 6.175 ,

$5.825,0,0.6,3$

0,36 ,

CYLIND, 6.175,

$5.825,0,0.6,3$

6,42 ,

CYLIND, 6.175 ,

$5.825,0,0.6,4$

2,48 ,

CYLIND, 6.175 ,

$5.825,0,0.6,4$

8,54 ,

CYLIND, 6.175 ,

$5.825,0,0.6,5$

4, 60,

CYLIND, 6.175 ,

$5.825,0,0.6,6$ 0,66 ,

CYLIND, 6.175,

$5.825,0,0.6,6$

6,72 ,

CYLIND, 6.175 ,

$5.825,0,0.6,7$

2, 78,

CYLIND, 6.175 ,

$5.825,0,0.6,7$

8,84 ,

CYLIND, 6.175 ,

$5.825,0,0.6,8$

4, 90,

FLST, 5, 5, 6, OR

$\mathrm{DE}, 2$

FITEM, 5, 11

FITEM, 5, - 15

CM, YY, VOLU

VSEL, , ,

, P51X

CM,_Y1, VOLU

CMSEL, S, Y

CMSEL, $S$, Y1

VATT,

$\begin{array}{ll}1, & 1, \\ 3, & 0\end{array}$

CMSEL, $S, Y Y$

CMDELE, $Y$

CMDELE, Y1

FLST , 5, 88, 4, 0

RDE, 9

FITEM, 5, 86

FITEM, 5, - 87

FITEM, 5, 90

FITEM, 5,-91

FITEM, 5, 95

FITEM, 5, 97

FITEM, 5, -105

FITEM, 5, 107

FITEM, 5, - 180

CM,_Y, LINE

LSEL, ,

, P51X

CM,_Y1, LINE

CMSEL, , $Y$

LESIZE, _Y1, ,

$1,1,1,1$

FLST, 5, 5, 6, OR

$\mathrm{DE}, 2$
FITEM, 5, 11

FITEM, 5, - 15

CM, Y Y, VOLU

VSEL, , ,

, P51X

CM, Y1, VOLU

CHKMSH, 'VOLU'

CMSEL, S, Y

VSWEEP, Y 1

CMDELE, $Y$

CMDELE, Y1

CMDELE, Y2

FLST , 5, 5, 6, OR

$\mathrm{DE}, 2$

FITEM , 5, 6

FITEM, 5, -10

CM, Y, VOLU

VSEL, , ,

, P51X

CM,_Y1, VOLU

CMSEL, S, Y

CMSEL, S,_Y1

VATT,

1,

CMSEL, $S,{ }_{-} Y$

CMDELE, _Y

CMDELE, Y1

FLST, 5, 104, 4,

ORDE, 12

FITEM , 5, 27

FITEM, 5, 30

FITEM, 5, 33

FITEM, 5, 37

FITEM, 5, -47

FITEM, 5, 49

FITEM, 5, -133

FITEM, 5, 136

FITEM, 5, -137

FITEM, 5, 140

FITEM, 5, 142

FITEM, 5, 144

CM, YY, LINE

LSEL, , ,

, P51X

CM,_Y1, LINE

CMSEL, , Y Y

LESIZE, _Y1, ,

$, 1,1,1$

FLST, 5, 5, 6, OR

$\mathrm{DE}, 2$

FITEM, 5, 6

FITEM, 5, -10

CM, Y Y, VOLU

VSEL, , ,

, P51X

CM,_Y1, VOLU

CHKMSH, 'VOLU'

CMSEL, $S, Y$

VSWEEP, Y Y1

CMDELE, $Y$

CMDELE,_Y1

CMDELE, Y2

FLST , 5, 5, 6, OR

$\mathrm{DE}, 2$

FITEM, 5, 1

FITEM, $5,-5$

CM, Y, VOLU
VSEL, , ,

, P51X

CM,_Y1, VOLU

CMSEL, $S, Y$

CMSEL, S, YY1

VATT,

1, 3 ,

CMSEL, $S,{ }_{-} Y$

CMDELE, $Y$

CMDELE,_Y1

FLST $, 5, \overline{7} 4,4,0$

RDE, 6

FITEM, 5, 1

FITEM, 5, -68

FITEM, 5,70

FITEM , 5, - 73

FITEM, 5, 80

FITEM, 5, 84

CM, _Y, LINE

LSEL, , ,

, P51X

CM,_Y1, LINE

CMSEL, , Y

LESIZE, _Y1, ,

$1,1,1$

FLST, 5, 5, 6, OR

$\mathrm{DE}, 2$

FITEM, 5, 1

FITEM, 5, -5

CM, Y Y, VOLU

VSEL, , ,

, P51X

CM,_Y1, VOLU

CHKMSH, 'VOLU'

CMSEL, $S,-Y$

VSWEEP, Y1

CMDELE, YY

CMDELE, Y1

CMDELE,_Y2

/CFORMAT, 32, 0

/UI, MESH, OFF

CSYS, 0

FLST , 3, 15, 6, 0

RDE, 2

FITEM, 3, 1

FITEM, 3, - 15

VSYMM, X, P51X,

$, \quad, 0,0$

FLST, 3, 30, 6, 0

RDE, 2

FITEM, 3, 1

FITEM, 3, - 30

VSYMM, Y, P51X,

$, 0,0$

FLST, 2, 10, 6, 0

$\mathrm{RDE}, 4$

FITEM , 2, 21

FITEM, 2, - 25

FITEM, 2, 36

FITEM, 2, -40

VCLEAR, P51X

FLST , 5, 10, 6, 0

RDE , 4

FITEM, 5, 21

FITEM , 5, - 25

FITEM, 5, 36

FITEM, 5, -40

$\mathrm{CM},-\mathrm{Y}, \mathrm{VOLU}$ 


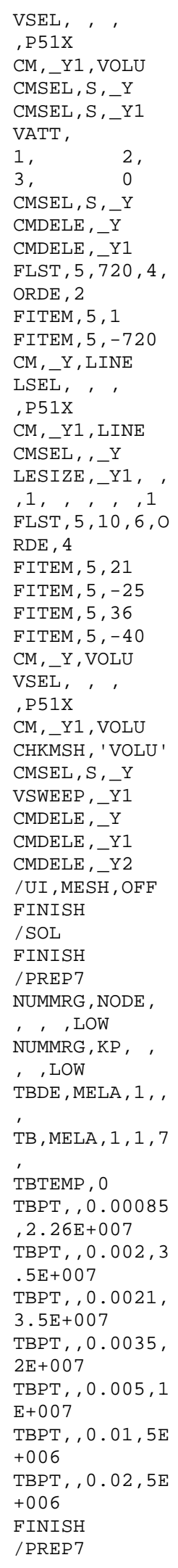

FLST , 3, 60, 6, 0

RDE, 2

FITEM, 3, 1

FITEM, 3, -60

VGEN, 2, P51X,

', , , 0.6,

, $\odot$

FLST, 3, 120, 6,

ORDE, 2

FITEM, 3, 1

FITEM, 3, -120

VGEN, 2, P51X,

', , , 1.2,

FLST, 3, 240, 6,

ORDE, 2

FITEM, 3, 1

FITEM, 3, - 240

VGEN, 2, P51X,

', , 2.4,

FLST , 3, 420, 6,

ORDE, 2

FITEM, 3, 61

FITEM, 3, - 480

VGEN , 2, P51X,

', , 4.2,

FLST, 3, 900, 6,

ORDE, 2

FITEM, 3, 1

FITEM, 3, - 900

VGEN , 2, P51X,

' ' , $, 9,, 0$

VSEL, S, LOC, Z,

$17.4,18$

ESLV, S

FLST, 2, 60, 6, 0

RDE, 2

FITEM, 2, 1741

FITEM, 2, -1800

VCLEAR, P51X

FLST, 5, 20, 6, 0

RDE, 8

FITEM, 5, 1751

FITEM, 5, - 1755

FITEM, 5, 1766

FITEM, 5, -1770

FITEM, 5, 1781

FITEM, 5, - 1785

FITEM, 5, 1796

FITEM, 5, - 1800

CM, _Y, VOLU

VSEL, , ,

, P51X

CM,_Y1, VOLU

CMSEL, $S,-Y$

CMSEL, S, Y1

VATT,

$\begin{array}{ll}1, & 5, \\ 3, & 0\end{array}$

CMSEL, S, Y Y

CMDELE, $\bar{Y}$

CMDELE,_Y1

FLST, 5, 780, 4,

ORDE, 120

FITEM, 5, 13445

FITEM, 5, -

13452
FITEM, 5, 13456

FITEM, 5, -

13460

FITEM, 5, 13464

FITEM, 5, -

13468

FITEM, 5, 13472

FITEM, 5, -

13476

FITEM, 5, 13480

FITEM, 5, -

13484

FITEM, 5, 13488

FITEM, 5, -

13492

FITEM, 5, 13496

FITEM, 5, -

13500

FITEM, 5, 13504

FITEM, 5, -

13508

FITEM, 5, 13512

FITEM, 5, -

13516

FITEM, 5, 13520

FITEM, 5, -

13524

FITEM, 5, 13528

FITEM, 5, -

13532

FITEM, 5, 13536

FITEM, 5, -

13540

FITEM, 5, 13544

FITEM, 5, -

13548

FITEM, 5, 13552

FITEM, 5, -

13556

FITEM, 5, 13560

FITEM, 5, -

13564

FITEM, 5, 13569

FITEM, 5, -

13576

FITEM, 5, 13580

FITEM, 5, -

13584

FITEM, 5, 13588

FITEM, 5, -

13592

FITEM, 5, 13596

FITEM, 5, -

13600

FITEM, 5, 13604

FITEM, 5, -

13608

FITEM, 5, 13612

FITEM, 5, -

13616

FITEM, 5, 13620

FITEM, 5, -

13624

FITEM, 5, 13628

FITEM, 5, -

13632

FITEM, 5, 13636

FITEM, 5, -

13640
FITEM, 5, 13644

FITEM, 5, -

13648

FITEM, 5, 13652

FITEM, 5, -

13656

FITEM, 5, 13660

FITEM, 5, -

13664

FITEM, 5, 13668

FITEM, 5, -

13672

FITEM, 5, 13676

FITEM, 5, -

13680

FITEM , 5, 13683

FITEM, 5, -

13684

FITEM, 5, 13688

FITEM, 5, -

13692

FITEM, 5, 13696

FITEM, 5, -

13700

FITEM, 5, 13704

FITEM, 5, -

13708

FITEM, 5, 13712

FITEM, 5, -

13716

FITEM, 5, 13720

FITEM, 5, -

13724

FITEM, 5, 13728

FITEM, 5, -

13732

FITEM, 5, 13736

FITEM, 5, -

13740

FITEM, 5, 13744

FITEM, 5, -

13748

FITEM, 5, 13752

FITEM, 5, -

13756

FITEM, 5, 13760

FITEM, 5, -

13764

FITEM, 5, 13768

FITEM, 5, -

13772

FITEM, 5, 13776

FITEM, 5, -

13780

FITEM, 5, 13784

FITEM, 5, -

13788

FITEM, 5, 13792

FITEM, 5, -

13796

FITEM, 5, 13800

FITEM, 5, -

13804

FITEM, 5, 13808

FITEM, 5, -

13812

FITEM, 5, 13816

FITEM, 5, -

13820
FITEM, 5, 13824

FITEM, 5, -

13828

FITEM, 5, 13832

FITEM, 5, -

13836

FITEM , 5, 13840

FITEM, 5, -

13844

FITEM, 5, 13848

FITEM, 5, -

13852

FITEM, 5, 13856

FITEM, 5, -

13860

FITEM , 5, 13864

FITEM, 5, -

13868

FITEM, 5, 13872

FITEM, 5, -

13876

FITEM , 5, 13880

FITEM, 5, -

13884

FITEM, 5, 13888

FITEM, 5, -

13892

FITEM, 5, 13896

FITEM, 5, -

13900

FITEM, 5, 13904

FITEM, 5, -

13908

FITEM, 5, 13912

FITEM, 5, -

13916

FITEM, 5, 13919

FITEM, 5, -

14400

CM,_Y, LINE

LSEL, , ,

, P51X

CM,_Y1, LINE

CMSEL, , Y

LESIZE, _Y1, ,

$1,1,1,1$

FLST, 5, 20, 6, 0

RDE, 8

FITEM, 5, 1751

FITEM, 5, -1755

FITEM, 5, 1766

FITEM, 5, -1770

FITEM, 5, 1781

FITEM, 5, -1785

FITEM, 5, 1796

FITEM, 5, -1800

CM, Y Y, VOLU

VSEL, , ,

, P51X

CM,_Y1, VOLU

CHKMSH, 'VOLU'

CMSEL, $S,-Y$

VSWEEP,, $\bar{Y} 1$

CMDELE, _Y

CMDELE, YY1

CMDELE, Y 2

FLST , 5, 20, 6, 0

RDE, 8

FITEM, 5, 1741 
FITEM, 5, - 1745

FITEM, 5, 1756

FITEM, 5, -1760

FITEM, 5, 1771

FITEM, 5, -1775

FITEM, 5, 1786

FITEM, 5, -1790

CM, Y, VOLU

VSEL, , ,

, P51X

CM,_Y1, VOLU

CMSEL, S, YY

CMSEL, S, Y Y1

VATT,

1, 7,

CMSEL, S, $\stackrel{\odot}{\text { Y }}$

CMDELE, $-\bar{Y}$

CMDELE, Y1

FLST , 5, 780, 4, ORDE, 120

FITEM, 5, 13445

FITEM, 5, -

13452

FITEM, 5, 13456

FITEM, 5, -

13460

FITEM, 5, 13464

FITEM, 5, -

13468

FITEM, 5, 13472

FITEM, 5, -

13476

FITEM, 5, 13480

FITEM, 5, -

13484

FITEM , 5, 13488

FITEM, 5, -

13492

FITEM, 5, 13496

FITEM, 5, -

13500

FITEM, 5, 13504

FITEM, 5, -

13508

FITEM, 5, 13512

FITEM, 5, -

13516

FITEM, 5, 13520

FITEM, 5, -

13524

FITEM, 5, 13528

FITEM, 5, -

13532

FITEM, 5, 13536

FITEM, 5, -

13540

FITEM, 5, 13544

FITEM, 5, -

13548

FITEM, 5, 13552

FITEM, 5, -

13556

FITEM, 5, 13560

FITEM, 5, -

13564

FITEM, 5, 13569

FITEM, 5, -

13576
FITEM, 5, 13580

FITEM, 5, -

13584

FITEM , 5, 13588

FITEM, 5, -

13592

FITEM, 5, 13596

FITEM, 5, -

13600

FITEM, 5, 13604

FITEM, 5, -

13608

FITEM, 5, 13612

FITEM, 5, -

13616

FITEM, 5, 13620

FITEM, 5, -

13624

FITEM, 5, 13628

FITEM, 5, -

13632

FITEM, 5, 13636

FITEM, 5, -

13640

FITEM, 5, 13644

FITEM, 5, -

13648

FITEM, 5, 13652

FITEM, 5, -

13656

FITEM, 5, 13660

FITEM, 5, -

13664

FITEM, 5, 13668

FITEM, 5, -

13672

FITEM, 5, 13676

FITEM, 5, -

13680

FITEM, 5, 13683

FITEM, 5, -

13684

FITEM, 5, 13688

FITEM, 5, -

13692

FITEM, 5, 13696

FITEM, 5, -

13700

FITEM, 5, 13704

FITEM, 5, -

13708

FITEM, 5, 13712

FITEM, 5, -

13716

FITEM, 5, 13720

FITEM, 5, -

13724

FITEM, 5, 13728

FITEM, 5, -

13732

FITEM, 5, 13736

FITEM, 5, -

13740

FITEM, 5, 13744

FITEM, 5, -

13748

FITEM, 5, 13752

FITEM, 5, -

13756
FITEM, 5, 13760

FITEM, 5, -

13764

FITEM, 5, 13768

FITEM, 5, -

13772

FITEM, 5, 13776

FITEM, 5, -

13780

FITEM, 5, 13784

FITEM, 5, -

13788

FITEM, 5, 13792

FITEM, 5, -

13796

FITEM, 5, 13800

FITEM, 5, -

13804

FITEM, 5, 13808

FITEM, 5, -

13812

FITEM, 5, 13816

FITEM, 5, -

13820

FITEM, 5, 13824

FITEM, 5, -

13828

FITEM, 5, 13832

FITEM, 5, -

13836

FITEM, 5, 13840

FITEM, 5, -

13844

FITEM, 5, 13848

FITEM, 5, -

13852

FITEM, 5, 13856

FITEM, 5, -

13860

FITEM, 5, 13864

FITEM, 5, -

13868

FITEM, 5, 13872

FITEM, 5, -

13876

FITEM, 5, 13880

FITEM, 5, -

13884

FITEM, 5, 13888

FITEM, 5, -

13892

FITEM, 5, 13896

FITEM, 5, -

13900

FITEM, 5, 13904

FITEM, 5, -

13908

FITEM, 5, 13912

FITEM, 5, -

13916

FITEM, 5, 13919

FITEM, 5, -

14400

CM,_Y, LINE

LSEL, , ,

, P51X

CM,_Y1, LINE

CMSEL, , Y
LESIZE, Y1, ,

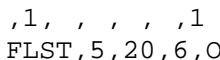

RDE, 8

FITEM, 5, 1741

FITEM, 5, -1745

FITEM, 5, 1756

FITEM, 5, -1760

FITEM, 5, 1771

FITEM, 5, -1775

FITEM, 5, 1786

FITEM, 5, -1790

CM, Y, VOLU

VSEL, , ,

, P51X

CM,_Y1, VOLU

CHKMSH, 'VOLU'

CMSEL, S, Y Y

VSWEEP, YY1

CMDELE,_Y

CMDELE,_Y1

CMDELE, YY2

FLST , 5, 10, 6, 0

RDE , 4

FITEM, 5, 1761

FITEM, 5, - 1765

FITEM, 5, 1776

FITEM, 5, -1780

CM, Y Y, VOLU

VSEL, , ,

, P51X

CM,_Y1, VOLU

CMSEL, S, Y Y

CMSEL, $S,-Y 1$

VATT,

1,6 ,

CMSEL, S, YY

CMDELE, $\bar{Y}$

CMDELE, Y1

FLST , 5, 780, 4,

ORDE, 120

FITEM, 5, 13445

FITEM, 5, -

13452

FITEM, 5, 13456

FITEM, 5, -

13460

FITEM, 5, 13464

FITEM, 5, -

13468

FITEM, 5, 13472

FITEM, 5, -

13476

FITEM, 5, 13480

FITEM, 5, -

13484

FITEM , 5, 13488

FITEM, 5, -

13492

FITEM, 5, 13496

FITEM, 5, -

13500

FITEM, 5, 13504

FITEM, 5, -

13508

FITEM, 5, 13512

FITEM, 5, -

13516

FITEM, 5, 13520

FITEM, 5, -

13524

FITEM, 5, 13528

FITEM, 5, -

13532

FITEM , 5, 13536

FITEM, 5, -

13540

FITEM, 5, 13544

FITEM, 5, -

13548

FITEM, 5, 13552

FITEM, 5, -

13556

FITEM, 5, 13560

FITEM, 5, -

13564 
FITEM, 5, 13704

FITEM, 5, -

13708

FITEM, 5, 13712

FITEM, 5, -

13716

FITEM, 5, 13720

FITEM, 5, -

13724

FITEM, 5, 13728

FITEM, 5, -

13732

FITEM, 5, 13736

FITEM, 5, -

13740

FITEM, 5, 13744

FITEM, 5, -

13748

FITEM, 5, 13752

FITEM, 5, -

13756

FITEM, 5, 13760

FITEM, 5, -

13764

FITEM, 5, 13768

FITEM, 5, -

13772

FITEM, 5, 13776

FITEM, 5, -

13780

FITEM, 5, 13784

FITEM, 5, -

13788

FITEM, 5, 13792

FITEM, 5, -

13796

FITEM, 5, 13800

FITEM, 5, -

13804

FITEM, 5, 13808

FITEM, 5, -

13812

FITEM, 5, 13816

FITEM, 5, -

13820

FITEM, 5, 13824

FITEM, 5, -

13828

FITEM, 5, 13832

FITEM, 5, -

13836

FITEM, 5, 13840

FITEM, 5, -

13844

FITEM, 5, 13848

FITEM, 5, -

13852

FITEM, 5, 13856

FITEM, 5, -

13860

FITEM, 5, 13864

FITEM, 5, -

13868

FITEM, 5, 13872

FITEM, 5, -

13876

FITEM, 5, 13880

FITEM, 5, -

13884
FITEM, 5, 13888

FITEM, 5, -

13892

FITEM, 5, 13896

FITEM, 5, -

13900

FITEM, 5, 13904

FITEM, 5, -

13908

FITEM, 5, 13912

FITEM, 5, -

13916

FITEM, 5, 13919

FITEM, 5, -

14400

CM, YY, LINE

LSEL, , ,

, P51X

CM,_Y1, LINE

CMSEL, , $Y$

LESIZE, YY1,

$, 1,,,, 1$

FLST, $5,10,6,0$

RDE, 4

FITEM, 5, 1761

FITEM, 5,-1765

FITEM, 5, 1776

FITEM, 5, -1780

CM,_Y, VOLU

VSEL, , ,

, P51X

CM, YY1, VOLU

CHKMSH, 'VOLU'

CMSEL, $S,-Y$

VSWEEP,_Y1

CMDELE, $Y$ Y

CMDELE, YY1

CMDELE,_Y2

FLST , 5, 10, 6, 0

RDE, 4

FITEM, 5, 1746

FITEM, 5, - 1750

FITEM, 5, 1791

FITEM, 5, -1795

CM, Y Y, VOLU

VSEL, , ,

, P51X

CM, Y1, VOLU

CMSEL, $S,-Y$

CMSEL, S, YY1

VATT,

1 ,

8 ,

CMSEL, $S,-Y$

CMDELE, $Y$

CMDELE,_Y1

FLST, 5, 780, 4 ,

ORDE, 120

FITEM, 5, 13445

FITEM, 5, -

13452

FITEM, 5, 13456

FITEM, 5, -

13460

FITEM, 5, 13464

FITEM, 5, -

13468

FITEM, 5, 13472
FITEM, 5, -

13476

FITEM, 5, 13480

FITEM, 5, -

13484

FITEM, 5, 13488

FITEM, 5, -

13492

FITEM, 5, 13496

FITEM, 5, -

13500

FITEM, 5, 13504

FITEM, 5, -

13508

FITEM, 5, 13512

FITEM, 5, -

13516

FITEM, 5, 13520

FITEM, 5, -

13524

FITEM, 5, 13528

FITEM, 5, -

13532

FITEM, 5, 13536

FITEM, 5, -

13540

FITEM, 5, 13544

FITEM, 5, -

13548

FITEM, 5, 13552

FITEM, 5, -

13556

FITEM, 5, 13560

FITEM, 5, -

13564

FITEM, 5, 13569

FITEM, 5, -

13576

FITEM, 5, 13580

FITEM, 5, -

13584

FITEM, 5, 13588

FITEM, 5, -

13592

FITEM, 5, 13596

FITEM, 5, -

13600

FITEM, 5, 13604

FITEM, 5, -

13608

FITEM, 5, 13612

FITEM, 5, -

13616

FITEM, 5, 13620

FITEM, 5, -

13624

FITEM, 5, 13628

FITEM, 5, -

13632

FITEM, 5, 13636

FITEM, 5, -

13640

FITEM, 5, 13644

FITEM, 5, -

13648

FITEM, 5, 13652

FITEM, 5, -

13656

FITEM, 5, 13660
FITEM, 5, -

$$
13664
$$

FITEM, 5, 13668

FITEM, 5, -

13672

FITEM, 5, 13676

FITEM, 5, -

13680

FITEM , 5, 13683

FITEM, 5, -

13684

FITEM, 5, 13688

FITEM, 5, -

13692

FITEM, 5, 13696

FITEM, 5, -

13700

FITEM, 5, 13704

FITEM, 5, -

13708

FITEM, 5, 13712

FITEM, 5, -

13716

FITEM, 5, 13720

FITEM, 5, -

13724

FITEM, 5, 13728

FITEM, 5, -

13732

FITEM, 5, 13736

FITEM, 5, -

13740

FITEM, 5, 13744

FITEM, 5, -

13748

FITEM, 5, 13752

FITEM, 5, -

13756

FITEM, 5, 13760

FITEM, 5, -

13764

FITEM, 5, 13768

FITEM, 5, -

13772

FITEM, 5, 13776

FITEM, 5, -

13780

FITEM, 5, 13784

FITEM, 5, -

13788

FITEM, 5, 13792

FITEM, 5, -

13796

FITEM, 5, 13800

FITEM, 5, -

13804

FITEM , 5, 13808

FITEM, 5, -

13812

FITEM , 5, 13816

FITEM, 5, -

13820

FITEM, 5, 13824

FITEM, 5, -

13828

FITEM , 5, 13832

FITEM, 5, -

13836

FITEM, 5, 13840

FITEM, 5 , -

13844

FITEM, 5, 13848

FITEM, 5, -

13852

FITEM, 5, 13856

FITEM, 5, -

13860

FITEM, 5, 13864

FITEM, 5, -

13868

FITEM, 5, 13872

FITEM, 5, -

13876 


\begin{tabular}{|c|c|}
\hline VGEN, 2, P51X, & FITEM, 4, - \\
\hline,,, 1.2 & 14012 \\
\hline, 0 & FITEM , 4, 14015 \\
\hline $\begin{array}{l}\text { FLST, } 3,240,6, \\
\text { ORDE, } 2\end{array}$ & $\begin{array}{l}\text { FITEM, 4, - } \\
14016\end{array}$ \\
\hline FITEM, 3, 1741 & FITEM, 4, 14019 \\
\hline FITEM, 3, -1980 & FITEM, 4, - \\
\hline VGEN, 2, P51X, & 14020 \\
\hline,,, 2.4 & FITEM, $4,14 \odot 23$ \\
\hline & FITEM, 4, - \\
\hline FLST, 3, 480, 6, & 14024 \\
\hline ORDE, 2 & FITEM, 4, $14 \odot 27$ \\
\hline FITEM, 3, 1741 & FITEM, 4, - \\
\hline FITEM, 3, - 2220 & 14028 \\
\hline VGEN, 2, P51X, & FITEM, 4, 14031 \\
\hline${ }^{\prime},, 4.8$, & FITEM, 4, - \\
\hline & 14032 \\
\hline FLST, 3, 780, 6, & FITEM , 4, 14035 \\
\hline ORDE, 2 & FITEM, 4, - \\
\hline FITEM, 3, 1921 & 14036 \\
\hline FITEM, 3, - 2700 & FITEM, 4, 14039 \\
\hline VGEN, 2, P51X, & FITEM, 4, - \\
\hline, 7.8 & 14040 \\
\hline & FITEM, 4, 14043 \\
\hline ALLSEL, ALL & FITEM, 4, - \\
\hline NUMMRG, NODE， & 14044 \\
\hline , , , LOW & FITEM, $4,14 \odot 47$ \\
\hline NUMMRG, KP, , & FITEM, 4, - \\
\hline , , LOW & $14 \odot 48$ \\
\hline FINISH & FITEM, 4, 14051 \\
\hline /PREP7 & FITEM, 4, - \\
\hline$K, 55555,0, \odot, 4$ & 14052 \\
\hline 1.3 & FITEM, 4, 14055 \\
\hline $\mathrm{CM},-\mathrm{Y}, \mathrm{KP}$ & FITEM, 4, - \\
\hline KSEL, , , & 14056 \\
\hline 55555 & FITEM, 4, 14059 \\
\hline $\mathrm{CM},-\mathrm{Y} 1, \mathrm{KP}$ & FITEM, 4, - \\
\hline CMSEL, S, YY & 14060 \\
\hline CMSEL, S,_Y1 & FITEM, 4, 14063 \\
\hline KATT, & FITEM, 4, - \\
\hline 9, & 14064 \\
\hline 1, & FITEM, 4, 14069 \\
\hline CMSEL, S, YY & FITEM, 4, - \\
\hline CMDELE,_Y & 14072 \\
\hline CMDELE,_Y1 & FITEM, 4, 14075 \\
\hline FLST, $5,1,3,0 R$ & FITEM, 4, - \\
\hline $\mathrm{DE}, 1$ & 14076 \\
\hline FITEM, 5, 55555 & FITEM, 4, 14079 \\
\hline $\mathrm{CM}, \_\mathrm{Y}, \mathrm{KP}$ & FITEM, 4, - \\
\hline KSEL, , , , & 14080 \\
\hline , P51X & FITEM, 4, $14 \odot 83$ \\
\hline $\mathrm{CM}, \_\mathrm{Y} 1, \mathrm{KP}$ & FITEM, 4, - \\
\hline CMSEL, S,_Y & 14084 \\
\hline CMSEL, S,_Y1 & FITEM, 4, 14087 \\
\hline KESIZE, ALL, $\odot$ & FITEM, 4, - \\
\hline CMSEL, S,_Y & 14088 \\
\hline CMDELE,_Y1 & FITEM, 4, 14091 \\
\hline CMDELE,_Y & FITEM, 4, - \\
\hline KMESH, & 14092 \\
\hline 55555 & FITEM, 4, 14095 \\
\hline /UI, MESH, OFF & FITEM, 4, - \\
\hline NUMMRG , NODE, & 14096 \\
\hline , , , LOW & FITEM, 4, 14099 \\
\hline FLST, $4,121,1$, & FITEM, 4, - \\
\hline ORDE, 116 & 14100 \\
\hline FITEM , 4, 14005 & FITEM, 4, 14103 \\
\hline FITEM, 4, - & FITEM, 4, - \\
\hline 14008 & 14104 \\
\hline FITEM, 4, 14011 & FITEM, 4, 14107 \\
\hline
\end{tabular}

\begin{tabular}{|c|c|}
\hline FITEM, 4, - & FITEM, 4, - \\
\hline 14108 & 14200 \\
\hline FITEM, 4, 14111 & FITEM, 4, 14203 \\
\hline FITEM, 4,- & FITEM, 4, - \\
\hline 14112 & 14204 \\
\hline FITEM, 4, 14115 & FITEM, 4, 14207 \\
\hline FITEM, 4, - & FITEM, 4, - \\
\hline 14116 & 14208 \\
\hline FITEM, 4, 14119 & FITEM , 4, 14211 \\
\hline FITEM, 4, - & FITEM, 4, - \\
\hline 14120 & 14212 \\
\hline FITEM, 4, 14123 & FITEM, 4, 14215 \\
\hline FITEM, 4, - & FITEM, 4, - \\
\hline 14124 & 14216 \\
\hline FITEM, 4, 14127 & FITEM , 4, 14219 \\
\hline FITEM, 4, - & FITEM, 4, - \\
\hline 14128 & 14220 \\
\hline FITEM, 4, 14131 & FITEM, 4, 14223 \\
\hline FITEM, 4, - & FITEM, 4, - \\
\hline 14132 & 14224 \\
\hline FITEM, 4, 14135 & FITEM, 4, 14227 \\
\hline FITEM, 4, - & FITEM, 4, - \\
\hline 14136 & 14228 \\
\hline FITEM, 4, 14139 & FITEM, 4, 14231 \\
\hline FITEM, 4, - & FITEM, 4, - \\
\hline 14140 & 14232 \\
\hline FITEM, 4,14143 & FITEM, 4, 14235 \\
\hline FITEM, 4, - & FITEM, 4, - \\
\hline 14144 & 14236 \\
\hline FITEM, 4, 14147 & FITEM , 4, 14239 \\
\hline FITEM, 4, - & FITEM, 4, - \\
\hline 14148 & 14241 \\
\hline FITEM, 4, 14151 & $\mathrm{CP}, 1, \mathrm{ALL}, \mathrm{P} 51 \mathrm{X}$ \\
\hline FITEM, 4, - & FLST, $2,120,1$, \\
\hline 14152 & ORDE, 105 \\
\hline FITEM, 4, 14155 & FITEM, 2, 1 \\
\hline FITEM, 4, - & FITEM, 2, - 5 \\
\hline 14156 & FITEM , 2, 7 \\
\hline FITEM, 4, 14159 & FITEM, 2, 9 \\
\hline FITEM, 4, - & FITEM, 2, 11 \\
\hline 14160 & FITEM, 2, 13 \\
\hline FITEM, 4, 14163 & FITEM, 2, 15 \\
\hline FITEM, 4, - & FITEM, 2, 17 \\
\hline 14164 & FITEM, 2, 19 \\
\hline FITEM, 4, 14167 & FITEM, 2, 41 \\
\hline FITEM, 4, - & FITEM, 2, - 45 \\
\hline 14168 & FITEM, 2, 47 \\
\hline FITEM, 4, 14171 & FITEM, 2, 49 \\
\hline FITEM, 4, - & FITEM, 2, 51 \\
\hline 14172 & FITEM, 2, 53 \\
\hline FITEM, 4, 14175 & FITEM, 2, 55 \\
\hline FITEM, 4, - & FITEM, 2, 81 \\
\hline 14176 & FITEM, 2, - 85 \\
\hline FITEM, 4, 14179 & FITEM, 2, 87 \\
\hline FITEM, 4, - & FITEM, 2, 89 \\
\hline 14180 & FITEM, 2, 91 \\
\hline FITEM, 4, 14183 & FITEM, 2, 93 \\
\hline FITEM, 4, - & FITEM, 2, 95 \\
\hline 14184 & FITEM, 2, 121 \\
\hline FITEM, 4, 14187 & FITEM, 2, -124 \\
\hline FITEM, 4, - & FITEM, 2, 131 \\
\hline 14188 & FITEM, 2, -132 \\
\hline FITEM, 4, 14191 & FITEM, 2, 139 \\
\hline FITEM, 4, - & FITEM, $2,-140$ \\
\hline 14192 & FITEM, 2, 147 \\
\hline FITEM, 4, 14195 & FITEM, 2, - 148 \\
\hline FITEM, 4, - & FITEM, 2, 155 \\
\hline 14196 & FITEM, 2, -156 \\
\hline FITEM, & FITEM, 2, 201 \\
\hline
\end{tabular}

FITEM , 2, - 204 FITEM, 2, 211 FITEM, 2, - 212 FITEM, 2, 219 FITEM, 2, -220 FITEM, 2, 227 FITEM, 2, -228 FITEM, 2, 243 FITEM, 2, - 244 FITEM, 2, 251 FITEM, 2, - 252 FITEM, 2, 259 FITEM, 2, -260 FITEM, 2, 267 FITEM , 2, - 268 FITEM, 2, 275 FITEM, 2, - 276 FITEM, 2, 321 FITEM, 2, - 324 FITEM, 2, 331 FITEM, 2, -332 FITEM, 2, 339 FITEM, 2, -340 FITEM, 2, 347 FITEM, 2, - 348 FITEM , 2, 355 FITEM, 2, -356 FITEM, 2, 363 FITEM, 2, - 364 FITEM, 2, 371 FITEM, 2, - 372 FITEM, 2, 379 FITEM, 2, -380 FITEM, 2, 387 FITEM , 2, - 388 FITEM, 2, 395 FITEM, 2, - 396 FITEM, 2, 403 FITEM, 2, -404 FITEM, 2, 411 FITEM , 2, - 412 FITEM, 2, 419 FITEM, 2, -420 FITEM, 2, 427 FITEM, 2, - 428 FITEM, 2, 435 FITEM, 2, -436 FITEM, 2, 443 FITEM, 2, - 444 FITEM , 2, 451 FITEM, 2, - 452 FITEM, 2, 459 FITEM, 2, -460 FITEM, 2, 467 FITEM , 2, - 468 FITEM, 2, 481 FITEM, 2, 483 FITEM, 2, 485 FITEM, 2, 487 FITEM, 2, 489 FITEM, 2, 491 FITEM, 2, 493 FITEM, 2, 495 FITEM, 2, 501 FITEM, 2, 503 FITEM, 2, 505 FITEM, 2, 507 FITEM, 2, 509 FITEM, 2, 511 
FITEM, 2, 513

FITEM, 2, 515

/GO

D, P51X， , 0 , ,

, ,ALL, , , ,

'TBDE, MELA, 1, ,

'́, MELA , 1, 1, 8

'TBTEMP, $\odot$

TBPT, , 0.00085

, 2.26E+007

TBPT, , $0.002,3$

$.5 \mathrm{E}+007$

TBPT, , 0.0021 ,

3. $5 \mathrm{E}+007$

TBPT, , 0.0035 ,

$2 \mathrm{E}+007$

TBPT, , $0.005,1$

$\mathrm{E}+007$

TBPT, , $\odot .01,5 \mathrm{E}$

$+006$

TBPT, , $0.02,5 \mathrm{E}$

$+006$

TBPT, , $0.021,0$

TBDE, CONC, 1, ,

'TB, CONC , 1, 1, 9

'TBTEMP, $\odot$

TBDATA, $0.2,0$

. 2, 3. 5E+006, 3

$.5 \mathrm{E}+007,0, \odot$

TBDATA, $, \odot, \odot, \odot$

$.7,$, ,

TBDE, MELA, 2, ,

'TB, MELA , 2, 1, 4

'́'BTEMP, $\odot$

TBPT, , $0.002,4$

$\mathrm{E}+008$

TBPT, , $0.1,4 \mathrm{E}+$

$\odot \odot 8$

TBPT , , . 105, 2e

8

TBPT, $, .11,0$

NUMMRG, NODE,

, , LOW

NUMMRG, KP， ,

, , LOW

/PREP7

TBDE, MELA, 1, ,

'TB, MELA , 1, 1, 8

'TBTEMP, $\odot$

TBPT, , 0.00085

, $2.26 \mathrm{E}+007$

TBPT, , $0.002,3$

$.5 \mathrm{E}+007$

TBPT, , 0.0021 ,

3. $5 \mathrm{E}+007$

TBPT, , 0.0035 ,

$2 \mathrm{E}+007$

TBPT, , $0.005,1$

$\mathrm{E}+007$
TBPT, , $. .01,5 \mathrm{E}$
+006
TBPT, , $\odot .02,5 \mathrm{E}$
+006
TBPT, , $\odot .021, \odot$
/PREP7

$R, 1,2,0.0229$,

$0,90,2,0.0088$

RMORE, $\odot, \odot, \odot, \odot$

$, \Theta, \Theta$,

RMORE, $\odot$,

$\mathrm{R}, 2,2,0.0229$,

$0,90,2,0.0088$

'RMORE, 45, ๑, $\odot$,

$\odot, 0,0$,

RMORE, $\odot$,

$\mathrm{R}, 3,2,0.0229$,

$0,90,2,0.0088$

RMORE, $9 \odot, \odot, \odot$,

$\Theta, \Theta, \Theta$,

RMORE, $\odot$,

$\mathrm{R}, 4,2,0.0229$,

$\odot, 90,2,0.0088$

RMORE, -

$45, \odot, \odot, \odot, \odot, \odot$, RMORE, $\odot$,

$\mathrm{R}, 5,2,0.0076$,

$0,90,2,0.0051$

RMORE, $\odot, \odot, \odot, \odot$

$, \odot, \Theta$,

RMORE, $\odot$,

$\mathrm{R}, 6,2,0.0076$,

$0,90,2,0.0051$

RMORE, 45, $\odot, \odot$,

$\Theta, \Theta, \Theta$,

RMORE, $\theta$,

$\mathrm{R}, 7,2,0.0076$,

$\odot, 9 \odot, 2,0.0051$

RMORE, $9 \odot, \odot, \odot$,

$\odot, \odot, \Theta$,

RMORE, $\theta$,

$\mathrm{R}, 8,2,0.0076$,

$0,90,2,0.0051$

RMORE, -

$45, \odot, \odot, \odot, \odot, \odot$,

RMORE, $\odot$,

$\mathrm{R}, 9,4098981,4$ 098981,409898

$1,0,0, \Theta$,

RMORE, , , ,

'RMORE,

$\mathrm{R}, 9,4098981,4$ 098981,409898

$1,0,0,0$,

$\mathrm{R}, 8,2,0.0076$,

$0,90,2,0.0051$

'RMORE, -

$45, \odot, \odot, \odot, \odot, \odot$, RMORE, $\Theta$,
$\mathrm{R}, 4,2,0.0229$,

$0,90,2,0.0088$

'RMORE, -

$45, \odot, \odot, \odot, \odot, \odot$,

RMORE, $\odot$,

FINISH

FINISH

/PREP7

FINISH

/SOL

ANTYPE, $\odot$

CNVTOL, F,

, $0.1,2$, ,

CNVTOL, U,

, $0.1,2$, ,

ANTYPE, $\odot$

FINISH

/PREP7

FLST, 2, 120, 1, ORDE, 116

FITEM, 2, 13765

FITEM, 2, -

13768

FITEM, 2, 13771

FITEM, 2, -

13772

FITEM, 2, 13775

FITEM, 2, -

13776

FITEM, 2, 13779

FITEM, 2, -

13780

FITEM, 2, 13783

FITEM, 2, -

13784

FITEM, 2, 13787

FITEM, 2, -

13788

FITEM, 2, 13791

FITEM, 2, -

13792

FITEM, 2, 13795

FITEM, 2, -

13796

FITEM, 2, 13799

FITEM, 2, -

13800

FITEM, 2, 13803

FITEM, 2, -

13804

FITEM, 2, 13807

FITEM, 2, -

13808

FITEM, 2, 13811

FITEM, 2, -

13812

FITEM, 2, 13815

FITEM, 2, -

13816

FITEM, 2, 13819

FITEM, 2, -

13820

FITEM, 2, 13823

FITEM, 2, -

13824

FITEM, 2, 13829

FITEM, 2, -

13832
FITEM, 2, 13835

FITEM, 2, -

13836

FITEM, 2, 13839

FITEM, 2, -

13840

FITEM, 2, 13843

FITEM, 2, -

13844

FITEM, 2, 13847

FITEM, 2, -

13848

FITEM, 2, 13851

FITEM, 2, -

13852

FITEM, 2, 13855

FITEM, 2, -

13856

FITEM, 2, 13859

FITEM, 2, -

13860

FITEM, 2, 13863

FITEM, 2, -

13864

FITEM, 2, 13867

FITEM, 2, -

13868

FITEM, 2, 13871

FITEM, 2, -

13872

FITEM, 2, 13875

FITEM, 2, -

13876

FITEM, 2, 13879

FITEM, 2, -

13880

FITEM, 2, 13883

FITEM, 2, -

13884

FITEM, 2, 13887

FITEM, 2, -

13888

FITEM, 2, 13891

FITEM, 2, -

13892

FITEM, 2, 13895

FITEM, 2, -

13896

FITEM, 2, 13899

FITEM, 2, -

13900

FITEM, 2, 13903

FITEM, 2, -

13904

FITEM, 2, 13907

FITEM, 2, -

13908

FITEM, 2, 13911

FITEM, 2, -

13912

FITEM, 2, 13915

FITEM, 2, -

13916

FITEM, 2, 13919

FITEM, 2, -

13920

FITEM, 2, 13923

FITEM, 2, -

13924

FITEM, 2, 13927

FITEM, 2, -

13928

FITEM, 2, 13931

FITEM, 2, -

13932

FITEM, 2, 13935

FITEM, 2, -

13936

FITEM, 2, 13939

FITEM, 2, -

13940

FITEM, 2, 13943

FITEM, 2, -

13944

FITEM, 2, 13947

FITEM, 2, -

13948

FITEM, 2, 13951

FITEM, 2, -

13952

FITEM, 2, 13955

FITEM, 2, -

13956

FITEM, 2, 13959

FITEM, 2, -

13960

FITEM, 2, 13963

FITEM, 2, -

13964

FITEM, 2, 13967

FITEM, 2, -

13968

FITEM, 2, 13971

FITEM, 2, -

13972

FITEM, 2, 13975

FITEM, 2, -

13976

FITEM, 2, 13979 


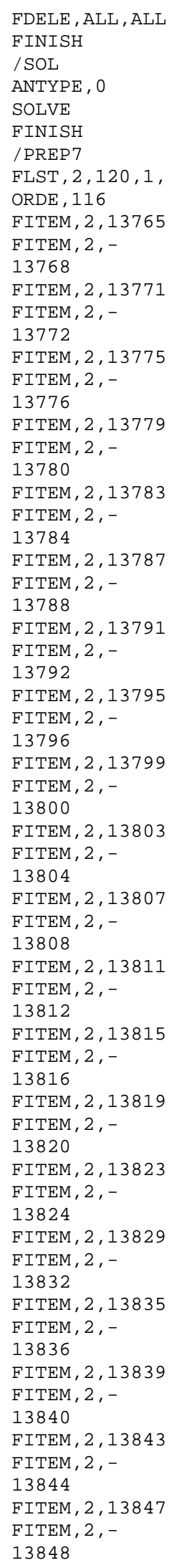

\begin{tabular}{|c|c|}
\hline FITEM, 2, 13851 & FITEM, 2, 13943 \\
\hline FITEM, 2, - & FITEM, 2, - \\
\hline 13852 & 13944 \\
\hline FITEM, 2, 13855 & FITEM, 2, 13947 \\
\hline FITEM, 2, - & FITEM, 2, - \\
\hline 13856 & 13948 \\
\hline FITEM, 2, 13859 & FITEM, 2, 13951 \\
\hline FITEM, 2, - & FITEM, 2, - \\
\hline 13860 & 13952 \\
\hline FITEM, 2, 13863 & FITEM, 2, 13955 \\
\hline FITEM, 2, - & FITEM, 2, - \\
\hline 13864 & 13956 \\
\hline FITEM, 2, 13867 & FITEM, 2, 13959 \\
\hline FITEM, 2, - & FITEM, 2, - \\
\hline 13868 & 13960 \\
\hline FITEM, 2, 13871 & FITEM, 2, 13963 \\
\hline FITEM, 2, - & FITEM, 2, - \\
\hline 13872 & 13964 \\
\hline FITEM, 2, 13875 & FITEM, 2, 13967 \\
\hline FITEM, 2, - & FITEM, 2, - \\
\hline 13876 & 13968 \\
\hline FITEM, 2, 13879 & FITEM, 2, 13971 \\
\hline FITEM, 2, - & FITEM, 2, - \\
\hline 13880 & 13972 \\
\hline FITEM, 2, 13883 & FITEM, 2, 13975 \\
\hline FITEM, 2, - & FITEM, 2, - \\
\hline 13884 & 13976 \\
\hline FITEM, 2, 13887 & FITEM, 2, 13979 \\
\hline FITEM, 2, - & FITEM, 2, - \\
\hline 13888 & 13980 \\
\hline FITEM, 2, 13891 & FITEM, 2, 13983 \\
\hline FITEM, 2, - & FITEM, 2, - \\
\hline 13892 & 13984 \\
\hline FITEM, 2, 13895 & FITEM, 2, 13987 \\
\hline FITEM, 2, - & FITEM, 2, - \\
\hline 13896 & 13988 \\
\hline FITEM, 2, 13899 & FITEM, 2, 13991 \\
\hline FITEM, 2, - & FITEM, 2, - \\
\hline 13900 & 13992 \\
\hline FITEM, 2, 13903 & FITEM, 2, 13995 \\
\hline FITEM, 2, - & FITEM, 2, - \\
\hline 13904 & 13996 \\
\hline FITEM, 2, 13907 & FITEM, 2, 13999 \\
\hline FITEM, 2, - & FITEM, 2, - \\
\hline 13908 & 14000 \\
\hline FITEM, 2, 13911 & /GO \\
\hline FITEM, 2, - & F, P51X, FX, 230 \\
\hline 13912 & $\odot \odot \odot$ \\
\hline FITEM, 2, 13915 & FINISH \\
\hline FITEM, 2, - & /SOL \\
\hline 13916 & TIME, 2 \\
\hline FITEM, 2, 13919 & SOLVE \\
\hline FITEM, 2, - & FINISH \\
\hline 13920 & /POST1 \\
\hline FITEM, 2, 13923 & SET, FIRST \\
\hline FITEM, 2, - & SET, $, 1,1,1,82$ \\
\hline 13924 & SET, $, 1,1,81$ \\
\hline FITEM, 2, 13927 & SET, $, 1,1,79$ \\
\hline FITEM, 2, - & SET, , , , , , , 77 \\
\hline 13928 & SET, $, 1,1,82$ \\
\hline FITEM, 2, 13931 & SET $, 1,1,1,81$ \\
\hline FITEM, 2, - & SET, $, 1,1,80$ \\
\hline 13932 & SET, $, 1,1,1,81$ \\
\hline FITEM, 2, 13935 & SET, $, 1,1,82$ \\
\hline FITEM, 2, - & SET, $, 1,1,1,81$ \\
\hline 13936 & SET, $, 1,1,1,82$ \\
\hline FITEM, 2, 13939 & FINISH \\
\hline FITEM, 2, - & /SOL \\
\hline 13940 & FINISH \\
\hline
\end{tabular}

\begin{tabular}{|c|c|}
\hline /PREP7 & FITEM, 2, - \\
\hline FDELE, ALL, ALL & 13848 \\
\hline FINISH & FITEM, 2, 13851 \\
\hline /SOL & FITEM, 2, - \\
\hline ANTYPE, $\odot$ & 13852 \\
\hline TIME, 1 & FITEM, 2, 13855 \\
\hline SOLVE & FITEM, 2, - \\
\hline FINISH & 13856 \\
\hline /PREP7 & FITEM, 2, 13859 \\
\hline FLST, 2, 120, 1, & FITEM, 2, - \\
\hline ORDE, 116 & 13860 \\
\hline FITEM, 2, 13765 & FITEM, 2, 13863 \\
\hline FITEM, 2, - & FITEM, 2, - \\
\hline 13768 & 13864 \\
\hline FITEM, 2, 13771 & FITEM, 2, 13867 \\
\hline FITEM, 2, - & FITEM, 2, - \\
\hline 13772 & 13868 \\
\hline FITEM, 2, 13775 & FITEM, 2, 13871 \\
\hline FITEM, 2, - & FITEM, 2, - \\
\hline 13776 & 13872 \\
\hline FITEM, 2, 13779 & FITEM, 2, 13875 \\
\hline FITEM, 2, - & FITEM, 2, - \\
\hline 13780 & 13876 \\
\hline FITEM, 2, 13783 & FITEM, 2, 13879 \\
\hline FITEM, 2, - & FITEM, 2, - \\
\hline 13784 & 13880 \\
\hline FITEM, 2, 13787 & FITEM, 2, 13883 \\
\hline FITEM, 2, - & FITEM, 2, - \\
\hline 13788 & 13884 \\
\hline FITEM, 2, 13791 & FITEM, 2, 13887 \\
\hline FITEM, 2, - & FITEM, 2, - \\
\hline 13792 & 13888 \\
\hline FITEM, 2, 13795 & FITEM, 2, 13891 \\
\hline FITEM, 2, - & FITEM, 2, - \\
\hline 13796 & 13892 \\
\hline FITEM, 2, 13799 & FITEM, 2, 13895 \\
\hline FITEM, 2, - & FITEM, 2, - \\
\hline 13800 & 13896 \\
\hline FITEM, 2, 13803 & FITEM, 2, 13899 \\
\hline FITEM, 2, - & FITEM, 2, - \\
\hline 13804 & 13900 \\
\hline FITEM, 2, 13807 & FITEM, 2, 13903 \\
\hline FITEM, 2, - & FITEM, 2, - \\
\hline 13808 & 13904 \\
\hline FITEM, 2, 13811 & FITEM, 2, 13907 \\
\hline FITEM, 2, - & FITEM, 2, - \\
\hline 13812 & 13908 \\
\hline FITEM, 2, 13815 & FITEM, 2, 13911 \\
\hline FITEM, 2, - & FITEM, 2, - \\
\hline 13816 & 13912 \\
\hline FITEM, 2, 13819 & FITEM, 2, 13915 \\
\hline FITEM, 2, - & FITEM, 2, - \\
\hline 13820 & 13916 \\
\hline FITEM, 2, 13823 & FITEM, 2, 13919 \\
\hline FITEM, 2, - & FITEM, 2, - \\
\hline 13824 & 13920 \\
\hline FITEM, 2, 13829 & FITEM, 2, 13923 \\
\hline FITEM, 2, - & FITEM, 2, - \\
\hline 13832 & 13924 \\
\hline FITEM, 2, 13835 & FITEM, 2, 13927 \\
\hline FITEM, 2, - & FITEM, 2, - \\
\hline 13836 & 13928 \\
\hline FITEM, 2, 13839 & FITEM, 2, 13931 \\
\hline FITEM, 2, - & FITEM, 2, - \\
\hline 13840 & 13932 \\
\hline FITEM, 2, 13843 & FITEM, 2, 13935 \\
\hline FITEM, 2, - & FITEM, 2, - \\
\hline 13844 & 13936 \\
\hline FITEM, 2, 13847 & FITEM, 2, 13939 \\
\hline
\end{tabular}

/PREP7

FDELE, ALL, ALL
FINISH

/SOL

TIME, 1

FINIS

/PREP7

ORDE, 116

FITEM, 2, 13765

FITEM, 2, 13771

FITEM, 2, -

13772

FITEM, 2, -

13776

FITEM, 2, -

FITEM, 2, 13783

FITEM, 2, -

13784

FITEM, 2, -

13788

FITEM, 2, 13791

FITEM, 2, -

FITEM, 2, 13795

FITEM, 2, -

13796

FITEM, 2, -

13800

FITEM, 2, 13803

FITEM, 2, -

FITEM, 2, 13807

FITEM, 2, -

13808

FITEM, 2, 13815

FITEM, 2, -

13816

FITEM, 2, -

13824

FITEM , 2, 13829

13832

FITEM, 2, 13835

13836

FITEM, 2, 13839

FITEM, 2, -

FITEM, 2, 13843

13844

FITEM, 2, 13847

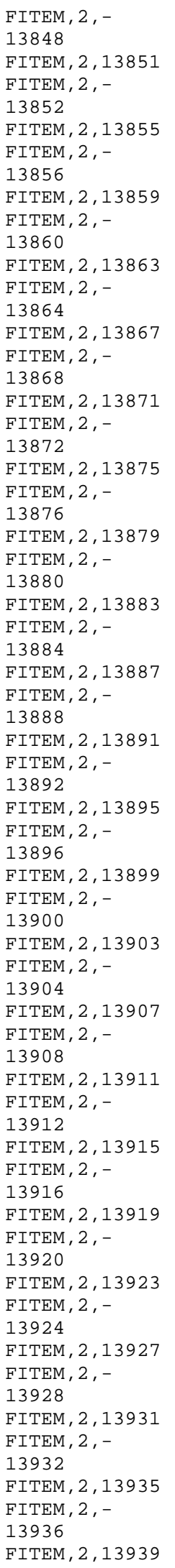




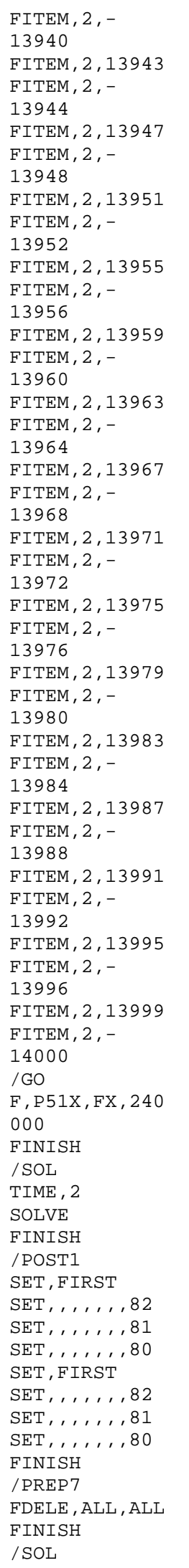

\begin{tabular}{|c|c|}
\hline ANTYPE, $\odot$ & FITEM, 2, - \\
\hline TIME, 1 & 13852 \\
\hline SOLVE & FITEM , 2, 13855 \\
\hline FINISH & FITEM, 2, - \\
\hline /PREP7 & 13856 \\
\hline FLST $, 2,120,1$, & FITEM, 2, 13859 \\
\hline ORDE, 116 & FITEM, 2, - \\
\hline FITEM 2,13765 & 13860 \\
\hline FITEM, 2, - & FITEM, 2, 13863 \\
\hline 13768 & FITEM, 2, - \\
\hline FITEM, 2, 13771 & 13864 \\
\hline FITEM, 2, - & FITEM, 2, 13867 \\
\hline 13772 & FITEM, 2, - \\
\hline FITEM, 2, 13775 & 13868 \\
\hline FITEM, 2,- & FITEM, 2, 13871 \\
\hline 13776 & FITEM, 2, - \\
\hline FITEM, 2, 13779 & 13872 \\
\hline FITEM, 2, - & FITEM, 2, 13875 \\
\hline $13780^{\prime}$ & FITEM, 2, - \\
\hline FITEM, 2, 13783 & 13876 \\
\hline FITEM, 2, - & FITEM , 2, 13879 \\
\hline 13784 & FITEM, 2, - \\
\hline FITEM, 2, 13787 & 13880 \\
\hline FITEM, 2, - & FITEM , 2, 13883 \\
\hline 13788 & FITEM, 2, - \\
\hline FITEM, 2, 13791 & 13884 \\
\hline FITEM, 2, - & FITEM, 2, 13887 \\
\hline 13792 & FITEM, 2, - \\
\hline FITEM, 2, 13795 & 13888 \\
\hline FITEM, 2, - & FITEM, 2, 13891 \\
\hline 13796 & FITEM, 2, - \\
\hline FITEM, 2, 13799 & 13892 \\
\hline FITEM, 2, - & FITEM, 2, 13895 \\
\hline 13800 & FITEM, 2,- \\
\hline FITEM, 2, 13803 & 13896 \\
\hline FITEM, 2, - & FITEM , 2, 13899 \\
\hline 13804 & FITEM, 2,- \\
\hline FITEM, 2, 13807 & 13900 \\
\hline FITEM, 2, - & FITEM , 2, 13903 \\
\hline 13808 & FITEM, 2, - \\
\hline FITEM, 2, 13811 & 13904 \\
\hline FITEM, 2,- & FITEM, 2, 13907 \\
\hline 13812 & FITEM, 2, - \\
\hline FITEM , 2, 13815 & 13908 \\
\hline FITEM, 2, - & FITEM, 2,13911 \\
\hline 13816 & FITEM, 2, - \\
\hline FITEM, 2, 13819 & 13912 \\
\hline FITEM, 2, - & FITEM, 2, 13915 \\
\hline 13820 & FITEM, 2, - \\
\hline FITEM, 2, 13823 & 13916 \\
\hline FITEM, 2, - & FITEM, 2, 13919 \\
\hline 13824 & FITEM, 2, - \\
\hline FITEM, 2, 13829 & 13920 \\
\hline FITEM, 2, - & FITEM , 2, 13923 \\
\hline 13832 & FITEM, 2, - \\
\hline FITEM, 2, 13835 & 13924 \\
\hline FITEM, 2, - & FITEM, 2, 13927 \\
\hline 13836 & FITEM, 2, - \\
\hline FITEM, 2, 13839 & 13928 \\
\hline FITEM, 2, - & FITEM, 2, 13931 \\
\hline 13840 & FITEM, 2, - \\
\hline FITEM , 2, 13843 & 13932 \\
\hline FITEM, 2, - & FITEM, 2, 13935 \\
\hline 13844 & FITEM, 2, - \\
\hline FITEM, 2, 13847 & 13936 \\
\hline FITEM, 2, - & FITEM, 2, 13939 \\
\hline 13848 & FITEM, 2, - \\
\hline FITEM, 2, 13851 & 13940 \\
\hline & FITEM , 2, 13943 \\
\hline
\end{tabular}

\begin{tabular}{|c|c|}
\hline FITEM, 2, - & $\mathrm{SET}, 1, \ldots, 1,54$ \\
\hline 13944 & $\mathrm{SET}, \ldots, \ldots, 1,55$ \\
\hline FITEM, 2, 13947 & SET, $, 1,1,, 56$ \\
\hline FITEM, 2, - & $\mathrm{SET}, \ldots, \ldots,, 57$ \\
\hline 13948 & SET, $, 1,1,, 58$ \\
\hline FITEM , 2, 13951 & $\mathrm{SET}, \ldots, \ldots,, 59$ \\
\hline FITEM, 2, - & $\mathrm{SET}, 1,1,1,60$ \\
\hline 13952 & $\mathrm{SET}, \ldots, \ldots, 61$ \\
\hline FITEM, 2, 13955 & $\mathrm{SET}, \ldots, \ldots, 62$ \\
\hline FITEM, 2, - & SET, $, 1,1,, 63$ \\
\hline 13956 & $\mathrm{SET}, \ldots, \ldots, 64$ \\
\hline FITEM, 2, 13959 & $\mathrm{SET}, \ldots, \ldots, 65$ \\
\hline FITEM, 2, - & SET, $, 1,1,1,66$ \\
\hline 13960 & $\mathrm{SET}, \ldots, \ldots, 67$ \\
\hline FITEM, 2, 13963 & $\mathrm{SET}, 1,1,1,69$ \\
\hline FITEM, 2, - & SET,,,,,, 68 \\
\hline 13964 & $\mathrm{SET}, 1,1,1,69$ \\
\hline FITEM, 2, 13967 & $\mathrm{SET}, 1,1,1,70$ \\
\hline FITEM, 2, - & $\mathrm{SET}, \ldots, \ldots, 71$ \\
\hline 13968 & $\mathrm{SET}, 1,1,, 72$ \\
\hline FITEM, 2, 13971 & $\mathrm{SET}, \ldots, \ldots, 73$ \\
\hline FITEM, 2, - & $\mathrm{SET}, \ldots, \ldots, 74$ \\
\hline 13972 & SET, $, 1,1,75$ \\
\hline FITEM, 2, 13975 & $\mathrm{SET}, \ldots, \ldots, 76$ \\
\hline FITEM, 2, - & SET $, 1,1,1,77$ \\
\hline 13976 & SET,, 79 \\
\hline FITEM, 2, 13979 & $\mathrm{SET}, 1,1,1,78$ \\
\hline FITEM, 2, - & SET, $, 1,1,79$ \\
\hline $13980^{\circ}$ & $\mathrm{SET}, \ldots, \ldots,, 80$ \\
\hline FITEM, 2, 13983 & $\mathrm{SET}, 1,1,1,81$ \\
\hline FITEM, 2,- & SET, , , 82 \\
\hline 13984 & FINISH \\
\hline FITEM, 2, 13987 & /POST26 \\
\hline FITEM, 2, - & FILE, ' $35-\mathrm{H}-$ \\
\hline 13988 & 1','rst','.' \\
\hline FITEM, 2, 13991 & /UI, COLL, 1 \\
\hline FITEM, 2, - & NUMVAR, 200 \\
\hline 13992 & SOLU, 191, NCMI \\
\hline FITEM, 2, 13995 & $\mathrm{~T}$ \\
\hline FITEM, 2, - & STORE, MERGE \\
\hline 13996 & FILLDATA, 191 \\
\hline FITEM, 2, 13999 & $,, 1,1$ \\
\hline FITEM, 2, - & REALVAR, 191,1 \\
\hline 14000 & 91 \\
\hline$/ \mathrm{GO}$ & NSOL, 2,14241 \\
\hline$F, P 51 X, F X, 230$ & U, X, UX_2 \\
\hline$\odot \circ \odot$ & STORE, MERGE \\
\hline FINISH & FINISH \\
\hline /SOL & /PREP7 \\
\hline TIME, 2 & $\mathrm{R}, 9,4098981,4$ \\
\hline SOLVE & ๑98981, 409898 \\
\hline FINISH & $1, \odot, \odot, \Theta$ \\
\hline /POST1 & $\mathrm{R}, 1,2,0.0229$ \\
\hline SET, FIRST & $0,90,2,0.0088$ \\
\hline SET, $, \ldots, 1,82$ & , \\
\hline SET, , , , 42 & RMORE $, \odot, \odot, \odot, \odot$ \\
\hline SET, , , , , 43 & $, \odot, \odot$ \\
\hline $\mathrm{SET}, \ldots, \ldots, 44$ & RMORE, $\odot$, \\
\hline $\mathrm{SET}, 1,1,, 46$ & $\mathrm{R}, 2,2,0.0229$ \\
\hline SET, , , , 45 & $\odot, 9 \odot, 2, \odot . \odot \odot 88$ \\
\hline SET, $, 1,1,46$ & \\
\hline SET, & RMORE $, 45, \odot, \odot$, \\
\hline SET, $1,1,1,49$ & $0,0,0$ \\
\hline SET, $, 1,1,48$ & RMORE, $\odot$, \\
\hline SET, $, 1,49$ & $\mathrm{R}, 3,2,0.0229$ \\
\hline $\mathrm{SET}, \ldots, \ldots, 50$ & $\odot, 9 \odot, 2, \odot . \odot \odot 88$ \\
\hline SET, & \\
\hline SET, $, 1,1,52$ & RMORE $, 9 \odot, \odot, \odot$, \\
\hline SET, , , , , 53 & $\odot, \odot, \odot$, \\
\hline
\end{tabular}




\begin{tabular}{|c|c|c|}
\hline $\begin{array}{l}\text { RMORE, } \odot, \\
\text { FINISH }\end{array}$ & RMORE, $\odot, \odot, \odot, \odot$ & TBDE, MELA, 2 , , \\
\hline /SOL & RMORE, $\odot$ & 'TB, MELA, 2, 1, 4 \\
\hline FINISH & $\mathrm{R}, 6,2, \odot . \odot \odot 76$ & \\
\hline /PREP7 & $0,90,2,0.0076$ & TBTEMP, $\odot$ \\
\hline FINISH & & ТВРТ, $, 0.0 \odot 2,4$ \\
\hline /SOL & RMORE $, 45, \odot, \odot$, & $E+\odot \odot 8$ \\
\hline $\begin{array}{l}\text { FDELE, ALL, ALL } \\
\text { ACEL }, \odot, \odot, 9.81\end{array}$ & $\begin{array}{l}\odot, \odot, \odot, \\
\text { RMORE, } \odot,\end{array}$ & $\begin{array}{l}\text { TBPT, , } \odot .1,5 \mathrm{E}+ \\
\odot \odot 8\end{array}$ \\
\hline & $\mathrm{R}, 7,2,0.0076$ & TBPT, $, 0.105,2$ \\
\hline FINISH & $\odot, 9 \odot, 2,0.0 \odot 76$ & $E+008$ \\
\hline /POST1 & , & TВPT, $, 0.11,50$ \\
\hline FINISH & RMORE, $9 \odot, \odot, \odot$, & FDELE, ALL, ALL \\
\hline /SOL & $\odot, \odot, \odot$ & FINISH \\
\hline ANTYPE, 0 & RMORE, $\odot$, & /SOL \\
\hline NSUBST $, 1,1,1$ & $\mathrm{R}, 8,2, \odot . \odot \odot 76$ & ANTYPE, $\odot$ \\
\hline EQSLV, -1 & $\odot, 9 \odot, 2, \odot . \odot \odot 76$ & CNVTOL, , -1, 2 \\
\hline TIME, 1 & , & ANTYPE, $\odot$ \\
\hline /POST1 & RMORE, - & NLGEOM, $\odot$ \\
\hline SET, FIRST & $45, \odot, \odot, \odot, \odot, \odot$, & NSUBST, 5, 6, 4 \\
\hline FINISH & RMORE, $\odot$, & AUTOTS, -1 \\
\hline /PREP7 & $\mathrm{R}, 8,2, \odot . \odot \odot 76$ & FINISH \\
\hline TBDE, MELA, 2, , & $\odot, 9 \odot, 2, \odot . \odot \odot 76$ & /PREP7 \\
\hline 'TB, MELA , 2, 1, 4 & 'RMORE, - & ACEL $, 0,0,9.81$ \\
\hline & $45, \odot, \odot, \odot, \odot, \odot$, & FINISH \\
\hline TBTEMP, $\odot$ & RMORE, $\odot$, & /SOL \\
\hline TBPT, , $0.0 \odot 2,4$ & $\mathrm{R}, 1,2,0.0229$ & SOLVE \\
\hline$E+008$ & $\odot, 9 \odot, 2,0.0 \odot 88$ & FINISH \\
\hline TBPT, , $0.1,4 \mathrm{E}+$ & & /PREP7 \\
\hline 008 & RMORE, $\odot, \odot, \odot, \odot$ & ACEL, $8,0,9.81$ \\
\hline ТВРТ, , $0.105,2$ & $, \odot, \odot$ & \\
\hline$E+008$ & RMORE, $\odot$, & FINISH \\
\hline TBPT, , $0.11,0$ & $\mathrm{R}, 9,4098981,4$ & /SOL \\
\hline FINISH & 098981,409898 & TIME, 2 \\
\hline /PREP7 & $1,0,0,0$ & SOLVE \\
\hline$R, 2,2,0.0229$ & FINISH & FINISH \\
\hline$\odot, 90,2,0.0088$ & /PREP7 & /POST1 \\
\hline & $\mathrm{R}, 9,4098981,4$ & SET, FIRST \\
\hline RMORE, $45, \odot, \odot$, & 098981,409898 & SET, , , , , , 11 \\
\hline$\odot, 0,0$ & $1,0,0,0$ & SET, , , , , 10 \\
\hline RMORE, $\odot$, & TBDE, CONC, 1, & SET, $, 1,, 1,9$ \\
\hline $\mathrm{R}, 5,2,0.0076$, & & FINISH \\
\hline$\odot, 9 \odot, 2, \odot . \odot \odot 51$ & $\mathrm{~TB}, \mathrm{CONC}, 1,1,9$ & /SOL \\
\hline , & , & ANTYPE, $\odot$ \\
\hline RMORE, $\odot, \odot, \odot, \odot$ & TBTEMP, $\odot$ & TIME, 1 \\
\hline$, \Theta, \Theta$ & TBDATA, $, 0.2,0$ & FINISH \\
\hline RMORE, $\odot$, & $.2,3.5 \mathrm{E}+\odot \odot 6,-$ & /PREP7 \\
\hline$R, 6,2,0.0076$, & $1,0,0$ & ACEL $, 0,0,9.81$ \\
\hline$\odot, 90,2,0.0051$ & TBDATA, $, \odot, \odot, \odot$ & \\
\hline & $.7,1$, & FINISH \\
\hline RMORE $, 45, \odot, \odot$, & TBDE, MELA, 1, & /SOL \\
\hline$\odot, \odot, \odot$ & & SOLVE \\
\hline RMORE, $\odot$, & TB, MELA $, 1,1,6$ & TIME, 2 \\
\hline$R, 1,2,0.0229$ & & FINISH \\
\hline $0,90,2,0.0088$ & TBTEMP, $\odot$ & /PREP7 \\
\hline & TBPT, , ๑.๑००८5 & ACEL, $6.5,0,9$. \\
\hline RMORE, $\odot, \odot, \odot, \odot$ &, $2.26 \mathrm{E}+\odot \odot 7$ & 81, \\
\hline$, \odot, 0$ & TBPT, , $, . . \odot \odot 2,3$ & FINISH \\
\hline RMORE, $\odot$, & $.5 \mathrm{E}+007$ & /SOL \\
\hline$R, 1,2,0.0229$ & TBPT, ,, .0021, & SOLVE \\
\hline$\odot, 90,2,0.0 \odot 88$ & $3.5 \mathrm{E}+007$ & FINISH \\
\hline 1 & TBPT, ,,. $.0 \odot 35$, & /POST1 \\
\hline RMORE, $\odot, \odot, \odot, \odot$ & $2 \mathrm{E}+\odot \odot 7$ & SET, FIRST \\
\hline$, 0,0$ & TBPT, , $0.005,1$ & SET $, 1,1,1,10$ \\
\hline RMORE, $\odot$ & $\mathrm{E}+007$ & SET $, 1,1,1,9$ \\
\hline$R, 5,2,0.0076$ & TBPT, , $\odot .01,5 \mathrm{E}$ & $\mathrm{SET}, r, 1,10$ \\
\hline$\odot, 9 \odot, 2,0.0 \odot 76$ & +006 & FINISH \\
\hline ' & & /SOL \\
\hline
\end{tabular}

\begin{tabular}{|c|c|}
\hline ANTYPE, $\odot$ & ANTYPE, $\odot$ \\
\hline TIME, 1 & NSUBST, 20, 21, \\
\hline ACEL $, \odot, \odot, 9.81$ & 19 \\
\hline & TIME, 1 \\
\hline SOLVE & ACEL, $\odot, \odot, 9.81$ \\
\hline TIME, 2 & \\
\hline ACEL $, 7,0,9.81$ & SOLVE \\
\hline , & TIME, 2 \\
\hline SOLVE & ACEL $, 7.8,0,9$ \\
\hline FINISH & 81, \\
\hline /POST1 & SOLVE \\
\hline SET, FIRST & FINISH \\
\hline SET, , , , , 11 & /POST1 \\
\hline $\mathrm{SET},,,, 1,10$ & SET, FIRST \\
\hline SET, $, 1,1,9$ & $\mathrm{SET}, 1,1,1,40$ \\
\hline SET, $, 1,1,8$ & $\mathrm{SET}, \ldots, \ldots, 39$ \\
\hline SET $, 1,1,1,7$ & SET, $, 1,1,1,38$ \\
\hline $\mathrm{SET}, \ldots, \ldots, 11$ & $\mathrm{SET}, \ldots, \ldots, 37$ \\
\hline FINISH & $\mathrm{SET}, 1,1,1,38$ \\
\hline /SOL & $\mathrm{SET}, \ldots, \ldots, 39$ \\
\hline ACEL $, 7,0,9.81$ & FINISH \\
\hline & /SOL \\
\hline ANTYPE, $\odot$ & ANTYPE, $\odot$ \\
\hline TIME, 1 & TIME, 1 \\
\hline ACEL $, \odot, \odot, 9.81$ & ACEL $, 0,0,9.81$ \\
\hline '́SOLVE & '́LOLE \\
\hline TIME, 2 & TIME, 2 \\
\hline ACEL $, 7.5,0,9$. & ACEL, - \\
\hline 81 & $7.7,0,9.81$ \\
\hline SOLVE & SOLVE \\
\hline FINISH & FINISH \\
\hline /POST1 & /SOLUTION \\
\hline SET, FIRST & ANTYPE, $\odot$ \\
\hline SET $, 1,,, 1,11$ & ANTYPE, $\odot$ \\
\hline FINISH & TIME, 1 \\
\hline /SOL & ACEL, $\odot, \odot, 9.81$ \\
\hline ACEL $, 7.5, \odot, 9$. & \\
\hline 81, & SOLVE \\
\hline ACEL $, \odot, \odot, 9.81$ & TIME, 2 \\
\hline & ACEL, $7.6,0,9$. \\
\hline ANTYPE, $\odot$ & 81, \\
\hline TIME, 1 & SOLVE \\
\hline SOLVE & FINISH \\
\hline TIME, 2 & /P0ST1 \\
\hline ACEL, $8.5,0,9$. & SET, FIRST \\
\hline 81, & SET, , , , , , 37 \\
\hline SOLVE & $\mathrm{SET}, \ldots, \ldots, 40$ \\
\hline FINISH & $\mathrm{SET}, \ldots, \ldots, 39$ \\
\hline /POST1 & FINISH \\
\hline SET, FIRST & /SOL \\
\hline SET, $, 1,, 1,11$ & ANTYPE, $\odot$ \\
\hline FINISH & TIME, 1 \\
\hline /SOL & ACEL $, \odot, \odot, 9.81$ \\
\hline ANTYPE, $\odot$ & ' \\
\hline TIME, 1 & SOLVE \\
\hline ACEL $, 0, \odot, 9.81$ & TIME, 2 \\
\hline & ACEL, - \\
\hline SOLVE & $7.5,0,9.81$ \\
\hline TIME, 2 & SOLVE \\
\hline ACEL, - & FINISH \\
\hline $8,0,9.81$ & /POST1 \\
\hline SOLVE & SET, LIST, 999 \\
\hline FINISH & SET, FIRST \\
\hline /POST1 & $\mathrm{SET}, 1,1,1,38$ \\
\hline SET, FIRST & SET, $, 1,1,39$ \\
\hline SET $, 1,1,1,11$ & SET, $, 1,1,40$ \\
\hline FINISH & /INPUT, 'amir- \\
\hline /SOL & base \\
\hline
\end{tabular}

ANTYPE, $\odot \quad$ ANTYPE, $\odot$

ACEL, $\odot, \odot, 9.81 \quad 19$

'SOLVE

TIME, 2

ACEL , 7, 0, 9.81

SOLVE

SET, $, 1,1,10$

SET, , , , , 9

FINISH

/SOL

'ANTYPE, $\odot$

TIME, 1

ACEL $, \odot, \odot, 9.81$

SOLVE

ACEL, $7.5,0,9$.

FINISH

/POST1

, 11

ACEL $, 7.5,0,9$.$$
\text { ACEL, } 0,0,9.81
$$

ANTYPE, $\odot$

TIME, 1

SOLVE

ACEL , 8. 5, $\odot, 9$.$$
\text { SOLVE }
$$

FINISH

POST1

SET, , , , , , 11

FINISH

ANTYPE, $\odot$

TIME, 1

ACEL, $0,0,9.81$

SOLVE

TIME, 2

SOLVE

FINISH

SET, FIRST

FINISH

base 


\begin{tabular}{|c|c|c|}
\hline shear', 'txt', & SOLVE & SET, LAST \\
\hline 'C: \Users\Raz & FINISH & PLCRACK, $\odot, \odot$ \\
\hline myar\Desktop \} $&{\text { /POST1 }} &{\text { SET, LIST, } 999} \\
{\hline 1,1,0} &{\text { SET, FIRST }} &{\text { SET, },,,, n} \\
{\hline \text { FINISH }} &{\text { SET, }, 1,, 1,39} &{, 35} \\
{\hline \text { /POST26 }} &{\text { SET, , , , } 38} &{\text { PLCRACK }, \odot, \odot} \\
{\hline \text { FILE，' } 35-\mathrm{H}-} &{\text { FINISH }} &{\text { SET, LIST, } 999} \\
{\hline \text { 1','rst','.' }} &{\text { /SOL }} &{\text { SET, }, 1,1,1} \\
{\hline \text { /UI, COLL, } 1} &{\text { ANTYPE, } \odot} &{, 32} \\
{\hline \text { NUMVAR, } 200} &{\text { TIME, } 1} &{\text { PLCRACK, } \odot, \odot} \\
{\hline \text { SOLU, 191, NCMI }} &{\mathrm{ACEL}, \odot, \odot, 9.81} &{\text { SET, PREVIOUS }} \\
{\hline \mathrm{T}} &{\text {, }} &{\text { PLCRACK, } \odot, \odot} \\
{\hline \text { STORE, MERGE }} &{\text { FINISH }} &{\text { FINISH }} \\
{\hline \text { FILLDATA, 191, }} &{\text { /POST1 }} &{\text { /SOL }} \\
{\hline,,, 1,1} &{\text { FINISH }} &{\text { FINISH }} \\
{\hline \text { REALVAR, } 191,1} &{\text { /SOL }} &{\text { /POST1 }} \\
{\hline 91} &{\text { SOLVE }} &{\text { SET, PREVIOUS }} \\
{\hline \text { NSOL, } 2,14241 \text {, }} &{\text { TIME, } 2} &{\text { PLCRACK, } \odot, \odot} \\
{\hline U, X, \quad U X \_2} &{\text { ACEL, - }} &{\text { SET, LIST, } 999} \\
{\hline \text { STORE, MERGE }} &{7,0,9.81} &{\text { SET, }, 1,1,} \\
{\hline \text { FINISH }} &{\text { SOLVE }} &{, 27} \\
{\hline \text { /PREP7 }} &{\text { FINISH }} &{\text { PLCRACK, } \odot, \odot} \\
{\hline \text { TBDE , MELA, } 1,} &{\text { /POST1 }} &{\text { SET, NEXT }} \\
{\hline} &{\text { SET, FIRST }} &{\text { PLCRACK, } \odot, \odot} \\
{\hline \text { TB, MELA, } 1,1,6} &{\text { SET }, 1,1,1,40} &{\text { SET, NEXT }} \\
{\hline} &{\text { SET, }, 1,, 1,39} &{\text { PLCRACK, } \odot, \odot} \\
{\hline \text { TBTEMP, } \odot} &{\text { FINISH }} &{\text { SET, NEXT }} \\
{\hline \text { TBPT, , }, .0 \odot \odot 85} &{\text { /SOL }} &{\text { PLCRACK, } \odot, \odot} \\
{\hline 2.26 \mathrm{E}+\odot \odot 7} &{\text { ANTYPE, } \odot} &{\text { FINISH }} \\
{\hline \text { ТВРТ, }, 0.002,3} &{\text { TIME }, 1} &{\text { /SOL }} \\
{\hline .5 \mathrm{E}+007} &{\text { ACEL }, 0,0,9.81} &{\text { FINISH }} \\
{\hline \text { ТВРТ, , }, . .0 \odot 21 \text {, }} &{\text { - }} &{\text { /POST1 }} \\
{\hline 3.5 \mathrm{E}+007} &{\text { SOLVE }} &{\text { SET, NEXT }} \\
{\hline \text { TBPT, , }, .0035,} &{\text { TIME, } 2} &{\text { PLCRACK, } \odot, \odot} \\
{\hline 2 \mathrm{E}+\odot \odot 7} &{\text { ACEL, - }} &{\text { SET, LIST, } 999} \\
{\hline \text { TBPT, }, 0.005,1} &{6.9,0,9.81} &{\text { SET, }, r, r} \\
{\hline E+007} &{\text { SOLVE }} &{, 26} \\
{\hline \text { ТВPT, , }, .01,5 \mathrm{E}} &{\text { FINISH }} &{\text { PLCRACK, } \odot, \odot} \\
{\hline+006} &{\text { /POST26 }} &{\text { SET, NEXT }} \\
{\hline \text { TBDE, CONC, } 1,} &{\text { FILE, ' } 35-\mathrm{H}-} &{\text { PLCRACK, } \odot, \odot} \\
{\hline} &{\text { 1', 'rst','.' }} &{\text { SET, NEXT }} \\
{\hline \text { TB, } \operatorname{CONC}, 1,1,9} &{\text { /UI, COLL, } 1} &{\text { PLCRACK }, \odot, \odot} \\
{\hline} &{\text { NUMVAR, } 200} &{\text { SET, NEXT }} \\
{\hline \text { TBTEMP, } \odot} &{\text { SOLU, 191, NCMI }} &{\text { PLCRACK, } \odot, \odot} \\
{\hline \text { TBDATA },, \odot .2, \odot} &{\mathrm{T}} &{\text { SET, NEXT }} \\
{\hline .2,3.5 \mathrm{E}+006,3} &{\text { STORE, MERGE }} &{\text { PLCRACK, } \odot, \odot} \\
{\hline .5 \mathrm{e} 7,0,0} &{\text { FILLDATA, 191, }} &{\text { SET, NEXT }} \\
{\hline \text { TBDATA, }, \odot, \odot, \odot} &{,, 1,1} &{\text { PLCRACK, } \odot, \odot} \\
{\hline .7,1,} &{\text { REALVAR, } 191,1} &{\text { SET, NEXT }} \\
{\hline \text { TBDE, CONC , } 1,} &{91} &{\text { PLCRACK }, \odot, \odot} \\
{\hline} &{\text { NSOL, } 2,14241 \text {, }} &{\text { SET, PREVIOUS }} \\
{\hline \text { TB, CONC }, 1,1,9} &{U, X, U X \_2} &{\text { PLCRACK }, \Theta, \odot} \\
{\hline} &{\text { STORE, MERGE }} &{\text { SET, NEXT }} \\
{\hline \text { TBTEMP, } \odot} &{\text { /INPUT, 'amir - }} &{\text { PLCRACK, } \odot, \odot} \\
{\hline \text { TBDATA }, 0.2, \odot} &{\text { base }} &{\text { SET, NEXT }} \\
{\hline .2,3.5 \mathrm{E}+006,3} &{\text { shear', 'txt', }} &{\text { PLCRACK, } \odot, \odot} \\
{\hline .5 \mathrm{E}+0 \odot 7,0,0} &{\text { 'C: \Users } \backslash \text { Raz }} &{\text { SET, NEXT }} \\
{\hline \text { TBDATA, }, \odot, \odot, \odot} &{\text { myar\Desktop \} } &{\text { PLCRACK, } \odot, \odot} \\
{\hline .7,1,} &{1,1,0} &{\text { SET, NEXT }} \\
{\hline \text { FINISH }} &{\text { SET, LIST, } 999} &{\text { PLCRACK, } \odot, \odot} \\
{\hline \text { /SOL }} &{\mathrm{SET},,,{ }^{\prime},} &{\text { SET, LAST }} \\
{\hline \text { ANTYPE, } \odot} &{21} &{\text { PLCRACK }, \odot, \odot} \\
{\hline \text { TIME, } 1} &{\text { PLCRACK }, \odot, \odot} &{\text { SET, LIST, } 999} \\
{\hline \text { ACEL }, 0,0,9.81} &{\text { SET, NEXT }} &{\text { SET, }, 1,} \\
{\hline} &{\text { PLCRACK, } \odot, \odot} &{, 29} \\
{\hline \text { SOLVE }} &{\text { SET, LIST, } 999} &{\text { PLCRACK, } \odot, \odot} \\
{\hline \text { TIME, } 2} &{\mathrm{SET},,,,, 1,} &{\text { SET, NEXT }} \\
{\hline A C E L \text {, - }} &{25} &{\text { PLCRACK }, \odot, \odot} \\
{\hline 7.5,0,9.81,} &{\text { PLCRACK, } \odot, \odot} &{\text { PLCRACK, } \odot, \odot} \\
\hline\end{array}$
\end{tabular}

FINISH

$\mathrm{R}, 1,2,0.0229$

$0,90,2,0.0088$

RMORE, $\odot, \odot, \odot, \odot$

$, \Theta, \Theta$,

RMORE, 0 ,

$R, 5,2,0.0076$,

$\odot, 90,2,0.0076$

RMORE, $\odot, \odot, \odot, \odot$

0,0 ,

RMORE, $\odot$,

TBDE, CONC, 1, ,

TB, CONC , 1, 1, 9

'TBTEMP, $\odot$

TBDATA, , 0.2 , .

$5,3 \cdot 5 \mathrm{E}+006,3$.

$5 \mathrm{E}+007, \odot, \odot$

TBDATA, $, \odot, \odot, \odot$

.7, ,

TBDE, MELA, 1, ,

TB, MELA , 1, 1, 6

'T'BTEMP, $\odot$

TBPT, , 0.00085

, $2.26 \mathrm{E}+007$

TBPT, , $\odot .0 \odot 2,3$

$.5 \mathrm{E}+007$

TBPT, , 0.0021 ,

$3.5 \mathrm{E}+007$

TBPT, , $0.004,3$

$\mathrm{E}+007$

TBPT, , $0.005,1$

$\mathrm{E}+007$

TBPT, , $0.01,1 \mathrm{E}$

$+006$

TBDE, MELA, 1, ,

TB, MELA , 1, 1, 6

'TBTEMP, $\odot$

TBPT, , 0.00085

, $2.26 \mathrm{E}+007$

TBPT, , $0.002,3$

$.5 \mathrm{E}+007$

TBPT, , 0.0021 ,

3. $5 \mathrm{E}+007$

TBPT, , $0.004,3$

$\mathrm{E}+007$

TBPT, , 0.005, 1

$\mathrm{E}+007$

TBPT, , $0.01,1 \mathrm{E}$

$+006$

FINISH

/SOL

ANTYPE, $\odot$

TIME, 1

ACEL, $\odot, \odot, 9.81$

SOLVE

TIME, 2

ACEL, -

$6.9,0,9.81$

SOLVE

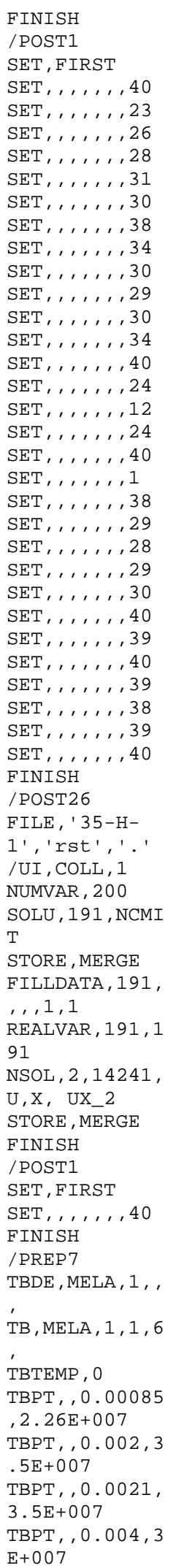

241 


\begin{tabular}{|c|c|c|c|c|}
\hline TBPT, , $0.005,1$ & SET $, 1,1,1,28$ & SET $, 1,,, 1,32$ & ACEL, - & FITEM, 4, 14083 \\
\hline$E+007$ & SET, $, 1,1,40$ & SET $, 1,1,1,33$ & $6.9,0,9.81$ & FITEM, 4, - \\
\hline ТВPT, $, 0.01,1 \mathrm{E}$ & SET, , , , , 29 & $\mathrm{SET}, \ldots, \ldots, 34$ & FINISH & 14084 \\
\hline+006 & SET $, 1,1,1,30$ & SET, $, 1,1,1,33$ & /PREP7 & FITEM, 4, 14087 \\
\hline MPTEMP, , ו, ו, ו, & SET, $, 1, r, 29$ & SET, $, 1,1,32$ & CPDELE, , , ALL & FITEM, 4, - \\
\hline & SET, FIRST & $\mathrm{SET}, \ldots, \ldots, 31$ & CPDELE $, 1,1, \mathrm{AL}$ & 14088 \\
\hline MPTEMP , 1, $\odot$ & SET, $, 1,1,1,30$ & SET, $, 1,,,, 30$ & $\mathrm{~L}$ & FITEM, 4, 14091 \\
\hline MPDE, EX, 2 & $\mathrm{SET},, \ldots, \ldots, 32$ & SET, , , , , 29 & CEDELE $, 2,6$, , A & FITEM, 4, - \\
\hline MPDE, NUXY, 2 & SET $, 1,1,1,34$ & PLCRACK, $\odot, \odot$ & NY & 14092 \\
\hline MPDE, PRXY, 2 & SET, $, 1,1,1,36$ & FINISH & CEDELE, 2, , AL & FITEM, 4, 14095 \\
\hline MPDATA, EX, 2, , & $\mathrm{SET}, 1,1,, 33$ & /POST1 & $\mathrm{L}$ & FITEM, 4, - \\
\hline $2 \mathrm{E}+011$ & SET, , , , , , 32 & SET, LIST, 999 & CPDELE, 2,6, , A & 14096 \\
\hline MPDATA, PRXY, 2 & $\mathrm{SET},, \ldots,, 31$ & SET,,,,,$r$ & LL & FITEM, 4, 14099 \\
\hline, 0.3 & SET, $, 1,1,1,30$ &, 30 & FLST, $4,121,1$, & FITEM, 4, - \\
\hline TBDE, MELA, 2, & SET, , , , , , , 31 & PLCRACK, $\odot, \odot$ & ORDE, 116 & 14100 \\
\hline & SET, FIRST & SET, PREVIOUS & FITEM, 4, 14005 & FITEM, 4, 14103 \\
\hline TB, MELA $, 2,1,4$ & SET, $, 1,,, 34$ & PLCRACK, $\odot, \odot$ & FITEM, 4, - & FITEM, 4, - \\
\hline , & SET, $, 1,1,39$ & PLCRACK, $\odot, \odot$ & 14008 & 14104 \\
\hline TBTEMP, $\odot$ & SET, $, 1,1,1,38$ & SET, NEXT & FITEM, 4, 14011 & FITEM, 4, 14107 \\
\hline TBPT, , $, 0.002,4$ & SET, , , , , , , 37 & PLCRACK, $\odot, \odot$ & FITEM, 4, - & FITEM, 4, - \\
\hline$E+008$ & SET, $, 1,1,1,36$ & FINISH & 14012 & 14108 \\
\hline TBPT, $, 0.1,5 \mathrm{E}+$ & FINISH & /POST1 & FITEM , 4, 14015 & FITEM, 4, 14111 \\
\hline$\odot \odot 8$ & /P0ST1 & SET, LIST, 999 & FITEM, 4, - & FITEM, 4, - \\
\hline TBPT, , $0.105,2$ & SET, LIST, 999 & SET, $, 1,1$, & 14016 & 14112 \\
\hline$E+008$ & SET, $, 1,1$, &, 29 & FITEM, 4, $14 \odot 19$ & FITEM, 4, 14115 \\
\hline TBPT, , $0.11,50$ &, 36 & PLCRACK, $\odot, \odot$ & FITEM, 4, - & FITEM, 4, - \\
\hline FINISH & PLCRACK, $\odot, \odot$ & SET, NEXT & 14020 & 14116 \\
\hline /PREP7 & SET, PREVIOUS & PLCRACK, $\odot, \odot$ & FITEM, 4, 14023 & FITEM, 4, 14119 \\
\hline FINISH & PLCRACK, $\odot, \odot$ & FINISH & FITEM, 4, - & FITEM, 4, - \\
\hline /SOL & SET, PREVIOUS & /PREP7 & 14024 & 14120 \\
\hline ACEL, - & PLCRACK, $\odot, \odot$ & TBDE, CONC, 1, & FITEM, 4, $14 \odot 27$ & FITEM, 4, 14123 \\
\hline $6.9,0,9.81$ & SET, LIST, 999 & & FITEM, 4, - & FITEM, 4, - \\
\hline FINISH & SET, $, r, r$ & $\mathrm{~TB}, \mathrm{CONC}, 1,1,9$ & 14028 & 14124 \\
\hline /POST1 & 40 & & FITEM, 4, 14031 & FITEM, 4, 14127 \\
\hline SET, FIRST & PLCRACK, $\odot, \odot$ & TBTEMP, $\odot$ & FITEM, 4, - & FITEM, 4, - \\
\hline SET, LIST, 999 & FINISH & TBDATA $, 0.2,0$ & 14032 & 14128 \\
\hline SET, $, 1,1$, & /P0ST1 & $.5,3.5 \mathrm{E}+006,3$ & FITEM, 4, 14035 & FITEM, 4, 14131 \\
\hline 28 & SET, LIST, 999 & $.5 \mathrm{E}+007,0, \odot$ & FITEM, 4, - & FITEM, 4, - \\
\hline SET, LIST, 999 & $\mathrm{SET}, r,{ }_{1}$, & TBDATA $, \odot, \odot, \odot$ & 14036 & 14132 \\
\hline SET, $, 1,1$, &, 33 & .7, & FITEM, 4, 14039 & FITEM, 4, 14135 \\
\hline, 28 & PLCRACK, $\odot, \odot$ & TBDE, CONC, 1, & FITEM, 4, - & FITEM, 4, - \\
\hline PLCRACK, $\odot, \odot$ & SET, LIST, 999 & & 14040 & 14136 \\
\hline SET, NEXT & SET, $, 1, r$ & TB, CONC $, 1,1,9$ & FITEM, 4,14043 & FITEM, 4, 14139 \\
\hline PLCRACK, $\odot, \odot$ &, 36 & , & FITEM, 4, - & FITEM, 4, - \\
\hline SET, NEXT & PLCRACK, $\odot, \odot$ & TBTEMP, $\odot$ & 14044 & 14140 \\
\hline PLCRACK, $\odot, \odot$ & SET, LIST, 999 & TBDATA, , $\odot .2, \odot$ & FITEM, 4, $14 \odot 47$ & FITEM, 4, 14143 \\
\hline SET, NEXT & SET, $, 1,1$, & $.5,3.5 \mathrm{E}+006,3$ & FITEM, 4, - & FITEM, 4, - \\
\hline PLCRACK, $\odot, \odot$ &, 35 & $.5 \mathrm{E}+007, \odot, \odot$ & 14048 & 14144 \\
\hline SET, NEXT & PLCRACK, $\odot, \odot$ & TBDATA $, \odot, \odot, \odot$ & FITEM, 4, 14051 & FITEM, 4, 14147 \\
\hline PLCRACK, $\odot, \odot$ & SET, PREVIOUS & $.7,1$, & FITEM, 4, - & FITEM, 4, - \\
\hline SET, NEXT & PLCRACK, $\odot, \odot$ & FINISH & 14052 & 14148 \\
\hline PLCRACK, $\odot, \odot$ & FINISH & /POST1 & FITEM, 4, 14055 & FITEM, 4, 14151 \\
\hline SET, LIST, 999 & /POST1 & SET, LIST, 999 & FITEM, 4, - & FITEM, $4,-$ \\
\hline SET, $, 1,1$, & SET, LIST, 999 & $\mathrm{SET}, r,, 1$, & 14056 & 14152 \\
\hline, 38 & $\mathrm{SET},{ }_{1},{ }_{1}, 1$ &, 30 & FITEM, 4, $14 \odot 59$ & FITEM, 4, 14155 \\
\hline PLCRACK, $\odot, \odot$ &, 33 & PLCRACK, $\odot, \odot$ & FITEM, 4, - & FITEM, 4, - \\
\hline SET, LIST, 999 & SET, , , & SET, LIST, 999 & 14060 & 14156 \\
\hline SET, r, &, 32 & SET, $, r, r$ & FITEM, 4, 14063 & FITEM, 4, 14159 \\
\hline, 36 & PLCRACK, $\odot, \odot$ &, 38 & FITEM, 4, - & FITEM, 4, - \\
\hline PLCRACK, $\odot, \odot$ & SET, LIST, 999 & PLCRACK, $\odot, \odot$ & 14064 & 14160 \\
\hline SET, LIST, 999 & $\mathrm{SET}, 1,1,1$, & FINISH & FITEM, 4, 14069 & FITEM, 4, 14163 \\
\hline SET, , , , , &, 30 & /POST1 & FITEM, 4, - & FITEM, 4, - \\
\hline, 34 & PLCRACK, $\odot, \odot$ & FINISH & 14072 & 14164 \\
\hline PLCRACK, $\odot, \odot$ & SET, FIRST & /SOL & FITEM, 4, 14075 & FITEM, 4, 14167 \\
\hline SET, PREVIOUS & SET, $, 1,1,, 30$ & FINISH & FITEM, 4, - & FITEM, 4, - \\
\hline PLCRACK $, \odot, \odot$ & SET,,,,, 31 & /PREP7 & 14076 & 14168 \\
\hline SET, FIRST & SET $, 1,1,1,29$ & FINISH & FITEM, 4, 14079 & FITEM, 4, 14171 \\
\hline SET, $, 1, n, 26$ & SET, $, 1,1,30$ & /SOL & FITEM, 4, - & FITEM, 4, - \\
\hline SET, , , , , , 27 & SET, $, 1,1,31$ & & 14080 & 14172 \\
\hline
\end{tabular}


FITEM, 4, 14175

FITEM, 4, -

14176

FITEM , 4, 14179

FITEM, 4, -

14180

FITEM , 4, 14183

FITEM , 4, -

14184

FITEM , 4, 14187

FITEM , 4, -

14188

FITEM , 4, 14191

FITEM, 4, -

14192

FITEM, 4, 14195

FITEM, 4, -

14196

FITEM, 4, 14199

FITEM, 4, -

14200

FITEM, 4, 14203

FITEM, 4, -

14204

FITEM, 4, 14207

FITEM, 4,

14208

FITEM , 4, 14211

FITEM, 4, -

14212

FITEM , 4, 14215

FITEM, 4, -

14216

FITEM, 4, 14219

FITEM, 4, -

14220

FITEM , 4, 14223

FITEM, 4, -

14224

FITEM, 4, 14227

FITEM, 4, -

14228

FITEM, 4, 14231

FITEM, 4, -

14232

FITEM , 4, 14235

FITEM, 4, -

14236

FITEM, 4, 14239

FITEM, 4, -

14241

CP , 1, UX, P51X

FLST, 4, 121, 1, ORDE, 116

FITEM, 4, 14005

FITEM, 4, -

14008

FITEM , 4, 14011

FITEM, 4, -

14012

FITEM , 4, 14015

FITEM, 4, -

14016

FITEM , 4, 14019

FITEM, 4, -

14020

FITEM, 4, 14023

FITEM , 4, -

14024
FITEM, 4, 14027

FITEM, 4, -

14028

FITEM, 4, 14031

FITEM, 4, -

14032

FITEM, 4, 14035

FITEM, 4, -

14036

FITEM, 4, 14039

FITEM, 4, -

14040

FITEM, 4, 14043

FITEM, 4, -

14044

FITEM, 4, 14047

FITEM, 4, -

14048

FITEM, 4, 14051

FITEM, 4, -

14052

FITEM, 4, 14055

FITEM, 4, -

14056

FITEM, 4, 14059

FITEM, 4,

14060

FITEM, 4, 14063

FITEM, 4, -

14064

FITEM, 4, 14069

FITEM, 4, -

14072

FITEM, 4, 14075

FITEM, 4, -

14076

FITEM , 4, 14079

FITEM, 4, -

14080

FITEM, 4, 14083

FITEM, 4, -

14084

FITEM, 4, 14087

FITEM, 4, -

14088

FITEM, 4, 14091

FITEM, 4, -

14092

FITEM, 4, 14095

FITEM, 4, -

14096

FITEM, 4, 14099

FITEM, 4, -

14100

FITEM, 4, 14103

FITEM, 4, -

14104

FITEM, 4, 14107

FITEM, 4, -

14108

FITEM, 4, 14111

FITEM, 4, -

14112

FITEM, 4, 14115

FITEM, 4, -

14116

FITEM, 4, 14119

FITEM, 4,

14120
FITEM, 4, 14123

FITEM, 4, -

14124

FITEM, 4, 14127

FITEM, 4, -

14128

FITEM, 4, 14131

FITEM , 4, -

14132

FITEM, 4, 14135

FITEM, 4, -

14136

FITEM, 4, 14139

FITEM, 4, -

14140

FITEM, 4, 14143

FITEM, 4, -

14144

FITEM, 4, 14147

FITEM, 4, -

14148

FITEM, 4, 14151

FITEM, 4, -

14152

FITEM, 4, 14155

FITEM, 4, -

14156

FITEM, 4, 14159

FITEM, 4, -

14160

FITEM, 4, 14163

FITEM, 4, -

14164

FITEM, 4, 14167

FITEM, 4, -

14168

FITEM, 4, 14171

FITEM, 4, -

14172

FITEM, 4, 14175

FITEM, 4, -

14176

FITEM, 4, 14179

FITEM, 4, -

14180

FITEM, 4, 14183

FITEM, 4, -

14184

FITEM, 4, 14187

FITEM, 4, -

14188

FITEM, 4, 14191

FITEM, 4, -

14192

FITEM, 4, 14195

FITEM, 4, -

14196

FITEM, 4, 14199

FITEM, 4, -

14200

FITEM, 4, 14203

FITEM, 4, -

14204

FITEM, 4, 14207

FITEM, 4, -

14208

FITEM, 4, 14211

FITEM, 4, -

14212
FITEM, 4, 14215

FITEM, 4, -

14216

FITEM , 4, 14219

FITEM, 4, -

14220

FITEM, 4, 14223

FITEM, 4, -

14224

FITEM , 4, 14227

FITEM, 4, -

14228

FITEM , 4, 14231

FITEM, 4, -

14232

FITEM, 4, 14235

FITEM, 4, -

14236

FITEM, 4, 14239

FITEM, 4, -

14241

CP , 1, UY, P51X

FINISH

/SOL

ANTYPE, $\odot$

TIME, 1

SOLVE

FINISH

/PREP7

FLST, 4, 121, 1,

ORDE, 116

FITEM, 4, 14005

FITEM, 4, -

14008

FITEM , 4, 14011

FITEM, 4, -

14012

FITEM , 4, 14015

FITEM, 4, -

14016

FITEM , 4, 14019

FITEM, 4, -

14020

FITEM , 4, 14023

FITEM, 4, -

14024

FITEM, 4, 14027

FITEM, 4, -

14028

FITEM, 4, 14031

FITEM, 4, -

14032

FITEM, 4, 14035

FITEM, 4, -

14036

FITEM, 4, 14039

FITEM, 4, -

14040

FITEM, 4, 14043

FITEM, 4, -

14044

FITEM , 4, 14047

FITEM, 4, -

14048

FITEM, 4, 14051

FITEM, 4, -

14052

FITEM , 4, 14055

FITEM , 4, -

14056

FITEM, 4, 14059

FITEM, 4, -

14060

FITEM , 4, 14063

FITEM, 4, -

14064

FITEM , 4, 14069

FITEM, 4, -

14072

FITEM, 4, 14075

FITEM, 4, -

14076

FITEM , 4, 14079 


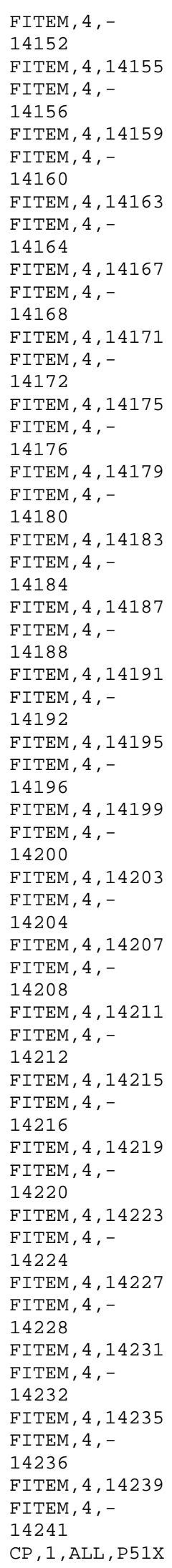

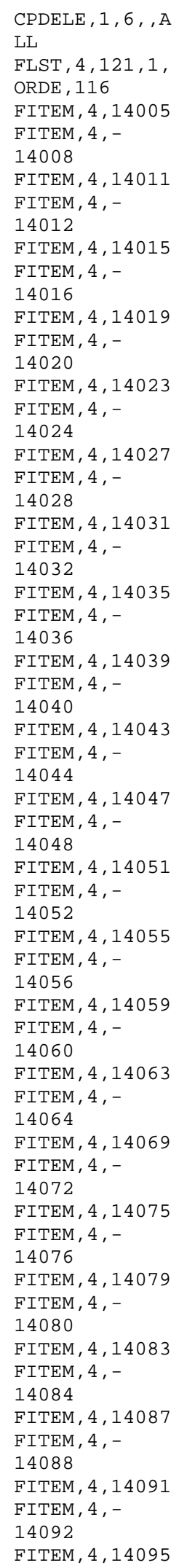

FITEM, 4, -

14096

FITEM, 4, 14099

FITEM, 4, -

14100

FITEM, 4, 14103

FITEM, 4, -

14104

FITEM, 4, 14107

FITEM, 4, -

14108

FITEM, 4, 14111

FITEM, 4, -

14112

FITEM, 4, 14115

FITEM, 4, -

14116

FITEM, 4, 14119

FITEM, 4, -

14120

FITEM, 4, 14123

FITEM, 4, -

14124

FITEM, 4, 14127

FITEM, 4, -

14128

FITEM, 4, 14131

FITEM , 4, -

14132

FITEM, 4, 14135

FITEM, 4, -

14136

FITEM, 4, 14139

FITEM, 4, -

14140

FITEM, 4, 14143

FITEM, 4, -

14144

FITEM, 4, 14147

FITEM, 4, -

14148

FITEM, 4, 14151

FITEM, 4, -

14152

FITEM, 4, 14155

FITEM, 4, -

14156

FITEM, 4, 14159

FITEM, 4, -

14160

FITEM, 4, 14163

FITEM, 4, -

14164

FITEM, 4, 14167

FITEM, 4, -

14168

FITEM, 4, 14171

FITEM, 4, -

14172

FITEM, 4, 14175

FITEM, 4, -

14176

FITEM, 4, 14179

FITEM, 4, -

14180

FITEM, 4, 14183

FITEM, 4, -

14184

FITEM, 4, 14187

\begin{tabular}{|c|c|}
\hline FITEM, 4, - & SET, $,, 1,10$ \\
\hline 14188 & $\mathrm{SET}, \ldots, \ldots, 12$ \\
\hline FITEM, 4, 14191 & SET, FIRST \\
\hline FITEM, 4, - & FLST $, 5,121,1$, \\
\hline 14192 & ORDE, 116 \\
\hline FITEM, 4, 14195 & FITEM, 5, 14005 \\
\hline FITEM, 4, - & FITEM, 5, - \\
\hline 14196 & 14008 \\
\hline FITEM, 4, 14199 & FITEM, 5, 14011 \\
\hline FITEM, 4, - & FITEM, 5, - \\
\hline 14200 & 14012 \\
\hline FITEM, 4, 14203 & FITEM, 5, 14015 \\
\hline FITEM, 4, - & FITEM, 5, - \\
\hline 14204 & 14016 \\
\hline FITEM, 4,14207 & FITEM, 5, 14019 \\
\hline FITEM, 4, - & FITEM, 5, - \\
\hline 14208 & 14020 \\
\hline FITEM, 4, 14211 & FITEM, 5,14023 \\
\hline FITEM, 4, - & FITEM, 5, - \\
\hline 14212 & 14024 \\
\hline FITEM, 4, 14215 & FITEM, 5, 14027 \\
\hline FITEM, 4, - & FITEM, 5, - \\
\hline 14216 & 14028 \\
\hline FITEM, 4, 14219 & FITEM, 5,14031 \\
\hline FITEM, 4, - & FITEM, 5, - \\
\hline 14220 & 14032 \\
\hline FITEM, 4, 14223 & FITEM, 5, 14035 \\
\hline FITEM, 4, - & FITEM, 5, - \\
\hline 14224 & 14036 \\
\hline FITEM, 4, 14227 & FITEM, 5, 14039 \\
\hline FITEM, 4, - & FITEM, 5, - \\
\hline 14228 & 14040 \\
\hline FITEM, 4, 14231 & FITEM, $5,14 \odot 43$ \\
\hline FITEM, 4, - & FITEM, 5, - \\
\hline 14232 & 14044 \\
\hline FITEM, 4, 14235 & FITEM, 5, 14047 \\
\hline FITEM, 4, - & FITEM, 5, - \\
\hline 14236 & 14048 \\
\hline FITEM, 4, 14239 & FITEM, 5, 14051 \\
\hline FITEM, 4, - & FITEM, 5, - \\
\hline 14241 & 14052 \\
\hline $\mathrm{CP}, 1, \mathrm{ALL}, \mathrm{P} 51 \mathrm{X}$ & FITEM, 5, 14055 \\
\hline FINISH & FITEM, 5, - \\
\hline /SOL & 14056 \\
\hline ANTYPE, $\odot$ & FITEM, 5, 14059 \\
\hline SOLVE & FITEM, 5, - \\
\hline FINISH & 14060 \\
\hline /POST1 & FITEM , 5, 14063 \\
\hline SET, LIST, 999 & FITEM, 5, - \\
\hline SET, $, 1,1$, & 14064 \\
\hline 13 & FITEM, 5, 14069 \\
\hline SET, FIRST & FITEM, 5, - \\
\hline SET, $, 1,1,1,4$ & 14072 \\
\hline SET, $, 1,1,1,5$ & FITEM, $5,14 \odot 75$ \\
\hline SET, $, 1,1,1,7$ & FITEM, 5, - \\
\hline SET $, 1,, 1,20$ & 14076 \\
\hline SET, , , , , , 11 & FITEM, 5, 14079 \\
\hline SET,,,,, 13 & FITEM, 5, - \\
\hline SET, , , , , , 15 & 14080 \\
\hline SET, , , , , , 17 & FITEM, $5,14 \odot 83$ \\
\hline SET, $, \ldots, 1,19$ & FITEM, 5, - \\
\hline SET, $, 1,1,, 8$ & 14084 \\
\hline SET, , , , , 2 & FITEM, 5, 14087 \\
\hline SET, $, 1,1,1,5$ & FITEM, 5, - \\
\hline SET $, 1,1,1,7$ & 14088 \\
\hline SET, , , , , , 17 & FITEM, 5, 14091 \\
\hline SET, , , , , , 12 & FITEM, 5, - \\
\hline SET, , , , , 15 & 14092 \\
\hline SET $, 1,1,1,7$ & FITEM, 5, 14095 \\
\hline
\end{tabular}




\begin{tabular}{|c|c|c|c|c|}
\hline FITEM, 5, - & FITEM, 5, - & FITEM, 5, - & $\{35-\mathrm{H}-1$ Table & TBPT, , $0.005,1$ \\
\hline 14096 & 14156 & 14216 & & $E+007$ \\
\hline FITEM, 5, 14099 & FITEM, 5, 14159 & FITEM, 5, 14219 & -eui, 'ansys: : & TBPT, , $0.01,1 \mathrm{E}$ \\
\hline FITEM, 5, - & FITEM, 5, - & FITEM, 5, - & report: :finis & +006 \\
\hline $14100^{\circ}$ & $14160^{\circ}$ & 14220 & hed' & TBDE, MELA, 2, \\
\hline FITEM, 5, 14103 & FITEM, 5, 14163 & FITEM, 5, 14223 & FINISH & \\
\hline FITEM, 5,- & FITEM, 5,- & FITEM, 5, - & /PREP7 & TB, MELA, 2, 1, 4 \\
\hline 14104 & 14164 & 14224 & MPTEMP, , , , , , & \\
\hline FITEM , 5, 14107 & FITEM , 5, 14167 & FITEM , 5, 14227 & & TВTEMP, $\odot$ \\
\hline FITEM, 5, - & FITEM, 5,- & FITEM, 5, - & MPTEMP $, 1,0$ & ТВРТ, , $\odot . \odot \odot 2,4$ \\
\hline 14108 & 14168 & 14228 & MPDE, DENS, 1 & $E+008$ \\
\hline FITEM, 5, 14111 & FITEM , 5, 14171 & FITEM , 5, 14231 & MPDATA, DENS, 1 & ТВРТ, $, 0.1,5 \mathrm{E}+$ \\
\hline FITEM, 5, - & FITEM, 5, - & FITEM, 5, - &, 2400 & $\odot \odot 8$ \\
\hline 14112 & 14172 & 14232 & MPTEMP, , , , , , , & ТВPT, , $0.105,2$ \\
\hline FITEM, 5, 14115 & FITEM , 5, 14175 & FITEM , 5, 14235 & & $E+\odot \odot 8$ \\
\hline FITEM, 5, - & FITEM, 5, - & FITEM, 5, - & MPTEMP, 1,0 & TВPT, , $0.11,50$ \\
\hline 14116 & 14176 & 14236 & $M P D E, E X, 1$ & TBDE, MELA, 2, \\
\hline FITEM, 5, 14119 & FITEM, 5, 14179 & FITEM, 5, 14239 & MPDE, NUXY, 1 & \\
\hline FITEM, 5, - & FITEM, 5, - & FITEM, 5, - & MPDE, PRXY, 1 & TB, MELA, $2,1,4$ \\
\hline 14120 & $14180^{\prime}$ & $14241^{\prime}$ & MPDATA, EX, 1, & \\
\hline FITEM, 5, 14123 & FITEM, 5, 14183 & NSEL, S, & $2.66 \mathrm{E}+010$ & TBTEMP, $\odot$ \\
\hline FITEM, 5,- & FITEM, 5,- & P51X & MPDATA, PRXY, 1 & ТВРТ, $, 0.0 \odot 2,4$ \\
\hline 14124 & 14184 & SET, LIST, 999 &, 0.2 & $E+008$ \\
\hline FITEM, 5, 14127 & FITEM, 5, 14187 & SET, $, 1, r$, & TBDE, CONC, 1, & ТВPT, , $0.1,5 \mathrm{E}+$ \\
\hline FITEM, 5,- & FITEM, 5, - & 14 & & $\odot \odot 8$ \\
\hline 14128 & 14188 & ALLSEL, ALL & TB, $\mathrm{CONC}, 1,1,9$ & ТВPT, , $\odot .105,2$ \\
\hline FITEM $, 5,14131$ & FITEM , 5, 14191 & ALLSEL, ALL & & $E+008$ \\
\hline FITEM, 5, - & FITEM, 5,- & FINISH & TBTEMP, $\odot$ & ТВРТ, $, 0.11,50$ \\
\hline 14132 & 14192 & /PREP7 & TBDATA, $, \odot .2, \odot$ & MPTEMP, $, 1,1$, \\
\hline FITEM, 5, 14135 & FITEM, 5, 14195 & IGESOUT, ' tgyt & $.5,3.5 E+006,3$ & \\
\hline FITEM, 5, - & FITEM, 5, - & $1,1,1,1,0$ & $.5 \mathrm{E}+\odot \odot 7, \odot, \odot$ & MPTEMP $, 1, \odot$ \\
\hline 14136 & 14196 & FINISH & TBDATA, $, \odot, \odot, \odot$ & MPDE, EX, 2 \\
\hline FITEM, 5, 14139 & FITEM, 5, 14199 & eui, 'package & $.7,1$, & MPDE, NUXY, 2 \\
\hline FITEM, 5, - & FITEM, 5, - & require & TBDE, MELA, 1, & MPDE, PRXY, 2 \\
\hline 14140 & 14200 & ansys' & & MPDATA, EX, 2, , \\
\hline FITEM, 5, 14143 & FITEM , 5, 14203 & reui, 'ansys: : & TB, MELA $1,1,6$ & $2 \mathrm{E}+011$ \\
\hline FITEM, 5, - & FITEM, 5, - & report: :setdi & , & MPDATA, PRXY, 2 \\
\hline 14144 & 14204 & rectory & TBTEMP, $\odot$ &, 0.3 \\
\hline FITEM, 5, 14147 & FITEM, 5, 14207 & "C:/Users/Raz & TBPT, ,, $.0 \odot \odot 85$ & FINISH \\
\hline FITEM, 5, - & FITEM, 5, - & myar/Desktop/ &, $2.26 \mathrm{E}+\odot \odot 7$ & /SOL \\
\hline 14148 & 14208 & New folder & ТВPT, $, 0.0 \odot 2,3$ & ANTYPE, $\odot$ \\
\hline FITEM, 5, 14151 & FITEM, 5, 14211 & (2)"' & $.5 \mathrm{E}+007$ & ANTYPE, $\odot$ \\
\hline FITEM, 5, - & FITEM, 5,- & reui, 'ansys: : & ТВРТ,, 0.0021, & NLGEOM, 1 \\
\hline 14152 & 14212 & report: :table & $3.5 \mathrm{E}+\odot \odot 7$ & ACEL, - \\
\hline FITEM, 5, 14155 & FITEM , 5, 14215 & capture 1 & $\begin{array}{l}\text { TBPT, , }, .0 \odot 4,3 \\
\mathrm{E}+\odot \odot 7\end{array}$ & $6.9,0,9.81$ \\
\hline
\end{tabular}




\section{References}

ATC (1978). Tentative Provisions for the Development of Seismic Regulations for buildings. ATC Report 3-06, Applied Technology Council, Redwood City, California.

ATC-19 (1995). Structural Response ModificFraiation Factors. ATC Report 19, Applied Technology Council, Redwood City, California.

ACI 350.3-06, 2006. Seismic design of liquid-containing concrete structures (ACI 350.3-06) and commentary (350.3R-06). American Concrete Institute (ACI) Committee 350, Environmental Engineering Concrete Structures, Farmington Hills, Mich.

American Society of Civil Engineering (ASCE), 2010. Minimum design loads for buildings and other structures, ASCE Standard ASCE/SEI 7-10

ANSYS Inc. ANSYS help manual (Version 11.1), 2004. Global headquarters, Southpointe, 275 Technology drive, Canonsburg, PA 15317

ACI 318-08, American Concrete Institute Committee 318, 2008. Building Code Requirements for Structural Concrete and Commentary. Farmington Hills, Mi, USA.

ACI 371R-08, 2008, Guide for the analysis, design and construction of elevated concrete and composite steel-concrete water storage tanks American Concrete Institute, ACI Committee 371, Farmington Hills, MI, USA.

API 650, 1998, "Welded steel tanks for oil storage”, American Petroleum Institute Standard, Washington, DC.

ANSI/AWWA D100-96, 1996, "Welded steel tanks for water storage”, American Water Works Association, Colorado.

Burns, NH., Siess, CP., 1962, Load-deformation characteristics of beam-column connections in reinforced concrete. Civil Engineering Studies, SRS no. 234, University of Illinois, Urbana.

Bertero,VV. Strength and deformation capacities of buildings under extreme environments. In Structural Engineering and Structural Mechanics, Pister KS (ed.). Prentice-Hall: Englewood Cli4s, NJ, 1977; 211-215.

Cheng-Tzu, T.H., Saeed Mirza,M., Sunny,C.S., 1981, Nonlinear Analysis of Reinforced Concrete Frames, Computer and Structures, Vol 13, pp. 223-227.

Clough, R., Penzien, J., 1993, Dynamics of structures. 2nd Edition, New York: McGraw-Hill, Inc. 
Claudio E. Todeschini, Albert C. Bianchini, and Clyde E. Kesler, "Behavior of Concrete Columns Reinforced with High Strength Steels,” ACI Journal, Proceedings, Vol. 61, No. 6, June 1964,pp. 701-716.

Dutta,S.C., Dutta, S., Roy,R., 2009, "Dynamic behavior of R/C elevated tanks with soil-structure interaction" Engineering Structures, Volume: 31 Issue: 11 Pages: 2617-2629.

Dahmani, A. Khennane, B., Kacia, S., 2010, Crack Identification in Reinforced Concrete Beams Using ANSYS Software, Strength of Materials, Vol. 42, No. 2.

El Damatty A.A., Korol RM, Mirza F.A., 1997, Stability of elevated liquid-filled conical tanks under seismic loading, part I—-theory. Earthq Eng Struct Dyn, 26: 1191-208.

El Damatty, A.A, Korol RM, Mirza F.A., 1997, Stability of elevated liquid-filled conical tanks under seismic loading, part II—applications. Earthq Eng Struct Dyn, 26:1209-29.

Elnashai,A.S, Di Sarno, L., 2008, Fundamentals of earthquake engineering, John wiley \& sons Ltd.

Hognestad, E. A Study of Combined Bending and Axial Load in Reinforced Concrete Members, Bulletin 399, University of Illinois Engineering Experiment Station, Urbana, Ill., November 1951, 128 pp.

El Damatty AA, Saafan MS, Sweedan AMI. Experimental study conducted on a liquid-filled combined conical tank model. J Thin Walled Struct 2005;43: 1398-417.

Elnashai, A.S. and Mwafy, A.M.(2002). Overstrength and force reduction factors of multistorey reinforced-concrete buildings, The Structural Design of Tall Buildings, 11(5), 329-351.

Fajfar P, Gaspersic P. The N2 method for the seismic damage analysis of RC buildings. Earthquake Engineering and Structural Dynamics 1996;25:31-46.

FEMA, NEHRP guidelines for the seismic rehabilitation of buildings. FEMA 273, Federal Emergency Management Agency, 1996.

FEMA P695, Quantification of Building Seismic Performance Factors, Federal Emergency Management Agency, 2009

Freeman, S. A. (1990). "On the correlation of code forces to earthquake demands." Proc. 4th U.S.-Japan Workshop on Improvement of Building Structural Design and Construction Practices, ATC-15-3 Report, Applied Technology Council, Redwood City, California.

Gaston JR, Siess CP, Newmark NM. A layered finite element non-linear analysis of reinforced concrete plates and shells. Civil Engineering Studies, SRS No. 389, University of Illinois, Urbana, 1972. 
Gollwitzer, S., and Rackwitz, R. (1990). "On the reliability of Daniels systems.” Struct. Safety, 7, 229-243.

Husain, M., and Tsopelas, P. (2004). "Measures of structural redundancy in R/C buildings. I: Redundancy indices.” J. Struct. Eng. 130(11), 1651-1658.

Housner GW. The dynamic behavior of water tanks. Bull Seismol Soc Amer 1963;53(2):381-9.

Holzer et al. 1975. SINDER. A Computer Code for General Analysis of Two-Dimensional Reinforced Concrete Structures. Report. AFWL-TR-74-228 Vol. 1. Air Force Weapons Laboratory, Kirt-land, AFB, New Mexico.

Hwang, H. and Shinozuka, M. (1994). "Effects of large earthquake on the design of buildings in eastern united states.” Proc. Fifth U.S. National Conference on Earthquake Engineering, Chicago, Illinois.

IBC., 2011, “International Building Code” , International Code Council, Inc., USA:ICC.

James K. Wight, Jr., James G. Macgregor, Reinforced concrete: mechanics and design - 6th ed.2009

Krolicki, J. Maffei, G. M. Calvi, Shear Strength of Reinforced Concrete Walls Subjected to Cyclic Loading, Journal of Earthquake Engineering, 15(S1):30-71, 2011

Mander, J.B., Kim, J.H, and Dutta, A.; Shear-Flexure Interaction Seismic Analysis and Design; pg. 369-383; Modeling of Inelastic Behavior of RC Structures Under Seismic Loads: ASCE/SEI 2001.

Krawinkler, H., and Nassar, A. A. (1992). "'Seismic design based on ductility and cumulative damage demands and capacities.' Nonlinear seismic analysis and design of reinforced concrete buildings, P. Fajfar and H. Krawinkler, eds., Elsevier Applied Science, New York.

Kowalsky, M. J. and Priestley, M. J. N. [2000] "Improved analytical model for shear strength of circular reinforced concrete columns in seismic regions,”ACI Structural Journal 97(3), 388-396.

Kachlakev,D., Obispo, S.L., Yim, S., Chansawat, K., Potisuk, T., Finite Element Modeling of Reinforced Concrete Structures Strengthened with FRP Laminates - Final Report , May 2001.

Willam, K. J., Warnke, E. D. "Constitutive Model for the Triaxial Behavior of Concrete". Proceedings, International Association for Bridge and Structural Engineering. Vol. 19. ISMES. Bergamo, Italy. p. 174. 1975.

Kwak, H.G., Kim, S.P., 2002, Non-linear analysis of RC beams based on moment-curvature relation. Comput Struct 80 7/8, pp. 615-628. 
Livaog`lu. R., Dog־angu“n. A., 2005, Seismic evaluation of fluid-elevated tankfoundation/soil systems in frequency domain. Struct Eng Mech; 21(1):101-19.

Livaoglua, R., and Dogangu, A., 2007, Effect of foundation embedment on seismic behaviour of elevated tanks considering fluid-structure-soil interaction, Soil Dynamics and Earthquake Engineering, 27 (9), pg. 855-863 963;53(2):225-307.

Mwafy, A.M. and Elnashai, A.S,(2002), Calibration of force reduction factors of RC building, , Journal of Earthquake Engineering, 6(2), 239-273

Mwafy, A.M. and Elnashai, A.S,(2002), Overstrength and force reduction factors of multistory reinforced-concrete buildings, Struct. Design Tall Build. 11, 329-351 (2002)

Memari, A M. Ahmadi, M M. Rezaee, B. Behaviour of reinforced concrete water towers during Manjil-Roudbar earthquake of June 1990, Proceedings of the Tenth World Conference on Earthquake Engineering; Madrid, 19-24 July 1992. A A Balkema, Rotterdam, 1992, volume 9, pages 4953-4953.

Miranda, E., and Bertero, V. V. (1994). “Evaluation of strength reduction factors for earthquakeresistant design.’’ Earthquake Spectra, 10(2), 357-379.

Moses, F. (1974). “'Reliability of structural systems.’’ J. Struct. Div., ASCE, 100(9), 1813-1820.

Moslemi M, Kianoush MR, Pogorzelski W. Seismic response of liquid-filled elevated tanks. Eng Struct 2011;33:2074-84.

Malhotra, P. K., Wenk, T., and Weiland, M., 2000. Simple procedure of seismic analysis of liquid-storage tanks, J. Struct. Eng. Int., IABSE 10 (3), 197-201

Mander, J.B., Priestley, M.J.N. and Park, R. 1988. Theoretical Stress-Strain Model for Confined Concrete, Journal of Structural Engineering. ASCE. 114(3). 1804-1826.

Mickleborough NC, Ning F, Chan CM. Prediction of the stiffness of reinforced concrete shear walls under service loads. ACI Struct J 1999;96(6):1018-26.

Menoni, S., Pergalani, F., Boni, M.P., Petrini, V., 2002, Lifelines earthquake vulnerability assessment: a systemic approach, Soil Dynamics and Earthquake Engineering 22, 1199-1208.

MacGregor, J.G. 1997. Reinforced Concrete Mechanics and Design Third Edition. Prentice Hall.

Nazari, A., 2009, Seismic response of reinforced concrete elevated water towers, MASc Thesis, Ryerson University. 
Newmark, N. M., and Hall, W. J. (1982). Earthquake spectra and design. Earthquake Engineering Research Institute, Oakland, Calif.

Nassar AA, Krawinkler H. Seismic demands for SDOF and MDOF systems. Report No. 95, The John A.Blume Earthquake Engineering Center, Stanford University, Stanford, 1991.

Osteraas, J. D. and H. Krawinkler, (1990). Strength and Ductility Considerations in Seismic Design, John A. Blume Earthquake Engineering Centre, Report 90, Stanford University, California.

Papanikolaou, V.K., Elnashai, A.S. and Pareva, J.F. (2006). Evaluation of conventional and adaptive pushover analysis II: Comparative results. Journal of Earthquake Engineering, 10 (1), $127-151$.

Park, R. (1988). Ductility evaluation from laboratory and analytical testing. Proceedings of the 9th World Conference on Earthquake Engineering , Tokyo - Kyoto, Japan , Vol. VIII, pp. 605 616 .

PEER, 2006a, PEER NGA Database, Pacific Earthquake Engineering Research Center, University of California, Berkeley, California, Available at http://peer.berkeley.edu/nga/.

Rai, D.C., Singh, B., 2004, seismic design of concrete pedestal supported tanks, 13th World Conference on Earthquake Engineering, Vancouver, B.C., Canada, Paper No. 230.

Rai, D.C., 2002. Seismic retrofitting of R/C shaft support of elevated tanks. Earthquake Spectra, (18): 745-760.

Rai, D. C., 2001. Performance of elevated tanks in Mw 7.7 Bhuj earthquake of January 26, 2001, Abstracts, International Conference on Seismic Hazard with Particular Reference to Bhuj Earthquake of January 26, 2001, Oct. 3-5, New Delhi.

Rai DC., 2002, Review of Code design forces for shaft supports of elevated water tanks. In: Proceedings of 12th symposium on earthquake engineering. p. 1407-18.

Shepherd, R., 1972. Two mass representation of a water tower structure, J. Sound Vib. 23 (3), 391-196.

Saiidi M, Sozen MA., Simple nonlinear seismic analysis of R/C structures, Journal of the Structural Division, ASCE 1981;107(ST5):937-51.

Steinbrugge, KV., Rodrigo, FA., The Chilean earthquakes of May1960: a structural engineering viewpoint. Bull Seismol Am.

Shakib, H., Omidinasab, F., Ahmadi M.T., 2010, Seismic Demand Evaluation of Elevated Reinforced Concrete Water Tanks, International Journal of Civil Engineering, 8: 3, 204-220. 
Uang, C. M. and Bertero, V. V. (1986). Earthquake Simulation Tests and Associated Studies of a 0.3-Scale Model of Six-story Concentrically Braced Steel Structures. Earthquake Engineering Research Center, Report No. UCB/EERC 86/10, University of California, Berkeley, California.

Uang, C. M. (1991). "Establishing R(or Rw) and Cd factor for Building Seismic provisions." Journal of Structural Engineering, ASCE, 117(1), pp. 19-28.

Uang, C. M. and Maarouf, A. (1993). "Safety and Economy Considerations of UBC Seismic Force Reduction Factors.” Proc. the 1993 National Earthquake Conference, Memphis, Tennessee.

Veletsos, A.S., and Tang, Y., 1986. Dynamics of vertically excited liquid storage tanks. ASCE Journal of Structural Engineering, 112(6): 1228-1246.

Villaverde, R, 2009, Fundamental concepts of earthquake engineering, Taylor and Francis group, 6000 Broken Sound Parkway NW, Suite 300

Vamvatsikos, D., and Cornell, C.A., 2002, "Incremental Dynamic Analysis," Earthquake Engineering and Structural Dynamics, Vol. 31, Issue 3, pp. 491-514.

Wang, C.H., and Wen, Y.K. (2000). "Evaluation of pre-Northridge low-rise steel buildings. II: Reliability.” J. Struct. Eng., 126(10), 1169-1176.

Whittaker, A. S., Uang, C. M., and Bertero, V. V. (1987). Earthquake Simulation Tests and Associated Studies of a 0.3-Scale Model of Six-story Eccentrically Braced Steel Structures. Earthquake Engineering Research Center, Report No. UCB/EERC 87/02, University of California, Berkeley, California. 